\title{
Louis Bréhier
}

\author{
Membre de l'Institut
}

\section{Le monde byzantin : \\ La civilisation byzantine}

(1950)

\section{Collection l'Évolution de l'Humanité}

Éditions Albin Michel, 1950 et 1970, Paris

Un document produit en version numérique par Jean-Marc Simonet, bénévole, professeur retraité de l'enseignement de l'Université de Paris XI-Orsay Courriel: imsimonet@wanadoo.fr

Dans le cadre de la collection: "Les classiques des sciences sociales" Site web: http://classiques.uqac.ca/

Une collection développée en collaboration avec la Bibliothèque Paul-Émile-Boulet de l'Université du Québec à Chicoutimi Site web: http://bibliotheque.uqac.ca/ 
Cette édition électronique a été réalisée par Jean-Marc Simonet, ancien professeur des Universités, bénévole.

Courriel:jmsimonet@wanadoo.fr

À partir du livre :

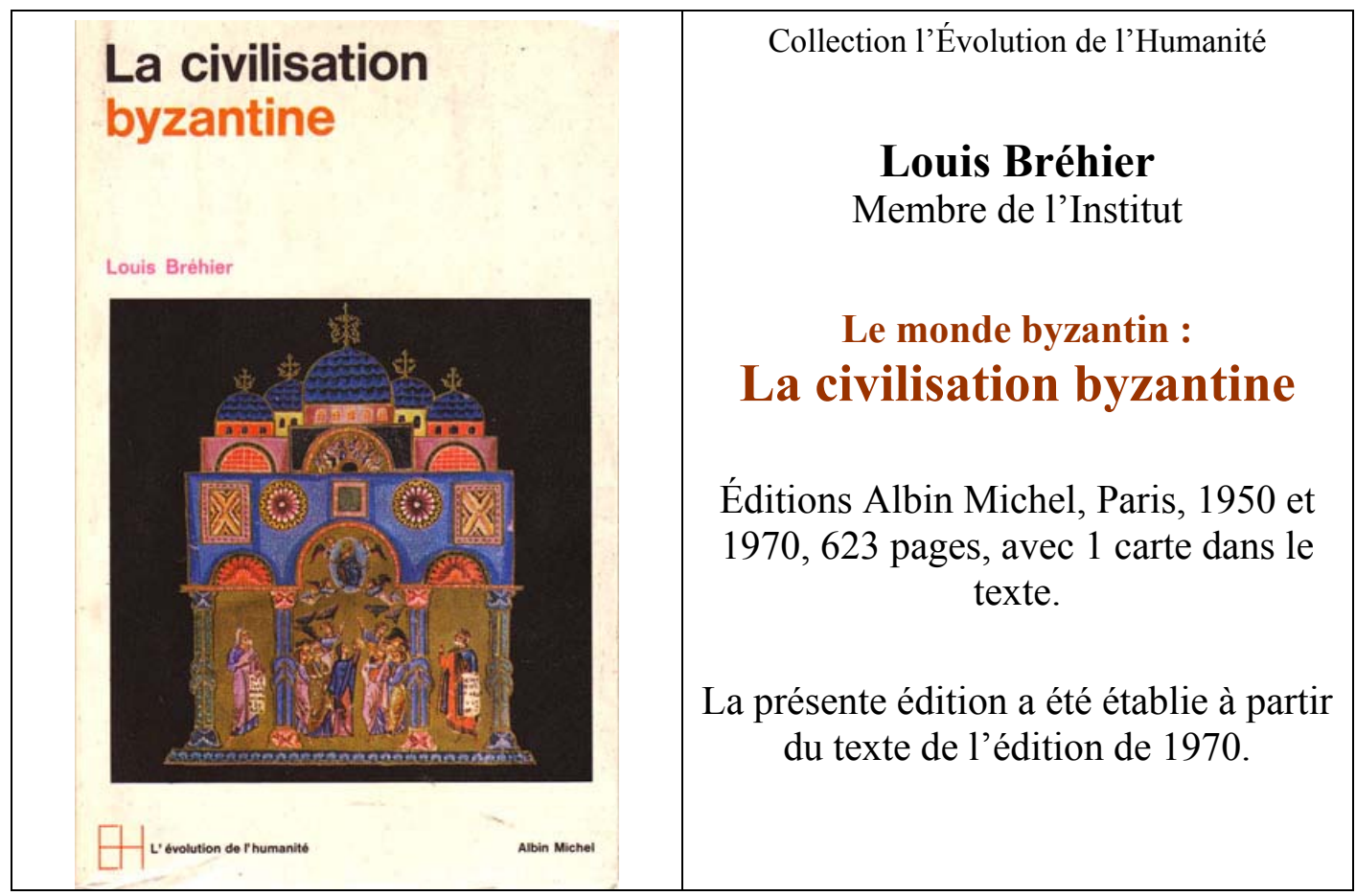

Polices de caractères utilisées :

Pour le texte: Times New Roman, 14 et 12 points.

Pour les notes de bas de page : Times New Roman, 10 points.

Édition électronique réalisée avec le traitement de textes Microsoft Word 2004 pour Macintosh.

Mise en page sur papier format : LETTRE (US letter), 8.5' x 11'’)

Édition numérique réalisée le 24 février 2006 à Chicoutimi, Ville de Saguenay, province de Québec, Canada. 


\section{Table des matières}

$\underline{\text { Introduction }}$

\section{LIVRE PREMIER — LA VIE PRIVÉE}

CHAPITRE PREMIER. - La famille

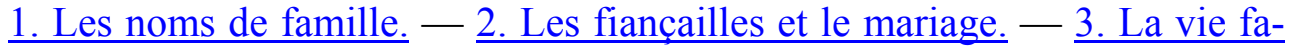
miliale. -4 . La propriété familiale.

CHAPITRE II. - La vie matérielle

$\underline{\text { 1. L'habitation. }}$ - 2. Le mobilier. $-\underline{\text { 3. Le costume. }}-\underline{4}$. Les repas. $-\underline{5}$. Les bains.

CHAPITRE III. - La vie privée des empereurs

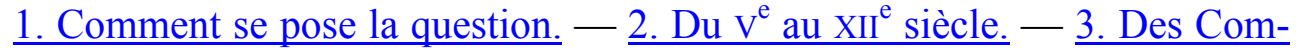
nènes à la fin de l'Empire.

\section{LIVRE DEUXIÈME — LA VIE URBAINE}

CHAPITRE IV. - La vie à Constantinople

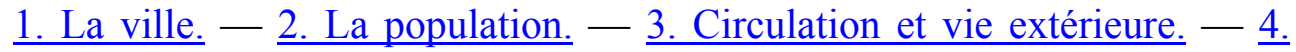

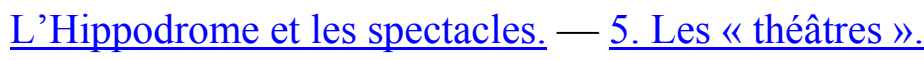

CHAPITRE V. - La vie urbaine dans les provinces

$\underline{1 .}$ Alexandrie et les villes d'Égypte. - 2. Antioche. - 3. Dans les provin-

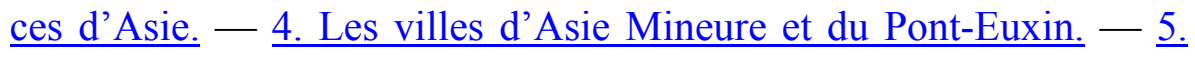
$\underline{\text { L'Occident : Illyricum, Hellade. }}$ - $\underline{6 . \text { L'Occident byzantin. }}$ 


\section{LIVRE TROISIÈME - LA VIE ÉCONOMIQUE}

CHAPITRE VI. - Les campagnes et l'économie rurale

$\underline{1 .}$ Les domaines ruraux. -2 . Éléments des grands domaines. $-\underline{3 \text {. Condi- }}$ $\underline{\text { tion et vie des paysans. }}-\underline{4}$. Les travaux des champs. $-\underline{5 \text {. La chasse. }}$

CHAPITRE VII. - L'industrie et le commerce

$\underline{1 .}$ Des origines aux conquêtes arabes. -2 . Conséquences économiques des

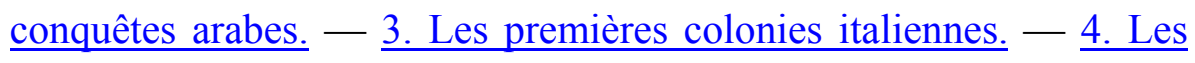
industries de luxe à Byzance. $-\underline{5 \text {. La fin de l'étatisme et les colonies }}$ étrangères. $-\underline{6}$. L'expropriation et la conquête économique de Byzance.

\section{LIVRE QUATRIÈME — LA VIE SPIRITUELLE}

CHAPITRE VIII. - La vie religieuse

$\underline{1 .}$ Les édifices religieux. $-\underline{2}$. Mobilier et instruments du culte. $-\underline{3}$. Les li$\underline{\text { turgies et la messe. }}-\underline{4}$. Les fidèles. $-\underline{5 \text {. Le culte des saints et des }}$ $\underline{\text { reliques. }}-\underline{6}$. Le culte des icônes.

CHAPITRE IX. - Superstitions, dissidents

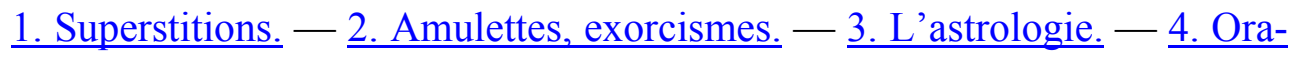
cles, voyants, explication des songes. -5 . Dissidents. Hérétiques. $\underline{6 . \text { Les Juifs. }- \text { 7. Colonies musulmanes. }}$

\section{LIVRE CINQUIÈME — LA VIE INTELLECTUELLE}

CHAPITRE X. - La littérature byzantine

$\underline{1 .}$ La vie intellectuelle et ses conditions. -2 . Langue littéraire et parler $\underline{\text { vulgaire. }}-\underline{3 \text {. Caractères de la littérature byzantine. }-\underline{4} \text {. Les œu- }}$ vres : la prose, la rhétorique. $-\underline{5 .}$ L'histoire. $-\underline{6 \text {. L'hagiographie. }-}$ 7. Récits apocryphes, romans. $-\underline{8}$. Pamphlets, satires. 
CHAPITRE XI. - La poésie

1. La poésie savante. - 2. La poésie rythmique. - 3. La musique byzan$\underline{\text { tine. }}-\underline{\text { 4. L'épopée. }}-\underline{5 \text {. Poèmes chevaleresques. }}-\underline{6 \text {. Poésie en }}$ $\underline{\text { langue populaire. }}-\underline{7}$. Le théâtre.

CHAPITRE XII. - La philosophie et les sciences

1. La philosophie et le dogme. - 2. La philosophie autonome. - 3. Mysti-

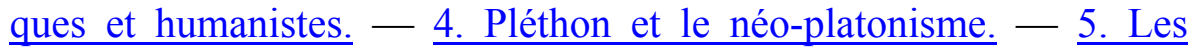
$\underline{\text { sciences. }}$

CHAPITRE XIII. - L'enseignement

$\underline{1 . L}$ 'enseignement public jusqu'aux iconoclastes. -2 . La restauration de l'enseignement public. - 3. De Constantin Monomaque à la conquête franque. - 4. L'enseignement public à Nicée et sous les Paléologues. - $\underline{\text {. L'école patriarcale. }}$ - $\underline{6}$. Les écoles monastiques.

CHAPITRE XIV. - L'art byzantin

$\underline{1 .}$ Au berceau de l'art byzantin. $-\underline{2}$. Les destinées de l'art byzantin. $-\underline{3}$. Les créations de l'art byzantin. $-\underline{4}$. La rénovation artistique sous les $\underline{\text { Paléologues. }}$ - $\underline{5 \text {. Manuscrits historiés et arts somptuaires. }}$

CHAPITRE XV. - L'expansion de l'art byzantin

$\underline{\text { 1. Les importations. }}-\underline{2}$. Les influences (Occident). $-\underline{3 \text {. Les influences }}$ $\underline{\text { (Orient). }}$ - $\underline{4}$. Péninsule des Balkans. $-\underline{5 \text {. Pays roumains. }}-\underline{6 \text {. Rus- }}$ $\underline{\text { sie. }}$

\section{$\underline{\text { CONCLUSION }}$}

Fin du texte

TABLE DES REFERENCES BIBLIOGRAPHIQUES

INDEX ALPHABÉTIQUE

$\underline{\text { Carte - Constantinople au Moyen Age. }}$ 


\section{Introduction}

Exposer dans l'ordre des temps les destinées de Byzance, décrire les transformations de ses institutions politiques, ne donne pas une idée complète de la place que le Monde byzantin tient dans l'histoire universelle par sa civilisation. Comment vivaient les habitants de l'Empire, quels étaient leurs usages, parfois plus forts que les lois, comment concevaient-ils la vie matérielle, religieuse, morale, intellectuelle, quel fut dans ce peuple néohellénique, mélangé d'éléments étrangers, le développement de la science, de la littérature, de l'art à travers les siècles?

Ce sont ces faits d'une importance primordiale qui constituent la civilisation d'un peuple. Les institutions nous montrent l'histoire de l'État, de sa formation, de son développement, de sa chute : la civilisation est l'histoire du peuple lui-même. Elle nous révèle son tempérament, son idéal, sa vie dans sa réalité concrète. Par exemple, l'histoire des institutions nous apprend quel était le statut juridique des factions du Cirque, ainsi que les détails des cérémonies palatines et de la vie officielle du basileus, ou encore l'organisation ecclésiastique ; l'histoire de la civilisation nous permettra d'assister à une séance de l'Hippodrome, de découvrir ce qu'était la vie privée des hôtes du Grand Palais, ainsi que les pratiques religieuses des fidèles.

Krause dès 1869, Hesselig en 1907, Gelzer (H.) en 1909, Runciman en 1933, pour n'en citer que quelques-uns, ont publié sur la Civilisation byzantine des livres remarquables ${ }^{1}$ mais ils ont compris sous

Krause, Die Byzantiner des Mittelalters in ihren Staats-Hof und Privatleben; H. Gelzer, Byzantinische Kulturgeschichte; Steven RunCIMAN, Byzantine Civilisation. 
le même titre l'histoire de la civilisation et celle des institutions celleci tient d'ailleurs la place principale dans leurs ouvrages. En fait, l'histoire de la civilisation byzantine n'a jamais été présentée séparément et dans son ensemble. L'œuvre intellectuelle de Byzance, sa littérature, son art, a donné lieu depuis longtemps à des disciplines autonomes, dont l'intérêt s'est accru au fur et à mesure des découvertes nouvelles. L'histoire du peuple, de sa vie privée et publique, de ses usages traditionnels, de ses occupations, de la culture de ses différentes classes, est encore à faire. On ne la connaît jusqu'ici que par des études de détail, perdues dans la masse d'articles de revues ou de mélanges jubilaires.

Dans cette troisième étude sur Le Monde byzantin, on s'est efforcé d'exposer d'une manière systématique, tout au moins dans ses grandes lignes, cette histoire de la civilisation byzantine. Il ne faut pas se dissimuler d'ailleurs les difficultés que présente ce programme. Alors que les sources de l'histoire chronologique et constitutionnelle de Byzauce sont bien groupées, celles de l'histoire de sa civilisation sont dispersées à l'infini. A côté des renseignements que l'on peut tirer de toutes les sources écrites, les découvertes archéologiques enrichissent chaque jour nos connaissances sur la vie intime des populations. La trouvaille d'objets domestiques, des plus vulgaires, peut en éclairer tout un aspect. A plus forte raison la découverte d'œuvres d'art, celle des documents d'archives, papyrus, diplômes impériaux ou privés des bibliothèques monastiques, et aussi des inscriptions, apportent les témoignages de haute valeur qui permettent d'apprécier l'œuvre civilisatrice de Byzance.

Avant d'entreprendre cette tâche, il serait injuste de méconnaître les secours offerts par plusieurs chapitres relatifs à la vie et à l'expansion intellectuelle de Byzance dans les ouvrages cités plus haut. D'autre part, la société byzantine a été décrite avec un véritable charme dans les livres déjà anciens d'Augustin Marrast ${ }^{2}$, plus près de nous, dans les délicieuses Figures byzantines de Charles Diehl ${ }^{3}$ et les récits pittoresques et colorés de Gustave Schlumberger ${ }^{4}$. En Grèce, Phédon Koukoulès a commencé dans l'Annuaire de la Société des

Aug. MARRAST, Esquisses byzantines.

Ch. DIEHL, Figures byzantines.

G. SCHLUmBerger, Récits de Byzance et des croisades; du même, Byzance et les croisades. 
Etudes byzantines d'Athènes une série d'études admirablement informées et des plus captivantes sur les mœurs de la société byzantine ${ }^{5}$. Nous aurons souvent l'occasion de nous autoriser de ces précieux travaux, les premiers qui aient commencé jusqu'ici à explorer ce domaine, peu connu, d'une manière systématique.

$\underline{\text { Retour à la Table des Matières }}$ tême; Id., De la nourriture et des soins donnés aux petits enfants; Id., L'assistance aux indigents dans l'Empire byzantin. 


\section{LIVRE PREMIER \\ La vie privée}




\title{
Chapitre premier
}

\author{
La famille
}

Retour à la Table des Matières

Malgré les conceptions nouvelles, dues au christianisme, la famille antique gréco-romaine est restée à Byzance la cellule sociale. Elle forme une société parfaite, composée des parents, des enfants, des serviteurs libres, des esclaves, qui vivent sous l'autorité du père de famille. Son autonomie est affirmée par l'usage du nom de famille héréditaire.

\section{Les noms de famille}

\section{Retour à la Table des Matières}

A Constantinople, deux usages différents furent d'abord en vigueur la tradition hellénique, qui consistait à l'origine à désigner chaque individu par un nom propre, suivi de celui de son père ou d'un aïeul paternel: Demosthenes Demosthenous, Theophrastos Theodorou, etc., mais qui admet, dès l'antiquité, l'addition d'un surnom ${ }^{6}$; l'usage romain conservé par les immigrés latins dans la ville fondée par Constantin et comportant le praenomen: Petrus, le nomen gentilicium: Marcellinus, le cognomen : Felix Liberius ( $\mathrm{VI}^{\mathrm{e}}$ siècle) ${ }^{7}$. C'est à partir de cette époque que des nouveautés apparaissent. D'une part, le no-

\footnotetext{
S. REINACH, Traité d'épigraphie grecque, 1885, 504-507.

7 Petrus Marcellinus Felix Liberius, patrice, $\mathrm{VI}^{\mathrm{e}}$ siècle. Sur ce personnage, Le Monde byzantin (Institutions), éd. 1970, 326.
} 
men gentilicium, qui était porté par les affranchis, disparaît ${ }^{8}$ et le nom unique est parfois suivi de la mention du pays d'origine ${ }^{9}$. D'autre part, l'usage des surnoms se multiplie. Ils n'ont d'abord qu'une valeur individuelle, comme le montrent les expressions qui les désignent:

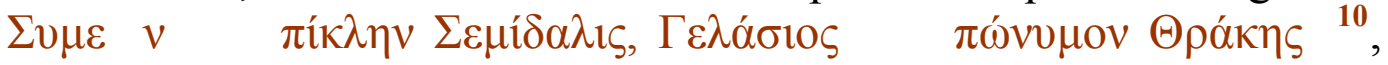
mais dès l'an mille ils commencent à devenir héréditaires et la plupart des familles se distinguent par un nom qui leur appartient en propre ${ }^{11}$.

L'usage primitif (nom individuel suivi du nom paternel) s'est conservé, mais le nom du père est suivi du vocable poulos (fils) : Argyropoulos, Strategopoulos, etc. ${ }^{12}$. Ce qui prédomine, comme en Occident, ce sont les sobriquets d'origine populaire, parfois vulgaires, fixés pour des siècles : difformités : $\pi \lambda \alpha \tau v \pi$ ó $\delta 10 \varsigma$ (pied-plat), $\chi \varepsilon i \lambda \varsigma$

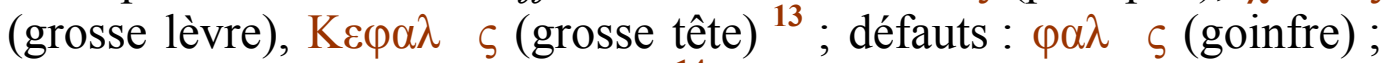

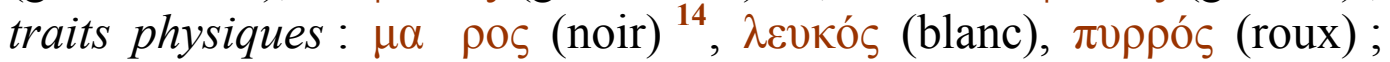
diminutifs de noms de baptême : Nikolitzès, Théophilitzès, Grégoras ; noms d'animaux: airoulos (le chat), pardos (léopard), choiros (cochon); noms de métiers: Paléologue ( $\pi \alpha \lambda \alpha \iota_{0} \lambda \gamma_{\gamma} \varsigma$ ) serait synonyme de fripier mabulant et Phocas, de fabricants de foyers en argile,

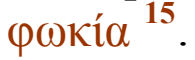

Cette concordance entre le processus des noms de famille à Byzance et en Occident offre cet intérêt de montrer le caractère européen, dans le fond, de la société byzantine, en dépit des apports orientaux qu'elle a reçus. En Asie et en particulier chez les Arabes, on ne constate pas cette évolution favorable à l'autonomie familiale.

Comme le montrent plusieurs adresses des constitutions de Justinien à des personnages pourvus d'un seul nom, Démosthène, Bélisaire: KoukOules, Le sens et l'orthographe de quelques noms de familles byzantines, 3-35.

Jean Lydus, Jean de Cappadoce, etc.

R.P.B., 834 (a. 1027-1030) : Syméon dit Semidalis, Gélase surnommé le Thrace, etc.

MORITZ, Die Zuname, B.Z., VII, 450.

Ibidem, 451. - Usage courant chez les peuples primitifs. Cf. le vitch slave, le witz allemand, le $f i t z$ anglais, l'ibn arabe.

Constantin Képhalas, auteur d'une anthologie.

Surnom de Jean II Comnène. GUILlaUme de TYR, Historia rerum in partibus transmarinis gestarum, XV, 23.

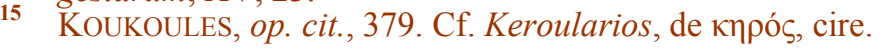




\section{Les fiançailles et le mariage}

\section{$\underline{\text { Retour à la Table des Matières }}$}

L'origine légale de la famille est le mariage, transformé par le christianisme, qui a donné au consentement mutuel des deux époux la valeur d'un sacrement. On sait avec quelle difficulté l'Église a imposé sa conception de l'indissolubilité du nœud ainsi contracté aux peuples germaniques établis en Occident, tandis que l'Asie conservait la polygamie. A Byzance, la loi civile, qui reconnaissait le divorce par consentement mutuel, était en désaccord avec la législation ecclésiastique, qui finit par l'emporter dans la pratique. Sur un papyrus du $\mathrm{VI}^{\mathrm{e}}$ siècle on lit un contrat de divorce entre Fl. Callinicus et Aurelia Cyra, qui attribuent leur désaccord à un méchant démon et conviennent d'avoir en commun la garde de leur fils, Anastase ${ }^{16}$; mais dans la suite la loi civile mit de nombreux obstacles à cette pratique ${ }^{17}$.

L'innovation la plus importante, due à l'Eglise, fut la valeur légale donnée aux fiançailles bénies par un prêtre. Leur rupture injustifiée par l'une des parties était punie d'amendes pécuniaires et de peines spirituelles ${ }^{18}$. De là naquirent d'étranges abus : des familles fiançaient des enfants en bas âge pour des raisons d'intérêts et il fallut même que la loi civile défendît de fiancer un enfant avant l'âge de sept ans, tandis que l'âge légal du mariage était de douze ans pour les filles, de quatorze ans pour les garçons ${ }^{19}$. L'accord était conclu par chartes écrites, s'il s'agissait de mineurs. A Chypre, les fiancés prêtaient serment sur des reliques devant témoins; ils échangeaient aussi des croix ou de petits reliquaires, $\gamma \kappa o ́ \lambda \pi \imath \alpha$, en garantie de leur ac$\operatorname{cord}^{20}$.

Ce qui ressort des sources, c'est d'abord que, suivant le conseil de saint Jean Chrysostome, les parents étaient pressés de marier leurs enfants ${ }^{21}$, c'est ensuite que les unions librement consenties par les deux

\footnotetext{
J. B. BuRY, History of the later Roman Empire, II, 407, 1; M.C., XI, 981-984.

H. MONNIER, Les novelles de Léon le Sage, 83-84.

R.P.B., 832; R.K.O R., 116; MONNIER, op. cit., 73-75.

LEON VI (empereur), Discours et cuvres diverses, 109; C.J., V, 60, 3; KouKOUles, Usages relatifs aux fiançailles et au mariage, 10 et $\mathrm{s}$.

Koukoules, op. cit., 13 et s.; Jean CANTACuZENe, Histoire, II, 108, 19.

Saint Jean Chrysostome, Homélies, V, P.G., 72, 426.
} 
conjoints étaient des plus rares. Elles se préparaient à l'insu des intéressés, obligés d'obéir à la volonté paternelle, et il existait même des intermédiaires, surtout féminins, qui se chargeaient, moyennant un salaire réglementé par la loi, de faire des mariages ${ }^{22}$.

Les noces. - Le jour du mariage fixé, les familles lançaient des invitations, dont on a conservé des formules ${ }^{23}$. Une cérémonie importante était l'ornementation de la chambre nuptiale, la veille du mariage. Elle était tendue de somptueuses tapisseries, on y exposait des objets précieux, tandis que des chœurs chantaient des morceaux de circonstance ${ }^{24}$.

Le jour du mariage, les invités se revêtaient d'habits blancs, qu'un ancien usage rendait obligatoires ${ }^{25}$. L'époux, vv́ $\mu \varphi 1$ s, accompagné de musiciens, venait chercher l'épousée, vv́ $\mu \varphi \eta$, qui paraissait magnifiquement parée et le visage fardé. Il lui soulevait le voile, car il était censé la voir pour la première fois. Alors commençait la pompe nuptiale. Au milieu de porteurs de torches, de chanteurs, de joueurs de cymbales, l'épousée, entourée de ses femmes, de ses parents, de ses amis, se dirigeait à pas lents vers l'église, tandis que, sur son passage, les roses et les violettes pleuvaient des fenêtres ${ }^{26}$. Les rites essentiels étaient le couronnement des deux époux et l'échange des anneaux. Habituellement, les couronnes étaient tenues par un parrain, le paranymphe, qui, dans les mariages impériaux, tendait un poêle d'étoffe précieuse sur la tête des mariés ${ }^{27}$.

On voit que, la cérémonie religieuse mise à part, les usages antiques se sont maintenus. C'est ainsi que la mariée entrait dans la maison de son époux, escortée de musiciens et de chanteurs, mais, sous

KeKaUmenos, Strategikon ou Logos nouthetitikos, 56; KouKoules, Usages relatifs aux fiançailles et au mariage, 11. Le Procheiron interdisait de donner à l'intermédiaire plus du vingtième de la dot; les Basiliques tolèrent jusqu'à dix livres d'or (720 nomismata). «Sois mon hôte demain. » KOUKOULES, op. cit., 22-23.

24 Zozime, Histoire (éd. Bekker), 249 (mariage d'Arcadius); MANASSES, Monodie sur la sébaste Théodora, V.V., 1930, p. 630.

25 Psellos, Discours, Chronographie, Correspondance, V, ép, 84, 322; Koukoules, op. cit. 27-28; THEOPHANES le CONFESSEUR, Chronographie, 446 (moines mariés de force par Michel Lachanodrakon). M.B.E.H. (Vie et mort de Byzance), éd. 1969, 82.

26 KOUKOULES, op. cit., 29-30.

27 Ibidem, 31-32; Constantin Dragasès est paranymphe de Phrantzès (1438), Georges PhrAnTZES, Chronique, 17; SCHLumBERGER, Mélanges d'archéologie byzantine, 67 et s. (anneau d'or avec portraits des époux bénis par le Christ); sur les rites, SYMEON DE THESSALONIQUE, Cuvres, 564 et s. 
l'influence de l'Église, des chants religieux remplaçaient souvent les hyménées populaires ${ }^{28}$. De même, le banquet nuptial était inséparable du mariage, mais les deux sexes mangeaient à part. Du moins les tables étaient chargées de toute la vaisselle précieuse dont disposait la famille et les épithalames ne cessaient pas jusqu'à la nuit. Les époux étaient alors conduits dans la chambre nuptiale et, le matin des noces, les parents et les amis venaient les réveiller en leur chantant des chœurs de circonstance ${ }^{29}$.

Contrats et donations. - Les mariés étaient liés, soit par, des engagements oraux, soit par des contrats écrits par des notaires devant témoins, surtout à partir $\mathrm{du} \mathrm{XI}^{\mathrm{e}}$ siècle. Conformément au droit romain, le mari ne pouvait aliéner la dot, mais devait la transmettre à ses héritiers ${ }^{30}$. Elle consistait non seulement en biens immobiliers, mais en monnaie d'or, en meubles, en esclaves, parfois même en pains de l'annone. De son côté, le mari faisait à sa femme une donation, qui constituait son douaire si elle devenait veuve, et qui consistait souvent en bijoux et autres objets ${ }^{31}$.

\section{La vie familiale}

$\underline{\text { Retour à la Table des Matières }}$

La famille byzantine a toujours l'aspect d'une monarchie en réduction, bien que les lois aient affaibli l'autorité paternelle, devenue un simple pouvoir de protection ${ }^{32}$. Sous l'influence du christianisme, la situation sociale de l'épouse fut singulièrement relevée. De Justinien aux Comnènes les lois lui assurèrent une protection efficace en prohibant les unions temporaires, en réduisant le nombre des cas de divorce et en honorant le mariage ${ }^{33}$. Rien n'est plus curieux à cet égard que

\footnotetext{
KouKoules, op. cit., 32-37.

Ibidem, 37-39; au festin il y avait parfois des mimes, malgré les interdictions de l'Église. PSEllos, op. cit., V, 319 et s.

C.J., V, $12(530)$.

KoukOules, op. cit., 18; Th. ReInaCH, Un contrat de mariage du temps de Basile le Bulgaroctone, 121 (apports d'une Juive de Mastaura vers 1030 : trousseau. bijoux, etc., le tout valant 14 nomismata).

32 Th. ReINACH, op. cit., 122: KoukOUles, op. cit., 18; H. MONNIER, Les novelles de Léon le Sage. 175 et $\mathrm{s}$.

33 J. B. BURY, History of the later Roman Empire, II, 401-402.
} 
les effusions lyriques de Léon VI dans les préambules de ses lois sur la sainteté du mariage et sur la beauté du cérémonial qui accompagne les noces ${ }^{34}$. Mais le mariage implique l'égalité des conditions et non celle des pouvoirs. La femme, dit le même prince, doit se souvenir qu'elle a été créée d'une côte d'Adam et n'être pour l'homme qu'une alliée, qu'une aide. C'est lui qui est le membre principal, « la tête du corps unique » formé par le mariage ${ }^{35}$.

Cette subordination de l'épouse ne diffère pas des conceptions occidentales de la même époque ; mais il est un trait qui sépare les deux civilisations, et c'est la réclusion des femmes byzantines au gynécée, parfois sous la garde des eunuques. A vrai dire, la Grèce antique connaissait déjà la séparation des sexes et les eunuques n'étaient pas inconnus à Rome. La famille byzantine n'en est pas moins plus orientale, plus asiatique que celle de l'antiquité grecque. L'Église ellemême réglementait bien avec sévérité les rapports entre les deux sexes, mais des prohibitions, comme celles du concile in Trullo de 692, s'appliquaient à la vie extérieure et non à l'organisation de la famille ${ }^{36}$. Comme on l'a dit justement, les mœurs furent plus fortes que les lois.

Sans doute on est frappé de l'allure très libre des impératrices et des princesses du sang à toutes les époques. Il suffit de rappeler des exemples comme ceux d'Athénaiis Eudokia au $\mathrm{V}^{\mathrm{e}}$ siècle, de Théodora sous Justinien, de Sklérène, la favorite de Constantin Monomaque, des princesses de la cour des Comnènes, qui s'entretenaient librement avec des savants, des poètes, des médecins. Mais, quand elles sortaient, leur visage n'en était pas moins voilé ; elles ne paraissaient ni dans les festins solennels, ni même, à partir d'une certaine époque, dans la loge impériale de l'Hippodrome ${ }^{37}$. Leur cas était d'ailleurs exceptionnel et les mœurs étaient beaucoup plus sévères chez les particuliers ${ }^{38}$.

Il va sans dire qu'à Byzance, comme partout ailleurs, il existait des ménages dans lesquels l'autorité maritale ne pesait pas lourd devant la

LEON VI (empereur), Novelles, 123, nov. 98.

Ibidem, 294, nov. 89; 370-371, nov. 112; H. MONNIER, op. cit., 82-83.

M.C., XIV, canons 12,45 et s., 62 et s.

Voir, ch. IV, p. 94.

G. BUCKLER, The women in byzantine law about 1100, dans B.N., XI, 1936, 391 et s. 
volonté féminine. Tel était celui de Théodore Prodrome, poète famélique, marié à une femme de bonne famille, qui lui avait apporté une belle dot, avec des maisons, de l'or, de l'argent.

Bientôt sa paresse et son inconduite finirent par l'exaspérer quand il rentrait ivre, elle le battait et le querellait; elle alla jusqu'à lui fermer la porte du logis. Cependant, comme une honnête femme, elle tenait sa maison, prenait soin de ses enfants, tissait elle-même ses robes de lin et de coton pendant que son indigne époux courait les cabarets. Elle lui reprochait amèrement de ne jamais lui faire de cadeau, de ne pas lui donner une robe neuve à Pâques, de la faire jeûner trop souvent et de laisser tomber sa maison en ruine ${ }^{39}$.

En fait, l'opinion publique était défavorable à la femme. Sans parler des lazzis, des proverbes populaires ${ }^{40}$, elle est généralement maltraitée dans la littérature. Kékauménos écrit qu'il est dangereux d'être en mauvais termes avec une femme, mais encore plus redoutable d'être son ami, surtout si elle est jolie, car on a alors à combattre trois adversaires : le diable, la grâce et les paroles ensorceleuses ${ }^{41}$. Les femmes elles-mêmes n'avaient pas très bonne opinion de leur sexe. Pour Kasia, qui pourtant rétorqua si bien le sot compliment de Théophile $^{42}$, la femme est un fléau, même si elle est belle ; mais si elle est laide, c'est pour elle le pire destin ${ }^{43}$. Anne Comnène elle-même a une pauvre opinion des femmes : elles sont bonnes, dit-elle, comme pleureuses, à cause de leur facilité à verser des larmes, mais les affaires sérieuses ne les concernent pas. Elles sont comme des vases percés, quand il s'agit de garder un secret. Elle regarde sa mère et son aïeule Anne Dalassène comme exceptionnelles et loue Irène Doukas, en danger d'être capturée par les Turcs, de n'avoir manifesté aucun mouvement de lâcheté, comme les femmes le font ordinairement ${ }^{44}$. Un poème tout à fait médiocre, le Miroir des femmes, établit la perversité

Théodore Prodrome, Poèmes, vers 46 à 262 (p. 184 et s.); Sp. Lambros, La femme chez les Byzantins, 262 et s.

40 Le monde entier peut périr : ma femme continue à se parer. K. KRUMBACHER, Mittelgriechisch Sprichwörter, B. Ak. W., 1900, 2.

41 Ch. DIEHL, Dans l'Orient byzantin, 161.

42 «Une femme a perdu le monde, lui dit Théophile; une femme l'a sauvé, répondit Kasia.» DIEHL, Figures byzantines, I, 134.

43 G. BUCKLER, B.N., XI, 415-416.

44 Anne ComnEne, Alexiade, IV, 4, 109; XV, 2., 463; Agathias, Histoire (552-358), 4, 157; G. BUCKLER, Anna Comnena, 116-177. 
féminine d'après la Bible, la littérature profane et les proverbes populaires ${ }^{45}$.

Il n'est donc pas étonnant que l'instruction des femmes ait été souvent négligée et presque toujours inférieure à celle des hommes. Les femmes lettrées, que l'on puisse citer à Byzance, sont peu nombreuses : Anne Comnène, la plus remarquable, n'a guère de rivale ${ }^{46}$. Dans la bourgeoisie, l'éducation des filles était réduite aux ouvrages manuels et à la lecture de l'Écriture sainte, avec quelques rudiments de lettres ${ }^{47}$.

La maison était le théâtre ordinaire de l'activité des femmes et elles n'en sortaient que très rarement. Michel d'Attalie, décrivant un tremblement de terre, raconte comme un fait anormal qu'on voyait dans les rues des femmes « ayant perdu toute pudeur " ${ }^{48}$. C'est dans son intérieur que Théoctiste, mère de Théodore Studite, femme austère, modeste et réservée, toujours vêtue de couleurs sombres, gouvernait d'une main ferme, mais rude, ses trois fils et sa fille, refaisant son éducation pour les bien élever et étudiant même la nuit ${ }^{49}$.

Si les femmes avaient à sortir, elles couvraient leur tête d'un voile de couleur qui encadrait le haut du visage et tombait en arrière en se recourbant par devant ${ }^{50}$. Le patrice Constantin, qui élevait lui-même sa fille Théophano, défendait de la laisser sortir sans être accompagnée de nombreux serviteurs ${ }^{51}$. Une des occasions de ces sorties était, en dehors des offices religieux, la fréquentation des bains publics, qui étaient les mêmes que ceux des hommes, mais ouverts à chaque sexe à des heures différentes. Cet usage était tellement enraciné que des costumes de bain figuraient dans les trousseaux des mariées ${ }^{52}$.

KRUMBACHER, B. Ak. W., 1905; Id., Geschichte der byzantinischen Literatur, 556 : exercice de rhétorique (en vers) de Jean Pediasimos, $\mathrm{XIV}^{\mathrm{e}}$ siècle, Sur la méchante femme, sur la femme bonne; WESSELY, dans B.Z., 1906, 354 et s.

46 G. BUCKLER, op. cit., 184-189 (liste des Byzantines lettrées).

47 LOPAREV, Vizantiiskiia Jitii Sviatuik, VIII-IX Viekov, 1910, 63; DIEHL, Figures byzantines, I, 113, 293 (Théodote, mère de Psellos).

48 LAMBros, La femme chez les Byzantins, 272.

DIEHL, op. cit., I, 213 et s.

LAMBROS, op. cit., 272 et s.

LOPAREV, op. cit., 1910, 18, 4.

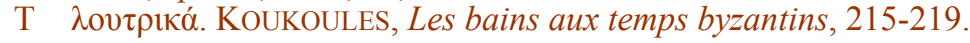


Loin de s'être atténuée, cette réclusion des femmes était toujours en usage aux derniers jours de Byzance. François Filelfe, secrétaire de la légation vénitienne à Constantinople en 1420, écrivait que les Grecques parlaient une langue plus pure que leurs maris, parce qu'elles n'avaient jamais de contact avec les étrangers et même avec leurs compatriotes. «Elles ne sortent jamais, sauf la nuit et le visage voilé, conduites par des serviteurs, quand elles vont à l'église ou visiter des parents très proches ${ }^{53}$.»

Les eunuques. - Le trait le plus caractéristique de la condition des femmes était l'usage des eunuques, seuls hommes admis à pénétrer dans les gynécées. On connaît leur rôle prépondérant au Grand Palais et dans l'État jusqu'au XII ${ }^{\mathrm{e}}$ siècle, mais beaucoup moins la place qu'ils tenaient chez les particuliers ${ }^{54}$. Importés en grande partie de la région du Caucase, ils coûtaient fort cher et des lois sévères interdisaient la castration d'enfants et d'esclaves nés dans l'Empire, mais leur renouvellement fréquent montre qu'elles étaient très mal appliquées ${ }^{55}$. On peut donc conclure que les eunuques devaient être assez nombreux, tout au moins dans les familles riches ${ }^{56}$. L'opinion leur était d'ailleurs défavorable et ils étaient l'objet de plaisanteries truculentes que nous conservent des proverbes populaires et des pièces satiriques, comme la Messe de l'Eunuque, parodie de l'office divin, où l'on voit un prêtre donner sa fille en mariage à un eunuque ${ }^{57}$.

Serviteurs et esclaves. - Suivant le rang social du maître et en dehors des eunuques, le ménage comprenait encore un assez grand nombre de serviteurs des deux sexes, de condition libre ou affranchis, parfois véritables parasites, rappelant les clients romains, et les esclaves proprement dits. A toutes les époques, des prédicateurs : saint Jean Chrysostome au $\mathrm{V}^{\mathrm{e}}$, au XIV ${ }^{\mathrm{e}}$ siècle Isidore de Thessalonique, s'élèvent contre la vanité des grands, qui ont besoin pour vivre d'un si nombreux personnel ou se pavanent avec ostentation dans les rues des vil-

Correspondance. R.E.G., 1888, I, 97. Il avait lui-même épousé une Grecque (voir chapitre XIII).

R. GUILland, Les eunuques dans l'Empire byzantin; Id., Fonctions et dignité des eunuques. C.J., IV, 42, 2 (a. 457-465); C.I.C.I., nov. 142 (a. 541), constate que sur 90 opérés il en survit à peine trois; LEON VI Novelles, nov. 60, 222 et s.

IBN KORDABBEH, Livre de routes et des royaumes, 482, cite une île au nord-ouest de la Sicile où l'on mutilait les esclaves.

Messe de l'Eunuque (XIII ${ }^{\mathrm{e}} \mathrm{XIV}^{\mathrm{e}} \mathrm{s}$ s); Épigrammes sur les enfants eunuques dans N.H., 1911, 13 et s.; Guilland, Les eunuques dans l'Empire byzantin, 234 et s.; cf. Platon, République, V, 22 (l'énigme de l'eunuque). 
les avec une suite de flatteurs et de parasites ${ }^{58}$. Un ménage aussi médiocre que celui de Théodore Prodrome, composé des deux époux, de quatre enfants et d'une vieille mère, n'avait pas moins de cinq valets et une nourrice ${ }^{59}$.

L'esclavage n'a cessé d'exister jusqu'à la fin du moyen âge mais, comparé à l'esclavage romain, il s'est adouci dans les lois ${ }^{60}$ et dans la pratique. Les affranchissements d'esclaves sont regardés comme une bonne œuvre; Grégoire de Nazianze affranchit tous ses esclaves par son testament ${ }^{61}$. Au IX ${ }^{\mathrm{e}}$ siècle, Théodore le Studite interdit l'emploi des esclaves dans les monastères ${ }^{62}$, mais il n'en est pas de même partout, car sainte Théodora de Thessalonique fait don au couvent où elle entre de 100 aurei et de trois esclaves ${ }^{63}$.

Sans doute l'esclavage finit par être considéré comme un état anormal, mais bien que la législation facilite de plus en plus les affranchissements, nul n'a jamais parlé de le supprimer. Le maître conserve sur l'esclave son pouvoir absolu et peut le châtier impunément. Théoctiste, dont il a été question, traitait bien ses servantes, mais ne leur passait aucun écart et accompagnait ses remontrances de soufflets, puis, prise de remords, elle leur demandait pardon à genoux ${ }^{64}$. Tous les maîtres n'avaient pas les mêmes scrupules, comme le montre l'histoire du frère de sainte Théophano, qui frappa un esclave avec une telle violence qu'il tomba lui-même évanoui ${ }^{65}$. Loin de disparaître, l'esclavage était en Orient plus florissant que jamais à la fin du moyen âge. Au XI ${ }^{\mathrm{e}}$ siècle, de grands propriétaires possédaient des esclaves par milliers et en faisaient des hommes d'armes ${ }^{66}$. Les guerres continuelles alimentaient le commerce des esclaves. C'est ainsi que les Almugavars, révoltés contre l'Empire, vendaient comme esclaves leurs nombreux prisonniers grecs, que des marchands de

\footnotetext{
O. TAFraLI, Thessalonique au XIV siècle, 21; Vie de saint Athanase l'Athonite, 64. Théodore Prodrome, Poèmes, vers 27, p. 47 et s., 186 et s.

Lois de Constantin. Voir PIGANIOL, L'empereur Constantin, 1932, 123.

Testament de saint Grégoire de Nazianze.

A. GARDNER, Theodore of Studium, his life and times, 71-72.

Vie de sainte Théodora de Salonique, V.V., XIX, 91.

DIEHL, Figures byzantines, 116.

Vie de sainte Théophano impératrice, première femme de Léon VI (éd. Hergenroether) et V.V., 1910, 91.

66 G. CEDrenos, Synopsis, II, 448, a. 1001 (P.G., 122, 180 et s.); Nicéphore BryenNe, Histoire, II, 26.
} 
Barcelone venaient acheter à Thèbes en Béotie ${ }^{67}$. En 1448, revenant de Constantinople, Peró Tafur ramène avec lui des esclaves qu'il a achetés à Caffa ${ }^{68}$.

Les enfants. - L'événement familial par excellence, la naissance d'un enfant, était accompagné de pratiques et d'usages d'origine antique, plus ou moins transformés par le christianisme. Il existait des moyens pour faciliter la conception, drogues bizarres qui n'étaient pas sans danger, opérations magiques ou phylactères ${ }^{69}$. Des astrologues prédisaient le sexe de l'enfant et tiraient son horoscope à sa naissance ${ }^{70}$. Des sages-femmes, en général sans connaissances médicales, mais bien pourvues de recettes superstitieuses, présidaient à l'accouchement ${ }^{71}$. L'enfant mis au monde était plongé dans un bain et emmailloté de bandelettes, comme le montrent les Nativités du

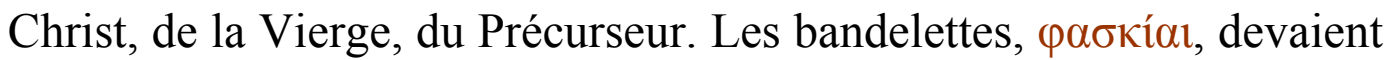
être de laine et l'enfant n'en était délivré qu'après quarante ou soixante jours ${ }^{72}$. La question de l'allaitement maternel était discutée à Byzance, comme ailleurs. Des hommes graves, tel Eustathe de Thessalonique, se plaignent que les mères abandonnent leurs enfants à des nourrices, et Psellos, dans l'Eloge de sa mère, rapporte une prière souhaitant à un nouveau-né de ne jamais téter d'autre sein que le sein maternel ${ }^{73}$. L'emploi du biberon n'était pas mieux vu. La Vie de saint Théodore Tiron, d'après un manuscrit $\mathrm{du} \mathrm{x}^{\mathrm{e}}$ siècle, montre un jeune veuf obligé d'élever lui-même son fils avec une bouillie de blé et d'orge additionnée d'eau et de miel, versée dans un vase en forme de verre. Aux premières dents, il lui donna du pain de froment en humectant ses lèvres de vin blanc, puis des fruits tendres et des légumes, mais il ne goûta aucune viande avant d'être dans toute sa force ${ }^{74}$.

L'enfant était conduit à l'église pour être baptisé, une semaine après sa naissance, tout au moins depuis $1 \mathrm{e} \mathrm{VI}^{\mathrm{e}}$ siècle, époque où le

RUBIO I LLUCH dans B.Z., 1940, 462 et s. (XIV s.)

Pero TAFUR, Travels and Adventures, 1435-1439, et A. VASILIEv, Pero Tafur... and his visit to Constantinople, Trebizond and Italy, 117.

PSELlOS, Discours..., V, 327 et s.; Id., Chronographie, I, 34 et s. (pratiques de Romain Argyre et Zoé).

KOUKOULES, Usages byzantins relatifs à la naissance et au baptême, 91-95.

Ibidem (recueil de pratiques et de formules); Vie de saint Porphyre de Gaza, 28 et s.

KOUKOULES, op. cit., 315 :, et s.

Eustathe de Thessalonique, Opuscula, 1438, 25 (Parek-bolai); Psellos, op. cit., V, 11; KOUKOULES, op. cit., 312.

74 Vie de saint Théodore Tiron, 225 et s. 
baptême des enfants n'était plus mis en discussion et avait été même rendu obligatoire ${ }^{75}$. Le rite consistait toujours dans une triple immersion, mais on a la preuve que l'on baptisait par infusion dès $1 \mathrm{le} \mathrm{VI}^{\mathrm{e}}$ siècle et même peut-être auparavant ${ }^{76}$. Avant d'accomplir le baptême, le prêtre imposait à l'enfant le nom choisi par le parrain, qui se tenait près de son filleul, un cierge allumé à la main. On choisissait de préférence le nom d'un saint ou d'une fête (Epiphanios, Paschasios), ou d'une vertu (Sophia, Elpis) ${ }^{77}$, ou impliquant la protection divine (Théophylacte, Théodore, Théodora). La superstition s'en mêlait parfois et on avait recours à des cierges allumés auxquels on attachait des noms : celui qui s'éteignait le dernier donnait la réponse de l'oracle ${ }^{78}$.

Le baptême terminé, on revenait en grande pompe à la maison, parfois avec des cierges allumés, en chantant le cantique : Tu es baptisé dans le Christ $^{79}$.

La première éducation. - Elle avait lieu pour les deux sexes au gynécée. Théoctiste y gardait ses fils jusqu'à sept ans et les instruisait elle-même ${ }^{80}$. La mère de Psellos, Théodote, agit ainsi. Elle défendit à ses servantes de raconter à l'enfant des histoires fantastiques, pleines de monstres épouvantables, mais elle lui narrait elle-même, ainsi qu'à sa fille, des épisodes de la Bible, qui ont enchanté les enfants de tous les temps : Isaac obéissant à son père, Jacob béni par Laban parce qu'il écoutait sa mère, l'Enfant Jésus soumis à ses parents dans la maison de Nazareth. Psellos retenait toutes ces histoires et montrait de si heureuses dispositions qu'il fut envoyé à l'école à cinq ans, et il en sortit à huit ans, déjà capable d'apprendre l'Iliade par cœur ${ }^{81}$. Plus modestement, la plupart des enfants apprenaient les fables d'Ésope.

Mais l'étude et les histoires alternaient avec le jeu. D'après saint Jean Chrysostome, les garçons jouaient avec des voitures, des ânes ou

Koukoules, op. cit., 120 et s.; D.A.C.L., II, 285 et s. (on attendait souvent au $40^{e}$ jour après la naissance).

J. PArgoire, L'Eglise byzantine de 527 à 847, p. 93; P. LeMErLe, Philippes et la Macédoine orientale à l'époque chrétienne et byzantine, 336 et s.; D.A.C.L., II, 389 et s.

KoukOUles, op. cit., 134.

Déjà en usage au V $\mathrm{v}^{\mathrm{e}}$ siècle. Saint JeAn Chrysostome, Homélies, hom. XII, 7; П $\alpha \lambda \alpha 10 \lambda{ }^{\gamma} \gamma \varepsilon 1 \alpha$

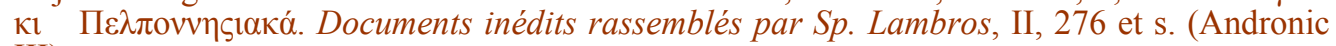
III).

Koukoules, op. cit., 137 et s.; SymeOn de Thessalonique, Euvres, 233. On jetait de la monnaie sur la route.

Ch. DIEHL, Figures byzantines, I, 118.

Ibidem, I, 298-301; A. RAMBAUD, Etudes sur l'histoire byzantine, 120 et s.; KouKOULES, op. cit., 321 et s. 
des chevaux d'argile, des maisons en terre et en pierres. Les osselets, les balles, les sistres, les sifflets, les flûtes, la toupie avaient aussi beaucoup de succès. Le jeu des cinq pierres $(\pi \varepsilon v \tau \alpha \lambda i \theta \alpha)$, d'une scolie de Tzetzès, n'est autre que notre marelle. Les petites filles avaient des poupées ( $v i v i ́ \alpha, v v_{\mu}(\alpha)$ en cire, en terre cuite, en plâtre, qu'elles habillaient avec le plus grand soin ${ }^{82}$. Il n'est jamais question dans les textes d'exercices physiques ou de jeux violents, mais notre information est loin d'être complète. Le goût des Byzantins pour la chasse et, comme on le verra plus loin, pour un jeu à cheval qui correspond au polo actuel, semble indiquer que, dans les hautes classes tout au moins, l'entraînement à ces exercices devait être précoce.

Funérailles et culte des morts. - Bien que la loi romaine, qui interdisait les inhumations dans l'enceinte des villes, n'ait été abrogée que par Léon VI ${ }^{83}$, il y avait longtemps qu'elle n'était plus appliquée et que le désir de reposer auprès des corps des saints avait multiplié le nombre des cimetières autour des églises ${ }^{84}$.

D'autre part, les usages funéraires, observés avec ferveur dans toutes les classes, portaient encore la marque de l'antiquité païenne. Telle était la coutume des pleureuses à gages, femmes échevelées, qui chantaient ou déclamaient des poèmes funèbres (myrologues), composés d'avance. Cette manifestation théâtrale de douleur avait lieu probablement dans l'église même et la foule s'y associait parfois; puis, avant que le cercueil fût emporté, les assistants, sur l'invitation de l'officiant, venaient donner au défunt le dernier baiser ${ }^{85}$.

On peut assigner la même origine à d'autres coutumes ${ }^{86}$, mais la plus importante, admise par l'Église, consistait en des réunions à jour fixe de parents et d'amis autour de la tombe du défunt, pour recommencer les lamentations et apporter des offrandes, parfois des gâ-

\section{Théophile : Theophanes, Continuatus, 113 et s.; Eustathe de Thessalonique, Opuscula,}

Koukoules, op. cit., 324 et s. Cf. l'histoire des prétendues poupées de Théodora, femme de 995, 64 (retrouve la toupie dans Homère).

83 LEON VI (empereur), Novelles, nov. 53, p. 202 et s.

84 A. Grabar, Martyrium, I, 487-496; J. LaSsus, Sanctuaires chrétiens de Syrie, 228-232; Anthologie grecque. I Anthologie Palatine, VIII, n ${ }^{\circ} 165$ (p. 82). Byzance, 76-78.

86 Couper les cheveux du mort, Eustathe de ThessaloniQue, op. cit., 1287; A. Vasiliev, Pero Tafur..., 113 (fermer sa maison toute l'année). 
teaux ${ }^{87}$, tandis qu'en Syrie et en Arménie on continuait, malgré les objurgations du clergé, à immoler des taureaux et des moutons sur les tombes ${ }^{88}$. Psellos, rentrant à l'improviste à Constantinople, trouva ses parents et amis réunis ainsi au cimetière, autour de la sépulture de sa sœur, dont il ignorait le décès ${ }^{89}$.

Alors qu'en Occident ces réunions avaient lieu le $3^{\mathrm{e}}$, le $7^{\mathrm{e}}$ et le $40^{\mathrm{e}}$ jour après les funérailles, suivant un usage emprunté aux Juifs, en Orient cette triple commémoration était célébrée les $3^{\mathrm{e}}, 9^{\mathrm{e}}$ et $40^{\mathrm{e}}$ jours. Le peuple avait imposé à l'Église la cérémonie du $9^{\mathrm{e}}$ jour, qui n'était justifiée par aucun précédent biblique. L'observance du $40^{\mathrm{e}}$ jour ne s'autorisait en outre ni de la Bible, ni même des usages païens helléniques. S'appuyant sur un texte de Vettius Valens, qui écrivait à Antioche $\mathrm{au} \mathrm{II}^{\mathrm{e}}$ siècle de notre ère, Franz Cumont a démontré que cette coutume remonte à la religion astrologique de Babylone, les nombres 3 , 7 et 40 étant des nombres parfaits, marquant l'achèvement d'un cycle lunaire ${ }^{90}$. La lune est maîtresse de la vie utérine : elle règle les phénomènes mensuels de la santé des femmes, préside à la formation des corps et aussi à leur dissolution. L'usage du triple office des morts est attesté dès la fin du $\mathrm{IV}^{\mathrm{e}}$ siècle par les Constitutions apostoliques, rédigées à Antioche, qui recommandent les prières et les aumônes et tolèrent les banquets funèbres ${ }^{91}$. Les exégètes, savants, théologiens et autres, ne manquèrent pas d'imaginer des explications de cet usage, sans remonter à sa véritable source. Le peuple croyait que l'âme du défunt restait sur la terre jusqu'au $3^{\mathrm{e}}$ jour, était jugée le $9^{\mathrm{e}}$ jour et paraissait le $40^{\mathrm{e}}$ jour devant le trône de Dieu, qui lui assignait un séjour jusqu'à la Résurrection ${ }^{92}$.

Sur le deuil, à part le deuil impérial, les renseignements sont sommaires. L'empereur le portait en blanc et ses sujets en noir ; l'office $\mathrm{du} 40^{\mathrm{e}}$ jour en marquait la fin, mais les particuliers l'abandonnaient dès le $9^{\text {e }}$ jour. D'autres signes de deuil consistaient à se couper les cheveux, à s'asseoir par terre, à déchirer ses vêtements ${ }^{93}$.

\footnotetext{
T кó $\lambda \lambda v \beta \alpha$ (colybe) Théodore Prodrome, Poèmes, 62 et s.

F. CUMONT, La triple commémoration de morts [dans l'Église byzantine], 281.

PSEllos, Discours, 29 et. s.; DIEHL, Figures byzantines, I, 306 et s.

CUMONT, op. cit., 278 et s.

Sur les Constitutions apostoliques, voir M.B.E.H. (Institut.), éd. 1970, 354 et s.

JORDANIS, De origine actibusque Gothorum, IV, 26; CUMONT, op. cit., 278 et s.

KOUKOULES, Le sens et l'orthographe de quelques noms de familles byzantines, XV, 73 et $\mathrm{s}$.
} 
Sépultures, cimetières. - Les corps des défunts étaient enfermés dans des sarcophages de pierre, de marbre, de porphyre, décorés ou non de sculptures suivant leur rang social. Les plus grandioses étaient les sarcophages des empereurs, conservés à l'église des SaintsApôtres, dont on a retrouvé toute une série ${ }^{94}$. Les cuves historiées de scènes évangéliques étaient réservées aux martyrs, aux saints et aux familles d'un rang élevé. Ceux qu'on a découverts à Constantinople, comme le célèbre fragment de Psamathia ${ }^{95}$, sont peu nombreux, alors que Rome et Ravenne en ont fourni de riches séries.

A toutes les époques aussi de grands personnages ont été ensevelis dans des tombes monumentales, placées dans les églises, comme celle du grand connétable Michel Tornikès, contemporain d'Andronic II, à Kahrié-Djami $^{96}$. On a même découvert à Constantinople en 1914, dans le quartier de l'Hebdomon, un hypogée analogue à ceux que l'on aménageait en Syrie en l'honneur des martyrs ${ }^{97}$. C'était une rotonde creusée dans le schiste et appareillée, de 15 mètres de diamètre. Elle était cantonnée d'une croix grecque qui la divisait en quatre chambres, autrefois couvertes en berceau; des loculi étaient creusés dans les piliers pour abriter des sarcophages, numérotés par des lettres grecques, mais d'autres tombes étaient dans des fosses et, dans l'une d'elles, on a découvert un sarcophage monolithe en marbre blanc décoré sur ses quatre parois. L'importance de cet hypogée semble montrer qu'il dépendait d'un monastère ${ }^{98}$.

Les tombes des particuliers, beaucoup plus modestes, étalent simplement creusées dans le sol. En 1935-1937, les fouilles de l'Université écossaise Saint-Andrews, dirigées par le professur J. H. Baxter, sur l'emplacement du Grand Palais de Constantinople, ont mis à jour près de l'ancienne Monnaie impériale un véritable cimetière d'un caractère populaire, installé à cet endroit près d'une église après la désertion du Grand Palais par les Comnènes ${ }^{99}$.

\footnotetext{
EBERSOLt, Mission archéologique de Constantinople, 1921, I, 1-27. VASILIEV, Imperial porphyry sarcophagi, D.O.P, 1948, 1 et s. Actes des 42 martyrs d'Amorium.

L. BREHIER, La Sculpture et les Arts mineurs byzantins, pl. IV; EBERSOLT, op. cit., 45 et s.

Th. SCHMITT, Kahrié-Djami, pl. 73 et s.; DIEHL, Etudes byzantines, 416 et s.

J. LASSUS, Sanctuaires chrétiens de Syrie, 152 et s.; GraBAR, Martyrium, I, 141 et s.

MACRIDY et EBERSOLt, Monuments funéraires de Constantinople, B.C.H., 1923 (antérieur au $\mathrm{VII}^{\mathrm{e}} \mathrm{s}$.).

BAXTER, The Great Palace of the Byzantine Emperors (rapport sur les fouilles de 1935-38) 27 et s.
} 
Les tombes étaient souvent signalées par des stèles de pierre ou de marbre, sur lesquelles était gravée une inscription qui exprimait la vénération des vivants à l'égard des morts. Une stèle découverte à Constantinople (quartier de Top-Hané) laisse voir sous des acrotères reliés par un petit arc, un médaillon vide qui devait renfermer le portrait du défunt, un certain Amachis, apothekarios (intendant d'un entrepôt) ${ }^{100}$, Phrygien de naissance, mort à cinquante ans ${ }^{101}$. Un médaillon en mosaïque du Musée de Stamboul et une épigramme de Manuel Philès confirment l'usage d'orner les tombes d'un portrait ${ }^{102}$.

Les inscriptions, en général très simples, ne donnent souvent que le nom du défunt, sa qualité de fidèle et des souhaits de vie bienheureuse.

Telles sont un grand nombre d'épitaphes des $\mathrm{V}^{\mathrm{e}}-\mathrm{VI}^{\mathrm{e}}$ siècles découvertes à Constantinople et en Asie Mineure : «Sephnas de bienheureuse mémoire, fédéré impérial, fidèle. - Hermione Théodoulê Domnos, néophyte (baptisée récemment), âgée de 20 ans et vierge » (Constantinople). — « Emplacement ( $\theta \dot{\varepsilon} \sigma 1 \varsigma)$, du serviteur de Dieu Florentianos et de son épouse bien-aimée ; ils gisent là » (Amasée du Pont). — « Ici gît le serviteur de Dieu Eugénis décédé dans l'indiction XII, le 12 juin, jour du sabbat » (Ancyre (Ankara), 12 juin 564) ${ }^{103}$.

A côté des inscriptions découvertes ainsi, de nombreuses épitaphes byzantines nous sont parvenues par des textes et en particulier par l'Anthologie Palatine, dont les livres VII et VIII contiennent exclusivement des épigrammes funéraires, celles du VIII ${ }^{\mathrm{e}}$ livre entièrement, sauf une, composées par saint Grégoire de Nazianze $(† 389)$, celles du $\mathrm{VII}^{\mathrm{e}}$ dues à Agathias de Myrina ${ }^{104}$. Devant cette abondance d'épitaphes, on est fondé à croire que ce sont de simples jeux, des poésies de salon composées dans des cercles lettrés. Ce qui justifie cette opinion, ce sont les sujets traités : Paul le Silentiaire écrit une épitaphe d'Homère (VII, 4), Agathias, celle d'une perdrix dévorée par un chat (VII, 204). Un grand nombre de ces petites pièces sont imitées des poètes alexandrins. Enfin, au milieu de cette société chrétienne, à une époque où le paganisme était traqué par les lois, on est étonné de

\footnotetext{
Sur ces entrepôts, M.B.E.H. (Institutions), éd. 1970, 293.

MACRIDY et EBERSOLT, loc. cit.

Ibidem, 356; Manuel Philes, Poèmes, 2, 17, dans Millet, R.A.C., 1911

MACRIDY et EBERSOlt (loc. cit., p. 32), 49.-54, n ${ }^{\text {os }} 6$ et 8 ; Fr. CUMONT, Nouvelles inscriptions du Pont, R.E.G., 1902, 311 et s., $\mathrm{n}^{\circ}$ 12; G. de JERPHANION, Mélanges d'archéologie anatolienne, $288, \mathrm{n}^{\circ} 62$.

104 Anthologie grecque, I, Anthologie Palatine, t. 4, 5 et 8, 1941, 1944.
} 
la place que la mythologie tient dans ces pièces. Il n'y est question que de l'Erèbe, de l'Achéron, de Minos, des Parques qui tranchent les jours des hommes, des Muses qui pleurent une jeune musicienne (VII, 612) et Julien l'Égyptien va jusqu'à supplier Pluton et Perséphone d'accueillir ses amis avec bienveillance (VII, 58).

Cependant la foi chrétienne de ces auteurs, férus de mythologie païenne, se révèle parfois par une remarque inattendue. Leurs épigrammes se trouvent d'ailleurs mêlées à des pièces dont l'inspiration est purement chrétienne : telle l'épitaphe de Diogène composée par son oncle et homonyme, l'évêque d'Amisos (Samsoun) « qui lui fera obtenir par ses prières une place dans le chœur des bienheureux »" (VII, 613); telle l'épitaphe de saint Jean l'Aumônier, patriarche d'Alexandrie (609-619) par son disciple Sophronius (VII, 679) ${ }^{105}$. Il est clair qu'on a affaire ici à des épitaphes réelles qui ont pu être inscrites sur des tombes.

Les épigrammes à thèmes mythologiques n'offrent d'ailleurs rien d'exceptionnel, si l'on considère l'instruction que recevaient les lettrés, chrétiens ou païens, dans les écoles publiques, à commencer par l'Université du Capitole de Théodose II. Il y avait longtemps que des Pères de l'Église, comme saint Basile, avaient reconnu la nécessité, pour les chrétiens, de l'étude de l'antiquité hellénique. On ne sera donc pas surpris de rencontrer dans les épitaphes composées par Grégoire de Nazianze les mêmes réminiscences mythologiques, les mêmes allusions à l'Érèbe, à l'Hadès, à l'âge d'or, aux Muses, que chez ses successeurs du $\mathrm{VI}^{\mathrm{e}}$ siècle. Il va jusqu'à prédire à un violateur de tombe qu'il sera châtié par les Érinnyes (VIII, 199). C'était pour lui une simple figure de rhétorique et il en fut de même pour les lettrés byzantins de toutes les époques ${ }^{106}$.

Ces épigrammes funéraires de saint Grégoire, consacrées à ses parents et à ses amis, sont intéressantes et parfois émouvantes, en nous montrant ce que pouvaient être les sentiments de famille dans cette société provinciale de Cappadoce. C'est avec une véritable tendresse

105 106

WALTZ, Inspiration païenne et sentiment chrétien dans les épigrammes funéraires du VI siècle, 16 et $\mathrm{s}$.

Anthologie grecque, op. cit., VI, 16 et s. (Introduction sur le caractère littéraire des épigrammes de Grégoire de Nazianze). 
que l'auteur parle de son père, avant lui évêque de Nazianze, de sa mère, Nonna, dont la vie et la mort ont été celles d'une sainte, de son amitié pour saint Basile, et de tous ceux qu'il a connus. Le nombre anormal de pièces consacrées à la même personne ( 52 pour sa mère) nous empêche de croire que ces épitaphes aient pu être gravées sur les tombes. Il en est certainement de même des épigrammes dans lesquelles il blâme des agapes rituelles célébrées sur les tombes des martyrs et qui dégénéraient en orgies (VIII, 166 à 172), ainsi que de celles qui concernent la profanation des cimetières, sacrilège, semble-t-il, très répandu en Cappadoce : tombes ouvertes pour y trouver de l'or, églises construites avec les pierres des tombes. Ces invectives ont pu être inscrites dans les cimetières sur des stèles, mais non sur des tombes. p030

\section{La propriété familiale}

\section{$\underline{\text { Retour à la Table des Matières }}$}

La propriété, définie par le droit romain et la législation impériale, était le fondement économique de la famille. Le père n'en était pas en général l'unique détenteur (régime dotal, douaire, enfants émancipés, etc.), mais il était seul apte à rédiger les actes qui la concernaient: testaments, donations, locations, affranchissements d'esclaves, etc. C'est par ces actes et spécialement par les testaments que nous pouvons nous faire une idée des fortunes familiales. Malheureusement les témoignages qui nous sont parvenus ne concernent que de grandes fortunes, mais permettent du moins d'imaginer les ressources des ménages moins fortunés.

Saint Grégoire de Nazianze, qui n'avait jamais été marié, rédigea son testament avant juillet 381, pendant que se tenait le deuxième concile œcuménique à Constantinople. Ses biens consistaient en esclaves, qu'il affranchit, en domaines fonciers, le domaine paternel de Nazianze, territoire d'élevage riche en troupeaux et en juments, et deux autres domaines, dont il a déjà donné l'un et vendu l'autre; en vêtements de bure, de soie, de drap, tuniques (sticharia), manteaux 
(pallia), légués à des diacres et à des civils ${ }^{107}$ (0107). Sa fortune mobilière consistait en 135 sous d'or partagés entre plusieurs légataires, mais cette somme n'en représentait qu'une faible partie, comme le montrent les rentes léguées à sa parente Ressina et destinées à lui permettre de vivre avec deux jeunes filles dans une maison rurale ${ }^{108}$.

La préface d'une novelle de Justinien montre ce que pouvait être au $\mathrm{VI}^{\mathrm{e}}$ siècle la fortune d'un membre de la classe sénatoriale ${ }^{109}$. Il s'agit du testament d'Hiérius, vir gloriosissimus, dont l'exécution donna lieu à des difficultés entre héritiers. Ceux-ci sont ses quatre fils, Constantin, Anthemius, Callipius, Alexandre, qui portent le titre de vir clarissimus. L'aîné, Constantin, est avantagé et reçoit la maison paternelle de Constantinople, une autre maison à Antioche et le domaine suburbain In Copariis. Les trois autres ne reçoivent que des domaines suburbains, villas de plaisance de caractère rural, avec leurs appartenances : maisons des maitres (praetoria), bâtiments d'exploitation (aedes), boutiques et ateliers (officinae), jardins, citerne, manège (hippodromus). Il leur est défendu d'aliéner ces domaines qu'ils devront transmettre à leur postérité et, si l'un d'eux meurt sans enfants, sa part reviendra à ses frères. En outre, par codicille, Hiérius décide que le domaine de Coparia, légué à Constantin, reviendra au fils de celuici, Hiérius, qui sera émancipé à la mort du testateur. On peut voir dans ces dispositions le désir d'assurer à une famille des biens perpétuels et inaliénables.

$\mathrm{Au} \mathrm{VIII}{ }^{\mathrm{e}}$ siècle, une famille riche était celle de Théophanes le Confesseur. Ses parents, Isaac et Théodote, possédaient une île de la mer Égée avec de nombreux serfs. Il avait trois ans à la mort de son père, qui avait été créé stratège du thème de l'Égée. A dix ans, suivant la pratique signalée plus haut, il fut fiancé à une riche héritière, Mégalo, qu'il épousa, âgé de dix-huit ans, pour obéir à sa mère. Mais les deux époux entrèrent chacun dans un monastère et Théophanes se retira dans celui de Polichnion, qui faisait partie de son héritage, puis en fonda un autre à Kalonymos, sur une terre qui avait appartenu aussi à son père. Nous avons là un exemple d'une fortune familiale fondée en partie sur la sécularisation de monastères à titre de charistikia ${ }^{110}$.

D'autres fortunes familiales, surtout après la renaissance du commerce maritime aux $\mathrm{X}^{\mathrm{e}}$ et $\mathrm{XI}^{\mathrm{e}}$ siècles, étaient dues à des spéculations.

107

108

108

110

C.I.C.I., nov. 159

Sur cette pratique M.B.E.H. (Institutions), 1970, p. 538; Vie de saint Théophanes le Confesseur; LOPAREV, Vizantiiskiia Jitii Sviatuik, 1910, 92-98; Vie de saint Théophanes (panégyrique), par saint THEODORE LE STUDITE, 11-23. 
Telle fut celle de Michel d'Attalie, qui a raconté lui-même sa propre histoire dans la Diataxis (règlement), qu'il rédigea pour ses fondations charitables ${ }^{111}$. Il naquit à Attalie, dans le premier quart du XI ${ }^{\mathrm{e}}$ siècle, de parents d'une condition assez modeste. Plus tard, il devait abandonner sa part d'héritage à ses frères et sœurs et même leur donner des secours. Vers 1034, il vint achever ses études à Constantinople.

Il se maria deux fois et l'une de ses femmes lui apporta un bien à Rodosto ; il parait n'avoir eu qu'un fils, Théodore, qui fut notaire impérial. Devenu juriste et homme d'affaires en renom, il gagna une fortune par des opérations financières et se rendit ainsi indépendant. Ses biens consistaient surtout en nombreuses maisons de rapport. Il en construisit plusieurs, dont il tirait de gros revenus, sur le terrain hérité de son épouse, à Rodosto, que des tremblements de terre et des incursions ennemies avaient ravagé. Ce quartier, situé à l'ouest de la ville, était à proximité d'un port très prospère, fréquenté par les Vénitiens. En faveur sous Michel VII, anthypatos et juge du Drome, il obtint en 1074 une exemption totale d'impôts pour ses biens situés à Rodosto et dans les environs ${ }^{112}$.

Une fortune plus modeste, mais supposant une assez grande aisance, était celle de Théodore Karabas, probablement un prêtre marié, dont on possède le testament, rédigé en 1314 en présence de dix-huit prêtres de la localité qu'il habitait et de deux moines d'un monastère de la Péribleptos ${ }^{113}$.

Marié deux fois, il a donné aux enfants du premier lit la dot de leur mère et partagé ses biens entre sa seconde femme, ses enfants et plusieurs fils adoptifs. Son avoir consistait en six maisons à un ou deux étages, voisines du cloître de la Péribleptos, possédées en commun avec son neveu Jean Attaliotès, plus loin d'autres demeures, dont une avec une cour où se trouvaient un puits et un réservoir, deux autres avec cour commune, une autre à un seul étage avec toit en coupole et colonnes. Il possède en outre des vignes, des troupeaux de bêtes à corne et de moutons, du vin dans ses caves, du blé et du millet dans ses greniers, une voi-

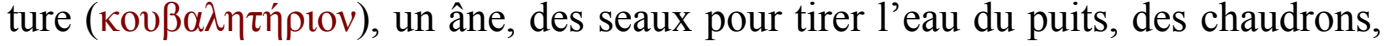
des coffres pour les vêtements de laine, quatre couvertures de soie, deux reliquaires pectoraux d'argent, une ceinture d'argent doré valant 8 nomismata, deux anneaux d'or et deux d'argent, une somme de 52 ducats, enfin des hypothèques d'une valeur de 17 nomismata sur deux maisons.

Si, comme on l'a supposé, ce testament est celui d'un prêtre de village, il dénote une véritable aisance. Sans doute ces nombreuses mai-

11

112

113 Testament de Théodore Karabas, 59-64, et Athonskie Document (éd. Bezobrazov), 70-73.

Michel D’AtTAlie, Histoire, 23 et s.

Ibidem, 27. 
sons devaient être des logis campagnards et la voiture, un char nécessaire à l'exploitation rurale. Il y a cependant une maison de maître ornée de colonnes et couverte d'une coupole. Le mobilier est sommaire et aucun livre n'est mentionné. Il est intéressant de constater que le numéraire est en ducats vénitiens, qui faisaient prime à cette époque, aux dépens de la monnaie impériale.

Ces quelques témoignages sur la propriété familiale montrent que les classes aisées des villes acquéraient volontiers des domaines ruraux qui leur assuraient des approvisionnements. On peut voir, d'autre part, que les maisons de rapport étaient nombreuses dans les villes dès le $\mathrm{XI}^{\mathrm{e}}$ siècle, ce qui laisse supposer que la petite bourgeoisie et les classes pauvres habitaient des appartements que leur louaient des propriétaires et souvent des spéculateurs. 


\section{Chapitre II}

\section{La vie matérielle}

Après avoir décrit la vie de la famille, les rapports entre ses membres, les usages suivis pour célébrer les événements qui jalonnaient son existence, il est nécessaire de rassembler les témoignages qui nous renseignent sur les besoins primordiaux de ces petites sociétés l'habitation, le costume, la nourriture, avec des éléments de luxe plus ou moins accusés suivant les conditions sociales.

\section{L'Habitation}

\section{Retour à la Table des Matières}

Les maisons bien conservées de la région basaltique de la Syrie centrale, évacuées par leurs habitants devant l'invasion arabe et abandonnées définitivement, sont restées intactes, et la plupart sont datées suivant l'ère des Séleucides par des inscriptions grecques. Bâties en magnifique appareil à joints vifs, avec des galeries, des balcons couverts, des terrasses, des cuisines souterraines, de larges écuries, elles témoignent d'une vie large et opulente, mais, avec leurs murs épais percés de rares fenêtres sur la rue, elles ne peuvent nous donner une idée exacte de l'habitation byzantine ${ }^{114}$. Toute la vie de la maison est axée sur une cour intérieure que bordent des appartements à plusieurs

114 M. DE VoGÜE, Syrie centrale : architecture civile et religieuse, du Ir au VII siècle; GARNIER et AMman, L'habitation humaine (ch. 14: Civilis. byz. et son influence); DE BEYLIE, L'habitation byzantine, 32-39; J. LASSUS, La vie économique dans la Syrie byzantine, A.C.E.B., VI, Paris, 1948. 
étages. La porte unique sur la rue est précédée d'un petit porche flanqué, d'un côté, d'une tour qui sert de logement au portier, de l'autre, d'une habitation réservée aux hôtes ${ }^{115}$. Ce sont presque les dispositions d'un monastère. Dans les rues à portiques usitées en Syrie ${ }^{116}$, les maisons ne faisaient pas corps avec les galeries.

Très différentes sont les maisons byzantines que nous connaissons par des monuments figurés, tels que la bordure de la mosaïque de Yakto découverte en 1932 et qui représente des édifices et des maisons privées d'Antioche au $\mathrm{V}^{\mathrm{e}}$ siècle ${ }^{117}$. Au lieu de s'isoler de la rue, elles sont percées de fenêtres, de longues baies rectangulaires, parfois même d'une galerie à jour qui rappelle la disposition d'une maison de Serdjilla (Syrie centrale). Chaque maison porte le nom de son fondateur. Celle dénommée $\mathrm{T} \Lambda$ covtíov, la maison de Léon, a une façade verte, percée de deux portes rectangulaires : elle est couverte d'un toit en tuiles rouges à double pente et ornée de colonnes portant une architrave. La maison d'Ardabur est plus importante : c'est un édifice en briques rouges avec une fenêtre à barreaux de même couleur. Le toit à double pente se termine par une sorte de pyramide. Sur le côté gauche se trouvait une longue salle, masquée par un édifice plus petit, et on aperçoit deux coupoles. Ardabur résidait à Antioche comme magister militum per Orientem (450-457). Il possédait une maison près de Constantinople, au promontoire de Sosthène, acquise par Hiérius dont nous avons signalé le testament ${ }^{118}$.

Au pied d'une colline voisine d'Antioche, garnie de cultures en terrasses, au milieu d'un paysage frais, avec un horizon de montagnes, les fouilles ont mis à jour les ruines d'une somptueuse villa du III siècle, remaniée deux cents ans plus tard. Ses larges salles et sa cour à exèdres étaient pavées de belles mosaïques, dont plusieurs à fond d'or ${ }^{119}$. C'était un véritable palais de type oriental, composé de deux parties, séparées par un couloir central avec, d'un côté, les appartements privés, de l'autre, de grandes salles de réception.

GARNIER et AMMAN, op. cit., 673.

DE BEYLIE, op. cit., 32-39.

J. LASSUS, Antioch-on-the-Orontes, I. The excavation of 1932. [La mosaïque de Yakto].

Ibidem, fig. XI; voir supra, 31.

J. LASSUs, Une villa de plaisance à Yakto, Princeton Univ., 1948, Antioch II, 95-107 et 137. 
Toutes ces demeures opulentes ne peuvent nous donner une idée de l'habitation des classes moyennes. Dans les grandes villes s'élevaient des maisons à cinq étages (exceptionnellement à sept et à neuf) dès le $\mathrm{V}^{\mathrm{e}}$ siècle. Ces étages étaient loués à des gens peu fortunés et souvent il y avait des difficultés entre locataires. Tzetzès se plaint de voisins qui, par suite de la crevaison des tuyaux, évacuaient les eaux ménagères par l'escalier ${ }^{120}$.

A partir du $\mathrm{IX}^{\mathrm{e}}$ siècle environ, la maison de la bourgeoisie aisée, à deux ou trois étages, est bâtie, soit en appareil alterné de briques et de moellons, soit en pierre revêtue de stuc, souvent polychrome, comme on le voit sur la mosaïque de Yakto; le marbre n'est employé que dans les palais. La façade principale, donnant parfois sur une rue à portiques, peut être ornée à la naissance du toit et sur les corniches saillantes qui séparent les étages; des balcons en encorbellement permettent de regarder dans la rue ${ }^{121}$. Les fenêtres sont rectangulaires ou cintrées, munies de petits carreaux de verre enclavés dans des châssis de plâtre; elles sont généralement grillées. Les toits sont en terrasse ou à deux versants. Les deux modes de couverture sont mélangés dans les représentations de villes, sur des mosaïques ou des peintures de manuscrits ${ }^{122}$ et, comme en Syrie, des coupoles surmontent les maisons importantes.

La porte d'entrée, en plein cintre ou rectangulaire, consistait souvent en battants de fer, garnis de clous à forte tête. On voyait aussi aux façades des maisons riches des escaliers extérieurs de pierre ou de marbre, qui aboutissaient à une porte en forme de trappe s'ouvrant par en bas ${ }^{123}$. On voit que, malgré des précautions indispensables, la maison byzantine n'était plus isolée et à l'écart de la vie de la cité, mais avait, comme les maisons occidentales au XII ${ }^{\mathrm{e}}$ siècle, de larges ouvertures sur le monde extérieur. C'est ce dont témoignent des règlements de voirie, interdisant les empiètements sur la voie publique ${ }^{124}$.

PSEllos, Discours..., ep. 21, 18; KouKoules, La maison byzantine (en grec), 87-91.

Comme le montre l'anecdote de la jeune fille brûlée vive pour avoir craché du haut d'un balcon, d'où elle regardait le convoi funèbre d'une basilissa, M.B.E.H. (Institutions), éd. 1970, note $\mathrm{n}^{\circ} 478$.

122 DE BeYLIE, op. cit., 56 et s. et pl. XXIX (plan de Constantinople dc 1450; maisons couvertes en terrasses surmontées de lanternons à coupoles); KouKOULES, op. cit., 34; DIEHL, Manuel d'Art byzantin, 426 et $\mathrm{s}$.

123 KouKOULeS, op. cit., 91.

124 Ibidem, 103. 
A l'intérieur, les pièces étaient disposées aux divers étages autour d'une grande salle, le triclinium, placé au rez-de-chaussée ou au premier étage, mais dont la hauteur était celle de l'édifice lui-même. C'était la salle de réception, réservée aux hommes. Le gynécée était à l'un des étages supérieurs. Des colonnes soutenaient les étages et les toits; elles étaient en marbre ou en bois, suivant les ressources des habitants. On attachait d'ailleurs une grande importance à l'ornementation : sol pavé de marbre ou de mosaïque, murs lambrissés de marbre ou décorés de peintures profanes ou sacrées, plafonds de cèdre, etc. Les pièces n'étaient parfois séparées que par des cloisons en planches ${ }^{125}$. Celles des maisons populaires étaient couvertes en charpente, dont les poutres étaient reliées par des roseaux. Un contemporain d'Eustathe de Thessalonique, Pédiaditès, décrit le triste état des huttes des paysans de Corfou, dont le toit est fait de roseaux liés par couples au moyen d'herbes. Le sol de ces pauvres maisons était en terre battue semée de coquillages et dans celles de condition moyenne, en charpente ou en briques ${ }^{126}$.

Dans beaucoup de maisons, comme dans les monastères, il existait une salle réservée au chauffage ( $\mu \alpha \gamma \varepsilon i \rho \varepsilon i ́ o v)$, en dehors de la cuisine où le foyer, placé très bas, était chauffé au bois. Il y avait parfois un four pour cuire le pain. La fumée s'échappait par des tuyaux quadrangulaires ${ }^{127}$. La présence de latrines dans toutes les maisons est attestée par les lois et par de nombreux écrivains ${ }^{128}$.

Enfin la maison était entourée de dépendances, qui montrent l'esprit pratique d'habitants soucieux de leurs aises et pourvus d'une nombreuse domesticité. C'était d'abord la cour, qui s'ouvrait sur la rue et communiquait par une autre porte avec le vestibule : elle était assez spacieuse pour qu'on pût s'y livrer à des exercices équestres. Au milieu se trouvait un puits ou une citerne. C'était ensuite un jardin, dans lequel se trouvaient parfois des bains privés. Il y avait des écuries et même des étables dans les maisons les plus pauvres ${ }^{129}$.

DieHL, op. cit., 427; KouKOULES, op. cit., 118 et s.

KOUKOULES, 99-102.

Ibidem, 100, 129; par exemple à Mistra, BEYLIE, 83

Koukoules, 132; Basiliques (T $\beta \alpha \sigma \imath \lambda \iota k \lambda \alpha ́)$, éd. Heimbach, I, 13.

KoukOules, 90, 132-138; THEODORET, Histoire ecclésiastique, ep. 18, 20. 
La dévotion des habitants se manifestait par de nombreuses représentations de la croix sur les murs, sur les portes et même sur les toits, mais les conciles avaient dû défendre de la figurer sur le sol ${ }^{130}$. Des inscriptions pieuses se trouvaient sur les murs du vestibule ${ }^{131}$. Plusieurs logis importants possédaient une chapelle privée ${ }^{132}$ et les familles les plus humbles avaient leur iconostase, oratoire où étaient suspendues les saintes images ${ }^{133}$.

Tous les renseignements donnés par les écrivains sont confirmés par les dispositions des maisons anciennes dont des parties ou des ruines subsistent encore. C'est ainsi que la maison seigneuriale de Melnik (Macédoine), que l'on date du $\mathrm{X}^{\mathrm{e}}$ siècle, est construite en appareil alterné, moellons et briques formant des figures géométriques. Elle est flanquée d'une tour carrée disposée pour la défense. A l'intérieur, une grande salle tient toute la hauteur du bâtiment et, autour d'elle, sont disposés deux étages de pièces latérales. Les fenêtres sont en plein cintre et on voit les restes d'un escalier en pierre ${ }^{134}$.

A Mistra, les ruines du palais habité par les despotes laissent voir au premier étage une salle qui occupe toute la longueur de l'édifice, avec une hauteur double de celle du rez-de-chaussée; au milieu, une abside est ménagée pour le trône ; les murs sont en maçonnerie revêtue de stuc ; la façade était ornée de balcons et les fenêtres étaient en plein cintre ${ }^{135}$. D'autres maisons antérieures à la conquête turque ont été retrouvées plus ou moins transformées, à Constantinople (maison près de Koum-Kapou avec balcon couvert et salles voûtées à tous les étages, maisons du Phanar, dont l'une avait été occupée par le bayle de Venise) ${ }^{136}$, et à Trébizonde (assez analogue à celle de Melnik, avec une toiture à quatre versants et une grande salle coupée ultérieurement en deux pièces) ${ }^{137}$. Le palais d'un grand dignitaire nous est décrit par son fondateur, Théodore Métochitès, grand-logothète d'Andronic II. Ce palais merveilleux, qui comprenait une chapelle et

\footnotetext{
Koukoules, 102; Concile in Trullo (692), canon 73.

Ibidem, 104 : Seigneur, bénis l'entée et la sortie. Amen. Cf. le culte de Panagia Portaïtissa à la porte des monastères.

C.I.C.I., nov. 58-131; LEON VI, Novelles, nov. 4, 20-25.

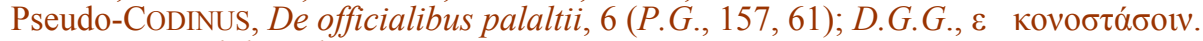

DIEHL, Manuel d'Art byzantin, 426 et s.; BEYLIE, op. cit., 72-75.

BEYLIE, 76, 140.

DIEHL, 427.

BEyliE, 75 (d'après les explorations de G. MiLlet, Les monastères et les églises de Trébizonde).
} 
était entouré de jardins délicieux aux eaux jaillissantes amenées à grands frais d'im-menses réservoirs, était au centre d'un magnifique et plantureux domaine. Mais Théodore, compromis dans la guerre entre Andronic II et Andronic III, vit son palais détruit par ordre du vainqueur en $1328{ }^{138}$.

\section{Le mobilier}

\section{Retour à la Table des Matières}

Le mobilier qui garnissait les appartements nous est connu surtout par des représentations figurées, souvent difficiles à dater, car telle peinture du XI ${ }^{\mathrm{e}}$ ou du XII ${ }^{\mathrm{e}}$ siècle, reproduisant un intérieur, peut être la copie d'un original ancien. Bien plus, dans les arts figurés de l'époque des Paléologues, on constate l'introduction systématique d'architectures et d'accessoires antiques.

Le bel ouvrage du général de Beylié sur L'Habitation byzantine présente tout un répertoire de dessins de meubles, sièges, tables, armoires, objets divers, extraits de mosaïques ou de peintures de manuscrits de toute époque ${ }^{139}$; on ne peut s'y référer qu'avec précaution et contrôler autant que possible leur témoignage par celui des écrivains ou des pièces parvenues jusqu'à nous.

Une très belle mosaïque murale de l'église de Daphni (fin du $\mathrm{XI}^{\mathrm{e}}$ siècle), dont le sujet est la Nativité de la Vierge, représente l'intérieur somptueux d'une maison aristocratique ${ }^{140}$. On y voit un lit recouvert d'une riche tenture historiée. L'accouchée est enveloppée à moitié dans une couverture brodée. Une servante agite sur sa tête un éventail de plumes ${ }^{141}$ et deux de ses compagnes, magnifiquement vêtues, apportent des mets dans des coupes. Une sage-femme, la serviette sur le

GuILland, Th. Metochitès. Description de son palais par lui-même, R.E.G., XXXV, 1922, 86-92.

BEYLIE, 84-94.

140 G. MiLLET, Le monastère de Daphni, pl. XVIII.

141 De même, pendant le sommeil d'Alexis Comnène et d'Irène (Anne Comnene, Alexiade, II, 70), une servante s'acquitte de cet office. 
bras, verse de l'eau avec une aiguière dans le bassin de cuivre où est plongé l'enfant qui vient de naître.

Dans certaines descriptions il est question d'armoires d'attache

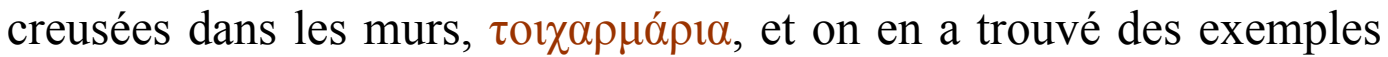
dans les maisons du Hauran et à Constantinople, au palais de TekfourSeraï, en formes de niches ${ }^{142}$.

Des armoires mobiles semblent, d'après les reproductions, n'avoir servi que comme bibliothèques. Elles étaient garnies de rayons, sur lesquels les livres étaient disposés à plat, possédaient deux portes avec serrure et étaient surmontées d'un fronton ${ }^{143}$.

Comme en Occident, on se servait surtout de coffres pour conserver les vêtements et les objets précieux. On pouvait voir à l'Exposition d'Art byzantin de 1931 un panneau d'un coffre provenant du Caire ( $\mathrm{VI}^{\mathrm{e}}-\mathrm{VII}^{\mathrm{e}}$ siècle) ${ }^{144}$. Il est fait de plaques de bois ajustées dans un cadre, les unes lisses, les autres garnies d'ornements sculptés : animaux courant dans des enroulements, tige ondulée, cantonnée de quatre lions, entrelacs, etc. Le coffre, plus petit, de la cathédrale de Terracine est remarquable par son ornementation zoomorphe, animaux réels et fantastiques, scènes de chasses sous des arcs en plein cintre, reposant sur des colonnes à fûts en hélice avec chapiteaux et bases semblables. Ce décor tout oriental indique un objet importé, mais dont la date est incertaine ${ }^{145}$.

On connaît surtout des coffrets destinés à conserver des bijoux ou des objets de petite dimension, comme le coffret en bois peint de la collection Volkonsky (XIII ${ }^{\mathrm{e}} \mathrm{s}$.) ${ }^{146}$, comme la série importante des élégants coffrets d'ivoire, où, dans des cadres faits de rosettes, parfois de monnaies, apparaissent des thèmes mythologiques, des épisodes de la vie d'Adam et Eve, des sujets de genre, chasseurs, belluaires, etc. Toutes ces œuvres délicates des $\mathrm{X}^{\mathrm{e}}$ et $\mathrm{XI}^{\mathrm{e}}$ siècles ne se trouvaient natu-

142

145 Catalogue de l'Exposition d'Art byzantin de 1931, n 563

A. MunOz, L'art byzantin à l'Exposition de Grottaferrata, 182 et s.; STRZYGOWSKI, Das orientalische Italien, 1908, 12.

46 G. DE JERPHANION, dans M. Schl., 416 et s. 
rellement que dans des maisons aristocratiques et finissaient par enrichir les trésors des églises ${ }^{147}$.

Nous connaissons mieux les meubles essentiels, et d'abord les tables qui servaient aux repas, rondes, carrées ou rectangulaires. La forme ronde paraissait plus solennelle : c'était celle de la table impériale aux banquets du Tribunal des Dix-Neuf lits ${ }^{148}$. A côté des tables en bois, il y en avait d'autres en matériaux précieux non seulement au Palais Sacré, mais dans les demeures des riches ${ }^{149}$. On conservait dans la famille du grand propriétaire paphlagonien qu'était saint Philarète, une table ronde, antique, incrustée d'ivoire, d'or et d'argent, si grande que trente-six convives pouvaient s'y asseoir ${ }^{150}$. Mais la table carrée ou rectangulaire, adoptée par l'Église byzantine comme autel liturgique, semble avoir été d'un usage courant ${ }^{151}$, tantôt sur quatre pieds, simples ou reliés par des traverses, tantôt portée sur des arcatures.

Les sièges variaient depuis la chaire à dossier, véritable fauteuil (kathedra $)^{152}$, employée pour manger à table, jusqu'aux bancs et simples tabourets, qui devaient être les plus usités. Il existait aussi des sièges bas sans dossier portés par six pieds carrés reliés par des $\operatorname{arcs}{ }^{153}$.

Les lits, comme nous l'a montré la mosaïque de Daphni citée plus haut, étaient portés sur quatre pieds et légèrement relevés au chevet ; d'autres, qui paraissent élevés et qu'on atteint par un escabeau, sont surmontés à la tête et aux pieds de panneaux de hauteur inégale ; d'autres sont entièrement plats. Les pieds assez larges ne peuvent être qu'en bois et sont généralement très ornés. Les lits des pauvres étaient de simples grabats, dont les représentations du miracle du Paralytique peuvent nous donner une idée ${ }^{154}$.

L. BREHIER, Le coffret byzantin de Reims et les coffrets d'ivoire à rosettes, 265.-282. C.D., 1933, 102; CONSTANTIN VII PORPHYROGENETE, De caerimoniis aulae byzantinae, 594. Asterius, Homélies, 209; Saint Jean Chrysostome, Homélies, P.G., 57, 289, 509.

Vie de saint Philarète le Miséricordieux, 136 et s.

BEYLIE, L'habitation byzantine, 187-189.

Ibidem. 187, 2; CONSTANTIN VII PORPHYROGENETE, op. cit., II, 57.

BEYLIE, 186.

Ibidem, 190-192; L. BREHIER, L'Art chrétien. Son developpement iconographique, I, 311. pl. 79; II, 131, 139. 
L'éclairage domestique était assuré soit par des lampes à huile,

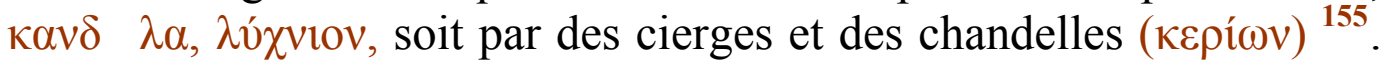
Les grands musées possèdent d'innombrables lampes en terre cuite rouge non vernissée, qui datent des $\mathrm{VI}^{\mathrm{e}}$ et $\mathrm{VII}^{\mathrm{e}}$ siècles et proviennent de Syrie, de Palestine, d'Égypte et d'Afrique. Elles sont timbrées de médaillons sigillés avec inscriptions et ornements variés. Une lampe découverte à Beyrouth est décorée des paons affrontés de chaque côté du hom assyrien ${ }^{156}$. Elles portent souvent des inscriptions pieuses : « La lumière du Christ brille pour tous ${ }^{157}$. » Certaines lampes étaient à récipient rond, sans anses, avec un bec très détaché orné de volutes. On trouve la même lampe avec une anse en forme d'anneau. D'autres avaient un récipient presque ovale et, au lieu d'anse, un manche plein. Les plus anciennes ne présentaient sur la partie concave du disque qu'un seul trou d'aération, qui servait à introduire l'huile et l'aiguille de bronze, d'os ou d'ivoire avec laquelle on remontait la mèche ${ }^{158}$.

Tenues à la main ou accrochées, ces lampes pouvaient s'adapter par le fond à un candélabre porté sur trois pieds ${ }^{159}$ ou à un lustre circulaire de bronze en forme de disque percé de trous (polycandilon), tenu par des chaînettes. Ces lustres servaient sans doute à éclairer les églises et on les fabriquait parfois en or et en argent, mais les dimensions modestes de quelques-uns de ceux que possèdent les musées permettent de supposer qu'on les trouvait aussi dans des maisons particulières ${ }^{160}$.

Les candélabres, généralement à trois pieds, et parfois enrichis d'émaux, pouvaient faire partie du mobilier des maisons riches, mais on les voyait surtout dans les églises, bien qu'aucune loi civile ou religieuse n'empêchât les particuliers d'employer les cierges, comme les simples chandelles, à des usages profanes. On voit d'ailleurs qu'un chandelier figurait dans les bagages du basileus partant pour la

\footnotetext{
Voir ces mots dans D.G.G.

DALTON, Byzantine Art and Archaeology, 607-609; D.A.C.L., VIII, 1113, 6607-6630 (véritable bestiaire).

157 (Liturgie de saint Basile). D.A.C.L., 1111; $\mathrm{n}^{0}$ 54; même formule sur une lampe de Gerasa (Arabie), datée de 744-745. Mgr DeVREESSE, Le patriarcat d'Antioche... jusqu'à la conquête arabe, 224.

158 D.A.C.L., VIII, 1086 et s.

159 Musée de Stamboul, catal. ${ }^{\circ} 270$.

160 G. SCHLUMBERGER, Un polycandilon byzantin, B.Z., II, 441-443; D.A.C.L., XIV, 1939, 13561360 .
} 
guerre ${ }^{161}$. On se servait aussi de torches, par exemple chez Théodore Prodrome ${ }^{162}$.

Il faut comprendre aussi dans le mobilier tous les objets, batterie de cuisine, objets de toilette, nécessaires à la vie quotidienne d'une famille. Dans un poème adressé à son bienfaiteur le sébastocrator ${ }^{163}$, Théodore Prodrome énumère toutes les dépenses nécessaires à la réparation de ses outils et de sa batterie de cuisine, et qu'il ne peut supporter. Il lui faut donner sans cesse de l'argent pour le coquemar (коико $\mu \mathrm{v}$, bouilloire), pour le crible à sasser le blé ou la farine, pour la torche, pour le rat de cave (on connaissait aussi les briquets à amadou) ${ }^{164}$, sans parler des provisions de combustibles et comestibles indispensables dans un ménage. A cette énumération on peut ajouter des objets de toilette (on a découvert un cure-oreilles en or du $\mathrm{X}^{\mathrm{e}}$ siècle, avec inscription exprimant des souhaits pour son propriétaire) ${ }^{165}$, des brûle-parfums en bronze ajouré provenant d'Égypte ${ }^{166}$, des balances et des poids ${ }^{167}$, des horloges (sabliers ou horloges hydrauliques) ${ }^{168}$. Un texte du Livre des Cérémonies, énumérant les objets emportés par un basileus en campagne, montre qu'on n'ignorait pas les chaises percées ${ }^{169}$.

\section{Le costume}

Retour à la Table des Matières

On a vu par l'exemple de plusieurs testaments que les vêtements étaient assez solides pour se transmettre d'une génération à l'autre : 
on les considérait comme un capital, qui entrait en ligne de compte dans l'évaluation d'une fortune.

Les formes du costume antique se sont conservées longtemps, mais transformées par l'emploi des étoffes de soie, dont les plis cassants n'avaient plus la souplesse du drap ou du lin. Des manteaux, comme la chlamyde, parfois brochée d'or, n'étaient plus drapés, mais tombaient raide. De là une décence étrangère à l'antiquité païenne : les vêtements ne dessinent plus la forme du corps, s'allongent de plus en plus et sont presque les mêmes pour les deux sexes. Des modes barbares apparaissent, notamment l'usage des fourrures, prohibé inutilement par une loi d'Honorius ${ }^{170}$.

Période ancienne. - Aux $\mathrm{V}^{\mathrm{e}}$ et $\mathrm{VI}^{\mathrm{e}}$ siècles, le vétement essentiel est toujours la tunique de drap ou de lin (sticharion), unique vêtement des ouvriers au travail, comme le montre la mosaïque de Yakto ${ }^{171}$, où des artisans la portent courte, relevée aux hanches par une ceinture et attachée seulement sur l'épaule gauche; plus loin, un manœuvre n'a d'autre vêtement qu'un pagne, sorte de caleçon très collant.

Les tuniques des classes aisées étaient souvent en soie et de couleurs variées : sur la mosaïque de Yakto on en voit une sans manches, indiquant une condition modeste, d'autres avec manches, ornées de bandes (clavi) verticales ou horizontales ${ }^{172}$. Suivant une mode orientale, des tuniques de luxe étaient décorées de bandes d'or cousues ou tissées dans l'étoffe (paragaudia). Le nom fut donné à la tunique ellemême, dont une loi de Valens réserva l'usage à certains dignitaires et à leurs femmes (369) ${ }^{173}$ et on la voit portée encore au $\mathrm{X}^{\mathrm{e}}$ siècle par les ostiarii (huissiers) dans les cérémonies palatines ${ }^{174}$.

Sur les tuniques étaient jetés des manteaux de forme diverse. Un personnage de la mosaïque de Yakto porte un ample manteau rouge (lacerna) sur sa tunique blanche à bandes horizontales ${ }^{175}$. Le camasus (кó $\mu \alpha \sigma \circ \varsigma)$ que Grégoire de Nazianze lègue à un diacre était un grand

J. Lassus, Antioch-in-the-Orontes, 140; Holmes, The age of Justinian and Theodora, I, 86; H. WeISS, Kostümkunde. Geschichte der Tracht und des Geräthes im Mittelalter, II, 23.

171 J. LASSUS, op. cit., 153, $\mathrm{n}^{\text {os }} 11,39,48,49$.

172 Ibidem, 153, ns 12, 14, 24, 25; HOLMES, The age of Justinian and Theodora, I, 87.

173 C. Th., X, XXI, 1; Testament de saint Grégoire de Nazianze, 76, 258.

174 Constantin VII Porphyrogenete, op. cit., I, 34 (V, I, 132).

175 J. LASSUS, op. cit., $\mathrm{n}^{\circ} 14$. 
manteau pelucheux à l'intérieur et à longs poils à l'extérieur ${ }^{176}$. Certains manteaux (pallia sigilliona) étaient ornés de figures brodées ou tissées, dont les sujets étaient empruntés aux Écritures, comme la toge d'un sénateur du $\mathrm{VI}^{\mathrm{e}}$ siècle, dans laquelle était tissé le cycle entier de la vie du Christ ${ }^{177}$.

Un manteau d'origine ancienne est la planète, vaste couverture ronde, percée au centre d'un trou pour passer la tête, tandis que les bords étaient relevés par les bras. Elle est d'origine romaine, mentionnée par Pline l'Ancien et Varron et désignée sous les noms divers de paenula, casula, infula, planeta, phenolion. Avant de devenir la chasuble ecclésiastique, elle fut un vêtement civil, vêtement de pluie ou de voyage, munie parfois d'un capuchon. Elle était portée par les gens du peuple et même, d'après Procope, par les esclaves ${ }^{178}$. C'est le vêtement des personnages figurés sur les mosaïques de SaintApollinaire-le-Nouveau à Ravenne dans le cycle de la Vie publique et des Miracles du Christ.

Le costume féminin consiste dans la longue tunique talaire à manches souvent brodées, sur laquelle est quelquefois jeté un voile (palla). Sur la mosaïque de Yakto ce voile est rouge et posé sur une coiffe blanche. Une autre femme porte une longue robe jaune à ceinture basse et un voile rougeâtre retombant en plis sur l'épaule droite. Elle tient à la main un enfant vêtu d'une tunique à manches, serrée à la taille et ornée de clavi comme les tuniques d'Antinoé ${ }^{179}$.

Les splendides mosaïques de Ravenne montrent ce qu'était le costume de cour au temps de Justinien et de Théodora. A SaintApollinaire-le-Nouveau, les martyrs, qui se dirigent en procession vers la Vierge, portent une longue tunique blanche ornée de deux rangs de feuillages et, entre ceux-ci, d'une large bande de pourpre et d'or aux dessins variés et un manteau broché d'or à manches courtes, drapé de biais pour laisser voir la tunique et bordé de perles séparées par des émeraudes. Les perles et les pierreries sont semées à profusion

\footnotetext{
Testament de saint Grégoire de Nazianze, 250-263.

D'après un sermon de Théodoret, évêque de Cyr, † 458, P.G., 83, 617; BREHIER, L'Art chrétien. Son développement iconographique, 60; Testament de saint Grégoire de Naztanze; cf. l'Adoration des Mages sur la robe de Théodora à Saint-Vital de Ravenne.

178 Procope DE CESAREE, De Bellis, Vand. II, 26; D.A.C.L., III, 1914; DIEHL, Ravenne (« Villes d'art célèbres »).

179 J. LASSUS, op. cit., 132 et s., $154 \mathrm{n}^{\text {os }} 10,18,45$.
} 
sur la ceinture qui enserre la taille, sur le large collet qui contourne la robe à la naissance du cou, sur le bandeau qui retient les cheveux relevés au sommet de la tête, d'où part un voile aérien qui descend sur les épaules ${ }^{180}$. A Saint-Vital, les suivantes de Théodora portent un costume aussi riche et assez semblable, mais les tuniques et les manteaux, disposés comme à Saint-Apollinaire, sont des couleurs les plus variées et les plus chaudes. Les thèmes géométriques, les étoiles, les fleurettes qui les décorent, diffèrent pour chacune d'elles et rappellent la décoration des tissus coptes ${ }^{181}$.

Transformation du costume. - Au contact des peuples barbares et des Orientaux, des modes nouvelles apparaissent au VII ${ }^{\mathrm{e}}$ siècle. Aux vêtements qui étaient encore de coupe classique, larges et longs, plus ou moins drapés, succèdent des vêtements étroits et collés au corps. Le plus caractéristique est le scaramange, justaucorps muni d'un collet et fermé sur la poitrine et sous la taille, mais fendu par derrière avec des basques tombant jusqu'aux genoux.

Le scaramange est en réalité un vêtement de cheval, qui vient du pays des cavaliers nomades, des steppes asiatiques. On le trouve déjà figuré sur un dessin découvert à Doura-Europos, et dans deux peintures du temple des dieux palmyréniens (III ${ }^{\mathrm{e}}$ siècle) ${ }^{182}$. Il fut adopté par la cavalerie p044 sassanide et ce fut au cours des guerres avec la Perse qu'il fut importé à Byzance. Il est représenté sur des objets provenant de l'Altaï (statuette de cavalier en or massif, ancien Musée de l'Ermitage), quelquefois en soie, fourré de zibeline à l'intérieur, et sur des étoffes chinoises ${ }^{183}$. Au $\mathrm{X}^{\mathrm{e}}$ siècle, le scaramange est porté par les dignitaires palatins et par l'empereur lui-même, surtout quand il va à cheval ${ }^{184}$; il est alors teint des nuances les plus délicates et souvent rehaussé d'or, et il finit par être adopté dans toutes les cérémonies et jusqu'à la fin de l'Empire ${ }^{185}$.

J. EBERSOlt, Les arts somptuaires de Byzance, 42; DieHL, La peinture byzantine (dans Histoire de l'Art byzantin), pl. 7.

DIEHL, op. cit., pl. 10.

182 F. CUMONT, L'uniforme de la cavalerie orientale et le costume byzantin, 181.

183 N. KonDAKOv, Les costumes orientaux à la cour byzantine, 19 et s., et A.C.E.B., Bucarest, I (1924) (étoffes de Mozat et de Bamberg).

184 CONSTANTIN VII PORPHYROGENETE, I, 97; KONDAKOV, op. cit., 12-16.

185 Pseudo-Codinus, De officialibus palatii, IV, 17; KONDAKOV, op. cit., 40 et s. 
Le costume populaire a subi la même transformation, le même rétrécissement. La tunique, jadis large, devient un habit étroit à manches

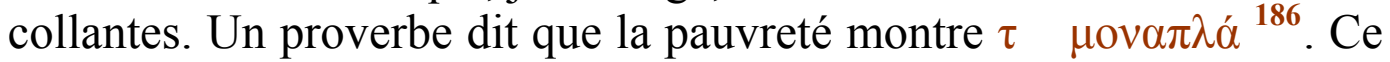
terme de monaplon désignerait un tissu léger et peu serré. Des chausses collantes couvraient le genou ou même toute la jambe et, depuis le $\mathrm{V}^{\mathrm{e}}$ siècle, on avait abandonné les sandales antiques pour les souliers orientaux ou les bottines ${ }^{187}$. Les ouvriers portaient aussi un court manteau, himation, hypokamisos ${ }^{188}$.

Les costumes des hautes classes consistaient en tuniques, qui enveloppaient le corps tout entier, et en vêtements de dessus, qui tombaient jusqu'aux pieds. Entre les vêtements des deux sexes il n'y avait presque pas de différence. Luitprand remarque que, contrairement aux Francs, les Grecs portent des manteaux traînants à longues manches, avec des cheveux longs qui accentuent le caractère féminin de ce costume ${ }^{189}$. Lorsque, au $\mathrm{X}^{\mathrm{e}}$ siècle, le basileus partait en expédition, il emportait des vêtements d'apparat, destinés à être distribués : des scaramanges de couleurs variées et historiés de thèmes décoratifs tissés dans l'étoffe et empruntés à la faune (paons, aigles, lions) (on donnait à ces vêtements le nom du sujet qui les ornait), enfin, des colobia, vêtements de maison de plusieurs nuances ${ }^{190}$.

Si les pièces du costume restaient les mêmes, les modes n'en variaient pas moins au cours des âges.

Le donateur d'un évangéliaire, fonctionnaire de thème du temps de Basile II, le proximos Jean, d'origine arménienne, s'est fait représenter vêtu d'une tunique azurée tombant jusqu'aux genoux, à manches longues et serrées ; par-dessus, un lourd manteau de pourpre galonné d'or, à manches larges, et fendu dans le bas pour faciliter la marche ; enfin, le buste est enveloppé d'une sorte de gilet brodé d'or, à manches très courtes et froncées comme des ruches, semblable à une cuirasse d'or, mais Adontz, qui a publié ce portrait, y voit la partie supérieure du manteau ${ }^{191}$.

\footnotetext{
186 Psellos, Discours..., V, 161; Koukoules, Sur quelques vêtements byzantins, IV, 94 et s.

187 H. WEISS, Kostümkunde. Geschichte der Tracht und des Geräthes im Mittelalter, II, 7274, fig. 34 et 35 . Les hauts dignitaires portaient des souliers bas ouverts sur le devant (campagia), les cavaliers des bottes (tsangia) et, au XII ${ }^{\mathrm{e}}$ siècle, les élégants des chaussures à longues pointes :

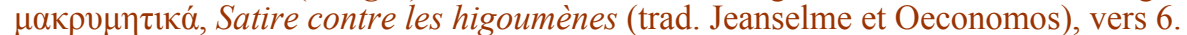
Vie de saint Philarète le Miséricordieux, 135; Théodore PRODROME, Poèmes, 62 et s. LUITPRAND, Relatio de legatione; H. WeISS, op. cit., II, 81 et s. Constantin VII Porphyrogenete, app. I, 9-10, et II, 2 (P.G, 112, 884 et s., 984 et n. 77). ADONTZ, Notes arméno-byzantines, B.N., 1935, 169-170 (planche en couleur).
} 
Sous les Comnènes, les vêtements avaient atteint un luxe qui frappait les voyageurs, comme Benjamin de Tudèle ${ }^{192}$. Le chroniqueur français Eude de Deuil, qui a vu les ambassadeurs envoyés par Manuel Comnène au roi Louis VII à Ratisbonne, écrit qu'ils portaient de riches habits de soie, courts, bien serrés, avec des manches étroites, « ce qui les rend lestes et dégagés comme des athlètes " ${ }^{193}$. Il s'agit là d'une mode nouvelle. Cet habit court ressemble à celui que portait Andronic Comnène en 1182 : une robe violette de toile d'Ibérie, ouverte sur le devant et s'arrêtant aux genoux, ne lui couvrant les bras

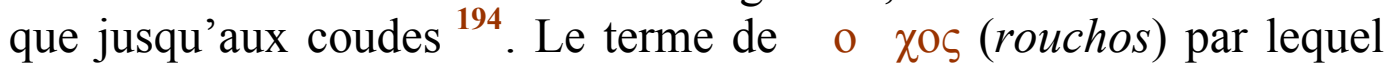
Nicétas désigne ce vêtement viendrait du mot germanique rock, ce qui indiquerait un vêtement occidental analogue au bliaud ${ }^{195}$.

Cette mode devait être passagère et, à l'époque des Paléologues, les vêtements étaient redevenus longs et se rapprochaient de plus en plus des modèles orientaux : tunique dorée et ample manteau vert semé de fleurettes pourpres (Théodore Métochitès sur le tympan en mosaïque de Kahrié-Djami, vers 1300) ${ }^{196}$; long caftan d'un vert bronze foncé, historié de médaillons cernant des griffons adossés, et serré à la taille (le mégaduc Apokaukos, 1341-1345, au frontispice d'un manuscrit d'Hippocrate) ${ }^{197}$.

D'après Nicéphore Grégoras, les édits d'Andronic II réglementant le costume et la coiffure des nobles furent oubliés sous son successeur (1328-1341) et les élégants adoptèrent des costumes étrangers : on ne vit bientôt plus que des habits et des bonnets à la bulgare, à la triballe (serbes), à la syrienne, à l'italienne ${ }^{198}$. Tel était le skaranikon, vêtement de plusieurs couleurs divisées par des bandes et à fond blanc, regardé comme d'origine persane ${ }^{199}$.

Coiffures. - Les coiffures, peu usitées dans l'antiquité classique, sauf en voyage, étaient au contraire d'un usage courant en Orient,

\footnotetext{
H. WeISS, op. cit., II, 81 et s.; BenJAMIN DE Tulede, Voyages.

EUDE DE DEUIL, De Ludovici VII profectione in Orientem, II.

NicETAs Khoniates, Histoire, P.G. $(139,140)$, Alexis II, 11; Andronic, I, 2.

Pseudo-CodinUs, De officialibus palatii, note de Gretser, 223.

Th. SchmitT, Kahrié-Djami, 89, pl. 58.

Paris, gr. 2144, XIV s., f $\mathrm{f}^{\mathrm{o}} 11 \mathrm{a}$; J. EBERSOLT, La Miniature, byzantine, pl. LVIII.

NICEPHORE GREGORAS, Histoire romaine, XI, 11.

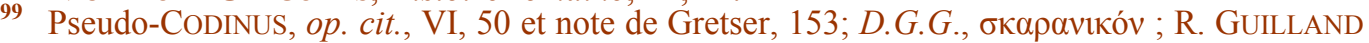
dans B.N., 1948, 127 et s.
} 
d'où la mode en vint à Byzance. A la fin $\mathrm{du} \mathrm{X}^{\mathrm{e}}$ siècle, le proximos Jean portait sur ses longs cheveux blonds un bonnet souple, bleu clair, fixé par un ruban croisé par devant ${ }^{200}$. Michel VI (1046-1057) imposa à tous ses sujets le port d'un bonnet de lin teint en rouge, qu'il avait porté dans sa jeunesse ${ }^{201}$. La coiffure faisait partie des insignes des dignitaires et était donc sévèrement réglementée. Ceux qui entourent Nicéphore Botaniatès au frontispice d'un manuscrit (1078-1081) portent des bonnets rouges ou blancs, qui leur cachent le front et sont munis de glands ${ }^{202}$.

Un chapitre du pseudo-Codinus décrit les coiffures des dignitaires : le tissu, la forme, la couleur, les dimensions, les broderies, la décoration en perles ou pierreries, tout y est minutieusement réglé ${ }^{203}$. Au $\mathrm{XIV}^{\mathrm{e}}$ siècle, certains de ces couvre-chefs atteignaient des dimensions extravagantes, comme celui de Théodore Métochitès à Kahrié-Djami : c'est une sorte de haut bonnet de soie blanche, strié de bandes rouges, de plus en plus large dans le haut ${ }^{204}$. La toupha était une tiare surmontée d'un haut panache de plumes retombant autour de la tête ; Justinien la portait sur sa statue du Forum Augustaeon ${ }^{205}$. Le skiadion était un bonnet commun aux laïcs et aux ecclésiastiques ${ }^{206}$. La kalyptra, en forme de pyramide, avait été empruntée aux Turcs, mais Andronic Comnène, l'usurpateur, la portait déjà ${ }^{207}$. Le kamelaukion était une haute calotte conique, divisée en secteurs réunis au sommet par un gros bouton avec un large bord par derrière et sur le front, où il formait une longue visière. C'est le chapeau que porte Jean VIII Paléologue (1425-1448) sur son buste du Vatican, sur une médaille de Pisanello et sur un relief des portes de Saint-Pierre de Rome. A l'église de la Pantanassa de Mistra, un personnage porte le même chapeau, qui est une coiffure civile sans caractère officiel et dont l'origine paraît très ancienne; il a été comparé aux chapeaux de feutre à bords re-

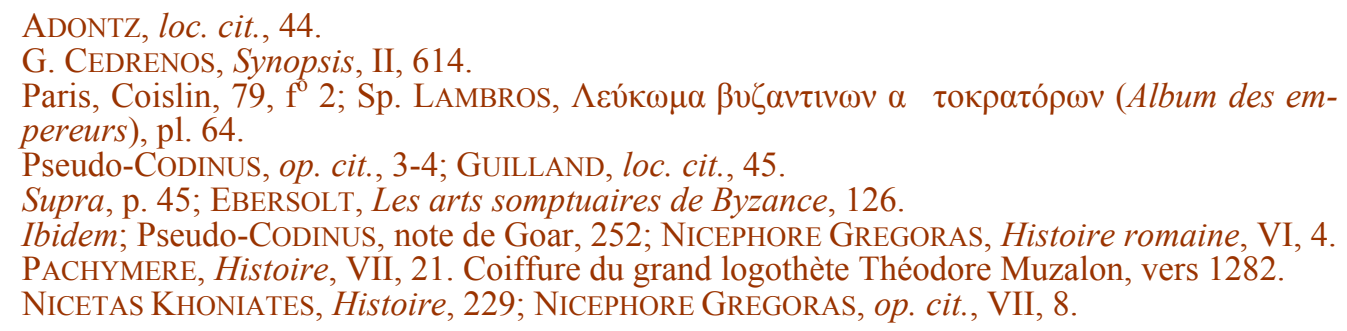


troussés par derrière et à pointe par devant ${ }^{208}$, à la mode en France au $\mathrm{XV}^{\mathrm{e}}$ siècle ; la ressemblance est en effet certaine et ce serait une importation française, probablement par l'intermédiaire de la Morée franque ${ }^{209}$.

Cheveux et barbe. - Dans la période ancienne, les hautes classes, suivant l'usage des Romains, se rasaient la barbe et portaient les cheveux courts. Seuls les philosophes conservaient leur barbe, et l'on sait quelles railleries excitait celle de l'empereur Julien. Sous Justinien, les Bleus firent scandale en portant la barbe et les moustaches, en laissant pousser leurs cheveux par derrière et les coupant sur le front à la mode des Huns ${ }^{210}$. Le premier empereur qui porta la barbe, ce qui lui valut le surnom de Pogonat, fut Constantin IV (668-685), bien que, sur la mosaïque de Ravenne, il soit figuré entièrement rasé ${ }^{211}$.

Les pouvoirs publics, l'Église comme l'État, attachaient la plus grande importance à la question ${ }^{212}$. Les conciles s'élevaient contre les hommes qui portaient leurs cheveux en tresse comme des femmes ou des boucles (obtenues à l'aide de bigoudis) tombant jusqu'à la ceinture $^{213}$. D'autres teignaient barbe et cheveux en noir avec des œufs de corbeaux ${ }^{214}$. Constantin V aurait ordonné à ses sujets de se raser la barbe $^{215}$ et Théophile, qui était chauve, aurait pris la même mesure pour le port des cheveux, mais, comme l'a montré Bury, il s'agirait d'un règlement militaire ${ }^{216}$. Toujours est-il que la question de la barbe a tenu une place parmi les griefs qui aboutirent au schisme entre les patriarches de Constantinople et l'Église romaine ${ }^{217}$. Pour les Grecs, la barbe était le signe de la dignité qui séparait l'homme de l'eunuque $^{218}$. On rasait les cheveux et la barbe aux criminels ${ }^{219}$ et,

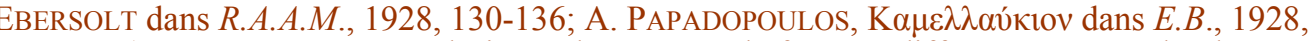
293 et s. (Le même terme a pu désigner des couvre-chefs assez différents, comme la plus ancienne tiare papale.) C. EnLART, Le Costume (Manuels d'archéologie fr. III), 169, fig. 160-162; G. Millet, Monuments byzantins de Mistra, pl. 90, 4 et 152, 4. PROCOPE DE CESAREE, Anecdota, VII, 9; KOUKOULES, La coiffure des Byzantins, 14 L. BREHIER, Nouvelles recherches sur l'histoire de la sculpture byzantine, pl. 31 et 33. Il en était encore ainsi en Italie après 1815 et en France sous Napoléon III. KouKOUles, op.cit., 4 et s.; Concile in Trullo (692), canon 6. MAZARIS, Dialogos nekrikos (Descente aux Enfers), 135.

Vie de saint Etienne le Nouveau, P.G., 113 (paraît suspect).

16 Theophanes, Continuatus, XVII, 107-109; J. B. BURY, History of the Eastern Roman Empire (802-867), 121, 1.

217 L. BREHIER, Le schisme oriental du XI siècle, 184 et s.

218 D'où l'emploi fréquent de l'épithète de $\beta \alpha \rho \beta \alpha ́ \tau \tau o s$, passée en roumain, en opposition aux eunuques glabres. 
dans une curieuse conversation que Peró Tafur, à son retour d'Orient, eut à Ferrare avec Jean VIII (fin de 1437), le basileus reprocha à l'Espagnol d'avoir rasé la barbe qu'il avait laissé pousser pendant son voyage, en lui disant qu'elle était pour un homme un signe de dignité et d'honneur ${ }^{220}$.

Costume féminin. - Depuis la période ancienne, le costume féminin a moins changé que celui des hommes, bien qu'il n'ait plus la même ampleur et accuse moins les formes du corps. Les monuments figurés sont rares, car on ne connaît guère que des portraits d'impératrices et de princesses dans leur costume officiel. Les deux pièces essentielles sont toujours la tunique (sticharion) à bordure plus ou moins riche et un manteau (himation), de forme variable : tantôt une pièce carrée ou rectangulaire, tantôt un segment de cercle (paenula), dont on plaçait le bord supérieur sur l'épaule en le laissant retomber par devant. S'il y avait assez d'étoffe, on faisait passer le pan de l'épaule gauche sur l'épaule droite et inversement, le bord supérieur couvrant la tête. Cette ordonnance devint la marque de l'honnête femme et fut employée pour représenter la Vierge. Un autre genre de manteau, semblable à la chlamyde masculine, était attaché sur une épaule avec une fibule ${ }^{221}$.

Sur la couronne envoyée par Constantin Monomaque à un roi de Hongrie sont représentées deux Vertus, l'Humilité et la Vérité, ainsi que deux danseuses en mouvement, agitant une écharpe au-dessus de leur tête. Ces quatre figures portent le même costume : un manteau court serré à la taille par une ceinture gemmée et une jupe longue tombant jusqu'aux pieds. Le justaucorps des danseuses est plus court et leur jupe d'une plus grande ampleur, mais les pièces du costume sont les mêmes, les couleurs aussi chatoyantes, les ornements aussi riches ${ }^{222}$.

Tous ces vêtements étaient en soie, dont on connaissait plusieurs variétés, mais les élégantes employaient aussi le lin, venu d'Égypte,

AnNe Comnene, Alexiade, XII, 7, III, 77.

DIEHL, Un voyageur espagnol à Constantinople, Peró Tafur, 119-120.

H. WEISS, Kostümkunde. Geschichte der Tracht und des Geräthes im Mittelalter, II, 76. Cf. Naomi Mitchison, Anna Comnena (portrait d'Anne Cornnène restitué d'après les textes; voile semblable à celui des Madones).

222 L. BReHIER, La Sculpture et les Arts mineurs byzantins, pl. LXV; Duthuit-VolBACH, Art byzantin, pl. 60 . 
du Pont et de Macédoine. On recherchait les étoffes fines, les tissus dits aériens, $v \varepsilon \mu i ́ \tau \sigma 1 \alpha$, en dépit des reproches des prédicateurs contre l'indécence des costumes trop transparents ${ }^{223}$.

Coiffure féminine. - De tout temps aussi les coiffures compliquées des Grecques étaient flétries sans succès du haut de la chaire ${ }^{224}$. Les dames d'Antinoé aplatissaient la chevelure sur le haut de la tête et la faisaient retomber de chaque côté en énormes coques ${ }^{225}$. Aux $\mathrm{V}^{\mathrm{e}}$ et $\mathrm{VI}^{\mathrm{e}}$ siècles prédominait dans les hautes classes la coiffure en bourrelet sur le front, retenue par des cordons de perles fines; on y a vu, sans trop de preuves, une perruque ${ }^{226}$. Cependant à toutes les époques, l'usage des perruques n'était pas rare chez les deux sexes ${ }^{227}$. De même, les femmes ont aimé de tout temps les cheveux frisés sur le front et les boucles tombant en grappes sur les tempes, en les divisant par une raie médiane ${ }^{228}$. Les cheveux étaient parfois enfermés dans une résille, faite de lacets d'or et d'argent, ou retenus sur la nuque par de larges peignes d'ivoire et d'écaille ou par un bandeau de lin ${ }^{229}$. La femme de Philarète ( $\mathrm{VIII}^{\mathrm{e}}$ siècle) portait sur la tête un phakiolion, sorte de turban ${ }^{230}$. Enfin, quelle que fût la coiffure, une femme honnête, hors de sa maison, devait toujours s'envelopper la tête d'un voile ${ }^{231}$.

L'usage des parfums, dont la fabrication était l'occupation favorite de l'impératrice Zoé ${ }^{232}$, et celui des fards étaient le complément obligatoire de la toilette féminine. La mode était aux sourcils minces teints en noir et accompagnant des yeux noirs, agrandis avec le khôl obtenu par la carbonisation incomplète de diverses plantes grasses ${ }^{233}$. $\mathrm{Au} \mathrm{XV}$ siècle, Jean Eugénikos, nomophylax de Thessalonique, adressait, bien inutilement, une violente mercuriale aux femmes qui teignaient en rouge leurs lèvres et leurs joues, et en noir les sourcils et

\footnotetext{
KouKoules, Sur quelques vêtements byzantins, 1939, 142-164.

Saint Jean Chrysostome, Homélies, P.G., 59, 520 (Contre les femmes qui frisent leurs cheveux et les ornent d'or); Saint GrEGOIRE DE NAZIANZE, Homélies, 884.

G. SCHLumBerger, La journée d'une élégante à Antinoé. Lectures pour tous, II, août 1900, p. 963-972. 
les paupières; il les montrait s'enfermant soigneusement, pour que nul ne vînt les déranger pendant cette opération ${ }^{234}$.

Parures et bijoux. - Les bijoux, les perles fines, les pierres précieuses étaient beaucoup plus répandus dans la société byzantine qu'en Occident. Afin d'empêcher la fuite de la monnaie impériale dans l'Inde, Léon ${ }^{\text {er }}$ publia une loi somptuaire qui montre que les particuliers ornaient de perles, d'émeraudes et d'améthystes les brides, les selles et jusqu'aux mors de leurs chevaux, leurs ceinturons, les fibules qui attachaient leurs chlamydes ${ }^{235}$.

Les monuments figurés montrent que les deux sexes recherchaient également les joyaux, qui valaient d'ailleurs plus par leur caractère artistique que par la profusion de matières précieuses : or en lames minces, perles minuscules, pierreries sans valeur ${ }^{236}$. Les collections publiques ou privées possèdent de nombreux exemplaires de bijoux qui concordent avec ceux des costumes représentés sur les monuments. Tels sont ceux du trésor de Mersine (Asie Mineure) (colliers de médaillons avec pendentifs, boucles d'oreille en forme de poires, ornés en filigrane d'animaux divers, découverts en grand nombre dans d'autres centres (ancien Musée de l'Ermitage). Le trésor de Kérynia (Chypre, collection Morgan) contenait une ceinture d'or faite de 16 médaillons, dont les plus grands représentent un empereur sur un quadrige (au nom de Maurice et Tibère, 582-602), des bracelets d'or décorés de pampres, des colliers de feuilles ajourées auxquelles sont suspendues des croix, des pendants d'oreille garnis d'oiseaux affrontés ${ }^{237}$.

Ce ne sont là que quelques spécimens des parures charmantes qui ornaient les costumes. Il faut y joindre les bagues d'or, joliment historiées de feuillages ou d'animaux stylisés, avec des inscriptions au nom de leur propriétaire ${ }^{238}$, des objets de caractère religieux (bagues à

\footnotetext{
Eustratiades dans E.B., 1931, 42-46.

C.J., XI, 12; H. MonNIER, Les novelles de Léon le Sage, 115.

E. MOLINIER, Histoire générale des arts appliqués à l'industrie, 45.

DAlton, Byzantine Art and Archaeology, 35; L. BREHIER, La Sculpture et les Arts mineurs byzantins, 44-45.

238 BREHIER, op. cit., pl. LXXIII, LXXIV (VII ${ }^{\mathrm{e}}-\mathrm{XI}{ }^{\mathrm{e}}$ s.); DuTHUIT-VOLBACH, Art byzantin, pl. 49 A; G. SCHLUMBERGER. dans A.I.C.R., 1905, 139 et s.
} 
thèmes iconographiques, croix pectorales, petits eukolpia ou reliquaires) ${ }^{239}$, et enfin des fibules.

Les fibules tenaient moins de place dans le costume byzantin, composé surtout de pièces cousues et ajustées, que dans les vêtements drapés des anciens, mais on les recherchait comme parure et on distinguait la $\pi \varepsilon \rho o ́ v \eta$, agrafe en forme d'arc, et la $\pi$ ó $\pi \eta$ (à Rome fibula), disque, bouclier. La première servait à attacher la chlamyde sur l'épaule au $\mathrm{VI}^{\mathrm{e}}$ siècle ${ }^{240}$, la seconde était le fermail qui fixait un manteau sur la poitrine. Ces fibules étaient en or, en argent, en bronze, rehaussées de perles et de pierreries, historiées d'ornements et même de figures, garnies de pendentifs comme celle qui attache la chlamyde de Justinien sur la mosaïque de Saint-Vital à Ravenne. On les considérait souvent comme des insignes et, malgré l'abandon de la chlamyde au $\mathrm{XII}^{\mathrm{e}}$ siècle, elles ne disparurent pas du costume impérial. Au couronnement de l'empereur Baudouin, en 1204, "lui pendit-on au cou une grande et moult riche pierre au lieu de fermail, que l'empereur Manuel avait achetée 7200 marcs » ${ }^{241}$.

\section{Les repas}

$\underline{\text { Retour à la Table des Matières }}$

Les repas se prenaient en famille, mais, en cas d'invitation d'étrangers, les femmes n'y paraissaient pas ${ }^{242}$.

Coutumes des repas. - Il y avait trois repas : le $\pi \rho o ́ \gamma \varepsilon v \mu \alpha$ (progeuma), déjeuner du matin; le $\gamma \varepsilon \mu \alpha$ (geuma), au milieu du jour; le $\delta \varepsilon \pi v o v$ (deipnon), souper, à la fin du jogur. On appelait $\rho \imath \sigma \tau o v$ (ariston), le repas du milieu ${ }^{243}$.

G. Schlumberger dans B.Z., 1893; Frolow dans R.E.S., 1944 (Vatopédi, xiv ${ }^{\mathrm{e}}$ siècle).

Justinien, Théodora et leur suite à Saint-Vital de Ravenne.

BJElAIEV, Fibules byzantines, 49 et s.; ROBERT DE CLARI, La conqueste de Constantinople, 95; KalintinskiJ, La question des fibules en Russie, M.O., I, 377-386.

242 Vie de saint Philarète le Miséricordieux, 138 et s.

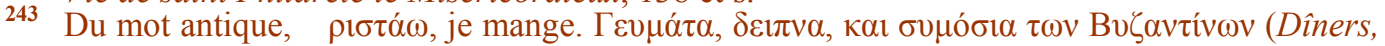
soupers et banquets), E.B., 1932, p. 97-99. 
La maîtresse de maison épongeait la table et la recouvrait de la nappe, $\mu \varepsilon v \sigma \alpha ́ \lambda$ rov, plus ou moins riche ${ }^{244}$. Sur la table étaient disposées des serviettes (mandylia), ainsi que des bols à laver les mains, ce qui était la preuve d'une bonne éducation ${ }^{245}$. L'usage de manger couché sur un lit autour d'une table ronde ou en sigma se maintint dans les maisons riches jusqu'au $\mathrm{X}^{\mathrm{e}}$ siècle et fut abandonné, sauf aux festins solennels du Palais Sacré. Procope montre Théodora arrivant chez un noble au milieu d'un repas et s'installant sur un lit ${ }^{246}$. Dans ce cas, la place d'honneur était à gauche de l'amphitryon ${ }^{247}$.

Les convives changeaient de chaussures avant de se mettre à table. $\mathrm{Au}$ moment où il apprit l'invasion de Bohémond (octobre 1107), Alexis Comnène était en train de dénouer les cordons de ses souliers pour aller dîner. « Et maintenant, dit-il, mettons-nous à table ${ }^{248}$. »

Assis sur des chaises ou des bancs, les convives récitaient d'abord une prière qui correspondait au Bénédicité ${ }^{249}$. Il arrivait qu'il n'y eût, sur les tables des gens peu fortunés, qu'une écuelle en bois ou en terre, dans laquelle chacun des convives puisait sa nourriture avec ses mains, d'où la nécessité de se laver les mains avant et après les repas ${ }^{250}$. Cependant, on connaissait les cuillers, mais celles qu'on a pu découvrir (trésors de Lampsaque et de Kérynia) sont des couverts luxueux en argent, décorées d'animaux et d'inscriptions niellées. Elles ne devaient pas être d'un usage courant ${ }^{251}$.

On a même la preuve que la fourchette n'était pas inconnue. Une grande fourchette à deux ou trois dents (fuscinula) était d'un emploi courant dans les sacrifices juifs et païens. On en fabriqua de plus petites et on s'en servit, dès l'antiquité, dans les repas ${ }^{252}$. La fourchette se conserva en Orient et fut introduite à Byzance. Elle figure couram-

\footnotetext{
LUITPRAND, Relatio de legatione, II, 32 (remarque l'étroitesse de la nappe impériale).

5 Eustathe de Thessalonique, Opuscula, P.G., 136, 664 D; D. C. Hesseling, Essai sur la civilisation byzantine, 247.

246 Procope de CeSAREe, Anecdota, 61, 15. Dans la figuration de la Cène, Jésus et les Apôtres sont toujours couchés autour d'une table en sigma.

CONSTANTIN VII PORPHYROGENETE, De caerimoniis aulae byzantinae, II (Vogt, II, 57).

ANNE COMNENE, Alexiade, XII, 9, 7 (III, 85).

Dîners, soupers et banquets, E.B., 1932, 130 et s.

Ibidem, 105 et s, 129.

Dalton, Byzantine Art and Archaeology, 567, 573; Duthuit-VolBaCH, Art byzantin, pl. 53. G. DE Jerphanion, La Voix des Monuments, II, 244 et s. (historique de l'emploi ancien de la fourchette).
} 
ment sur les tables représentées dans la vie publique du Christ sur les fresques des églises cappadociennes (Noces de Cana, Cène) ${ }^{253}$. Un texte décisif montre son emploi, au moins à la cour. Une princesse impériale qui avait épousé un doge de Venise avait apporté dans sa nouvelle patrie tous les raffinements de la cour de Byzance ; en particulier, elle se servait pour manger de fourchettes d'or à deux dents, mais elle en fut sévèrement blâmée par le principal apôtre de la réforme ecclésiastique Pierre Damien ${ }^{254}$.

Vaisselle et verrerie. - Des peintures de manuscrits représentent des festins dont les tables sont chargées de vaisselle et de verrerie, plats, assiettes, tasses, écuelles, vases de toute grandeur, coupes, burettes, etc. ${ }^{255}$. Les noms de ces objets sont donnés par les écrivains et dénotent une grande variété de récipients, les uns luxueux, d'autres tout à fait communs ${ }^{256}$. Les fouilles nombreuses exécutées depuis dix ans à Constantinople et sur le territoire des anciennes provinces de l'Empire ont permis de mieux connaître cette céramique, grâce aux innombrables débris exhumés ${ }^{257}$. Comme à l'époque romaine, on employait la terre cuite non vernissée pour la vaisselle commune : vases, plats, amphores, ampoules, parfois en terre brune avec reliefs (terra sigillata), parfois avec figures peintes en noir sur fond blanc (animaux, têtes humaines) ${ }^{258}$. Dans les ménages aisés, la poterie vernissée, originaire d'Orient, paraissait seule sur les tables. A côté de pièces de musées, comme la célèbre coupe de Constantin (Christ trônant entre l'empereur et Fausta) ${ }^{259}$, le bol à fond vert clair, historié d'un guerrier courant, lance et bouclier en avant ${ }^{260}$, ou le bassin du Musée du Louvre, dont le fond est occupé par une tête grotesque au triple menton ${ }^{261}$, on a pu reconstituer, avec les milliers de tessons dé-

253 Cappadoce, p1.65, 7; 101; 177, 2; 281, 1. Le manche se termine parfois par un bouton circu-

4 PIERRE DAMIEN, Institutio monialis : «furcinulis aurets atque bidentibus » (mariage de Domenico Silvo avec une fille de Constantin Doukas, 1049); Th. OUSPENSKY, Le procès d'hérésie de Jean Italos, 23 et s.

255 H. BORDIER, Peintures des manuscrits grecs de la Bibliothèque Nationale, 236 (Comment. sur Job, Paris, gr. 135, fo 9a, a.1368); DIEHL, Manuel d'Art byzantin, 880, fig. 435; StrZYGOWSKI, Die Miniaturen de serbischen Psalter, 46, pl. XXVIII; G. Millet, Monuments byzantins de Mistra, pl. 120; DIEHL, La Peinture byzantine, pl. XLVIII (festin d'Hérode). KOUKOULES, dans E.B., 1933, 108 et s.

Sera étudiée ch. VII.

DALTON, op. cit., 606 et s. (fragments de Baouit).

Ibidem, 609 et s.; D.A.C.L.. III, 2465, fig. 3240.

Catalogue de l'Exposition d'Art byzantin de 1931, nº 626.

L. BREHIER, La Sculpture et les Arts mineurs byzantins, pl. LXXVI. 
couverts, les principaux modèles courants, remarquables par la variété de leur coloris et de leur ornementation : thèmes géométriques, tresses, spirales, damiers, feuillages, animaux réels ou fantastiques, plus rarement figure humaine. Certaines pièces datées de l'époque macédonienne ont un aspect métallique qui les apparente à la faience hispano-mauresque ${ }^{262}$.

La verrerie n'était pas moins remarquable. Les fabriques syriennes avaient conservé leur antique renommée. A la fin $\mathrm{du} \mathrm{XI}^{\mathrm{e}}$ siècle, le moine occidental Théophile vante la supériorité de la verrerie byzantine, ses belles coupes et fioles en verre coloré, orné de feuillages, d'animaux et d'hommes. Malheureusement on ne connaît guère que des pièces de grand luxe, dont la plus belle collection est au trésor de Saint-Marc de Venise ; la plupart des pièces sont montées sur orfèvrerie $^{263}$.

Ordre d'un repas. Nourriture. - Théodore Prodrome décrit ironiquement les repas sommaires, mais substantiels, de son voisin le savetier. Dès l'aurore il se fait acheter des tripes et du fromage valaque, boit quatre grandes rasades de vin et se met au travail. A midi il jette son alène et donne à sa femme le menu : bouilli, matelote, ragoût. Il se lave, s'assied, boit du vin doux dans un grand gobelet, dit son bénédicité et mange ${ }^{264}$.

Dans les maisons aisées on faisait plus de cérémonie. Il y avait trois services ou entrées ( $\mu$ ívбor) : des hors-d'œuvre propres à exciter l'appétit ( $\tau \pi \rho \circ \delta$ ó $\pi \tau 1 \alpha)$, des viandes rôties $(\tau \quad$ o $\tau \tau$ ó $\mu 1 v \sigma o v)$, le des-

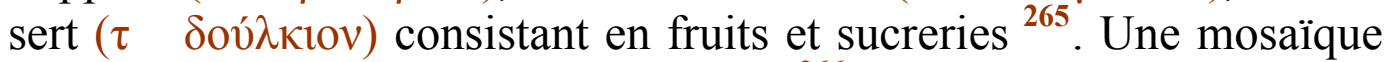
découverte à Daphné près d'Antioche ${ }^{266}$ montre les plats d'argent d'un repas ainsi ordonné, préparés sur une table de marbre noir : gros artichauts et saucière de sauce blanche ; pieds de cochon grillés ; œufs dans des coquetiers d'émail bleu, avec petites cuillers à longs man-

263

(1)

265

266

M. R. Demangel, Contribution à la topographie de l'Hebdomon, 136 et s.; BAXTER, The Great Palace of the Byzantine Emperors, 57 et s.

EBERSOLT, Les arts somptuaires de Byzance, 11 et s.; DiEHL, Manuel d'Art byzantin, 710; SCHLUMBERGER, Le siège, la prise et le sac de Constantinople par les Turcs en 1453, I, 697; II, 421, 441, 513.

THEODORE Prodrome, Poèmes prodromiques (à Jean Comnène, vers 54-63); DieHL, Figures byzantines, II, 54.

J. B. BURY, The imperial administrative System in the ninth Century (Philotée, ch. 3); KoukOules, dans E.B., 1933, 133.

FISCHER, Fouilles de l'Université de Princeton (Antioche, 1933-36). 
ches ; poisson, dit capitaine, à la chair blanche ; jambon ; canard rôti ; gâteaux faits de couches de biscuits, et beaux fruits. Sur la table, des pains ronds et un grand canthare de vin.

Ce repas somptueux d'allure très moderne ne nous renseigne pas sur les mets favoris et la cuisine des classes bourgeoises. Le iatrosophiste (médecin) Hiérophile $\left(\mathrm{XI}^{\mathrm{e}}-\mathrm{XII}^{\mathrm{e}} \mathrm{s}\right.$.) a joint à un calendrier de régime, d'inspiration hippocratique, un certain nombre de recettes caractéristiques que l'on peut compléter par celles qui figurent dans la Satire contre les higoumènes, pamphlet attribué à Theodore Prodrome $^{267}$. On voit, d'après ces renseignements, que la cuisine était très épicée, à grand renfort de poivre, de cannelle, de moutarde et d'ail, comme le montre la recette du porc rôti arrosé de vin miellé. On aimait les olives confites dans la saumure, le garum, sauce préparée avec le sang du garus (poisson de mer). A la viande de boucherie et à la volaille, on joignait dans les menus le gibier rôti. A un festin impérial, l'ambassadeur Luitprand reçoit de Nicéphore Phocas un chevreau farci d'ail, d'oignons et de poireaux, nageant dans la saumure ${ }^{268}$.

Les poissons indiqués par Hiérophile sont le skorpias (scorpen provençal), le surmulet, le cabot, la dorade avec assaisonnement d'aromates. On les frit avec de la farine de moutarde, on les entoure d'une sauce avec nard et coriandre. D'après la Satire contre les higoumènes, on les mange bouillis, avec une sauce épaisse de purée de merluche. La même pièce atteste la consommation de poissons salés, de scombres (maquereaux) et de palamèdes, méprisés ainsi que le caviar ; par contre, les grenouilles, les esturgeons, les limandes sont très recherchés et le thon est regardé comme une nourriture commune ${ }^{269}$.

Hiérophile recommande de manger des légumes et des salades avec la viande, et n'indique que le pourpier cuit avec sauce au garum, la laitue, la blette, le chou, le melon et les figues blanches avec du sel, les fèves, la trigonnelle, les haricots réduits en farine, les lentilles, les asperges, les champignons. Comme dessert, il préconise les fruits secs, raisins, amandes, pistaches, pommes de pin, pommes cuites et, pour les gourmets, de la compote de coing, des grenades, des dattes, 
de la crème au miel et au nard ${ }^{270}$. Les higoumènes terminaient leur

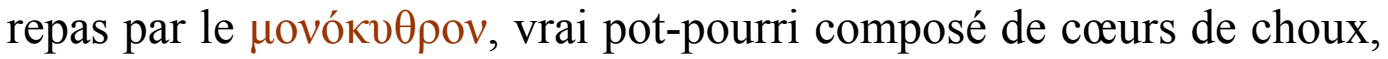
de poissons salés et fumés de Transoxiane, de 14 œufs, de plusieurs sortes de fromages, d'huile, de poivre, de 12 têtes d'ail, de 15 maquereaux secs, le tout arrosé d'une écuelle de vin doux ${ }^{271}$.

Les jours d'abstinence et surtout le grand carême étaient scrupuleusement observés. Par une vraie bizarrerie, le poisson proprement dit était défendu comme aliment gras, tandis que les crustacés et les coquillages étaient considérés comme maigres. Le fromage était per-

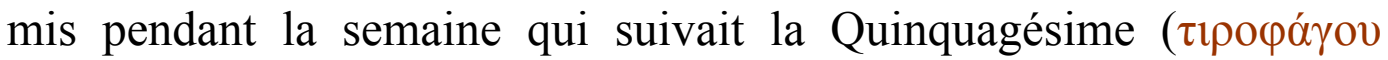
$\beta \delta o ́ \mu \alpha \varsigma$ semaine du fromage) et interdit à partir du premier dimanche du carême ${ }^{272}$.

Les médecins, imbus de la doctrine d'Hippocrate sur les humeurs, publiaient des calendriers indiquant pour chaque saison et même chaque mois les mets favorables ou nocifs. Leur vogue paraît avoir été grande ${ }^{273}$.

En dehors des vins indigènes, on recherchait les vins de Chypre, de Syrie, de Palestine, d'Afrique du Nord. Au VI è siècle, grâce aux colonies de Syriens, la réputation des vins de Gaza avait pénétré jusqu'en Gaule $^{274}$, mais l'expansion de l'islam, à partir du VII ${ }^{\mathrm{e}}$ siècle, ruina la viticulture méditerranéenne. Pour conserver les vins de Grèce, on y mêlait déjà de la poix, de la cire et même du plâtre. Luitprand déclare qu'ils n'étaient pas buvables ${ }^{275}$.

Le pain de pure farine de froment indigène, $\kappa \alpha \theta \alpha \rho \quad \varsigma \quad \rho \tau o \varsigma$, était universellement recherché et figurait sur presque toutes les tables byzantines, sauf sur celles des indigents. On distinguait trois qualités de pains. Les deux premières différaient d'après la finesse du tamisage, la troisième, couleur de son et comportant des farines étrangères, était considérée comme impure ${ }^{276}$. Les higoumènes mangeaient du pain de

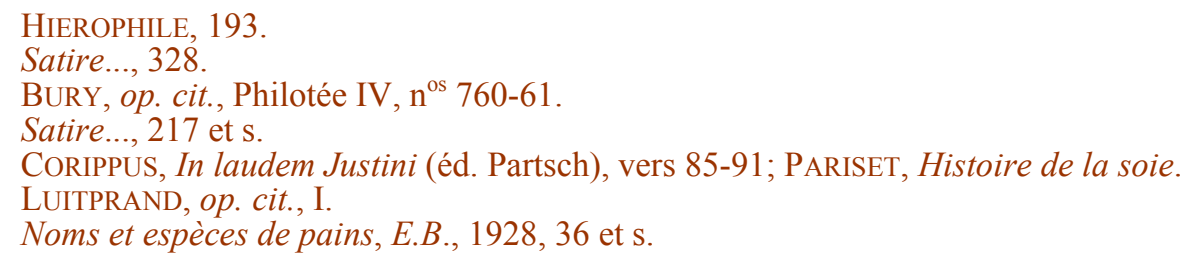


semoule ( $\sigma \varepsilon \mu \imath \delta \alpha ́ \lambda \iota v o v)$, les moines un grossier pain de son ( $\pi \imath \varepsilon \varepsilon \rho \alpha ́ \tau o v)$ ou roulé dans la cendre ${ }^{277}$.

\section{Les bains}

$\underline{\text { Retour à la Table des Matières }}$

Sauf dans les palais et les très grandes maisons, où il existait des bains privés, les particuliers continuaient comme dans l'antiquité à se servir des thermes publics où, ainsi qu'on l'a vu, les femmes ellesmêmes étaient admises à certaines heures. Le goût très vif des Byzantins pour les bains est attesté par le grand nombre de thermes, élevés la plupart du temps par des empereurs à Constantinople et dans les villes de province. Ils portaient en général le nom de leur fondateur ${ }^{278}$.

Ce goût pour les bains était si vif qu'on se baignait souvent plusieurs fois par jour aux $\mathrm{V}^{\mathrm{e}}$ et $\mathrm{VI}^{\mathrm{e}}$ siècles et même des ecclésiastiques avaient cette habitude, condamnée par des médecins comme Alexandre de Tralles ${ }^{279}$. Puis il y eut à partir du VIII ${ }^{\mathrm{e}}$ siècle une réaction marquée contre l'abus des bains, due surtout aux progrès de l'ascétisme. S'abstenir de bains fut regardé comme une œuvre méritoire, bien que l'on ait continué à construire des thermes dans les monastères ${ }^{280}$. On en arriva au XII ${ }^{\mathrm{e}}$ siècle à regarder comme excessif de prendre trois bains par semaine ${ }^{281}$ et les calendriers de régime en prescrivaient de trois à huit par mois suivant la saison. L'heure préférée était généralement la huitième ou la neuvième au milieu du jour, et les femmes se baignaient seulement à la dixième heure ${ }^{282}$.

L'organisation des thermes n'avait guère varié depuis l'époque romaine. Le plus grand luxe était déployé dans les thermes importants : façades magnifiquement ornées de colonnes et de sculptures,

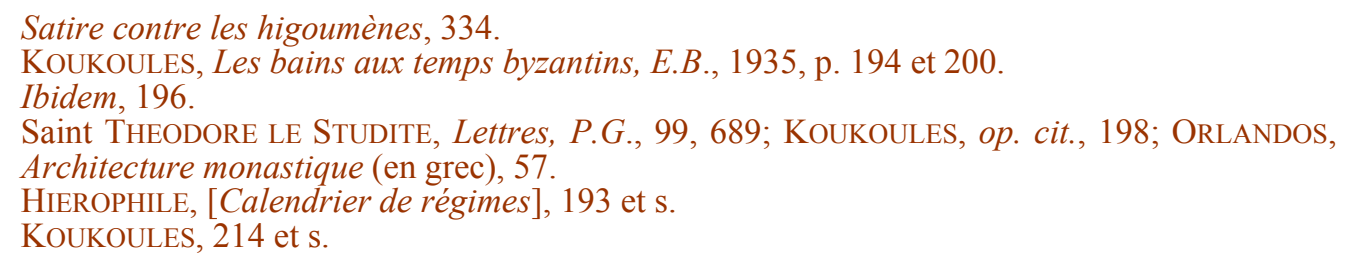


souvent mythologiques; à l'intérieur, mosaïques murales figurant des scènes de théâtre ou de palestres, des portraits d'empereurs ou de philosophes, des astres sous la forme humaine et, aux thermes de Zeuxippe, tout un monde de statues antiques ${ }^{283}$.

De grands vestibules conduisaient aux galeries qui flanquaient les salles principales, avec des vestiaires et même des latrines. L'espace où l'on se baignait avait, comme les anciennes étuves, la forme d'une rotonde couverte en coupole (tholos). L'eau était chauffée dans une chaudière de bronze fixée sur un fourneau de fer ou de pierres ignifuges. La cuve, d'où l'eau coulait dans la baignoire par un tuyau terminé par une tête d'homme ou d'animal, ressemblait à un grand tonneau, qui contenait toujours de l'eau tiède ${ }^{284}$. Enfin il est question chez les écrivains d'étuves destinées aux bains de vapeur et chauffées comme à l'époque romaine par des hypocaustes ${ }^{285}$. Les thermes avaient en outre des piscines, soit d'eau chaude, soit d'eau froide, dans lesquelles on pouvait nager ${ }^{286}$. Cette organisation, qui fonctionnait admirablement au temps de Justinien, existait encore au $\mathrm{X}^{\mathrm{e}}$ siècle, mais ensuite on en perd les traces.

Retour à la Table des Matières

Ibidem, 206 et s.

Ibidem, 209 et $\mathrm{s}$

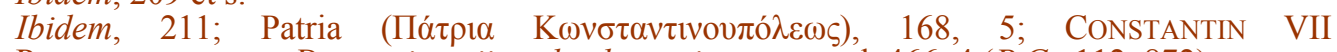
Porphyrogenete, De caerimoniis aulae byzantinae, append. 466, 4 (P.G., 112, 872).

KOUKOULES, op. cit., 206. 


\section{Chapitre III \\ La vie privée des empereurs}

\section{Comment se pose la question}

$\underline{\text { Retour à la Table des Matières }}$

La vie officielle d'un basileus a été décrite dans l'Histoire des institutions. On peut y voir le nombre imposant de fêtes et de solennités auxquelles il prenait part suivant les rites d'une véritable liturgie, plus ancienne que celle de l'Église et qui fut conservée jusqu'à la fin de l'Empire $^{287}$.

Trompés par les apparences et tenant compte exclusivement des rituels de cour tels que le Livre des Cérémonies, d'éminents historiens, Rambaud, par exemple, ont présenté la vie d'un basileus comme une cérémonie perpétuelle, une vie vraiment pontificale, qui ne lui laissait aucun loisir. Une étiquette inéluctable « lui dictait l'emploi de chaque jour de l'année. Il passait sa vie au milieu des cantiques, des psaumes, des processions ${ }^{288}$. Le rapprochement, quelquefois établi, entre la vie quotidienne d'un basileus et celle que menait Louis XIV à Versailles, est un pur anachronisme. L'étiquette de la cour de France est d'origine féodale : elle dérive des services domestiques, considérés comme tout à fait honorables, que des vassaux devaient à leur suzerain. C'est par une simple métaphore qu'on donne le nom de liturgie à ces usages.

\footnotetext{
M.B.E.H. (Institutions), 1. I ${ }^{\mathrm{er}}$, ch. II, éd. 1970, 58-71.

A. RAMBAUD, Etudes sur l'histoire byzantine, 207.
} 
En réalité, la vie officielle d'un empereur, fonction publique, n'occupait ni tous ses instants, ni même toutes ses journées. Il n'était pas continuellement occupé de cérémonies, de conseils, de silentia, mais, en marge de ses occupations officielles, il menait une vie domestique comme tous ses sujets. On ne connaissait à Byzance ni le grand, ni le petit lever. Des subalternes, des eunuques, des esclaves s'acquittaient, à l'intérieur du koïton, de services réservés, à Versailles, à des princes du sang.

Sans doute les cérémonies énumérées dans le Livre des Cérémonies ou dans les Offices du pseudo-Codinus paraissent former un nombre effarant, mais beaucoup furent introduites dans le calendrier impérial à des époques différentes et d'autres tombèrent en désuétude. Au reste, l'histoire de la vie de cour à Byzance comprend deux périodes, séparées par l'avènement des Comnènes. Du $\mathrm{V}^{\mathrm{e}}$ au XII ${ }^{\mathrm{e}}$ siècle la tradition romaine, renforcée d'emprunts à l'étiquette de la cour persane, fut la source de la liturgie impériale, qui atteignit son maximum d'extension au $X^{\mathrm{e}}$ siècle. Sous les Comnènes, l'influence occidentale, due aux contacts multipliés avec les croisés, l'abandon du Grand Palais pour les Blachernes, eurent pour résultat la simplification de l'étiquette et la suppression de beaucoup de cérémonies ; ce mouvement fut encore accentué sous les Paléologues, à mesure que diminuèrent les ressources de l'État ${ }^{289}$.

\section{Du v $v^{e}$ au $X^{e}{ }^{e}$ siècle}

$\underline{\text { Retour à la Table des Matières }}$

L'appartement impérial. - Au Grand Palais on distinguait des salles d'apparat, destinées aux réceptions (Chalcé, Magnaure, Tribunal des Dix-Neuf Lits) et les appartements installés au palais de Daphné, entourés de hautes murailles. D'autres salles de réception, élevées au-delà de Daphné (Chrysotriclinium, Justinianos), ne se confondirent jamais avec la demeure privée de la famille impériale. 
$\mathrm{Au} \mathrm{VI}^{\mathrm{e}}$ siècle, Justinien continua à habiter la maison, relativement modeste, située sur la Propontide, où il résidait avant son avènement. Il se levait avant l'aurore, se couchait très tard et, sans souci d'aucune étiquette, se relevait la nuit pour travailler ou se promener en médi$\operatorname{tant}{ }^{290}$.

$\mathrm{Au} \mathrm{X}^{\mathrm{e}}$ siècle, une étiquette très simple régnait dans les appartements impériaux. Le pappias (portier) ouvrait les portes du palais dès l'aurore. Un cubiculaire éveillait le basileus en frappant trois coups à sa porte avec une clef. Celui-ci, une fois habillé, se rendait à la salle du trône, où il priait devant une icône, puis donnait audience à ses conseillers ou à des étrangers. Lorsqu'il les avait congédiés, le pappias agitait ses clefs pour faire sortir tout le monde et le palais était fermé à la troisième heure ${ }^{291}$.

Ruptures avec l'étiquette. - On est étonné de la liberté d'allure de certains empereurs, qui sortaient du palais la nuit, sans aucune suite, pour inspecter les rues de Constantinople. Léon VI voulut ainsi s'assurer par lui-même que les postes de police, disposés aux carrefours, pour ramasser les vagabonds et les emprisonner jusqu'au lendemain, faisaient consciencieusement leur service. Sorti du palais, il se heurta à un premier poste et se racheta avec 12 nomismata. Au deuxième poste il se racheta encore, mais au troisième, il fut dépouillé de ses vêtements, battu et emprisonné. Le lendemain il se fit reconnaître du portier de la prison et put en sortir. Rentré au palais, il fit châtier ceux qui l'avaient laissé passer et récompenser ceux qui l'avaient arrêté $^{292}$.

Le même prince alla surprendre un soir les moines du monastère de Psamathia, dont son père spirituel, Euthyme, était higoumène. Pour entrer il fit résonner le marteau de la porte d'entrée, comme un simple particulier, et voulut dîner avec les moines ${ }^{293}$.

\footnotetext{
290 Le Blant, Inscriptions chrétiennes de la Gaule, Aed. I, 7 (p. 32-33), An. 12-13 (p. 82, 88-89); DIEHL, Justinien et la civilisation byzantine au VI siècle, 17.

291 Constantin VII Porphyrogenete, op. cit., II, 1; EBersolt, Mélanges d'histoire et d'archéologie byzantines, 17.

292 LuITPRAND, Antapodosis, I, 11, 277

293 Vie de saint Euthyme, patriarche, IX, 1-18, p. 27.
} 
Le triste Michel IV le Paphlagonien (1034-1041), se sentant environné de complots, se livrait aussi aux expéditions nocturnes. Il partait du palais à cheval et galopait à travers les rues. Les habitants, qui ne l'ignoraient pas, restaient chez eux et les conciliabules devenaient ainsi impossibles ${ }^{294}$.

La table impériale. - De nombreux témoignages montrent qu'à l'exception des festins solennels, fixés par le calendrier de la cour, le basileus mangeait avec sa famille, sans plus de cérémonie que ses sujets, servi, non par de hauts dignitaires, mais par des esclaves.

On ne voit pas d'ailleurs que la table impériale fût plus luxueusement servie que celle des particuliers. Celle de Justinien l'était même beaucoup moins : il ne mangeait jamais de viande et ne buvait pas de vin; il se nourrissait d'herbes sauvages conservées dans du sel et du vinaigre et jeûnait parfois deux jours de suite aux veilles des fêtes ${ }^{295}$. De même Nicéphore Phocas, qui menait au palais la vie d'un ascète, ne consentit à manger de la viande que lorsque ses directeurs de conscience lui en eurent donné l'ordre ${ }^{296}$. Basile II vivait avec la simplicité d'un soldat ${ }^{297}$.

Trait caractéristique surtout, qui montre combien les coutumes byzantines ressemblaient peu à l'étiquette de Versailles, les empereurs dînaient en famille avec l'impératrice et leurs enfants ${ }^{298}$ et surtout, honneur que Louis XIV ne fit jamais à personne, invitaient leurs sujets à leur table. Il est vrai que le marchand de cire que Nicéphore $\mathrm{I}^{\mathrm{er}}$ invita à dîner, dut payer cette faveur de presque toute sa fortune ${ }^{299}$, mais c'est là un cas exceptionnel. On voit Michel III, au cours d'une chasse, s'asseoir à table avec Théodora, sa mère, plusieurs sénateurs et son écuyer, Basile, le futur empereur ${ }^{300}$. Léon VI fait manger avec lui dans la plus belle salle du palais Constantin Doukas, qui s'était échappé de sa prison de Bagdad, où son père, Andronic, avait été

\footnotetext{
PSELlos, Chronographie, XII $(1,59)$.

Procope de Cesaree, De Aedificiis, I, 7, p. 32; Anecdota, 13 (p. 88 et s.). (Concordance entre les deux textes : DIEHL, Justinien et la civilisation byzantine au VI siècle, 17.)

LEON LE DIACRE, Histoires, III, 9.

PSEllos, op. cit., I, 4; DiEHL, Choses et gens de Byzance, I, 333.

CONSTANTIN VII PORPHYROGENETE, op. cit., II, 15 TheOPHANES, Continuatus, 161-104.

Theophanes le COnfesseur, Chronographie, 487 et s.; HeYD, Histoire $d u$ commerce $d u$ Levant (trad. Furcy-Reynaud), 206.

300 Theophanes, Continuatus, op cit., 248.
} 
massacré ${ }^{301}$. Nicéphore Phocas reçoit Luitprand, ambassadeur d'Otton le Grand, au Palais de la Source et le retient à dîner; pendant le repas il fait lire un commentaire de saint Jean Chrysostome sur les Actes des apôtres ${ }^{302}$. Citons encore le repas où Nicéphore Botaniatès, sentant son trône ébranlé, convie le grand-domestique Alexis Comnène et son frère Isaac, plaçant l'un à sa droite, l'autre à sa gauche. D'autres invités garnissaient la table et le service était fait par des esclaves, sous la direction d'un maître d'hôtel ${ }^{303}$.

Parfois même, ni plus ni moins que chez quelque bon bourgeois, un perroquet égayait les convives et ce fut grâce à cette circonstance que le futur Léon VI sortit de la prison où Basile, son père, l'avait enfermé $^{304}$. Enfin les empereurs s'invitaient sans cérémonie à dîner chez leurs sujets ou acceptaient leur hospitalité. Nous avons cité Léon VI s'asseyant à la table des moines de Psamathia, qu'il va surprendre un soir ${ }^{305}$. Le même prince accepte en 908 l'invitation d'un magnat, Constantin Lips, à assister à l'inauguration d'une église qu'il a construite près des Saints-Apôtres et déjeune avec lui ${ }^{306}$. Michel III, chevauchant à la tête de son escorte, aperçoit une pauvre femme sortant d'un bain, descend de cheval et lui demande de le recevoir pour manger du pain de son et du fromage piquant: embarras de la femme qui n'a pas de provisions chez elle, mais l'empereur s'improvise cuisinier et sommelier, déjeune avec son hôtesse et rentre à pied au palais ${ }^{307}$.

Occupations personnelles. - Ainsi, en dépit d'un calendrier chargé de nombreuses fêtes et des obligations créées par le gouvernement de l'Empire, il restait encore assez de temps aux empereurs pour faire place dans leur vie à des occupations toutes personnelles, qui variaient suivant leurs goûts.

En dehors de la célébration des fêtes de l'Église, la dévotion privée tenait une grande place dans la vie de la plupart des souverains. Le Grand Palais avait ses sanctuaires, où les clercs de la chapelle célé-

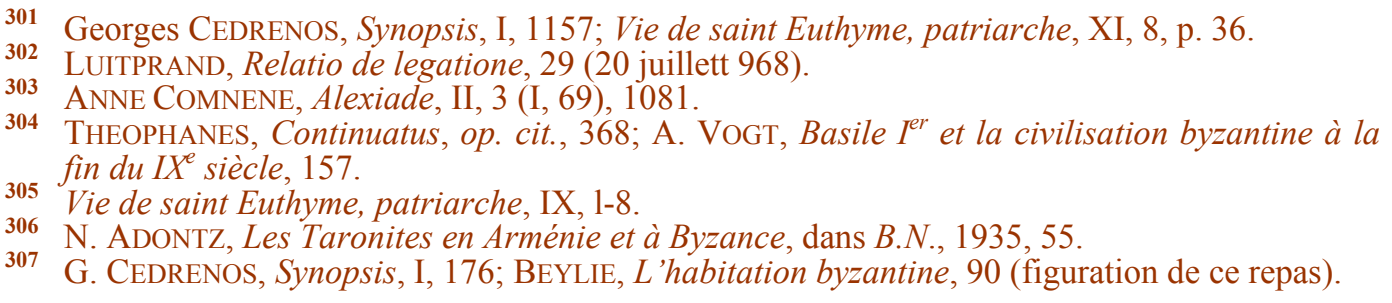


braient les offices, et certains empereurs aimaient à se mêler aux chœurs des chantres, comme Léon l'Arménien, assassiné pendant qu'il chantait matines, la nuit du 26 décembre 820, et Théophile, qui dirigeait lui-même des chœurs et faisait exécuter des hymnes de sa composition ${ }^{308}$. D'autres, comme Nicéphore Phocas et Michel IV, menaient sous la pourpre une vie ascétique ${ }^{309}$.

Plusieurs souverains devaient à leur éducation le goût de la littérature, de l'éloquence, de la théologie, de l'art, de la musique. Théodose II passait une partie de la nuit à lire et, pour permettre à ses serviteurs de dormir, se servait d'une lampe perfectionnée, entretenue automatiquement. Il savait aussi modeler, peindre et calligraphier ${ }^{310}$. Au $\mathrm{X}^{\mathrm{e}}$ siècle, Constantin Porphyrogénète avait les mêmes occupations, mais avec une variété plus grande d'aptitudes : peintre, orfèvre, sculpteur, musicien, versé dans les arts mécaniques, historien, archéologue, d'un savoir encyclopédique ${ }^{311}$. Les ouvrages écrits par lui-même ou sous sa direction forment encore aujourd'hui une des sources essentielles de notre connaissance du monde byzantin ${ }^{312}$. Léon VI, son père, est aussi un intellectuel, mais de moindre envergure. Comme d'autres empereurs, il joignait à ses goûts littéraires celui des sciences occultes ${ }^{313}$.

Mais les occupations plus frivoles n'étaient pas rares. Ainsi que dans la plupart des cours du moyen âge, il y avait au Palais Sacré des fous, des nains, des bouffons qui égayaient les souverains par leurs facéties et leur liberté de langage, comme le fou de Théophile, Denderis ${ }^{314}$, comme le favori de Constantin Monomaque, Romain Boïlas, dont le bégaiement comique et les facéties d'un goût douteux faisaient la joie de la cour ${ }^{315}$.

\footnotetext{
Theophanes, Continuatus, 120-21. LeOn Le DiACRE, Histoires, V, 5-6.

DieHL, Dans l'Orient byzantin, 752 et s.; Id., Choses et gens de Byzance, III, 321; Psellos, Chronographie, 74-75.

310 Socrate, Histoire ecclésiastique, VII, 22; Sozomene, Histoire ecclésiastique, Préface et IX, 13.

311 Theophanes, Continuatus, VI, 25, 36.

312 A. Rambaud, L'Empire grec au X Xiècle. Constantin Porphyrogénète; G. MoRAVCSIK, Byzantino-turcica. I : Die byzantinischen Quellen der Geschichte der Türkvölker, 204 et s.

Vie de saint Euthyme, patriarche, 10, p. 69.

314 Sp. Lambros, Les bouffons des empereurs byzantins (en grec); THeOphanes, Continuatus, $172,88$.

315 PSELlos, Chronographie, II, 38-45.
} 
D'autres empereurs se délassaient en jouant aux dés. Une épigramme de l'Anthologie Palatine décrit une partie de Zénon à un jeu qui ressemblait au trictrac ou au jacquet ${ }^{316}$. Au XI ${ }^{\mathrm{e}}$ siècle, l'incapable Constantin VIII était si passionné pour ce jeu qu'il y passait une partie de la nuit et faisait attendre des ambassadeurs pour ne pas interrompre une partie commencée ${ }^{317}$. Le jeu des échecs, venu de l'Inde par l'inter-médiaire de la Perse, était connu aussi à Byzance depuis le $\mathrm{VI}^{\mathrm{e}}$ siècle ${ }^{318}$.

La plupart des empereurs trouvaient aussi le temps de s'adonner à des sports variés dans l'enceinte même du Grand Palais. Théodose II, qui s'exerçait au tir à l'arc et à lancer le javelot ${ }^{319}$, passe pour avoir mis à la mode un jeu de balle d'origine iranienne qui se jouait à cheval et n'est autre que le polo, importé en même temps en Chine et, sous le nom de tzykanisterion, à Byzance ${ }^{320}$. Ce jeu devint le sport favori des empereurs, qui s'y livraient avec des dignitaires, dans un manège disposé à l'intérieur du palais ${ }^{321}$. Les joueurs se servaient pour pousser la balle d'un maillet terminé en forme de raquette recourbée (tzykanion). Divisés en deux camps, ils se lançaient tour à tour la balle ${ }^{322}$. Des stades réservés à ce jeu existaient à Éphèse et à Trébizonde ${ }^{323}$.

Les empereurs aimaient aussi le jeu de paume ${ }^{324}$, ainsi que le spectacle des luttes athlétiques, pugilat, pancrace, etc. ${ }^{325}$, et l'hippodrome situé à l'entrée du Bosphore, au faubourg Saint-Mamas, parait avoir été réservé à leur usage, comme le montre l'exemple de Michel III, qui y conduisait des chars sous la livrée des Bleus ${ }^{326}$. La chasse était surtout le passe-temps favori de la plupart des empereurs. Michel III,

Anthologia graeca epigrammatum Palatina cum Planudea (éd. Stadtmüller), III, nº 82.

PSELLOS, I, 30.

LeBEAU, Histoire du Bas-Empire (éd. revue par Saint-Martin), IX, 222.

SOCRATE, op. cit., VII, 22.

Po-lo, mot thibétain désignant une balle en bois de saule; à l'origine ce jeu aurait été un exercice militaire d'entraînement. Introduit au XVII siècle dans l'Inde, à la cour du Grand Mogol, il passa de là en Angleterre au XIX ${ }^{\mathrm{e}}$ siècle. (Notice de R. Grousset, musée Cernuschi, qui expose des statuettes chinoises de joueurs de polo d'époque Tang, VIII ${ }^{\mathrm{e}}-\mathrm{IX}^{\mathrm{e}}$ siècle.)

Theophanes, Continuatus, III, 43; Constantin VII Porphyrogenete, De admistrando imperio, IX, 173; EBERSOLT, Le Grand Palais de Constantinople, 140 et s.

Luttes, jeux athlétiques, tournois, 114-117 (représenté sur une miniature persane du $\mathrm{XV}^{\mathrm{e}} \mathrm{s}$.).

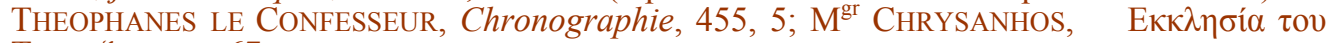

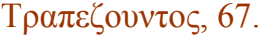

Theophanes, Continuatus, VI, 397 (le 6 juin 913 le basileus Alexandre fut pris d'un coup de sang après une partie et mourut deux jours après).

PSELlOS, Chronographie, VIII, 6-7 (1, 28-30).

Theophanes, Continuatus, IV, 35, 212 et s.; Pseudo-Symeon, Magister, Chronique, 714; PARGOIRE, Les Saints Mamas, I.R.I., IX, 1904, 273. 
Basile $\mathrm{I}^{\mathrm{er}}$, Romain II, Isaac Comnène sont cités comme de grands chasseurs. Les empereurs avaient à leur portée l'agréable parc du Philopation situé à l'extérieur de la Grande Muraille, clos de murs, boisé, giboyeux, bien arrosé ${ }^{327}$, mais ils partaient aussi en véritables expéditions, escortés de l'Hétairie, en Thrace ou en Asie Mineure. On voyait Romain II présider les jeux de l'Hippodrome le matin, dîner ensuite avec des sénateurs, puis jouer au tzykanisterion et gagner plusieurs parties, enfin, le soir venu, aller chasser en Asie et rentrer au palais après avoir tué quatre sangliers ${ }^{328}$. Aussi passionné pour la chasse, Isaac Comnène chevauchait en poussant de grands cris pour exciter ses chiens et arrêtait le gibier en pleine course en le perçant d'une flèche. Il chassait aussi au faucon et lançait la javeline contre les ours et les sangliers ${ }^{329}$. Loin d'habiter toujours le Palais Sacré, les souverains allaient souvent se reposer dans les nombreux palais qu'ils possédaient dans la banlieue de Constantinople, soit près de la Grande $\mathrm{Mu}-$ raille (palais de la Source), soit au voisinage de la Corne d'Or (Lac d'Argent), soit sur la rive européenne de la Propontide (Hebdomon) ou, en face, sur la côte d'Asie (Chalcédoine, Hiéria où se tint le concile iconoclaste de 754$){ }^{330}$. Comme leurs sujets, ils fréquentaient les sources thermales de la région volcanique située au pied de l'Olympe de Bithynie, entre Brousse et Eski-Schehr (Dorylée). Là se trouvaient les Thermes Pythiens reconstruits par Justinien et où Théodora se rendait avec une escorte de 4000 hommes ${ }^{331}$. Ces bains continuèrent à être fréquentés par les empereurs jusqu'au $\mathrm{X}^{\mathrm{e}}$ siècle ${ }^{332}$.

327 F. Chalandon, Les Comnène, II, 7-8; Theophanes, Continuatus, V, 14-15, 248; G. BuCKLER, Anna Comnena, 299.

Theophanes, Continuatus, VI, 5, 492; Diehl, Dans l'Orient byzantin, 254 et s.

329 PSELlOS, Chronographie, VII, 72-73 (128 et s.).

330 PARgOIRE, L'amour de la campagne à Byzance et les villas impériales, E.O., 1908, XI, 15 et Hieria, I.R.I., IV, 1899.

331 Procope de CeSAree, De Aedificiis, V, 3, 156; Theophanes le Confesseur, Chronographie, 186.

332 Theophanes le Confesseur, 196; Theophanes, Continuatus, VI, 49, 184; PaUl LE Silentiaire, Poèmes, 355-364 (S.-G. Mercati, Rivista di Studi Orientali, 1924, a montré que le véritable auteur du poème est Léon Magister, qui l'a dédié à Constantin VII). 


\section{Des Comnènes à la fin de l'Empire}

$\underline{\text { Retour à la Table des Matières }}$

Transformation de la vie palatine. - L'avènement des Comnènes amène de grands changements dans la vie officielle du basileus, devenue de moins en moins absorbante. L'étiquette n'a pas disparu, la pompe des cérémonies n'est pas moins grande, mais leur nombre a diminué et la liberté d'allure des empereurs et de leur entourage est beaucoup plus accentuée.

Ces changements sont dus aux contacts plus fréquents et plus intimes avec les Occidentaux, les Francs, alors en grande faveur et peu soucieux de l'étiquette. Leur influence augmenta encore après les deux mariages successifs de Manuel Comnène avec des princesses franques, Berthe de Sulzbach en 1146 et Marie d'Antioche en 1161.

D'autre part, les trois premiers Comnènes sont des hommes de guerre, plus souvent dans les camps qu'à Constantinople ; ils sont entourés de leurs nombreux parents, frères, neveux, etc., auxquels ils ont distribué les plus hauts emplois, d'où une cordialité plus grande entre le basileus et ses subordonnés et une vie plus simple qu'à la cour des empereurs macédoniens.

Le Palais des Blachernes. - Enfin un événement, dont on ne peut exagérer l'importance, est l'abandon du sanctuaire de la religion impériale, du Grand Palais, par Alexis Comnène et le transport de la cour au Palais des Blachernes, situé au fond de la Corne d'Or, sur une hauteur d'où on dominait la ville et la campagne et dont le mur extérieur se confondait avec la Grande Muraille. Le somptueux palais de Tekfour-Seraï, à la façade si richement décorée, devait être compris dans son enceinte, mais on le connaît surtout par les descriptions d'Eude de Deuil, l'historien du roi de France Louis VII, qui y reçut l'hospitalité en 1147, et de Benjamin de Tudèle, de Guillaume de Tyr et autres voyageurs ${ }^{333}$. Le moine théologien Joseph Bryenne prononça devant

333 EBERsolt, Constantinople byzantine et les voyageurs du Levant, 33, 35, 39; ETIENNE DE Novgorod, Pèlerinage à Constantinople, 60 et s.; Benjamin DE Tudele, Voyages, 47 et s.; DIEHL, La Société byzantine à l'époque des Comnènes, 23-27; Du CANGE, Constantinopolis Christiana, II, 130. 
l'empereur, entre 1416 et 1425, vingt et un discours sur la Trinité dans diverses salles de ce palais, dont ses manuscrits donnent la nomenclature ${ }^{334}$.

Les témoignages sont unanimes sur la magnificence de ses appartements décorés de peintures, "où l'or brille de toute part», de sa grande cour pavée de marbre : «Je ne sais, dit Eude de Deuil, ce qui lui donne le plus de prix ou de beauté, la subtilité de l'art ou la richesse de la matière. " On vantait surtout le Grand Triclinium de porphyre, où se tint le concile de $1166^{335}$, à la suite duquel les manuscrits de Bryenne citent l'appartement impérial (koïton), distinct des pièces de réception, une église des Saints-Apôtres, le triclinium d'Elie et le Sekréton du palais ${ }^{336}$. L'Espagnol Peró Tafur, qui vit ce palais vers 1439 , le trouve mal tenu, sauf les appartements impériaux, où les souverains vivaient d'ailleurs à l'étroit ${ }^{337}$.

Le Palais des Blachernes, lorsque les Comnènes s'y installèrent, était pour eux une résidence plus agréable, plus confortable que le Grand Palais, avec son dédale d'appartements et de salles de réception accumulés pendant des siècles : dans ce faubourg éloigné ils jouissaient d'un air plus sain, d'une sécurité plus grande et menaient une vie plus simple et plus agréable. Le Grand Palais n'en demeurait pas moins le sanctuaire de la monarchie impériale. C'est de là que le basileus partait toujours pour se rendre à Sainte-Sophie le jour de son couronnement et ce fut là, dans la salle du Chrysotriclinium, que Manuel Comnène reçut solennellement le roi Amaury de Jérusalem en 1171, bien qu'il lui eût préparé une hospitalité somptueuse aux Blachernes ${ }^{338}$.

La vie d'Alexis Comnène. - Alexis Comnène résida aux Blachernes dès son avènement (1081). Il y réunit le Sénat en 1083 et tint un concile dans le Grand Triclinium en $1086^{339}$. Dans sa vie domestique on constate un curieux mélange d'étiquette et de laisser-aller.

\footnotetext{
MeYer dans B.Z., 1896, 75-111.

NiCETAS KhONIATES, Histoire, P.G., 140,236; Chalandon, op. cit., II, 648.

MEYER, loc. cit.

A. VASILIEv, Peró Tafur and his visit to Constantinople, Trebizond and Italy, 111 et s.

Pseudo-CoDInUs, De officialibus palatii, 17 (101); GUILLAUME DE TYR, Historia rerum in partibus transmarinis gestarum, XX, 2 (985); SCHLUMBERGER, Campagnes du roi Amaury I ${ }^{\text {er }}$ de Jérusalem... 1906, 325 et s.

339 M.B.E.H. (Vie et mort de Byzance), éd. 1969, 246.
} 
L'eunuque de garde entre dans la chambre du basileus avant son réveil, les mendiants en approchent sans être arrêtés et un ennemi du basileus y pénètre pour l'assassiner : c'est grâce au sang-froid d'une servante qu'il ne peut accomplir son crime ${ }^{340}$. Dans ses rapports avec les étrangers, Alexis tenait à la pompe traditionnelle et à l'observation de l'étiquette ${ }^{341}$, mais dans son palais il menait une véritable vie de famille et on n'y constate pas la moindre trace de réclusion des femmes. L'impératrice et ses filles sont au chevet d'Alexis malade et Anne Comnène sert d'arbitre entre les médecins dont les avis différaient ${ }^{342}$.

Bien qu'Alexis soit l'un des empereurs les plus actifs qui aient gouverné Byzance, il disposait de nombreux loisirs quand il habitait Constantinople. Sur le conseil de ses médecins, il se livrait aux exercices physiques, montait à cheval, jouait au polo dans le manège du palais et aimait passionnément la chasse ${ }^{343}$. A son réveil, il jouait aux échecs avec quelques-uns de ses parents ${ }^{344}$. Il entretenait une ménagerie dans laquelle se trouvait un lion ${ }^{345}$. Il assistait aux jeux de l'Hip-podrome et ce fut même à l'un de ces spectacles qu'il gagna, en prenant froid, la maladie qui devait l'emporter ${ }^{346}$. Enfin il trouvait le temps de lire et d'étudier, surtout la théologie, et s'occupait avec sollicitude de l'école qu'il avait fondée près de l'église Saint-Paul pour les enfants des prisonniers de guerre ou de familles peu fortunées ${ }^{347}$. A son exemple, princes et princesses lisaient les auteurs grecs, aimaient les discussions théologiques et avaient parfois leur poète attitré $^{348}$. L'érudition de la fille aînée d'Alexis, Anne Porphyrogénète, n'était donc pas un fait isolé, bien que poussée à un degré exceptionnel.

Protocole de son entrevue avec Bohémond à Déabolis (1107), ANNE COMNENE, op. cit., XIII, 9 (III, 118 et s.).

DiEHL et GuILland, L'Europe Orientale de 1081 à 1453, 97-98. 
Manuel Comnène. - La cour d'Alexis et celle de Jean Comnène conservaient une certaine allure de sévérité, qui disparut sous le règne de Manuel (1118-1143), marqué par le triomphe à Byzance des modes et des idées de l'Occident. En dehors des cérémonies officielles, qui revêtirent sous son règne un très grand éclat, ses occupations personnelles furent multiples et la variété de ses goûts est déconcertante. Homme de guerre avant tout, il exerçait lui-même ses soldats et portait une lance et un bouclier si lourds, que Raimond d'Antioche luimême avait peine à les manier ${ }^{349}$. Il aimait surtout les tournois à la française, en présence des dames de la cour, et descendait parfois dans l'arène ${ }^{350}$. Il jouait de longues parties de polo avec ses courtisans ${ }^{351}$ et avait une passion pour la chasse aux bêtes fauves, avec l'épervier, le faucon et même des léopards apprivoisés ${ }^{352}$.

Cependant cet homme d'action avait une véritable prédilection pour les lettres et les sciences. Il lisait des ouvrages de géographie, de tactique, de sciences naturelles et d'astrologie. Il était versé dans la médecine et la chirurgie il soigna son beau-frère l'empereur Conrad III, tombé malade pendant la croisade de 1148 ; et, dans une chasse aux environs d'Antioche en 1159, le roi de Jérusalem Baudouin III s'étant démis le bras, Manuel descendit de cheval et, à la stupéfaction de tous, lui fit l'opération nécessaire ${ }^{353}$. Rappelons enfin qu'il était passionné pour la théologie et composait des ouvrages qu'il lisait dans les synodes et dont la hardiesse effrayait ses contemporains ${ }^{354}$.

A la vie officielle du palais, Manuel préférait les villégiatures dans ses maisons de plaisance de la Propontide, où se succédaient les fêtes entremêlées de festins, de concerts, de danses, d'exercices de jongleurs et de mimes. Aucune étiquette ne régnait dans les repas intimes que Manuel prenait avec ses frères et ses cousins, repas égayés par les facéties de son favori, le grand-logothète Jean Kamatéros, capable de vider d'un trait une énorme coupe de porphyre qui datait de Nicéphore

\footnotetext{
Jean KINNAMOS, Epitome, III, 16.

350 Ibidem, III, 15; Nicetas KhONIATES, Histoire, III, 5; DiEHL, La Société byzantine à l'époque des Comnènes, 15; Ekphrasis sur un tournoi dans N.H., t. V, 15 et s.

351 Jean Kinnamos, op. cit., VI, 5; Chalandon, Les Comnène, II, 205 et s.

352 PANTECHNES, archevêque de Philippopoli, La chasse à l'once; CHALANDON, op. cit., II, 237 et s.; KouKOULES, E.B., 1932, 1-33 (analyse de traités de cynégétique).

353 GUILlaume DE TYR, Historia rerum in partibus transmarinis gestarum, XVIII, 25; Jean Kinnamos, Epitome, IV, 21 (37); ChALANDON, op. cit., II, 453.

354 M.B.E.H. (Institutions), éd. 1970, 348 et s.
} 
Phocas et contenait 5 litres de vin. Ces beuveries dégénéraient parfois en querelles et il arriva un jour que le basileus fut blessé d'un coup d'épée en voulant séparer les combattants ${ }^{355}$.

Dynastie des Anges. - Isaac l'Ange et Alexis III font triste figure à côté des Comnènes : ils ne songeaient guère qu'à s'évader de la vie officielle. Isaac habitait surtout le magnifique palais qu'il s'était fait construire dans une île de la Propontide. Il vivait là, entouré de ses concubines et de ses bouffons, qu'il admettait en même temps que les princesses impériales : à sa table les propos étaient des plus libres ${ }^{356}$. Portant encore moins d'intérêt aux affaires de l'Empire, Alexis III était entièrement oisif, occupé uniquement de ses plaisirs et gaspillant le trésor public pour les satisfaire. Obligé en 1202 d'aller combattre une révolte en Asie Mineure, il abandonna la poursuite de son chef, réfugié chez le sultan d'Iconium, renvoya ses troupes, s'arrêta à Brousse et organisa un voyage de plaisance dans la Propontide. Toute la cour se réunit sur la galère impériale où se succédèrent les jeux, les festins, les danses, les concerts. Puis, au moment où le navire se rapprochait de Constantinople, il fut pris par une violente tempête et se réfugia à Chalcédoine. De là le basileus et ses hôtes parvinrent à gagner l'un des ports du Grand Palais où ils s'installèrent. Alexis voulait retourner aux Blachernes, mais ses astrologues l'avertirent que la position des planètes était défavorable. Il attendit donc en menant joyeuse vie et en faisant donner des jeux à l'Hippodrome. Le 4 mars lui fut annoncé comme un jour heureux, à condition de partir avant le lever du soleil. A l'heure dite, un navire était à l'ancre et la famille impériale allait s'embarquer, lorsqu'il se produisit un tremblement de terre. Plusieurs personnes furent blessées et un cubiculaire fut englouti dans le sol : le navire n'en partit pas moins et ramena le basileus aux Blachernes par la Corne d'Or ${ }^{357}$.

Période de Nicée et Paléologues. - Dans l'existence si active des empereurs de Nicée qui, lorsqu'ils n'étaient pas en expédition, passaient leurs journées à s'occuper des affaires, il n'y avait de place, ni pour les cérémonies multiples, ni pour les plaisirs et les distractions.

355 Nicetas KhONIATES, Histoire, III, 3.

Jean KinNamos, III, 17; DieHL, La Société byzantine à l'époque des Comnènes, 32; NICETAS KHONIATES, III, 5-7, (809 et s.); Sp. LAMBros, Les bouffons des empereurs byzantins, 391.

357 NiCETAS KHONIATES, III, 6-7 (900-912). 
Ils trouvaient du moins le temps de développer l'instruction et d'organiser des écoles ${ }^{358}$.

Après la reprise de Constantinople, les cérémonies solennelles reparurent, mais très réduites. Aux grandes fêtes, les processions à Sainte-Sophie devinrent plus rares et les offices étaient célébrés à l'intérieur du palais, présidés plus souvent par le protopappas que par le patriarche ${ }^{359}$. L'appauvrissement du trésor impérial explique la simplification des festins d'apparat, où l'empereur, non plus couché sur un lit, mais assis à une table, est le seul à manger, en présence des dignitaires qui se tiennent debout autour de lui et reçoivent suivant leur grade une assiette d'or ou d'argent, qu'ils doivent restituer après la cérémonie ${ }^{360}$. Même simplification pour les audiences, qui avaient lieu deux fois par jour et où les dignitaires étaient introduits par ordre hiérarchique, sans autre cérémonie ${ }^{361}$.

Le basileus disposait donc d'une grande partie de la journée pour s'occuper des affaires publiques et satisfaire ses goûts personnels. Michel Paléologue rétablit l'orphelinat de l'église Saint-Paul fondé par Alexis Comnène, dirigeant lui-même son administration, se faisant adresser des rapports sur les études, allant même à certains jours assister aux exercices et distribuer des récompenses ${ }^{362}$.

Avec Andronic II, l'État connaît la détresse financière. Le souverain mène une vie sobre et réglée ; sa table est frugale et peu délicate : une pièce de bœuf en est souvent le mets principal. Andronic supportait facilement la faim et la soif. Il passait des nuits en prières, lisait et écrivait beaucoup et répondait lui-même aux libelles dirigés contre son gouvernement. Il avait créé au Palais impérial une Académie qu'il présidait et où, à des jours fixes, se réunissaient des lettrés, qui discutaient des questions de tout genre et, en particulier, de sciences. Nicéphore Grégoras y présenta un plan de réforme du calendrier julien. Ce

\footnotetext{
THEOdORE II LASCARIS, Euvres, ep. XIV; J.B. PAPADOPOUlos, Théodore II Lascaris, 85-87. Pseudo-Codinus, De officialibus palatii, XIV, 76-82; EBERSOLT, Mélanges d'histoire et d'archéologie byzantines, 99-100.

360 Pseudo-CODINUS, op. cit., VI, 53; EBERSOLT, op. cit., 83 et s.

361 Pseudo-Codinus, V; EBerSOlt, op. cit., 16.

362 PACHYMere, Histoire, IV, 14 (729).
} 
fut sur ce modèle que se fondèrent les académies italiennes de la Renaissance ${ }^{363}$.

A la différence de son aïeul, Andronic III (1328-1341) fut un soldat, commandant lui-même ses troupes, entraîné aux exercices physiques, avec un goût marqué pour les tournois à la française, où il rompait lui-même des lances. Malgré la pénurie du trésor, il conserva un somptueux équipage de chasse, que Jean Cantacuzène devait supprimer $^{364}$.

Après lui l'Empire, épuisé par deux guerres civiles et les attaques ottomanes, lutte pour son existence et perd toutes ses ressources. Les pierreries de la couronne sont en gage à Venise; au couronnement de Jean Cantacuzène (1347), des pierres fausses décorent les ornements impériaux et des plats d'étain remplacent la vaisselle d'or et d'argent ${ }^{365}$. Les derniers Paléologues n'avaient guère le temps ni les moyens de donner des fêtes ; mais, jusqu'à la chute finale, ils attachent la plus grande importance au maintien d'une certaine étiquette, ce qui ne les empêche pas d'accueillir avec simplicité et cordialité les étrangers de passage, comme le montrent les rapports de l'Espagnol Peró Tafur avec Jean VIII ${ }^{366}$. Et ils n'ont pas perdu le goût des lettres : ils réservent une part de leurs loisirs à la protection des lettrés et $\mathrm{du}$ haut enseignement. Manuel II (1391-1425) fut non seulement le protecteur des humanistes, tels que Georges Scholarios, Gémiste Pléthon, Bessarion, mais il fut lui-même l'un des derniers et des plus remarquables écrivains de Byzance ${ }^{367}$.

Ainsi des témoignages, qui s'étendent sur une histoire millénaire, montrent que tous les empereurs sans exception menaient, à côté d'une vie officielle plus ou moins chargée de cérémonies suivant les époques, une vie domestique qui ne devait pas différer beaucoup de celle de la haute aristocratie.

\section{$\underline{\text { Retour à la Table des Matières }}$}

363

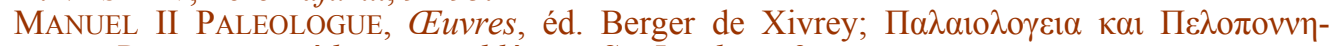
біака. Documents inédits rassemblés par Sp. Lambros, 3. 


\section{LIVRE DEUXIÈME \\ La vie urbaine}




\section{Chapitre IV}

\section{La vie à Constantinople}

\section{La ville}

$\underline{\text { Retour à la Table des Matières }}$

A la fois européenne et asiatique, Constantinople était au moyen âge un trait d'union entre deux mondes. A une époque où la vie urbaine avait à peu près disparu de l'Occident, où les habitants de l'ancienne Rome se retranchaient dans les ruines antiques transformées en forteresses, Constantinople était la seule ville de la chrétienté qui méritât le nom de capitale, la seule dont la population, à l'abri de ses remparts, longtemps inexpugnables, ait pu créer une civilisation originale, qui rayonna dans le monde byzantin et au-delà de ses frontières.

Innombrables sont les témoignages qui attestent l'admiration universelle dont Constantinople était l'objet. L'effet que sa magnificence produisait sur les étrangers dépassait toujours ce qu'ils pouvaient imaginer. Tous sont d'accord là-dessus, depuis les chefs barbares du $\mathrm{IV}^{\mathrm{e}}$ siècle $^{368}$ jusqu'aux croisés de $1095^{369}$ ou de $1204^{370}$.

On a souvent reproduit le témoignage de Villehardouin sur le saisissement des rudes chevaliers d'Occident à la vue de la ville immense, avec les hautes murailles 
« dont elle était close tout autour à la ronde, et ces superbes palais, et ces hautes églises,... et la longueur, la largeur de la ville ». Ils ne pouvaient croire qu'il y eût au monde une autre ville aussi puissante. " Et sachez qu'il n'y eut homme si hardi à qui la chair ne frémit. »

Pour Robert de Clari, on ne vit jamais si belle ville, ni au temps d'Alexandre, ni au temps de Charlemagne,

« et je ne pense pas qu'il y eut tant d'avoir comme on trouva au cœur de Constantinople. Et si témoignoient les Grecs que les deux parts de l'avoir du monde étoient en Constantinople ».

La réputation de Constantinople avait pénétré en Chine où on la confondait avec l'Empire, appelé dans les textes chinois fou-in (la Ville) et non thoun (l'État) ${ }^{371}$. Pour les Grecs eux-mêmes, Constantinople était la Ville par excellence, ou la Ville Impériale, le Tzarigrad des Russes ${ }^{372}$.

Mais le plus bel éloge qui ait été écrit de la cité incomparable date de la veille de sa chute : c'est celui de Manuel Chrysoloras dans une lettre écrite à Jean VIII (1425-1448), témoignage d'autant plus touchant qu'il montre, contrairement à l'opinion ancienne, combien les Grecs qui réfléchissaient sentaient profondément le danger qui les menaçait, eux et le monde entier ${ }^{373}$.

L'écrivain rappelle la situation de la ville qui regarde deux continents et se trouve être le point de jonction des mers du nord et du sud, véritable porte impé-

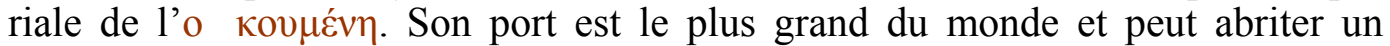
nombre incalculable de navires. Elle est entourée d'une couronne de murs comparables à ceux de Babylone, flanqués de nombreuses tours remarquables par leur hauteur et, si chacune était isolée, elle serait déjà un objet d'admiration. " Deux nations puissantes et sages, dont l'une possédait alors l'Empire, dont l'autre l'avait exercé auparavant, toutes deux réussissant dans tous les arts et douées de nobles ambitions, les Romains et les Hellènes, créèrent cette cité avec l'aide des autres peuples et choisirent un endroit qui leur permettait de commander à tout l'univers. La nature semblait avoir préparé une île de marbre pour sa construction ${ }^{374}$. »

371 ANDREADES dans Metron (revue de Statistique), décembre 1920, 6.

372 PSEllos, Discours..., V, 229; BESSARION, dans Documents inédits rassemblés par Sp. Lambros, III, 289; DIEHL, En Méditerranée, 372.

373 Lettre écrite en 1406 après son ambassade à Londres, Manuel CHRYSOLORAS, Correspondance, IX, 393; DIEHL et GuILland, L'Europe Orientale de 1081 à 1453.

374 Allusion aux carrières de marbre de Proconnèse. 
Chrysoloras décrit ensuite avec complaisance ses monuments magnifiques, ses colonnes triomphales, ses portiques, ses palais, ses hippodromes, ses arsenaux, ses stations navales entourées de murs, ses tours bâties dans les flots, son aqudeduc, ses citernes avec des voûtes soutenues parfois par des forêts colonnes, ses nombreux thermes, ses fontaines publiques. Il vante la beauté de ses environs, $\tau$ $\pi \rho \circ \alpha \sigma \tau \varepsilon \quad \alpha$, dont les édifices rivalisaient pour la splendeur avec ceux de la cité. Il rappelle enfin cette ville continue qui s'étend de Galata et de Scutari au PontEuxin $^{375}$.

Les transformations de la ville. - Malheureusement cette description ne correspondait plus au temps où Chrysobras écrivait, mais rappelait un passé déjà lointain. Jusqu'à la catastrophe de 1204, aucun peuple étranger n'avait encore pu forcer l'enceinte de Théodose II, complétée dans la suite des âges par de nouvelles défenses. Endommagée par des tremblements de terre, des incendies et des émeutes, Constantinople conservait cependant l'aspect monumental qu'elle devait aux reconstructions de Justinien et de ses successeurs, jusqu'au temps des Comnènes, où la ville atteignit sa plus grande prospérité.

Mais le sac de 1204 lui porta un coup fatal et la négligence des croisés, qui l'occupèrent pendant soixante ans, acheva sa ruine. Les voyageurs des $\mathrm{XIV}^{\mathrm{e}}$ et $\mathrm{XV}^{\mathrm{e}}$ siècles, qui la visitèrent, l'Arabe AboulFéda ${ }^{376}$, les Espagnols Clavijo et Peró Tafur montrent les quartiers du centre dépeuplés, couverts de ruines, avec de grands jardins et même des champs ensemencés. L'église Sainte-Sophie se dresse au milieu d'un quartier délabré, les citernes sont comblées et plantées de vignes, le Grand Palais est devenu une vaine pâture ${ }^{377}$ et un cimetière de pauvres gens s'y est installé ${ }^{378}$. Manuel Chrysoloras lui-même, à la fin de sa lettre, mentionne la disparition de nombreux portiques qui permettaient autrefois de parcourir toute la ville à l'abri de la boue et du soleil, et celle des innombrables statues qui décoraient les édifices et dont il ne reste plus que les bases ${ }^{379}$. L'Hippodrome lui-même était en grande partie ruiné.

Stations du Bosphore, faubourg de Chrysopolis (Scutari) et Eaux-Douces d'Asie.

ABOULFEDA, Géographie, XIV siècle, trad. Reinaud, t. 2, 315 et s.

P. Merimee, Etude sur les arts au Moyen Age, 335 et s.; A. VAsiliev, Pero Tafur..., 113; BERTRANDON DE LA BROQUIERE, Le Voyage d'outre-mer : "y a beaucoup plus de vuyde que de plain ».

378 Psellos, Chronographie, 393.

379 M. R. Demangel, Contribution à la topographie de l'Hebdomon, 23. 
L'aspect de la ville byzantine. - A part quelques églises plus ou moins défigurées et la partie centrale de l'Hippodrome (place de l'Atmeïdan), la ville byzantine était presque entièrement cachée par les constructions turques, maisons privées, grandes mosquées, édifices publics. Il y a un demi-siècle, on ne pouvait guère en tenter la restitution qu'avec l'aide de textes : chroniques et œuvres littéraires, récits des voyageurs, compilations anonymes du $\mathrm{X}^{\mathrm{e}}$ siècle, véritables guides archéologiques sous le titre de Patria Konstantinoupoleos ${ }^{380}$, pleins de renseignements toographiques, historiques, légendaires sur les quartiers et les édifices.

A ces témoignages précieux on peut joindre aujourd'hui celui du sol lui-même, grâce aux fouilles nombreuses, que de grands incendies ont rendues possibles depuis 1918. Les Turcs ayant assis leurs maisons (la plupart en bois) sur des ruines d'édifices byzantins, on a pu retrouver non seulement des fondations, mais des fragments importants de constructions, notamment sur l'emplacement du Grand Palais, dans le quartier des Manganes, à l'Hebdomon, etc. ${ }^{381}$. Du Vieux Sérail et du Ministère de la justice, qui faisait face à Sainte-Sophie, jusqu'à la Porte d'Or s'étend un champ de fouilles ininterrompu, véritable « parc archéologique » qui renferme encore bien des secrets ${ }^{382}$.

Ce sont ces découvertes qui ont permis à l'un des chercheurs les plus actifs, Ernest Mamboury, de restituer le plan en relief et le plan par terre de la Constantinople byzantine ${ }^{383}$. La ville comprenait, d'une part, les parties basses : côte de la Propontide et rives de la Corne d'Or, d'autre part les parties hautes : au sommet, des collines coupées de dépressions. Les habitants ne pouvaient asseoir leurs maisons que sur des terrains plats, d'où l'aménagement de terrasses, les pentes remblayées étant soutenues par des murs étayés eux-mêmes d'arcades, que dissimulent souvent des bâtisses d'époque turque. Les murs de remblais pouvaient atteindre 14 mètres d'épaisseur, par exemple au-dessus de la Corne d'Or. C'est ainsi qu'entre le Forum Tauri et la mer on a retrouvé cinq grandes terrasses échelonnées en hauteur et communiquant par des escaliers.

Beaucoup d'édifices étaient construits sur des citernes (par exemple l'église de la Pammacaristos, Fétiyé-Djami, XIV région). Les fouilles montrent que les fon-

\footnotetext{
Patria, éd. Preger, 1907.

Demangel, op. cit. ; Demangel et Mamboury, Le quartier des Manganes et la première région de Constantinople.

382 A.C.E.B., VI, Paris, 1948, t. II p. 21 A. GABriel expose « le projet de création d'un parc archéologique à Istanbul ».

383 A.C.E.B., VI, Paris, 1948, t. II, p. 243-253; E. MambOURY, Contribution à la topographie générale de Constantinople par l'étude du modèle de la ville.
} 
dations des murs atteignaient la couche dévonienne humide du sol et c'est ce qui justifie l'opinion de Malalas, d'après qui la ville était bâtie sur pilotis.

Le plan par terre était celui d'une ville hellénistique avec des dispositions analogues à celles de Priène ou de Pergame : de grandes lignes directrices entre lesquelles s'ouvraient des rues moins larges, des ruelles étroites et des places. Du Forum Tauri partaient deux grandes voies dessinant un Y, une branche conduisant vers l'ouest, à la Porte d'Or, l'autre vers le nord-est, à l'église des SaintsApôtres ${ }^{384}$. Comme Priène, Constantinople était bâtie en amphithéâtre.

\section{La population}

\section{$\underline{\text { Retour à la Table des Matières }}$}

Les chiffres. - Le chiffre de la population a varié au cours des siècles, suivant les vicissitudes de l'Empire. On ne peut naturellement retrouver dans les sources des chiffres précis, mais quelques points de repère bien établis permettent des approximations.

D'après la Notitia Urbis du $\mathrm{V}^{\mathrm{e}}$ siècle, la ville comprenait 322 vici (rues), 4388 domus (maisons de maîtres), 20 boulangeries publiques, 120 boulangeries privées. Il n'est pas question, comme à Rome, d'insulae, immeubles de rapport isolés par quatre rues, et on peut se demander si par domus il faut entendre un hôtel aristocratique. Quoi qu'il en soit, le chiffre de 25 habitants par domus, souvent proposé et qui donnerait 109000 habitants, semble trop faible, si l'on réfléchit au grand nombre de serviteurs et d'esclaves qui habitaient ces maisons. Il faut au moins compter 500000 à 600000 habitants ${ }^{385}$ et un discours de Thémistius prononcé à la même époque montre l'accroissement rapide de la population qui étouffait dans l'enceinte étroite de Constantin ${ }^{386}$. Elle aurait dépassé un million à l'époque de Justinien ${ }^{387}$, mais le chiffre de 70000 barbares immigrés, que donne Procope, parait relativement faible ${ }^{388}$. Les mesures prises par Justinien pour débarrasser la ville des plaideurs de province et des aventuriers de

384

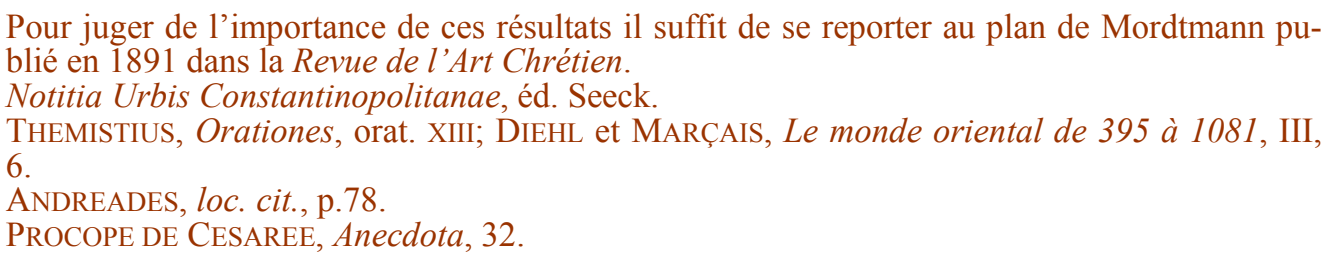


toute espèce qui s'y rendaient en foule, laissent supposer une population flottante des plus nombreuses ${ }^{389}$. Les environs étaient aussi très peuplés. En 617, les Avars emmenèrent 270000 captifs pris dans la banlieue ${ }^{390}$.

Causes de dépopulation. - Rien n'était plus instable en réalité que le chiffre de cette population, que des fléaux périodiques venaient décimer (tremblements de terre, pestes, incendies, émeutes accompagnées de massacres et dont des immigrés venaient de gré ou de force combler les vides) ${ }^{391}$.

La répartition des habitants à l'intérieur de l'enceinte était d'ailleurs très inégale. La densité la plus forte se trouvait sur les rivages, le long de la Corne d'Or et de la Propontide, dans le quartier de Psamathia, aux abords de la Mésé et des Forums, dans la région des sept collines. Au VII siècle, la population se porta dans le quartier des Blachernes, englobé dans l'enceinte par Héraclius, et au-delà de la Corne d'Or, dans les faubourgs des Sykes. Par contre, la vallée du Lycos, dont le cours était souterrain, ne fut jamais très peuplée ; elle parut favorable aux fondations monastiques, comme celle de Lips fondée $\mathrm{au} \mathrm{X}^{\mathrm{e}}$ siècle et restaurée par Théodora, veuve de Michel VIII Paléologue, pour des religieuses ${ }^{392}$.

Cependant, par suite de nouveaux fléaux, comme la peste de 1076 accompagnée de famine ${ }^{393}$, le chiffre de la population paraît avoir été beaucoup plus faible en 1204. Villehardouin, relatant les incendies qui eurent lieu en avril de cette année, dit qu'il y eut plus de maisons brûlées qu'il n'y en a dans les trois plus grandes villes de France. Or, la population de Paris à cette époque aurait été de 100000 habitants ${ }^{394}$. De toute manière, Constantinople devait en avoir moins de 500000 et jamais, après la restauration de Michel Paléologue, elle ne put recouvrer son ancien chiffre. Elle fut d'ailleurs décimée par de nouveaux

\footnotetext{
DIEHL, Justinien et la civilisation byzantine au VI s., 432 et s.

M.B.E.H. (Vie et mort de Byzance), éd. 1969, 54.

Ibidem, 77. De 398 à 751 on compte cinq tremblements de terre importants, cinq épidémies de peste et de nombreuses émeutes, dont la Sédition Nika en 532, qui détruisit le centre de la ville.

R. JANIN, Topographie de Constantinople byzantine, 225 (sépultures impériales découvertes en 1929).

393 Zonaras, Epitome, II, 289; G. CEDRENOS, Synopsis, 856 et s.

394 Villehardouin, La Conquête de Constantinople, $\mathrm{n}^{\circ} 247$.
} 
fléaux, dont le plus terrible fut la peste noire, qui sévit dans la ville pendant deux ans (1348-1349) ${ }^{395}$, et par de nouvelles épidémies qui firent de nombreuses victimes en 1416 et en 1447-1448, la veille même de la conquête ${ }^{396}$. Pendant le siège de 1453 , une bonne partie de la ville était déserte, mais on ne peut accepter le témoignage du marchand florentin Tetaldi, qui réduit à 36000 au plus le chiffre de ses habitants, s'il est exact que Mahomet II ait fait 60000 prisonniers. Critobule estime à 50000 le nombre des esclaves des deux sexes ${ }^{397}$.

Eléments de la population. - A toutes les époques, cette population était en partie cosmopolite. Sans doute la masse était formée de Grecs, considérés comme autochtones, mais, comme dans toutes les grandes villes, beaucoup de ces «Byzantins de Byzance » descendaient de provinciaux ou même d'étrangers immigrés ${ }^{398}$, qui ne tardaient pas, dès la deuxième génération, à s'imprégner de l'esprit local, à manifester une certaine fierté d'être natifs de la ville, à s'arroger le titre de politikoi par opposition aux thematikoi (provinciaux). De là un goût pour la plaisanterie et pour la satire qui se rencontre dans toutes les capitales, où les hommes publics sont rarement épargnés. A Constantinople, cette blague s'est manifestée à toutes les époques, depuis les quolibets qui assaillaient l'empereur Maurice jusqu'aux plaisanteries dont Michel Stratiotique, surnommé le Vieux, était la victime ${ }^{399}$. On a noté aussi leur humeur casanière, due à un véritable engouement pour leur ville natale. Psellos n'en était jamais sorti avant l'âge de seize ans : il n'avait jamais vu les remparts et encore moins la campagne ${ }^{400}$.

Parmi les immigrés étrangers, les plus nombreux furent de tout temps les Arméniens, qui fuyaient les persécutions des Perses et plus tard celles des Arabes, ou étaient poussés par l'ambition d'entrer dans

\footnotetext{
Jean CANTACUZENE, Histoire, IV, 8.

Doukas, Chronique universelle, ch. 20; G. Phrantzes, Chronique, I, 38; Lambros, N.H., XII, 170-172.

Critobule D'Imbros, De rebus gestis Mechemetis II, 1, 66; Pears, The destruction of the Greek Empire, New York, 1903, 193 et s.

398 Patria (éd. Preger), II; Dictionnaire des Apocryphes de l'Ancien et du Nouveau Testament (trad. Migne), I, 27.

399 TheOPhylacte DE SimocatTa, Histoire (éd. de Boor), VIII, 4; Theophanes LE CONFESSEUR, Chronographie, 236, 28; DIEHL, Choses et gens de Byzance, III, 771.

400 DIEHL, Figures byzantines, I, 305.
} 
la hiérarchie impériale ${ }^{401}$. Un témoignage curieux de leurs efforts pour s'helléniser est un glossaire arméno-grec sous la forme d'un manuel de conversation, découvert sur un papyrus grec du Fayoum de la première moitié du VII ${ }^{\mathrm{e}}$ siècle ${ }^{402}$.

Ce fut surtout dans le dernier quart du $\mathrm{IX}^{\mathrm{e}}$ siècle qu'affluèrent les étrangers, soit pour s'engager dans l'armée impériale, soit pour des entreprises commerciales. C'est probablement après la première invasion russe, en 860, que des marchands de Kiev obtiennent un premier établissement ${ }^{403}$, transporté dans la suite au faubourg de SaintMamas, où des Bulgares sont admis au $\mathrm{X}^{\mathrm{e}}$ siècle $^{404}$.

$\mathrm{Au} \mathrm{XI} \mathrm{e}^{\mathrm{e}}$ siècle arrivèrent des Géorgiens, clercs, moines et nobles, comme Grégoire Pakourianos, l'un des meilleurs généraux d'Alexis Comnène ${ }^{405}$. Les Arabes eux-mêmes possédaient une colonie dotée d'une mosquée ${ }^{406}$ et, sous les Comnènes, des prisonniers turcs, comme Jean Axouch, furent amenés à Constantinople et se convertirent au christianisme ${ }^{407}$. Mais ce fut surtout à cette époque que se formèrent les colonies d'Occidentaux: Varanges Anglo-Saxons qui possédaient leurs églises distinctes ${ }^{408}$, chevaliers normands venus pour s'engager dans l'armée impériale, Français et Italiens attirés par les Comnènes, qui leur confiaient des fonctions publiques ${ }^{409}$ et, avant tout, établissements permanents des colonies commerciales des républiques italiennes et catalane ${ }^{410}$.

Après l'occupation franque de Constantinople, pendant laquelle les Vénitiens jouirent d'un véritable monopole commercial et même politique, toutes ces colonies furent rétablies par les Paléologues et s'accrurent même de nouveaux immigrés, comme les Castillans que

401

Le patriarche Antoine Cauleas est le fils d'un soldat phrygien émigré à Constantinople. (LOPAREV dans V.V., XVII, 148); Joseph LAURENT, L'Arménie entre Byzance et l'islam, 190194. En 778 les cinq stratèges d'Orient portent des noms arméniens.

M. LEROY, Un papyrus arméno-grec, dans B.N., 1938, 513-537.

A. VASILIEV, The russian Attack of Constantinople in 860, p. 229.

R.K.O.R., 549, 556; PARGOIRE dans E.O., XI, 1908, 203 et s.

Germaine RoulllaRD, Léon Kephalas, dans B.Z., 1930, 444 et s.

Voir ch. IX.

Chalandon, Les Comnène, II.

R. LOPEZ, L'origine des colonies commerciales permanentes dans le Levant byzantin et moderne; A. VASILIEV, The opening Stage of the Anglo-Saxons..., A.I.K., 1935.

NiCETAS KHONIATES, Histoire, VI, 2 «fonctionnaires étrangers qui crachent le grec plus qu'ils ne le parlent »; GUILLAUME DE TYR, Historia rerum in partibus transmarinis gestarum, XXII, 10.

LOPEZ, op. cit. 
Peró Tafur trouva en 1438 à Byzance, au retour de son voyage au Kiptchak $^{411}$. On voyait enfin dans la ville une partie de ces Gasmouls, issus de mariages entre Occidentaux et indigènes, renommés pour leur intelligence et leur audace ${ }^{412}$.

Constantinople était donc au moyen âge, comme elle l'est restée dans les temps modernes, la ville où se coudoyaient toutes les races, où l'on entendait tous les idiomes du monde connu, mais où l'hellénisme conservait toujours la prééminence.

\section{Circulation et vie extérieure}

$\underline{\text { Retour à la Table des Matières }}$

A toutes les époques les voyageurs ont été frappés du caractère populeux des rues de Constantinople, dont le réseau serré, interrompu par de larges places, facilitait la circulation.

La Mésé. - La rue centrale, Mćđך, était bordée de chaque côté de portiques à deux étages. Elle partait du Forum Augustaeum, traversait le Forum de Constantin, place circulaire, avec deux entrées faites d'arcades en marbre de Proconnèse et, au centre, la colonne de porphyre surmontée de la statue de Constantin à la tête radiée. La Mésé traversait ensuite le Forum Tauri, le Forum d'Anastase, le Forum d'Arcadius et franchissait l'ancienne enceinte constantinienne.

De là elle aboutissait, soit à la Porte d'Or après avoir traversé le quartier de Psamathia, confondue ainsi avec la Voie triomphale, soit, après avoir obliqué vers le nord-ouest, à la porte de Selymbria ${ }^{413}$.

Les rues principales, dont plusieurs partaient de la Mésé, étaient pavées, mesuraient au moins 5 mètres de large et étaient bordées de portiques, parfois à un étage et garnis de statues. Chacun de ces porti-

VASILIEV, Pero Tafur..., 91 et s.

O. TAFRALI, Thessalonique au XIV siècle, 43.

La première solution est acceptée par la plupart des historiens; la deuxième est une conjecture de Mordtmann (Esquisses..., 60 et s.) d'après qui la Porte d'Or était réservée exclusivement au basileus. 
ques ( $\mu \beta 0 \lambda \mathrm{or})$ avait son nom particulier: embolos de Saint-Georges, embolos russe, etc. ${ }^{414}$. Au $\mathrm{V}^{\mathrm{e}}$ siècle plusieurs s'ouvraient sur des salles publiques (auditoria); ailleurs on y installait des tables sur lesquelles on vendait toute espèce de marchandises ${ }^{415}$.

Les marchés. - Mais le véritable centre des affaires était la partie de la Mésé comprise entre le Grand Palais et le Forum de Constantin, sur une longueur de 570 mètres.

On lui donnait le nom d'agora (marché) ${ }^{416}$. C'était là qu'était concentré le commerce des métaux précieux. Le gouvernement obligeait les orfèvres et argentiers à y installer leurs boutiques. Pillés et brûlés sous Justinien pendant la sédition Nika, ces magasins furent réinstallés à la même place, comme l'indique le Livre du Préfet au $\mathrm{X}^{\mathrm{e}}$ siècle ${ }^{417}$. Non loin de là, les changeurs (trapezitai) installaient sans doute leurs tables (trapezai), couvertes d'espèces d'or et d'argent, qui excitaient les convoitises des Barbares.

Un croisé flamand de l'armée du roi Louis VII, ébloui à la vue de ces richesses, se jeta sur les tables en criant Haro et rafla tout ce qu'il put, tandis que les trapézistes s'enfuyaient épouvantés avec leurs trésors. Le roi de France réclama le coupable au comte de Flandre et le fit pendre ${ }^{418}$.

En 1403, les changeurs occupaient toujours la même rue, mais, d'après Clavijo, des ceps étaient installés en face de leurs tables et on $\mathrm{y}$ attachait les délinquants ${ }^{419}$.

$\mathrm{Au} \mathrm{XIV}$ siècle le voyageur arabe Ibn-Batoutah note l'existence de marchés distincts pour chaque profession (on les fermait la nuit) et décrit les bureaux des écrivains publics, installés près de SainteSophie sous un berceau de vigne et de jasmin : dans des boutiques en bois et sur des estrades siégeaient les écrivains, chaque groupe dirigé

AnTOINE, archevêque de Novgorod, Le livre du pèlerin; EBERSOLT, Constantinople byzantine et les voyageurs du Levant, 36.

415 Holmes, The age of Justinian and Theodora, I, 142-148.

416 R. Guilland, Autour du Livre des Cérémonies de Constantin Porphyrogénète. La Mésè, A.C.E.B., VI, Paris, 1948, t. II, 171-182.

417 Livre du Préfet, $25(41)$.

418 EUDE DE DeUIL, De Ludovici VII profectione in Orientem, 4.

419 MerimeE, Etude sur les arts au Moyen Age, 356. 
par un chef désigné par le titre de juge ${ }^{420}$. Un siècle plus tard, la vente des comestibles avait envahi les abords de Sainte-Sophie. On y vendait du pain, du vin, du poisson, des coquillages autorisés les jours de jeûne, et l'on pouvait consommer ces mets sur place, car on y avait installé de grandes tables de pierre où les nobles mangeaient, confondus avec le peuple ${ }^{421}$.

Les petits métiers. - Les rues de Constantinople étaient aussi animées par des marchands ambulants, qui sollicitaient de l'ouvrage ou criaient leurs marchandises. Théodore Prodrome énumère les brodeurs en or, les cordonniers, les marchands de petit-lait avec leur calebasse sur l'épaule, les marchands de tissus, les fabricants de moulins à poivre, les portefaix qui, après avoir peiné tout le jour, recevaient pour salaire un petit gobelet de vin et une portion de ragoût ${ }^{422}$.

Il y avait aussi dans les rues des astrologues, des magiciens, des diseurs de bonne aventure. Parfois de prétendus prophètes soulevaient de véritables paniques en annonçant la fin du monde. Le nombre incalculable d'étrangers qui visitaient Constantinople avait fait naître le métier fructueux de cicérone.

A Constantinople, dit le pèlerin russe Étienne de Novgorod vers 1350, on est comme dans un grand bois et on ne peut marcher sans un bon guide. Si, par avarice ou pauvreté, on ne donne pas d'argent, on ne peut ni voir, ni baiser les saintes reliques ${ }^{423}$.

On ferait un gros volume de toutes les inepties que ces guides improvisés racontaient à leurs naïfs clients : les crapauds de pierre qui parcouraient les rues en dévorant les ordures ménagères ${ }^{424}$, la statue de Justinien donnée pour celle de Constantin, que les navigateurs aperçoivent en mer à une distance d'une journée ${ }^{425}$, les légendes relatives aux monuments de l'Hippodrome ${ }^{426}$, celle de Charlemagne qui, après avoir pris Jerusalem, revient par Constantinople et force

420

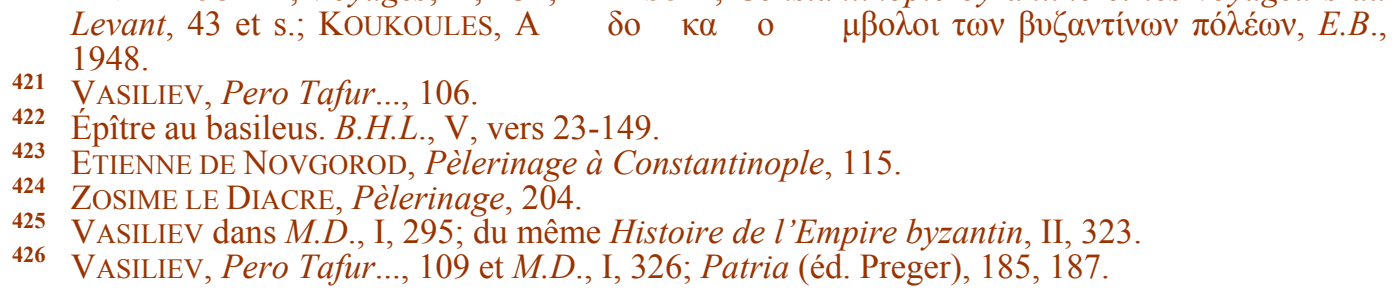

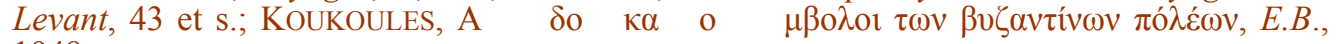
1948.

421 VASILIEV, Pero Tafur..., 106.

422 Épître au basileus. B.H.L., V, vers 23-149.

423 ETIENNE DE NOVGOROD, Pèlerinage à Constantinople, 115.

424 Zosime Le DiACRE, Pèlerinage, 204.

425 VASILIEV dans M.D., I, 295; du même Histoire de l'Empire byzantin, II, 323.

426 VAsiliev, Pero Tafur..., 109 et M.D., I, 326; Patria (éd. Preger), 185, 187.

Ibn Batoutah, Voyages, II, 431; EBersolt, Constantinople byzantine et les voyageurs $d u$ 
l'empereur à jurer qu'il observera le carême et ne prononcera plus de condamnation à mort ${ }^{427}$, celle de l'ange qui veille sur SainteSophie ${ }^{428}$, etc.

La vie de société. - La prédominance de la tradition hellénique s'affirmait par le caractère sociable des habitants qui avaient, comme leurs ancêtres, le goût des longues conversations et des discussions en plein air. Au temps de Justinien, la bonne société se rencontrait sous les portiques de l'Augustaeon. C'est ce qu'on appelait faire son ago$r a, \gamma o \rho a ́ \zeta \varepsilon v v$. Bélisaire s'y montrait après son retour d'Italie ${ }^{429}$. Les libraires y avaient leurs boutiques et y exposaient leurs nouveautés. On y rencontrait des nouvellistes qui discutaient politique et théologie et en venaient parfois aux coups. Des chansons contre Théodora circulaient ainsi sous le manteau ${ }^{430}$. Les gens du peuple eux-mêmes étaient férus de théologie depuis l'époque des grands conciles œcuméniques, alors que les discussions sur la Trinité et la nature du Christ avaient lieu ouvertement sur les places publiques et jusque dans les boutiques des boulangers ${ }^{431}$. On sait d'ailleurs qu'à toutes les époques il a existé à Constantinople une opinion publique que les empereurs devaient ménager et qui impliquait une véritable solidarité entre ses habitants, une conscience collective.

La circulation. - Les rues, larges pour l'époque, mais qui paraîtraient aujourd'hui étroites, étaient sillonnées, aux $\mathrm{V}^{\mathrm{e}}$ et $\mathrm{VI}^{\mathrm{e}}$ siècles, de nombreuses voitures sans ressort, les plus riches peintes et dorées, avec un attelage de mules harnachées d'or. Saint Jean Chrysostome décrit les chars somptueux des dames de haut rang, accompagnées d'eunuques aux livrées éclatantes, ou encore les nobles montés sur des chevaux blancs avec des selles brodées d'or, entourés de serviteurs armés de bâtons pour faire ranger les piétons et criant: "Circulez, faites place ! \ Ceux qui allaient aux bains envoyaient d'avance leurs

VASILIEV dans B.N., 1932, 110 et s.

M.D., I, 294 et s.

Procope De CeSAREe, B.G., III, 258; IORGA, Histoire de la vie byzantine, I, 159.

DIEHL, Justinien et la civilisation byzantine, 435 et $\mathrm{s}$.

SOCRATE, Histoire ecclésiastique, V, 20-21; SOZOMENE, Histoire Ecclésiastique, VII, 6, 1217; THEOdORET, Histoire Ecclésiastique, V, 16; Hesseling, Essai sur la civilisation byzantine, 124. 
esclaves annoncer leur arrivée et préparer tout ce qui était nécessaire $^{432}$.

$\mathrm{Au} \mathrm{XII}{ }^{\mathrm{e}}$ siècle, Benjamin de Tudèle est encore frappé du luxe déployé par les nobles. Il note leurs habits d'étoffes cramoisies couverts de broderies et trouve que, montés sur leurs chevaux richement harnachés, ils ressemblent à des princes ${ }^{433}$.

Les contrastes. - Mais à côté de cette opulence, les voyageurs du $\mathrm{XII}^{\mathrm{e}}$ siècle notent les quartiers sordides et misérables, les ruelles étroites et noires, où l'on n'y voit pas en plein jour, où les vols et les meurtres sont fréquents, les taudis à deux pas des palais ${ }^{434}$. Les services de la voirie y étaient inconnus. Benjamin de Tudèle a vu des tanneurs jeter devant leur porte l'eau qui servait à préparer leurs peaux ${ }^{435}$. Le transfert de la cour au palais des Blachernes avait eu pour résultat la formation d'un nouveau quartier aristocratique, plus sain, plus aéré que les abords du Grand Palais. Ce quartier, peu habité jusque-là, comprenant de grands jardins et de vastes citernes, se couvrit d'hôtels somptueux bâtis par les grands. Le palais de Tekfour-Seraï en est peut-être un vestige ${ }^{436}$. La ville, qui était encore si bien approvisionnée en eau à la fin du IX ${ }^{\mathrm{e}}$ siècle ${ }^{437}$, en manque à l'époque des Comnènes par suite de l'insuffisance des aqueducs. Sur les plaintes qui lui furent adressées, notamment par Eustathe de Thessalonique ${ }^{438}$, Manuel Comnène fit capter de nouvelles sources et construire un nouvel aqueduc $^{439}$.

Cortèges et spectacles de la rue. - A toutes les époques, l'animation des rues était augmentée par le passage de processions solennelles qui attiraient des foules compactes et causaient souvent des accidents.

432

Holmes, The age of Justinian and Theodora, I, 89; KouKoules, Les bains aux temps byzantins, 216 et s.

BENJAMIN DE TUDELE, Voyages, 49-50.

EUDE DE DeuIL, De Ludovici VII profecyione in Orientem, 66; G. MerCATI dans B.Z., 1897; F. Cognasso, Partiti politici e lotte dinastiche in Bizanzio alla morte di Manuele Comneno, 241.

BENJAMIN DE TUDELE, 49-50.

DiEHL et GuILland, L'Europe Orientale de 1081 à 1453, p. 93-94.

HAROUN BEN JAHJa, Récit [de prisonnier de guerre], 222 et s.

COGNASSO, op. cit., 278.

Chalandon, Les Comnène, II, 233; Nicetas Khoniates, Histoire, VIII, 3. 
Au sacre du patriarche Germain en 715 , il y avait une telle presse que la mère de saint Étienne le Nouveau, alors enceinte, faillit être écrasée ${ }^{440}$. Au printemps de 972, Jean Tzimiskès, avant son départ pour le front russe du Danube, se rendit pieds nus du Grand Palais à Sainte-Sophie, puis à Sainte-Marie des Blachernes. L'empereur tenant une croix était précédé d'une immense théorie de prêtres et de dignitaires, chantant à pleine voix des litanies. «Le peuple infini qui bordait les rues, qui peuplait les fenêtres, les crêtes des murs et les toits des maisons, reprenait en chœur, avec ses cent mille voix, ces prières instantes ${ }^{441}$. »

Un feuillet d'ivoire du $\mathrm{VI}^{\mathrm{e}}$ siècle représente une translation de reliques. Un patriarche, reconnaissable à ses ornements, est assis, tenant une châsse sur ses genoux, au haut d'un char à deux chevaux attelés de front, qu'un dignitaire mène par la bride. En avant, trois personnages porteurs de cierges sont reçus par un basileus. Des curieux regardent la scène, les uns sous des portiques, d'autres au premier étage de baies ménagées entre des colonnes ou grimpés sur un toit ${ }^{442}$.

Une curieuse peinture d'un des manuscrits des Homélies du moine Jacques nous montre d'une manière réaliste une foule faisant la haie et attendant un cortège : elle est composée de gens de tout âge et des deux sexes sagement rangés les uns derrière les autres ${ }^{443}$.

Lorsqu'il s'agissait d'un événement aussi important que la translation de l'icône d'Édesse en $944^{444}$ ou du triomphe d'un basileus victorieux, l'affluence était encore plus grande et toute la ville était en fête.

Le Livre des Cérémonies nous a conservé un récit tout protocolaire de l'entrée triomphale de Basile $\mathrm{I}^{\mathrm{er}}$ à Constantinople, après la défaite des Pauliciens en 872. L'empereur passe la nuit au monastère des Abramites, hors de l'enceinte. Le lendemain, accompagné du prince héritier, tous deux montés sur des chevaux blancs aux harnachements garnis de pierres précieuses, le basileus est d'abord acclamé par les dèmes, puis, arrivé à la Porte d'Or, il reçoit le Préfet de la Ville, qui lui offre une couronne de lauriers. Alors, au milieu d'une foule innombrable, il suit la Voie Triomphale, dont le sol est jonché de fleurs, dont les portiques sont tendus d'étoffes précieuses décorées de bouquets de roses et de myrtes. A sa suite marchaient les principaux captifs arabes avec les chars remplis de butin. Un arrêt avait lieu au Forum de Constantin, où l'empereur entrait dans l'église de la Vierge, et changeait ses vêtements militaires pour revêtir la tunique de pourpre et

\footnotetext{
Vie de saint Étienne le Nouveau, 1077.

DIEHL, Choses et gens de Byzance, I, 82-84.

Id., Manuel d'Art byzantin, 303, fig. 152.

Vatic. gr. 1162, 69 Vo; L. BREHIER, Les miniatures des Homélies du moine Jacques et le théâtre religieux à Byzance, 16, pi. vi, 4 .

444 Constantin VII PorPhyrogenete, De imagine Edessa, 21-23; VAsILIEV, Vizantija i Arabui za Vremja Makedonskoj dinastii, II, 250 et s.
} 
la chlamyde brochée d'or. Le cortège était reçu ensuite à Sainte-Sophie par le Patriarche et gagnait enfin le Grand Palais ${ }^{445}$.

Le récit de l'entrée de Nicéphore Phocas à Constantinople, après sa proclamation à l'Empire, est beaucoup plus vivant ${ }^{446}$. Du dromon impérial il descendit à l'Hebdomon, où il monta sur un cheval blanc caparaçonné de pourpre et d'or. Devant lui on portait six étendards d'étoffes précieuses. Pour parvenir à SainteSophie par la Voie Triomphale, il dut fendre les flots de la foule qui l'acclamait. «Grands et petits, riches et pauvres, ceux de la noblesse comme ceux des factions, ceux des faubourgs et ceux du port, artisans par centaines de mille, moines innombrables, soldats et matelots en congé, paysans de Thrace et de Bithynie... portant, malgré le grand soleil d'été, des torches allumées, brûlant de l'encens, agitant de petits drapeaux. Partout résonnaient les trompettes, les nacaires « timbales de cavalerie », les tambours, les cymbales. Partout éclataient, incessantes, les acclamations inouïes de tout ce peuple! ». Comment se figurer l'entrée de cette foule hurlante sous les voûtes sublimes de Sainte-Sophie, dont l'éclat des lumières faisaient vibrer les tons des mosaïques à fond d'or !

Mais ces pompes triomphales étaient exceptionnelles. D'autres spectacles plus modestes excitaient la curiosité des badauds, en particulier celui des animaux exotiques, éléphants conduits par des cornacs, chameaux montés par des nègres, etc. ${ }^{447}$ Trop souvent aussi les rues étaient parcourues par des processions infamantes de condamnés à mort ou à la mutilation, criminels, conspirateurs, souvent de haut rang, montés à rebours sur des ânes et frappés de verges. Loin de fuir ces parades sinistres, la foule les recherchait et y manifestait sa cruauté. Des princesses impériales, n’osant se montrer ouvertement, n’avaient pas honte de regarder ces spectacles à la dérobée ${ }^{448}$.

\section{L'Hippodrome et les spectacles}

L'Hippodrome, dont on a montré ailleurs l'organisation administrative, les diverses destinations et le caractère de ses factions, a tenu jusqu'au XII ${ }^{\mathrm{e}}$ siècle une place considérable dans la vie de Constantino-

Constantin VII Porphyrogenete, De caerimoniis aulae byzantinae, II, 19; VAsiliev, op. cit., II, 35-37.

DIEHL, Dans l'Orient byzantin, 298-308 (16 août 963); BEYLIE, L'habitation byzantine, 110.

EBersolt, La Miniature byzantine, XLIII, 2; DIEHL, Choses et gens de Byzance, I, 757.

Anne Comnene, Alexiade, XII, 6 (III, 72-73); Chalandon, Les Comnène, II, 22. 
ple. Il est donc nécessaire d'exposer ce que nous savons de son aménagement et des spectacles qui s'y déroulaient.

L'engouement pour les courses. - Les courses de chars, attelés de deux à quatre chevaux (biges et quadriges), dont l'origine remontait aux anciens jeux helléniques, étaient le sport favori des Grecs et des Romains. Les habitants de Constantinople, quel que fût leur rang social, de l'empereur au dernier des calfats, se passionnaient pour les succès des auriges dont ils avaient adopté la couleur. Il était de bon ton dans les cercles aristocratiques de s'intéresser exclusivement aux chevaux et aux courses. C'était là le principal sujet de conversation et les discussions sur les jeux du Cirque étaient fréquentes ${ }^{449}$.

Grégoire de Nazianze décrit ces amateurs de courses comme de vrais forcenés, bondissant, criant, imitant un cocher, frappant des chevaux imaginaires, échangeant entre eux des auriges, des chevaux, des écuries « et souvent si pauvres qu'ils n'ont pas de quoi manger pour un jour $\gg{ }^{450}$.

Des mosaïques africaines représentent plusieurs écuries entretenues à grands frais. Revêtus de riches couvertures, les chevaux sont devant leur mangeoire, avec le nom de chacun d'eux : Delicatus, Polidoxus, Alcides, etc., et le souhait Vincas ${ }^{451}$. On sait que le goût de Constantin $\mathrm{V}$ pour les chevaux lui avait valu le surnom de Kaballinos et que, après avoir fait détruire les mosaïques du Milliaire d'Or qui représentaient les conciles œcuméniques, il les avait remplacées par les portraits de ses cochers favoris ${ }^{452}$. Plus étonnant encore était l'engouement pour ses chevaux du patriarche Théophylacte (933956) ${ }^{453}$, fils de Romain Lécapène, empereur.

Les cochers eux-mêmes avaient pris une véritable importance dans l'État. On les comblait de richesses et d'honneurs. Après leur mort, on leur élevait au $\mathrm{V}^{\mathrm{e}}$ siècle des statues de bronze, parfois même au palais du Sénat ${ }^{454}$. Sur la base, conservée, qui supportait la statue de Por-

Claudiana carmina (In Eutropium II, vers 326-354); Saint JEAN ChrYsostome, Homélies, première homélie sur Lazare, texte et trad. dans CONSTANTIN VII PORPHYROGENETE, De caerimoniis (comment. II, 135).

451 Musée de Constantine. BERNARD dans B.A.C.T.H., 1906

452 Vie de saint Étienne le Nouveau, 1172.

453 R. GROUSSET, Histoire des Croisades et du royaume franc de Jérusalem, 44 et s. On lui attribuait mille chevaux qu'il nourrissait lui-même de blé et de fruits.

454 Patria (éd. Preger), I, 14; EBERSOLT dans B.N., 1931, 560 et s. 
phyrios, des bas-reliefs représentent les victoires de l'aurige, debout sur son char, vêtu de la tunique courte sans manches, les jambes couvertes de molletières, la ceinture garnie de lanières de cuir entrecroisées, tenant la palme et la couronne ${ }^{455}$. Des poètes célébraient leurs succès ${ }^{456}$ et l'on faisait remonter l'origine des quatre factions à la victoire d'Alexandre le Grand aux Jeux Olympiques ${ }^{457}$. Un des thèmes favoris du décor des tissus précieux au $\mathrm{VI}^{\mathrm{e}}$ siècle figurait, encadrés dans des médaillons, des cochers dirigeant leurs quadriges en pleine course $^{458}$.

Les cochers n'en étaient pas moins recrutés à l'origine dans les basses classes, mais, au $\mathrm{IX}^{\mathrm{e}}$ siècle, on voit ce métier exercé par des nobles, comme l'un des 42 Martyrs d'Amorium en $845^{459}$ et, exceptionnellement, par le basileus Michel III, dans son hippodrome de Saint-Mamas, et les courtisans qu'il forçait à revêtir la casaque de l'une des factions ${ }^{460}$.

L'édifice. - L'Hippodrome de Byzance avait été construit par Septime Sévère (après 195) à la ressemblance du Circus Maximus de Rome, mais le terrain était en pente et il fallut des galeries de soutènement pour supporter l'édifice, qui mesurait environ 500 mètres de

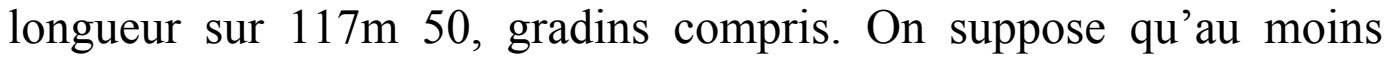
30000 spectateurs pouvaient prendre place sur les gradins. La place actuelle de l'Atmeïdan conserve les monuments principaux qui se dressaient dans l'axe de l'édifice sur la spina, autour de laquelle tournaient les chars. C'est d'abord l'obélisque érigé par Thoutmès III à Héliopolis, en 1700 avant l'ère chrétienne, et amené à Constantinople par ordre de Théodose le Grand en 390 ; il repose sur quatre dés de bronze, établis sur une base décorée de reliefs qui figurent l'empereur présidant les jeux. C'est ensuite la colonne de bronze provenant de Delphes, faite de trois serpents enroulés, dont les têtes se dressaient

55 VAsiliev, The Monument of Porphyrius, 40 et s.; EBersolt dans R.A., 1911, I, 76 et s.

456 VASILIEV, op. cit., 40 et s. (32 épigrammes sur Porphyrios), Voir sa biographie restituée par Vasiliev dans D.O.P., IV, 1948, 41 et s. ; Actes des 42 martyrs d'Amorium.

457 G. MiLLet, Les noms des auriges dans les acclamations de l'Hippodrome, 279.

458 Étoffe provenant d'Aix-la-Chapelle, L. BREHIER, La Sculpture et les Arts mineurs byzantins, 99, pl. LXXXIV.

459 Il s'appelait Bassoïs et était de naissance noble. Actes des 42 martyrs d'Amorium, rédaction $\Delta$, V.V., XVII, 81.

460 TheOPHANES, Continuatus, Michel, 21; A. RAMBAUd, L'Empire grec au Xe siècle. Constantin Porphyrogénète, 72; J. B. BURY, A History of the Eastern Roman Empire, 162; A. VOGT, Basile $I^{e r}$ et la civilisation byzantine à la fin du IX siècle, 7. 
autrefois pour soutenir le trépied d'or dédié à Apollon après la victoire de Platées (479 avant l'ère chrétienne). C'est enfin un obélisque de pierres maçonnées, jadis revêtu de plaques de bronze et restauré, d'après une inscription, par Constantin Porphyrogénète (944-959) ${ }^{461}$.

Entre ces monuments on voyait un grand nombre de groupes sculptés, comme celui de la Louve allaitant Romulus, et de statues : des œuvres arrachées aux temples païens, comme l'Héraklès de Lysippe, à côté de statues impériales, comme celle d'Irène juchée sur une colonne au milieu d'une phiale ${ }^{462}$. Un reste d'une fontaine de ce genre en marbre blanc, garni de reliefs figurant les jeux, a été retrouvé en 1845 ; des trous circulaires ouverts sur les parois pouvaient donner naissance à un jet d'eau qui retombait dans un bassin ${ }^{463}$.

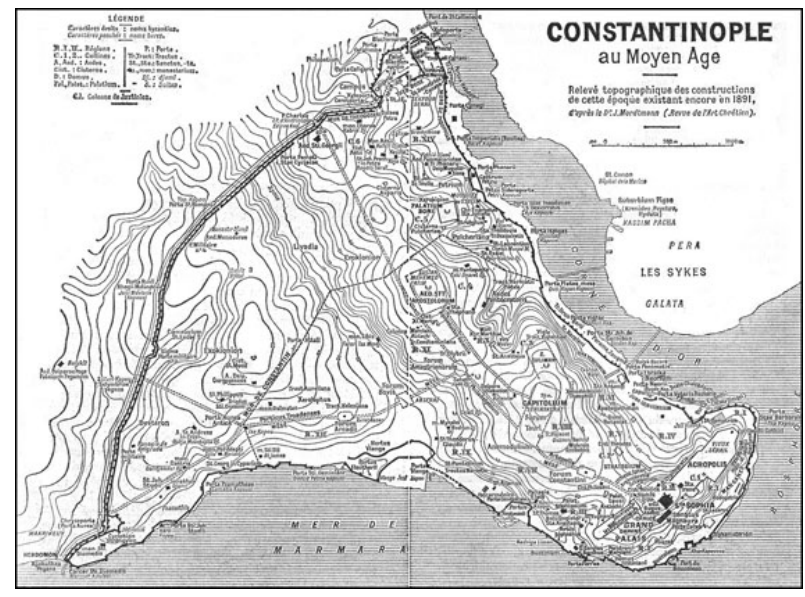

Carte - Constantinople au Moyen Age. (carte plus grande)

Avant la fin du XIX ${ }^{\mathrm{e}}$ siècle, mis à part les monuments de la place de l'Atmeïdan, on ne connaissait guère l'aspect de l'Hippodrome que par des gravures des $\mathrm{XV}^{\mathrm{e}}$ et $\mathrm{XVI}^{\mathrm{e}}$ siècles qui n'en représentaient que les ruines ${ }^{464}$. La plus importante est celle que Panvinio tira d'une Topographie de Constantinople composée vers 1450 . Elle reproduit au sud, du côté de la mer, l'extrémité de l'hémicycle avec des arcades, au nord un mur percé de baies qui donnait accès aux écuries. Dans l'arène on aperçoit la file des obélisques et des colonnes, ainsi que de nombreux monticules provenant de la démolition des gradins et des maisons bâties à l'intérieur de l'enceinte ${ }^{465}$.

\footnotetext{
C.I.G., IV, 8703.

BANBURI, Imperium Orientale sive antiquitates Constantinopolitanae, I, 43.

Ch. TEXIER, Etude sur la topographie de l'Hippodrome, dans R.A., 1845, 152.

EBERSOLT, Constantinople byzantine et les voyageurs du Levant, 63, 87-89.

PANVINIO, De ludis circensibus. Venise, $1600=$ BANBURI, op. cit., II, 664; BEYLIE, L'habitation byzantine, 57 et s. pl. XXXII.
} 
De nos jours le sous-sol de l'Hippodrome a été exploré à plusieurs reprises. Derrière le Musée des Janissaires à l'ouest, des jardins en terrasse laissent voir les murs de briques qui formaient la courbure terminale (sphendoné), et des terrassements artificiels indiquent la place des gradins ${ }^{466}$. Au nord-ouest de la mosquée d'Ahmed, Adolphe Thiers découvrit en 1907 une série d'écuries couvertes de berceaux en briques reposant sur des murs parallèles, le long de l'ancienne piste ${ }^{467}$.

Des fouilles plus profondes furent exécutées en 1918 et en 1932 par Mamboury et Wiegand. Sous la sphendoné furent mises à jour 25 chambres concentriques donnant sur un couloir circulaire éclairé par de grandes fenêtres à un niveau inférieur à la piste. Des chambres analogues longeaient les murs du Grand Palais : de ce côté, le départ de deux arcs paraît être un reste de la colonnade qui subsistait encore au $\mathrm{XV}^{\mathrm{e}}$ siècle. On reconnut l'existence d'une fontaine à la base de l'obélisque de Constantin VII, avec écoulement sur les quatre faces, et on retrouva la base de la Colonne de Delphes, faite d'un simple chapiteau : cette colonne qui était creuse avait été transformée aussi en fontaine $^{468}$.

En 1927 et 1928, Casson et Talbot Rice firent plusieurs sondages dans l'axe des monuments. Résultat inattendu, ils ne retrouvèrent aucune trace d'une terrasse semblable à celle du Circus Maximus, mais des terres rapportées pour racheter la déclivité du sol. La spina, si on peut appeler ainsi la ligne axiale des monuments, n'aurait présenté aucun relief ${ }^{469}$.

Le Kathisma et les carceres. - Comme le Circus Maximus à Rome, 1'Hippodrome de Constantinople était attenant au Palais Impérial et le basileus passait directement de ses appartements dans la tribune qui lui était réservée, le Kathisma. La plupart des archéologues depuis Labarte, et en dernier lieu Ebersolt, voyaient cette tribune au-

\footnotetext{
Observation de l'auteur, mission 1910.

D.A.C.L., VI, 1925, 28-37.

MAMBOURY et WIEGAND, Kaiserpaläste von Konstantinopel.

469 Par contre ROBERT DE CLARI (La conqueste de Constantinople, 88) a vu une « masière » de 15 pieds de haut et de 10 de large portant des statues. Il y a donc eu des remaniements après 1204.
} 
dessus des écuries (carceres), qui formaient à l'extrémité orientale un bâtiment perpendiculaire aux gradins. Pour gagner le Kathisma, le basileus, partant du palais de Daphné, aurait suivi une longue galerie entourant le quart de la périphérie de l'Hippodrome, ce qui est peu vraisemblable $^{470}$. Le Livre des Cérémonies montre Théophile passant sous le Kathisma pour gagner le palais de Daphné, ce qui eût été impossible si l'on admet la théorie de Labarte ${ }^{471}$.

Piganiol et Vogt ont montré que le Kathisma, construit sur le modèle de la tribune impériale de Rome, était un véritable palais contigu à l'église Saint-Étienne de Daphné et placé sur le long côté sud-est de l'Hippodrome. Un escalier secret en colimaçon (cochlea) reliait l'église à la tribune, mais le basileus y accédait par un large escalier de pierre qui aboutissait aux portes de bronze de la loge impériale ${ }^{472}$. Devant cette loge se trouvait une terrasse, le $P i^{473}$ ou Stama, surmontant un portique. Une des faces de la base de l'obélisque montre, derrière les chancels ajourés d'un balcon, l'empereur debout devant des gardes armés de lances et rangés en ligne, à ses côtés des dignitaires portant des bourses ${ }^{474}$.

Les carceres étaient aménagés dans une tour flanquée de deux ailes et surmontés d'un quadrige de bronze enlevé à un temple de l'île de Chios sous Théodose $\mathrm{II}^{475}$. Les splendides chevaux de bronze furent emportés à Venise en 1204 et placés au-dessus du grand portail de Saint-Marc.

A chacune des ailes, six portes s'ouvraient pour laisser passer les chars. Une autre porte, située à la base de la tour, donnait accès à une grande cour, ouverte du côté de la ville (dihippion), avec les écuries des factions sur les côtés.

On y transportait, la veille des courses, les chevaux qui devaient courir, les véritables écuries étant plus éloignées. Au-dessus de la

\footnotetext{
470 EBersolt, Constantinople byzantine, 56, 3; du même : Le Grand Palais de Constantinople, 49-51, 151 et s.; J. LABARTE, Le palais impérial de Constantinople et ses abords, 1861.

471 EBersolt (Le Grand Palais de Constantinople, 17) cite lui même ce texte.

472 Piganiol, A.C.E.B., II Belgrade, 1926, et B.N., 1936 383; ConstANTIN VII PorphyroGENETE, De caerimoniis..., II, 7 et Vogt, Comment. II, 119-122 et B. N., 1935, 476-485.

473 VOGT, loc. cit.

474 D.A.C.L., VI, 2393

475 Ch. PICARD, La Sculpture antique, II (Origines de la sculpture byzantine), 476.
} 
porte, se trouvait une tribune qui servait au directeur des jeux; elle a été prise à tort pour la tribune impériale ${ }^{476}$.

Une représentation à l'Hippodrome. - En dehors des monuments figurés, la source principale consiste dans les chapitres du Livre des Cérémonies compilés par Constantin Porphyrogénète. Par une étude critique de ces textes, G. Millet y a reconnu les traces de deux ouvrages distincts, dont des passages ont été combinés arbitrairement : $1^{\circ}$ le Livre du Maître des cérémonies, dont le rôle était essentiel, rédigé probablement sous Michel III, mais avec des éléments d'âges divers, plusieurs formules datant de Justinien, d'autres du VIII ${ }^{\mathrm{e}}$ siècle $; 2^{\circ}$ le Livre des factions qui contient avant tout les chœurs et les acclamations et n'indique de la cérémonie que ce que les choristes ont besoin de savoir pour intervenir au moment voulu. On y reconnait des formules qui ne peuvent dater que du $\mathrm{V}^{\mathrm{e}}$ siècle, et les noms des auriges correspondent à ceux du roman d'Alexandre ${ }^{477}$. Constantin Porphyrogénète a combiné ces deux éléments en un traité unique, dans son désir de constituer un type officiel de célébration des jeux ${ }^{478}$.

Les préparatifs d'une représentation duraient deux jours. L'avantveille, les factions avaient demandé au basileus l'autorisation de célébrer la fête et exécuté le soir une danse aux flambeaux. La veille, lorsque le voile annonciateur de la représentation avait été suspendu à la porte de l'Hippodrome, les factions se rendaient dans les carceres et acclamaient l'empereur, chaque faction exprimant pour elle-même des souhaits de victoire. Puis avait lieu dans les écuries l'inspection des chevaux, qui devaient être sains et intacts ${ }^{479}$.

Mais voici le grand jour arrivé. A la porte de l'Hippodrome, un tesserarius recueille les jetons qui sont exigés des spectateurs et les gradins se remplissent. Au palais de Daphné l'empereur a revêtu ses ornements, s'est prosterné, cierge en main, dans les divers oratoires et a gagné le triclinium du Kathisma qui précède la tribune. Là a lieu la réception solennelle des dignitaires qui ont le privilège d'assister aux jeux dans la tribune impériale. Le maître des cérémonies, par

\footnotetext{
476 Piganiol, loc. cit. A Rome aussi la loge du magistrat président des jeux était distincte de la loge impériale. A Constantinople le président était le Préfet de la Ville.

477 Supra, p. 86-7.

478 G. MiLLET, M.K, 281-295.

479 CONSTANTIN VII PORPHYROGENETE, op. cit., I, 68 et s.
} 
l'intermédiaire du préposite, vient annoncer au basileus que tout est prêt : les chars sont attelés, le peuple est rangé sur les gradins, les démarques et les démocrates des factions sont à leur poste, la garde impériale est rangée autour de ses étendards.

Le moment est solennel: sur un signe de l'empereur, les portes s'ouvrent, le maître des cérémonies relève un pan de la chlamyde impériale, le basileus paraît à la tribune, monte sur l'estrade où est placé son trône et bénit trois fois le peuple, traçant une croix avec le pan relevé du manteau, d'abord au milieu, puis à droite du côté des Vénètes et à gauche vers les Prasini.

Que l'on veuille bien se figurer la scène : la monstrueuse enceinte avec ses portiques, ses statues, ses monuments, son obélisque rappelant des âges d'une antiquité fabuleuse, ses trophées de victoires, des Grecs sur les Barbares, des empereurs chrétiens sur le paganisme, - ses gradins étendus à perte de vue, chargés d'un peuple innombrable, incliné sous la bénédiction de l'autocrator et faisant retentir l'édifice d'un tonnerre d'acclamations; puis, dans un silence absolu, les chœurs des factions, accompagnés des orgues d'argent, et l'adoration publique de l'empereur par les dignitaires, qui prennent place ensuite à ses côtés; enfin, suivant l'antique usage, le souverain jetant la serviette, la mappa, dans l'arène et, à ce signal, les portes des carceres s'ouvrant en même temps et les auriges s'élançant sur la piste, poursuivis des cris frénétiques des spectateurs, chacun acclamant sa couleur favorite, huant et défiant ses adversaires.

On reconnaîtra que le monde de ce temps ne connaissait guère de spectacle aussi grandiose et l'on comprendra l'admiration qu'il excitait chez les étrangers, que l'on ne manquait jamais d'inviter à en jouir ${ }^{480}$.

La course (missus, $\mu 1 \lambda \lambda \alpha$, palma) comportait quatre quadriges aux quatre couleurs, qui devaient faire sept tours de piste. A une travée de portique étaient suspendus des œufs d'autruche et on en retirait un à chaque course : en face se trouvaient sept dauphins de bronze jetant de l'eau.

480 R.K.O.R., 1255 (invitation des Pisans par Alexis $I^{\mathrm{er}}$ en l'année 1111). 
L'ordre dans lequel sortaient les chars était préalablement tiré au sort au moyen d'une urne contenant des boules et des numéros, fixée au milieu d'un portique : une sculpture représente deux auriges qui la font basculer à coups de fouet ${ }^{481}$.

Plusieurs monuments montrent des huissiers arrêtant les chars lorsque la course est terminée et le vainqueur arrivant à la borne et levant les bras, tandis qu'un personnage vêtu d'une toge, costume officiel du Préfet de la Ville, lui tend une palme ${ }^{482}$. La victoire était soulignée par les acclamations rythmées de la faction victorieuse, avec répons du peuple entier en l'honneur de l'aurige et du basileus, qui était supplié d'accorder la récompense, consistant en trois nomismata et une couronne ${ }^{483}$.

Les courses commençaient le matin et se poursuivaient toute la journée, interrompues par le repas, que le basileus et les dignitaires prenaient dans le triclinium du Kathisma, tandis que les spectateurs sortaient leurs provisions. Il y avait huit courses, quatre le matin et autant l'après-midi ${ }^{484}$. $\mathrm{Au} \mathrm{XI}^{\mathrm{e}}$ siècle, l'impératrice et ses dames d'hon-neur assistaient aux jeux du haut de l'église Saint-Étienne de Daphné, comme l'indique une fresque de Sainte-Sophie de Kiev figurant une représentation à l'Hippodrome ${ }^{485}$; mais il est certain qu'il n'en était pas ainsi auparavant, comme le montre un relief de l'obélisque de Théodose, où l'on. distingue la basilissa assise à côté de l'empereur ${ }^{486}$.

Les intermèdes. - Les courses de char étaient interrompues par des intermèdes variés, dont le peuple était très friand, et cet usage venait aussi de Rome. Il y avait tour à tour des exhibitions d'animaux exotiques, des scènes comiques, des tableaux vivants, des acrobaties de tout genre.

Découverte en 1834 (musée de Berlin). L’urne est reproduite sur divers monuments. DALTON, Byzantine Art and Archaeology, 490, fig. 293 (psautier d'Utrecht).

482 D.A.C.L., VI, 2389, fig. 5714 et 5716.

483 Constantin VII Porphyrogenete, I, 69 (II, 126); D.A.C.L., VI, 2388; en 880 le vainqueur reçoit une couronne d'or et une livre d'or, HAROUN BEN JAHJA, Récit, 215. 
A l'étage inférieur de la face sud-est de la base de l'obélisque, deux ballerines dansent, tandis que deux musiciens jouent, l'un de la flûte de Pan, l'autre du syrinx à plusieurs tuyaux. Sur le relief de la fontaine, des joueurs de, flûte et de psaltérion font danser des personnages : dans les angles deux orgues à soufflet sont manœuvrées par des enfants ${ }^{487}$.

Anastase aurait défendu les chasses et les combats d'animaux qui faisaient souvent des victimes ${ }^{488}$. Cependant, sur le diptyque consulaire de son neveu daté de 517, où le cirque est figuré, un picador à cheval excite des animaux auxquels deux hommes s'apprêtent à lancer des nœuds coulants, tandis que d'autres cherchent à se mettre à l'abri ${ }^{489}$. Les peintures de Sainte-Sophie de Kiev montrent plusieurs intermèdes de ce genre ${ }^{490}$.

Sous Romain II, en 960, l'écuyer d'un dignitaire, Philorsios, debout sur la selle d'un cheval lancé au galop, jonglait avec une épée, aux applaudissements des spectateurs ${ }^{491}$. Peu de temps après, Nicéphore Phocas, ayant usurpé le trône et sentant sa popularité diminuer, offrit aux spectateurs de l'Hippodrome un choix d'intermèdes organisés à grands frais avec des figurants exotiques : baladins venus de l'Inde, bouffons et acrobates arabes, danseurs scandinaves vêtus de peaux de bêtes. Il y avait aussi des chiens habillés des costumes de tous les peuples connus, des bêtes fauves avec leurs gardiens, un crocodile enchaîné, une mule à deux têtes et un chien savant appelé Python, qui pouvait découvrir des objets cachés et désigner la personne la plus avare ou la plus généreuse de la société ${ }^{492}$.

Moins heureuse fut l'initiative de ce prince, à son retour de Syrie (966-967), en faisant simuler un combat en plein Hippodrome par les soldats de sa garde : les spectateurs effrayés voulurent fuir et un grand nombre d'entre eux fut écrasé ${ }^{493}$.

L'Hippodrome sous les Comnènes et les Anges. — On a la preuve que la célébration des jeux se poursuivit régulièrement jusqu'en 1204, mais ils ne paraissent pas tenir dans la vie de Constantinople la même place qu'au $\mathrm{X}^{\mathrm{e}}$ siècle. Les empereurs guerriers des époques suivantes n'ont guère le loisir de présider les courses. De plus, l'émigration du basileus et de la cour aux Blachernes devait avoir sa répercussion sur les destinées de l'Hippodrome.

Les témoignages sur la persistance des jeux n'en sont pas moins nets. Ce sont ceux des étrangers, des princes scandinaves, recueillis dans les sagas ${ }^{494}$, de Ben-

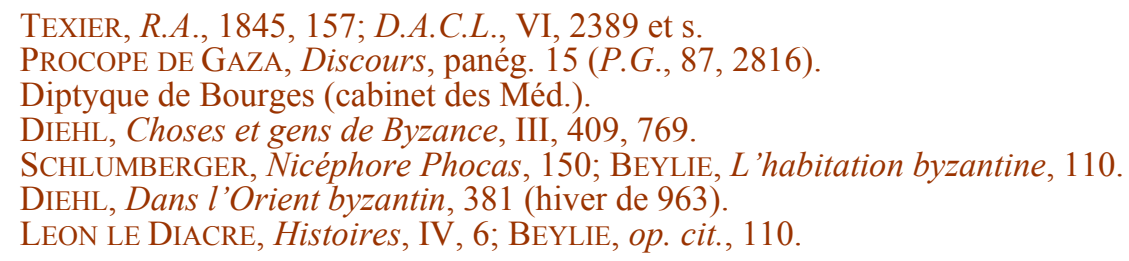


jamin de Tudèle ${ }^{495}$, de l'Arabe Edrisi ${ }^{496}$. Les factions existent toujours : Théodore Prodrome adresse au césar Nicéphore Bryenne une pièce sur l'excellence des couleurs verte et rouge, beaucoup plus nobles que le bleu et le blanc ${ }^{497}$. Dans ses œuvres figurent d'ailleurs des hymnes des dèmes en l'honneur de Jean Comnène (1118-1143) ${ }^{498}$. Manuel (1143-1180) fait célébrer des jeux en l'honneur des souverains de passage à sa cour, Kilidj Arslan, sultan d'Iconium en 1162, Amaury, roi de Jérusalem en 1171; mais, à côté des courses de chars, apparaissent les courses montées et même les tournois à la française ${ }^{499}$. Pendant le séjour de Kilidj Arslan, un homme de sa suite prétendit avoir trouvé le secret du vol vêtu d'une ample tunique dont les pans étaient attachés de manière à former de vastes poches, qu'il essaya de gonfler d'air, il monta sur le balcon qui surmontait la porte centrale des carceres et s'élança tout d'un coup, mais ce fut pour s'écraser sur le sol au milieu des rires des spectateurs ${ }^{\mathbf{5 0 0}}$.

Bien que, sous la dynastie des Anges, il soit encore question des représentations de l'Hippodrome, lorsque Alexis III donne des jeux à l'occasion du mariage simultané de ses deux filles, c'est au parais des Blachernes qu'ils ont lieu ${ }^{501}$.

La fin de l'Hippodrome. - Après la prise de Constantinople par les croisés, le 12 avril 1204, Robert de Clari vit encore « la place que l'on appelait les Jeux de l'Empereur », les 30 ou 40 gradins destinés aux spectateurs, la tribune impériale et les monuments de la Spina ${ }^{502}$, mais au cours du pillage qui suivit la victoire, l'Hippodrome fut dépouillé de ses richesses et abandonné ${ }^{503}$. Les ressources de l'Empire restauré étaient trop précaires pour que les Paléologues pussent jamais songer à rétablir l'institution coûteuse des jeux publics. L'Hippodrome déserté tomba en ruine. Aux XIV et XV ${ }^{\mathrm{e}}$ siècles, on les montrait aux voyageurs comme une curiosité. Clavijo en $1403^{504}$, Buondelmonti en $1419^{505}$, Peró Tafur en $14399^{506}$ signalent au midi 30 immenses colonnes reliées par des arcs dans la partie circulaire, reproduites dans le dessin anonyme publié par Panvinio ${ }^{507}$.

\footnotetext{
Riant, Expéditions et pèlerinages des Scandinaves en Terre Sainte, 160, 199 (vers 1103). BENJAMIn DE Tudele, Voyages (en 1172, le jour de Noël).

EDRISI, Géographie, trad. Jaubert, a 1153; EBERSOLT, Constantinople byzantine et les voyageurs du Levant, 34.

P.G., 133, 1007 et s.; TANNERY, A.A.E.G., 1887, 107.

Ed. LAMBROS, N.H., II, 385 et s.

Nicetas Khoniates, Histoire, III, 5; Satire contre les higoumènes, 324; SCHLumberger, Campagnes du roi Amaury..,, 311-335. Chalandon, Les Comnène, II, 421 et s.

501 Nicetas KhONIATES, Histoire, Al. 111, III, 2 et 6.

502 RoBert DE Clari, La Conqueste de Constantinople, 88.

503 Nicetas KhONIATES, op. cit. (de Statuis), I. XXI.

504 P. MERIMEE, Etude sur les arts au Moyen Age, 317-321.

505 Gerola, La vedute di Costuntinopoli di Crisioforo Buondelmonti, 273 et s.

506 Vasiliev, Pero Tafur..., 108 et s.; Anonyme russe. Description de Constantinople, 237 (vers 1424-1453).

507 Supra, p. 90.
} 
Tel qu'il était, l'Hippodrome était encore utilisé par des particuliers qui y organisaient des courses de chevaux montés, comme le montre une curieuse lettre écrite par le fils du mégaduc Notaras à Nicolas Karysténos, qui se trouvait au concile de Florence avec Jean VIII (14381439) ${ }^{508}$.

Les derniers Occidentaux qui virent encore les ruines de l'Hippodrome furent l'artiste hollandais Pieter Kœck van Alast qui fit graver des planches sur bois en 1533 et Pierre Gylle d'Albi, attaché à l'ambassade de Gabriel Luetz d'Aramon (1544-1557). Il nota les colonnes de marbre blanc, dont les fûts et les chapiteaux gisaient épars sur le sol, On venait de les renverser pour édifier un kiosque au sultan Soliman ${ }^{509}$.

\section{Les « théatres »}

\section{$\underline{\text { Retour à la Table des Matières }}$}

L'importance prise par les jeux de l'Hippodrome à Byzance a porté les historiens à laisser dans l'ombre d'autres spectacles et en particulier le théâtre ${ }^{510}$. Bien que le terme de théâtre, $\theta \varepsilon \dot{\varepsilon} \alpha \tau \rho o v$, ait pu désigner une salle de réunion quelconque ${ }^{511}$, on a la preuve qu'il s'appliquait aussi à des édifices réservés à des pièces dramatiques.

On ne sait pas grand-chose d'un Grand Théâtre construit par Septime Sévère à la mode antique dans la première région, dont on voyait encore l'emplacement au $\mathrm{XV}^{\mathrm{e}}$ siècle, mais saint Jean Chrysostome le montre fréquenté par l'impératrice Eudokia ${ }^{512}$ et il est cité au $\mathrm{XI}^{\mathrm{e}}$ siècle par Psellos ${ }^{513}$. D'autres théâtres dus à Constantin se trouvaient près de Sainte-Irène, dans le quartier des Blachernes, dans le faubourg des Sykes (celui-ci restauré par Justinien) ${ }^{514}$.

П $\alpha \lambda \alpha 10 \lambda o ́ \gamma \varepsilon 1 \alpha . .$. Documents inédits rassemblés par Sp. Lambros, II, 183.

EBERSOLT, Constantinople byzantine et les voyageurs du Levant, 76-78; WIEGAND dans M.D.A.L, 1908, pl. I, fig. 2: d'après Pieter Koeck (montre les gradins de la courbure);

GYLLIUS, Topographia Constantinoupoleos, II, 299.

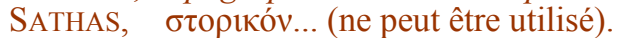

Synonyme d'auditorium, salle de conférences.

Saint Jean Chrysostome, Homélies, hom. X (P.G., 62, 371).

Voir dans R.Q.H., 1931, 260.

Ibidem, 259-296. 
Dans le programme des fêtes qu'un nouveau consul doit offrir au peuple, Justinien mentionne la procession " qui conduit au théâtre » réservé à la comédie, à la tragédie, aux chœurs et à tous les genres de

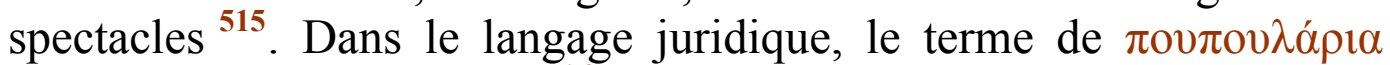
désigne ces établissements ${ }^{516}$, ce qui semble leur donner un caractère essentiellement plébéien.

Ce terme correspond bien au genre des pièces que l'on y représentait. Depuis longtemps le théâtre classique était tombé en désuétude et avait été remplacé par le mime $(\mu \mu \mathrm{\mu})^{517}$, farce à la fois réaliste et bouffonne. Les acteurs jouaient sans masques, de manière à faire concourir à l'action des jeux de physionomie, où les grimaces avaient la place prépondérante, — d'où le personnage de Sannio (le grimacier). Une autre révolution était l'introduction des actrices sur la scène et on y voyait même des enfants. Acteurs et actrices se grimaient à l'aide de fards pour représenter les personnages les plus variés ${ }^{518}$.

Un autre caractère du mime est la création de personnages types, qui reparaissent avec les mêmes traits, les mêmes costumes, le même caractère : Ardalion, le vieillard frivole, Scholasticus, le pédant, etc., ancêtres du Polichinelle ou de l'Arlequin de la comédie italienne ${ }^{519}$. Les sujets étaient empruntés à la vie courante, parfois à la mythologie. Les coups, les soufflets, les obscénités, les mots équivoques, les bouffonneries immorales étaient la loi du genre. Il y avait aussi des tableaux vivants, des défilés de troupes, des processions, des apparitions de fantômes, supposant toute une machinerie ${ }^{520}$.

Mais nous connaissons surtout le mime par des textes antiques et par les attaques des Pères de l'Eglise contre son immoralité ${ }^{521}$. On a peu de renseignements sur les mimes à l'époque byzantine ${ }^{522}$. Son

C.I.C.I., nov. 105 (28 décembre 537).

VoGT dans R.Q.H., 1931, 260 (d'après la Synopsis legum de Psellos).

Littéralement : l'imitateur.

REICH, Der Mimus (Berlin, 1903), 598

Ibidem, 436.

VoGT, loc. cit., 259-296.

ReICH, op. cit., 86, 116 (contre-attaque des mimes contre Grégoire de Nazianze, devenu patriarche).

522 S. REINACH, A.I., C.R., 19 mai 1918 (essai pour reconstituer un mime d'après un passage de Psellos sur les mystères du paganisme). 
existence et son succès jusqu'au $\mathrm{XV}^{\mathrm{e}}$ siècle n'en sont pas moins prouvés.

Et d'abord, par la législation qui définit la condition sociale des mimes, le Code Théodosien, qui interdit d'enlever les actrices du théâtre et les rive à leur métier ${ }^{523}$; celle de Justinien, époux d'une ancienne mime, qui rend légal le mariage d'une actrice avec toutes les conséquences pour ses enfants ${ }^{524}$. En revanche, le concile Quinisexte (692) excommunia les mimes, auteurs, acteurs et actrices, et interdit ces spectacles aux clercs et aux moines.

En dépit de cette prohibition, le mime poursuivit sa carrière et s'enrichit même de types nouveaux, comme l'Arabe ou l'Arménien, grâce aux immigrés étrangers ${ }^{525}$. On a vu la place que tenait le mime à l'Hippodrome, où par sa bouffonnerie, écrit un rhéteur, «il adoucissait la fureur des factions » ${ }^{526}$. La musique et la danse tenaient beaucoup de place dans ces représentations et, à côté des mimes, se tenait toujours un musicien, prêt à l'accompagner ${ }^{527}$.

Avec le pouvoir les mimes prenaient souvent de grandes libertés, comme celui qui révéla à l'empereur Théophile l'indélicatesse du préfet Nicéphore, coupable d'avoir confisqué un navire appartenant à une veuve. Théophile le fit arrêter et brûler vif au milieu de l'Hippodrome ${ }^{528}$. L'Église n'était guère plus respectée et l'on voyait sur la scène des moines et des religieuses. Une pièce immonde, la Messe de l'homme sans barbe ${ }^{529}$, était une parodie de la liturgie, et c'était sous cette inspiration que le jeune Michel III s'amusait avec ses amis déguisés en clercs à parodier les cérémonies religieuses ${ }^{530}$.

La survie du mime au $\mathrm{XI}^{\mathrm{e}}$ siècle est attestée par le témoignage de Psellos, qui note que Constantin Monomaque souffrant ne prenait plus aucun plaisir à la musique, à la danse, aux jeux des mimes, qui reproche à ses disciples de fréquenter plutôt le théâtre que son école ${ }^{531}$ et se plaint que son gendre, en dépit de son titre de patrice et protospathaire, vive avec des mimes et des farceurs ${ }^{532}$.

$\mathrm{Au} \mathrm{XII}^{\mathrm{e}}$ siècle, c'est Théodore Prodrome qui déplore la mésestime où est tombé le savoir : les livres ne rapportent plus d'argent, car il n'y en a plus aujourd'hui que pour les bouffons et les mimes ${ }^{53}$. A la même époque, Zonaras et Balsamon donnent des commentaires tendancieux du $51^{\mathrm{e}}$ canon du concile Quinisexte, en

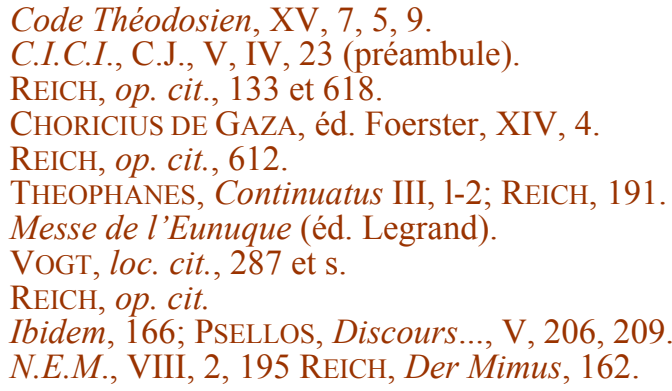


soutenant qu'il ne prohibe pas le mime d'une manière absolue, mais seulement les rires inconvenants, l'indécence des costumes et les gestes lascifs des actrices ${ }^{\mathbf{5 3 4}}$.

Ainsi, loin d'avoir disparu, le mime antique a survécu à toutes les prohibitions, à toutes les censures et la décadence des spectacles de l'Hippodrome lui a peut-être donné un regain de vitalité. Adopté par les conquérants ${ }^{535}$, il aurait survécu dans les spectacles turcs des marionnettes : leur protagoniste, Karagöz, environné de nombreux figurants de tous pays, serait le successeur authentique des personnages du mime byzantin, dont il a retenu les bouffonneries et l'obscénité ${ }^{536}$. 


\section{Chapitre V}

\section{La vie urbaine dans les provinces}

\section{Retour à la Table des Matières}

Constantinople devait son prestige à son titre et à son statut juridique : Nouvelle Rome, première métropole de l'Empire, résidence du gouvernement impérial ; mais elle n'était en réalité que la dernière venue des capitales hellénistiques. Longtemps avant elle, sans parler de l'ancienne Rome, les trois villes d'Alexandrie, Antioche et Carthage étaient regardées comme des villes mondiales, plus étendues et plus peuplées que la ville de Constantin, construite, comme on l'a vu, sur leur modèle.

D'autre part, tandis que, dans l'Occident ravagé par les invasions barbares, les villes, dont les enceintes se rétrécissaient de plus en plus, finirent par disparaître, la civilisation urbaine se maintint en Orient. On a calculé que les villes comptant 100000 habitants n'étaient pas rares en Asie Mineure, en Syrie, en Mésopotamie, en Égypte avant l'invasion arabe, et même dans les provinces danubiennes et l'Illyrium, avant celle des Avars et des Slaves.

Aux $\mathrm{V}^{\mathrm{e}}$ et $\mathrm{VI}^{\mathrm{e}}$ siècles, loin de diminuer, le nombre des villes d'Orient s'est accru, grâce aux fondations impériales, comme celles de Dara par Anastase (505), de Justiniana I ${ }^{\mathrm{a}}$ par Justinien en $535{ }^{537}$. 


\section{Alexandrie et villes d'Égypte}

\section{$\underline{\text { Retour à la Table des Matières }}$}

Alexandrie. - Alexandrie conservait au $\mathrm{VI}^{\mathrm{e}}$ siècle toute l'importance qu'elle avait dans l'antiquité. Sa population, composée de Grecs, noyés sous le nombre des indigènes, ainsi que de grosses colonies de juifs et de Syriens, atteignait près de 600000 habitants ${ }^{538}$. Son plan régulier, qui datait de sa fondation, était encore intact. Des fouilles exécutées en 1874 ont permis de retrouver la longue rue, bordée de monuments, qui reliait le Grand Port au port fluvial du lac Maréotis. Une enceinte, d'époque byzantine, partait de la Porte de la Lune, voisine du port d'Eunoste, à l'ouest, et se dirigeait vers l'est, en laissant en dehors le faubourg de Rhacotis au sud-ouest, l'ancien Bruchion, le quartier Canopique, le faubourg d'Éleusis à l'est. L'Hippodrome était situé dans cette région, où se trouvait aussi le quartier juif ${ }^{539}$. Le merveilleux Phare, restauré au $V^{\mathrm{e}}$ siècle par le patrice Ammonios, signalait toujours l'entrée du Grand Port et il en est encore question au XII ${ }^{\mathrm{e}}$ siècle ${ }^{540}$.

Les derniers païens. - La victoire du christianisme avait eu pour résultats la destruction de plusieurs temples païens, comme le Sérapéum en $389^{541}$, et la construction d'églises et de monastères, que vinrent peupler d'innombrables moines. Le Sérapéum avait fait place à une basilique dédiée à saint Jean-Baptiste et une cathédrale fut construite sur l'emplacement du Templum Caesaris, élevé par Cléopâtre en face du Grand Port ${ }^{542}$. On a montré ailleurs la toute-puissance du patriarche d'Alexandrie sur son Église et sa place importante dans l'administration de la ville ${ }^{543}$.

Anthologia graeca épigrammatum Palatina cum Planudea, éd. Stadtmüller, II, 138; le Phare, décrit par Edrisi, est figuré sur la mosaïque de Djerasch (Transjordanie), découverte en 1929 (Formes, février 1930).

541 Marcellinus Comes, Annales (éd. Mommsen), 62; StrZYgOwSKI, Eine Alexandrinische Weltchronik, pl. VI.

542 D.A.C.L., I, 107 et s. De même le martyrium de saint Marc, les catacombes de Karmouz, etc.

543 M.B.E.H. (Institutions), éd. 1970, 361 
Cependant le paganisme était si fortement enraciné en Égypte, qu'il opposa une grande résistance, en particulier dans les milieux intellectuels, parmi les philosophes, dont les familles formaient de véritables communautés et se mariaient entre elles. Telle était la famille des Horapollo (fin du $\mathrm{V}^{\mathrm{e}}$ siècle), qui joignaient à la connaissance de la philosophie néoplatonicienne celle des doctrines et des rites de l'ancienne religion égyptienne ${ }^{544}$. C'était dans les écoles publiques que se trouvait le principal centre de ce néopaganisme, dont la figure la plus curieuse est celle d'Hypatie, fille de Théon le Géomètre. De réputation irréprochable, elle portait le manteau des philosophes et donnait des leçons publiques. Synésius, futur évêque de Cyrène, était l'un de ses disciples ${ }^{545}$, et des magistrats, comme le préfet augustal Oreste, lui demandaient souvent conseil. Ce fut ce qui la perdit : au cours d'une émeute contre les Juifs, Oreste, insulté par des moines, fit saisir l'un d'eux et le fit expirer sous les tortures. Le peuple exaspéré se vengea sur Hypatie, qui sortait au même instant de sa maison sur un char, et la massacra sauvagement (415) ${ }^{546}$.

En dépit des édits impériaux, il existait encore en 486, à Manouthis près d'Alexandrie, un temple d'Isis avec ses prêtres, ses statues, ses oracles et ses fidèles qui molestaient les chrétiens ${ }^{547}$. Ce fut sous Justinien qu'une campagne systématique fut entreprise contre le paganisme égyptien, mais il n'avait pas encore tout à fait disparu au début du VII ${ }^{\mathrm{e}}$ siècle ${ }^{548}$.

Les habitants. - La population comprenait quatre éléments : le

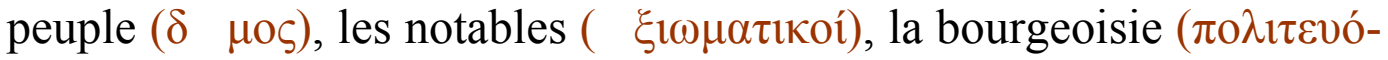

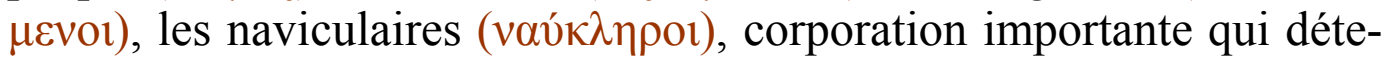
nait le monopole des transports de l'annone et du commerce avec l'Occident. On voit ces éléments se coaliser pour mener une action politique, par exemple en 457, lorsqu'ils cherchent à se justifier auprès de l'empereur Léon d'avoir élu patriarche Timothée Ailouros ${ }^{549}$.

\footnotetext{
544 G. Hanotaux, Histoire de la nation égyptienne, III, 135; J. MASPERO, Horopollon et la fin du paganisme égyptien, dans B.I.F.C., XI, 181 et s.

Bury, History of the later Roman Empire, I; J. MASPERO, op. cit., XI, 181 et s.; DrUON, Synesius, 1859.

546 BURY,op. cit., I, 127 et s.

547 J. MASPERO, Histoire des patriarches d'Alexandrie (518-610), 33; Vie de Sévère, patriarche monophysite d'Antioche, II, 17, 27 et s.

548 Fliche et MARTIn, Histoire de l'Église, IV, 442 et s.; J. MASPERO, op. cit.: sanctuaires détruits par le patriarche Andronic (616-622).

549 EvagRIos, Histoire ecclésiastique, II, 9; M. GELZER, Studien zur byzantinischen Verwaltung Aegyptens, 18, 2.
} 
La plus grande partie des habitants vivait de l'industrie et du commerce, industries de luxe (verrerie, tissage de la soie et de la laine, tapisserie, sculpture sur porphyre et pierres dures), commerce d'alimentation, grand commerce méditerranéen et avec l'Inde par les ports de la mer Rouge ${ }^{550}$. Tous les témoignages s'accordent sur la difficulté de gouverner cette population, toujours prête à se soulever. « Dans cette ville, à cause de l'allure libre du peuple, les fonctionnaires n'administrent la chose publique qu'avec crainte », écrit un anonyme au $\mathrm{V}^{\mathrm{e}}$ siècle ${ }^{551}$, et au $\mathrm{VI}^{\mathrm{e}}$ siècle, Maximien, archevêque de Ravenne, note cette race fière, séditieuse, toujours inquiète et en état de guerre civile ${ }^{552}$. Les émeutes avaient souvent une cause religieuse ou partaient de l'Hippodrome. Les Coptes avaient en outre des sentiments d'hos-tilité contre l'hellénisme, que l'Empire représentait pour eux, et, au VII ${ }^{\mathrm{e}}$ siècle, leur langue nationale était le principal idiome d'Alexan-drie ${ }^{553}$.

Cet état d'agitation perpétuelle avait fini par diminuer la richesse et il s'était formé une immense classe de prolétaires nourris soit par l'État, soit par l'Église ${ }^{554}$.

Provinces. - Par son peuplement et ses relations mondiales, Alexandrie dépassait de beaucoup en importance les localités provinciales la civilisation urbaine ne s'en maintenait pas moins dans toute l'Égypte avant l'invasion arabe, comme le prouvent les papyrus et les nécropoles explorées, qui nous révèlent l'organisation administrative ${ }^{555}$ et la prospérité des villes du Delta et de la vallée du Nil. La liste d'Hiéroclès (avant 535) cite 73 villes pour 6 provinces ${ }^{556}$, la notice de Georges de Chypre (règne de Maurice, 582-602), 53 villes pour 7 provinces ${ }^{557}$.

Ces cités ( $\pi$ ó $\lambda \varepsilon 1 \varsigma$ ) peuplées surtout de Grecs à l'origine, avaient été fondées par les Lagides et les empereurs romains, bâties d'après un

\footnotetext{
Voir ch. VII.

Anonyme. Totius orbis descriptio, II, 520.

Agnellus, Liber Pontificalis ecclesiae Ravennatis, P.L., CVI, 608 et s. (d'après les notes de voyage de Maximien, venu à Alexandrie avant 546).

553 J. MASPERO, op. cit., 39 et s.

Ibidem; Vie de saint Jean l'Aumônier (par LEONCE DE NAPLES).

M.B.E.H. (Institutions). éd. 1970, 167.

Hierocles, Synekdemos. P.G., 113.

GeORGES DE CHYPRE, Descriptio orbis romani (éd. Gelzer).
} 
plan d'ensemble analogue à celui d'Alexandrie, avec des rues bordées de portiques à colonnades et coupées à angle droit, des agoras spacieux, des édifices d'utilité publique, bains, aqueducs, greniers fortifiés ${ }^{558}$. Leurs immenses nécropoles attestent une population encore importante au moment de l'invasion arabe.

Antinoé, métropole de la Thébaïde, fondée par Hadrien en 132, était construite autour de deux rues principales qui se coupaient à angle droit, larges de 14,61 m. Ces rues étaient bordées de portiques voûtés, avec de belles colonnes corinthiennes. Les fouilles de Gayet (1890-1900) ont mis à jour de nombreuses sépultures d'époque byzantine d'une grande richesse, portraits funéraires et tissus historiés. Les églises étaient nombreuses. En face de la ville, située sur la rive droite du Nil, se trouvait Hermopolis ${ }^{559}$.

Dans la Haute-Égypte, Akhmin-Panopolis est connue surtout par sa nécropole, qui a révélé une industrie de la tapisserie très florissante et de nombreux portraits de défunts, indiquant une population très riche ${ }^{560}$.

Oxyrhynchos, métropole de l'Arcadie, possédait un hippodrome bien organisé. Les papyrus qui en proviennent donnent des renseignements sur ses écuries de courses et sur leur administration, ainsi que sur les disputes violentes entre les factions, qui avaient leurs répercussions jusque dans les campagnes environnantes ${ }^{561}$.

\section{Antioche}

$\underline{\text { Retour à la Table des Matières }}$

Antioche. - Fondée par Séleucus Nicator en 301 avant J.-C., Antioche ne tarda pas à devenir la plus grande ville d'Orient et la rivale d'Alexandrie. Cependant, malgré le caractère hétérogène de sa population, l'hellénisme y était plus pur qu'en Égypte. Le grec était la langue courante et ses écoles de philosophes et de rhéteurs étaient renommées longtemps avant la fondation de Constantinople ${ }^{562}$.

\section{byzantine, 225}

559

560 D.A.C.L., I, 1042 et s.

The Oxyrhyncus Papyri (éd. et trad. Grenfell et Hunt), I, 45; Greek Papyri in the British Museum (éd. Kenyon et Bell), III, 227, 18; G. RouILLARD, L'administration de l'Egypte byzantine, 191; Yvonne JANNSENS, dans B.N., 1936, 515.

562

DIEHL, Justinien et la civilisation byzantine au VI siècle, 572. 
Situation, topographie. - L'Oronte, venu du sud, sort de sa vallée profonde et se dirige vers la mer au sud-ouest, entre le Kasios et l'Amanus, par une faille où les basaltes alternent avec les formations tertiaires. Antioche est située sur la rive gauche du fleuve, navigable au moyen âge jusqu'à la mer ${ }^{563}$. Entourée de jardins bien arrosés, la ville, disposée en amphithéâtre, s'étageait sur les pentes du mont Silpios, que gravissait l'enceinte de Justinien, franchissant des précipices, et que couronnait une puissante citadelle ${ }^{564}$. Les ruines imposantes de ces ouvrages sont conservées, mais de la capitale de l'Orient il ne reste qu'un village ${ }^{565}$.

Le site d'Antioche était grandiose et ses habitants, ses rhéteurs, comme Libanius, célébraient l'air sain, la fraîcheur des sources et des jardins délicieux dont elle était entourée ${ }^{566}$.

A deux heures de la ville, se trouvait le faubourg de Daphné, où, sous les ombrages de cyprès centenaires protégés par la loi, on voyait un vieux temple d'Apollon et un sanctuaire des Nymphes, que fréquentaient encore les païens au $\mathrm{V}^{\mathrm{e}}$ siècle ${ }^{567}$. D'un hémicycle en forme de théâtre, couvert d'un toit en tuile, supporté par des colonnes de marbre blanc, une cascade, formée par les deux sources de Castalie et de Pallas, franchissait trois gradins pour tomber dans la piscine en forme d'exèdre qui figurait l'orchestre de ce théâtre d'eau ${ }^{568}$.

Plan, construction. - Appelée Antioche la Belle, puis, sur le conseil de Syméon Stylite, la Ville de Dieu, Théoupolis ${ }^{569}$, elle était bâtie sur un plan régulier avec de longues rues droites bordées de portiques; l'une d'elles traversait la ville de part en part sur une longueur de 36 stades (4 kilomètres). Son vaste théâtre était taillé en plein roc sur les pentes du Silpius ${ }^{570}$. Depuis l'antiquité elle était divisée en quatre quartiers, entourés chacun de murs (tétrapole de Strabon), mais enfermés dans une enceinte commune. Le troisième quartier avait été

\footnotetext{
PHILIPPSON, Das byzantinische Reich als geographische Erscheinung, 185.

D.A.C.L., I, 282 ; D.H.G.E., III, 563-566; DIEHL, op. cit., 567 et s.

D.A.C.L., II, 2359 et s.

LIBANIUS, Discours, or. 1, 1,80.

Saint JEAN D’ÉPHESE, Histoire de l'Eglise, III, 29; Jean MALAlas, Chronographie, Bonn, 307; DIEHL, Justinien et la civilisation byzantine au VI siècle, 369.

568 J. LASSUS, Antioch-on-the-Orontes, 129 et s., fig. 10.

569 DIEHL, op. cit., 568 et s.

D.A.C.L., II, 60.
} 
crée par Antiochus Epiphanes (175-164 av. J.-C.) dans l'île de l'Oronte où se trouvaient à l'époque byzantine le Palais Impérial, précédé du magnifique portique du Tétrapyle, et peut-être la statue de la Fortune d'Antioche (Tyché). Théodose II avait embelli la ville de nouveaux monuments construits par des architectes envoyés de Constantinople (408-450) ${ }^{571}$.

Le splendide pavement en mosaïque découvert dans la villa de Yakto, faubourg de Daphni, est décoré au centre des exploits des chasseurs célèbres, mais son intérêt principal est dû à sa bordure de tableautins, qui représente des édifices d'Antioche et des scènes de la rue ${ }^{572}$.

Elle montre ce qu'était la ville au $\mathrm{V}^{\mathrm{e}}$ siècle, avec ses monuments, ses portes de ville, ses places ornées de statues, ses fontaines, son stade olympique, ses églises, ses maisons avec les noms de leurs propriétaires, ses ateliers, ses boutiques, ses auberges. La ville était bâtie en pierres appareillées, les édifices couverts en charpentes avec toits en tuile, la plupart bordés de portiques, qui évoquent les rues à colonnades. On y voit parfois des galeries ouvertes au premier étage, et, sauf une exception, ce sont des architraves qui retombent sur les colonnes. Les coupoles sont rares ${ }^{573}$. C'est une place publique, avec un gros arbre, dont on ne voit que le tronc noueux, et des statues privées de tête sur des socles, dont l'un, plus élevé, supportait l'effigie d'un guerrier appuyé sur sa lance ${ }^{574}$. C'est encore un pont sur 1'Oronte aux flots verdâtres, qu'une femme, tenant un enfant par la main, se prépare à traverser ${ }^{575}$, et un édifice polygonal, couvert d'une coupole de même profil, qui pourrait être la cathédrale construite par Constantin ${ }^{576}$. Rien de plus vivant que les scènes de la rue qui, malgré la maladresse du dessin, semblent prises sur le vif et ne diffèrent pas sensiblement de ce qu'on peut y photographier aujourd'hui ${ }^{577}$. Ici ce sont deux mulets attachés l'un derrière l'autre et portant des ballots, avec leur conducteur qui lève son bâton d'un geste naturel ${ }^{578}$. Plus loin on

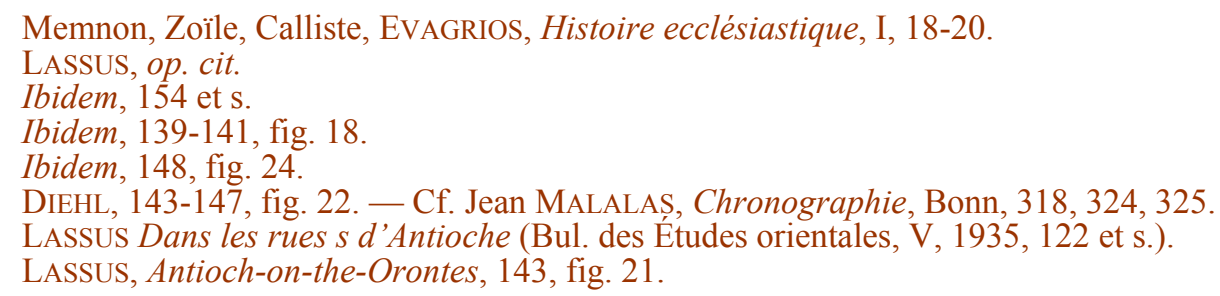


voit des boutiques ouvertes sur la rue avec leurs marchands et leurs clients : une poissonnerie, un marchand d'huile, une boucherie ou une charcuterie ${ }^{579}$. Un porteur, à la tunique courte et serrée à la taille, bras et pieds nus, retient d'une main un long paquet roulé, attaché sur son dos, et, de l'autre, une corde passée sur son épaule gauche ${ }^{580}$. Ailleurs ce sont des buveurs ou des joueurs assis à une table couverte de jetons et tenant le cornet de dés à la main ${ }^{581}$.

La population. - Les quartiers du centre étaient très peuplés au ye siècle. La population, évaluée à 500000 habitants à l'époque romaine, serait descendue à 200000 au temps de saint Jean Chrysostome ${ }^{582}$ et remontée à $300000 \mathrm{au} \mathrm{VI} \mathrm{e}^{\mathrm{e}}$ siècle ${ }^{583}$.

Cette population très remuante, impressionnable et superstitieuse, était renommée pour son esprit frondeur. L'empereur julien, qui en avait été la victime, s'indignait contre les jeunes désœuvrés, qui ne s'occupaient que de courses et de spectacles et s'adonnaient à une perpétuelle débauche, contre la liberté des femmes et contre le manque de respect du peuple pour les princes comme pour les dieux ${ }^{584}$. Le goût pour les fêtes grandioses était le principal souci du peuple ${ }^{585}$ et les émeutes étaient fréquentes dans cette population cosmopolite composée de Grecs, de Syriens et de Juifs : celle de 387, où les révoltés abattirent les statues impériales et qui fut châtiée cruellement par Théodose, était restée comme un sinistre souvenir ${ }^{586}$. Les Syriens, qui avaient continué à parler leur langue nationale, habitaient surtout les faubourgs, qui portaient d'ailleurs des noms syriaques ${ }^{587}$.

Jeux et spectacles. - Sous Commode (180-192), Antioche avait acheté des Eléens le droit de célébrer tous les quatre ans les Jeux Olympiques. Le premier eut lieu avec une pompe extraordinaire et dura quarante-cinq jours, mais ils furent supprimés en 521 par Justin

Ibidem, 134, 137, 149, fig. 15, 16, 48.

Ibidem, 149, fig. 48.

Ibidem, 133 et s., fig. 1213 (jeu de trictrac, analogue à celui mentionné supra, p. 62).

Saint Jean Chrysostome, Homélies, P.G., 50, 591.

Jean MAlalas, Chronographie, Bonn, 400; DIEHL, Justinien... 570.

Misopogon dans R. DEVREESSE, Le patriarcat d'Antioche... jusqu'à la conquête arabe, 112 et s.; D.A.C.L., II, 2368 et s. 
$\mathrm{I}^{\text {er } 588}$. Ces fêtes avaient pour théâtre Daphni et l'une des mosaïques de Yakto montre le stade avec sa porte encadrée de deux tours, sa piste blanche et jaune ainsi que ses gradins, surmontés à la courbure d'une tour beaucoup plus haute ${ }^{589}$.

Mais Antioche possédait aussi un Hippodrome dès le IV ${ }^{\mathrm{e}}$ siècle ${ }^{590}$ et la violence des querelles entre les factions égalait celle de Constantinople. Saint Jean Chrysostome prêchait en vain contre les courses. Ses auditeurs écoutaient avec admiration ses homélies, mais retournaient le lendemain à l'Hippodrome.

Cependant, de ces édifices, le plus fréquenté était le théâtre. Au temps de Libanius (314-395), on y jouait encore des pièces classiques, comme les Acharniens d'Aristophane ${ }^{591}$. Au siècle suivant, au contraire, le mime, dont la Syrie était d'ailleurs la terre natale, avait fini par supplanter le théâtre classique ${ }^{592}$. Aux attaques des chrétiens fervents qui le regardaient comme d'origine démoniaque, le rhéteur Choricius de Gaza opposait une apologie en règle, dans laquelle il montrait les services de tout genre que pouvait rendre le mime (guérison des malades atteints de mélancolie, grâces obtenues de l'empereur, à qui le mime seul pouvait parler librement) ${ }^{593}$.

La religion. - A la fin du $\mathrm{IV}^{\mathrm{e}}$ siècle, un peu plus de la moitié des habitants seulement était chrétienne, mais dans cette ville de plaisir, d'après des prédicateurs comme saint Jean Chrysostome, la vie religieuse aurait tenu peu de place. La réalité devait être assez différente. Le culte des apôtres et surtout celui de saint Pierre, qui fonda l'Église d'Antioche avant celle de Rome, était célébré avec ferveur et les Antiochiens rappelaient avec orgueil que le qualificatif de chrétien était né dans leur cité ${ }^{594}$. L'école théologique d'Antioche avait tenu une grande place dans les controverses religieuses des $\mathrm{IV}^{\mathrm{e}}$ et $\mathrm{V}^{\mathrm{e}}$ siècles et les patriarches, pour être moins puissants que ceux d'Alexandrie, jouissaient cependant d'une grande autorité ${ }^{595}$.

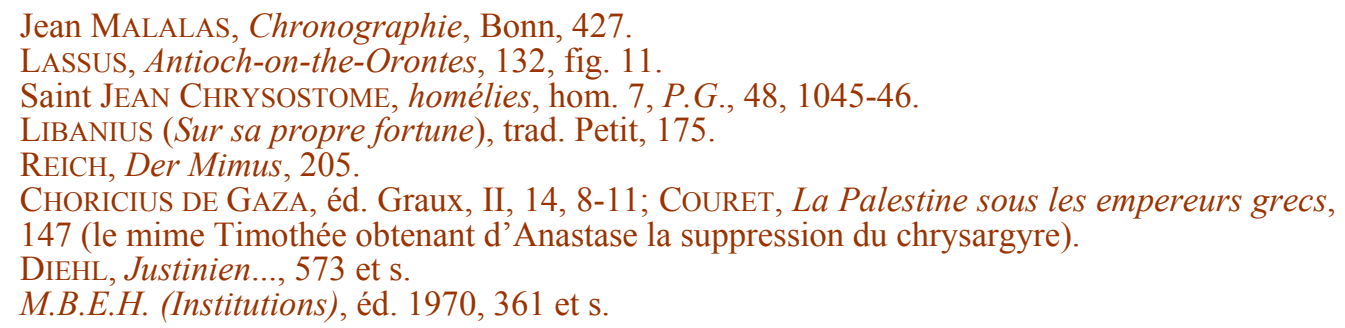


$\mathrm{Au} \mathrm{VI}$ e siècle, la ferveur religieuse du peuple d'Antioche se manifestait par le culte des martyrs, dont les reliques, vénérées dans des édifices spéciaux (martyria), reçurent plus tard un emplacement dans les basiliques, où l'on enterrait les personnages de marque, auprès du corps des saints, et qui attiraient des foules de pèlerins ${ }^{596}$. Les églises elles-mêmes étaient souvent construites aux frais de riches bourgeois, à Antioche comme dans toute la Syrie ${ }^{597}$. Les monastères étaient nombreux dans la ville et aux environs. Les moines, en particulier les stylites, et les reclus, qui habitaient souvent au dernier étage de la tour de façade d'une basilique, étaient l'objet d'une grande vénération ${ }^{598}$.

L'un des plus célèbres de ces ascètes était saint Syméon l'Ancien, qui vivait au sommet d'une colonne, non loin de l'embouchure de l'Oronte (Port Saint-Syméon, aujourd'hui Qal'at Sem'an). De son vivant, il attirait déjà de nombreux pèlerins auxquels il adressait des homélies. Sa réputation était si grande qu'il était connu jusqu'à Lutèce et il faisait saluer sainte Geneviève par les marchands syriens qui venaient le vénérer avant leur départ pour la Gaule. Un grand monastère s'était installé près de cet endroit ; après la mort du saint en 459, on éleva autour de la colonne une vaste cour circulaire, sur laquelle s'ouvraient quatre basiliques, dont la plus grande, située à l'est, se terminait par une abside ${ }^{599}$. La vie de saint Syméon le Nouveau, qui vécut soixante-huit ans sur une colonne (524-592), au Mont Admirable, à quelques heures d'Antioche, reproduisit exactement celle du premier Syméon, mais, à cause du manque de ressources, le monument, élevé sur le modèle de celui de Qal'at Sem'an, n'eut ni la même ampleur, ni la même beauté ${ }^{600}$.

Un curieux épisode de l'histoire d'Antioche montre l'ardeur religieuse de ses habitants. Un tremblement de terre ayant ravagé la ville en 588, toute la population, pieds nus, un rameau d'olivier à la main, alla en procession jusqu'à un mille de la cité, par un froid terrible, sous la neige tombante, chantant des litanies et des supplications ${ }^{601}$.

\footnotetext{
LASSUS, Sanctuaires chrétiens de Syrie, 123-160; GRABAR, Martyrium, I, 152-167 et 207-214. LASSUS, op. cit., 249-260.

Ibidem, 277-283; LASSUS, Images de Stylites (Bul. des Etudes orientales, II, 67-88); Vie de sainte Geneviève, S.R.M., III, 226 et s.

599 JERPHANION, La Voix des Monuments, I, 111-133.

600 LASSUS, Sanctuaires chrétiens de Syrie, 285 et s.

601 Saint JEAN D'ÉPHESE, Vie des bienheureux orientaux, 226; DIEHL, Justinien, 577.
} 
Par contre, l'esprit satirique et frondeur des habitants n'épargnait ni le clergé, ni même les patriarches.

Cette même année, le comte d'Orient Astérius ${ }^{602}$, brouillé avec le patriarche Grégoire, excita le peuple contre lui en l'accusant d'avoir pris part à Daphné à des sacrifices païens. Grégoire fut insulté par la populace et ridiculisé au théâtre. L'empereur Maurice révoqua Astérius, mais le nouveau comte d'Orient, Jean, laissa attaquer le patriarche, qu'un banquier accusa d'inceste et qui n'osa plus sortir de son palais, après avoir mis la ville en interdit. Il parvint cependant à s'échapper, à aller se justifier auprès du basileus et à faire condamner son calomniateur au fouet ${ }^{603}$.

La ville commerciale. - Grâce à sa situation géographique, Antioche était, jusqu'à l'occupation arabe, un des entrepôts les plus importants de l'Empire. Par ses deux ports, Séleucie, en aval sur la rive droite de l'Oronte, et Saint-Syméon sur la rive gauche, à l'embouchure du fleuve, elle participait au commerce méditerranéen, relié ainsi aux points d'arrivée des caravanes asiatiques : route de $\mathrm{Ci}$ licie à travers les Portes Syriennes (passes de l'Amanus à 670 mètres d'altitude). Plus au nord, l'Amanus, percé d'une large brèche, laissait passer la route de Mésopotamie, utilisée aujourd'hui par le chemin de fer de Bagdad ${ }^{604}$. Intermédiaire entre l'Inde et l'Extrême-Orient d'une part, les pays d'Occident occupés par les Barbares d'autre part, Antioche était, par son commerce, la rivale d'Alexandrie ${ }^{605}$.

Les désastres et la décadence. - Malheureusement ces sources de richesse furent taries au $\mathrm{VI}^{\mathrm{e}}$ siècle par les fléaux qui s'abattirent successivement sur Antioche : tremblement de terre du 29 mai 526, qui détruisit presque toute la ville et fit des milliers de victimes; nouveaux séismes en 528 et 539 ; surprise d'Antioche par Chosroès, massacres, incendies, pillages, survivants emmenés en captivité et établis en Perse dans une Nouvelle Antioche (539-540) ${ }^{606}$.

Justinien reconstruisit la ville, dont il ne restait plus que les remparts, mais il fallut réduire l'enceinte et laisser en dehors l'île de

\footnotetext{
602 Evagrios, Histoire ecclésiastique, V, 18; DIEHL, Justinien 577.

603 Evagrios, op. cit., V, 18; DiEHL, op. cit., 577.

604 PHILIPPSON, Das byzantinische Reich als geographische Erscheinung, 185 et s.

605 Diehl, op. cit., 570; PROCOPE DE CESAREE, De Aedificiis, V, 5; PARISET, Histoire de la soie.

606 Diehl, op. cit., 579 et s.; Procope De Cesaree, De Aedificiis, II, 10; du même : De Bellis, II, VIII, 7, IX, XIII, 15.
} 
l'Oronte et les maisons construites dans les méandres du fleuve, auquel on creusa un nouveau lit plus rectiligne. Procope énumère complaisamment les grandes constructions de Justinien, mais, comme l'a remarqué Jean Lassus, ce sont des édifices d'utilité publique et il n'est pas question d'églises ou de palais. Justinien a fait aménager des citernes, des canaux, des remparts, mais il n'a pas cherché à embellir la nouvelle ville. Elle avait été trop touchée pour être complètement restaurée en si peu de temps. L'heure de la décadence avait sonné pour elle ${ }^{607}$.

\section{Dans les provinces d'Asie}

Retour à la Table des Matières

Ancienne en Syrie, en Mésopotamie et en Palestine, la vie urbaine avait même gagné les provinces arabes dès les premiers temps de l'Empire romain. Loin d'avoir disparu au $\mathrm{VI}^{\mathrm{e}}$ siècle, les villes étaient devenues plus nombreuses et plus prospères. Fait significatif, des hippodromes avaient été construits dans des centres qui n'en avaient jamais possédé ${ }^{608}$.

Sources. - Le Synekdemos d'Hiéroklès compte 145 villes dans le diocèse civil d'Orient ${ }^{609}$ et, pour un territoire moins étendu, dans sa Description de l'univers romain, Georges de Chypre cite 197 villes, sans compter les castra et climata fondés par Justinien ${ }^{610}$.

Villes de Syrie. - Antioche avait été détruite si profondément par les Perses qu'elle ne put jamais retrouver son ancienne prospérité. Par un contraste saisissant, les autres villes d'Orient, épargnées par l'invasion, ne furent jamais aussi riches, la vie urbaine n'y fut jamais aussi brillante que dans la deuxième moitié du $\mathrm{VI}^{\mathrm{e}}$ siècle. Ce fut alors que les villes s'embellirent d'édifices somptueux, dans la construction desquels dominaient le souci de la richesse et celui de l'élégance : dans les basiliques, dans les tombes monumentales, dans les monastè-

\footnotetext{
Procope de Cesaree, De Aedificiis, II, 10; Diehl, op. cit., 582-584; LASSUS, op. cit., 304. Jean MaLALAS, Chronographie, vers 518-520, à Séleucie d'Isaurie.

HIEROCles, Synekdemos, ch. 46-55.

GEORGES DE CHYPRE, Descriptio orbis romani, ch. 4-15.
} 
res, dans les maisons privées de l'aristocratie municipale règne la même magnificence ${ }^{611}$.

Nous avons déjà décrit les villes populeuses de la région basaltique du Hauran, dont les maisons, solidement construites et bien aménagées, furent évacuées le même jour à l'approche des Arabes et sont aujourd'hui en plein désert, où on les a retrouvées sous les sables presque intactes ${ }^{612}$. D'autres villes nous sont connues par leurs ruines, mises à jour par des fouilles.

Telle était Apamée sur l'Oronte, fondée comme Antioche par Séleucus Nicator, explorée à fond par la mission archéologique belge, sous la direction de F. Mayence. La ville, qui couvrait 20 hectares, était traversée par une grand-rue bordée de portiques, large de 23,50 $\mathrm{m}$, sur une longueur de 2 kilomètres. Des pavements de mosaïques à thèmes mythologiques décoraient les trottoirs sous les portiques. Le plus beau est celui qui ornait une maison, dans une salle qui mesurait 130 mètres carrés. Dans un magnifique cadre de verdure se détachent, sur un fond clair, des belluaires et des animaux de grandeur naturelle et d'une vérité saisissante. Une date de l'ère des Séleucides inscrite sur cette œuvre magnifique correspond à l'année 539 de l'ère chrétienne ${ }^{613}$.

Dans ces villes opulentes, les mêmes goûts du plaisir et des sports se manifestaient avec la même frénésie qu'à Antioche. L'itinéraire d'un Occidental, qui visita la Syrie, énumère les talents spéciaux, nous dirions les vedettes, que produit chacune de ses villes. Laodicée est renommée pour ses auriges, Tyr et Béryte pour leurs mimes, Césarée pour ses pantomimes, Héliopolis pour ses joueurs de flûte, Gaza pour ses boxeurs (joueurs de pancrace), Ascalon pour ses lutteurs ${ }^{614}$. Béryte (Beyrouth) devait surtout son prestige à son École de Droit qui rivalisait avec celle de Constantinople ${ }^{615}$.

LASSUS, op. cit., 304 et s.

Ibidem, 47. Voir supra, p. 32.

Transportée à Bruxelles au Musée du Cinquantenaire. F. MAYENCE, La mission belge d'Apamée dans B.A.B.L., VI, 1935.

614 Anonyme. Totius orbis descriptio, 57 et s.

615 P. COLLINET, Histoire de l'École de droit de Beyrouth. Voir ch. XIII. 
Palestine et Arabie. - En même temps que Jerusalem, la Ville Sainte, qui passait au moyen âge pour le centre du monde, l'omphalos vers lequel on se tournait pour prier ${ }^{616}$, les autres villes de Palestine conservaient le prestige d'avoir été le théâtre de la vie terrestre du Christ. Des sanctuaires avaient été construits sur les lieux mêmes où s'étaient passés les événements décisifs rapportés par les Évangiles : la basilique de la Nativité à Bethléem, les trois églises du Thabor, à l'endroit même où Pierre voulait dresser trois tentes ${ }^{617}$. Pour mieux faire revivre ces souvenirs, des peintres et des sculpteurs avaient créé une iconographie nouvelle, reproduite sur les petits objets que les pèlerins rapportaient dans leur pays.

La vie urbaine s'étendait alors au-delà du Jourdain et dans la province d'Arabie, comme en témoigne la mosaïque de Mâdaba (découverte en 1897), qui représentait avec une grande exactitude les villes de Palestine, depuis le delta du Nil, vraisemblablement, d'après ses dimensions, jusqu'à Antioche. Le pays s'y développe de l'ouest à l'est, avec ses montagnes, ses vallées, ses rivières. Les montagnes de Judée sont noires, avec des assises pierreuses marquées par de petits traits. La vallée du Ghor et le désert du Sinai sont d'un blanc mat. La mer Morte est nuancée de vert, avec des bandes noires. Dans le Jourdain se jouent de petits poissons jaunes et noirs. Les villes donnent l'impression de la réalité : par exemple, les murailles de Jéricho, avec trois grandes tours de hauteur inégale, séparées par des portes à fronton, la rue à portiques de Gaza conduisant à une basilique, les trois obélisques d'Ascalon commémorant des martyrs égyptiens, enfin un vrai plan de Jerusalem, avec ses rues bordées de portiques et, au milieu, la tour monumentale du Saint-Sépulcre. On reconnaît au nord la porte Saint-Étienne, flanquée de deux tours, devant elle une esplanade décorée d'une colonne, à la suite la grande rue longitudinale, dans l'angle nord-ouest de nombreuses maisons et, à l'ouest, la porte de Jaffa. Une inscription, dans l'abside de l'église, semble la dater de l'époque de Justinien ${ }^{618}$.

Piganiol, Hemisphairion et Omphalos des Lieux Saints (emplacement de la Croix), C.A. I, $1945,7-14$

617 A. GRABAR, Martyrium II, 129-206.

618 R.R.P.P. VINCENT et ABEL, Jérusalem nouvelle, II, 99 et s.; D.A.C.L., X, 1931, 806-885, fig. 7416 et s., pl. 820 et 836 . 
En Transjordanie, un pavement en mosaïque de l'église de $\mathrm{Na}$ 'im, localité non identifiée jusqu'ici, représentait un bestiaire, lequel, d'après une inscription, fut remplacé vers 729-730 par des thèmes géométriques ${ }^{619}$, mais ce qui ajoute à l'intérêt de sa découverte, c'est sa bordure topographique qui rappelle celle de la mosaïque de Yakto. Ici les monuments et les églises de Palestine, avec leurs noms, sont séparés par des arbres. Il ne reste plus que douze tableautins, c'est-àdire la moitié de la bordure primitive ${ }^{620}$.

A Bostra, métropole de la province d'Arabie, on a pu explorer les ruines d'une cathédrale, construite en 512 sur un plan circulaire. Sa coupole de même plan avait 37 mètres de diamètre et retombait sur un tambour supporté par huit piliers, laissant place à un déambulatoire annulaire inscrit dans un carré, avec quatre exèdres aux angles. Le baldaquin abritant l'autel se dressait au centre, supporté par une colonnade en quatre-feuilles ${ }^{621}$.

Dans la même province, Gérasa (Djérasch) était une ville importante, très prospère à l'époque romaine. Ses fortifications furent refaites au $\mathrm{V}^{\mathrm{e}}$ siècle et, sous Justinien, le comte Fl. Elias reconstruisit en partie la grande rue à colonnades, qui aboutissait au Forum. L'exploration des ruines a révélé l'existence de onze monuments chrétiens, dont un groupe compact d'édifices d'un seul tenant; ils donnent, par une façade de 30 mètres, sur cette rue, à laquelle leur axe est perpendiculaire. C'est d'abord la cathédrale, de plan basilical (fin du IV ${ }^{\mathrm{e}}$ siècle), suivie d'une cour à portiques, avec une fontaine miraculeuse au centre, puis une seconde basilique, le martyrium de SaintThéodore, élevé par le prêtre Énée en 496. Cet édifice communiquait avec un baptistère et un atrium rectangulaire ${ }^{622}$. Un groupe analogue, moins complexe et disposé en largeur, comprenait la rotonde de SaintJean-Baptiste, inscrite dans un carré et flanquée sur les côtés de deux basiliques dédiées, l'une à saint Georges, l'autre aux saints Cosme et Damien. Cet ensemble datait de 529-533 environ ${ }^{623}$. La dernière église construite à Gérasa fut probablement celle de l'évêque Géné-

\footnotetext{
619 Probablement pour obéir à l'édit du calife Yézid. Cf. M.B (Vie et mort de Byzance), 1969, p. 78.

620 R.A., XII, 1938, 109.

621 LASSUS, Sanctuaires chrétiens de Syrie, 150 et s.; DIEHL, Justinien..., 587.

622 LASSUS, op. cit., 38-40, fig. 18.

623 Ibidem, 152, fig. 67; D.A.C.L., XIII, 879 et s.
} 
sios en 610 , vingt-deux ans avant l'invasion arabe ${ }^{624}$. Cette grande ville, où le grec était la langue dominante, éprouvée par le tremblement de terre de 746, se maintint cependant jusqu'à la chute des Ommiades (750), mais disparut après le transfert du califat à Bagdad.

Cet ensemble d'œuvres grandioses implique des ressources considérables, dues à une grande prospérité économique, qui ne disparut pas avec l'occupation arabe. Ce fut en Syrie d'ailleurs que les conquérants s'initièrent à la civilisation urbaine.

Mésopotamie. - En Mésopotamie, la ville forte de Dara, construite par Anastase en 505, en face de la ville perse de Nisibe, était un modèle d'urbanisme ${ }^{625}$.

Édesse, capitale de l'Osroène depuis l'époque romaine, était peuplée de Syriens, mais, sous la domination des Séleucides, l'hellénisme s'y était introduit et y avait propagé son art et sa littérature. Édesse n'en resta pas moins une ville orientale et c'est ce qui la distingue des grandes villes syriennes. Vassale des rois hellénistiques, elle vivait, depuis la fin du second siècle avant l'ère chrétienne, sous la dynastie des Abgar, auxquels le titre royal avait été concédé, mais le syriaque resta toujours la langue officielle, comme en témoignent les inscriptions ${ }^{626}$.

La ville était située au pied d'un massif rocheux, dans une plaine fertile et bien arrosée. Dans la ville même, un étang alimenté par les eaux souterraines du plateau sud-ouest avait valu à Édesse le nom de Callirhoé, « la ville aux belles eaux », suivant Pline l'Ancien. Sur ses bords s'élevaient des palais d'été des rois et des nobles, ainsi que la plus ancienne église. Les contreforts de la montagne formaient une défense naturelle, à quoi s'ajoutaient une double enceinte et une citadelle, à l'intérieur de laquelle était construit le palais d'hiver. Vingtcinq ruisseaux traversaient la ville et allaient grossir le Skirtos ${ }^{627}$, cours d'eau irrégulier, affluent de l'Euphrate. Sous Justinien, une de ses crues provoqua une inondation désastreuse qui détruisit une partie

\footnotetext{
LASSUS, op. cit., 205.

Restaurée par Justinien. PRocope DE CESAREe, De Aedificiis, 2, 3.

Des inscriptions en grec datent des premiers siècles de l'ère chrétienne. D.A.C.L., IV, 1921, 2103 et $\mathrm{s}$.

627 Le Sauteur (Daïçan actuel).
} 
de la ville : l'empereur restaura Édesse, fit rectifier le lit du Skirtos et creuser un tunnel dans le roc pour détourner son cours à sa sortie de la ville ${ }^{628}$.

Édesse était bâtie régulièrement et ses rues aboutissaient à six portes fortifiées. Elle était décorée de belles places, comme le Forum entouré de portiques, au bord du Skirtos, et de nombreux monuments : des thermes, un théâtre, un hippodrome, un grand hôpital et de nombreuses églises ${ }^{629}$.

Le christianisme était en effet très ancien à Édesse et, bien que la date de son introduction soit mal connue, il est certain qu'elle est antérieure à l'an 200, car la conversion d'Abgar VIII, après un voyage à Rome en 207, est un fait historique. Édesse est donc l'un des premiers États qui aient fait du christianisme une religion officielle ${ }^{630}$.

Nous n'avons à nous occuper ici, ni du développement de l'Église d'Édesse, ni de sa puissante école théologique, dite l'École des Perses, parce que ses premiers maîtres étaient venus de Nisibe. Notons seulement que la littérature théologique d'Édesse est en langue syriaque, ainsi que la Bible dite Peschitto ${ }^{631}$. Le caractère syrien et oriental de la ville se manifestait dans son architecture religieuse. Une hymne syriaque en l'honneur de la cathédrale d'Édesse, reconstruite par Justinien après l'inondation de 524, récemment rééditée et traduite en français, a permis à André Grabar de la reconstituer dans ses grandes lignes et d'en pénétrer le sens symbolique ${ }^{632}$. Elle était dédiée à la Sagesse Divine (Sainte Sophie). Bâtie entièrement en pierre, d'aspect cubique, elle était couverte d'une coupole aveugle sur trompes d'angle ${ }^{633}$, entourée de parvis ornés de trois portiques à colonnes. A l'intérieur, les murs étaient revêtus de marbre blanc «lumineux comme la sainte Face d'Édesse ». La coupole figurait un ciel étoilé et était entourée de mosaïques à fond d'or : image de l'univers malgré sa petitesse.

PROCOPE DE CESAREe, De Aedificiis, II, 6; Rubens Duval, Histoire politique, religieuse et littéraire d'Édesse.

629 R. DUVAL, op. cit.; D.A.C.L., IV, 2059 et s.

630 Allié de Septime-Sévère qui l'avait reçu à Rome. D.A.C.L., IV, 2005 et s.; FLICHE et MARTIN, Histoire de l'Église, I, 286; II, 126.

631 R. DUVAL, op. cit.; J.B. CHABOT, Littérature syriaque, 1932.

${ }^{632}$ C.A., II, 1947, 29-68 (DUPONT-SOMMER et GRABAR).

633 Procédé persan, déjà connu en Chaldée 3000 ans avant J.-C., L. BREHIER, Le Style roman. 
Édesse était d'ailleurs célèbre dans la chrétienté et faisait partie des Lieux saints visités par les pèlerins. Elle possédait deux reliques insignes : une lettre que le Christ aurait écrite à un roi Abgar, et qui fut montrée à Sylvia Aetheria à la fin du $\mathrm{IV}^{\mathrm{e}}$ siècle, et un portrait miraculeux du Christ imprimé sur un linge (mandylion). Il en sera question plus loin ${ }^{634}$.

\section{Les villes d'Asie Mineure et du Pont-Euxin}

\section{$\underline{\text { Retour à la Table des Matières }}$}

A part les massifs du centre, région de culture et d'élevage à l'époque byzantine, de grandes villes monumentales et peuplées, datant pour la plupart des temps hellénistiques, s'élevaient, nombreuses, surtout à proximité des côtes et dans les îles. La dynastie attalide et les empereurs romains y avaient laissé leur empreinte. Hiéroclès énumère 372 villes pour l'Anatolie, dont 43 pour la seule province d'Asie ${ }^{635}$.

Dans toutes ces villes, où le grec seul était parlé, les monuments antiques étaient encore intacts et depuis le $\mathrm{IV}^{\mathrm{e}}$ siècle de nombreux monuments chrétiens avaient augmenté leur splendeur. Plusieurs de ces édifices, à Éphèse, à Nicée, à Ancyre, évoquaient les souvenirs des grands conciles.

Éphèse. - Métropole de la province d'Asie, Éphèse était restée un port fluvial important, sur le Caystros, à 5 kilomètres de la mer, au débouché de quatre vallées ${ }^{636}$. Comme dans l'antiquité, la ville commerçante, située auprès du port, était surmontée d'une acropole. C'était là qu'à l'époque byzantine se trouvaient les principaux sanctuaires chrétiens, rebâtis presque tous par Justinien. Le plus important était celui de Saint-Jean-l'Évangéliste, simple ciborium en plein air au $\mathrm{III}^{\mathrm{e}}$ siècle, édifice en croix libre au $\mathrm{V}^{\mathrm{e}}$ siècle, avec la tombe du saint au

\footnotetext{
Silviae Etheriae peregrinatio, IX, 3; D.A.C.L., I, 1907, 87-97.

Guide de la Peinture (Hermeneia), trad. Didron, Manuel d'iconographie chrétienne, grecque et latine.

636 Du Caïque, de l'Hermos du Caystros, du Méandre. Vidal DE LA Blache et Gallois, Géogra phie universelle, t. VII : Péninsules méditerranéennes.
} 
centre géométrique, enfin celui que fit élever Justinien sur le même plan, mais avec cinq coupoles, sur le modèle des Saints-Apôtres de Constantinople ${ }^{637}$. Avec sa fête patronale du 27 décembre coïncidait une foire qui amenait à Éphèse un nombre si considérable de commerçants, que les droits de douane atteignaient ce jour-là 100 livres d'or ${ }^{638}$.

En face de cette cathédrale se trouvait le martyrium des Sept Dormants, objet d'un culte fervent. Il comprenait la grotte dans laquelle sept frères, fuyant la persécution de Décius en 250, se seraient réfugiés et endormis, pour se réveiller sous Théodose, et au-dessus, un vaste sanctuaire comprenant une église et des salles funéraires où on enterrait les défunts ${ }^{639}$. D'autres martyria, remontant à une époque très ancienne, se trouvaient dans une enceinte à ciel ouvert ${ }^{640}$. Dans la ville basse, sur le Forum, les fouilles allemandes ont mis à jour l'église double dédiée à la Vierge, composée de deux basiliques avec bas-côtés étroits communs aux deux édifices bâtis sur le même axe. Ce fut là que se tint le troisième concile œcuménique en $431^{641}$.

Bithynie. - Province asiatique la plus rapprochée de Constantinople, la Bithynie, devenue au VIII ${ }^{\mathrm{e}}$ siècle le thème de l'Opsikion, possédait deux grandes villes : Nicée, la métropole, théâtre des événements les plus considérables de l'histoire de Byzance, depuis le premier concile œcuménique jusqu'au transfert dans ses murs du gouvernement impérial et de la cour, pendant la durée de l'Empire latin. L'autre grande ville était Nicomédie, port situé au fond d'un véritable fjord, étroit et enfoncé dans les terres.

Nicée avait été fondée en 316 avant l'ère chrétienne sur les bords du lac Ascanios, dans la plaine située au pied de l'Olympe de Bithynie. Créée de toutes pièces, elle avait reçu le plan régulier d'un damier, avec quatre grandes voies centrales se coupant à angle droit et aboutissant à quatre portes fortifiées, que l'on pouvait apercevoir du carrefour central ${ }^{642}$. Ce plan s'était conservé à l'époque byzantine,

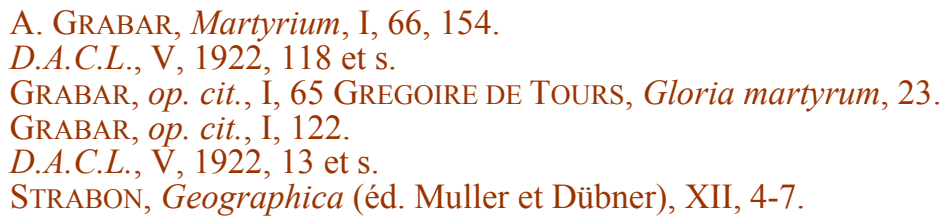


tandis qu'aujourd'hui il ne subsiste de la glorieuse ville qu'un village au milieu d'une vaste enceinte presque déserte, qui mesurait 1200 mètres de large sur un kilomètre de long ${ }^{643}$. L'enceinte, tracée en polygone irrégulier, a été remaniée par les Romains, les Byzantins et les Seldjoukides; elle se composait d'une muraille flanquée de tours semi-circulaires, d'un deuxième rempart jalonné de tours semblables, et d'un fossé, dans lequel on pouvait déverser l'eau du lac Ascanios. Cette enceinte, construite en briques, est en grande partie conservée. Dans ses murailles sont encastrées les quatre portes, décorées de sculptures, dues à la munificence des empereurs romains. Celle de l'est était un bel arc de triomphe, qu'une inscription honorifique attribue à Hadrien ${ }^{644}$.

A l'époque byzantine, Justinien fit reconstruire magnifiquement le palais, répara l'aqueduc qui amenait l'eau à la ville, ainsi que les thermes publics, voisins de l'hôtellerie des courriers, et dota Nicée d'églises et de monastères ${ }^{645}$. De toutes ces merveilles il ne subsiste aujourd'hui que les ruines de l'église Sainte-Sophie, bâtie sur plan basilical. Son exploration a conduit Brounov à reconnaître quatre périodes de constructions depuis $1 \mathrm{e} \mathrm{V}^{\mathrm{e}}$ siècle jusqu'aux Paléologues ${ }^{646}$ et, encore aujourd'hui assez bien conservée, une minuscule église à coupole sur tambour polygonal émergeant d'un massif carré, avec des traces d'archaïsme ; dédiée à la Dormition de la Vierge, elle date probablement de la première moitié du IX ${ }^{\mathrm{e}}$ siècle ${ }^{647}$.

Phrygie et provinces diverses. - Ancyre (aujourd'hui Angora ou Ankara) était, depuis l'antiquité romaine, métropole de la Phrygie, célèbre par le temple d'Auguste et l'inscription dans laquelle il rappelait sa carrière politique. Construite sur un plateau, abritée par de hautes montagnes des influences maritimes, Ancyre n'a jamais dû être un grand centre. Son climat continental est fait de contraste et toujours sec (26 cm de pluie par an). A l'époque byzantine, la seule richesse du pays était l'élevage dans les steppes qui règnent encore aujourd'hui, et c'est par un vrai paradoxe que les Turcs ont fait de cette « ville sévère

\footnotetext{
643 TeXIER, Description de l'Asie Mineure, I, pl. V et VI: JANIN, Nicée..., E.O., 1925 XXVIII, 482 et s.; D.A.C.L., XII, 1935, fig. 8828.

JANIN, loc. cit.

Procope de CeSAReE, De Aedificiis, V, 3 (154).

Dans E.O., XXVIII, 1925, 471 et s.

DiEHL, Etudes byzantines, 352 et s.; WulfF, Die Koimesis-Kirche..., Strasbourg, 1903.
} 
dans son cirque de hauteurs mornes " la capitale de leur république ${ }^{648}$. De l'époque byzantine il reste la puissante citadelle construite sur la montagne qui domine la ville, les ruines de l'église SaintClément, basilique à coupole, assez semblable à celle de la Dormition de Nicée, et de nombreux débris de sculptures, en particulier des chapiteaux aux aigles ${ }^{649}$. C'est dire qu'on ne sait à peu près rien sur la vie des habitants d'Ancyre, sinon qu'ils eurent à souffrir des guerres entre le califat de Bagdad et l'Empire et que leur ville, prise et dévastée par El Motassim en 838, fut reconquise et restaurée en 859 par Michel III et le spatharocandidat Basile ${ }^{650}$. Dans le temple d'Auguste, transformé en église, une longue inscription funéraire est au nom d'Eustathe, turmarque du thème des Bucellaires, dont Ancyre était la capitale ${ }^{651}$.

Nous ne possédons plus guère de renseignements sur la vie des habitants des villes de l'intérieur, en dehors des notices épiscopales et des explorations d'églises. En Cappadoce, des traditions hittites s'étaient conservées dans l'architecture. Dans la région d'Urgub, le Père de Jerphanion a signalé que, sans parler des monastères, la plupart des habitations privées sont en partie souterraines. Il en est ainsi à Urgub, où les maisons escaladent une falaise aride et semblent plaquées contre le rocher, au pied duquel s'étend une plaine bien arrosée et fertile ${ }^{652}$. Les auteurs byzantins appellent les habitants de la Cappadoce troglodytes et racontent qu'ils vivent sous terre ${ }^{653}$.

Ports et villes maritimes. - Les côtes d'Anatolie, si richement découpées, entourées d'îles, d'archipels, de chersonnèses, étaient favorables à l'établissement de ports et de mouillages, aménagés depuis une haute antiquité et toujours florissants à l'époque byzantine. Il est souvent question dans les sources de phares construits ou restaurés, à Césarée de Palestine ${ }^{654}$, à Smyrne en 671 par un haut dignitaire, Ambrosius Mylasoeus, anthypatos ${ }^{655}$. En Pamphylie, le grand port,

VIDAl De la Blache, Géographie universelle, t. VIII : Asie occidentale, Haute Asie, 96-100, pl. XV et XVI.

G. DE JERPHANION, Mélanges d'archéologie anatolienne, 113 et 241.

H. GREGOIRE, Inscriptions historiques byzantines, 437-449. Le spatharocandidat, directeur des travaux, serait le futur empereur Basile.

H. GREGOIRE, op. cit., 449-453.

G. DE JERPHANION, Les églises rupestres de Cappadoce, I, 1925, 6-42.

LEON LE DiACRE, Histoires, III, 1 (35); Synopsis Chronike ad a. 1261 (éd. Sathas), 205.

PROCOPE DE GAZA, Discours, 2817 (panégyr. d'Anastase, 19).

Anthologie grecque. I, Anthologie Palatine (éd. P. Waltz), IX. 
d'origine hellénistique, était Attalie, chef-lieu du thème maritime des Cibyrrhéotes. Les fouilles de Turkanbey ont mis à jour les ruines de la ville byzantine, qui devait être splendide ${ }^{656}$.

Les côtes de la mer Egée et celles de Hellade se confondent. De ce côté, il n'est guère de port antique, Smyrne, Rhodes, Milet, etc., dont l'exploration ne révèle quelque construction byzantine. Les rivages de la mer Noire étaient jalonnés par les ports d'Héraclée, Amastris, Sinope, Trébizonde et, au-delà de la côte du Caucase par les ports de Crimée, au delà de l'embouchure du Danube par ceux de la péninsule des Balkans. L'existence de ces ports suppose une vie urbaine très active, sur laquelle nous n'avons que des renseignements épars.

Trébizonde. - De tous les ports de la mer Noire, le plus important était celui de Trébizonde, ancienne colonie grecque, dont la situation au débouché des routes du Caucase et de la Perse lui avait valu beaucoup de prospérité à toutes les époques de son histoire. Cependant, c'est après l'établissement dans ce simple chef-lieu de thème d'un État organisé sur le modèle de l'État impérial de Constantinople, sous la dynastie des Grands Comnènes, que Trébizonde, devenue une capitale, atteignit son plus grand développement ${ }^{657}$.

Au-dessus des flots de la mer Noire, comme «bâtie en plein ciel », la ville étageait ses maisons, ses églises, ses tours, sa citadelle surmontant le palais impérial, auquel on accédait par un majestueux escalier. Les remparts descendaient vers la mer, rendus inaccessibles par des ravins profonds. Aux alentours, des prairies, des eaux courantes, des chênes, des vergers, la vigne sur les coteaux et, au loin vers le sud, les montagnes neigeuses. La ville comprenait trois étages. Au sommet, la vieille Acropole et le palais impérial dominant la seconde en-

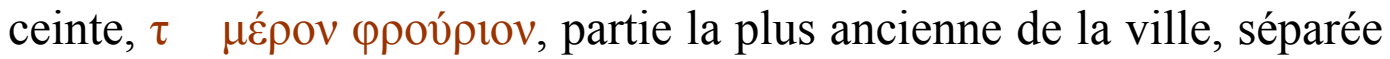
par un rempart de la ville basse, $\tau$ кó $\tau \omega$ ppoúpıov, centre commercial communiquant avec la ville moyenne par deux grandes portes. L'agora, à l'est, était le principal bazar et les auberges et hôtelleries étaient en dehors de l'enceinte. C'était aussi le quartier des ateliers et des marchands «qui vendaient les choses les plus précieuses du

656 D.H.G.E., V, 148 et s.

657 DiEhl, Dans l'Orient byzantin, 204-206; DiEHL et GuILLAND, L'Europe Orientale de 1081 à 1453, p. 420-435 (Guilland). 
monde ${ }^{658}$. Près de la porte du Môle se trouvaient les établissements des Génois, protégés par une véritable forteresse. C'était sur la grandplace, où s'accumulaient les marchandises de l'Europe et de l'Asie, que, par suite de l'étroitesse de la ville, avaient lieu les réjouissances populaires et même les fêtes solennelles de la cour, le dimanche de

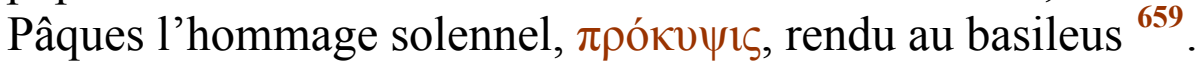

La ville proprement dite, aux rues étroites, où se trouvait la cathédrale à la curieuse toiture de cuivre, la Panaghia Chrysoképhalos, était habitée par le haut clergé, l'aristocratie, des employés subalternes, des marchands ${ }^{660}$. Les églises, changées aujourd'hui en mosquées, étaient nombreuses et presque toutes étaient des basiliques en croix grecque, à coupole, mais avec un allongement de la branche occidentale ${ }^{661}$. L'augmentation des habitants, due à l'extension du commerce, avait fait déborder la ville hors de l'enceinte et au-delà des ravins, sur lesquels étaient construits des ponts. De grands faubourgs s'étaient formés, entourés de prairies et de jardins, avec leurs quartiers et leurs églises. En cas de danger la population se réfugiait dans la ville, où elle était comprimée, si bien que l'empereur Alexis II (1297-1330) fit élargir l'enceinte et, par des travaux difficiles, diminuer la largeur des ravins ${ }^{662}$.

Sous les Grands Comnènes la ville était prospère et bien adminis-

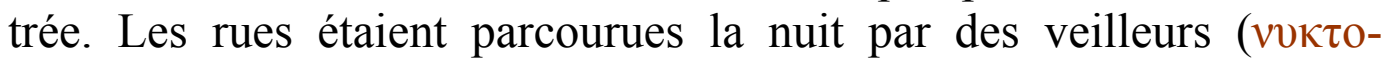
$\tau \alpha \lambda \alpha \lambda i ́$ (), qui acquittaient aux fermiers des impôts une redevance pour pouvoir exercer leur profession. Des fragments d'inscriptions montrent qu'Alexis II, sur leur plainte, rétablit l'exemption de cette charge, qui leur avait été déjà accordée ${ }^{663}$. L'eau était amenée en abondance par un grand aqueduc construit par Justinien ${ }^{664}$ et dédié à saint Eugène, le patron vénéré de la ville, martyrisé sous Dioclétien; son culte tenait une place semblable à celle de saint Démétrius à Thessalonique. Non seulement une église et un monastère lui étaient dé-

\footnotetext{
BeSSARIOn, Éloge de Trébizonde (éd. Lambros, N.H., XIII, 1916).

$\mathrm{M}^{\mathrm{gr}}$ CHRYSANTHOS, op. cit., 70-73.

Ibidem, 68.

G. Millet, Les monastères et les églises de Trébizonde, B.C.H., 1895, 419 et s.

BESSARION, op. cit., 187; CHRYSANTHOS, op. cit., 62, 75.

H. Gregorre, Les veilleurs de nuit à Trébizonde, dans B.Z., 1909, 490 et s.; G. BratianU, Recherches sur le commerce génois dans la mer Noire au XIII siècle, 177.

664 PROCOPE DE CESAREE, De Aedificiis, III, 7 (99).
} 
diés ${ }^{665}$, mais son effigie était sculptée sur les tours des remparts et gravée sur les monnaies ${ }^{666}$; la plupart des enfants recevaient son nom à leur baptême ${ }^{667}$, les recueils des miracles qui lui étaient attribués étaient lus avec ferveur ${ }^{668}$, un theatron, situé au sud de la grandplace, servait aux panégyries célébrées en son honneur ${ }^{669}$.

Non loin de là un tzykanisterion servait aux courses de chars et aussi au jeu de polo.

Ainsi, sous la dynastie des Grands Comnènes, Trébizonde était devenue la capitale de l'Orient, le grand marché de la mer Noire et l'un des principaux centres intellectuels de l'hellénisme, mais avec quelques éléments étrangers, venus des provinces voisines d'Asie, comme en font foi certains termes turcs, usités dans la toponymie urbaine.

Crimée. - Comme au temps de Mithridate, Trébizonde était en relations commerciales avec la Crimée, dont la partie maritime était occupée par une tribu de Goths, placés sous l'autorité de Byzance, tandis que dans les steppes du nord s'établirent successivement des Huns et plusieurs peuples touraniens, nomades qui cherchaient les routes de l'Occident ${ }^{670}$.

Nous ne reviendrons pas sur la curieuse constitution municipale de Kherson ${ }^{671}$, mais, ce qu'il importe de signaler, c'est la longue persistance de la vie urbaine dans cette vieille colonie byzantine. Nous connaissons d'ailleurs mal la vie de ces étranges cités où la langue gothique se maintint longtemps ${ }^{672}$, mais où le grec s'imposa aux indigènes, d'où une population polyglotte : tel Goth de Crimée, venu à Novgorod au XII ${ }^{\mathrm{e}}$ siècle, parlait grec, latin et russe ${ }^{673}$.

Dans ces villes, la classe dominante était celle des marchands, qui entreprenaient de longs voyages pour amener les produits du nord dans les ports de Crimée. Cette population bigarrée était remuante et

\footnotetext{
DIEHL, Un voyageur espagnol à Constantinople. Peró Tafur, 135 et s., 141 et s., 415 et s. Ibidem, 409-411.

Ibidem.

Jean EUGENIKOS dans DiEHL, op. cit., 67 et 218.

DIEHL, op. cit., 66; Venetia COTTAS, Le théâtre à Byzance, 80-85.

M.B.E.H. (Vie et mort de Byzance), éd. 1969, 11-14; Ph. MEYER, Des Joseph Bryennos Schriften und Bildung, 21-57.

671 M.B.E.H. (Institutions), éd. 1970, 169.

672 Ph. MeYer, op. cit., 3738; WALAFrid StRABO, Liber de exordiis, P.L., 114 et 327.

673 Ph. MEYER, op. cit., 123.
} 
«crier comme un Goth » était passé en proverbe au VI ${ }^{\mathrm{e}}$ siècle ${ }^{674}$. Justinien prit les villes de Crimée sous sa protection, rebâtit leurs fortifications, occupa Bosporos (Kertch) où, d'après une inscription, il aurait rétabli le titre royal. Enfin il édifia des églises et des monastères, même dans la péninsule de Taman. Procope nous apprend qu'à Dory les Goths, qui fournissaient des guerriers à l'Empire, n'étaient pas encore « enfermés dans des villes » ${ }^{675}$.

La sollicitude du gouvernement impérial pour la Crimée continua à se manifester après Justinien, comme le montrent quelques témoignages : découverte à Kherson en 1906 des ruines d'une église en croix grecque du $\mathrm{IX}^{\mathrm{e}}$ siècle $^{676}$; inscription de Kherson au nom d'Isaac Comnène, datée de 1059, rappelant la restauration « des porter de fer du praetorion » et de l'ensemble du kastron (citadelle) par Léon, patrice et stratège du thème de Kherson ${ }^{677}$. La vie urbaine était encore florissante en Crimée au moment de l'invasion turque et s'était propagée dans la Russie méridionale.

\section{L'Occident : Illyricum, Hellade}

$\mathrm{Au} \mathrm{VII}{ }^{\mathrm{e}}$ siècle le contraste est grand entre l'Asie, riche en villes, et l'Occident dépeuplé par les invasions : destruction par les Huns de Sirmium, la grande forteresse du Danube (448) ${ }^{678}$, , ruine des villes dalmates par les Avars et les Slaves, dont la ruée fait disparaître les évêchés et les villes. Salone, la ville des martyrs, la capitale chrétienne de l'Adriatique, est anéantie, en même temps que d'autres cités, dont il n'est plus question dans l'histoire. Une partie de ses habitants se réfugia dans le palais de Dioclétien, qui était fortifié, et y mena d'abord la vie d'un peuple assiégé, puis les Barbares devenant moins hostiles, ils créèrent une véritable ville, qui conserva son nom primitif,

674

675

675

677

677

678 F DvorNIK

Constantin et de Méthode vues de Byzance, 253. 
le Palais (Spalato, Split), transformant en églises le tombeau de Dioclétien et d'autres monuments païens, respectant les voies principales et en particulier la belle colonnade du vestibule et l'imposante façade du palais proprement dit ${ }^{679}$.

La vie urbaine, qui disposait là d'un cadre tout préparé, se rétablit donc facilement à Spalato. Il n'en fut pas de même à Sirmium (Mitrovitsa), reprise aux Gépides en 565 par Justin II, mais qui resta pendant dix-sept ans l'un des principaux points stratégiques de la longue bataille qui se livra entre Byzance, les Avars et les Slaves (565-589) ${ }^{680}$. Il en fut de même dans toutes les villes du Danube, dont plusieurs du moins, comme Belgrade, ne disparurent pas.

De même les villes de langue latine de l'Adriatique, Raguse, Zara, Dyrrachium, Aquilée, parvinrent à se défendre contre les envahisseurs, tandis que, dans les îles du Rialto, Venise devenait une ville, organisée peu à peu sur le modèle de Constantinople, dont elle adoptait la civilisation, mais non la langue.

Thessalonique. - Dans la péninsule des Balkans, grâce à sa situation stratégique et à sa résistance aux Barbares, Thessalonique devint, après la destruction des villes du Danube, la capitale de l'Illyricum, le centre stratégique le plus important de l'Empire après Constantinople. Ville de fondation hellénistique ${ }^{681}$, bâtie en amphithéâtre sur les pentes du mont Kortiach, probablement avec un plan en échiquier, elle a retenu de son ancienne disposition la longue rue actuelle du Vardar, qui prolongeait la via Egnatia, et aboutit au splendide arc de triomphe de Galère élevé vers 306 av. J.-C. Sa position à l'embouchure du Vardar en faisait un port fluvial de premier ordre, marché d'une grande activité. Sa foire annuelle, qui commençait le jour de la fête du patron de la ville, saint Démétrius, le 20 octobre, durait six jours et attirait des marchands de toute race et de toute langue. C'était en même temps l'époque du grand pèlerinage, fréquenté pendant toute l'année. Ce culte de saint Démétrius était aussi fervent que celui de saint Eugène à Trébizonde, de saint André à Patras, de saint Marc à Venise. 
Les Miracles de saint Démétrius étaient figurés dans la somptueuse basilique qui lui était dédiée, et leur recueil, qui avait une valeur officielle, est une des principales sources de l'histoire de la cité et, en particulier, des efforts infructueux des Slaves pour s'en emparer ${ }^{682}$.

La population, en majorité hellénique, comptait en effet de nombreux Slaves immigrés. Thessalonique était un centre d'études slaves et ce fut là probablement que Cyrille et Méthode se préparèrent à leurs missions ${ }^{683}$.

Thessalonique apparaît donc depuis le $\mathrm{VI}^{\mathrm{e}}$ siècle comme l'une des grandes capitales de l'Empire, ville commerciale, centre religieux et de haute culture. Non seulement elle conservait une partie de ses monuments antiques, mais elle était un centre d'art chrétien presque aussi riche que Constantinople et elle a conservé un nombre imposant d'églises et de sanctuaires décorés de mosaïques, très bien restaurés par les architectes de la Commission hellénique des Monuments historiques ${ }^{684}$.

Philippes. - Construite par Philippe, père d'Alexandre le Grand, dans une plaine fertile, située sur un contrefort des Balkans au nord, encadrée à l'ouest par le mont Pangée et à l'est par l'Orbelos, dont un éperon formait son acropole, cette ville dut son développement à ce qu'elle était une étape de la via Egnatia et communiquait facilement avec le port de Néapolis (Kavala actuel) ${ }^{685}$. Saint Paul y débarqua et ce fut par lui que la première église chrétienne fut créée en Europe ${ }^{686}$. Philippes était alors une ville prospère et le demeura, comme l'attestent ses monuments, son Forum et ses deux grandes basiliques si originales, l'une $\mathrm{du}^{\mathrm{e}}$ siècle, l'autre datant du règne de Justinien, mais jamais achevée ${ }^{687}$. Puis la ville fut occupée par les Bulgares vers $836^{688}$, reprise par Byzance, mais ne put jamais se relever. La dernière inscription qu'elle a livrée date de Nicéphore Phocas et rappelle

682

VidAL DE LA Blache et Gallois, Géographie universelle, t. VII, péninsules méditerranéennes, 523 et s.; O. TAFrALI, Topographie de Thessalonique, 1-30, 148 et s.; du même: Thessalonique au XIV siècle, 15-41, 130 et 148.

DVORNIK, Les légendes de Constantin..., 14-16; TAFRALI, Thessalonique, des origines au XIV siècle, 140-142.

DIEHL, Monuments chrétiens de Salonique (sur ces monuments, voir ch. XIV).

P. LEMERLE, Philippes et la Macédoine orientale à l'époque chrétienne et byzantine, 9-11.

Ibidem, ch. I.

Ibidem, 283-291 et atlas.

Ibidem, 115-118, 135-138. 
la construction d'une nouvelle enceinte en $965^{689}$. Les notices épiscopales montrent le déclin de sa métropole, restée sans titulaire pendant de longues années dès le XIV ${ }^{\mathrm{e}}$ siècle. Bien que le titre de métropolite de Philippes ait été conféré jusqu'en 1721, il y avait longtemps que la ville n'existait plus ${ }^{690}$, et il a fallu les fouilles en profondeur de Paul Lemerle, exécutées de 1935 à 1939, pour mettre ses ruines à jour. Malheureusement, comme il le dit, on connaît moins son histoire intérieure que les événements historiques dont elle fut le théâtre.

Hellade. - Les villes de Grèce, si nombreuses dans l'antiquité, ont disparu, en grande partie, à cause des ravages des Goths, de la suppression des oracles, des jeux, des sanctuaires païens et de l'Université d'Athènes par Justinien (529). Dans les siècles suivants, la piraterie des Slaves, des Narentans, des Sarrasins occidentaux acheva d'appauvrir le pays. Les villes, qui continuèrent à porter des noms illustres, apparaissent déchues ou même réduites à l'état de bourgs. A Athènes le Parthénon fut transformé en église dédiée à la Vierge $(\pi \alpha \rho \theta \varepsilon \dot{\varepsilon} \vee \varsigma)^{691}$ et l'impératrice Eudokia (Athénaïs), mariée à Théodose II (423-450), enrichit sa ville natale de douze sanctuaires chrétiens ${ }^{692}$. Athènes, encore très prospère à l'avènement de Justinien, n'était plus, au VII siècle, qu'une très petite ville, dont cet empereur avait fait une forteresse, en utilisant les monuments du passé ${ }^{693}$.

Parmi les villes préservées de la ruine, Thèbes était devenue la plus importante et ce fut elle qui fut choisie comme chef-lieu du thème des Helladiques créé à la fin du $\mathrm{VII}^{\mathrm{e}}$ siècle. Lorsque Irène vint épouser Léon le Khasar, Athènes, sa patrie, n'était plus qu'une petite ville de province ${ }^{694}$, attachée avec ferveur au culte des icônes. On attribue à Irène, sans preuve certaine, la construction à Athènes de la gracieuse église de la Panaghia Gorgoépiko (dite Ancienne Métropole), qui ne suppose pas une ville très peuplée ${ }^{695}$, comme le confirment les autres églises médiévales d'Athènes, dont le style et les dimensions sont semblables.

Ibidem, 141-144.

Ibidem, 241-280.

FougERES, Athènes (V.A.C., 1912), 154 et s. (elle devint la cathédrale d'Athènes).

DIEHL, Figures byzantines, 1,30 .

W. MiLLER, Essays on the Latine Orient, 33.

DieHL, op. cit., 1, 78 et s.; du même: Manuel d'Art byzantin, 453-458; G. Millet, L'École grecque dans l'architecture byzantine, $192 \mathrm{et} \mathrm{s}$.

695 W. MILLER, op. cit., 48 et s. 
Les populations des villes de Hellade, souvent écrasées d'impôts, devaient être très remuantes. En 1040 elles vont jusqu'à appeler les Bulgares, qui occupent un moment Le Pirée et maltraitent les pèlerins d'Occident. En 1082 les villes commerçantes (et par conséquent prospères), énumérées dans le chrysobulle accordé par Alexis Comnène aux Vénitiens, sont: Thèbes, Athènes, Corinthe, Nauplie, Coron, Corfou, Euripe (Nègrepont), Démétrias (golfe de Volo) ${ }^{696}$. Au XII ${ }^{\mathrm{e}}$ siècle, l'industrie de la soie s'était installée à Thèbes. Les pêcheurs de pourpre de la mer Egée étaient exempts de la taxe militaire. Rappelons que Thèbes fut pillée par les Normands, qui transportèrent les plus habiles tisserands en soie à Palerme. Après leur départ, l'industrie de la soie fut reconstituée et recouvra son activité ${ }^{697}$. Par contre, les habitants des villes ignorent complètement le glorieux passé de leur pays et parlent un langage inintelligible pour un lettré de Constantinople, tel que leur archevêque, Michel Khoniatès ; il se sent devenir barbare au milieu des barbares, ses diocésains ${ }^{698}$.

Péloponnèse. - Après les invasions des tribus slaves, qui s'installent au VII ${ }^{\mathrm{e}}$ siècle dans la région du Taygète (Milinges et Ezérites) ${ }^{699}$, la vie urbaine décline à l'intérieur du Péloponnèse et ne se maintient que sur les côtes de la péninsule, à Corinthe, à Patras, à Coron, à Modon, à Monemvasia. La cité qui tient une place si grande dans l'histoire de la Grèce antique, Sparte, n'est plus qu'une petite ville de province, à peine citée dans les chroniques et connue uniquement par la vie de saint Nikon le Métanoïte, un obscur thaumaturge du $\mathrm{X}^{\mathrm{e}}$ siècle ${ }^{700}$. Originaire du Pont, Nikon avait consacré sa vie à la prédication et devait son surnom à ce qu'il commençait ses sermons par la phrase rituelle : "Metanoeite, faites pénitence ». Il dut ses premiers succès à la conversion des Crétois renégats, redevenus sujets de l'Empire après la conquête de leur île par Nicéphore Phocas en 961, puis il visita la Grèce et s'établit définitivement à Sparte, où il acquit une grande popularité ${ }^{701}$. Son biographe, qui paraît avoir été son dis-

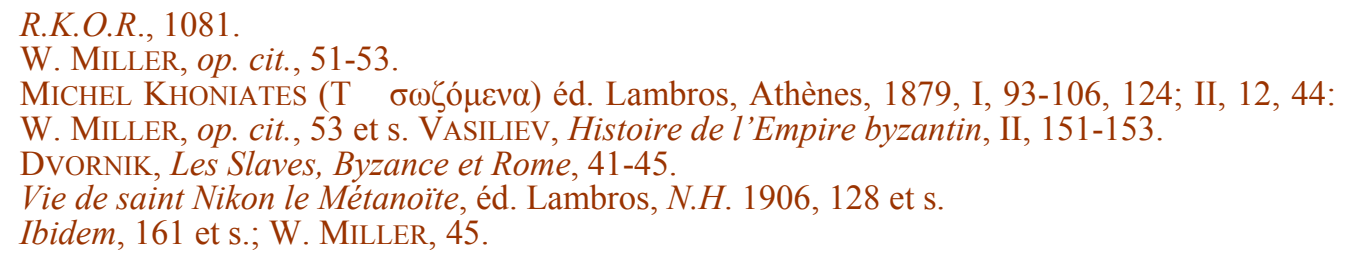


ciple, place à la fin de sa vie la prédiction de la révolte des deux Bardas contre Basile II et la capitulation de Skléros ${ }^{702}$.

Le tableau que le biographe de saint Nikon fait de Sparte est celui d'une ville assez peu importante, cependant siège d'un évêque et d'un stratège ${ }^{703}$. Sa population comporte des notables ${ }^{704}$, le peuple et une colonie de Juifs que saint Nikon détermine les autorités à expulser de l'enceinte de la ville, à la fin d'une épidémie qui avait fait de nombreuses victimes ${ }^{705}$. Ces colonies israélites étaient nombreuses et prospères au $\mathrm{XII}^{\mathrm{e}}$ siècle et se composaient quelquefois d'agriculteurs ${ }^{706}$. A Sparte même les Juifs se livraient au commerce maritime, notamment au $\mathrm{X}^{\mathrm{e}}$ siècle avec Venise. Ce commerce était alimenté par des industries locales : teintures en pourpre, fabrication du parchemin, industrie de la soie ${ }^{707}$. La ville était d'ailleurs divisée sur la question des Juifs, et un de leurs protecteurs, Malakinos, renommé pour son savoir profane ${ }^{708}$, faisait une opposition violente à saint Nikon et introduisait subrepticement des Juifs dans la ville ${ }^{709}$. Vers 998, lorsque les Bulgares essayèrent d'envahir le Péloponnèse, il fut accusé d'apostasie (tentative de désertion). Arrêté et emprisonné, il fut trop heureux d'avoir recours à l'intervention de Nikon pour obtenir sa grâce de Basile II ${ }^{710}$.

De son glorieux passé, Sparte avait conservé son agora, qui servait de piste pour les courses montées et le jeu de paume ${ }^{711}$. Le stratège, très sportif, venait sans façon jouer à la paume avec ses administrés. Ce fut sur cette place qu'après une procession solennelle du clergé et du peuple, Nikon posa la première pierre d'une église, à la construction de laquelle tous les habitants participèrent de leurs deniers. Les matériaux et la main-d'œuvre étaient fournis par la région. Le jour de la consécration, on s'aperçut qu'il y avait des malfaçons ${ }^{712}$ et lorsque

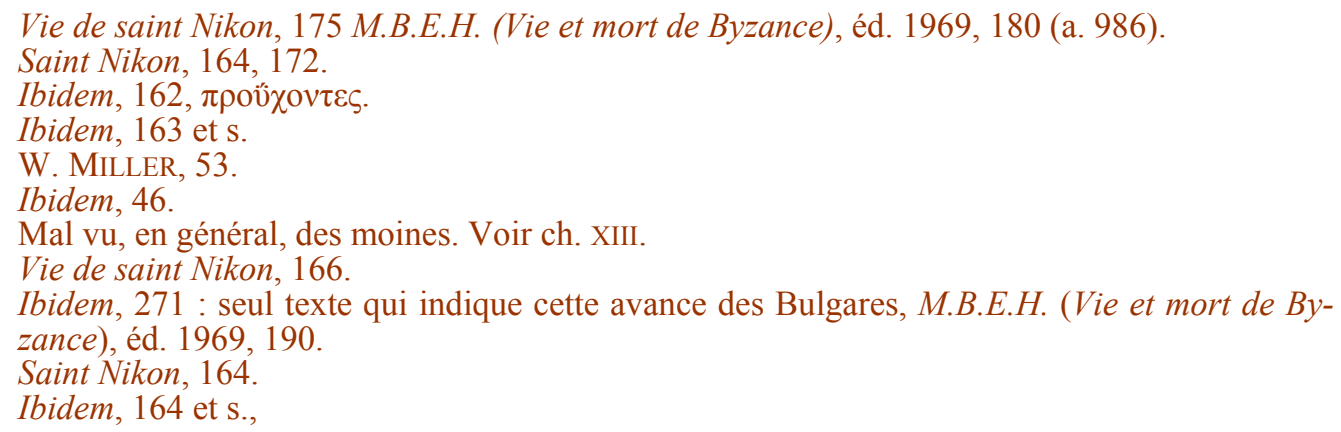


les joueurs de paume voulurent reprendre leurs exercices, pendant qu'on célébrait l'office divin, ils s'attirèrent une sévère admonestation de Nikon, qui eut une vive altercation avec le gouverneur ${ }^{713}$.

Telle était la vie qu'on menait au $\mathrm{X}^{\mathrm{e}}$ siècle dans une petite ville de province, où quelques lettrés parlaient encore des Lois de Lycurgue, à la sagesse desquelles ils comparaient les exhortations d'un moine éloquent ${ }^{714}$. D'ailleurs saint Nikon ne se bornait pas à prêcher la pénitence à Sparte, mais il pénétrait aussi chez les Slaves du Taygète : Milinges et Ezérites ${ }^{715}$, ainsi que chez les Maïnotes, restés païens, et il fit parmi ces peuples de nombreuses conversions ${ }^{716}$.

Vis-à-vis du pouvoir impérial, Sparte était surtout une place de guerre. Cependant en 1209 elle fut occupée par les Francs et devint le fief de La Crémonie ${ }^{717}$. La conquête du Péloponnèse se poursuivit non sans résistance. Le siège de Monemvasia, aujourd'hui village de pêcheurs, qui était au XIII ${ }^{\mathrm{e}}$ siècle l'un des grands ports d'escale de la Méditerranée, dura deux ans (1246-1248) ${ }^{718}$. En 1245 Guillaume de Villehardouin s'était emparé de Corinthe et de Nauplie. Pour venir à bout des clans slaves et maïnotes, il fit construire sur un contrefort du Taygète le château de Mistra et restaurer la forteresse du Magne ${ }^{719}$.

On sait que Guillaume de Villehardouin, fait prisonnier à la bataille de Pélagonia (1259), dut céder le château de Mistra à l'Empire, que Constantin, frère de Michel VIII, y établit sa résidence, et que vers 1265 les habitants de Sparte, menacés d'une nouvelle attaque de Villehardouin, se réfugièrent sous les remparts du château occupé par les Impériaux ${ }^{720}$. Une nouvelle ville naissait et, sous le gouvernement d'un despote, allait devenir la capitale du Péloponnèse, le dernier refuge de l'hellénisme, le plus récent exemple d'une ville créée de toutes pièces.

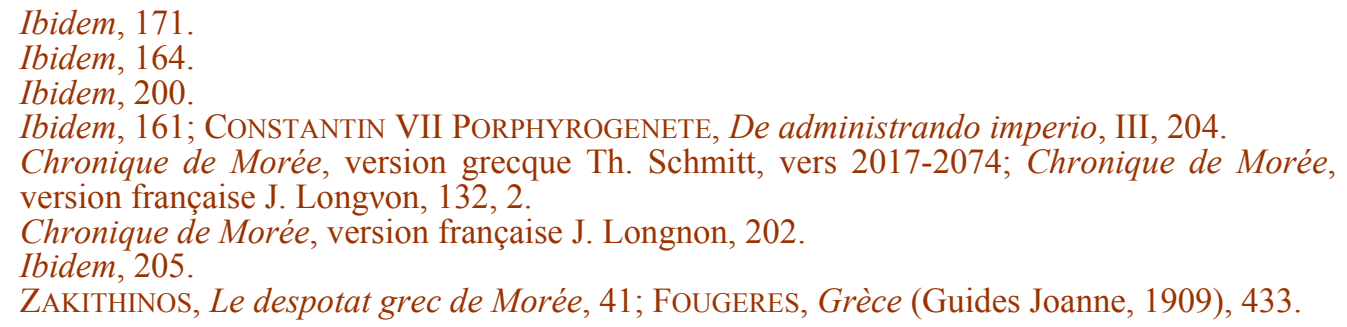


Aujourd'hui Mistra n'est plus guère qu'un champ de ruines, depuis qu'en 1779 une révolte des Albanais a détruit la cité et que les Grecs ont rebâti une Nouvelle Sparte dans la plaine en 1834. Construite sur un terrain en pente, dont le château de Villehardouin occupe le sommet, à 621 mètres d'altitude, Mistra comprenait plusieurs quartiers séparés par de fortes déclivités. C'est d'abord l'ensemble le mieux conservé, la Métropole, avec sa cathédrale dédiée à saint Démétrius, rebâtie en 1302, et son atrium en charpente, à deux étages. Elle est à 380 mètres d'altitude et fait partie de la Ville Basse, avec son curieux monastère de la Péribleptos, construit sur un terrain en pente $\left(2^{\mathrm{e}}\right.$ moitié du XIV ${ }^{\mathrm{e}}$ siècle). Les voûtes de ses absidioles s'appuient sur des pignons diaphragmes qui rappellent ceux de l'art roman auvergnat ${ }^{721}$.

La rue principale du nord, conduisant à la Métropole, est pavée avec des galets de rivière, encombrée d'orties et d'arbres poussés au hasard et voûtée sur une assez grande longueur ${ }^{722}$. Une vue splendide s'étend sur la plaine de Laconie et laisse découvrir le port de Gythaeion. On arrive ainsi à un quartier plus riche, dominé par la petite église en croix grecque de l'Evanguélistria, en laissant à gauche le chemin de la colline de la Pantanassa. A droite, le groupe de l'Afendiko, souveraine du Brontochion (1290-1295) et des SaintsThéodores (1366) ${ }^{723}$.

La rue principale gagnait la Ville Haute par des lacets et arrivait au Palais du Despote, entouré d'une enceinte, percée des portes de Nauplie $^{724}$ et de Monemvasia. Il subsiste un morceau du mur dirigé à l'est vers la Pantanassa et ce mur descendait en formant un réduit défendu par deux tours. La porte principale, Sideroporta, était située près de l'église Saint-Nicolas et fermée d'un double vantail. Au même niveau se trouvent des maisons avec, au premier étage, des balcons portés par des corbeaux que relient des arcs. Beaucoup sont privées de leurs toitures. Les Turcs avaient transformé ce quartier en bazar et éri-

721 G. Millet, Monuments byzantins de Mistra, pl. 2-3, 17-20, 22-29; STRUCK, Mistra, 28-29; G. MILLET, L'École grecque dans l'architecture byzantine, 206-234.

722 STRUCK, Mistra, 72 et s.

(723) ZAKITHINOS, Le despot

ZaKithinOs, Le despotat gree de Morée, 81 et s.; G. Millet, Inscriptions byzantines de Mistra (a. 1314-15); ORLANDOS dans E.B., 1936, 443-448. Brontochion (tonnant) serait le nom primitif du quartier.

724 STRUCK, op. cit., 132 et s. 
gé une mosquée à la place de l'église de la cour, dédiée à sainte Sophie $^{725}$.

Le palais du gouvernement est dominé dans son ensemble par la terrasse de Sainte-Sophie. Il consistait en une série de salles, dont deux surtout, se coupant à angle droit et formant un grand hall, allaient rejoindre les murs d'enceinte. Les murs de l'aile droite, la plus ancienne ( $\mathrm{XIV}^{\mathrm{e}}$ siècle), étaient percés de fenêtres en arcs aigus. L'aile gauche, qui a plus d'unité, comprend plusieurs étages de salles voûtées sur 40 mètres de long, avec des fenêtres en plein cintre et des murs décorés de stuc peint. A la façade, un revêtement de sculpture et, à l'intérieur, un double portrait d'un despote et d'une despoïna semblent indiquer la salle du trône ${ }^{726}$. Plus haut, à une hauteur de 512 mètres, se dressait la basilique Sainte-Sophie, bâtie par le despote Manuel Cantacuzène (1350) et allongée d'un narthex ${ }^{727}$.

Dominant la Ville Haute de 100 mètres, avec ses tours crénelées, ses murs grisâtres et ses brèches nombreuses, le château de Villehardouin est assis sur un rocher allongé et à pic, au pied de la muraille du Taygète. Les restes de la construction franque sont peu nombreux et les ouvrages actuels datent des époques byzantine et turque ${ }^{728}$. Au sud-ouest, une cour plus basse (baile des forteresses d'Occident) comprenait les logements de la garnison, une chapelle, une tour de guet arrondie, à la pointe du rocher. A gauche étaient les appartements du prince et de la princesse. Une citerne était creusée dans le rocher ${ }^{729}$.

Enfin, au pied du château, vers le sud-ouest, le monastère de la Vierge-Reine, Pantanassa, est relié par un chemin à la Ville Haute et descend par des pentes vertigineuses à la Péribleptos. La Pantanassa fut fonde entre 1428-1445, par Jean Frangopoulos, protostator du despote Constantin Dragasès, sur un éperon des plus pittoresques de la Ville Haute ${ }^{730}$, que rend plus gracieux encore le porche à colonnade, accompagné d'un clocher carré à deux étages, chacun à trois arcades,

\footnotetext{
Ibidem, 111-113, 153; Millet, Inscriptions byzantines, pl. VII, 11; BEYLIE, L'habitation byzantine, pl. XXXV-XXXVIII.

STRUCK, 132 et $\mathrm{s}$.

Ibidem, 134-136; MiLLET, pl. 31-33.

STRUCK, 138.

Ibidem, 138-141; Millet pl. 6, 13 et 7.

MILLET, pl. 35-40.
} 
celle du centre dépassant les autres. Aux étages supérieurs, des pignons pénètrent dans une flèche ${ }^{731}$. On ne peut nier là le travail d'un maître gothique, champenois d'origine ${ }^{732}$.

Aujourd'hui c'est au milieu de ruines informes qu'il faut se figurer cette dernière création urbaine. On ignore où Gémiste Pléthon, le dernier des Hellènes, le maître de Bessarion, donnait son enseignement et rêvait de régénérer la Grèce : c'est par la pensée qu'il faut évoquer dans ces ruines sordides la splendeur des édifices, la magnificence des processions, l'activité de l'industrie et du commerce, le dernier effort de vitalité donné par Byzance.

\section{L'Occident byzantin}

$\underline{\text { Retour à la Table des Matières }}$

En Occident, les villes ont progressivement disparu au contact des peuples barbares ou ne se sont maintenues que par une survie temporaire de la civilisation antique, ou par une restauration byzantine. Mais l'on n'y voit guère de tradition continue, que l'on puisse comparer à celle des villes orientales ou helléniques.

Carthage et l'Afrique. - Carthage, regardée comme une des capitales de l'Empire, n'avait pas souffert de la domination vandale de 433 à 538 et conservait sous Justinien les splendeurs de son passé romain : l'aqueduc d'Hadrien venant du Massif du Zaghouan, son Forum, son amphithéâtre, son théâtre sur la colline de l'Odéon, le palais proconsulaire au sommet de la colline historique de Byrsa, ses larges rues coupées à angle droit, en particulier celle des banquiers. La ville et le port, jusque-là ouverts, avaient été entourés de fortifications sous Théodose II en $425^{733}$. Le Cirque, situé au sud-ouest de Byrsa, avait à peu près les dimensions du Circus Maximus de Rome. Enfin de grandes basiliques chrétiennes rappelant les martyrs de Carthage, celle de Damous-el-Karita, avec ses neuf nefs, ou celle de Saint-Cyprien, dé-

\footnotetext{
Id., L'École grecque dans l'architecture byzantine, 137-39.

C. ENLART, Quelques monuments d'architecture en Grèce, dans R.A.C., 1897, 311.

A. Audollent, Carthage romaine, 128-237; description de L. BERTRAND dans Saint Augustin (1913), 96 et s. et d'A. RAMBAUD : L'empereur de Carthage (1904).
} 
couverte en 1915, dataient du IV $V^{\mathrm{e}}$ siècle, et Justinien en avait augmenté le nombre ${ }^{734}$.

La restauration byzantine, qui suivit la chute du royaume vandale, fut d'ailleurs la période la plus brillante du développement urbain en Afrique. A l'abri des forteresses élevées par Justinien, une grande prospérité régnait dans des régions aujourd'hui désertes et les ports entretenaient un commerce actif avec Constantinople, la Gaule et 1'Italie ${ }^{735}$. Byzance occupait les ports de Tripolitaine et de Byzacène, les puissantes citadelles de l'intérieur, les deux Mauritanies jusqu'à Septem (Ceuta). A l'Afrique se rattachaient les Baléares, Algésiras, la Corse, la Sardaigne ${ }^{736}$. Sur les côtes, le style des constructions était tout byzantin, tandis que les traditions latines s'étaient conservées à l'intérieur ${ }^{737}$. L'enseignement avait été réorganisé et il est curieux de constater que le grec y tenait une grande place ${ }^{738}$.

Rien ne laissait prévoir qu'en quelques années une civilisation aussi brillante disparaîtrait devant l'islam.

Rome et l'Italie. - A Rome et en Italie, la guerre des Goths a laissé des ruines, auprès desquelles les dégâts causés en Afrique paraissent moins importants. Les déprédations d'Alaric, le pillage de Rome par Genséric, la guerre de Totila, l'expédition des Lombards ont ruiné ou dévasté un grand nombre de villes. C'est pendant le $\mathrm{V}^{\mathrm{e}}$ et le $\mathrm{VI}^{\mathrm{e}}$ siècle que la Rome antique a disparu et que la population amoindrie a commencé à s'installer dans les ruines des anciens monuments. C'est au même moment, en particulier sous saint Grégoire le Grand, que, comme dans toutes les villes, les pouvoirs municipaux, les questions de ravitaillement, de justice et de défense tombent de plus en plus à la charge des évêques, et ce mouvement prend d'autant plus d'ampleur qu'il s'agit du pontife qui possède alors la primauté d'honneur dans l'Église universelle. Déjà se dessinent à Rome et dans les villes italiennes les linéaments du régime médiéval, dont les ducs ne sont plus les représentants du basileus auprès des sujets, mais ceux des populations vis-à-vis du pouvoir. Au régime urbain succède le pouvoir féo-

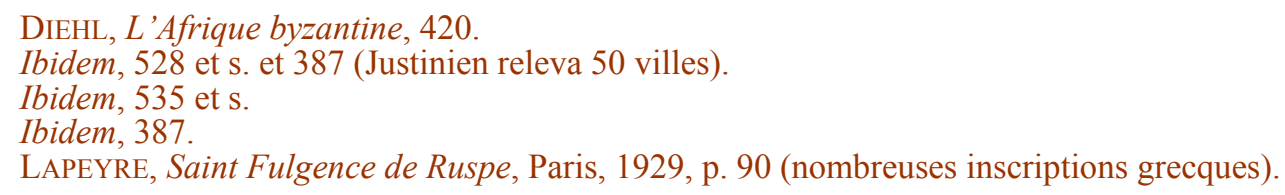


dal. A Rome la colonne triomphale élevée sur le Forum en l'honneur de Phocas est la dernière manifestation du loyalisme romain envers l'empereur ${ }^{739}$.

Il en est ainsi dans toutes les villes, et c'est d'ailleurs peu après cette époque, pendant la persécution iconoclaste, que la population de Rome est composée en partie d'émigrés, grecs ou syriens, dont quelques-uns occupent la chaire de saint Pierre et qui introduisent dans le calendrier liturgique de Rome les usages de Constantinople : l'église Sainte-Marie-Antique et sa décoration en sont des témoignages concluants ${ }^{740}$.

A la différence des autres cités, Ravenne est depuis Honorius la ville impériale, résidence des empereurs d'Occident, d'Honorius à Romulus Augustulus, de 395 à 476, puis de Théodoric et d'Amalasonthe (478-534), enfin des représentants du pouvoir impérial, les exarques, jusqu'en $754^{741}$. Succédant à une station navale du Haut-Empire, Ravenne fait figure, pendant cette période, de la plus grande ville de l'Italie, embellie surtout par Galla Placidia, fille de Théodose le Grand, par Théodoric, par Justinien, avec le concours de Julien l'Argentier. Ravenne représente ainsi l'une des périodes décisives de l'art byzantin. En outre, son faubourg de Classis est occupé par une colonie de Syriens ${ }^{742}$ qui possède le monopole du commerce avec l'Orient, dont elle introduit en Italie non seulement les produits naturels, mais les œuvres d'art et les usages. Des œuvres comme les poèmes de Sidoine Apollinaire, au $\mathrm{V}^{\mathrm{e}}$ siècle, ou la chronique un peu plus tardive des évêques de Ravenne, d'Agnellus, nous permettent de connaître l'activité de la ville qui fut longtemps la plus grande colonie byzantine de l'Italie.

Chassée au VIII ${ }^{\mathrm{e}}$ et au XI $\mathrm{XI}^{\mathrm{e}}$ siècle de cette Italie qui fut le berceau de son Empire, Byzance conserva du moins une véritable suprématie spirituelle et artistique, qui se perpétua jusqu'à la Renaissance, sur Venise, sur l'Italie méridionale et sur l'éblouissante Sicile des rois nor-

Fliche et Martin, Histoire de l'Eglise, V, ch. I et II. Sur le monument de Phocas, D.A.C.L., V, 1923, 2060 et C.I.L., VI, 1200.

740 DE GRUNEISEN, Sainte Marie Antique, Rome, 1911.

741 DieHL, Ravenne (V.A.C., 1903), 109 et s.; VON Simon, Sacred fortress. Byzantine Art and Statecraft in Ravenna, Chicago, 1948.

${ }^{742}$ L. Brehier, Les colonies d'Orientaux en Occident au commencement du Moyen Age. Ext. B.Z., XII, 1903, 1-38. 
mands. Mais la civilisation urbaine qui jette son éclat dans ces régions n'est plus celle de Byzance dans sa pureté : un nouveau type de ville monumentale apparaît et, dégagé de l'inspiration exclusive d'une seule culture, réunissant dans une même enceinte ce que les civilisations des peuples ont produit de plus beau, prépare un cadre fait à souhait pour un nouvel humanisme.

Retour à la Table des Matières 


\section{LIVRE TROISIÈME La vie économique}




\section{Chapitre VI}

Les campagnes et l'économie rurale

\section{Les domaines ruraux}

Retour à la Table des Matières

La campagne, $\chi \omega ́ \rho \alpha$; s'opposait à la cité, đó $\lambda ı \varsigma$, et lui était subordonnée administrativement. Elle comprenait des villages, $\kappa \quad \mu \alpha 1$, petits organismes très nombreux jusqu'au premier démembrement de l'Empire au VII ${ }^{\mathrm{e}}$ siècle, desservis par des chorévêques, et des domai-

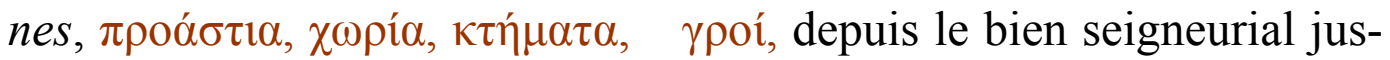
qu'au lopin de terre du paysan ( $\sigma \tau \alpha ́ \sigma t o v)$. Souvent des villages étaient enclavés dans un grand domaine et la distinction n'était pas toujours nette entre les fonctionnaires municipaux (protocomètes), qui recevaient des ordres du gouverneur de province, et le $\mu \varepsilon i \zeta \zeta \omega v, \mu \varepsilon i \zeta o ́ \tau \varepsilon \rho o \varsigma$, majordome d'un domaine particulier ${ }^{743}$.

Chaque domaine formait une unité désignée par un nom propre. C'est ainsi qu'après son abdication en 730, le patriarche Germain se retire dans son domaine patrimonial du Platanion ${ }^{744}$. Les petits domaines, englobés plus tard dans une grande propriété par héritage ou achat, conservaient leur nom primitif : une donation par Michel Paléologue de 748 modia (environ 62 hectares) comportait vingt-deux noms de propriétés ${ }^{745}$. Au IV ${ }^{\mathrm{e}}$ siècle, un type de domaine moyen est représenté par Annési, propriété de saint Basile, située au pied d'une

743 organismes en Egypte, de l'époque romaine au VII ${ }^{\mathrm{e}}$ siècle, G. HANOTAUX, Histoire de la na-

THEOPHANES LE CONFESSEUR, Chronographie, 407-409.

ANDREADES dans B.Z., 1928. 
haute montagne couverte de forêts, dans une plaine fertile et bien arrosée, coupée de deux côtés par de profondes vallées. La maison est abritée par une autre gorge, qui se relève par une éminence, d'où on a la vue de la plaine et celle d'un fleuve poissonneux qui tombe en chutes pittoresques ${ }^{746}$.

Le domaine de Boskytion, situé dans la région de l'Olympe de Bithynie et dont l'higoumène Platon, oncle de Théodore le Studite, avait fait un monastère, offrait la même fraîcheur ${ }^{747}$. En Asie Mineure les points d'eau étaient naturellement recherchés et ce qui faisait la valeur des 48 domaines que Philarète, beau-père de Constantin VI, possédait dans le Pont au VIII ${ }^{\mathrm{e}}$ siècle, c'est que chacun d'eux possédait une source d'eau vive ${ }^{748}$.

Variations du prix des terres. - On n'a de renseignements que par les documents de l'Athos, qui indiquent des prix extrêmement variables. A Chilandar, des paysans de Serrès vendent de petits lots de terres arables, dont le prix peut varier de 2 à 9 ducats. Entre 1296 et 1333, le prix d'un modius de vigne $(\sigma \tau \rho \varepsilon ́ v \mu \alpha)$ peut passer de 1 à 24 nomismata et l'écart est parfois encore plus sensible ${ }^{749}$. Les terres étaient mesurées avec des cordes et des attelages de bœufs, par un apographeus impérial ${ }^{750}$. Une miniature de l'Octateuque du Sérail montre des paysans tirant des cordes devant le maître du champ, vêtu d'une chlamyde : un autre personnage tire des boules d'un sac pour enregistrer les mesures ${ }^{751}$.

Le régime de la propriété byzantine ne fut jamais stable, par suite des confiscations, des guerres, des invasions, auxquelles il était exposé.

On ne peut croire que les paysans de Serrès aient vendu de leur plein gré une si grande quantité de vignes au monastère de Chilandar entre 1293 et $1333^{752}$. Voici d'autres exemples caractéristiques. Le domaine de Mésolimné près de Thessalonique appartenait à Étienne Maleinos, il a été donné par Nicéphore Botaniatès à un mercenaire franc, Othon, et à Léon Baasprakintès. Il leur est ensuite confisqué, à la suite de leur trahison, d'accord avec Raoul de Pontoise. Sur ces

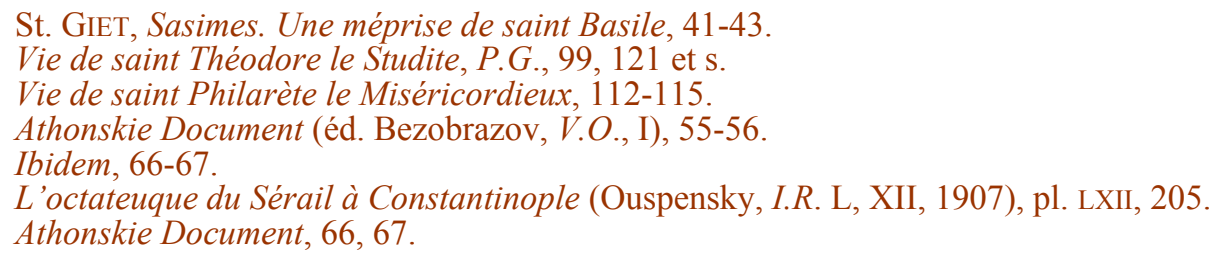


entrefaites, Alexis Comnène arrive au pouvoir et récompense ses partisans avec des terres confisquées. L'un d'eux, Leon Képhalas, avait résisté six mois dans Larissa assiégée par Bohémond et permis ainsi au basileus de dégager la place. Alexis, apprenant que Léon et son père avaient été de ses premiers partisans sous Nicéphore, et que lui-même avait été gratifié par ce prince d'un domaine dont il n'avait jamais été mis en possession, lui fait don, entre autres biens, du domaine de Mésolimné ${ }^{753}$. Les dons de terres comme récompenses politiques devinrent monnaie courante.

Dans les siècles suivants, les archives monastiques montrent certains biens tombés en déshérence, soit en totalité, soit seulement par moitié. La négligence avec laquelle étaient dressés les actes donnait souvent matière à procès. Au XIV ${ }^{\mathrm{e}}$ siècle, pendant les guerres civiles, le désordre régnait dans la chancellerie. Tel bien pouvait être donné de bonne foi à deux personnes distinctes, par exemple le $\chi \omega$ píov donné à titre héréditaire par Andronic IV à son familier Manuel Tarchaniotès (mai 1378), bien que ce terrain eût été déjà partagé entre deux autres favoris du même prince, ou encore le cadeau que Manuel II fait à l'une de ses tantes d'un édifice $\left(\begin{array}{ll}\alpha & \lambda \eta\end{array}\right)$ de Thessalonique, que ses grands-parents, Anne de Savoie et Andronic, avaient donné à des religieuses de cette ville. En 1415, il attribue la maison à sa tante, puis à l'État, puis au monastère de Lavra. Enfin, à la suite d'une réclamation des nonnes, il abroge les trois diplômes et partage le tout entre les deux monastères de Thessalonique et de Lavra ${ }^{754}$.

\section{2. Éléments des grands domaines}

\section{$\underline{\text { Retour à la Table des Matières }}$}

On a pu voir dans les deux premiers volumes du Monde byzantin que l'histoire sociale de Byzance ne fut qu'une lutte perpétuelle entre les grands propriétaires fonciers et le pouvoir central. La conquête du pouvoir par les archontes termina la lutte. Ce dont il s'agit ici est tout différent : c'est la vie réelle menée dans ces domaines, leur administration, les éléments de leur population et leur exploitation que l'on veut essayer de décrire.

753 R.K.O.R., 1134; G. RoulLLARD, Un grand bénéficiaire sous Alexis Comnène : Léon Képhalas, dans B.Z., 1930, 444 et s.

754 G. Rouillard, Les actes de Lavra à l'époque des Paléolopues, A.C.E.B., V, Rome, 1936, 300-307. 
Les grands domaines apparaissent, en Orient comme en Occident, après la grande crise économique du $\mathrm{III}^{\mathrm{e}}$ siècle. Le remembrement des terres est dû à la diminution de la valeur de l'argent et aux charges qui pèsent sur les petits propriétaires, obligés de se placer par contrats sous la protection des grands et de devenir coloni adscripticii ${ }^{755}$ : le patron reçoit le droit de percevoir l'impôt sur les paysans et de le verser directement au fisc. L'État a longtemps essayé d'éluder cette législation qui constitue le régime de l'autopragie et fait des hauts fonctionnaires, pris dans l'aristocratie, les détenteurs du pouvoir et de la richesse ${ }^{756}$.

Les domaines des Apion en Égypte. - L'organisation la mieux connue est celle des Apion en Égypte, véritable dynastie sur laquelle les papyrus nous renseignent de 488 à 625 environ. C'est une famille de hauts fonctionnaires, qui ne sont pas nécessairement d'origine égyptienne, mais dont les intérêts paraissent attachés à la région d'Oxyrhynchos, métropole de l'Arcadie.

Le premier connu est Apion Théodose-Jean, comte illustre du Consistoire Sacré et praeses (gouverneur) de la province d'Arcadie ${ }^{757}$. C'est sans doute le même qui, monophysite, est stratège d'Anastase en Perse en 503, puis se rallie à l'orthodoxie sous Justin I ${ }^{\text {er }}$ et est créé Préfet du Prétoire ${ }^{758}$.

Sous Justinien, la famille est en pleine ascension. Le fils d'Apion $\mathrm{I}^{\mathrm{er}}$, Stratégios $\left(\mathrm{I}^{\mathrm{er}}\right)$, comte des domestiques et grand propriétaire d'Oxyrhynchos est préfet augustal avant 523. Justinien le charge de le représenter en 533 à une conférence tenue entre des évêques orthodoxes et monophysites. On apprend, par le procès-verbal du concile, qu'après avoir été magister officiorum, il était devenu comte des largesses sacrées avec le titre de gloriosissimus patricius ${ }^{759}$. Il exerce ces fonctions pendant la plus belle période du règne de Justinien, au

C.Th., XI, 24,6; G. RouILlarD, L'administration de l'Égypte byzantine, 13 (plus ancien contrat sur papyrus, 488).

756 ROUILlard, op. cit., 13-15; E. RochiE-HARDY, The large Estates of byzantine Egypt, 51; G. STEIN, Geschichte des spätrömischen Reiches, 375.

757 The Oxyrhyncus Papyri, 877; ROCHIE-HARDY, op, cit., 25.

758 PROCOPE DE CESAREE, B.P., I, 8; il occupait cette charge le $1^{\text {er }}$ décembre 518, d'après C.J., VII, 63, 3.

759 M.C., VIII, 817-18; E. RoCHIE-HARDY, The large Estates of Byzantine Egypt, 26 et s. 
moment de la promulgation du Code, des grandes victoires de Bélisaire, de la reconstruction de Sainte-Sophie, de la paix avec la Perse. Procope vante la noblesse de sa naissance et sa sagesse : il le donne comme l'un des deux dignitaires chargés d'apaiser les querelles entre Arabes alliés des Perses ou des Romains ${ }^{760}$. L'édit XIII (réforme de l'Égypte) fait l'éloge de son administration ${ }^{761}$. Stratégios ne négligeait d'ailleurs pas ses domaines et se faisait envoyer les rapports de ses intendants à Constantinople, tandis qu'aux plus hautes dignités de l'État, il joignait celle, plus modeste, de pagarque d'Oxyrhynchos ${ }^{762}$.

Apion II, fils de Stratégios, l'un des derniers particuliers qui aient reçu le consulat (540), semble avoir fait toute sa carrière en Égypte, où il est duc de Thébaïde (549-550) et signalé à plusieurs reprises comme tribun, défenseur ou pagarque d'une localité située dans ses domaines ${ }^{763}$. Après lui, les Apion redeviennent entièrement égyptiens. On a retrouvé un projet de partage de sa succession, rédigé au moment de sa mort par ses héritiers (577-579). Le dernier Apion mentionné par les papyrus est Stratégios III (615-625) et il n'est plus question de cette famille après l'invasion perse ${ }^{764}$.

Les Apion ne sont pas d'ailleurs les seuls grands propriétaires d'Égypte cités à cette époque : ils sont du moins les plus considérables. A côté d'eux, quelques autres ont des domaines dispersés dans plusieurs nomes, où ils sont représentés par des intendants ou des fermiers généraux. Une liste de vingt personnes notables, dont plusieurs femmes et des groupes d'héritiers, énumère les paiements effectués au fisc en $570{ }^{765}$. Tout cela est peu de chose à côté du véritable État que constituaient les domaines des Apion.

Ces domaines étaient répartis sur quatre nomes, les plus importants autour d'Oxyrhynchos et dans le Fayoum ${ }^{766}$. Quelques chiffres donnent une idée de leur richesse. Dans ces domaines, l'excédent des recettes sur les dépenses est évalué à 178 livres d'or par an, ce qui re-

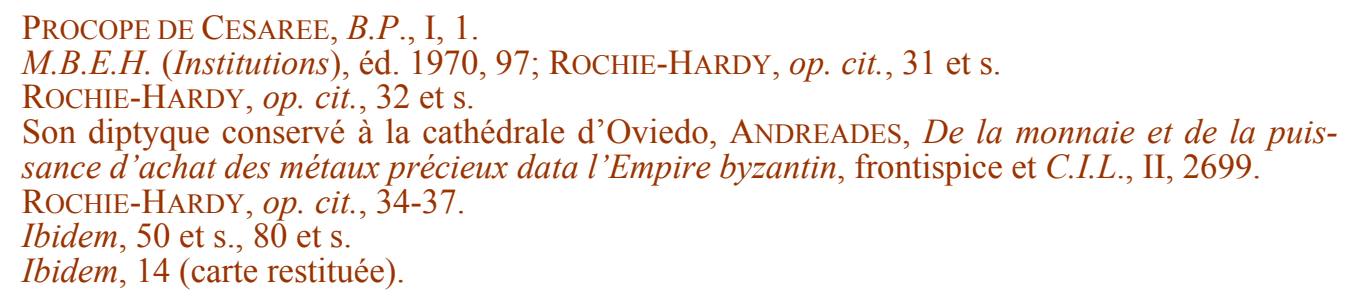


présente le traitement d'un préfet augustal. Les Apion avaient, pour administrer ces terres, au moins vingt fondés de pouvoir, qui possédaient leur signature (pronoètes). Quand ils résident dans un domaine, la quantité de grains requise pour le service « de notre seigneur et maître » est toujours mentionnée, ainsi que le vin et les autres provisions (cellarica) ${ }^{767}$. Les employés qui administrent ces domaines forment un corps bien constitué, tout à fait en marge des agents de l'État. Les actes mentionnent des caissiers (plusieurs connus par leurs noms), des banquiers, des chartulaires, des juristes. Le scholasticus Théodore de Cynopolis reçoit un don annuel de 50 artabae de froment ${ }^{768}$. Le service des transports, par bateaux, par chevaux, par messageries, est bien organisé. En 612 un batelier est chargé de conduire un rhéteur à Alexandrie ${ }^{769}$. Les vastes écuries comprenaient des chevaux pour courriers rapides ( $\xi u ́ \varsigma \delta \rho o ́ \mu o \varsigma)$ ou pour messages habi-

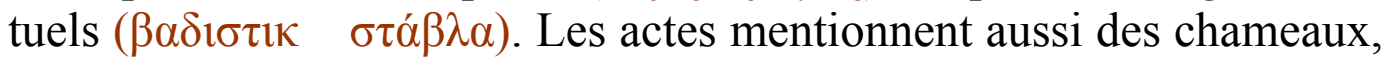
des mulets et toute une flottille sous des stolarques (capitaines appointés) pour le service par eau entre Oxyrhynchos et Alexandrie ${ }^{770}$.

Les principaux services étaient naturellement ceux qui étaient chargés de recueillir les taxes en monnaie et en nature, les caissiers pour la monnaie, les bateliers pour les grains. Il existait d'ailleurs une sorte de banque domaniale, car on voit des bateliers délivrer des grains prêtés à un village par un Apion ou ordonner des paiements en grains pour le compte de leur maître. Le vin était délivré directement par les vignerons au cellier domanial, dirigé par un sommelier,

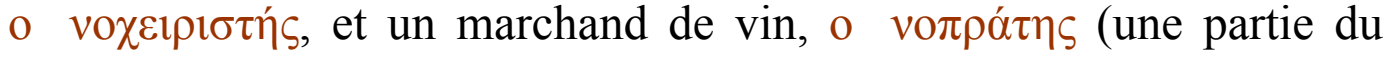
vin étant vendue, le reste servant à la consommation du domaine). Il y avait une organisation semblable pour la production de l'huile ${ }^{771}$.

L'autopragie des Apion. - Les attributions de l'État abandonnées à ces grands propriétaires sont des plus importantes. L'argent dû au fisc est envoyé directement à Alexandrie sans passer par les mains des officiers de la pagarchie. Ces envois d'argent sont escortés par des soldats privés et des caissiers du domaine ${ }^{772}$. En dépit des prohibi-

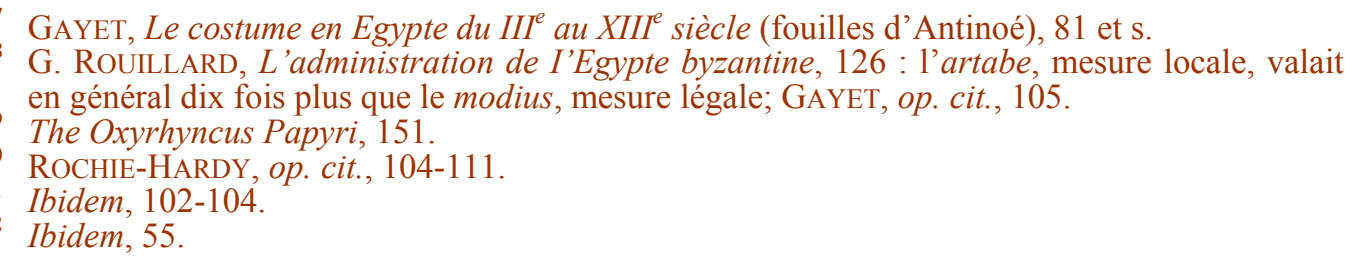


tions impériales, en effet, à l'exemple des chefs d'armée, les grands propriétaires fonciers se sont mis en Cappadoce, comme en Égypte, à enrôler des buccellaires, chargés de remédier à l'insuffisance de la police impériale, mais souvent plus redoutables qu'elle ${ }^{773}$. Un usage encore plus abusif est celui des prisons privées, qui apparaissent à la fin du $\mathrm{IV}^{\mathrm{e}}$ siècle et, malgré la sévérité des lois, sont devenues une pratique courante sous Justinien, en particulier dans les domaines des Apion ${ }^{774}$.

Un acte daté de 538 montre qu'il y a 139 prisonniers, qu'ils reçoivent du vin aux grandes fêtes de Pâques, de l'Épiphanie, de saint Michel, comme dans les prisons publiques, que ce sont des colons fugitifs ou des villageois sur lesquels on veut faire pression. Un pétitionnaire, dont on a emprisonné la femme et saisi la propriété, demande que sa terre soit libérée et que sa femme soit gardée jusqu'à ce qu'il ait payé ce qu'il devait ${ }^{775}$.

Les grands propriétaires ont donc un rôle souverain dans toute la vie politique, administrative, sociale et économique de l'Égypte. Ils imposent leurs mesures et leurs étalons et jusqu'à leur monnaie à ceux qui traitent des affaires avec eux ${ }^{776}$. Ils s'occupent des irrigations, élèvent des digues privées, font creuser des citernes par des corpora-

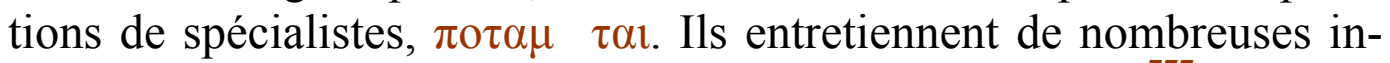
dustries, moulins, pressoirs, boulangeries, thermes, etc. ${ }^{777}$. Ils sont pris comme arbitres, on pourrait dire comme juges de paix, dans les litiges ${ }^{778}$. Ils s'occupent même des réjouissances publiques, ils entretiennent un hippodrome à Oxyrhynchos et paraissent favoriser impartialement les deux factions. C'est là d'ailleurs que paraît être leur principale résidence et le siège de leur administration ${ }^{779}$.

Ce régime domanial, qui fait songer à celui qui devait, avec de grandes différences d'ailleurs, s'implanter en Occident, disparut avec la conquête arabe, qui rétablit en Égypte la bureaucratie centralisée de l'époque des Ptolémées ${ }^{780}$.

774

775

776

777

778

779

780

Ibidem, 60 et s.; C.I.C.I., nov. J., 30 (538); RoulllarD, op. cit., 167, 1 (contrat entre Apion et un protophylax, chef de ses gardes).

ROCHIE-HARDY, op. cit., 67 et s.

Ibidem, 68-70; The Oxyrhyncus Papyri, nº 255.

ROCHIE-HARDY, 73.

Ibidem, 112 et s.

Ibidem, 72.

Ibidem, 136 et s., 83 et s. (actes mentionnant les thermes, le cellier, la cuisine, la consommation quotidienne de 9 mesures de vin sur, un mouton, 3 jeunes porcs, 4 pigeons, 29 œufs).

ROCHIE-HARDY, 146-148; Papyrus littéraire d'Aphrodite (éd. Jean Maspero), VIII siècle. 
Pour les autres régions et les périodes suivantes, on est loin de disposer de documents aussi complets que les archives domaniales des Apion. D'après une anecdote recueillie dans le Livre des Thèmes, Justinien aurait reçu de Thomas, chef du village de Lykandos, 10 troupeaux de 1000 brebis, chacun d'une couleur différente ${ }^{781}$.

VII ${ }^{e}$-VIII ${ }^{e}$ siècle. - Certaines Vies de saints donnent des renseignements. La Vie de saint Théophanes de Sigriané, né vers 760, montre la concentration de la propriété par une union matrimoniale, qui fait de ce personnage, filleul de l'empereur Léon IV (775-780), l'un des plus riches héritiers de l'Archipel, lorsqu'il embrasse la vie monastique, après avoir affranchi ses nombreux serfs et distribué ses biens aux pauvres ${ }^{782}$.

Un des exemples les plus remarquables de grand propriétaire de la même époque est celui de Philarète le Miséricordieux, dont la fille fut la triste épouse de Constantin VI ${ }^{783}$. Ses domaines se trouvaient dans le thème des Arméniaques, dans la vallée du fleuve Amnias, qui se jette dans la mer Noire entre Sinope et l'embouchure de l'Halys ${ }^{784}$. Il possédait 48 domaines bien délimités $(\pi \rho \circ \alpha ́ \sigma \tau \imath \alpha)$, chacun avec une source d'eau vive, qui tombait d'une certaine hauteur, ce qui permettait les irrigations. Ses troupeaux comprenaient 100 bœufs soumis au joug pour le travail de la terre et 600 au pâturage, ainsi que 800 juments, 80 mulets et chevaux de selle, 12000 brebis, un très grand nombre de ruches; il lui en restait encore 250 après sa ruine ${ }^{785}$. Sa maison était un édifice antique, magnifique et spacieux, avec un beau mobilier dont une table ronde en ivoire incrusté d'or, faite pour 36 convives $^{786}$.

La famille de Philarète qui vivait sur ce territoire en 778 se composait des parents, d'un fils et deux filles mariées et de leurs enfants, en

781 CONSTANTIN VII PORPHYROGENETE, De thematibus (anecdote suspecte mais symbolique).

782 Vie de saint Théophanes le Confesseur; LOPAREV, Vizantiiskiia Jitii Sviatuik, 92-98; L. BREHIER, Les populations rurales au IX siècle d'après l'hagiographie byzantine, 179.

783 Vie de saint Philarète le Miséricordieux; M.B.E.H. (Vie et mort de Byzance), 1969, 87 et s et Institutions, 1970, 32.

784 LOPAREV, op. cit., 72 (analyse de sa vie due à son petit-fil Nicétas); Vie de saint Philarète le Miséricordieux.

785 Vie de saint Philarète le Miséricordieux, 112 et s., 134-136.

786 Ibidem, 136 et $\mathrm{s}$. 
tout 30 personnes ${ }^{787}$, mais la mort avait éclairci les rangs de cette famille patriarcale, qui comprenait en outre un grand nombre de serviteurs (serfs, esclaves, colons) ${ }^{788}$.

Après avoir montré quels étaient les domaines de son aïeul au temps de sa splendeur, le biographe de saint Philarète, son petit-fils Nicétas, décrit les causes qui l'ont fait péricliter ${ }^{789}$. Nous voyons ainsi comment un magnifique domaine, édifié par des générations, pouvait disparaître en quelques années.

En Asie Mineure, le principal danger venait des incursions arabes, raids périodiques, pendant lesquels les terres étaient ravagées, les récoltes brûlées et les populations emmenées en captivité. Bien que le biographe ne précise pas, il fait allusion à des razzias de ce genre qui endommagèrent gravement les domaines de Philarète ${ }^{790}$. Plus intéressant encore est le tableau de la conscription des hommes et des chevaux assujettis au service pour préparer une expédition contre les Sarrasins. Le corps impérial, détaché du thème, commandé par un chiliarque, un centenier, un cinquantenier, s'établit dans un camp ( $\sigma \tau \rho \alpha \tau o ́ \pi \varepsilon \delta o v)$ et les paysans s'y rendent avec leurs chevaux et leurs chars. Les réfractaires sont menacés du supplice du fouet. Le cheval d'un pauvre paysan étant mort subitement de coliques, il va trouver Philarète qui lui donne son propre cheval ${ }^{791}$.

Ce trait touchant jette un jour surprenant sur les rapports entre un grand propriétaire et les paysans qui lui étaient plus ou moins subordonnés. Il est vrai que Philarète le Miséricordieux est présenté comme exceptionnel et que ses vertus lui ont mérité les honneurs de la sainteté. On n'en constate pas moins, en considérant sa conduite d'un point de vue plus terre à terre, que la grande propriété revêtait dans certaines régions un caractère patriarcal, et que, d'une part, une générosité trop grande du bienfaiteur, d'autre part un manque de scrupule de la part des bénéficaires, arrivaient à mettre une grande propriété en péril. A l'époque où commence le récit de Nicétas, Philarète ne possède plus que sa maison paternelle, un petit bien, un unique serf, une seule

Ibidem, 140 et $\mathrm{s}$.

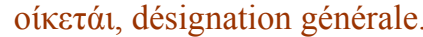

Ibidem, introd. sur Nicétas 96-98.

Ibidem, 115.

Ibidem, 124-127. 
servante et quelques bestiaux ${ }^{792}$. Il n'en continue pas moins ses générosités, jusqu'à être réduit avec sa famille au dénuement le plus complet, au moment où un événement inattendu relève sa fortune ${ }^{793}$.

Occident. - Dans la plupart des provinces d'Occident, la concentration de la grande propriété est aussi marquée avant le $\mathrm{X}^{\mathrm{e}}$ siècle.

Le protospathaire Léon, qui a achevé en 873-874 l'église de Skripú en Béotie, commencée par Basile le Macédonien et ses deux fils Constantin et Léon, était vraisemblablement le propriétaire d'un grand domaine situé sur l'emplacement de l'ancien Orchomène ${ }^{794}$.

Nous connaissons un peu mieux l'étendue des richesses de la bienfaitrice de Basile le Macédonien, Danielis ${ }^{795}$, la riche veuve, qui possédait 80 domaines dans la région de Patras, avec des champs, des villes entières, des troupeaux, des ateliers où des femmes tissaient des soieries, des tapisseries, des toiles de lin. Dans sa maison s'entassaient les coffres remplis de lingots précieux, de vêtements splendides, de vaisselle d'or et d'argent. Elle voyageait dans une litière, accompagnée de 300 jeunes esclaves, qui se relayaient, lorsqu'elle vint rendre visite à Basile vers $880{ }^{796}$. Elle légua tous ses biens à Léon VI, qui affranchit 3000 de ses esclaves et les envoya comme colons en Italie.

A la fin du $\mathrm{XI}^{\mathrm{e}}$ siècle, après la période pendant laquelle des empereurs clairvoyants s'efforçaient de mettre obstacle au développement de la grande propriété laïque et ecclésiastique, les grands domaines, bien que moins étendus, sont redevenus le régime normal de la terre.

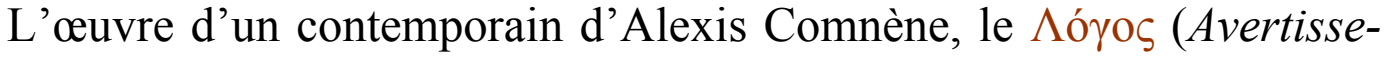
ment) de Kékauménos, jette un jour curieux sur l'état d'esprit et les opinions d'un propriétaire campagnard de ce temps ${ }^{797}$. Ancien fonctionnaire du thème de Hellade, il s'est retiré à la campagne, pour laquelle il a une véritable prédilection. Il n'y a pas, selon lui, de meil-

\footnotetext{
Ibidem, 114-116.

Ibidem, 116-234; L. BREHIER, Concours de beauté à Byzance dans Gesta Francorum et aliorum Hierosolymitanorum, 1937.

794 STRZYGOWSKI dans B.Z., 1894, 9-10 (il n'y a pas trace d'un village à cet endroit).

795 THEOPHANES, Continuatus, XI, 241 (Basile).

796 DieHL, Figures byzantines, I, 160; A. VoGT, Basile $I^{e r}$ et la civilisation byzantine à la fin du IX siècle, $89,384$.

797 KeKAUMENOS, Strategikon ou Logos nouthetitikos (éd. Vasiliev : Récits d'un grand seigneur byzantin du XI siècle).
} 
leure manière de vivre que « de travailler la terre. Fais du blé, du vin, fais de la culture et de l'élevage et tu seras heureux " ${ }^{798}$. Doué d'un sens pratique un peu terre à terre et avant tout économe, il blâme également les emprunts et les prêts d'argent, même s'il s'agit d'entreprendre une affaire avantageuse. Philarète ne serait pas son homme et il fait un portrait amusant des ruses employées par des emprunteurs pour se faire livrer la grosse somme, qu'ils oublieront de restituer. Il a surtout le désir de l'indépendance et il n'y a qu'à la campagne qu'on puisse en jouir. D'après lui, l'empereur ne devrait réserver les titres de cour, patrices, protospathaires, etc., qu'aux seigneurs et propriétaires locaux. C'est par eux qu'il lève les taxes sur les paysans, mais ceux-ci doivent être " traités en chrétiens, comme des hommes et non comme des bêtes ». Le seigneur doit être pour eux un père, à qui on s'adresse dans les difficultés. Et il étend ce mode de gouvernement patriarcal à tout l'Empire : au lieu de rester emprisonné dans son palais, le basileus devrait visiter les thèmes et redresser les injustices ${ }^{799}$.

A cette époque, ce sont les empereurs eux-mêmes qui favorisent l'ascension de la grande propriété. Deux frères de naissance géorgienne, émigrés dans l'Empire dans la deuxième moitié du XI ${ }^{\mathrm{e}}$ siècle, $\mathrm{y}$ acquièrent une fortune territoriale. Apasios Pakourianos, duc d'Antioche, y acquiert des biens qu'il échange avec l'empereur contre un domaine situé dans le thème de Thessalonique ; après avoir agrandi ce domaine, il lègue ses propriétés à son frère Grégoire, duc de Trébizonde ${ }^{800}$. Celui-ci, propriétaire de plusieurs fiefs dans les provinces du Caucase, avait reçu de Michel VII (1071-1078) d'importants domaines dans les régions balkaniques de Philippopoli et Mosynopolis, dont plusieurs monastères, le château de Petritzos, la villa de Zaoutzi dans la région d'Arnphipolis, le village de Sténimachos ${ }^{801}$.

Nous avons là un exemple du processus qu'a suivi la formation des grandes fortunes territoriales et de la disparition de la petite propriété. Le sol appartient désormais exclusivement aux puissants, archontes ou monastères autonomes. C'est la situation que trouvent les conquébyzantin, A.C.E.B., V, Rome, 1937, 190 et s.

800 Typikon de Grégaire Pakourianos (monastère de Petrizos), éd. L. Petit, Introd., VIII.

801 Ibidem, VIII-IX. 
rants francs du Péloponnèse en 1204, et il est à remarquer que la plupart des familles qui se partagent le sol, les Mélissènes, les Vranas, les Cantacuzènes, sont presque toutes parentes de la maison impériale ${ }^{802}$. Lorsqu'un siècle plus tard les Paléologues ont reconquis une partie de la Morée franque, on y retrouve les mêmes familles d'archontes, plus solidement établies que jamais, et quelques-unes, comme celle de Gémisthos (Pléthon), ont le droit de lever elles-mêmes des taxes sur les paysans ${ }^{803}$.

Pendant la période de Nicée, une initiative intéressante fut prise par Jean Vatatzès (1222-1254) qui, après avoir fait la paix avec le sultan d'Iconium, s'efforça de repeupler les terres désertées pendant les guerres et par suite des abus du fisc. Il se constitua un vaste domaine rural, qu'il fit planter en céréales et en vignes, réservant une partie pour les bois et les pâturages, peuplés de bétail et bordés de vastes métairies. Il fit vendre les produits de son domaine et, avec les bénéfices qu'il obtint sur la vente des œufs, il put offrir une couronne d'or sertie de pierres précieuses à l'impératrice ${ }^{804}$.

Nous possédons quelques renseignements sur la richesse de ces grandes propriétés de la fin de la période byzantine, qui avaient pu échapper au fisc et à la guerre. Du palais de Théodore Métochitès, grand-logothète d'Andronic II vers 1328, dépendaient de nombreux vignobles, couvrant de vastes terrains et plantés par crus. Il y avait aussi de nombreux pâturages avec des têtes de bétail de toute espèce, chevaux, porcs, brebis, chèvres, un nombre élevé de chameaux et de dromadaires, des bêtes de labour. Chaque fermier avait son domaine qui lui permettait de vivre largement ${ }^{805}$.

De la même époque date l'énumération des biens que possédait Jean Cantacuzène sur le territoire de Phères en Thessalie et qui furent confisqués au début de la guerre civile en 1341 par le gouverneur Guy de Lusignan. Le bétail était nombreux : 500 bœufs, 2500 juments, 200 chameaux, 300 mulets, 5000 ânes, 50000 porcs, 70000 moutons, des magasins remplis de blé et des coffres pleins de lingots et de pièces d'or et d'argent. Toute cette fortune, accumulée pendant plu-

\footnotetext{
RoDD, The princes of Achaia, Londres, 1907, 1, 104 et s. ZAKITHINOS, Le despotat grec de Morée, 122.

NiCEPHORE Gregoras, Histoire romaine, I, 2, 6; Georges AKropolites, Chronique, 41.

R. GuILland, Le palais de Théodore Métochitès dans R.E.G., 1921, 93 et s.
} 
sieurs générations, fut livrée au pillage et détruite en quelques jours ${ }^{806}$.

\section{Condition et vie des paysans}

$\underline{\text { Retour à la Table des Matières }}$

Le problème de la petite propriété paysanne fut le drame interne qui troubla l'Empire pendant toute son existence. La disparition de la paysannerie libre fut une des causes profondes de sa chute.

Le servage et le colonat. - $\mathrm{Au} \mathrm{V}^{\mathrm{e}}$ siècle, les grands domaines étaient cultivés par plusieurs catégories de travailleurs qui se ramenaient à deux : les paysans libres de leur personne, mais attachés à la

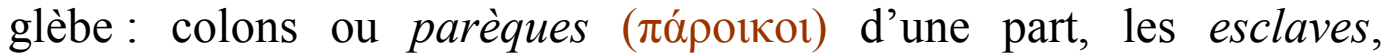

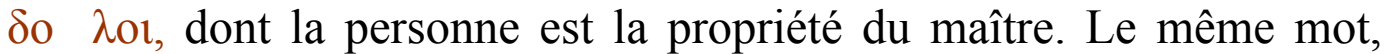
$\delta o v \lambda \varepsilon i ́ \alpha$, désigne le servage et l'esclavage. Ce sont les historiens qui ont adopté le terme de serfs pour désigner les esclaves établis sur une parcelle qu'ils ont à cultiver et dont ils sont aussi inséparables que les animaux de trait. Parèques et douloi sont donc pratiquement dans la même situation et ne peuvent abandonner leur tenure. Ils ne sont distincts qu'aux yeux du fisc, qui regarde les parèques comme des personnes soumises à l'impôt et les douloi comme des choses, propriété

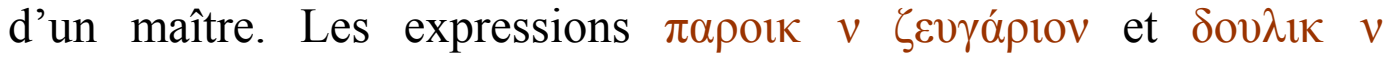

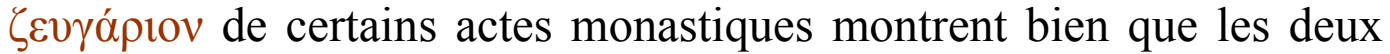
catégories d'attelages et leurs conducteurs sont considérés comme faisant également partie de l'instrumentum fundi ${ }^{807}$.

C'est ce que montrent au vie siècle des épithètes comme

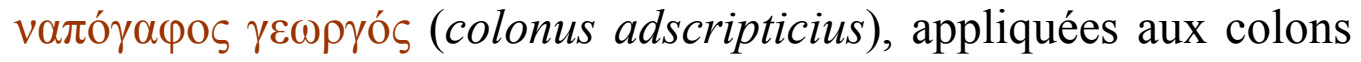
non esclaves, attachés au sol, «bien que libres, traités en esclaves dans le pays où ils sont nés $\gg{ }^{808}$. Ces colons sont parfois d'anciens hommes libres tombés dans la misère, ne possédant en propre qu'un léger peculium, obligés de se vendre à des puissants. La seule diffé-

Jean CANTACUZENE, Histoire, III, 31.

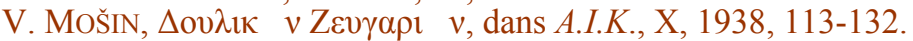

C.J., XI, 52; PANTECHNES, archevêque de Philippopoli, La chasse à l'once, 84 et s. 
rence avec les esclaves, c'est que leur maître ne peut les transporter ailleurs.

$\mathrm{Au} \mathrm{VI}{ }^{\mathrm{e}}$ siècle, ces colons étaient naturellement nombreux dans les grands domaines comme ceux des Apion en Égypte. Les évasions n'étaient pas rares et on a des listes de colons fugitifs qui se transportaient d'un domaine à l'autre. Pour les en empêcher, on établissait entre eux une solidarité et ils devaient répondre par contrat les uns des autres. C'est ainsi qu'Aurélius Pamouthios, ouvrier plombier, d'Oxyrhynchos, après avoir prêté serment par Dieu et par l'empereur, déclare qu'il répond d'Aurélius Abraham, colonus adscripticius. Il promet que ce colon résidera dans le domaine de Tarouthinos avec sa famille et son bétail sans changer de place. En cas de forfaiture, Pamouthios s'engage à payer 8 sous d'or et à se laisser enfermer dans la prison de la glorieuse maison ${ }^{809}$.

L'affranchissement des serfs était regardé comme une bonne œuvre. Lorsqu'en 780 Théophanes le Confesseur, propriétaire notable des îles de l'Archipel, entre dans un monastère, il affranchit tous ses

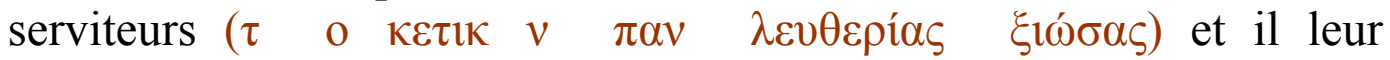
confère des diplômes, $\lambda \varepsilon \gamma \alpha ́ \tau \alpha$, qui leur donnent le droit d'aller où ils voudront ${ }^{810}$.

Travailleurs libres et petits propriétaires. - On a cependant la preuve que, malgré l'extension des grands domaines, la petite propriété n'a jamais disparu entièrement, en droit et en fait. Il est encore question dans les lois de Justinien de $\mu \tau \sigma \theta \omega \tau \alpha i ́$ (salariés), paysans libres, qui payent l'impôt et peuvent affermer des terres contre un droit en nature ou en argent. Lorsque le bail est venu à expiration, ils peuvent se transporter ailleurs ${ }^{811}$. Cet usage est donc légal, mais on ignore dans quelle mesure il est respecté.

La législation fiscale, décrite dans le $2^{\mathrm{e}}$ volume du Monde byzantin, montre au contraire dans leur réalité, aux $\mathrm{VII}^{\mathrm{e}}$ et $\mathrm{VIII}^{\mathrm{e}}$ siècles, des communautés de paysans libres ${ }^{812}$. La Loi agricole (nomos georgi$k o s$ ), qui nous renseigne sur la vie de ces petites sociétés, nous est connue par de nombreux manuscrits, dont les plus anciens ne sont pas antérieurs au $\mathrm{XI}^{\mathrm{e}}$ siècle. Elle $\mathrm{y}$ figure presque toujours dans

809 Rochie-HARDY, The large Estates of byzantine Egypt, 76; The Oxyrhyncus Papyri, 135.

810 Vie de saint Théophanes le Confesseur, ch. III; LOPAREV, Vizantiiskiia Jitii Sviatuik, XVII, $92-$ 98.

811 C.I.C.I., nov. 53, 14; Recueils d'inscriptions : HANTON, Lexique explicatif.., d'Asie Mineure, $\mathrm{n}^{\circ}$ 84; ZACHARIAE VON LINGENTHAL, Geschichte des griechisch-römischen Rechts, 216-226.

812 M.B.E.H. (Institutions), éd. 1970, 152. 
l'appendice du texte de l'Ekloga des empereurs isauriens et d'un grand nombre d'autres recueils juridiques, comme le Prochiron ou l'Epanagoge. J. de Malafosse, qui a entrepris une étude critique sur ces manuscrits, en suit la tradition jusqu'au XVII ${ }^{\mathrm{e}}$ siècle. Il constate que les 85 articles de la Loi agricole sont à peu près disposés dans le même ordre à toutes les époques, mais que, par rapport aux textes les plus anciens, ils sont remplis d'interpolations et accompagnés de gloses multiples, qui modifient la législation suivant l'état social et économique ${ }^{813}$. La date probable de la rédaction actuelle doit être placée à la fin du VII ${ }^{\mathrm{e}}$ ou au début du VIII ${ }^{\mathrm{e}}$ siècle ${ }^{814}$, mais, bien que son auteur invoque la législation de Justinien, elle est surtout une rédaction d'un droit coutumier très vivant, en fonction de la vie paysanne et de la prospérité agricole ${ }^{815}$. Elle concerne avant tout des paysans libres et non attachés à la glèbe ${ }^{816}$.

La Loi agricole est donc une loi de garantie, qui n'a rien à voir avec le régime du mir communautaire d'origine slave ${ }^{817}$. Elle assure au contraire à chaque paysan la propriété de ses biens, établit une série de mesures pour les protéger et un code pénal pour les torts faits aux particuliers et au village ${ }^{818}$.

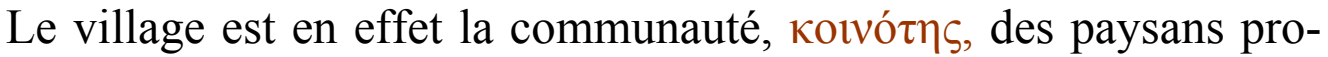
priétaires du sol, qui s'assemblent pour délibérer, agissent ensemble ${ }^{819}$, et sont collectivement responsables vis-à-vis du fisc du paiement des impôts ${ }^{820}$.

Mais le village de la Loi agricole n'est pas une simple unité fiscale. On peut se le représenter comme entouré de vergers et de vignes, dont les haies qui les clôturent indiquent la possession individuelle. Plus loin, des champs en culture, bien que non clôturés, sont aussi des objets de propriété privée. Par contre, les bois, les pâturages sont la propriété commune du village, dont les habitants les exploitent en commun. Ces communaux sont protégés contre les déprédations par des pénalités. Des amendes sont infligées à ceux qui laissent errer leur

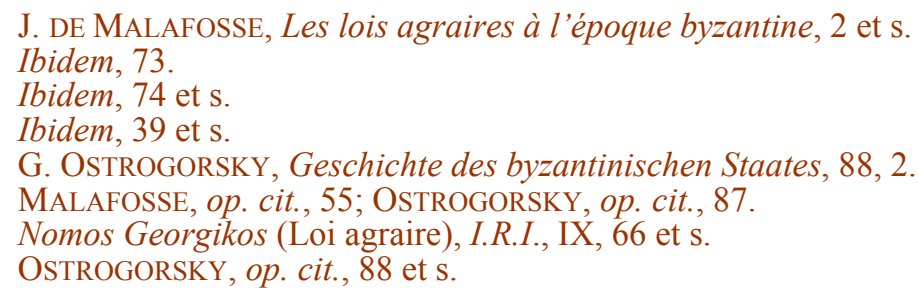


bétail dans le champ du voisin avant qu'il soit récolté. D'autre part, ceux qui défrichent une partie des communaux peuvent en devenir propriétaires ${ }^{821}$.

Dans ces petites sociétés les litiges n'étaient pas rares, surtout quand il s'agissait de l'appropriation d'un terrain resté indivis. Dans ce cas, il y avait procès et le plaignant, que ce fût la communauté ou l'un de ses membres, avait recours à l'usage très primitif de la cla-

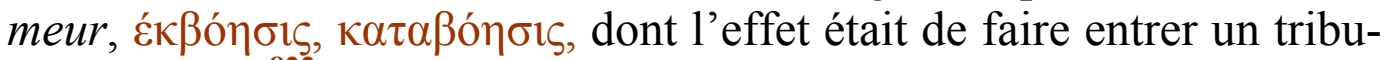
nal en action ${ }^{822}$.

Par exemple, un habitant trouve-t-il un terrain propre à l'établissement d'un atelier ou d'un moulin, il peut en disposer s'il n'y

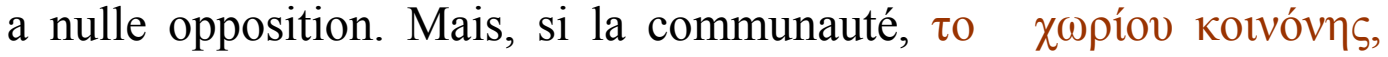
revendique cet endroit comme un bien commun, après un vote qui doit être unanime, elle permettra au constructeur d'exploiter son établissement, mais en sera copropriétaire avec lui ${ }^{823}$. Un autre plante un arbre dans un endroit non partagé et l'entretient. S'il y a partage et si le sort assigne le lot à un autre, c'est au planteur de l'arbre qu'il est assigné. Mais si le paysan dépossédé du lot crie à l'injustice, on donne un autre lot au propriétaire de l'arbre ${ }^{824}$.

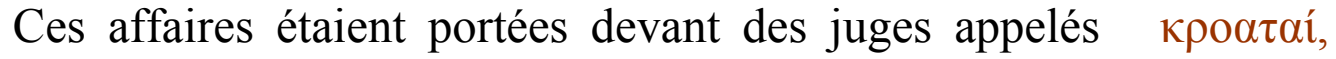
auditeurs, nom caractéristique indiquant ceux qui écoutent l'ekboésis ${ }^{825}$, et qui devaient être choisis dans la communauté même.

La nouvelle extension du servage. - La petite propriété s'est donc développée au VII ${ }^{\mathrm{e}}$ siècle aux dépens du servage. Les ouvriers agricoles libres, qui se chargent de labourer une vigne ou un champ après traité avec un propriétaire et moyennant un salaire, $\rho \rho \alpha \beta v \alpha$, sont mentionnés dans la Loi agricole, qui ne connaît que des hommes libres ou des esclaves ${ }^{826}$. Le servage ne devait pas tarder à reparaître avec l'essor nouveau de la grande propriété. Les parèques dont il est question dans les actes, au XIV ${ }^{\mathrm{e}}$ siècle, bien que d'origine libre, sont

\footnotetext{
Nomos Georgikos, J.H.S., 97 et s.; St. Runciman, Byzantine Civilisation (éd. fr., 1934), 221 et $\mathrm{s}$.

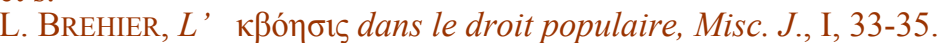

Nomos Georgikos, I.R.I., 64; FERRINI, dans B.Z, 1898, 558-571, $\mathrm{n}^{\circ} 78$.

Nomos Georgikos, I.R.I., 63; B.Z., 1898, n 32.

Ibidem, I.R.I., 25; L. BREHIER, loc. cit., 34.

Ibidem, I.R.I., 31; B.Z., 1898, 16.
} 


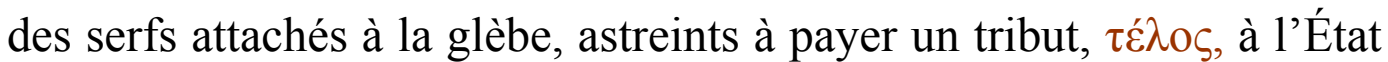
et soumis aux mêmes corvées que les esclaves ${ }^{827}$.

Les taxes paraissent proportionnelles aux lots et au cheptel dévolus à un parèque, mais il est difficile de retrouver la règle suivie pour l'établissement de ces impôts ${ }^{828}$.

$\mathrm{Au}$ village de Mamitzona, les lots ont une triple origine : $1^{\circ}$ par héritage : Léon, fils de Kalojoannès, possède un lot qui provient de son père et de son aïeul ; 21 par don $(\pi \alpha \rho \alpha \delta \delta ́ \sigma \varepsilon \omega \zeta)$ d'un propriétaire ; $3^{\circ}$ apporté en dot par une épouse ; Théophylacte a reçu d'une première femme un modius de vigne et d'un second mariage 5 modii $1 / 2$ de terres arables. Ces terres sont souvent tombées en déshérence ou restées en friche ${ }^{829}$. On voit aussi un parèque, Manuel Pandeios, acheter de Jean Vatatza 2 modii de vignes, ce qui montre que les serfs avaient le droit de posséder des biens en propre ${ }^{830}$.

Tous les témoignages de cette époque montrent le servage répandu dans tout l'Empire. Dans la région de Thessalonique, à côté des paysans grecs, il y avait beaucoup de Slaves et de Koutzovalaques. On distinguait les étrangers par le terme de $\pi \rho о р к \alpha \theta \eta \dot{\mu \varepsilon v o u . ~ C e r t a i n s ~ a c t e s ~}$ réservent le nom de parèques aux serfs des monastères exempts d'impôts et appellent douloparèques ceux des propriétés laïques ${ }^{831}$.

La vie paysanne. - Des miniatures $\mathrm{du}_{\mathrm{XI}}^{\mathrm{e}}$ siècle représentent les étroits corps de logis, avec toits à double versant et ouvertures minuscules, qui servaient de gîtes aux paysans ${ }^{832}$. Les témoignages les plus précis sur la maison paysanne sont les cabanes carrées, véritables cubes de pierres dont les murs latéraux supportent des dalles en guise de toiture, retrouvées dans les explorations du Hauran (Syrie centrale). A l'intérieur, une ou deux pièces au plus. Quelques maisons sur plan rectangulaire montraient à l'intérieur un arc médian de pierre, destiné à soutenir les dalles du toit. Il y avait aussi plusieurs maisons à un étage avec escalier de pierre à l'extérieur. Dans ce cas, le bas était réservé aux bestiaux et le haut à la famille ${ }^{833}$. Au $\mathrm{V}^{\mathrm{e}}$ siècle, certaines

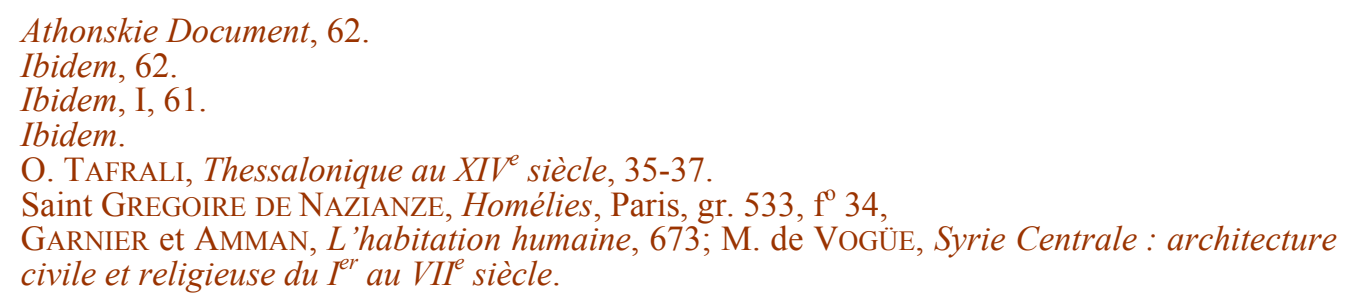


fermes syriennes, formant une agglomération autour d'une cour, possédaient une salle réservée au culte chrétien, appelée déjà la basilique ${ }^{834}$.

Malheureusement, ces témoignages ne concernent qu'un canton et une époque. La question de l'habitation rurale, à Byzance, n'a jamais été traitée et la superposition des races variées qui occupaient le sol augmente les difficultés.

Les actes du XIV ${ }^{\mathrm{e}}$ siècle énumèrent les familles qui habitaient ces pauvres demeures; en général, elles ne sont pas nombreuses et leur avoir est mince :

Exemple de tenure riche à Eunouchos sur le Strymon en 1318: Théophanès Alodoubinos et son épouse, Kali ; leurs deux fils, Mauropoulos et son épouse Marie, Sarakénos et son épouse Ennostia. Il faut probablement y ajouter des enfants en bas âge. Leur avoir consiste en 10 modii de vignes et un modius en jardin. Leur

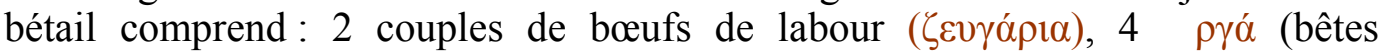
d'élevage), 2 cavales, 20 porcs, 120 moutons.

Exemple de tenure pauvre, dans le même village : la veuve Kodresa, sa fille Marie, son gendre Nicolas, sa petite-fille Anne. Avoir : 2 modii de vignes en 2 endroits, un jardin, un âne et une tête de bétail.

Le fisc taxe Aldoubinos à 7 hyperpères et Kodresa à la moitié d'une de ces monnaies ${ }^{835}$.

Plus rarement des cultivateurs habitaient des villes, lorsque leurs terres se trouvaient à proximité. A Thessalonique, au XIV siècle, l'archevêque Grégoire Palamas constate que les églises sont presque vides, car c'est la saison où les habitants sont occupés aux travaux des champs ${ }^{836}$.

Conditions du travail. — Sans parler des fléaux naturels : grêle ${ }^{837}$, épizooties, tremblements de terre, etc., le travail de la terre s'est heurté continuellement à de nombreux obstacles, dus à la situation politique et sociale de l'Empire. Dans beaucoup de régions, malgré l'organisation d'une police d'État, le brigandage était à l'état endémique. Des peintures de manuscrits montrent des laboureurs conduisant

\footnotetext{
J. LAssus, Sanctuaires chrétiens de Syrie, 25 et s.; voir ch. VIII, I. Actes de l'Athos, dans V.V., XVII, n ${ }^{\text {os }} 38$ et 39.

TAFRALI, Thessalonique au XIV siècle, 109.

GregoIRE DE NAZIANZE, Homélies or. XV (sur la grêle) et du même : Illustration du manuscrit Paris, gr, 510, f 78 a (D.A.C.L., VI, 1925, fig. 5421).
} 
des attelages de bœufs, attaqués par des brigands à cheval ${ }^{838}$. Ce sont des reproductions de faits véridiques.

$\mathrm{Au} \mathrm{IX}$ siècle et dans la première moitié $\mathrm{du} \mathrm{X}^{\mathrm{e}}$, c'était souvent l'émigration forcée devant les envahisseurs, raids arabes en Asie Mineure, pirates de la Méditerranée, qui obligeait les populations des îles à se réfugier sur le continent ${ }^{839}$. On peut même supposer que le trouble inévitable apporté dans la propriété du sol par ces exodes forcés, fut une des causes de la diminution de la petite propriété libre, qui se manifeste au XI siècle.

Enfin, dans la dernière période, celle de l'aggravation du sort des serfs, c'est la lourdeur des impôts qui pèsent sur la classe agricole, c'est l'âpreté du fisc, qui achève de ruiner l'agriculture. Dans une lettre à l'archevêque de Vidin, Théophylacte, archevêque d'Ochrida, se plaint de la conscription forcée d'un jeune garçon sur cinq, pour en faire un esclave ${ }^{840}$. "Les Comans, ajoute-t-il, infestent les campagnes, mais que sont-ils à côté de ceux de Constantinople, qui tombent sur nous, gens d'Ochrida?»

$\mathrm{Au} \mathrm{XIV}$ siècle, le mal avait empiré. Pendant la guerre civile des deux Andronic (1321-1328), les cultivateurs de la banlieue de Thessalonique furent dépouillés tour à tour par les deux partis. Les terres restèrent incultes et, en 1322, on ne put percevoir l'impôt ${ }^{841}$. Pour remettre leurs champs en culture et acquitter leurs impôts, les parèques durent faire des emprunts onéreux et devinrent la proie des usuriers, qui exigeaient des intérêts supérieurs à $12 \%{ }^{842}$. Un contemporain montre les biens saisis, les débiteurs pris à la gorge, traînés dans les rues à coups de bâton ${ }^{843}$. Lorsque, pendant la deuxième guerre civile, des bandes de Turcs parcoururent la Macédoine, les paysans se réfugièrent dans les villes, provoquant des épidémies qui contribuèrent à la propagation de la peste noire en $1348^{844}$.

H. Bordier, Peintures des manuscrits grecs de la Bibliothèque Nationale, 224 (Paris, gr. 74, $\mathrm{f}^{\mathrm{0}}$ 2223).

839 L. BREHIER, Les populations rurales au IX siècle, d'après l'hagiographie byzantine, 86.

840 THEOPHYLACTE, archevêque d'Ochrida, Correspondance, ep. XVI, 337.

841 Jean CANTACUZENE, Histoire, I,28; TAFRALI, Thessalonique, des origines au XIV siècle, 103.

842 TAFRALI, op. cit., 112-116.

843 Ibidem, 113; DEMETRIUS KYDONES, Correspondance (éd. Cammelli), 33 et s.

844 TAFRALI, op. cit., 103; Jean CANTACUZENE, IV, 9. 


\section{Les travaux des champs}

Les traités d'agriculture des anciens furent plusieurs fois l'objet de traductions et de compilations, mais n'eurent aucune influence sur la pratique ${ }^{845}$. Celle-ci, remontant à une tradition millénaire, resta toujours très primitive. Nos renseignements proviennent surtout de sources figurées, en particulier des peintures de manuscrits et de quelques ivoires. Ces figurations reproduisent souvent des modèles antiques qui avaient cessé d'être usités. D'autres, au contraire, ont des traits caractéristiques de l'époque où la peinture fut exécutée. Telles sont par exemple, dans l'illustration des Octateuques, les miniatures figurant le partage de la Palestine entre les tribus d'Israël ${ }^{846}$.

La culture. - Un manuscrit du poème d'Hésiode, Les Travaux et les Jours, datant du XIV ${ }^{\mathrm{e}}$ siècle, reproduit, dessinés à la plume, quelques instruments aratoires: la charrue ( $\mu \alpha \xi \alpha \varsigma)$, la faucille

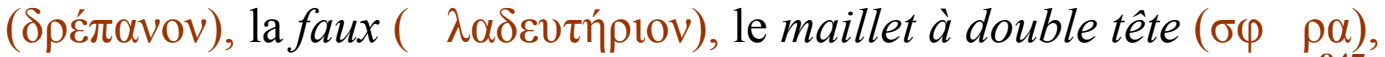
le plantoir ( Sur des miniatures et des coffrets d'ivoire, Adam, chassé du Paradis, tient un hoyau à deux dents, symbole de sa condamnation au travail de la terre ${ }^{848}$.

Plusieurs peintures de manuscrits montrent le costume sommaire des paysans: la tunique longue, parfois sans manches, serrée à la taille, plissée sur le devant ; une courte pèlerine, attachée par un gros nœud, couvre les épaules; les jambes sont garnies de chausses, aux pieds des souliers sans talons et la tête nue ${ }^{849}$. Quand il pousse la charrue, le travailleur n'est vêtu que d'une légère tunique sans manches, sur laquelle est passée une casaque fendue des deux côtés comme le scaramange ${ }^{850}$.

\footnotetext{
Geoponika; liste dans KRUMBACHER, Geschichte den byzantinischen Literatur, 261 et s. L'Octateuque du Sérail à Constantinople, pl. XLI, 264-269. BORDIER, op. cit., 259 (Paris, gr. 2786, fo 140).

Saint GREGOIRE DE NAZIANZE, $\mathrm{f}^{\mathrm{o}} 52 \mathrm{v}^{\mathrm{o}}$; L. BREHIER, Le coffret byzantin de Reims et les coffrets d'ivoire à rosettes, 272 (planche).

Saint Gregoire DE NAZIANZE, f $17 \mathrm{v}^{\mathrm{o}}$; BORDIER, op. cit., fig. 17.

50 SChlumberGer, L'Épopée byzantine, I, 517 (Paris, gr. 533, f ${ }^{\mathrm{o}}$ 34, $\mathrm{XI}^{\mathrm{e}}$ siècle).
} 
On assiste de même aux principales opérations agricoles. C'est d'abord le défrichage: des travailleurs abattent des arbres, d'autres cherchent à en extirper les racines, d'autres, détail précieux, creusent des trous et se préparent à y enfoncer de grosses bornes de propriété, en forme de colonnes avec chapiteaux ${ }^{851}$.

Les scènes de labourage sont nombreuses. La charrue représentée est toujours l'araire, bien que la charrue à roues fût déjà connue des Romains. L'araire figuré dans les peintures consiste en une tige recourbée, attachée au joug de l'attelage, à laquelle sont fixés le soc et le manche que tient le laboureur ${ }^{852}$. L'araire est encore très usité, non seulement en Orient, mais en France : en Auvergne et dans le Midi. De l'avis d'un spécialiste, le travail de l'araire n'est pas inférieur à celui des charrues à roues: il est seulement plus difficile à conduire ${ }^{853}$.

L'initiale $\mathrm{H}$ d'un manuscrit des homélies de saint Jean Chrysostome est faite de deux jeunes gens entièrement nus, sauf un pagne de mousseline blanche. Chacun d'eux puise d'une main dans un sac et sème le grain ${ }^{854}$.

La moisson est plus rarement figurée. Sur l'Octateuque du Sérail, deux paysans en longue tunique cueillent les épis dans un champ de blé ${ }^{855}$. Un coffret d'ivoire de la collection Morgan (New York) montre Adam, vêtu d'une tunique à col brodé, coupant le blé avec une faucille; à droite, Ève, en vêtement plus long, porte une lourde gerbe sur ses épaules ${ }^{856}$.

Pour le dépiquage du blé, on peut supposer que les Grecs du moyen âge se servaient du même instrument préhistorique que leurs prédécesseurs et même leurs successeurs des temps modernes. Il consiste en un traîneau allongé, armé sur sa face inférieure de pointes

L'Octatenque du Sérail à Constantinople, pl. XLI, 264, 266 et 269.

SCHLUMBERGER, op. cit., I, pi. xi, 27; BORDIER, op. cit., 275 ( $\mathrm{XV}^{\mathrm{e}}$ siècle).

Charrue entièrement en bois, sauf une pointe de fer, vue à La Banne-d'Ordanche, Puy-deDôme (Jean Caudron, ingénieur agricole).

${ }^{854}$ Paris, gr. 806, fo $67 \mathrm{v}^{\mathrm{o}}, \mathrm{XII}^{\mathrm{e}}$ siècle; BORDIER, 193.

855 L'Octateuque..., pl. XXXII, 205, 1.

${ }^{856}$ E. MOLINIER, Histoire générale des arts appliqués à l'industrie, I (Ivoires), pl. IX bis, p. 106; SCHLUMBERGER, op. cit., II, 280 et s 
de silex disposées en quinconces. Le blé est étendu sur une aire circulaire au sol durci. Une paire de bœufs tire l'instrument sur lequel le conducteur se place debout pour en augmenter le poids. Cet attelage tourne en rond plusieurs heures; la foulée des animaux et le sciage des épis provoquent le dépiquage. Cet instrument, dont on trouve la

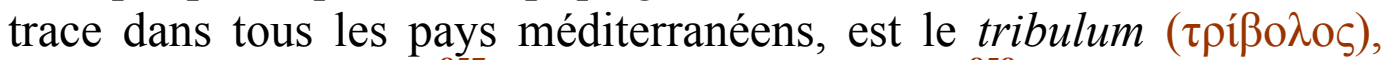
bien connu des Grecs ${ }^{857}$ et des agronomes latins ${ }^{858}$.

Le travail de la vigne, la taille des arbres fruitiers figurent aussi dans les peintures ${ }^{859}$. Les vendanges donnaient lieu à de grandes fêtes, vestiges du culte bachique. Nous avons mentionné ailleurs la fête officielle que présidait l'empereur à cette occasion ${ }^{860}$. Dans ces pays à faibles précipitations, l'entretien des jardins et des vergers était un souci continuel. Pour peu qu'ils fussent négligés, ils étaient rapidement envahis par le désert, comme on en vit des exemples en Egypte au IV ${ }^{\mathrm{e}}$ siècle ${ }^{861}$.

L'élevage. - Les pâturages tenaient une place considérable dans l'économie agricole de Byzance. Jusqu'à l'occupation turque, l'Asie Mineure était renommée comme terre d'élevage et l'on sait qu'elle était le principal centre de remonte de la cavalerie impériale. On trouvait aussi de magnifiques régions d'élevage dans les hautes vallées de la péninsule des Balkans, parcourues par les immenses troupeaux de ces Valaques, Bulgares et Comans, qui soulevèrent un scandale sous Alexis Comnène, à cause de leurs rapports avec les moines de l'Athos, et dont la révolte contre les mesures fiscales d'Isaac l'Ange fut à l'origine du soulèvement vlacho-bulgare de 1186 .

C'était donc une population de nomades répandue en Macédoine, dans les massifs du Rhodope et des Balkans. Ils pratiquaient la transhumance, d'où de nombreuses difficultés avec les propriétaires dont ils traversaient les terres. Pour l'été, des bergeries ( $\mu \alpha v \delta \rho \alpha i$ ) étaient installées à proximité des pâturages et des forêts par les grands propriétaires et par l'État et, moyennant une dîme, les pâtres pouvaient

\footnotetext{
Anthologie grecque, I, Anthologie Palatine, t. VI, 104 ( $\mathrm{1}^{\mathrm{er}}$ siècle après J.-C.).

VARRon, De re rustica, 1, 52; VIRGILE, Géorgiques, I, 164; LUQUET et RIVET, Sur le tribulum, M.I., 613-631.

SChluMBERGER, op. cit., I, 473 (Tétraévangile, Paris, gr. 74, XI ${ }^{\mathrm{e}}$ siècle).

860 M.B.E.H. (Institutions), éd. 1970,71 et s.

${ }^{861}$ Papyrus de Théadelphie (éd. Jouguet); Paris, gr. 533, fo $34 \mathrm{v}^{0}$ (Grégoire de Nazianze, BORDIER, Peintures des manuscrits, 143).
} 
s'y loger avec leurs familles et faire paitre librement leurs troupeaux $^{862}$.

On peut constater que les chiffres fabuleux donnés par les sources sur l'importance des troupeaux, comme les dix mille brebis que Thomas, chef du village de Lykandos, aurait données à Justinien ${ }^{863}$, proviennent souvent du souvenir du patriarche Job, dont les imaginations étaient hantées. Un tableau du commentaire d'Olympiodore sur le $L i$ vre de Job représente en quatre compartiments des brebis, des ânesses, des chamelles avec un chamelier en turban et burnous blanc, des génisses ${ }^{864}$. Sous l'influence de l'Évangile, le métier pastoral était idéalisé et avait accès dans l'art religieux, comme le montrent l'admirable Bon Pasteur du mausolée de Galla Placidia à Ravenne, le David gardant ses troupeaux du Psautier de Paris, et les innombrables figurations des bergers de la Nativité. Les illustrations de certains manuscrits reproduisent les mêmes thèmes, mais d'une manière plus simple et plus proche de la réalité ${ }^{865}$.

Un tableau, d'un accent tout à fait idyllique, représente dans un manuscrit d'Oppien la fin d'une journée de travail : au premier plan, le maître, baguette en main, surveille ses travailleurs; deux valets déchargent un char de blé, un autre dételle les bœufs, un garde-chasse tire un lièvre de la gueule d'un chien ${ }^{866}$.

Les méthodes d'élevage étaient souvent des plus sommaires. Les porcs paissaient en liberté. Le futur ascète de l'Olympe de Bithynie, Joannice le Grand, originaire du village de Marykatos, fils de Myritziko et d'Anastaso, gardait les porcs à l'âge de sept ans. Il les poussait au pâturage en faisant sur chacun d'eux le signe de la croix, puis les laissait errer à l'aventure. Ils revenaient d'eux-mêmes à l'étable et jamais il n'en perdit un seul ${ }^{867}$.

L'empereur Michel le Bègue, d'une famille très modeste d'Amorium, Phrygie supérieure (820-829), avait appris toute une série de recettes empiriques en grande faveur dans les campagnes :

\footnotetext{
G. Rouillard, La dime des bergers vainques sous Alexis Comnène, M.I., 779 et s.

Voir supra, p. 143.

BORDIER, op. cit., 235 (Paris, gr. 135, $\mathrm{f}^{\circ} 8 \mathrm{v}^{\mathrm{o}}$ ), a. 1368.

SCHLUMBERGER, op. cit., I, 513, 517.

BORDIER, 275 (Paris, gr. 2736, $\mathrm{f}^{\mathrm{o}} 15 \mathrm{v}^{\mathrm{o}}$ ), $\mathrm{XV}^{\mathrm{e}}$ siècle.

Vie de saint Joannice le Grand, 332; LOPAREV, Vizantiiskiia Jitii Sviatuik, XVIII, 91; L. BREHIER, Les populations rurales au IX siècle, d'après l'hagiographie byzantine, 183.
} 
Recettes pour empêcher les chevaux et les ânes de lancer des ruades, pour savoir si un petit cochon deviendra gras ou maigre, quelles vaches, quelles brebis deviendront fécondes et donneront de bon lait. Il reconnaissait à première vue les mulets aptes à porter des fardeaux et ceux qui étaient bons pour la selle, les chevaux propres à la course ou à la réquisition pour l'armée ${ }^{868}$.

Un autre élevage fructueux et très répandu était celui des abeilles, comme le montre l'exemple de saint Philarète ${ }^{869}$. Des peintures de manuscrits représentent des ruches en forme de petites cabanes peintes en jaune, à toit cylindrique, avec de petites fenêtres par devant, au milieu des arbustes ${ }^{870}$.

Charrois et attelages. - Les transports nécessaires au travail de la ferme étaient faits dans des charrettes attelées de bœufs sous le joug, conduits à l'aiguillon. L'absence de ferrure enlevait au bœuf sa supériorité de traction sur le cheval ${ }^{871}$. Ces charrois étaient nombreux : au $\mathrm{XI}^{\mathrm{e}}$ siècle, de nombreuses charrettes amenaient à Rodosto, centre du commerce des céréales, le blé, vendu dans les charrettes mêmes ${ }^{872}$. Un équipage de ce genre figure dans l'Octateuque du Sérail ${ }^{873}$.

On sait que le commandant Lefebvre des Noettes a montré l'infériorité du rendement de l'attelage antique, dû surtout au collier souple qui cravatait l'encolure du cheval et le forçait, pour avancer, à tirer sur ce collier par la gorge, " comme un chien sur sa laisse ». De plus, les chevaux étaient attelés de front et les ferrures, connues déjà en Occident, ne furent pas adoptées à Byzance avant le $\mathrm{IX}^{\mathrm{e}}$ siècle : la persistance de l'esclavage serait due à ce mode primitif d'attelage ${ }^{874}$. Dans les transports de la poste publique, au $\mathrm{V}^{\mathrm{e}}$ siècle, le poids maximum que pouvait charger une voiture était fixé à 1500 livres, soit 492 kilogrammes, chiffre dérisoire ${ }^{875}$.

Si justes que soient ces observations, les conclusions appellent certaines réserves. L'attelage en file n'était pas ignoré des anciens

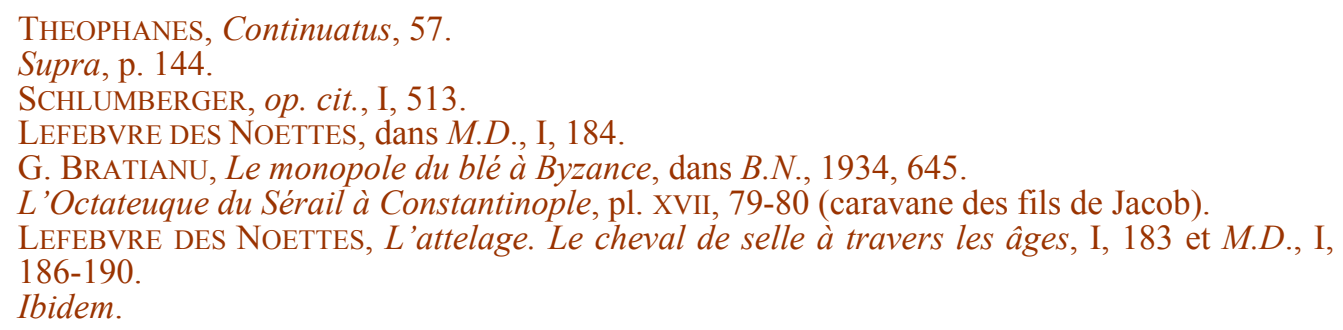


Grecs : au moins pour le transport des gros matériaux, l'attelage était composé de couples de chevaux disposés en files ${ }^{876}$. A Byzance, on ne voit pas que les esclaves aient été jamais employés à la traction. C'est avec un attelage de 60 bœufs qu'en 1453 Mahomet II fait transporter son canon géant d'Andrinople à Constantinople.

De l'aveu même de Lefebvre des Noettes, à partir du VIII siècle, les peintures byzantines d'attelage accusent quelques perfectionnements, dont le résultat est de dégager légèrement le cou du cheval ${ }^{877}$.

Cheval de selle. - Jusqu'au $\mathrm{IX}^{\mathrm{e}}$ siècle, les monuments figurés montrent le maintien du harnachement antique, composé uniquement du tapis sanglé et du mors de bridon. L'étrier et la selle, originaires de Chine, se répandent en Perse et sont adoptés par les Arabes, puis par Byzance ${ }^{878}$. La ferrure à clous apparaît en Occident et à Byzance au $\mathrm{IX}^{\mathrm{e}}$ siècle, comme le montre une peinture d'un manuscrit biblique ${ }^{879}$. De plus, la Tactique de Léon VI mentionne l'étrier et la ferrure à clous dans l'équipement du cavalier ${ }^{880}$.

Outillage. La forge. — La forge était le complément de l'outillage agricole et elle figurait parmi les travaux imposés à Adam et Eve après la chute. C'est sur les coffrets d'ivoire du $X^{\mathrm{e}}$ siècle qu'elle est représentée le plus souvent. Eve, assise ou à genoux, manie les soufflets qui correspondent à un fourneau maçonné, à côté duquel Adam, vêtu en paysan, frappe à coups de marteau sur une enclume, en tenant un objet avec une longue pince ${ }^{881}$.

Moulins hydrauliques. - Enfin le moulin à eau, bien connu des anciens depuis Mithridate ${ }^{882}$ et décrit exactement dans une épigramme d'Antipater de Thessalonique (époque de l'ère chrétienne) ${ }^{883}$, n'était pas non plus ignoré à Byzance. Cédrénos raconte que, sous Constantin le Grand, le Perse hellénisé Métrodore fit un

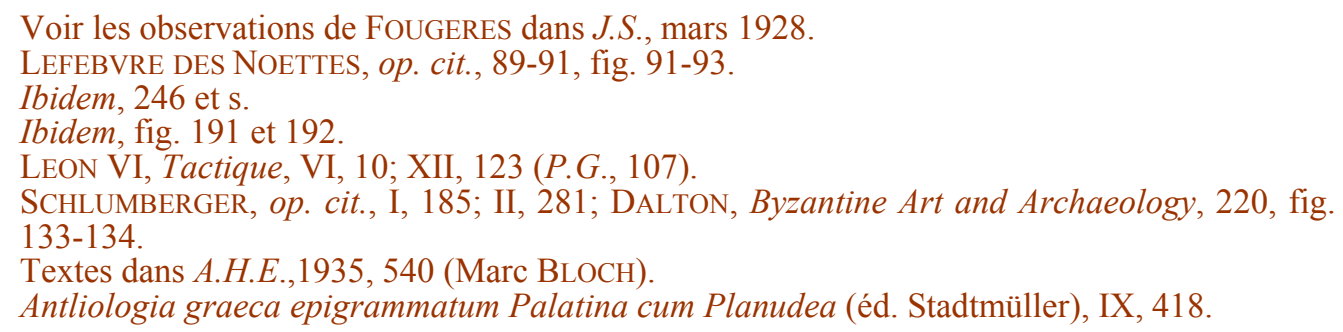


voyage dans l'Inde et y construisit des moulins à eau, jusque-là inconnus des brahmanes ${ }^{884}$.

Les témoignages décisifs sur l'emploi du moulin à eau à Byzance se trouvent dans les typika et actes de fondation d'hospices ou de monastères. Ils confirment l'observation de Marc Bloch sur l'utilisation de ces moulins, à l'origine, pour nourrir un personnel nombreux, sans que les autres méthodes de broyage aient disparu ${ }^{885}$.

Le typikon de Grégoire Pakourianos pour le monastère de Pétritzos et l'hospice de Sténimachos (Macédoine), rédigé en 1083, prévoit un moulin hydraulique pour l'hospice ; il sera surveillé par un parèque affranchi de toute servitude, et placé parmi les moulins impériaux et privés qui se trouvent déjà à Sténimachos. Le typikon prévoit en même temps l'établissement de moulins mus par des animaux ${ }^{886}$.

Comme l'a montré Marc Bloch, la conséquence économique de l'adoption du moulin à eau fut une nouvelle spécialisation. Jusque-là le pistor était à la fois broyeur (meunier) et boulanger : désormais les deux professions sont distinctes. D'autre part, pour la première fois, la traction animale est remplacée par un engin mécanique ${ }^{887}$.

\section{La chasse}

$\underline{\text { Retour à la Table des Matières }}$

Sur un coffret d'ivoire du musée de Reims on voit un chasseur, la tunique retroussée, tenant d'une main un lièvre par les pattes, de l'autre, sur l'épaule, un bâton auquel est emmanchée une hure de sanglier. L'homme rentre sans doute au logis, la figure rieuse, exprimant la joie causée par une bonne journée de chasse ${ }^{888}$.

La chasse était en effet le principal plaisir de toutes les classes de la société byzantine, l'agrément par excellence qu'offrait la campa-

\footnotetext{
884 Georges Cedrenos, Synopsis, P.G., 562.

885 Marc BLOCH, loc. cit., 553.

886 Typikon de Grégoire Pakourianos (Monastère de Petritzos), éd. L. Petit, 13, 48.

A.H.E., 1935, 542.

L. BREHIER, Le coffret byzantin de Reims..., 272.
} 
gne. On a pu voir déjà le temps que les empereurs y consacraient ${ }^{889}$, mais ce goût était répandu à Byzance dans tous les milieux, depuis les paysans jusqu'aux plus grands seigneurs. Sans parler des monuments figurés, il existe toute une littérature cynégétique qui donne les renseignements les plus complets sur les usages et les pratiques des $\mathrm{Ne}-$ mrods de Byzance ${ }^{890}$.

Engins et appeaux. - Les moyens les plus modestes sont ceux qu'emploient les paysans pour prendre le gibier au piège. Une peinture de manuscrit montre une sorte d'équivalent de notre chasse au gabion dans les terrains marécageux. Sous une tente, un chasseur étendu sur un lit, gouverne son piège au moyen d'un long fil, qui se déroule entre des cages pleines d'oiseaux destinés à servir d'appât ${ }^{891}$. On employait comme piège un filet à l'embouchure étroite ${ }^{892}$. On connaissait aussi la chasse aux appeaux pour prendre des oiseaux chanteurs au moyen de branches d'arbre enduites de glu, et de cages d'oiseaux destinés à attirer leurs congénères ${ }^{893}$.

Équipages de chasse. - Les grands propriétaires et les princes entretenaient de coûteux équipages comprenant des piqueurs et valets de chiens, esclaves ou libres, dont plusieurs spécialistes, comme le skopeus (бколєús), chargé de dépister le gibier, comme les rabatteurs,

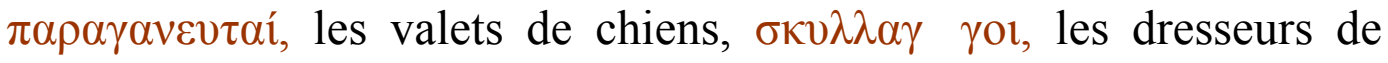

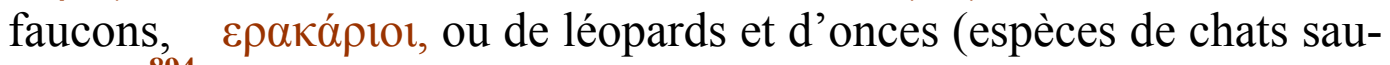
vages) ${ }^{894}$.

La chasse aux oiseaux rapaces, faucons, éperviers, aigles, milans, etc., bien connue des Grecs et des Romains, était très usitée à Byzance. Des ouvrages, sur leur élevage et leur emploi, étaient rédigés par des spécialistes, comme Constantin Manassès, auteur d'une description de la chasse aux grues à l'aide de faucons ${ }^{895}$. Les fauconniers portaient l'oiseau sur le poing gauche et, pour se garantir de leurs griffes, avaient des gants de peau, protégeant la main et le coude. Les pat-

\footnotetext{
Ch. III, p. 62-63.

Koukoules, Chasses de l'époque des Comnènes et des Paléologues, 5 et s. (bibliographie). SCHLUMBERGER, op. cit., 1, 513; KOUKOULES, op. cit., 12 et s.

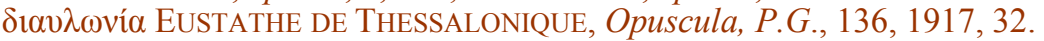

KoukOules, 12 et s.; Bordier, Peintures des manuscrits grecs..., 272.

KOUKOULES, 5 et $\mathrm{s}$.

MANASSES, $\quad \kappa \varphi \rho \alpha \sigma 1 \varsigma \kappa v v \eta \gamma \varepsilon \sigma i ́ o v ~ \gamma \varepsilon \rho \alpha ́ v \omega v$, chasse au faucon, éd. Kurtz (écrit vers 1170, d'après une allusion à une ambassade égyptienne sous Manuel Comnène.
} 
tes de l'oiseau, munies de clochettes, étaient attachées par des courroies passées sous les doigts du chasseur ${ }^{896}$. On l'employait beaucoup pour la chasse aux perdrix. Le chasseur à l'affût imitait le chant des perdrix, que les rabatteurs faisaient sortir de leurs gîtes. Le fauconnier lâchait l'oiseau, qui lui rapportait son gibier, mais, tout en le flattant, il lui abandonnait la tête du volatile, qu'il coupait avec son épée ${ }^{897}$. La chasse au faucon était tellement populaire que les enfants eux-mêmes y étaient initiés. Le futur apôtre des Slaves, Constantin, avait un faucon avec lequel il chassait les petits oiseaux : un jour, le faucon lâché fut emporté par un vent violent et ne revint plus ; l'enfant fut si désolé qu'il ne mangea pas de deux jours ${ }^{898}$.

Les perdrix étaient aussi chassées à l'arc et avec des chiens courants. Pour les lièvres, on employait en même temps chiens et faucons et on les chassait parfois à cheval ${ }^{899}$. Le renard était chassé pour sa peau. Les cerfs, les daims, les gazelles, les sangliers étaient nombreux dans la péninsule des Balkans. On trouvait encore des ours en Asie Mineure et dans la région de l'Olympe de Macédoine ${ }^{900}$.

Les chiens de chasse se divisaient en chiens courants et en limiers. Les chiens de Crète étaient renommés pour leur flair, ceux de l'Inde, de très grande taille, pour la chasse au gros gibier ${ }^{901}$. On faisait venir des chiens étrangers et l'on voit un familier de l'empereur Jean VIII demander des chiens de grande taille au roi d'Aragon Ferdinand en $1426^{902}$. On dressait aussi des chevaux pour la chasse à courre. A la veille de la prise de Constantinople, le mégaduc Lucas Notaras fait cadeau à son fils de trois chevaux habitués à suivre les chemins les plus difficiles ${ }^{903}$.

Ordre d'une grande chasse. - Les chasseurs, vêtus d'habits courts, la tête nue ou coiffée d'un bonnet conique, partent avant le lever du soleil. Leurs armes sont l'arc, avec le carquois garni de flèches en bandoulière, une épée ou un poignard à la ceinture, souvent un

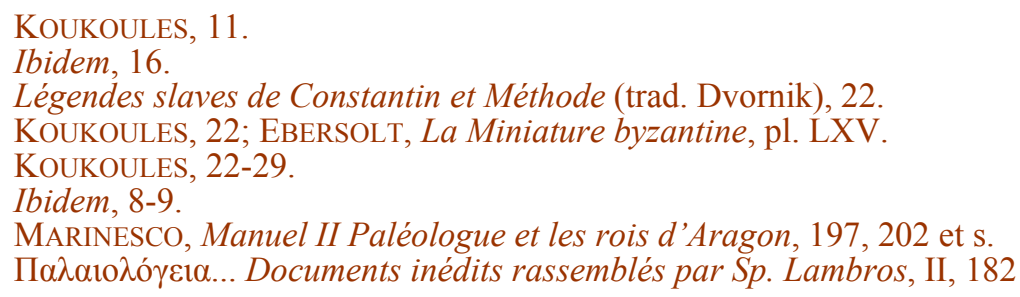


fouet ou une verge, parfois une massue, une hache ou un épieu et un filet sur les épaules ${ }^{904}$. Parvenus au rendez-vous, ils se rangent en ordre et en silence. Un épopte (inspecteur) muni d'une baguette veille au bon ordre. Tantôt ils se placent en rang à de courts intervalles; parfois ils forment un cercle où l'on pousse le gibier, ou ils se divisent en quatre groupes pour cerner leurs proies et modifient l'ordre suivant les circonstances.

La pêche. - La vie des pêcheurs ne nous est connue que par des lois ou par des érudits, tels que Tzetzès et autres, qui emploient des termes antiques pour rapprocher les usages antiques des méthodes de pêche et des engins de leur temps: les barques, les filets garnis de liège, parfois disposés sur des pieux dans la mer, et la pêche nocturne des crustacés au harpon, à la lueur des torches. La place tenue, comme on l'a vu, par les poissons dans l'alimentation byzantine, montre que la pêche devait être un métier fructueux. Les pêcheurs formaient des corporations sous le patronage des saints Phocas et Georges, protecteurs des matelots ${ }^{905}$.

Koukoules, 6 et s.; EBersolt, op. cit., pl. LXVI, 2 (costume des chasseurs); Bordier, Peinture des manuscrits grecs de la B.N., 272 et s., fig. 450.

905 KoukOULES dans E.B., 1948, 28 et S.; LEON VI, empereur, Novelles, nov. 56 (212); H. MonNIER, Les novelles de Léon le Sage, 121; Paris, gr. 533 (Grég. de Naz., $\mathrm{X}^{\mathrm{e}}$ siècle), $\mathrm{f}^{\mathrm{O}}$ 84; SCHLUMBERGER, L'Épopée byzantine, I, 513, 517. 


\section{Chapitre VII}

\section{L'industrie et le commerce}

\section{Retour à la Table des Matières}

Sans revenir ici sur la doctrine économique qui régnait à Byzance ${ }^{906}$, rappelons seulement que l'industrie et le commerce étaient étroitement contrôlés par l'État, qui réglementait, fabriquait, achetait, vendait ${ }^{907}$, se réservait des monopoles, surveillait les entreprises privées. L'État exigeait la bonne qualité de la fabrication et en fixait la quantité ainsi que le prix.

Ce dirigisme n'avait pas, comme aujourd'hui, un but de rationnement. La préoccupation des empereurs était surtout d'assurer le ravitaillement de Constantinople, l'approvisionnement des ateliers du Palais en matières premières, de refréner la cupidité des marchands et de faire rentrer le plus d'argent possible dans les caisses de l'État.

Comme l'a fait remarquer Georges Bratianu, ce régime a vécu tant que le pouvoir central a été fort. Quand il s'est affaibli, le marché libre a prédominé et les monopoles ont disparu, jusqu'au jour où ils ont été concédés à des colonies étrangères, qui ont ruiné l'État byzantin ${ }^{908}$. C'est à partir des Comnènes que ce recul de l'économie dirigée devient de plus en plus sensible.

Nous ne reviendrons pas sur ces faits, mais nous chercherons à montrer ce que furent la vie industrielle et le commerce sous ces différents régimes, la monnaie, instrument des échanges, les routes du grand commerce, les techniques industrielles, en un mot la vie byzantine sous son aspect économique. 


\section{Des origines aux conquêtes arabes}

La doctrine étatiste, héritée de Dioclétien, a régné sans beaucoup de résistance jusqu'à la fin du $\mathrm{XI}^{\mathrm{e}}$ siècle. La principale cause de sa durée est la persistance de la monnaie saine pendant huit cents ans. Depuis la réforme de Constantin jusqu'au règne d'Alexis Comnène, le sou d'or de Byzance faisait prime sur les marchés internationaux. A Ceylan, au VI ${ }^{\mathrm{e}}$ siècle, il était préféré à la monnaie perse ${ }^{909}$.

La monnaie. - Le système monétaire de Byzance datait de Constantin, qui supprima la monnaie d'argent dépréciée et adopta le monométallisme or ${ }^{910}$. L'unité courante fut le sou d'or (solidus aureus, vó $\mu 1 \sigma \mu \alpha)$ qui pesait 4 grammes 52 à 61 centigrammes. On en taillait 72 à la livre d'or, $\lambda i ́ \tau \rho \alpha$, monnaie de compte, qui représenterait en poids 327 grammes ${ }^{911}$. Dans les gros paiements, les sommes étaient évaluées en livres ou en kentenaria (100 livres).

Le rapport de l'or à l'argent était de 13,71 à la fin du IV ${ }^{\mathrm{e}}$ siècle. La livre d'or valait 1000 pièces d'argent ou miliaresia. Le miliaresion pesait 2 grammes 24 et représentait 12 fois moins que le sou d'or. Il y avait aussi en circulation le keration d'argent, qui valait la moitié d'un miliaresion ${ }^{912}$.

Constantin avait établi aussi un rapport précis entre le follis, monnaie de cuivre, et les monnaies d'argent, mais on fabriqua trop peu de pièces de cuivre et de mauvaise qualité, sans marque de valeur. D'où la réforme d'Anastase en 498 : il fit frapper de larges folles de bronze, marqués $M$ et valant 40 sesterces (obole), ainsi que de petites pièces de 20,30 et 5 sesterces ${ }^{913}$.

909

ANDREADES, De la monnaie et de la puissance d'achat des métaux précieux dans l'Empire byzantin, 81 (d'après KOSMAS INDIKOPLEUSTES, Topographie chrétienne, 148).

F. Lot, La fin du monde antique et le début du Moyen Age, éd. 1968, p. 105-106. Valeur en poids d'or, monnaie française avant 1914 : à peu près $15 \mathrm{f} 61$; ANDREADES, op. cit., 75. ANDREADES, 75.

Ibidem, 80-81; F. Lot, op. cit., 105 et s.; C.Th., XIII, 2, 1 (397), VIII, 4, 27 (422); CONDURACHI, Le prix de l'or au début du Ve siècle dans R.S.E., 1942, 419 et s.

OstrogOrSKY, Geschichte des byzantinischen Staates, 39 J. B. BURY, History of the later Roman Empire, I, 446; ANDREADES, op. cit., 79 et s.; MARCELlinUs COMES, Annales, (éd. Mommsen), 498; Jean MALALAS, Chronographie, XVI, 400. 
Dans les paiements, les sous d'or n'étaient pas comptés, mais pesés, car beaucoup étaient rognés et l'industrie des peseurs d'or était lucrative ${ }^{914}$. Bien qu'il y ait eu sous Justinien une crise économique en Égypte, les découvertes ont montré que la frappe de ses monnaies avait été abondante, ce qui suppose un commerce florissant. Procope semble l'accuser à tort d'avoir altéré les monnaies, car les sous d'or à son effigie qui ont été découverts ne justifient nullement cette accusation ${ }^{915}$.

Commerce d'Extrême-Orient. - Depuis l'époque alexandrine, le commerce le plus lucratif était celui du Levant ; son importance s'était accrue encore à Byzance au $\mathrm{VI}^{\mathrm{e}}$ siècle, où, plus que jamais, on recherchait ses articles de luxe, dont les deux principaux étaient les épices et la soie. Des marchands audacieux, qui, par terre ou par mer, cherchaient à atteindre les marchés de l'Arabie, de l'Inde, de la Chine, ou à s'en rapprocher le plus possible, risquaient beaucoup pour gagner beaucoup ${ }^{916}$.

$\mathrm{Au} \mathrm{VI}$ e siècle, Constantinople avait succédé à Alexandrie et à Antioche comme principal entrepôt des marchandises d'Orient. La soie y parvenait sous forme de soie grège ou de pièces d'étoffes, qui alimentaient les ateliers du Palais et le commerce d'exportation.

C'était aussi à Constantinople qu'était concentré le commerce des épices : poivre, cannelle, clou de girofle, etc., très employés dans la pharmacopée et aussi monnaie d'échange avec les Barbares ${ }^{917}$. Après le premier siège de Rome par Alaric en 408, parmi les articles exigés pour la rançon de la ville, figuraient 3000 livres de poivre ${ }^{918}$. D'autre part, ces produits, regardés comme venus de pays merveilleux, permettaient aux empereurs de faire des dons aux chefs barbares et aux églises des pays étrangers ${ }^{919}$.

Des $\chi \rho v \sigma \omega v \varepsilon \varsigma$ estampillaient les lingots d'or. DiEHL, Une crise monétaire au VI siècle, dans R.E.G., 1919, 158-166.

915 PROCOPE DE CESAREE, Anecdota, 22-25; BURY, History of the later Roman Empire, II, 357.

916 D. C. Hesseling, Essai sur la civilisation byzantine, 61.

917 Ibidem, 59.

918 ZOSIME LE DiACre, Pèlerinage, V, 41; SOZOMEne, Histoire ecclésiastique, IX, 6.

919 DIEHL, Justinien et la civilisation byzantine..., 534; HEYD, Histoire du commerce du Levant, I, 18. 
Route terrestre de la soie. - Dès l'époque romaine, un négociant macédonien, Maes Titianos, avait reconnu les étapes de cette route et envoyé ses agents à Kachgar, dans l'oasis du Tarim, principal entrepôt de la soie ${ }^{920}$. C'était là qu'arrivaient les caravanes venues de Si-nganfou. Du côté occidental les caravanes partaient d'Antioche, passaient l'Euphrate à Hiérapolis (Mabough), traversaient le territoire des Parthes par Ecbatane (Hamadan), Rhagès (près de Téhéran), Hékatompylos, l'oasis de Merv, Bactrès, et gagnaient le Pamir, au pied duquel se trouvait la Tour de pierre. Là se faisaient les échanges entre caravanes chinoises et occidentales. A Kachgar la route bifurquait, au nord par Issedon Scythica (Koutcha), Issedon Serica (Leou-lan) et la porte de Daxata (Yu-men-Kouan), au sud, par Yarkand, Khotan, Miran; puis les deux routes se rejoignaient à Throana (Touen-houang). Les caravanes pénétraient alors en Chine et atteignaient Sera Metropolis ( $\mathrm{Si}$ ngan-fou) et Saraga ou Thinae (Lo-yang, Honan-fou) ${ }^{921}$.

On peut supposer quel temps mettaient les pièces de soie parties de Si-ngan-fou pour arriver jusqu'à Antioche. Les difficultés étaient considérables. Les caravanes devaient traverser de grandes étendues désertiques et franchir les plus hautes montagnes de l'Asie, le ThianChan, le Pamir, l'Himalaya. Une curieuse expérience en a été faite de nos jours. En 1931, l'expédition Audouin-Dubreuil, organisée par la maison Citroën, se proposa de suivre la route millénaire de la soie. Partie de Beyrouth en avril 1931 avec un équipement des plus perfectionnés, elle mit un an, un mois et 23 jours pour atteindre Pékin, le 12 février 1932, après avoir fait près de 11000 kilomètres, dont 6000 en territoire chinois ${ }^{922}$. Sous Justinien les caravanes mettaient 150 jours, de la Chine à la frontière perse et 80 , de cette frontière à celle de Byzance $^{923}$.

La monarchie sassanide, en effet, traversée par les caravanes, n'avait pas tardé à s'emparer du monopole de la vente de la soie, qui lui arrivait par les oasis de Sogdiane (Boukhara, Samarcande), où s'arrêtaient les caravanes chinoises. Plusieurs villes-frontières entre

920

R. Grousset, L'empire des Steppes, 79 (d'après Ptolémée citant Maxime de Tyr); J. DAHLMANN, Die Thomas Legende... (plus anciens rapports du christianisme avec l'Inde), 72. GROUSSET, op. cit., 78-80.

AudouIn-DuBREUIL, Sur la route de la soie (Carnet de route de la Méditerranée à la mer de Chine). A Sinagar, avant la traversée de l'Himalaya, l'expédition dut abandonner les automobiles et les chenilles pour repartir à cheval et en caravane.

DIEHL, Justinien..., 535. 
Byzance et la Perse avaient été désignées pour le marché de la soie : au sud Callinicum sur l'Euphrate, au centre Nisibe, au nord Artaxarta et probablement Doubios. C'était là que se rencontraient les marchands perses, hindous et byzantins. De plus, les Perses s'ingéraient aussi dans les transports maritimes en dirigeant les ballots de soie sur le golfe Persique, où ils étaient embarqués pour Alexandrie ${ }^{924}$. Ce fut pour échapper à ce monopole que Justinien fit alliance avec le roi d'Axoum (négus d'Ethiopie), dont les navires, partis d'Adoulis, fréquentaient les marchés de Ceylan où les Chinois apportaient la soie ; mais cette alliance donna peu de résultats, les Perses ayant une situation privilégiée à Ceylan ${ }^{925}$.

Il n'est donc pas étonnant que la deuxième guerre de Justinien avec la Perse ait eu pour résultat une telle augmentation du prix de la soie brute, que les ateliers impériaux furent gênés dans leurs achats. Le basileus fixa alors un maximum de prix d'achat (15 sous d'or la livre) ${ }^{926}$, mais les marchands perses refusèrent de s'y conformer et cessèrent toute vente. Les manufactures privées, manquant de matière première, fermèrent leurs ateliers et beaucoup d'ouvriers allèrent travailler dans les manufactures perses. Ce fut alors que le Syrien Pierre Barsymès, comes largitionum et directeur des ateliers du Palais, décida Justinien à passer par les exigences des marchands perses, mais en réservant à l'État le monopole de l'achat de la soie. Les ateliers du Palais retrouvèrent toute leur activité et bientôt ne suffirent plus à la demande, si bien que le « comte des largesses » put vendre de la soie à des manufactures privées. L'achat de la soie fut ainsi régularisé et l'État, étant seul acheteur, vint plus facilement à bout des exigences des marchands perses $(540-546)^{927}$.

Quelques années après eut lieu un événement qui devait avoir une importance considérable pour l'industrie de la soie. Vers 552-554, deux moines, originaires de l'Asie centrale, importèrent à Byzance des œufs de vers à soie dans une canne plombée et réussirent à les faire éclore et à les nourrir avec des feuilles de mûrier. Justinien, à qui ils avaient d'abord proposé cette importation, les récompensa magni-

\footnotetext{
Ibidem, 535 et $\mathrm{s}$.

Ibidem, 539-540; PARISET, Histoire de la soie, I, 177 et s.

BURY, A History of the eastern Roman Empire, II, 441.

Procope DE CESAREE, Anecdota, 25 (accuse Barsymès de spéculations); DieHL, Justinien, 340-342; BURY, op. cit., II, 331.
} 
fiquement et ordonna de planter des mûriers ${ }^{928}$. Mais les résultats de cette précieuse acquisition ne pouvaient se faire sentir que dans la suite et, dans le traité qui mit fin à la guerre de Perse, les stipulations anciennes relatives à la vente de la soie furent renouvelées ${ }^{929}$.

Ce fut après la mort de Justinien que le monopole perse fut menacé. Les Turcs (Tou-Kiou des Chinois), originaires de l'Altaï, se révoltèrent contre les Mongols et fondèrent l'empire des Turcs occidentaux, qui occupa la Transoxiane et se rendit maître de la route de la soie. Le Sogdien Maniakh, chef de caravane, alla trouver Chosroès de la part du khagan Istämi, mais ses offres furent repoussées et défense fut faite aux marchands perses d'acheter la soie en Transoxiane. Ce fut alors qu'Istämi envoya Maniakh à Constantinople et fit alliance avec Justin II (567-578). Sans doute, depuis l'introduction des vers à soie à Byzance, des manufactures de soieries avaient été créées, mais la production était encore insuffisante. Les Turcs eurent ainsi un débouché pour la vente de la soie et, ce que n'avait pu obtenir Justinien, Justin II se libéra du monopole perse ${ }^{930}$. L'industrie et le cornmerce de la soie n'en restèrent pas moins prospères en Iran. Le voyageur chinois Hiouen-tsang, qui longea la frontière de Perse au début du VII siècle, vante l'habileté des tisseurs de soie ou de laines et des fabricants de tapis, recrutés d'ailleurs parmi les artisans des provinces byzantines de Syrie et d'Asie Mineure, venus de bon gré ou amenés de force au cours des guerres entre les deux Empires ${ }^{931}$.

Route maritime du commerce oriental. - La voie de la mer Rouge et de l'océan Indien était connue depuis la plus haute antiquité. Sous le règne d'Auguste, un navigateur, Hippalos, découvrit le régime des moussons de l'océan Indien et, cessant de suivre les côtes, se lança en pleine mer pour atteindre le marché de Ceylan ${ }^{932}$. D'après un Grec établi à Bérénice sur la mer Rouge, à l'époque de Claude et de Néron, c'était de ce port que partait chaque année la flotte de l'Inde

Procope de Cesaree, B.G., IV, 17 (552); Diehl, Justinien, 542; Bury, II, 331, Theophanes DE BYZANCE, IV, 270.

DIEHL, op. cit., 148; Cardinal PITRA, Hymnographie de l'Église grecque, 71-80.

Grousset, op. cit., 124-129; HeYD, Histoire du commerce du Levant, I, 14 et s.; G. MoraVCSIK, Byzantino-turcica, I : Die byzantinischen Quellen der Geschichte der Türkvölker, I, 42.

HeYd, op. cit., I, 17; Procope de CesAree, Anecdota, 25.

J. Dahlmann, Die Thomas Legende..., 24 et s 
qui visitait en premier lieu les ports de l'Afrique orientale, puis traversait l'océan Indien jusqu'à Ceylan ${ }^{933}$.

Ces traditions étaient toujours vivantes à l'époque byzantine. Le canal du Nil n'était plus utilisé, mais plusieurs ports de la mer Rouge recevaient les produits de l'Arabie, de l'Afrique orientale et des Indes. Le principal était Klysma (près de l'emplacement actuel de Suez), défendu par une forteresse. On y apportait l'encens du pays d'Hymiar (Yémen), la casse de la côte des Somalis, la myrrhe, l'aloès et tous les parfums ${ }^{934}$. C'était encore Aïla, situé au fond du golfe d'Akaba, à l'entrée duquel se trouvait l'île de Iotabé, où était installée la douane impériale. Aïla recevait des produits de l'intérieur de l'Afrique : les défenses d'éléphant, l'écaille des îles Dioscorides (Socotora), l'ébène, le santal et les bois précieux, les parfums d'Arabie et de la côte des Aromates (Somalis), enfin les produits de l'Inde ${ }^{935}$.

Le royaume d'Axoum possédait, comme on l'a vu, le port d'Adoulis, au sud de la mer Rouge. Il armait pour l'Inde, mais recevait aussi les produits d'Afrique, qu'il exportait: encens, épices, papyrus, ivoire, et l'or que les caravanes rapportaient, en échange du sel et du fer ${ }^{936}$.

Le marché de Ceylan. - L'île de Ceylan (Taprobane) était le but de toutes ces flottes parties des ports de la mer Rouge. C'était là que se tenait un marché permanent, fréquenté par des flottes chinoises qui apportaient la soie et les épices et par des navires venus de l'Inde et de la Perse. Nous ne sommes guère renseignés sur le nombre des sujets byzantins qui prenaient part à ce commerce, Kosmas étant à peu près notre seule source ${ }^{937}$. Toujours est-il que l'Inde et ses produits étaient, si l'on peut dire, à la mode, à Constantinople. Une salle du Grand Palais située près du Consistoire s'appelait o voó́ (les Indiens) ${ }^{938}$ et l'on a découvert à Lampsaque un plat d'argent représentant l'Inde sous la figure d'une femme assise, coiffée d'un turban, des

933

934

935

936

937

938 
bracelets au-dessus du coude, tenant un grand arc, entourée de singes à longue queue, d'un perroquet, d'une outarde avec, à ses pieds, deux belluaires entravant un lion et un tigre ${ }^{939}$. Plus tard les Byzantins devaient faire leurs délices des aventures de la jeunesse de Bouddha dans le roman de Barlaam et Joasaph traduit en grec ${ }^{940}$.

A Ceylan même, les Perses étaient prépondérants. Ils y envoyaient des navires, qui rapportaient les denrées précieuses à l'entrepôt établi à l'embouchure du Tigre et de l'Euphrate. Nombreux et bien accueillis des Cinghalais, ils jouissaient de privilèges et d'exemptions d'impôts. La monnaie byzantine n'en faisait pas moins prime dans les transactions ${ }^{941}$.

L'île de Ceylan produisait elle-même l'améthyste en abondance. Elle recevait les produits de l'Inde entière et ses flottes allaient en Indochine, et même en Chine, chercher la soie et les épices ${ }^{942}$.

Un marchand : Kosmas Indikopleustès. - Kosmas est le type de ces marchands, peut-être en même temps armateurs, qui ne craignaient pas les voyages lointains. Il se dit né en Égypte et énumère ses voyages. Il connaît bien la mer Rouge et l'Éthiopie. Il se trouvait au port d'Adoulis en 525, au moment où le roi d'Éthiopie préparait une expédition contre les Homérites (Yémen) ${ }^{943}$. D'après son témoignage, il a voyagé en Perse, en Arabie, «dans les golfes romains » (golfes d'Akaba et de Suez). En outre, il a été dans l'Inde intérieure et a croisé du côté de la Barbarie, où se trouve situé Zingion, à la bouche de l'Océan. Rien de plus obscur que cet itinéraire, car il place Ceylan dans cette Inde intérieure, laquelle, d'après Bury, serait la côte d'Arabie ou celle d'Afrique, qualifiée de Barbarie. Ce qui rend l'une de ces deux hypothèses vraisemblable, c'est qu'il dit avoir navigué le long des côtes de l'île de Dioscorides (Socotora). L'expression les Indes aurait été étendue à tous les pays des épices et des parfums, aux côtes d'Arabie et d'Afrique ${ }^{944}$. 
Il en résulte que, malgré son surnom d'Indikopleustès, il n'est pas certain qu'il ait dépassé le golfe Persique et soit allé jusqu'à Ceylan. Tous les détails qu'il donne sur cette île et son marché proviendraient de récits d'autres navigateurs ${ }^{945}$, tels que celui de Sopatros.

Envoyé à Ceylan avant le règne de Justin, Sopatros saisit l'occasion d'humilier un ambassadeur perse, qui prétendait devant le roi de Ceylan que son maître était plus grand que l'empereur romain. Interrogé à son tour, Sopatros se contenta de montrer au roi un sou d'or romain et une drachme perse d'argent. Le Cinghalais n'hésita pas à proclamer que le souverain qui frappait de telles monnaies d'or était le plus grand ${ }^{946}$.

Est-on d'ailleurs trop affirmatif en soutenant que Kosmas n'est pas allé à Ceylan? Ce n'est certainement qu'une hypothèse, mais que beaucoup de traits qu'on peut relever dans son récit justifient.

Esprit curieux, il raconte tout ce qu'il a vu en Éthiopie : les animaux rares, les arbres à épices et même les monuments, par exemple, à Adoulis, un trône de marbre et d'or, couvert d'une inscription au nom d'un Ptolémée. Le roi d'Axoum lui demande de la lui copier. Il le fait avec l'aide d'un autre marchand, son ami Ménas ${ }^{947}$. Ce sont là des souvenirs personnels et un récit vécu. Or on ne trouve rien de pareil dans les renseignements qu'il donne sur Ceylan et son marché. Ou bien il cite ses sources comme dans le récit de Sopatros, ou bien il reste dans le vague et n'affirme même pas formellement qu'il ait entrepris cette expédition.

Son livre, malheureusement, n'est pas un récit de voyage, mais un véritable traité de cosmologie, qu'il s'efforce de mettre d'accord avec l'Ancien Testament. On a supposé que, lorsqu'il écrivait cette Topographie chrétienne, vingt-cinq ans, dit-il, après son séjour à Adoulis, c'est-à-dire vers 550, il s'était fait moine, comme son ami Ménas ${ }^{948}$, et c'est la cosmologie telle qu'on l'entendait dans les écoles monastiques qu'il expose ${ }^{949}$. Il avoue d'ailleurs que sa doctrine lui a été communiquée par un certain Patrice, venu du pays des Chaldéens avec son disciple Thomas d'Édesse, et devenu par la suite évêque de toute la Perse ${ }^{950}$.

\footnotetext{
BURY, History of the later Roman Empire, II, 320.

Ibidem, 332-334.

D.A.C.L., 824 .

Ménas était au monastère de Raithu (Sinai).

BURY, op. cit., II, 320.

D.A.C.L., VIII, 1928, 821-829.
} 
Rejetant la théorie de la sphéricité de la Terre, par des arguments tels que l'impossibilité des antipodes, il enseigne que la Terre a la forme d'un rectangle, qui était celle du Tabernacle construit par Moïse. Placée au centre du monde, entourée de l'Océan, au-delà duquel est le Paradis terrestre, la Terre est couverte, comme d'une voûte, par le ciel et le firmament ${ }^{951}$.

L'ouvrage, aujourd'hui en douze livres, n'en comprenait que cinq à l'origine. Les autres auraient été écrits pour répondre à des contradicteurs. Les renseignements sur Ceylan sont dans le livre XI, qui semble extrait d'un autre ouvrage ${ }^{952}$.

Le texte de Kosmas est parvenu dans trois manuscrits. Le Vaticanus gr. 699, écrit en onciales, ne contient que les six premiers livres : il est regardé comme le plus ancien et daterait du $\mathrm{X}^{\mathrm{e}}$ siècle. Le Sinaïticus $1186, \mathrm{XI}^{\mathrm{e}}$ siècle, contient les douze livres, mais le douzième est incomplet. Le Laurentianus Plut. IX, 28 (fin du $\mathrm{XI}^{\mathrm{e}}$ siècle). Ces trois manuscrits sont illustrés de cartes et de dessins, de figures et d'épisodes de l'Ancien et du Nouveau Testament, enfin d'animaux et de plantes. Certains dessins peuvent provenir d'une tradition remontant à Kosmas ${ }^{953}$.

Commerce avec les peuples du Nord. - Par les ports de Crimée, Kherson et Bosporos, où Justinien avait rétabli l'autorité impériale ${ }^{954}$, des marchands apportaient aux Goths, aux Huns, aux Avars, les épices d'Orient et les produits des industries de Constantinople et de Syrie. Ils rapportaient en échange les fourrures du Nord, peut-être l'ambre de la Baltique et, du Lazique, les esclaves échangés contre du blé et du vin ${ }^{955}$.

Le principal témoignage sur ces relations est dû aux objets d'argenterie byzantine $\mathrm{du} \mathrm{VI}^{\mathrm{e}}$ siècle découverts en Russie et en Sibérie. L'abondance des trouvailles est particulièrement remarquable dans l'ancien gouvernement de Perm. Ce sont des plats d'argent peu profonds, de dimensions différentes, ornés d'une croix pattée, cernée d'une couronne végétale, niellée sur un fond de lignes concentriques ondulées. Au revers sont des poinçons de contrôle aux effigies impé-

BURY, II, 319-320.

D.A.C.L., VIII. (Les livres XI et XII manquent dans les manuscrits regardés comme les meilleurs.)

D.A.C.L., VIII, 839-845.

VASILIEV, The Goths in the Crimea, 70-76.

DIEHL, Justinien et la civilisation byzantine au VI siècle, 537. 
riales nimbées. On reconnaît Maurice, Phocas, Héraclius, grâce à la comparaison avec leurs monnaies ${ }^{956}$.

D'autres découvertes célèbres ont été faites : à Sébastopol, un reliquaire d'argent, orné de médaillons du Christ et des apôtres ${ }^{957}$; à Kertch, en 1891, le bouclier surmonté d'un anneau de suspension, représentant, gravé au trait, un empereur, la tête nimbée, à cheval, une lance à la main; il est précédé de la Victoire agitant une couronne et suivi d'un garde, abrité sous un immense bouclier timbré du monogramme du Christ ${ }^{958}$.

Ces objets pénétraient au loin, comme le montre le plat d'argent, traité au repoussé et qui figure deux anges adorant la croix gemmée, découvert en 1867 aux îles Bérézoff sur l'Obi (Sibérie) ${ }^{959}$. Son origine syrienne est probable. Il en est de même d'un autre plat d'argent découvert dans l'ancien gouvernement de Perm. Il représente le Christ en croix et, dans des médaillons reliés par des entrelacs, plusieurs thèmes évangéliques. Mais, tandis que les anges du plat sibérien se rattachent encore à l'art classique, la Crucifixion de Perm est traitée d'une manière qui rappelle l'art des peuples barbares. Très mystérieuse est l'origine de cette œuvre étrange, exécutée peut-être par un artisan barbare pour une communauté chrétienne ${ }^{960}$.

Commerce avec l'Occident. - $\mathrm{Au} \mathrm{VI}$ siècle, l'Occident, occupé en grande partie par les peuples barbares, était un débouché assuré pour le commerce de Constantinople et des grandes villes de l'Orient byzantin. Les victoires de Justinien sur les Vandales et les Goths avaient rendu à Byzance la maîtrise de la mer et assuré la liberté de la navigation, qui allait être très active jusqu'à l'invasion arabe.

Le commerce entre l'Orient et l'Occident était fait par les marchands des ports de Syrie, d'Asie Mineure, d'Égypte, confondus sous le nom de Syriens. Ils importaient en Italie les produits reçus des Indes et de la Chine. Il en était ainsi depuis la fondation de l'Empire.

\footnotetext{
956 MaCUlEVIČ, Argenterie byzantine en Russie; sur les poinçons de contrôle, M.B.E.H. (Institutions), éd. 1970, p. 206.

957 DALTON, Byzantine Art and Archaeology, 565.

958 DIEHL, op. cit., 30, fig. 12; on y voit le portrait de Justinien.

959 DiEHL, Manuel d'art byzantin, $319, \mathrm{f}^{\circ} .360$.

960 Chwolson, POKRowsky et SMIRnov, Matériaux pour l'archéologie de la Russie, SaintPetersbourg, 1899, pl. XXII, 2.
} 
Jusque-là les marchands italiens envoyaient des flottes chercher ces produits. L'île de Délos, aujourd'hui rocher stérile, était l'immense entrepôt de ces marchandises, où chaque firme romaine avait ses magasins, ses hangars, ses sanctuaires ; mais pendant les guerres civiles ce commerce fut ruiné et ce fut alors que commencèrent les navigations des Syriens vers l'Occident ${ }^{961}$. Non seulement ils fréquentaient les ports de l'Occident, mais ils établissaient des colonies à demeure dans toutes les grandes villes, à Rome, à Naples, à Ravenne, à Carthage, à Marseille, à Narbonne, etc. Quelques Syriens y exerçaient toute espèce de métiers, notamment celui de mimes. Ils étaient en général peu considérés des Romains ${ }^{962}$.

Ces colonies survécurent après l'occupation de l'Occident par les peuples germaniques. Il y eut même une renaissance du commerce méditerranéen sous Justinien : bien plus, les navigateurs, devenus plus audacieux, franchirent les Colonnes d'Hercule, affrontèrent l'Océan et atteignirent les îles Britanniques.

Colonies syriennes. - Une des plus puissantes colonies de Syriens était celle de Rome, où un quartier oriental se développa au pied de l'Aventin ${ }^{963}$. Des Syriens entrèrent dans le clergé romain et leur influence fut telle qu'au VII ${ }^{\mathrm{e}}$ et au VIII ${ }^{\mathrm{e}}$ siècle la plupart des papes sont des Grecs ou des Orientaux ${ }^{964}$.

Très nombreuses et très prospères étaient les colonies syriennes établies en Gaule. Nous sommes bien renseignés par des inscriptions funéraires, en grec, et surtout par les ouvrages de Grégoire de Tours. Ces colonies avaient eu pour points de départ les ports de Marseille et de Narbonne, mais elles s'étaient avancées très loin à l'intérieur. Dans les villes gallo-romaines encore debout sous la domination franque, les Syriens formaient des corporations (on disait alors des nations), qui détenaient la plus grande partie du commerce et de l'industrie.

Lorsque le roi Gontran fait son entrée solennelle à Orléans le 4 juillet 585, les trois nations qui habitaient la ville, les Latins (Gallo-Romains), les Syriens et les

961

J. HATZFELD, Les trafiquants italiens dans l'Orient hellénique (1919).

L. BREHIER, Les colonies d'Orientaux en Occident au commencement du Moyen Age, 1-39.

Liber pontificalis Ecclesiae romanae, 1886, I, 341; DIEHL, Etude sur l'administration byzantine dans l'Exarchat de Ravenne, 278 et s.

L. BREHIER, op. cit., 4 et s. 
Juifs allèrent à sa rencontre avec leurs bannières et l'acclamèrent, chacun dans sa langue ${ }^{965}$ De même un concile tenu à Narbonne en 589 interdit le travail du dimanche aux Goths, aux Romains, aux Syriens, aux Grecs, aux Juifs ${ }^{966}$.

Des ports de la Méditerranée, l'immigration syrienne suivit les deux routes naturelles, à l'ouest celle du col de Naurouze et de la vallée de la Garonne, au nord les vallées du Rhône, de la Saône et de la Seine.

Un premier courant atteignit Bordeaux avant le $\mathrm{IV}^{\mathrm{e}}$ siècle, comme l'attestent des inscriptions funéraires ${ }^{967}$, et, au VI ${ }^{\mathrm{e}}$ siècle, Grégoire de Tours raconte l'histoire du marchand syrien Euphron, persécuté par l'évêque de Bordeaux, Berthramnus, jaloux de ses richesses et de sa précieuse relique de saint Serge ${ }^{968}$.

La seconde route, la plus importante, était jalonnée par les colonies de Vienne ${ }^{969}$, de Lyon, où un certain Constantin, né à Germanicia (Commagène), exerçait l'industrie des applications d'or et d'argent sur les métaux (ars barbaricaria) ${ }^{970}$, à Autun ${ }^{971}$.

Dans la vallée de la Loire, où nous avons cité la colonie d'Orléans, on voit des Syriens à Tours, où l'évêque Grégoire accueillait avec une véritable prédilection les récits qu'il nous a transmis sur l'Orient ${ }^{972}$. A Paris, les marchands syriens étaient nombreux et puissants. L'un d'eux se fit élire évêque à force de présents, destitua tous les titulaires des offices ecclésiastiques et les remplaça par des Syriens ${ }^{973}$. Dans la région rhénane, Trèves eut une importante colonie syrienne dès l'époque du Haut-Empire ${ }^{974}$ et ce fut peut-être de là que les Syriens se répandirent en Germanie ${ }^{975}$.

\footnotetext{
Gregoire De Tours, Euvres, H.F., VIII, 1.

M.C., IX, 1015-1017 (sous le roi wisigoth Reccared).

C. JULLIAN, Inscriptions chrétiennes de Bordeaux, I, n ${ }^{\text {os }}$ 68-71.

GregoIRE DE TOURS, H.F., VII, 31; L. BREHIER, op. cit., 13.

Allmer, Inscriptions de Vienne, IV, 395, nº 892; LE BLANT, Inscriptions chrétiennes de la Gaule, 415 (datée du mois syrien de Peritios, février); L. BREHIER, op. cit., 14.

C.I.L., XIII, 1945 (découverte en 1885).

L. BREHIER, op. cit., 14.

Id., Grégoire de Tours et l'Orient, Institut de France, 1939, XIII, 23-47; GREGOIRE DE TOURS, Gloria mart., ch. 94.

GREGOIRE DE TOURS, H.F., 26.

974 Le Blant, Inscriptions chrétiennes de la Gaule, $\mathrm{n}^{\text {os }}$ 225, 248 et 267; STRZYGOWSKI, Der Dom zu Aachen, 44.

975 L. BREHIER, op. cit., 17 et s.
} 
Les voyages réguliers d'importation. - $\mathrm{Au} \mathrm{VI}^{\mathrm{e}}$ siècle, les colonies syriennes d'Occident étaient approvisionnées en denrées orientales par des voyages annuels, ce qui laisse supposer un commerce florissant: c'est ainsi qu'à Alexandrie des armateurs étaient spécialisés dans le commerce avec les différents pays. Il existait des $\gamma \alpha \lambda \lambda o \delta \rho o ́ \mu o r$ (navires armés pour les ports de Gaule), des $\sigma \pi \alpha v o \delta \rho \pi$ ó $\mu$ or (dirigés sur l'Espagne), et d'autres destinés aux ports d'Italie ${ }^{976}$. Une flotte marchande appartenant à l'Église d'Alexandrie perdit dans l'Adriatique sa cargaison, qui consistait en blé, en argent, en tissus, en denrées précieuses ${ }^{977}$.

D'autres navires, de la même Église, chargés de 20 médinmes de blé, arrivèrent en Angleterre après vingt jours de traversée. Un chef anglo-saxon acheta la moitié de la cargaison pour un sou d'or par médimne et l'autre moitié avec du zinc, qui fut miraculeusement transformé en argent ${ }^{978}$. Un autre navire alexandrin, poussé par la tempête sur les côtes britanniques, revint avec une cargaison d'étain ${ }^{979}$.

Ces courriers réguliers pour l'Occident existaient aussi dans les ports de Syrie, comme le montrent deux anecdotes :

D'après la Vie de sainte Geneviève, saint Syméon Stylite interrogeait tes marchands qui revenaient de Gaule sur la sainte parisienne et lui envoyait son salut par leur intermédiaire ${ }^{980}$ (entre 451 et 459). Un autre témoignage montre que ces relations régulières avaient persisté au siècle suivant. Grégoire de Tours rapporte que près de Nice vivait un saint ermite, Hospitius, qui, pendant le carême, se nourrissait des mêmes racines que les solitaires de Thébaïde : chaque année des marchands égyptiens lui en apportaient une provision ${ }^{981}$.

Articles importés. - Il y avait d'abord les productions de la Syrie et de l'Égypte. Les vins de Gaza et de Sarepta étaient très renommés en Gaule et faisaient concurrence aux vins d'Italie ; plusieurs anecdotes montrent qu'on en faisait une grande consommation ${ }^{982}$. On importait aussi de 1'huile, qui était demandée à Marseille où on fabriquait déjà des savons, et beaucoup de fruits. Venaient ensuite les produits

\footnotetext{
976 Vie de saint Jean l'Aumônier, 68; G. RouILLARD, L'administration de l'Egypte byzantine, 82; HANOTAUX, Histoire de la nation égyptienne : L'Egypte chrétienne (DIEHL), 486.

977 Vie de saint Jean l'Aumônier, par LEONCE DE NAPLES, 28, 60; G. ROUILLARD, op. cit., 82.

978 H. DeleHAYE, Une vie nédite de saint Jean l'Aumônier, dans A.B., 1927, 30-32; R. LopeZ, Relations anglo-byzantines du VII au X $X^{e}$ siècle, dans B.N., 1948,145-147.

979 Vie de saint Jean l'Aumônier, 10; G. RouILLARD, op. cit., 82.

980 Vie de sainte Geneviève (425-513), S.R.M., III, 226 et s.

981 Gregoire De Tours, H.F., VI, 6; L. BreHIER, Les colonies d'Orientaux..., 12.

982 Gregoire De Tours, H.F., III, 19; Gloria confess., 64; BREHIER, op. cit., 20 et s.
} 
d'Orient: le papyrus d'Égypte, seule matière employée pour écrire ${ }^{983}$, l'encre de pourpre, enfin les épices, la soie et les parfums. Les tissus de coton, inconnus en Occident, faisaient l'admiration de Grégoire de Tours, qui décrit le fruit, venu de Palestine, qu'on lui avait apporté ${ }^{984}$. On recherchait surtout les soieries, qui entraient de plus en plus dans le costume civil et ecclésiastique et dont on se servait comme tentures. Grégoire de Tours achète ainsi une ancienne étoffe de soie, qu'on lui dit avoir servi d'enveloppe à la vraie Croix ; il la découpe en morceaux qu'il distribue à ses diocésains ${ }^{985}$.

Notons encore l'importation d'objets fabriqués, par exemple la verrerie de Sidon destinée à être exportée, comme l'indiquent des marques de fabrique en latin, à côté des inscriptions en grec ${ }^{986}$. Constantinople exportait aussi dans la Méditerranée, aussi bien en Égypte qu'en Italie ou en Afrique, des chapiteaux en marbre de Proconnèse, employés dans la construction des églises et des palais ${ }^{987}$.

Ce commerce actif entre l'Orient et la Gaule n'avait pas encore cessé au VIII siècle. En 716, Chilpéric II confirme à l'abbaye de Corbie deux chartes perdues de Clotaire III (656-673) et de Childéric II (673-675), l'exemptant des droits de tonlieu à la douane de Fos, pour les denrées acquises par ses hommes dans le port de Marseille, avec l'autorisation de requérir des chevaux de poste pour les transporter, mais en les soumettant à un contingentement. La liste de ces denrées et de la quantité autorisée donne une idée de l'importance du commerce entre l'Orient et la Gaule presque jusqu'à la fin de la période mérovingienne ${ }^{988}$ :

Huile, 10000 livres. - Poivre, 30 1. - Girofle, 2 1. - Cannelle, 1 1. Cumin, 150 1. - Nard, 2 1. - Riz, 20 1. - Hidrium (aromate), 30 1. Costum (racines), 30 1. - Dattes, 50 1. - Amandes, 100 1. - Figues, 100 1. — Pistaches, 30 1. — Olives, 100 1. - Garum (saumure de poisson usitée dans la cuisine byzantine), 30 muids. - Papyrus, 50 rames. - Piment, 10 1. - Pois chiches, 150 1. - Peaux, 10. - Cuirs de Cordoue, 10. 
Tous ces articles ne viennent pas forcément d'Orient, mais on distingue dans cette liste les stocks accumulés de produits apportés par les marchands syriens. Il est surtout remarquable d'y voir une pareille quantité de papyrus, ce qui prouve que la conquête de l'Egypte par Amrou (639-642) n'avait pas dû mettre fin à l'exportation du papyrus ${ }^{989}$.

\section{Conséquences économiques des conquêtes arabes}

\section{Retour à la Table des Matières}

Nous venons de voir que les conquêtes arabes du VII ${ }^{\mathrm{e}}$ siècle ne paraissent pas avoir arrêté le commerce des Syriens. Ce fut seulement après la conquête de l'Espagne visigothique par Tarik et Mouça en 711 et l'attaque de Constantinople par le calife Moslémah en 718, que la navigation cessa d'être libre et que le commerce des Syriens avec l'Occident disparut ${ }^{990}$. A partir de cette époque, le papyrus n'arriva plus en Gaule et, après l'épuisement des stocks, on commença à se servir de parchemin ${ }^{991}$. Le port de Marseille, si actif à l'époque mérovingienne, est vide. C'est le moment où les villes se dépeuplent et rétrécissent leurs enceintes. Sous les Carolingiens l'économie gauloise est devenue exclusivement rurale ${ }^{992}$. Ce qui est d'ailleurs certain, c'est que les colonies de marchands orientaux, si nombreuses sous les Mérovingiens, ont disparu. C'est tout au plus si les sources citent quelques Syriens chargés par Charlemagne de réviser le texte des Écritures ${ }^{993}$. D'autre part, il y eut des échanges d'ambassades entre Charlemagne, le calife Haroun al-Raschid et le patriarche de Jérusalem (797-807) ${ }^{994}$. Aucune de ces missions n'a utilisé le port de Marseille. Le Juif Isaac, qui ramène un éléphant et des présents du calife, voyage par l'Afrique et, de la Tunisie probablement, s'embarque et

\footnotetext{
Ibidem, 109.

F. LOT, H.G.M.A., I, 1922, 357; H. PIRENNE, La fin du commerce des Syriens, M.B., 681.

H. PIRENNE, Le commerce du papyrus, 108-110.

Id., Mahomet et Charlemagne, 77 et s.

Id., La fin du commerce des Syriens, 683 et s.

L. BREHIER, Les origines des rapports entre la France et la Syrie (Travaux du Congrès de la Syrie, Marseille, 1918), 15-39.
} 
aborde à Port-Vendres ${ }^{995}$. Des missions du calife viennent par l'Italie et abordent à Pise ${ }^{996}$.

Depuis la défaite des Arabes devant Constantinople en 718, les flottes byzantines tenaient toujours la mer, mais ne dépassaient pas l'Italie ou la Sicile.

La monnaie. - Le grand commerce ayant cessé, la monnaie d'or disparut presque entièrement de l'Occident, où elle faisait prime pendant l'époque mérovingienne. Charlemagne dut créer une monnaie d'argent dont la seule pièce réelle fut le denier ${ }^{997}$. En Orient au contraire la monnaie impériale, le besant, continua à être recherchée et protégée par le gouvernement byzantin ${ }^{998}$; elle resta intacte jusqu'aux dernières années du $\mathrm{XI}^{\mathrm{e}}$ siècle, tandis que la monnaie arabe, le dinar d'or, s'alignait sur elle ${ }^{999}$.

La vente et le change de l'or, de l'argent et des pierres précieuses étaient le

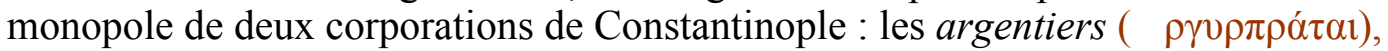
qui vendaient et achetaient les métaux précieux, et les changeurs ( $\tau \rho \alpha \pi \varepsilon \zeta i \tau \alpha)$, qui devaient fournir un répondant ${ }^{1000}$. Constantinople devint ainsi un marché de capitaux. Le prêt à intérêt, supprimé par Basile I ${ }^{\mathrm{er}}$, fut rétabli par Léon VI et l'intérêt augmenté ${ }^{1001}$.

Le pouvoir d'achat. - D'après quelques renseignements fournis par les sources et examinés par des spécialistes, le pouvoir d'achat de cette monnaie saine n'a cessé d'être grand, jusqu'à la crise de la fin du $\mathrm{XI}^{\mathrm{e}}$ siècle ${ }^{1002}$.

Le prix du blé, en mettant à part les périodes exceptionnelles (famines) et les spéculations comme celles des Phocas au $\mathrm{X}^{\mathrm{e}}$ siècle, aurait peu varié pendant trois siècles. D'après Andréadès, comparé à la monnaie grecque de 1914, il aurait valu 78 centimes par modius (6 $\mathrm{kg} 500)$ au IX ${ }^{\mathrm{e}}$ siècle, 98 centimes au siècle suivant. Un litre de vin valait 2 f 86 centimes. D'après le Livre des Cérémonies, les Sarrasins baptisés et agriculteurs recevaient par an 3 nomismata ( 45 francs), 6 de ces pièces

1001 LEON VI, Novelles, nov. 83 (280-2
ANDREADES, op. cit., 97, 106 et s.

Livre du Préfet (éd. et trad. Nicole), 22-26.

Annales Laurissenses Majores, M.G.H.S.S., I, 190 (a. 801).

Ibidem, I, 194 (a.807); BüCHNER, dans Die Provence in merowingische Zeit (Stuttgart, 1933) relève 17 itinéraires du VIII siècle, dont un seul par mer.

H. PirenNe, H.G.M.A., VIII, 95-98; ANDREADES, De la monnaie et de la puissance d'achat des métaux précieux dans l'Empire byzantin, 82-85.

LEON VI, empereur, Novelles, nov. 52 (199-201).

G. BRATIANU, Etudes byzantiues d'histoire économique et sociale, 225 et s. 
d'or par paire de bœufs et 54 modii de blé pour leurs semences et leur subsistance. Les chevaux et les mulets fournis à l'armée par les paysans d'Asie Mineure étaient estimés de 12 à 15 nomismata (125 à $180 \mathrm{f}$.) ${ }^{1003}$.

Sous Léon VI un marchand ambulant possédait 1000 nomismata (15 000 f.). A ce fonds il ajouta d'autres sommes appartenant à des tiers, et il acheta un stock de marchandises, mais il perdit 1500 nomismata (22 $500 \mathrm{f}$.), qu'il avait mis dans une bourse, et « je tombai, dit-il, d'une grande richesse dans une extrême pauvreté ». Un paysan, qui trouva cette bourse, fut considéré comme riche ${ }^{1004}$.

Transformation du grand commerce. - Les Arabes, qui avaient depuis une très haute antiquité l'expérience du trafic, s'emparèrent du monopole des échanges avec l'Asie orientale et l'intérieur de 1'Afrique. Leurs capitales, Damas, Badgad, Cordoue, rivalisèrent de magnificence avec Constantinople. Toutes les routes des épices et de la soie, tous les ports de Syrie étaient en leur pouvoir. Les marchands byzantins qui continuèrent à fréquenter ces ports virent leurs bénéfices singulièrement réduits par les droits qu'ils durent payer aux Arabes ${ }^{1005}$.

Malgré l'état de guerre continuel entre le basileus et le calife, en dépit des prohibitions impériales comme celle de Léon $\mathrm{V}^{1006}$, il y eut jusqu'au XII ${ }^{\mathrm{e}}$ siècle un commerce ininterrompu, souvent favorisé par les relations politiques, ambassades, traités de paix, entre Byzance et les Arabes. Antioche et Alexandrie redevinrent, comme Constantinople, de grands marchés internationaux ${ }^{1007}$. Il en résulta une aggravation de l'économie dirigée. Plus que jamais le marché libre fut sous le contrôle de l'État, en particulier celui de la soie. La réglementation laisse d'ailleurs supposer un commerce actif, qui n'est plus entièrement le monopole de l'État. Des particuliers, et des plus haut placés, commanditent des entreprises commerciales, comme le montre l'anecdote du navire appartenant à l'impératrice Théodora. L'empereur Théophile le fait brûler avec sa cargaison, non parce que ce commerce

\footnotetext{
1003 COnstantin VII Porphyrogenete, De caerimoniis aulae byzantinae, II, 49; AndreAdes, op. cit., 107-109.

1004 Synaxaire de l'église Sainte-Sophie (mss. de Patmos, $\mathrm{X}^{\mathrm{e}}$ siècle), éd. Delehaye, 722 et s.; A. VoGT, Basile I er et la civilisation byzantine à la fin du IX siècle, 122.

1005 ECK, Le commerce méditerranéen après l'invasion arabe, R.S.E., 1941, p. 33 et s.

1006 R.K.O.R., 400.

1007 HEYD, Histoire du commerce du Levant, I, 52 et s.
} 
est illégal, mais parce qu'il le trouve indigne d'une impératrice des Romains ${ }^{1008}$.

Recherches de nouveaux débouchés. - Si actif que fût le commerce avec les Arabes, il n'en était pas moins très onéreux. De là des tentatives pour découvrir de nouvelles routes commerciales afin d'atteindre, par celles du nord, les marchés d'Extrême-Orient et de reprendre les relations commerciales avec l'Occident par l'Adriatique et l'Italie.

Les ports de Crimée permirent aux marchands grecs d'entrer en contact avec les Khazars, dont la capitale, Itil sur la Volga, était un marché international dès le VIII ${ }^{\mathrm{e}}$ siècle ${ }^{1009}$.

Les Russes, entre Constantinople et Bagdad, reliaient les deux grands courants commerciaux dirigés, l'un vers la Baltique et les pays scandinaves, l'autre vers la mer Noire et la Caspienne. Grâce à cette position, ils subirent l'attraction de ces deux grands foyers de civilisation, le califat et Byzance. Ils avaient d'ailleurs chez eux les éléments d'un grand commerce : les fourrures, le miel (qui remplaçait le sucre) et les esclaves. Ils écoulaient ces produits vers les deux grands marchés. Les monnaies byzantines et arabes, découvertes si fréquemment en Russie, attestent l'existence de ces routes commerciales.

La conséquence de cette activité mercantile fut la création d'entrepôts fortifiés (gorods), construits par les Varègues, qui établirent leur domination sur les Slaves. Ces entrepôts devinrent des villes et, au moment où l'Occident ne connaissait plus guère que l'économie agricole, une civilisation urbaine se développait dans la plaine russe $^{1010}$.

Colonie russe à Constantinople. - Comme l'a montré Vasiliev, il y a identité entre les Normands qui ravageaient l'Empire carolingien et les Varègues, fondateurs du premier État russe ${ }^{1011}$. Normands et Varègues étaient guerriers et commerçants à l'occasion. Tous

1008 Theophanes, Continuatus, 101-104; BuRY, A History of the Eastern Roman Empire, 122-123 (a. 829 et s.).

1009 ECK, op. cit., 34

1010 H. PIRENNE, Les villes au Moyen Age, (Bruxelles, 1927), 46-52; ECK, op. cit., 37 et s.

1011 VASILIEV, The Russian Attack of Constantinople in 860, 3 et s. 
d'ailleurs n'étaient pas de simples pirates, mais beaucoup d'entre eux cherchaient à créer des établissements et des colonies de marchands à l'étranger. Le port de Volin, qu'ils avaient créé sur la Baltique, était, au dire d'un historien arabe, le plus grand et le mieux aménagé de l'Europe ${ }^{1012}$, mais c'était surtout le marché de Tsarigrad (Constantinople) qui était l'objet de leurs convoitises.

Vers 839 une ambassade du peuple des Russes (Rhos qui s'appellent eux-mêmes Suéones) vient trouver Théophile, qui les envoie à Louis le Débonnaire pour être rapatriés par mer, la route de terre étant occupée par des peuples féroces ${ }^{1013}$. Ces Russes venaient certainement de Kiev, où les Varègues s'étaient installés après en avoir chassé les Khazars ${ }^{1014}$. On ignore la cause de l'attaque des Russes contre Constantinople (26 juin 860 ), qui semble se relier aux courses entreprises déjà par les Varègues dans la Méditerranée ${ }^{1015}$; mais ce qui est certain, c'est qu'après leur défaite, les Russes envoyèrent une ambassade au basileus pour conclure la paix et demander le baptême. Un traité fut sans doute conclu, ouvrant aux Russes le commerce de l'Empire et peut-être les rangs de l'armée impériale ${ }^{1016}$.

Le premier traité connu entre les Russes et Byzance est celui d'Oleg avec Léon VI en 911 : il n'est certainement pas le premier, puisqu'il contient des clauses relatives à la colonie russe installée au faubourg de Saint-Mamas à Constantinople ${ }^{1017}$. D'autres accords, précédés de nouvelles attaques, furent conclus en 945 entre Romain Lécapène et Igor, en 971 entre Jean Tzimiskès et Sviatoslav, en 1046 entre Constantin IX et Iaroslav: ils contiennent tous des clauses commerciales.

Le faubourg de Saint-Mamas, où se trouvait la colonie des marchands russes, était situé hors de la ville, sur le Bosphore. Les plus grandes précautions étaient prises pour les empêcher d'abuser de

${ }^{1012}$ ECK, op. cit., 35. Il pouvait recevoir 300 navires.

1013 R.K.O.R., 438; VASILIEV, Vizantija i Arabui... za Vremja Amorijskoi dinastii, 183 et s.

${ }^{1014}$ VASILIEV, The Russian Attack..., 9-13.

1015 Ibidem, 17 et s., 55, 235-237.

1016 Theophanes, Continuatus, 33; VASILIEv, op. cit., 229 et s.

1017 Connu uniquement par la Chronique de Nestor: voir M.B.E.H. (Vie et mort de Byrance), 1969, 131,qui indique deux traités, l'un en 907 (après l'expédition d'Oleg), l'autre en 911; R. H. DolloY, Oleg's mythical campaign against Constantinople, dans B.A.B.L., 1949, 106 et s., regarde l'expédition comme légendaire, mais admet la réalité des 2 traités conclus avec Oleg. 
l'hospitalité impériale. Le nom de chacun d'eux, et celui de la ville d'où il venait, étaient enregistrés par un fonctionnaire impérial. Ils ne pouvaient entrer à Constantinople que par une seule porte, cinquante au maximum, sans armes et accompagnés d'un officier byzantin. Ils ne pouvaient acheter de soie que pour 50 pièces d'or et faisaient sceller leur marchandise par l'officier impérial. Les marchandises qu'ils apportaient étaient soumises à un droit de $10 \%$ ad valorem. Ils n'avaient pas le droit de passer l'hiver à Constantinople, mais le gouvernement leur assurait des vivres pour la route et des subsides pendant leur séjour à Saint-Mamas ${ }^{1018}$.

Au milieu du XI ${ }^{\mathrm{e}}$ siècle, la grande voie commerciale de la Russie, la route du Dniéper, fut interceptée par l'invasion de nouveaux peuples touraniens, les Petchénègues, les Comans, les Ouzes. Le commerce de la mer Noire se concentra à Kherson, qui devint l'intermédiaire entre la Russie et Byzance. L'usage de la route commerciale de Kherson à Kiev dépendait des rapports des Goths de Crimée avec les nomades. Certains marchands de Kherson poussaient jusqu'à Novgorod. Parmi les articles de ce commerce avec Constantinople, les salaisons du golfe nord-ouest de la mer d'Azov tenaient une grande place ${ }^{1019}$.

Colonie bulgare. - A la différence de la Russie, la Bulgarie était un pays purement agricole; de plus, l'exploitation des mines assurait de gros revenus à l'État. La Bulgarie était en outre traversée par trois routes commerciales aboutissant à la mer Noire, vers l'Europe centrale et à Thessalonique, avec déviation de Belgrade à Constantinople. Une grande quantité de marchandises traversait donc la Bulgarie et enrichissait les négociants bulgares, grecs, arméniens, sujets du prince. Depuis le khan Tervel (701-718), allié de Justinien II, il existait une colonie bulgare à Constantinople, probablement au faubourg Saint-Mamas ${ }^{1020}$.

La longue guerre du tsar Syméon contre 1'Empire (894-924) anéantit le commerce bulgare, mais dans les traités conclus entre les adversaires en 900 et en 924, la livraison annuelle aux Bulgares de 100 scaramanges brodés est un des articles du tribut exigé par Syméon ${ }^{1021}$. Par contre, on ne voit aucune clause commerciale dans le traité conclu

\footnotetext{
1018 J. PARgOIRE, Les Saint-Mamas de Constantinople, I.R.I., IX, 1904, 297-302; HEYD, Histoire du commerce du Levant, I, 69.

1019 VASILIEV, The Goths in the Crimea, 136-138.

1020 Sur le préjudice porté à cette colonie par le favori de Léon VI: Stylianos Zaoutzès, en 894, voir M.B.E.H. (Vie et mort de Byzance), 1969, 128-129.

1021 St. Runciman, The Emperor Romanus Lecapenus, 93; R.K.O.R., 604.
} 
en 927 entre Romain Lécapène et le régent bulgare au nom du tsar Pierre ${ }^{1022}$, mais l'union intime entre les deux pays, qui en résulta, laisse supposer que la situation commerciale des Bulgares à Constantinople fut rétablie.

\section{Les premières colonies italiennes}

\section{$\underline{\text { Retour à la Table des Matières }}$}

Le commerce méditerranéen, interrompu par l'invasion arabe, avait fini par reprendre son activité à la fin $\mathrm{du} \mathrm{IX}^{\mathrm{e}}$ siècle, mais sous le contrôle musulman et en supportant les gros risques dus aux corsaires et aux opérations militaires. Les ports italiens ne cessaient de trafiquer ouvertement avec les pays musulmans.

Le marché de Rome. - Les dons des papes aux églises énumérés par le Liber pontificalis attestent que Rome continuait à recevoir des produits d'Orient. Ce sont des étoffes historiées, des tentures, des tapis. Quelques-uns de ces articles pouvaient être fabriqués sur place ou provenir de l'Espagne arabe, mais la plupart venaient d'Antioche, d'Alexandrie, de Constantinople. Une partie du trésor des papes consistait d'ailleurs en dons des empereurs byzantins ${ }^{1023}$.

Rome était donc un marché des produits du Levant. Les évêques et les abbés de toute la chrétienté qui s'y rendaient, s'approvisionnaient en parfums, en épices, en tissus ${ }^{1024}$.

Le marché de Venise. - Par sa situation sur les îles incultes de la lagune, où l'on ne trouvait même pas d'eau potable, Venise ne pouvait vivre qu'en devenant un État commerçant. Duché byzantin incomplètement émancipé, en rapports constants avec Constantinople et par là même, remarque Pirenne, " initiée à une forme supérieure de civilisation », Venise dut à cette origine la prospérité de son commerce ${ }^{1025}$. Elle importa à Byzance le blé et les vins d'Italie, les bois de Dalmatie,

1022 DieHL, Figures byzantines, 180 et s.

1023 HEYD, Histoire du commerce du Levant, I, 94 et s.

${ }_{1022}$ F. GANSHOF, Note sur un passage de la vie de saint Géraud d'Aurillac, 295-307.

1025 H. PIRENNE, Les villes au Moyen Age, 75-77. 
le sel, les esclaves ; elle y acheta les étoffes, les épices et tous les produits d'Orient ${ }^{1026}$. En même temps ses commerçants fréquentaient le marché de Rome et trafiquaient avec les Musulmans d'Afrique et d'Orient. Ce furent des marchands vénitiens qui dérobèrent le corps de saint Marc à Alexandrie ${ }^{1027}$. Venise devint au $\mathrm{X}^{\mathrm{e}}$ siècle un grand marché des produits d'Orient, fréquenté par les Lombards et même par des Français. Un curieux épisode, extrait d'une œuvre hagiographique, illustre le caractère et l'étendue de son commerce :

Le biographe de saint Géraud, abbé du monastère d'Aurillac (879-909), raconte que, se trouvant à Rome (qu'il visita sept fois), Géraud acheta des étoffes précieuses. A son retour, passant par Pavie, il se vit entouré de marchands vénitiens et autres, qui lui offrirent des articles orientaux. Il leur montra les acquisitions qu'il avait faites à Rome, mais, quand il eut dit le prix, un Vénitien lui fit savoir qu'une de ces étoffes valait beaucoup plus et serait payée plus cher, même sur le marché de Constantinople. Pris de scrupules, Géraud fit rembourser le vendeur par un pèlerin qui allait à Rome. Pavie était donc un marché important du commerce vénitien et l'était encore au début du XI ${ }^{\mathrm{e}}$ siècle ${ }^{1028}$.

En 968 Luitprand rencontre des commerçants vénitiens à Constantinople, ce qui n'empêchait pas leurs relations avec les Musulmans ${ }^{1029}$.

Sur la plainte de Jean Tzimiskès, qui menaçait d'incendier les navires qui se livreraient à ce trafic, le doge Pierre Orseolo empêcha en 971 le départ de trois navires qui partaient pour El-Mediah, port de Kairouan, et pour Tripoli ${ }^{1030}$.

Cependant, en mars 992, le doge Pierre II Orseolo, qui s'était plaint des sévices exercés par les douaniers impériaux sur les marchands vénitiens, obtint de Basile II, non seulement satisfaction, mais des privilèges importants. Le fait que les marchands vénitiens soient placés sous la juridiction exceptionnelle du logothète du drome, indique qu'il existait déjà à Constantinople un embryon de colonie vénitienne ${ }^{1031}$.

Italie méridionale. - Sous la domination lombarde ou arabe, comme après la reconquête byzantine (876-892), les ports de l'Italie

1026 Ibidem, 77-80.

1027 HEYD, op. cit., I, 110 (vers 827).

1028 Vie de saint Géraud, écrite entre 936 et 942, A.S.B., oct. VI.; F. GANSHOF, op. cit., 295 et s.

1029 LUITPRAND, Relatio de legatione, 1.

1030 R.K.O.R., 738; HEYD, op. cit., I, 112 et s.

1031 R.K.O.R., 781; HeYD, J, 114 et s.; SCHLUMBERGER, L'Epopée byzantine, II, 312 et s. 
méridionale, Bari, Tarente, Reggio, Salerne, Amalfi, Naples, furent des marchés d'échanges des produits agricoles de ces régions contre les produits orientaux ${ }^{1032}$. Ce commerce fut de plus en plus prospère à mesure que la navigation redevint libre. Les marchands de l'Italie méridionale fréquentaient assidûment Constantinople dans la première moitié du XI ${ }^{\mathrm{e}}$ siècle. Ce n'était pas seulement les étoffes précieuses et les épices qu'ils achetaient, mais des œuvres d'art et les produits des industries de luxe, qu'ils rapportaient en Italie. Un peu avant 1078, Didier, abbé du Mont-Cassin, qui faisait reconstruire la grande basilique de son monastère, fit venir de Constantinople des maîtres habiles dans l'art de la mosaïque murale. Il envoya à Constantinople un moine, chargé de demander au basileus l'autorisation de faire fabriquer une table d'autel en or, décorée d'émaux et de pierres précieuses ${ }^{1033}$. En 1066 il avait commandé dans la Ville Impériale des portes de bronze décorées de figures damasquinées et niellées, semblables à celles qu'un marchand d'Amalfi, Pantaléon, le premier de la célèbre famille, avait offertes à la cathédrale de cette ville. Didier les avait beaucoup admirées et ce fut Maurus, fils de Pantaléon, qui prit les frais à sa charge ${ }^{1034}$.

La vogue de cet art délicat était grande dans l'Italie méridionale à cette époque, et ce furent des mécènes, comme les Pantaléon d'Amalfi ou un Landulf, noble de Salerne, qui contribuèrent de leurs deniers à son importation dans leur pays. Aux premiers on doit les portes de Saint-Paul-hors-les-Murs (1070), de la basilique du MonteSant'Angelo (1076), d'Atrani (1087); Landulf Butromil prit à sa charge celles de la cathédrale de Salerne ${ }^{1035}$.

La colonie amalfitaine dans l'Empire. - La famille des Pantaléon, qui possédait une maison à Constantinople, contribua à rendre plus intimes les rapports entre Amalfi et l'Empire. Le premier des Pantaléon est l'auteur d'un récit des événements qui aboutirent à l'excommunication du patriarche Michel Kéroularios par les légats de

\footnotetext{
1032 J. GAY, L'Italie méridionale et l'Empire byzantin, 580 et s.; HEYD, I, 97-100.

1033 LeOn D’Ostie, III, 18, 27; BertauX, L'art dans l'Italie méridionale, 272 et s.; J. GAY, op. cit., 596 et s.

1034 BerTauX, op. cit., 403 et s.; Dalton, Byzantine Art and Archaeology, 618.

1035 DAlton, op. cit., 618620; DieHL, Manuel d'Art byzantin, 714-716; L. BREHIER, Etudes sur l'histoire de la sculpture byzantine, 34-35, pl. XLVII-XLVIII; KINGSLEY PORTER dans M.Schl., 408-415 (portes de Monte Sant'Angelo).
} 
Léon IX, à Sainte-Sophie, le 15 juillet $1054{ }^{1036}$. Un autre citoyen d'Amalfi, Laycus, répandit dans toute la chrétienté un traité sur les azymes, dans lequel il adjurait les représentants des deux confessions d'éviter un schisme irréparable ${ }^{1037}$.

$\mathrm{Au} \mathrm{IX}^{\mathrm{e}}$ siècle, Amalfi avait échappé à la domination du duc lombard de Bénévent (839) et était devenue une république indépendante ${ }^{1038}$. Adossé à la montagne, sur un littoral étroit et âpre, sans autre communication avec la plaine de Campanie que les brèches ouvertes par les torrents qui se précipitent vers la mer, le territoire d'Amalfi n'offrait d'autre ressource à ses habitants que la navigation. Les forêts voisines leur fournissaient les bois nécessaires aux constructions navales et, dès le milieu du $\mathrm{IX}^{\mathrm{e}}$ siècle, leur marine était supérieure à celle de Naples. Leur trafic se porta d'abord vers les marchés musulmans d'Afrique, mais ne tarda pas à parcourir un champ plus vaste. On les trouve à Alexandrie au $\mathrm{X}^{\mathrm{e}}$ siècle, ce qui ne les empêche pas de mettre leur marine au service du Saint-Siège, puis de Byzance, dont ils se considèrent comme les sujets, lorsqu'elle reprend pied dans l'Italie méridionale. En 907 leur préfet (premier magistrat) reçoit le titre de spathaire candidat, puis en 920 , de patrice ${ }^{1039}$.

Mais ce fut au $\mathrm{XI}^{\mathrm{e}}$ siècle que le commerce d'Amalfi atteignit son plus haut degré de prospérité. Amalfi est alors le principal intermédiaire du commerce avec l'Afrique et avec l'Espagne musulmane. Elle a des comptoirs au Caire, en Syrie, à Durazzo dans l'Adriatique, et fait concurrence à Venise jusque sur le marché de Constantinople ${ }^{1040}$.

Aucune ville, écrit Guillaume d'Apulie, n'est plus riche en or, en agent, en étoffes de tout genre. Elle est habitée par de nombreux marins, aussi experts dans la connaissance du ciel que dans celle de la mer. On y apporte des marchandises d'Alexandrie et d'Antioche; on y connaît les Arabes et les Indiens, les gens de Sicile et d'Afrique ${ }^{1041}$.

A Constantinople la colonie des Amalfitains fut le premier établissement italien installé d'une manière permanente. Un grand nombre

\footnotetext{
1036 Anton MicheL, Amalfi und Jerusalem im griechischen Kirchenstreit, 52-54.

1037 Ibidem, texte de Laycus, 35-47.

1038 J. GAY, L'Italie méridionale et l'Empire byzantin, 54 et s.

1039 HEYD, Histoire du commerce du Levant, I, 99; J. GAY, op. cit., 247.

1040 J. GAY, op. cit., 585.

1041 Guillaume D’ApUlie, Gesta Roberti Wiscardi, III, 477 et s.
} 
de notables y résidaient, à l'exemple des Pantaléon. Ceux-ci avaient des relations dans tout l'Orient et leurs bienfaits ne se bornaient pas à leur pays. Maurus, fils du premier Pantaléon, fonda un hôpital à Antioche pour les pèlerins d'Occident. Grâce à leurs relations avec le calife fatimite, ils fondèrent à Jérusalem l'hospice de Sainte-Marie-laLatine, réservé aux Amalfitains ${ }^{1042}$. D'autre part, des Amalfitains se firent moines au Mont-Athos. Entre 980 et 1000, du vivant de saint Athanase, sept compagnons résidèrent d'abord à Iviron, puis obtinrent l'autorisation de construire entre Lavra et Karakallou un monastère des Amalfitains, pour y vivre suivant la règle bénédictine ${ }^{1043}$.

Ainsi, avant Gênes et Venise, Amalfi a tenu dans les marchés d'Orient une place prépondérante, mais la conquête normande de l'Italie méridionale ruina son commerce. Devenue sujette des Normands, ennemis de l'Empire, Amalfi perdit tout crédit à Constantinople. En 1082 Alexis Comnène subordonna sa colonie à Venise, qui eut désormais toutes les faveurs impériales ${ }^{1044}$.

\section{Les industries de luxe à Byzance}

\section{Retour à la Table des Matières}

Comme on vient d'en voir des exemples, le marché de Constantinople et tous les marchés méditerranéens étaient alimentés en grande partie par les industries de luxe qui avaient pris, du IX ${ }^{\mathrm{e}}$ au XI ${ }^{\mathrm{e}}$ siècle, un développement prodigieux. Nous n'avons pas à revenir sur le contrôle que l'État exerçait sur ces industries, mais on constate que ce fut à ce régime étatiste que l'on dut la bonne qualité des produits et l'intégrité de la monnaie.

Industries textiles. Le lin. - Après l'invasion arabe, Constantinople avait hérité des industries textiles de l'Égypte et en particulier de

\footnotetext{
1042 HEYD, op. cit., I, 101-403.

1043 Archives de l'Athos. Actes de Lavra (éd. Rouillard et Collomb), no 21(1018-1019); MEYER, Athos : Die Hauprurkunden der Athoskloster, 157 (lignes 22-27).

1044 J. GAY, op. cit., 1, 107.
} 
celle du lin, si répandue depuis l'époque romaine, ainsi que des tissus de coton, dont l'usage était d'ailleurs très rare ${ }^{1045}$.

Aux IX ${ }^{\mathrm{e}}$ et $\mathrm{X}^{\mathrm{e}}$ siècles, le tissage du lin avait pour centre la région du Strymon, celle du Pont et la ville de Cérasonte. La corporation des lintearii ( $\theta \omega v o \pi \rho \alpha ́ \tau \alpha)$ de Constantinople achetait ces étoffes pour les revendre aux tailleurs en tuniques et même à des particuliers, à condition que ceuxci ne les revendent pas. Ils entreposaient leurs tissus dans des boutiques ( $\rho \gamma \alpha \sigma \tau \eta \dot{\rho} \rho \alpha)$, mais ne pouvaient y faire de ventes et devaient porter leurs ballots au marché sur leurs épaules ${ }^{1046}$. Sur certaines toiles de lin, la décoration était peinte ou tissée dans l'étoffe même; d'autres étaient brodées de fils d'or et d'argent ${ }^{1047}$. A l'église de Hautvillers (Marne), des reliques de sainte Hélène, apportées de Rome à l'époque carolingienne, étaient enveloppées dans un tissu de lin filé au fuseau et brodé de médaillons reliés par des entrelacs cernant alternativement des aigles aux ailes éployées et des lions affrontés et adossés. Ce décor est complété par les beaux feuillages cruciformes qui remplissent l'espace entre les médaillons ${ }^{1048}$.

Drap, laine. - D'après une inscription chrétienne d'Asie Mineure, le $\beta \rho \alpha ́ k \alpha \rho t o \varsigma$ est un tailleur ordinaire. Le terme usité à Constantinople est $\beta \varepsilon \sigma \tau 10 \pi \rho \alpha ́ \tau \eta \zeta$, et l'on réservait le titre de á $\pi \tau \eta \zeta$ aux tailleurs de luxe, qui fabriquaient des vêtements de laine et de soie ${ }^{1049}$. Une peinture de l'Octateuque du Sérail (XII ${ }^{\mathrm{e}}$ siècle) représente un tailleur assis, jambes pendantes, sur un établi à six pieds, sous lequel on aperçoit l'étoffe qu'il est en train d'orner ${ }^{1050}$.

L'art de la tapisserie de haute laine est venu à la fois d'Égypte et de l'Iran. A toutes les époques, les tapisseries étaient recherchées à Byzance pour les tentures, les portières ( $\beta$ hov, velum) dont on faisait un grand usage dans les palais et les églises.

1045 Chwostov, Commerce oriental de l'Égypte gréco-romaine (en russe), Kazan, 1907 (voir J.S., 1910), 130 et s.

1046 Livre du Préfet, IX, 34.

1047 EBERSOLT, Les arts somptuaires de Byzance, 147

1048 MANCEAUX, Histoire de l'abbaye et du village de Hautvillers, 3 vol., Epernay, 1880, I, 222 et s.; III, 444-449 et planche. La toile, datée du XI siècle, est byzantine par son décor inspiré d'une étoffe de soie.

1049 HANTON, Recueils d'Inscriptions. Lexique explicatif.., B.N., 1927, 70, nº 262; Livre du Préfet, 39.

${ }^{1050}$ L'Octateuque du Sérail à Constantinople, pl. XXIV, 142. 
Héraclius avait trouvé dans le palais de Chosroès II, à Dastagard, une grande quantité de tapis de haute laine et d'autres brodés à l'aiguille ${ }^{1051}$. Au $\mathrm{X}^{\mathrm{e}}$ siècle, les jours de grandes réceptions au Grand Palais, on étendait sur le sol de précieux tapis de Perse ${ }^{1052}$.

Cependant l'art de la tapisserie était introduit à Constantinople et même dans les provinces comme le Péloponnèse, où la protectrice de Basile faisait fabriquer des tapis mœlleux pour la Nouvelle Église ${ }^{1053}$. Cette industrie se perpétue jusqu'au $\mathrm{XV}^{\mathrm{e}}$ siècle. A Thessalonique, sous les Comnènes, elle était exercée par les juifs ${ }^{1054}$.

Une tapisserie de haute lisse du XI ${ }^{\mathrm{e}}$ siècle, provenant de Saint-Géréon de Cologne, aujourd'hui au Musée des Tissus de Lyon, est faite de laine sur lin, ce qui donne un fond écru. Sur ces fonds se détachent des roues encerclant un griffon à tête de lion, qui déchirent un ruminant ; les roues sont reliées par de petits médaillons timbrés d'une tige de fleur ou d'un mufle de fauve. Il existe une véritable harmonie entre les teintes chamois, vertes, bleu pâle et mauves avec des rehauts de nuance rouille ${ }^{1055}$.

Le style monumental apparaissait sur une œuvre, dont une collection américaine ne possède plus que des fragments et qui, d'après une inscription, représentait un saint Théodore. D'après la dimension des fragments, notamment de la tête nimbée, le saint était figuré en pied, de grandeur naturelle. Le style dénote un art raffiné, par la délicatesse du modelé, qui rappelle l'art des icônes. La gamme des couleurs est riche et nuancée. Cette ouvre détériorée a pu faire partie d'un ensemble, destiné à un palais ou à une église ${ }^{1056}$.

Enfin, pendant son séjour à Paris en 1399, Manuel Il Paléologue fit don au duc Jean de Berry d'une tapisserie ornée de l'aigle à deux têtes figurant dans ses armes ${ }^{1057}$.

Industrie de la soie. - Après l'invasion arabe, l'industrie de la soie, si florissante en Syrie, surtout après l'importation des vers à soie, fut accaparée par les conquérants, mais prit un immense développement à Constantinople, où elle était déjà active au VI ${ }^{\mathrm{e}}$ siècle ${ }^{1058}$.

\footnotetext{
1051 TheOPHANES LE CONFESSEUR, Chronographie, 695.

1052 EBERSOLT, op. cit., 11 (la teinte favorite était le bleu de Perse).

1053 Theophanes, Continuatus, V, 76; EBERsolt, op. cit., 14.

1054 TAFRALI, Topographie de Thessalonique, 39 et s.

1055 Catalogue de l'Exposition d'art byzantin de 1931, n 1121.

1056 EBERSOLT dans G.B.A., 1925, 331-336.

1057 Décrite dans l'inventaire des objets d'art de Jean, duc de Berry (GUIFFREY, II, 1896, 262).

1058 PARISET, Histoire de la soie, I, 7.
} 
A côté des gynécées du Grand Palais, les manufactures privées se multiplièrent, soumises d'ailleurs aux règlements draconiens de 1'Éparque. Au $\mathrm{X}^{\mathrm{e}}$ siècle, cinq corporations s'occupaient de la fabrication et de la vente des soieries. Elles avaient à leur tête un exarque nommé par le Préfet ${ }^{1059}$. Il faut se rappeler d'ailleurs que les soieries tenaient une place énorme dans la vie byzantine, qu'il s'agisse du costume des hautes classes, de certaines chaussures, de tentures, des costumes et serviettes liturgiques, des couvertures d'évangéliaires, des étendards, etc. ${ }^{1060}$.

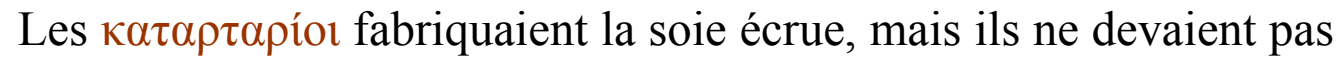
acheter plus de soie qu'ils ne pouvaient en travailler. Ces achats devaient être faits en commun par les membres de la corporation. Les $\mu \varepsilon \tau \alpha \xi o \pi \rho \alpha ́ \tau \alpha \iota l$ vendaient la soie écrue au Forum. Les tisserands en soie

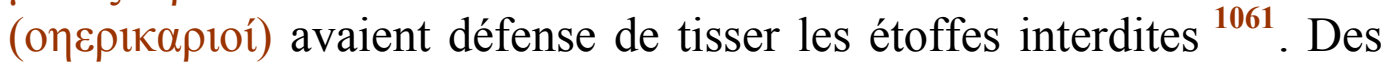
inspecteurs avaient le droit d'entrer dans leurs boutiques en tout temps et de contrôler leur travail. Il leur était en outre interdit d'acheter la soie à d'autres qu'aux métaxopratai. Les $\beta \varepsilon \sigma \tau 10 \pi \rho \alpha ́ \tau \alpha l$ achetaient et vendaient les vêtements de soie, sauf les étoffes interdites. Les vêtements qu'ils exportaient devaient porter la bulle de plomb du Préfet ${ }^{1062}$.

Mais l'usage de la soie était si répandu que les manufactures de Constantinople ne pouvaient suffire aux demandes. C'est ce qui explique qu'au XII ${ }^{\mathrm{e}}$ siècle des tissages de soieries aient été créés à Thèbes ${ }^{1063}$. Ils furent bientôt très renommés ${ }^{1064}$ et ils reprirent leur activité après le raid normand de 1146 et la déportation des tisseuses et brodeuses dans les ateliers de Palerme. En 1161 Benjamin de Tudèle y voit des juifs, qui comptent parmi les meilleurs tisserands et teinturiers de la Grèce, et en 1195 Alexis III envoie quarante scaramanges, sortis de ces ateliers, au sultan d'Iconium ${ }^{1065}$.

\footnotetext{
1059 Livre du Préfet, 29 et s.

1060 EBERSOLT, Les arts somptuaires de Byzance, 22.

1061 Réservées au basileus. Cf. LuITPRAND, Relatio de legatione, 55, 359 et s.

1062 Livre du Préfet, 34 et s.

1063 WEIGAND, Die helladische byzantinische Seidenweberei, 503-514.

1064 Satire contre les higoumènes, trad. Jeanselme et Oeconomos, 324.

1065 Benjamin De Tudele, Voyages, IV; W. Miller, Essays on the Latine Orient; Nicetas KHONIATES, Histoire, Al., III, I, 4.
} 
Les teinturiers. - La teinture était appliquée à toutes les étoffes de soie et de laine et parfois même de lin. Il existait au $\mathrm{V}^{\mathrm{e}}$ siècle une corporation (collegium) des murileguli, conchylileguli. Une loi de Théodose leur défend d'abandonner leur métier pour briguer les honneurs et elle est reproduite dans le Code Justinien ${ }^{1066}$. Au $\mathrm{X}^{\mathrm{e}}$ siècle il n'est pas question d'eux dans le Livre du Préfet, ce qui montre que, sauf dans les gynécées du Palais, cette industrie était libre. Ce qui confirme cette hypothèse, c'est la novelle 80 de Léon VI qui abroge les lois du $\mathrm{V}^{\mathrm{e}}$ siècle interdisant aux particuliers de porter des vêtements ornés d'empiècements ou de bordures de pourpre ${ }^{1067}$. Les autres teintes qui se rapprochaient de la pourpre, rose clair ou lilas, étaient tolérées.

Dès l'antiquité, à côté de la vraie pourpre, tirée du murex pêché sur les côtes de Laconie et de Syrie, on tirait la teinture de divers végétaux (oseille, garance) et surtout de la cochenille de Pologne (blatta) importée en Orient par les plaines russes et la mer Noire ${ }^{1068}$. On teignait parfois la chaîne et la trame d'une étoffe de deux couleurs différentes, on y tissait même les filaments d'un mollusque, la pina marina ${ }^{1069}$.

$\mathrm{Au} \mathrm{X}^{\mathrm{e}}$ siècle les teinturiers avaient atteint dans leur art une véritable maîtrise et, par de savants mélanges des deux tons de pourpre (cramoisie et améthyste), créaient les nuances les plus délicates : quatre tons de rose (ton jaune, rose tendre, deux roses foncés). Ils imitaient la couleur des fruits (abricot, pêche, citron, vert pomme), employant tantôt les tons vifs, tantôt les demi-teintes ${ }^{1070}$.

Voici d'ailleurs quelques spécimens d'assortiments de couleurs sur les étoffes byzantines du Trésor de la cathédrale de Sens : dessin bleu foncé, jaune clair et blanc sur fond chamois (suaire de saint Victor) ; soierie blanche à dessins damassés avec rehauts de pourpre violette (suaire de saint Savinien); dessin rouge cerise et or sur fond écru (suaire de saint Léon) ${ }^{1071}$; fond blanc, rehauts de pourpre violette et or (suaire de saint Siviard).

C.J., XI, VII, 11, 13 (a. 424).

1067 LEON VI, empereur, Novelles, 272-275.

1068 PARISET, op. cit., 7 et s. Tissus de Palmyre. - Pfister dans Parnassus, VII, 1935.

1069 EBERSOLT, op. cit., 20-22.

1070 Ibidem, 22 et $\mathrm{s}$.

1071 Catalogue de l'Exposition d'art byzantin de 1931, $\mathrm{n}^{\text {os }} 270,278,281$, 293; ChARTRAIRE, Le trésor de la cathédrale de Sens (« Memoranda », Paris), 9-11 et R.A.C., 1911. 
Le décor; les modèles iraniens. - Le nombre des fragments de tissus dispersés dans les collections est infini, mais on ne possède plus une seule pièce de grande dimension ${ }^{1072}$. Du moins, la composition décorative donne quelque idée de l'effet chatoyant que produisaient ces soieries avant leur dépeçage. Le modèle qui s'imposait à tous les tissus consistait dans la répétition sans fin du même thème, disposition tout orientale. Le schéma géométrique et la symétrie parfaite étaient la loi du genre.

Parfois il n'y a pas de cadre, mais le sujet est répété symétriquement entre des bandes décoratives tels les dompteurs de lions du $\mathrm{Mu}-$ sée de Cluny, qui se font face et ouvrent chacun la gueule d'un fauve ${ }^{1073}$.

Mais, le plus souvent, le sujet principal est encadré dans un cercle ou une ellipse formant une large bande, garnie de petits sujets décoratifs. Ces roues sont reliées entre elles par des disques, placés au nombre de quatre à l'extrémité de leurs axes. L'espace qui sépare les roues est garni d'animaux affrontés ou d'un décor végétal. Ce décor est d'origine iranienne et il fut appliqué à Constantinople aux thèmes les plus variés : aurige conduisant un quadrige ${ }^{1074}$, empereurs chassant le lion ${ }^{1075}$, thème païen du sacrifice aux Dioscures ${ }^{1076}$, thème chrétien de l'Annonciation ${ }^{1077}$, animaux isolés ou affrontés ${ }^{1078}$.

Cette ordonnance fut imitée dans les plus anciens tissus fabriqués en Occident ${ }^{1079}$, où les soieries byzantines excitaient une admiration sans bornes. Les poètes qui les décrivaient, racontaient qu'elles étaient tissées par les fées qui habitent les îles lointaines ${ }^{1080}$.

La broderie. - Les brodeurs et surtout les brodeuses enrichissaient souvent les tissus de décors variés. La broderie de fils d'or (ars

\footnotetext{
${ }^{1072}$ La plus importante est le linceul de soie cramoisie de la châsse de saint Remi à Reims (2,35 m sur 1,90 m), exposé à Paris en 1942.

1073 Exposition d'art byzantin .... n ${ }^{\circ}$ 214; L. BREHIER, La sculpture et les Arts mineurs byzantins, pl. LXXXV.

1074 BREHIER, op. cit., pl. LXXXIV.

1075 Ibidem, pl. XC.

1076 DiEHL, Manuel d'art byzantin.

$1077 \mathrm{Ph}$. LAUER, Le trésor du « Sancta Sanctorum » à Rome, F.E.P.M., XV, 1906.

1078 CHARTRAIRE, op. cit.

1079 Ibidem, 44.

${ }^{1080}$ E. MALE, L'art religieux du XII siècle en France, 344,
} 
barbaricaria) était exercée jusqu'en Gaule au $\mathrm{V}^{\mathrm{e}}$ siècle par des Syriens ${ }^{1081}$ et l'on y mélangeait parfois des perles fines Sur les rideaux suspendus entre les colonnes d'argent du ciborium qui abritait l'autel de Sainte-Sophie, on avait brodé trois arcades d'or sur un fond tissé en fils multicolores. Sous celle du milieu apparaissait l'image du Christ. Sur ses vêtements, les fils d'or étaient cousus au tissu par de petits points en fil de soie ${ }^{1082}$.

Le métier de brodeur sur or ( $\tau \varepsilon \chi v i ́ \tau \eta \varsigma)$ était très répandu encore au $\mathrm{XII}^{\mathrm{e}}$ siècle et très lucratif ${ }^{1083}$. Sur un manuscrit daté de 1368 une peinture représente des femmes assises dans un jardin fleuri, brodant à l'aiguille une étoffe ornée ; une autre, devant un métier à tisser, enroule le fil autour des fuseaux ${ }^{1084}$.

La broderie d'or et d'argent, enrichie de perles et de pierreries, était appliquée aux ornements ecclésiastiques, dont la somptuosité émerveillait les étrangers ${ }^{1085}$, aux voiles liturgiques, en particulier aux épitaphioi figurant le Christ mort veillé par les anges ${ }^{1086}$, sur les poêles et draps mortuaires ${ }^{1087}$, sur les étendards ${ }^{1088}$. A toutes les époques, la broderie servait à représenter, sur les vêtements d'apparat, des portraits et de larges compositions, comme le triomphe de Justinien sur Gélimer, en fils d'or sur un fond de pourpre ${ }^{1089}$, comme la Transfiguration, la réception des justes au ciel, la Communion des Apôtres sur la dalmatique dite de Charlemagne, au Vatican ${ }^{1090}$.

Autres industries de luxe. - Nous avons déjà cité les portes de bronze incrustées d'argent du XI ${ }^{\mathrm{e}}$ siècle ${ }^{1091}$. Des œuvres importantes, en bronze et autre métal, datent du règne de Théophile ${ }^{1092}$. Une technique très répandue depuis $l e \mathrm{~V}^{\mathrm{e}}$ siècle était celle des plats, disques

\footnotetext{
1081 Voir supra, p. 174.

1082 Paul Le Silentiaire, Poèmes (trad. ital. Veniero), vers 758-805.

1083 TheOdore Prodrome, E $\varsigma \tau \vee \beta \alpha \sigma \imath \lambda \varepsilon ́ \alpha$, vers 23, B.G.V., t. 5.

1084 Paris, gr. 135, f 22 vo; EBERSOLT, La Miniature byzantine, pl. LXIII, 2.

1085 IgNACE DE SMOLENSK, Pèlerinage, 143; EBERSOLT, Les arts somptuaires de Byzance, 118.

1086 Ochrida (1305), Chilanday, Salonique (musée d'Athènes), G. MILLET, Broderies religieuses de style byzantin, et B.C.H., 1905; L. BREHIER, La Sculpture et les Arts mineurs byzantins, pl. XCIV.

1087 TAFRALI, Le trésor byzantin et roumain du monastère de Pontna, pl. 51-57.

1088 S. G. MerCATI, Sull'iscrizione del cosidetto " vesillo navale » di Manuele Paleologo, Bessarione, 25, 1921, 149 et $\mathrm{s}$.

1089 CORRIPUS, In laudem Justini (éd. Partsch), vers 276 et s.

1090 BREHIER, La Sculpture et les Arts mineurs byzantins, pl. XCIII.

1091 Supra, p. 183.

1092 BREHIER, op. cit., pl. XLVI; EBERSOLT, Les arts somptuaires de Byzance, 58-64.
} 
(missoria, clypei), patènes, etc., en argent rehaussés d'or, traités au repoussé avec la reprise des détails à l'aide du burin. Un des premiers centres de la fabrication de ces objets, revêtus de poinçons de contrôle, paraît avoir été Antioche, puis cette technique s'implanta à Constantinople, où les objets d'or et d'argent furent enrichis de pierres précieuses et d'émaux ${ }^{1093}$.

L'industrie artistique qui évoque le mieux les splendeurs de Byzance est celle des émaux cloisonnés à fond d'or, dont l'origine iranienne est certaine et dont les plus anciens spécimens connus proviennent du butin des peuples barbares en contact avec Byzance ${ }^{1094}$. Dans des cloisons de métal, formées de petites bandes, qui suivaient les contours d'un dessin obtenu au burin, on déposait un mélange vitrifié incolore, formant le fondant, réduit en poudre fine. On mélangeait cette poudre avec des oxydes métalliques de couleurs variées. On procédait ensuite à plusieurs cuissons à de hautes températures.

L'émaillerie était usitée à Constantinople au VI siècle : des émaux décoraient les parements de l'autel de Sainte-Sophie ${ }^{1095}$; mais la grande époque de l'émaillerie byzantine est celle de la dynastie macédonienne. Rien de plus brillant, de plus somptueux que la staurothèque de Limbourg-sur-Lahn et aussi de plus représentatif de l'idéal byzantin et de son art de coloristes ${ }^{1096}$. Rien de plus original que le calice d'or de la collection Stocklet de Bruxelles, dont le fond est décoré de minuscules émaux cloisonnés figurant la Cène ${ }^{1097}$.

Il faut encore citer des travaux délicats, hérités de l'antiquité, comme le travail des pierres fines, taillées et gravées, puis enchâssées dans l'or pour faire des boucles d'oreilles, des bracelets, des anneaux, des fibules ${ }^{1098}$.

1093 Brehier, 35-37 et pl. LVIII-LX; Anne Comnene, Alexiade, III, 1 (I, 35) : présents d'Alexis Comnène à Henri IV.

1094 Par exemple, l'aiguière de Saint-Maurice d'Agaune (Valais), fabriquée à l'époque carolingienne avec les débris d'un sceptre de prince barbare. ALFOLDI, L'aiguière d'or de SaintMaurice en Valais; N. KONDAKOV, Le trésor de Nagy-Szent-Miklós (Hongrie) dans Revue by1095 zantine de l'Institut américain, 1, 1947.

1095 BREHIER, 39-40, pl. LXI.

1096 Ibidem, 41, pl. XII; voir p. 227.

1097 Ibidem, 41-43, pl. LXIII, pl. LXX-LXXII.

${ }^{1098}$ Les bijoux les plus anciens sont dus à des artisans coptes; à partir du IX $\mathrm{X}^{\mathrm{e}}$ siècle, prépondérance de Constantinople; aux pierres précieuses on ajoute l'émail et la niellure. EBERSOLT, Les arts somptuaires de Byzance, 143; BREHIER, La Sculpture et les Arts mineurs byzantins, 43-45, pl. LXXIII-LXXIV. 
Les pierres précieuses venaient presque exclusivement de l'Inde. On racontait que, sous Constantin, un aventurier d'origine perse, Métrodore, se faisant passer pour philosophe, alla dans l'Inde et, en pratiquant la continence, gagna la vénération des brahmanes, qui lui permirent de pénétrer dans leur sanctuaire. Là il vola tout ce qu'il put emporter de perles et de pierres précieuses et le roi du pays lui en donna d'autres pour Constantin. On expliquait ainsi la prodigieuse quantité de perles et de pierreries qui circulait dans l'Empire ${ }^{1099}$.

A cette technique se rattache la taille des pierres dures, jaspe vert ou sanguin, albâtre, onyx, etc., avec lesquelles on fabriquait des camées, des coupes et les beaux calices du trésor de Saint-Marc de Venise, sur lesquels se mélangent les techniques (montures d'orfèvrerie ornées de gemmes) ${ }^{1100}$. Remarquables par leur délicatesse sont les icônes en stéatite de saints militaires, d'anges, etc., qui rivalisent avec les ivoires taillés ${ }^{1101}$.

Rien de plus charmant que le travail des ivoiriers, dont les œuvres conservées nous renseignent sur les diverses périodes de la sculpture byzantine : diptyques consulaires des $\mathrm{V}^{\mathrm{e}}$ et $\mathrm{VI}^{\mathrm{e}}$ siècles, dont le modèle stéréotypé vient de Rome, monuments chrétiens, polyptyques, pyxides de la même époque, imitation de modèles antiques de la période macédonienne (coffrets à thèmes profanes, tableaux d'ensemble, triptyques, diptyques avec des reproductions de la draperie antique remarquables par la fermeté du style) ${ }^{1102}$.

Une peinture d'un manuscrit d'Oppien de Cilicie, à côté des vers décrivant les défenses d'un éléphant, montre un jeune ivoirier au travail. Il est assis devant un banc sur lequel on voit une sorte de rateau et un étau fait de tiges mobiles, entre lesquelles on distingue un morceau d'ivoire, un oiseau mal dégrossi, que l'artiste a l'air de limer. Pour ce travail on se servait aussi d'un maillet ou d'une scie, ainsi que de grattoirs ${ }^{1103}$.

Artisans et ouvriers. - Quel était le sort des ouvriers qui exécutaient ces merveilles? Leur instruction technique se faisait dans les ateliers, où ils entraient au sortir de l'enfance. Nous sommes renseignés là-dessus par quelques contrats d'apprentissage, dont les plus

1099 Georges CEDRENOS, Synopsis, I, 516 et s.; EBERSOLT, op. cit., IX.

1100 DIEHL, Manuel d'Art byzantin, 704-706.

1101 BREHIER, op. cit., 23-24, pl. XVIII-XX.

1102 Ibidem, 25-31, pl. XXI-XXXIX.

1103 OpPIEN DE CILICIE, Les Halieutiques. Les Cynégétiques. (trad. Bourquin), vers 489-514; D.A.C.L., VII, 1927, col. 1925. 
anciens, découverts en Égypte sur des papyrus, vont d'Auguste à la fin du III siècle : plusieurs se rapportent à l'industrie textile. Les apprentis sont des mineurs loués par leurs parents ou moyennant une somme payée par l'employeur. Le terme de l'apprentissage est de deux ans ${ }^{1104}$.

On retrouve des clauses analogues sur un papyrus de Panopolis (Akhmin), daté de 605, sous le règne de Phocas ${ }^{1105}$.

Contrat entre Aurelios Dioscoros Asynios et sa mère, Tibellia, du bourg de Thinos, d'une part ;

Et Aurelios Pachymios Psathos, de Panopolis, d'autre part :

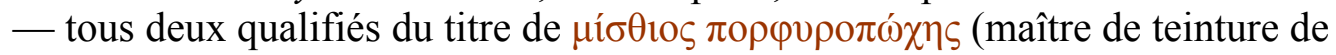
pourpre).

L'employeur s'engage à mettre l'apprenti en état d'exercer ce métier au bout de deux ans, à condition de recevoir de lui 11 mesures de blé. On remarquera qu'ici c'est l'apprenti qui doit une indemnité au patron. Comme à l'époque romaine, un fort dédit à payer est prévu par celle des deux parties qui résilierait le bail avant terme.

A Constantinople, et il en était ainsi dans beaucoup de villes, chaque corporation avait son quartier : les Verriers à la porte de la Verrerie ouvrant sur la Corne d'Or; les Fondeurs de bronze dans le quartier des Chalchoprateia, entre Sainte-Sophie et le Forum de Constantin ; les Fondeurs d'or et d'argent dans la Mésé, sous la surveillance directe du Préfet; les Orfèvres, les Tisserands en soie aux abords du Grand Palais ${ }^{1106}$.

L'État contrôlait le prix des denrées et des salaires. Après la peste de 542-543 il y eut une augmentation subite des prix. Par une novelle, Justinien rétablit les anciens prix des denrées et défendit toute augmentation de salaire sous peine d'une amende équivalent au triple de leurs bénéfices, infligée aux employeurs ${ }^{1107}$. En fait, le chômage n'existait guère et les ouvriers ne pouvaient être renvoyés que difficilement. Tout homme capable de travailler, trouvé sans emploi, était dirigé sur une œuvre d'utilité publique ou de charité ${ }^{1108}$. Pendant la

1104 Chwostov, Commerce oriental de l'Égypte gréco-romaine, 197.

1105 BRUNET DE PRESLE, N.E.M., XVIII, 2, 1865, 254.

1106 EBERSOLT, op. cit., 5 et s.; du même : Sanctuaires de Byzance, 54 et s.

1107 C.I.C.I., nov. 122 (544), on ignore comment l'édit fut appliqué; BURY, History of the later Roman Empire, II, 356.

1108 G. STEIN, Geschichte des spätrömischen Reiches, I, Vienne et 11, Paris, 186; BURY, The imperial administrative System in the ninth Century, 76. 
persécution des images, un grand nombre de spécialistes des industries de luxe se réfugièrent à Rome où, ainsi qu'on l'a vu, ils installèrent leurs métiers et importèrent en Italie l'art de l'Orient.

\section{La fin de l'étatisme et les colonies étrangères (1081-1204)}

\section{Retour à la Table des Matières}

Nous ne reviendrons pas sur la triste situation de l'Empire à l'avènement d'Alexis Comnène. Les spéculations sur le cours des blés sous Michel VII ${ }^{1109}$ et dix ans de guerres civiles ont jeté un tel trouble dans l'économie de l'Empire que, pour la première fois, le gouvernement impérial a dû affaiblir momentanément le titre du nomisma, que l'on désigne désormais sous le nom d'hyperpère ${ }^{1110}$.

Sans doute Alexis I ${ }^{\mathrm{er}}$ et ses successeurs relevèrent la situation politique, à l'intérieur comme à l'extérieur, mais ce fut aux dépens de la richesse de l'Empire. Pour faire face aux invasions des Normands d'Italie, qui voulaient s'emparer de Constantinople, ils durent faire alliance avec les républiques italiennes, Venise, Gênes, Pise, qui mirent leurs flottes au service de l'Empire, moyennant la concession d'établissements permanents à Constantinople et de privilèges commerciaux, qui ruinèrent l'industrie et le commerce de Byzance.

Par le traité conclu avec Venise en mai 1082, Alexis Comnène créait un dangereux précédent: la concession d'avantages économiques pour des raisons politiques. Ses successeurs devaient profiter de la leçon. Après le règne brillant de Manuel $\mathrm{I}^{\mathrm{er}}$, la vérité apparut et les Anges conduisirent l'Empire à sa ruine. Dans l'organisation de la croisade de Constantinople, les causes économiques tinrent une place prépondérante : Venise voulut recouvrer sa situation à Constantinople et en Grèce, mise en péril par les Génois.

Ainsi l'économie dirigée, l'étatisme, qui avait fait la grandeur et le succès des entreprises économiques de Byzance, disparaissait pour

\footnotetext{
1109 G. BRATIANU, Etudes byzantines d'histoire économique et sociale, 142-150.

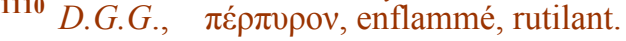


toujours. L'industrie et le commerce étaient désormais libres, mais les bénéfices de cette liberté allaient enrichir surtout des étrangers ou des grands propriétaires pourvus de privilèges.

Conséquences des croisades sur l'économie byzantine. - L'une des conséquences des croisades et de la création des États francs en Syrie fut de déposséder Constantinople de sa situation de marché central entre l'Orient et l'Occident. Le commerce des Indes et de la Chine aboutit désormais aux ports de Syrie, d'où des flottes italiennes les transportent en Occident. Avec ces produits orientaux, épices, parfums, soieries, etc., le fret de retour comporte ceux de Syrie et de Palestine : vins, olives, canne à sucre, coton, soie, verrerie de Tyr, teintures, etc. Ces flottes font en général deux voyages par an, à Pâques et à la Saint-Michel. Leur fret se compose de pèlerins et de quelques produits d'Occident, comme les gros draps de Flandre retravaillés en Lombardie. Constantinople ne pouvait soutenir cette concurrence son marché était désormais en marge des grandes voies commerciales.

Le réveil de l'Occident. - Il s'est passé en effet un des événements les plus importants de l'histoire universelle: le réveil de l'Occident, le passage d'une économie purement rurale à une nouvelle vie urbaine, dans laquelle la prépondérance appartient à des corporations d'artisans et de marchands. Bien plus, au XII siècle, la France, après l'Italie, eut aussi ses marchés internationaux, dont les foires de Champagne, fréquentées par des marchands venus de tous les coins de l'Europe, dépassaient en importance la célèbre foire de SaintDémétrius à Thessalonique.

On ne saurait attacher trop d'importance à cette révolution. Les pays européens de l'Ouest semblent se réveiller d'un long sommeil et, si grand que soit encore auprès d'eux le prestige de Byzance, ils créent eux-mêmes, par leurs propres forces, la civilisation qui deviendra celle du monde entier.

$\mathrm{Au} \mathrm{XII}{ }^{\mathrm{e}}$ siècle, il y avait encore des industries byzantines et leur réputation était toujours grande, mais on ne voyait plus guère de marchands grecs sur les routes du grand commerce et les étrangers seuls, les Italiens surtout, fréquentaient le marché de Constantinople, où leurs importations augmentaient sans cesse, aux dépens de la monnaie 
impériale. Il en était de même sur les autres marchés de l'Empire. La foire de Thessalonique attirait, non seulement les Italiens, mais les Francs, les Bulgares et les peuples du Nord. D'autres marchés se tenaient à Corinthe, à Almyros sur le golfe de Volo, à Nègrepont, Chios, Andros, Chrysopolis, Rodosto, Adramyttion, Attalie ${ }^{1111}$.

Le XII ${ }^{\mathrm{e}}$ siècle est vraiment l'époque où s'achève le réveil du grand commerce européen, mais ce n'est pas Byzance qui en profite. Située entre le monde arabe, l'Italie byzantine et l'Occident, la Sicile des rois normands semble avoir capté tous les arts, toutes les industries, toutes les ressources intellectuelles de ces sociétés, pour en faire, sous Roger II et ses successeurs, une des plus brillantes, des plus somptueuses civilisations qui aient jamais régné en Europe.

Les colonies étrangères dans l'Empire. - Désormais, suivant un mot de Nicétas, 1'empereur «cherche à gagner les bonnes grâces des Italiens, qui ont l'habitude d'entrer, voiles déployées, dans le port de la Reine des villes $\gg{ }^{1112}$.

C'est Venise qui apparaît la première. Alexis Comnène lui accorde la franchise dans tous les ports de l'Empire et, à Constantinople, un quartier situé sur la Corne d'Or en face de l'embarcadère pour Galata, les trois échelles situées sur ce quai et une boulangerie ${ }^{1113}$. A ce moment Venise avait des établissements à Corinthe, à Thèbes, à Nègrepont, à Saint-Jean-d'Acre, à Alexandrie. Ses banques ouvraient de larges crédits, avec paiements à terme, aux entreprises commerciales ${ }^{1114}$.

En 1111 Alexis I ${ }^{\text {er }}$, en guerre avec Bohémond, s'assure l'alliance de la république de Pise, en lui cédant l'importation en franchise de l'or et de l'argent et un droit réduit à $4 \%$ sur les autres articles. Les Pisans auront à Constantinople un quartier, des maisons, des magasins, une échelle, des places réservées à Sainte-Sophie et à l'Hippodrome ${ }^{1115}$.

\footnotetext{
1111 Chalandon, Les Comnène, II, 625 et s.

1112 NiCETAS KHONIATES, Histoire, 25 (Bonn).

1113 R.K.O.R., 1081; HEYD, Histoire du commerce du Levant, I, 193 et s.

1114 Archivio Veneto (Morozzo, Documenti...). Venise, 1940.

1115 R.K.O.R., 1255; HEYD, op. cit., I, 193 et s.
} 
Les Génois n'ont accès à Constantinople qu'en 1155, sollicités par Manuel Comnène, en guerre avec les Normands d'Italie. Ils obtiennent pour leur commerce la réduction des droits de douane à $4 \%$, mais le quartier qui leur est concédé est situé dans la région déjà occupée par les Vénitiens et les Pisans. Il en résulta une vive irritation des Pisans et des Vénitiens, qui pillèrent sauvagement le quartier génois en 1162. Après de longues négociations, Manuel établit les Génois hors de la ville (1169). Mécontents de cette mesure, ils finirent par obtenir le quartier de Koparion sur la Corne d'Or (1170), mais ce nouvel établissement fut encore mis à sac par les Vénitiens. L'année suivante, les Génois furent remis en possession de leur quartier ${ }^{1116}$.

La plupart des Italiens établis dans l'Empire ne payaient que $10 \%$ de droits sur les importations, les Génois et les Pisans $4 \%$ et les Vénitiens, qui formaient la colonie la plus nombreuse et qui étaient les plus arrogants, avaient franchise complète. Cette situation ne pouvait durer et eut pour résultat le terrible pogrom de 1182 contre les colonies occidentales. La politique maladroite des Anges fit le reste et acheva la ruine de l'Empire.

\section{L'Expropriation et la conquête économique de Byzance (1263-1453)}

\section{Retour à la Table des Matières}

Après la restauration incomplète de 1261, et malgré les efforts de Michel Paléologue pour le relever (1261-1282), l'Empire devient un pays passif et tombe sous le joug politique et économique des étrangers.

Deux causes de faiblesse surtout s'opposent à tout espoir de relèvement : la chute de la monnaie byzantine, qui détermine la frappe de l'or en Occident, et la situation de Constantinople, devenue un champ de bataille entre Gênes et Venise, qui se disputent son marché et la pénétration dans la mer Noire.

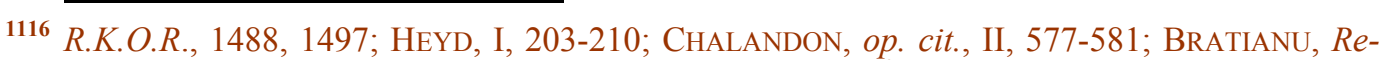
cherches sur le commerce génois dans la mer Noire au XII siècle, 73. 
La chute de la monnaie impériale. - Il y avait eu déjà, ainsi qu'on l'a vu, des crises passagères de la monnaie, mais elles avaient toujours été résolues. En 1204 l'hyperpère valait encore $90 \%$ du taux ancien ${ }^{1117}$. Les premières difficultés se présentèrent à Nicée sous Jean Vatatzès, qui frappa pour le commerce intérieur des pièces d'or à 16 carats d'or fin ${ }^{1118}$ et des pièces normales à 24 carats pour le commerce extérieur ${ }^{1119}$.

Après la reprise de Constantinople en 1261, Michel Paléologue ordonna la refonte des monnaies, mais fit tomber l'hyperpère à 9 , puis à carats ${ }^{1120}$.

Frappe de l'or en Occident. - Cette mauvaise monnaie faisait le plus grand tort au commerce international, au moment où il atteignait son plein développement, et ce fut ce qui détermina les Occidentaux à frapper des monnaies d'or. Frédéric II en avait déjà donné l'exemple avec son augustal. En 1252 Florence frappait le florin à la fleur de lis, qui eut tout de suite un grand succès. En 3284 le Grand Conseil de Venise décida la frappe de son ducat, qui ne tarda pas à faire prime $^{1121}$.

Conséquences sur la monnaie impériale. - Au début de son règne, Andronic II chercha à améliorer l'hyperpère, mais en $1302 \mathrm{Ve}-$ nise refuse cette monnaie, comme de mauvais aloi ${ }^{1122}$. Puis en 1304 , la solde qu'il fallut payer aux Almugavars précipita l'effondrement de la monnaie. Par suite de la pénurie du Trésor, on frappa des hyperpères à 5 parties d'or contre 19 d'alliage. M. Adrien Blanchet, qui a étudié les pièces d'Andronic II, a constaté que le mauvais alliage de cuivre y tenait la plus grande place. Cependant des pièces à double effigie (Andronic II et Michel IX, surtout Andronic II et Andronic III) accusent une réelle amélioration. Dans la suite il semble qu'on se soit efforcé de conserver le titre en diminuant le poids. Une pièce d'or de

\footnotetext{
1117 BRATIANU, op. cit., 227.

1118 Le carat valait un vingt-quatrième du poids total de l'hyperpère.

1119 BRATIANU, op. cit., 229 et s.; MORAVCSIK, Die byzantinischen Quellen der Geschichte der Türkvölker, 346; E. STEIN, Untersuchungen zur spätbyzantinischen Verfassungs- und Winschaftsgeschichte, 12 et s.; PACHYMERE, Histoire, II, 493. — En 1253 Guillaume de Rubrouck donne des hyperpères à des Tartars qui les frottent contre leur nez pour savoir s'ils sentent le cuivre.

1120 BRATIANU, op. cit., 230 et s.

1121 Ibidem, 222-224, 235-239 et M.D., I, 39.

1122 PACHYMERE, Histoire, 494 (Bonn).
} 
Jean $\mathrm{V}$ (vers 1391) ne pèse que $1 \mathrm{~g} 88^{1123}$, mais son titre est excellent. Au revers, l'effigie de saint Jean-Baptiste est du même type que celui du florin.

Ces expédients ne pouvaient permettre à la monnaie impériale de lutter contre les florins et les ducats, devenus l'instrument d'échange du grand commerce. Les paiements se faisaient d'ailleurs au poids, ce qui rendait l'amélioration du titre illusoire. Les hyperpères n'étaient plus considérés que comme une monnaie de compte et n'entraient dans les paiements qu'évalués en ducats ou en florins ${ }^{1124}$.

Mais on n'avait pas encore atteint le fond du précipice. Manuel II fit une nouvelle émission de monnaies à titre faible, de type vénitien. Jean VIII cessa de lutter et n'émit que des pièces d'argent et de cuivre. Le gouvernement vivait de crédits consentis par Venise et d'aumônes, payées en monnaies étrangères ${ }^{1125}$.

Les colonies étrangères à constantinople en 1453. - Sous les derniers Paléologues on retrouve les nombreuses colonies étrangères énumérées par le marchand italien Pegolotti, agent de la maison Bardi de Florence, qui pénétra en Chine et séjourna à Chypre (1324-1327), puis en 1335 à Constantinople ${ }^{1126}$. D'après lui, un cadeau bien placé faisait diminuer les droits de douane. Les Grecs qui réfléchissaient déploraient cette mainmise des étrangers sur les ressources qui faisaient autrefois la richesse de l'économie byzantine et la grandeur de l'État.

A l'origine, écrit Nicéphore Grégoras, on a permis [aux Latins] d'élever quelques petites et misérables constructions... Avec le temps ils sont arrivés à l'éclat et à la puissauce Les discordes des princes, l'affaiblissement des armées sont la cause de cette prospérité qui a mis entre leurs mains «non seulement toutes les richesses de Byzance et les revenus de la mer, mais encore routes les ressources publiques qui enrichissaient le trésor du prince ${ }^{1127}$.

1123 A. BLANCHET, Les dernières monnaies d'or des empereurs byzantins, 86-90 (1'hyperpère normal pesait 4 grammes).

1124 STEIN, op. cit., 13 et s.; DIEHL, Etudes byzantines, 248-250.

1125 STEIN (op. cit.) remarque qu'on ne connaît aucune monnaie de Constantin XI.

${ }^{1126}$ Francesco Belducci PEgOLOTTI, Practica della Mercatura; HeYD, Histoire du commerce du Levant, I, 482.

1127 NICEPHORE GREGORAS, Histoire romaine, 1096. 
En 1453 les colonies les plus puissantes sont toujours celles de Gênes et de Venise, qui ont organisé chacune un véritable État, avec son podestat, ses conseils, ses magasins, la première à Galata, l'autre en face, sur la Corne d'Or ${ }^{1128}$. Ces colonies dépendent étroitement de leurs métropoles : les conflits sont fréquents entre elles et le gouvernement impérial et se terminent toujours à leur avantage. Gênes recherche l'alliance des Turcs, mais tient à maintenir le régime byzantin, qui est pour elle si avantageux. Venise, au contraire, tout en ménageant les Turcs, craint beaucoup que la chute de Byzance ne lui enlève ses positions en Orient; mais au lieu de sauver l'Empire, elle continue à le dépecer et à tuer son commerce, qui n'est plus représenté qu'en Morée. Venise, déjà maîtresse de Thessalonique, convoite même le dernier asile de l'hellénisme, dont le principal port, Monemvasia, arme surtout pour la course.

A côté des Génois et des Vénitiens, les Paléologues avaient accueilli les marchands des autres pays d'Occident, mais leur avaient donné des privilèges moins avantageux. L'importation des produits de leurs pays respectifs laissait encore quelques bénéfices aux douanes impériales. On voyait sur les marchés des draps de Flandre, de Reims, de Florence et autres produits français.

Ce fut ainsi que le duc de Bourgogne, Philippe le Bon, fit vendre à Rhodes et sur d'autres marchés 110 pièces de drap de Wervicq, embarquées sur un navire qui allait secourir les chevaliers de Rhodes (1441). De 1444 à 1451 il entretint un grand navire à Constantinople ${ }^{1129}$.

En échange les Occidentaux achetaient des produits du Levant et de la Grèce byzantine, notamment le vin de Malvoisie (Monemvasia), très apprécié en Occident ${ }^{1130}$.

La plus ancienne de ces colonies était celle d'Ancône, qui datait de l'époque où Manuel Comnène avait occupé cette ville (1151-1168). Très prospère au $\mathrm{XIV}^{\mathrm{e}}$ siècle, cette colonie était gouvernée par un consul, nommé par la métropole. Andronic lui avait accordé la taxe de $2 \%$ à l'entrée et à la sortie des marchandises ${ }^{1131}$.

\footnotetext{
1128 BRATIANU, op. cit., 89-105; DiEHL, Etudes byzantines, 240-275.

1129 GRUNZWEIG, Un exemple de vente directe de drap flamand dans le Levant, dans B.N., IV, 427 et $\mathrm{s}$.

1130 W. Miller, Essays on the Latin Orient, 240; ZAKYThinos, Le despotat grec de Morée, 187.

1131 HEYD, op. cit., J, 474; D.H.G.E., art. Ancône.
} 
La république de Raguse, qui avait conquis son indépendance sur Byzance, Venise et la Hongrie, se rapprocha des Paléologues contre le danger turc (2 quart du XV ${ }^{\mathrm{e}}$ siècle). Manuel II vit dans ce rapprochement une alliée utile contre la guerre économique que Venise faisait à la Morée, mais ce fut seulement en 1431 que Constantin Dragasès, alors despote de Morée, accorda des privilèges à Raguse et, en 1451, un quartier à Constantinople ${ }^{1132}$.

Une puissante colonie de Catalans s'installa à Constantinople sous Andronic II. En 1290 le consul Dalmaccio était venu solliciter cette admission au nom des habitants de l'Aragon, de la Catalogne et de Majorque, des bourgeois de Barcelone, Valence et Tortose. Le basileus leur donna le droit de circuler dans l'Empire et leur accorda la taxe de $3 \%(1290){ }^{1133}$, mais ces nouveaux hôtes ne tardèrent pas à se montrer indésirables, associant la piraterie au commerce et se battant sans cesse avec les Génois. Un deuxième privilège leur fut accordé par Andronic II (octobre 1320), qui n'améliora pas la situation. Après la paix imposée par Gênes à Jean Cantacuzène (mai 1352), tous les ports de l'Empire furent fermés aux Catalans, mais une partie de la colonie resta à Constantinople ${ }^{1134}$.

En 1438 cette colonie est reconstituée. Jean VIII agrée, comme consul des Catalans, Pere de Rocafort, auparavant consul dans la colonie vénitienne de Modon. Une loge devait être construite à Constantinople, mais elle ne l'était pas en 1449, à cause d'un conflit entre le Conseil de Barcelone, qui révoqua Rocafort, et Alphonse V d'Aragon, qui le soutenait. Cette affaire ne fut terminée qu'en 1451 et le nouveau consul, Joan de la Via, resta en fonction jusqu'en $1453{ }^{1135}$.

Les ports de Provence, Marseille, Montpellier, Narbonne, faisaient un commerce actif avec Constantinople au XIV $^{\mathrm{e}}$ siècle et y importaient des produits indigènes.

\footnotetext{
1132 ZAKYTHINOS, op. cit., 221 et s,; ANDREEVA, Le traité de commerce de 1451 entre Byzance et Doubrovnik, dans B.N., 1935, 117-127.

1133 HEYD, op. cit., I, 476.

1134 D'OlWER, Note sur le commerce catalan à Constantinople en 1380 dans B.N., IV, 193.

1135 MARINESCO, Contribution à l'histoire des relations économiques entre l'Empire byzantin, la Sicile et le royaume de Naples de 1419 à 1453, A.C.E.B., V, Rome, 1936.
} 
Les risques étaient gros, à cause des corsaires vénitiens et catalans. La cargaison d'un seul navire de Montpellier, capturé ainsi en 1355, valait 1000 écus d'or. Parmi les importations en Orient on signale l'alun, les peaux, la cire, le blé ${ }^{1136}$.

Des privilèges furent accordés aux villes provençales par Andronic III : quartier à Constantinople, consul, taxe de $4 \%{ }^{1137}$. Ceux de Narbonne furent renouvelés par Jean $\mathrm{V}$ en $1346^{1138}$. Ce commerce fut moins actif au $\mathrm{XV}^{\mathrm{e}}$ siècle : cependant il $\mathrm{y}$ avait un navire provençal à Constantinople pendant le siège ${ }^{1139}$.

Florence, devenue une ville industrielle au XIII ${ }^{\mathrm{e}}$ siècle, commença à exporter ses produits et il s'y fonda de grandes compagnies commerciales, en même temps banques de crédit : les Peruzzi en 1274, ruinés en 1343, le principal débiteur, Édouard III, ayant répudié ses dettes ; les Bardi, devenus la compagnie la plus puissante, qui avaient 346 agents, comptables, caissiers, notaires. Ces compagnies étaient en nom collectif et servaient des intérêts variant de 5 à $20 \%$ à leurs déposants ${ }^{1140}$.

D'autre part, la prise de Pise par les Florentins en 1406 eut pour résultat l'anéantissement de la colonie pisane de Constantinople ${ }^{1141}$. Florence exportait ses étoffes par l'intermédiaire de Venise, en attendant l'aménagement d'un nouveau port à Livourne, mais son ambition était d'avoir un quartier à Constantinople ${ }^{1142}$. Les négociations commencèrent en 1430 et furent laborieuses. Ce fut seulement après le concile de Florence que Jean VIII, à qui la république avait avancé 100000 écus pour ses frais de voyage, lui concéda l'ancien quartier des Pisans ${ }^{1143}$.

Ainsi, loin de diminuer, le nombre des colonies occidentales de Constantinople n'avait pas cessé d'augmenter. Les dernières concessions ont été accordées à la veille même du siège de 1453 et plusieurs ne purent être suivies d'effet. L'expropriation de Byzance par les

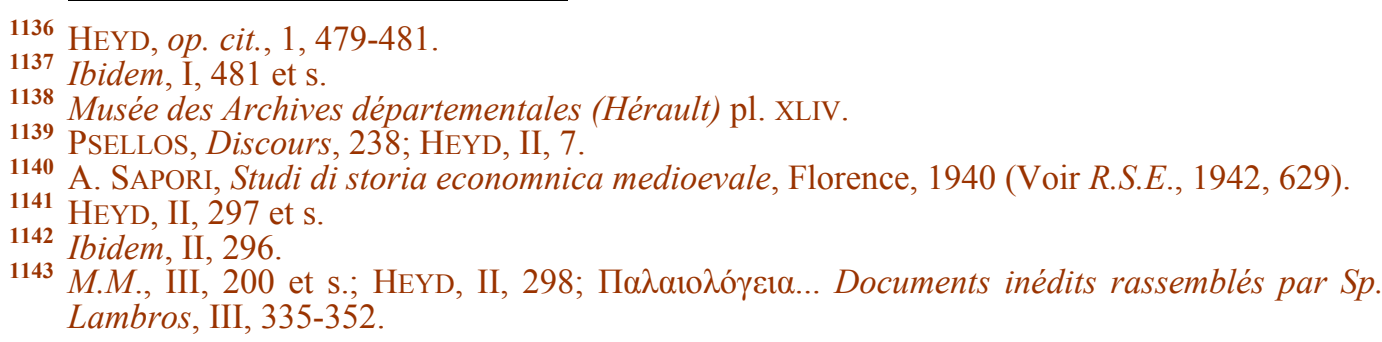


marchands d'Occident était totale et ne réussit même pas à la sauver de la conquête turque.

$\underline{\text { Retour à la Table des Matières }}$ 


\section{LIVRE QUATRIÈME La vie spirituelle}




\section{Chapitre VIII}

La vie religieuse

\section{Les édifices religieux}

$\underline{\text { Retour à la Table des Matières }}$

Les origines. - Le centre de la vie religieuse était l'église, salle du culte, lieu de réunion des fidèles, avec ses annexes : baptistère, martyria, sépultures, hospices, etc. A l'origine, tous ces services étaient aménagés dans une maison privée, domus ecclesiae, comme l'a montré la découverte, vraiment inespérée, de la maison des chrétiens de Doura-Europos, le 25 décembre 1931, et de son curieux baptistère, décoré de fresques symboliques ${ }^{1144}$. Cette maison ne différait en rien par son aspect des autres habitations privées. On suppose assez justement que la salle centrale pouvait être réservée à l'assemblée des fidèles. Les fouilles exécutées sous les basiliques majeures de Rome ont mis à jour des vestiges de maisons privées ${ }^{1145}$.

Après la Paix de l'Église, ce type de maison des chrétiens persista encore assez longtemps, mais un élément nouveau s'y ajouta et y occupa la place princiaple. Ce fut la basilique, salle rectangulaire, comprenant essentiellement une nef et des collatéraux, séparés par une colonnade, précédée souvent d'un atrium à portiques, prolongée par un transept, sur lequel s'ouvrait une abside.

On a beaucoup disserté sur les origines de la basilique et aujourd'hui même l'accord est loin d'être unanime entre les archéolo-

\footnotetext{
1144 SESTON, L'église et le baptistère de Doura-Europos; J. LASSUS, Sanctuaires chrétiens de Syrie, 11 et s.

1145 LASSUS, op. cit., 19-22.
} 
gues ${ }^{1146}$. Mais un fait historique vient d'être mis en lumière et semble clore la discussion : par la volonté de Constantin, les églises, jusque-là assez modestes, ont été construites magnifiquement, à la ressemblance des palais impériaux. L'ordonnance d'une basilique chrétienne, avec son atrium bordé de portiques, rappelle les salles hypètres, destinées aux cérémonies solennelles dans les palais impériaux du $\mathrm{IV}^{\mathrm{e}}$ siècle. La célèbre mosaïque de Saint-Apollinaire-le-Nouveau à Ravenne, qui représente une façade brillamment décorée, n'est pas, comme on le croit, la façade extérieure du palais, mais celle d'une cour bordée de colonnades, surmontées de spacieuses tribunes destinées à des spectateurs ${ }^{1147}$. On peut les comparer aux vastes catéchumènes de SainteSophie de Constantinople ${ }^{1148}$.

Églises byzantines. - Les églises byzantines, comme les basiliques occidentales, étaient conformes à ce programme de magnificence. Pavements en mosaïques, colonnades de marbre surmontées de chapiteaux ouvragés, lambris de marbre, mosaïques murales aux couleurs éclatantes sur des fonds d'azur et d'or, toutes les richesses étaient prodiguées pour décorer le palais du Seigneur. Aujourd'hui c'est par des intérieurs d'églises, tels que celui de Saint-Marc de Venise ou des édifices religieux de Ravenne, que nous pouvons nous faire quelque idée de la décoration des palais impériaux, dont aucun n'est parvenu jusqu'à nous.

Or le plan basilical était représenté dans les palais impériaux avec toutes ses variétés ${ }^{1149}$ et, loin d'être réservé à une catégorie spéciale d'édifices, il servait à toute espèce d'usage : salles de thermes, salles d'assemblées religieuses ${ }^{1150}$, d'associations sportives ${ }^{1151}$, édifices funéraires ${ }^{1152}$, salles judiciaires. Toutes ces constructions portaient le même nom de basilique. Les chrétiens ne firent que les adapter aux exigences de leur liturgie ${ }^{1153}$.

\footnotetext{
1146 Sur les théories récentes, LEMERLE, A propos de l'édifice cultuel chrétien, dans B.A.B.L., 34, 1948,306 et $\mathrm{s}$.

1147 DyGGVE, Ravennate palatium sacrum. La basilica ipetrale.

1148 Comme à Sainte-Sophie, la cour comportait une triple colonnade. En perspective on aperçoit des coupoles qui couvraient d'autres salles du palais.

1149 ZEILLER et HEBRARD, Spaloto, 1912.

1150 Basilique de la Porte Majeure à Rome.

1151 Basilique de Mactar (Tunisie) construite en 93 comme palestre. LEMERLE, loc. cit., 311 et s.

1152 La même avec le tombeau du fondateur.

1153 Voir DeLEHAYE, dans A.B., 1926, 43 et s.
} 
D'autre part, dès leur origine, les églises byzantines présentent un certain nombre de traits particuliers, qui n'ont fait que se multiplier au cours des siècles, par suite des modifications apportées à la liturgie.

On a remarqué d'abord que des sanctuaires chrétiens ont été installés dans des lieux de culte païen, à Olympie, dans la salle dite l'atelier de Phidias ${ }^{1154}$, à Delphes, au village de Kastri, au grand temple d'Apollon, à Dodone, auprès de l'oracle de Zeus ${ }^{1155}$, à Athènes, au Parthénon, devenu une église de la Vierge, au Théséion et dans d'autres petits temples ${ }^{1156}$. D'après la somptuosité des marbres découverts dans ces endroits, chapiteaux timbrés de croix, la plupart de ces changements dateraient de l'époque d'Arcadius et de Théodose II ; ils s'expliquent par l'attachement séculaire des populations aux sources sacrées, aux vieux oracles, aux heroa (tombes de héros). Il eût été difficile de contrarier ces habitudes comme le fit saint Martin en Occident, les missionnaires se contentèrent de christianiser ces sanctuaires païens ${ }^{1157}$.

Particularités des plans byzantins. - Certains usages sont communs à toute la chrétienté : l'orientation des églises, régulière seulement depuis le $\mathrm{V}^{\mathrm{e}}$ siècle ${ }^{1158}$; la séparation du clergé et des fidèles par une clôture en forme de chancel; l'abside, à la courbure de laquelle s'appuie le synthronon du clergé, dominé par la chaire épiscopale.

L'atrium, cour carrée bordée de portiques avec une phiale au milieu, qui précédait la basilique, était d'un usage constant à Constantinople ${ }^{1159}$, en Grèce et en Macédoine, dans les églises du littoral d'Anatolie et de Palestine, ainsi qu'à Rome depuis Constantin. Partout ailleurs, dans l'hinterland de l'Anatolie, de la Syrie, de l'Égypte, l'atrium n'était pas usité ${ }^{1160}$. Cette cour à portiques et colonnades existait, sous le nom de péristyle, dans les maisons hellénistiques de type pompéien. Dans les palais, comme on l'a vu plus haut, elle pre-

\footnotetext{
1154 L. BREHIER, Nouvelles recherches sur l'histoire de la sculpture byzantine.

1155 DyGGVe, Les traditions cultuelles de Delphes et l'Église chrétienne, C.A., III, 1948, 9-28.

1156 DIEHL, Justinien et la civilisation byzantine au VI siècle (voir supra p. 125); STRZYGOWSKI dans A.M., 1889, 271.

1157 E. MALE, La fin du paganisme en Gaule, R.D.M., juin 48, 385 et s.; DYGGVE, loc. cit. (sur la persistance actuelle de certains rites).

1158 Paulin DE Nole, Epistolae, ep. 31, P.L., 61, 33 : «non, ut usitatior mos est, orientem spectat » (parlant de sa basilique).

1159 Saint-Jean de Stoudios. Sainte-Irène, Sainte-Sophie, etc.

${ }^{1160}$ P. LEMERLE, Philippes et la Macédoine orientale à l'époque chrétienne et byzantine, 301 et s.
} 
nait un caractère monumental, qu'on retrouve dans l'atrium somptueux de la basilique de Philippes en Macédoine, élevée sur une terrasse qui dominait le Forum. Les fouilles de Paul Lemerle ont mis à jour les ruines de propylées grandioses, donnant accès à la terrasse par deux escaliers qui pénétraient dans l'atrium dallé de marbre, dont les quatre portiques étaient garnis de sveltes colonnes hautes de $6 \mathrm{~m} \mathrm{66}$, supportant des arcs et non une architrave. A l'ouest, le mur, incurvé au centre en exèdre, comprenait deux étages de colonnes, ioniques en bas, corinthiennes en haut. Par exception, le portique oriental est distinct du narthex, qui donnait accès à l'église par trois portails ${ }^{1161}$.

Nous n'avons pas à décrire ici la variété des plans qu'offre l'architecture byzantine basilique à colonnes, basilique à coupoles, croix grecque, octogone etc., mais à montrer l'adaptation de ces plans aux rites des liturgies orientales ${ }^{1162}$.

Or, au cours des siècles, ces rites se sont développés et modifiés, ce qui a entraîné de nouvelles dispositions. C'est ainsi qu'à l'origine il n'existait qu'un seul autel, $\beta \mu \alpha$ (bêma) sur lequel on célébrait les saints mystères, mais, à une époque ancienne, les liturgies orientales exigèrent deux autels secondaires : le diakonikon (trésor), sur lequel sont déposés les ornements liturgiques que les prêtres revêtent en récitant des oraisons appropriées, et la prothésis ou proskomidi, qui porte les dons que l'officiant dispose et bénit. Ce rite prit naissance lorsque les fidèles cessèrent d'apporter les dons en nature, vers les VII ${ }^{\mathrm{e}}$ ou VIII ${ }^{\mathrm{e}}$ siècles. En Syrie, des deux chambres latérales disposées au chevet, celle du nord, qui communique avec le sanctuaire par un passage étroit, est une sacristie, celle du midi, close du côté du sanctuaire, renferme le corps d'un saint et ouvre sur un bas-côté ${ }^{1163}$. Dans les églises byzantines, les deux autels accostent symétriquement le sanctuaire et sont à l'intérieur de la clôture.

Chancel et iconostase. - Le développement du culte des icônes a produit une modification très importante de cette clôture. A l'origine elle consistait en un simple chancel à hauteur d'appui. On en voit de

\footnotetext{
1161 Ibidem, 303-325; EBERSOLT, Monuments d'architecture byzantine.

1162 S. SALAVILLE, Liturgies orientales, I, 132, 2.

1163 LEMERLE, op. cit., 163, 180.
} 
nombreux exemplaires pleins ou découpés à jour à Ravenne ${ }^{1164}$. La clôture du sanctuaire de la basilique du Forum, à Philippes, était faite de dalles de marbre vert de Thessalie, couronnées d'une main courante, et de colonnes de même marbre, supportant un entablement de marbre gris ${ }^{1165}$. Le caractère monumental de cette clôture alla en s'accentuant. Elle devint un véritable portique à entablement avec chancels entre les colonnes, par exemple à Hosios Loukas ou à Torcello $\left(\mathrm{X}^{\mathrm{e}}-\mathrm{XI}^{\mathrm{e}}\right.$ siècle). On a pu comparer cette clôture à la frons scenae, façade permanente de palais sur la scène d'un théâtre antique ${ }^{1166}$. Le peuple voyait encore ce qui se passait dans le sanctuaire et, en particulier, l'officiant à l'autel, tourné vers l'assemblée.

Mais au VI ${ }^{\mathrm{e}}$ siècle, à Sainte-Sophie, sur les fûts recouverts d'argent de la clôture, Justinien fit suspendre des médaillons ciselés à l'effigie du Christ, de la Vierge, des milices célestes, des apôtres et d'autres saints, timbrés des monogrammes de l'empereur et de l'impératrice ${ }^{1167}$.

Cet exemple fut suivi de plus en plus, comme le montrent des témoignages de l'époque iconoclaste ${ }^{1168}$, mais c'est dans les églises rupestres de Cappadoce, qu'à côté de simples chancels réservés dans le roc (période ancienne) et de portiques à arcs outrepsés (église de Toqalé, fin $\mathrm{X}^{\mathrm{e}}$ siècle), apparaît, entre l'abside et la nef, un véritable mur de séparation, qui dépasse la hauteur des impostes de l'arc triomphal ${ }^{1169}$.

Ces murs séparatifs, qui se répandent à partir du XIII ${ }^{\mathrm{e}}$ siècle dans tout l'Orient $^{1170}$, ne font pas partie du décor architectonique de l'église comme les anciennes clôtures. Ils masquent complètement le sanctuaire et correspondent à un changement important dans l'ordre des cérémonies liturgiques. Exécutées en bois, percées de trois portes qui correspondent aux trois autels, celle du milieu qualifiée de porte royale, les iconostases offraient un vaste champ à la peinture d'icônes.

\footnotetext{
${ }_{1164}$ L. BREHIER, Études sur l'histoire de la sculpture byzantine, 3 et s., pl. XI, 3.

1165 LEMERLE, op. cit., 364.

1166 Sur ces clôtures et celles qui subsistent encore derrière les iconostases de certaines églises de l'Athos, voir L. BREHIER, Anciennes clôtures de chœur, dans A.C.E.B., V, Rome, 1936, t. II : Archeologia; DIEHL, L'église et les mosaïques du couvent de Saint-Luc en Phocide, 26.

1167 Paul Le Silentiaire, Poèmes; Diehl, Manuel d'art byzantin, 166; WulfF et Alpatov, Denkmäler der Ikonenmalerei, 47.

1168 NICEPHORE (patriarche, 806-815), Antirrhetici, III, 464-465 (a. 806-828).

1169 G. DE JERPHANION, Les églises rupestres de Cappadoce, I, 488-489.

1170 Pseudo-Germain, Histoire ecclésiastique, 389-392 (Sens mystique de l'iconostase).
} 
$\mathrm{Au} \mathrm{XIV}{ }^{\mathrm{e}}$ siècle, la révolution est accomplie dans le monde byzantin et ses dépendances, la Russie, les pays slaves, bulgare et roumain. Les cérémonies essentielles de la liturgie, désormais invisibles au peuple, ont une forme plus mystérieuse. Pour Syméon de Thessalonique, cette clôture marque la limite entre le monde sensible (la nef) et le monde intelligible. Les icônes ne sont ni choisies, ni disposées au hasard, mais ont pour thème central la Deisis, la prière de supplication de la Vierge et du Précurseur ${ }^{1171}$.

La nef (naos). - En avant de la clôture, sur les marches de l'escalier qui donnait accès au sanctuaire, se tenait le chœur des chantres. Cet endroit s'appelait la solea et, lorsque l'adoption des iconostases rendit le synthronon inutile, la chaire épiscopale y fut transportée ${ }^{1172}$. Dans les églises monastiques au chevet tréflé, comme celles de l'Athos, les moines, qui forment le chœur, occupent les deux absides secondaires ${ }^{1173}$.

Les fidèles étaient placés dans la nef et les bas-côtés, et la séparation des sexes était une règle absolue. Dans la partie hellénique de l'Empire, la plupart des basiliques étaient pourvues de tribunes, réservées aux femmes, d'où le nom de gynécée ou de catéchumènes, attribué à ces galeries ${ }^{1174}$.

En 1391 le voyageur russe Ignace de Smolensk, qui assiste à Sainte-Sophie au couronnement de Manuel II, aperçoit dans les tribunes les femmes « derrière des rideaux de soie. Personne ne peut voir les ornements de leur visage, tandis qu'elles voient tout ${ }^{1175}$.

Ces catéchumènes de Sainte-Sophie étaient d'une telle ampleur qu'on y avait aménagé une chapelle impériale et qu'on y tint des conciles ${ }^{1176}$.

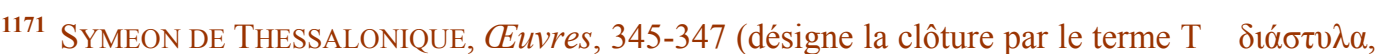
entre-colonnement. Celui d'iconostase désigne un support mobile, auquel les particuliers suspendaient les icônes. Celui de templon, désignant autrefois le sanctuaire, ne fut adopté qu'au XVI siècle pour la clôture); WULFF et ALPATOV, Denkmäler der Ikonenmalerei, 208, 290; L. BREHIER, La Sculpture et les Arts mineurs byzantins, pl. XLII.

1172 P. LEMERLE, Philippes et la Macédoine orientale à l'époque chrétienne et byzantine, 358, 9; 365,1 .

1173 Mon carnet de voyage.

1174 LEMERLE, op. cit., 355-357 (occupées à l'origine par les catéchumènes).

1175 IGNACE DE SMOLENSK, Pèlerinage, 143.

1176 Th. WhitTEMORE, The Mosaics of Haghia Sofia at Istanbul, III, The Imperial Portraits of the South Gallery. 
L'ambon était à l'origine une petite plate-forme arrondie, élevée de trois ou quatre marches, qui servait aux lectures scripturaires, aux prières collectives et même à la prédication. Puis la plate-forme s'éleva progressivement et il fallut un escalier pour l'atteindre. Enfin il devint une construction importante en maçonnerie, revêtue de plaques de marbre décorées souvent de sculptures ${ }^{1177}$, avec deux escaliers droits. L'ambon se trouvait toujours dans la nef, plus près du sanctuaire que du narthex.

Dans la basilique du Forum de Philippes, il se développait sur $7 \mathrm{~m} 76$ de longueur avec $1 \mathrm{~m} 80$ dans sa largeur. La plate-forme, dont P. Lemerle a retrouvé le centre, ainsi qu'un des piliers qui la portaient, était à $2 \mathrm{~m} 10$ au-dessus du sol. On y montait par deux escaliers de 9 marches ${ }^{1178}$. Sous Justinien, l'ambon de SainteSophie, placé au centre sous la coupole, ressemblait à une tour « éblouissante des feux d'innombrables pierres précieuses enchâssées dans des marbres aux teintes les plus rares ». Il était revêtu d'argent et d'ivoire et abrité par un baldaquin en forme de dôme couvert de plaques d'or gemmées et surmonté d'une croix ${ }^{1179}$. Il était assez spacieux pour servir au couronnement des empereurs. Le chœur des chantres s'y transportait parfois pour certains chants.

L'autel du sacrifice. - Le nom de l'autel, $\beta \mu \alpha$ (bêma), a été étendu au sanctuaire entier. L'autel consistait en une table rectangulaire, portée par quatre colonnes en général, mais le nombre des colonnes varie. A Nicopolis on en trouve neuf. Cette table est toujours creuse et elle est ornée de figures symboliques. Les tables circulaires ou en sigma, analogues aux tables des réfectoires monastiques, sont plus rares ${ }^{1180}$.

Sur la patène d'argent de Riha, où est figurée la Communion des Apôtres, l'Autel est une table rectangulaire recouverte d'une lourde draperie brodée, qui laisse voir trois pieds de la table. Il est abrité par un ciborium en forme de dôme, au centre d'un entablement porté par des colonnes ${ }^{1181}$.

Sous l'autel se trouvait quelquefois une chambre à reliques. C'est souvent une simple cavité. A Philippes (basilique du Forum), c'est une vraie confession (au sens occidental), revêtue de plaques de mar-

1177 Ambon de Saint-Georges de Thessalonique (Musée de Stamboul); G. DE Jerphanion, Mé-

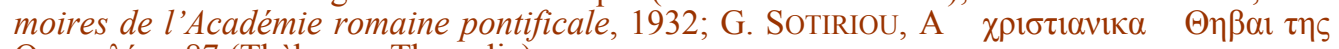
$\Theta \varepsilon \sigma \sigma \alpha \lambda i ́ a s, 87$ (Thèbes en Thessalie).

1178 LEMERLE, op. cit., 360 et s., pl. XXVI.

1179 PAUl Le Silentiaire, Poèmes, P.O., 86 b, 2251 et s.

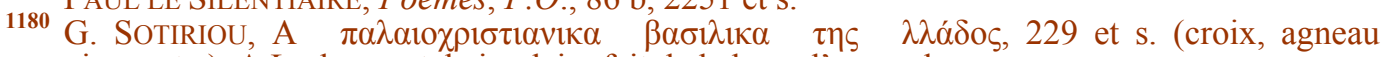
vigne, etc.). A Lesbos, autel circulaire fait de la base d'une colonne.

1181 BREHIER, La Sculpture et les Arts mineurs byzantins, pl. LIV. 
bre et dans laquelle on descend par un escalier. A Saint-Démétrius de Thessalonique c'est une vaste crypte ${ }^{1182}$.

Enfin des voiles brodés et historiés fixés aux colonnettes du baldaquin protégeaient l'autel, comme on le voit sur les autels figurés à Saint-Vital de Ravenne dans les mosaïques du chœur, qui représentent les sacrifices de Melchisédech, d'Abel et d'Abraham ${ }^{1183}$.

L'église byzantine connaissait aussi l'autel portatif, $v \tau \imath \mu \eta ́ v \sigma ı v$ (antimension), mais, au lieu de la pierre d'autel du clergé occidental, les Grecs se servaient de voiles, dans lesquels était insérée une relique et sur lesquels était figuré l'Ensevelissement du Christ. Cette coutume se répandit surtout pendant la persécution iconoclaste ${ }^{1184}$.

\section{Mobilier et instruments du culte}

\section{$\underline{\text { Retour à la Table des Matières }}$}

Bien qu'il existe beaucoup d'usages communs à toutes les Églises, les liturgies orientales n'en exigent pas moins un matériel de culte qui leur est propre.

Sur l'autel principal était posée une grande croix, de préférence revêtue d'argent ou d'or et sans le Crucifié ${ }^{1185}$. Une splendide croix du trésor de Lavra a pu servir à cet usage. Ses contours sont couverts de lames d'argent, entre lesquelles des lames de cuivre doré sont semées d'opales, de cristal de roche, de rubis, de jaspe, de saphirs, d'émeraudes, d'améthystes, disposés en files : au centre, un médaillon du Pantocrator et, aux extrémités, quatre médaillons de la Vierge et du Précurseur (Deisis) et des archanges Michel et Gabriel ${ }^{1186}$.

\footnotetext{
1182 LEMERLE, op. cit., 369.

1183 SOTIRIOU, op cit., 241243

1184 D.A.C.L., I, 1907, 231 et $\mathrm{s}$. (d'où l'accusation de célébrer la messe sur une icône).

1185 DIEHL, L'école artistique d'Antioche et les trésors d'argenterie syrienne, 113; Theophylacte DE SimocatTA, Histoire, V, 13 : croix d'or offerte par Chosroès II, réfugié dans l'Empire, à Sergiopolis; M.B.E.H. (Vie et mort de Byzance), 1969, 46, a. 590.

1186 Mission Millet-Bréhier à l'Athos, 1930 (inédit). Haut. 1,10 m. Bras, long. 0,72 m.
} 
Sur l'autel de la Prothésis étaient disposés les vases sacrés, le ca-

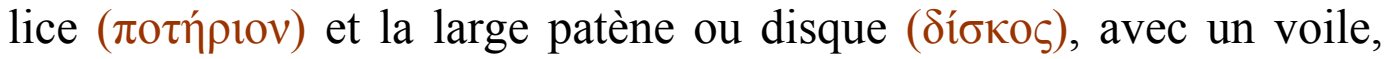
aër ( $\eta \rho)$, pour le calice et un autre pour la patène, soutenu par un support fait de deux tiges de métal croisées, l'astérisque ( $\sigma \tau \eta-$

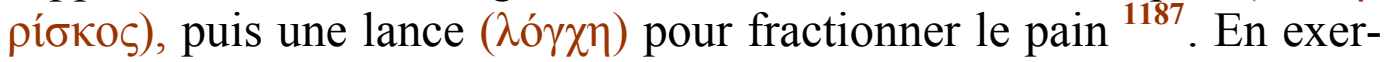
gue de la Communion des Apôtres, sur la patène de Riha, on aperçoit une tasse à long manche, peut-être un calice ministériel servant à la communion des fidèles, à côté d'une élégante amphore ${ }^{1188}$.

Un véritable calice ministériel a été découvert en même temps que la patène de Riha. C'est une coupe d'argent très profonde, supportée par un pied composé d'un col très mince, d'un nœud et d'une large base évasée. La forme est simple et élégante ; la pureté de la ligne rappelle l'antique. L'inscription en grandes capitales, qui se détache entre deux filets d'or, reproduit les paroles de la consécration ${ }^{1189}$. Le célèbre calice d'Antioche de l'ancienne collection Kouchakgi, qui a donné lieu à tant de controverses, est encore plus profond, mais en dépit de son décor religieux (le Christ et les apôtres trônant au milieu d'épais feuillages de vigne dans lesquels se joue toute une faune), ne semble pas avoir été destiné à un usage liturgique ${ }^{1190}$.

Les cuillers destinées à distribuer le précieux sang aux fidèles apparaissent en Syrie au $\mathrm{VII}^{\mathrm{e}}$ siècle, mais ce nouvel usage pénétra tardivement à Constantinople et on n'en connaît pas d'exemple avant le $\mathrm{IX}^{\mathrm{e}}$ siècle. Les belles cuillers découvertes avec des trésors, comme celui de Kérynia (Chypre), avaient donc une destination purement profane ${ }^{1191}$.

Les rhipidia ( $1 \pi i \delta 1 \alpha$ ), éventails destinés à écarter, des saintes espèces, les mouches et autres insectes, étaient aussi une pièce essentielle du mobilier. Ils consistaient la plupart du temps en disques de métal, emmanchés dans une hampe, et sur leurs faces étaient gravées les figures des chérubins et des séraphins, avec le trisagion «sanctus

\footnotetext{
1187 S. SAlaVille, Liturgies orientales, I, 45; FORTESCUE, The Orthodox Eastern Church, 408; EBERSOLT, Les arts somptuaires de Byzance, 110.

1188 BREHIER, Les trésors d'argenterie syrienne et l'école artistique d'Antioche, G.B.A., 1920

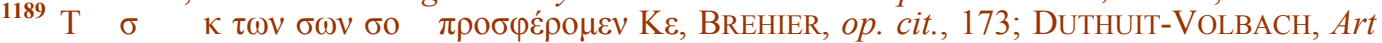
byzantin, pl. 43.

1190 BREHIER, La Sculpture et les Arts mineurs byzantins, pl. III; DE JERPHANION, Le calice d'Antioche, O.C., VII, 1926; DIEHL, L'école artistique d'Antioche et les trésors d'argenterie syrienne, 107.

1191 DE JERPHANION, Les églises rupestres de Cappadoce, I, 256, 2 et pl. 59, 4; EBERSOLT, Les arts somptuaires de Byzance, 26, 1 et 110.
} 
de la messe latine $»$. Des exemplaires d'éventails de ce genre, plus ou moins ornés, sont conservés dans plusieurs collections ${ }^{1192}$.

Les encensoirs anciens (thymiateria), figurés sur des mosaïques de Ravenne, consistent en seaux suspendus par des chaînes ${ }^{1193}$, mais, dès cette époque, ils affectaient des formes variées : petite boîte de bronze rectangulaire ajourée ${ }^{1194}$, coupe de bronze ou d'argent avec couvercle ajouré (Égypte), cuvette hexagonale en argent avec buste iconographique sur chaque face ${ }^{1195}$, etc.

L'usage, dans les églises, des chandeliers garnis de cierges, emprunté aux cérémonies païennes, est attesté au $\mathrm{IV}^{\mathrm{e}}$ siècle ${ }^{1196}$, mais ce n'est qu'à l'époque moderne qu'on a pris l'habitude de placer deux chandeliers allumés sur l'autel pendant la messe ${ }^{1197}$.

L'éclairage de l'église était assuré par des lustres en bronze (polycandela, polyelaia) garnis de cierges ou de lampes. Ils consistaient en cercles de bronze plus ou moins ornés, munis de chaînes de suspension ${ }^{1198}$.

Parmi les objets précieux exposés par Constantin Porphyrogénète pour les réceptions d'ambassadeurs arabes, figuraient 21 polycandela d'argent provenant de l'église Sainte-Marie du Phare. Les voyageurs russes Antoine (1200) et Étienne de Novgorod (1350) s'extasiaient sur l'éclairage merveilleux de Sainte-Sophie, dû à d'innombrables lampes ou candélabres d'argent garnis de cierges ${ }^{1199}$.

Les cloches, connues à Byzance dès $\mathrm{le} \mathrm{VI}^{\mathrm{e}}$ siècle, ne furent employées dans les églises que tardivement. Dans les villes, comme dans les monastères, leur place était tenue par le simandre ( $\sigma \eta \mu \alpha ́ v \tau \rho o v)$, longue planche ou bâton percé de trous, sur lesquels on frappait avec un marteau de fer ou un maillet ${ }^{1200}$. Il en était ainsi à Sainte-Sophie en 1200 et, vers 1437, les simandres étaient encore usités à Constanti-

\footnotetext{
1192 PERDRIZET dans F.E.P.M., X, 1903, 138 (éventails de Serrès ornés d'émaux); EBERSOLT dans R.A., 1911, 1, 407 et s.; L. BREHIER dans R.A., 1946, 19-28.

1193 DIEHL, Justinien et la civilisation byzantine au VI siècle, p1. I; D.A.C.L., V, 1922, fig. 4065.

1194 BREHIER, La Sculpture..., pl. XLIV.

1195 D.A.C.L., V, 1922, 26-27.

${ }_{1196}$ Saint ATHANASE, Lettre aux orthodoxes, P.G., 25, 229.

1197 D.A.C.L., III, 216-218

1198 EBersolt, op. cit., 64 SChlumberger, dans B.Z. 1893, 441; Brehier, op. cit. 34, pl. XLV, 3.

1199 Constantin VII Porphyrogenete, De caerimoniis..., 581 (Bonn); Antoine, archevêque de Novgorod, Le livre du pèlerin, 91 ÉTIENNE DE NovgOROD, Pèlerinage à Constantinople, 118.

1200 D.A.C.L., III, 1914 970; G. Millet, Recherches au Mont-Athos, B.C.H., 1905, 123-141.
} 
nople en même temps que les cloches. A côté des simandres manuels, dont on se sert toujours dans les monastères, de grands simandres étaient fixés aux tours et aux clochers ${ }^{1201}$.

Le costume et les ornements liturgiques. - Le caractère solennel de la liturgie s'exprimait par la somptuosité des costumes portés par les officiants. Cependant il n'en fut pas ainsi à l'origine. Dans la vie civile, évêques et prêtres ne se distinguaient pas des laïcs par leur costume et, en 428 , le pape Célestin $\mathrm{I}^{\mathrm{er}}$ est scandalisé en apprenant que des moines élevés à l'épiscopat continuent à porter leur costume monastique, le manteau et la ceinture ${ }^{1202}$. La même doctrine régnait à Byzance, mais il arriva que, dans la suite des âges, le costume civil se transformât, tandis que les clercs conservaient les modes d'antan, qui se fixèrent et devinrent des vêtements liturgiques ${ }^{1203}$.

Ces costumes, devenus les insignes des dignités ecclésiastiques, sont longtemps d'une grande simplicité. En 784 Tarasius, a secretis, élu au patriarcat, échange son costume de pourpre contre les vêtements plus simples d'un patriarche ${ }^{1204}$.

Sur le tableau du cortège de Justinien, à Saint-Vital de Ravenne, l'archevêque Maximien porte la longue tunique blanche (sticharion) et, par-dessus, la planète ou chasuble verte. Une bande d'étoffe blanche jetée sur ses épaules retombe sur sa poitrine, ornée d'une croix noire. C'est l'omophorion. Ses souliers sont noirs. Le prêtre et le diacre qui l'accompagnent sont simplement vêtus de la tunique à larges manches.

Depuis le IV $\mathrm{IV}^{\mathrm{e}}$ siècle l'omophorion est l'insigne épiscopal par excellence ${ }^{1205}$. Passé autour du cou, il retombe par devant en une seule bande. Il est d'abord en lin ou en laine.

Dans la suite des siècles, ce costume très simple se complique et s'enrichit ${ }^{1206}$. Il est à peu près fixé au XII siècle.

\footnotetext{
1201 AnTOINE, archevêque de Novgorod, Le livre du pèlerin, 97; Notice sur Constantinople (vers 1437), dans N.H., 1910, 361.

1202 L. CRISTIANI, Origines du costume ecclésiastique.., dans Misc. J., I, 69-80.

1203 Voir supra, ch. I, p. 30.

1204 THEOPHANES LE CONFESSEUR, Chronographie, 457-461.

1205 P. BATIFFOL, Etudes de liturgie, 66 et s.
} 
Les diacres portent désormais le sticharion de soie et l'orarion, écharpe enroulée autour du cou et retombant à gauche ${ }^{1207}$. Les prêtres conservent le sticharion de laine; un nouvel insigne est l'épitrachélion, qui correspond à l'étole romaine, mais est retenu à la

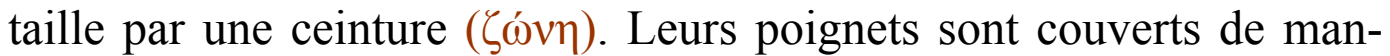
chettes et ils portent la chasuble (phélonion). Les évêques se distinguent par le sticharion de soie, l'épitrachélion et l'omophorion et, à la hauteur des genoux, une pièce d'étoffe très ornée, l'épigonation, qui a la forme d'un losange avec quatre glands aux angles. Ils sont coiffés d'une mitre et tiennent à la main une crosse ; sur leur poitrine, un encolpion, petit reliquaire qui correspond à la croix pectorale latine.

Le patriarche a eu longtemps le privilège exclusif de remplacer la chasuble par le sakkos, tunique courte fendue sur les côtés avec demimanches somptueusement brodées. Plus tard le sakkos fut attribué aux métropolites, puis aux simples évêques ${ }^{1208}$.

Les trésors d'églises et les collections conservent de somptueux ornements liturgiques, qui comptent parmi les chefs-d'œuvre de l'art byzantin par la richesse de leur coloris et la perfection de leurs broderies. Les thèmes iconographiques y sont fréquents à partir du $\mathrm{XIV}^{\mathrm{e}}$ siècle.

Au musée du Vatican, la pièce d'étoffe connue sous le nom de dalmatique de Charlemagne est en réalité un sakkos patriarcal du XIV siècle, en soie bleue, brodée d'or et de soies de divers tons. Sur le fond semé d'étoiles se détachent, d'un côté la Transfiguration, de l'autre la Gloire du Christ et les Justes accueillis au paradis. La double Communion des Apôtres est brodée sur les manches ${ }^{1209}$.

Un des plus beaux ensembles de ce genre est la collection du monastère de Poutna (Bucovine) fondé par Etienne le Grand (14571504). Tous les ornements liturgiques y sont représentés par des piè-

1206 H. WEISs, Kostümkunde. Geschichte der Tracht and des Geräthes im Mittelalter, II (Romains, Byzantins, Perses) 125, fig. 65; G. DE JERPHANION, Les églises rupestres de Cappadoce, I, 172, pl. 39, 4; 256, pl. 59, 3-4.

1207 G. DE JERPHANION, La Voix des Monuments, II, 279 et 280.

1208 H. WEISS, op. Cit., II, 131137; R. JANIN, Les églises orteiltales et les rites orientaux, 36-40 (costumes actuels).

1209 G. Millet, Broderies religieuses de style byzantin; BREHIER, La Sculpture et les Arts mineurs byzantins, pl. XCIII. 
ces d'une richesse extraordinaire. Les inscriptions en grec de nombreux exemplaires indiquent un travail byzantin ${ }^{1210}$.

\section{Les liturgies et la messe}

Retour à la Table des Matières

Les liturgies. - Sur le vaste territoire de l'Empire, tel qu'il était au $\mathrm{VI}^{\mathrm{e}}$ siècle, il existait un grand nombre de liturgies et d'usages régionaux, aussi bien dans l'Église orthodoxe que chez les dissidents.

Les liturgistes en distinguent trois types, mis sous les noms des Apôtres ou des Pères de l'Église, sans d'ailleurs aucune preuve :

$1^{\circ}$ Le type syriaque: liturgie grecque de saint Jacques; liturgie grecque de Timothée, patriarche d'Antioche (518-533). Ces deux liturgies furent traduites en syriaque : les jacobites composèrent plus de soixante liturgies dans cette langue ${ }^{1211}$.

$2^{\circ}$ Le type égyptien : liturgie grecque de saint Marc, qui date du $\mathrm{v}^{\mathrm{e}}$ siècle, mais on a découvert des textes plus anciens : liturgies coptes, dont celle dite de saint Cyrille a inspiré la liturgie éthiopienne dite des Douze Apôtres ${ }^{1212}$.

$3^{\circ}$ Le type byzantin, dérivé de la liturgie syriaque. Importé dans les patriarcats d'Orient par les orthodoxes (melchites), il a supplanté les autres rites. Il comprend :

La liturgie de saint Basile, à l'origine liturgie normale et quotidienne, qui n'est plus usitée que dix fois par an ${ }^{1213}$;

La liturgie de saint Jean Chrysostome, devenue quotidienne ;

La messe des Présanctifiés, pendant le carême, sauf le samedi et le dimanche ${ }^{1214}$.

1210 O. TAFRALI, Le trésor byzantin et roumain du monastère de Poutna, 56-72, pl. XLVII-XL. Voir ch. XV.

1211 J. B. Снавот, dans J.S., 1940, 78 et s.; Jean Kamateros, E $\sigma \alpha \gamma \omega \gamma \quad \sigma \tau \rho o v o \mu i ́ \alpha \sigma$ (en vers politiques), 247.

1212 Jean KAMATEROS, op. cit., 504.

${ }^{1213} \mathrm{Le} 1^{\text {er }}$ janvier (fête de saint Basile), les cinq dimanches du carême, les jeudi et samedi saints, les vigiles de Noël et de l'Épiphanie. 
$\mathrm{Au} \mathrm{VI}{ }^{\mathrm{e}}$ siècle la liturgie byzantine était encore très simple. L'Église arménienne, séparée de Byzance à cette époque, en a conservé la forme ancienne, qu'elle a développée librement.

Caractères et évolution des rites byzantins. - Comparés à la simplicité et à la clarté du rite romain, les rites byzantins se sont compliqués au cours des siècles et ont reçu de nombreuses additions. C'est ainsi qu'au $\mathrm{VI}^{\mathrm{e}}$ siècle, on ignorait la longue préparation des dons à l'autel de la prothésis. Les chants et les oraisons se sont multipliés, offrant un terrain magnifique aux symbolistes postérieurs, tels que le pseudo-Germain, Théodore, évêque d'Andida (Pamphylie) vers 1240, Nicolas Cabasilas (mort entre 1391 et 1400) ${ }^{1215}$, Syméon, archevêque de Thessalonique (mort en 1429).

Pour eux la messe est un drame sacré, qui se joue entre le célébrant, l'unique diacre et le peuple représenté par le chœur des chantres. Le diacre sert d'intermédiaire entre le célébrant et le peuple, dont il dirige les litanies et qu'il avertit, par de brèves exclamations, des moments successifs de la messe ${ }^{1216}$.

L'adoption de l'iconostase a entraîné aussi des changements profonds dans les rites. Autrefois, comme on l'a vu, il y avait un secretarium (sacristie) dans lequel les officiants revêtaient leurs ornements et où le pain et le vin apportés par les fidèles étaient préparés pour le sacrifice. Désormais tout se passe dans le sanctuaire, transformé en secretarium. Le mystère est absolu. C'est le rituel du silence ${ }^{1217}$.

Dans la liturgie romaine, l'accent est mis sur le sacrifice du Christ sous les espèces du pain et du vin; le rite byzantin s'attache surtout à la présence du Christ, entouré des milices célestes, depuis l'Évangile jusqu'à la consécration.

\footnotetext{
1214 J. PARgOIRE, L'Eglise byzantine de 527 à 847, 97-99; SALAVILLE, Liturgies Orientales, I, 13 15; sur les manuscrits liturgiques, KAMATEROS, op. cit., 308. Le principal est le Cod. Barber., 3, 55 (fin du VIII ${ }^{\mathrm{e}}$ siècle), qui a servi aux Pères du Concile de Florence.

1215 N. CABASILAS, Explication de la Divine Liturgie (commentaire liturgique le plus parfait).

1216 Ibidem, I, 58.

1217 P. BATIFFOL, Semaine religieuse de Paris, 2 janv. 1926, 20.
} 
Langues liturgiques. - $\mathrm{Au} \mathrm{VI}^{\mathrm{e}}$ siècle, le grec était d'un usage universel, même dans les églises dissidentes. Il n'y avait d'exception que pour les églises rurales de l'intérieur, qui priaient dans leur langue nationale. Les Goths de Crimée se servaient toujours de la Bible d'Ulfilas en langue gothique ${ }^{1218}$. Au $\mathrm{V}^{\mathrm{e}}$ siècle, Sahak et Mesrop traduisirent la Bible en arménien, et vers 523 Qardast, évêque de Harran, évangélisait les Huns et créait une liturgie hunnique ${ }^{1219}$. Le clergé grec n'en avait pas moins une prévention contre l'introduction des langues étrangères dans la liturgie, comme le montrent les règlements imposés aux Syriens et aux Ibères au monastère de Saint-Sabbas, au $\mathrm{VI}^{\mathrm{e}}$ siècle ${ }^{1220}$, et la légende de saint Hilarion le Géorgien (827$880)^{1221}$.

Ce furent les apôtres des Slaves, Constantin et Méthodius, qui assurèrent la victoire des liturgies nationales, malgré les résistances qu'ils rencontrèrent à Rome et en Moravie. Ils étaient préparés d'ailleurs à créer une liturgie en slavon par les nombreuses liturgies nationales dont ils avaient eu connaissance pendant leur séjour en Crimée ${ }^{1222}$.

Célébration de la messe byzantine. - Dans son état actuel la messe byzantine, d'après la liturgie de saint Jean Chrysostome, n'a guère changé depuis le $\mathrm{XV}^{\mathrm{e}}$ siècle. Elle comprend trois parties : la proskomidi, la messe des catéchumènes, la messe des fidèles ${ }^{1223}$.

La proskomidi (oblation) avait lieu à l'origine après la messe des catéchumènes, ce qui était plus logique ${ }^{1224}$. Elle remonte au VII ${ }^{\mathrm{e}}$ siècle, mais n'a reçu sa forme compliquée actuelle qu'au $\mathrm{XIV}^{\mathrm{e}}$ siècle. Avec la lance, le prêtre divise le pain fermenté en quatre parties portant les sigles $\Sigma$-XC-NI-KA ${ }^{1225}$. Il met à part la partie $\mathrm{XC}$, la pose sur la patène et l'entaille profondément. C'est l'immolation de l'Agneau, accompagnée d'oraisons, puis il la divise en parcelles en l'honneur de

\footnotetext{
1218 VASILIEV, The Goths in the Crimea, 113 et s.

1219 F. DvOrNIK, Les Slaves, Byzance et Rome au IX siècle, 69-70; MARQUART, Osteuropäische und Osiasiatische-Streifzuge, 301-302.

1220 M.B.E.H. (Institutions), éd. 1970, 424.

1221 Vie de saint Hilarion d'Ibérie (éd. Peeters, A.B., 1913), 236 et s.; LoPAREV, Vizantiiskiia Sviatuik, VIII-IX Viekov, V.V., XVII, 58 et s.

1222 DVORNIK, op. cit., 207-209.

1223 Jean KAMATEROS, op. cit., 34-97.

1224 Mentionnée encore ainsi par Pseudo-GERMAIN, Histoire ecclésiastique, 396 et s.

1225 Jésus-Christ, sois vainqueur!
} 
la Vierge, des anges et des saints, chaque parcelle portant un nom, parfois d'un fondateur ou d'un défunt ${ }^{1226}$.

Le calice est préparé plus simplement : le diacre verse le vin et une goutte d'eau: le prêtre bénit. Alors ont lieu l'offertoire (prothésis), oraison précédée et suivie d'encensements, la récitation du psaume L (Miserere) et la bénédiction finale des dons ${ }^{1227}$.

La messe des catéchumènes commence par la prière collective dirigée par le diacre, qui se tient devant l'iconostase. Il recueille (colligit) les intentions des fidèles (pour l'Église, pour la paix, etc.) qui, à chaque verset de ces litanies, répondent: Kyrie eleison. Suit le chant de deux antiphones (psaumes CII et XLV, louanges du Seigneur et Béatitudes), qui précède la Petite Entrée. Le prêtre remet l'évangéliaire au diacre et ils sortent par la porte nord de l'iconostase précédés de porteurs de cierges et d'éventails liturgiques, et rentrent dans le sanctuaire par la porte Royale ${ }^{1228}$.

Le chœur se transporte alors à l'ambon et chante longuement le Trisagion, pendant que le prêtre récite tout bas une oraison avant la lecture de l'Épître, qu'un lecteur vient faire au milieu de la nef ${ }^{1229}$, puis le diacre, élevant l'évangéliaire au-dessus de sa tête, sort du sanctuaire par la porte nord, monte à l'ambon et chante l'Évangile. Il donne ensuite le livre à baiser au prêtre, les portes du sanctuaire sont fermées, et c'était alors qu'avait lieu le renvoi des catéchumènes ${ }^{1230}$.

La messe des fidèles commence par une courte préparation (litanies), puis a lieu la Grande Entrée, rite le plus caractéristique et le plus original de la messe byzantine. Elle consiste à transporter solennellement les dons, placés dans le calice et la patène, de l'autel de la proscomidi au bêma. La procession sort par la porte nord, fait le tour de l'église et pénètre au bêma par la porte Royale pendant que le chœur chante le chéroubikon. Cette hymme, introduite dans la liturgie

\footnotetext{
1226 Sur l'origine de ce rite, S. SALAVILLE, Liturgies orientales, I, 40, 3.

1227 Ibidem, J, 27-32; KAMATEROS, op. cit., 309-312.

1228 Symbole de l'entrée du Christ à Jérusalem, Pseudo-GERMAIN, Histoire ecclésiastique.

1229 A la différence du rite romain, le texte est pris exclusivement dans les Epîtres apostoliques.

1230 Précédé de litanies. N'a plus lieu à partir du VII ${ }^{\mathrm{e}}$ siècle, SALAVILLE, op. cit., I, 58-92.
} 
sous Justin II (565-578), annonce l'entrée dans l'église du Christ et des milices célestes ${ }^{1231}$.

Ce rite ne fut adopté qu'à la fin du $\mathrm{VI}^{\mathrm{e}}$ siècle et non sans difficulté. Le patriarche Eutychios s'éleva contre le chant du chéroubikon devant des oblats non consacrés ${ }^{1232}$.

Le prêtre place la patène et le calice sur l'autel. Le diacre, revenu devant la porte Royale, dirige la prière litanique de l'offertoire qui rappelle les sacrifices de l'Ancien Testament. Après le rite du baiser de paix, les portes de l'iconostase étaient fermées et l'on récitait le Credo de Nicée, introduit à Antioche en 471 par Pierre le Foulon, patriarche monophysite, et adopté en 510 à Constantinople ${ }^{1233}$.

L'anaphore (oblation) répond au Canon latin, mais diffère dans les deux liturgies byzantines, beaucoup plus développée dans celle de saint Basile. Elle débute par le dialogue entre le célébrant et le chœur qui, dans toutes les liturgies, précède la Préface, suivie du chant du Trisagion (Sanctus).

Bien qu'une novelle de Justinien ait ordonné de faire l'oblation à voix haute ${ }^{1234}$, l'usage de la récitation secrète a persisté à Byzance, de manière à inspirer aux fidèles la vénération et la crainte ${ }^{1235}$. Pendant ces prières secrètes qui commémorent la Cène et la trahison de Judas, et, dans la liturgie de saint Basile, remontent jusqu'à la création de l'homme, le rideau de l'iconostase est baissé. Pour les Orientaux, c'est la récitation de l'épiclèse (invocation) qui est l'acte véritable de la consécration. Le Saint-Esprit est supplié d'opérer la transsubstantiation ${ }^{1236}$. $\mathrm{Au} \mathrm{XIV}{ }^{\mathrm{e}}$ siècle on intercale après l'épiclèse un tropaire en l'honneur du Saint-Esprit, puis le prêtre commémore la Vierge, le Précurseur, les saints, dont on invoque l'intercession, et le diacre fait lecture des diptyques, tablettes qui portent le mémento des morts et celui des vivants. Les diptyques de la messe de saint Basile sont parti-

1231 Salaville, op. cit., I, 97; texte dans D.A.C.L., III, 1914, 1281.

1232 Eutychios, De Paschate et sancta Eucharistia, P.G., 83, 2400; Pseudo-Germain, op. cit., 420; L. H. GRONDIJS, L'iconographie byzantine du Crucifié mort sur la croix, 78.

1233 R.P.B., 205.

1234 C.I.C.I., nov. 137 (565).

1235 BATIFFOL, Leçons sur la Messe, 289-292.

1236 Reproches de Cabasibas aux Latins, qui regardent la consécration accomplie par la commémoraison des paroles du Christ, CABASILAS, Explication de la Divine Liturgie, 150. 
culièrement longs ${ }^{1237}$. Les empereurs, l'armée, le patriarche, les évêques orthodoxes y figurent toujours en bonne place et l'on sait que la radiation des diptyques du nom d'un pape était la manifestation d'un schisme.

Puis le Pater était récité par le chœur, le rideau de l'iconostase était levé et le célébrant venait bénir le peuple. Retourné à l'autel, il élevait le pain au-dessus du calice et en opérait la fraction, les rideaux étant baissés. "Est rompu et partagé l'Agneau de Dieu, rompu sans être divisé... ", récite le prêtre. C'est le mélismos (division), que les peintures iconographiques figurent comme un enfant placé dans une coupe sur un autel ${ }^{1238}$.

Le prêtre fait tomber une parcelle du pain dans le calice ${ }^{1239}$, dans lequel le diacre verse quelques gouttes d'eau chaude. C'est le rite singulier du zéon (ferveur), en rapport avec la doctrine d'après laquelle l'eau qui découla avec le sang de la plaie du Christ mort, faite par la lance, est le symbole du Saint-Esprit, qui préserva le corps divin de la corruption jusqu'à la Résurrection. Ce rite s'introduisit dans la liturgie à la fin $\mathrm{du} \mathrm{VI}^{\mathrm{e}}$ siècle et, malgré ses rapports avec l'aphtartodocétisme ${ }^{1240}$, s'y implanta définitivement ${ }^{1241}$. Au XI ${ }^{\mathrm{e}}$ siècle, au moment de la polémique sur les azymes, le clergé grec chercha à justifier le zéon et ce fut à cette époque que, sur la croix, les peintures iconographiques représentèrent Jésus mort ${ }^{1242}$.

Après des prières préparatoires, le prêtre communie lui-même et communie ensuite le diacre, puis a lieu la communion des laïcs après l'ouverture de la porte Royale. A l'origine le prêtre déposait l'hostie dans la main droite, soutenue par la main gauche, du fidèle, qui buvait ensuite directement au calice. A partir du vile siècle, le diacre fait tomber des parcelles de pain dans le calice et le prêtre communie les fidèles avec une petite cuiller, dans laquelle se trouve un morceau de

1237 BRIGHTMANN, Liturgies Eastern and Western, 331-337.

1238 SAlaVille, Liturgies orientales, I, 51; A. GraBAR, La Peinture religieuse en Bulgarie, 91; J. D. STEFANESCU, L'illustration des liturgies dans l'art de Byzance, 113, pl. LXVIII.

1239 SALAVILLE, op. cit., I, 52.

1240 Grondiss, op. cit., 52-67, 83, première mention du rite sous Maurice, doctrine de l'incorruptibilité du corps du Christ sur la croix: M.B.E.H., (Vie et mort de Byzance), éd. $1969,41$.

1241 Grondis, op. cit., 90 et s.; P. ANDRIEU, Immixtio et Consecratio, 196 et s.

1242 Constitutions apostoliques, éd. Funk, I, 167; Concile Quinisexte (692), canon 101. 
pain imbibé de vin, pendant que le chœur chante le tropaire du jeudi saint ${ }^{1243}$.

La messe se termine par la purification du prêtre à l'autel de la Proskomidi et par le renvoi des fidèles (apolysis). Avant le $\mathrm{XV}^{\mathrm{e}}$ siècle, le diacre récitait une oraison derrière l'ambon et le prêtre, de la porte Royale, bénissait les fidèles ${ }^{1244}$.

La messe des Présanctifiés apparaît sous le patriarche Sergius en 615 , mais son plus ancien manuscrit date du IX $\mathrm{X}^{\mathrm{e}}$ siècle ${ }^{1245}$. D'après la législation du concile Quinisexte, elle est réservée à tous les jours du carême, sauf le samedi, le dimanche et le jour de l'Annonciation. Le dimanche, le prêtre dit la messe de saint Basile et consacre le pain nécessaire aux messes de la semaine, ainsi qu'une réserve d'eau et de vin. Ces hosties sont portées solennellement à l'autel; cette Grande Entrée était donc pleinement justifiée ${ }^{1246}$. La messe des Présanctifiés, à l'époque byzantine, était célébrée à trois heures de l'après-midi, heure de la mort du Sauveur et de la rupture du jeûne du carême. La cérémonie se confondait avec l'office de l'hespérinos (vêpres), qui en constituait la première partie. Les hosties étaient conservées dans une sorte de tabernacle (artophorion), placé dans la prothèse, où le prêtre allait procéder à la préparation, puis les rites se déroulaient dans le même ordre que dans les messes ordinaires ${ }^{1247}$. Le Vendredi saint, on ne célébrait aucune messe ${ }^{1248}$.

Livres liturgiques. - Les principaux sont l'Euchologe (missel), qui contient le texte des trois liturgies et ceux qui sont nécessaires pour l'administration des autres sacrements ; l'Évangéliaire (péricopes ou extraits des Évangiles pour chaque jour de l'année) ; l'Apôtre (Apostolos) renferme les Epîtres apostoliques ${ }^{1249}$.

La forme ancienne de ces livres à l'époque byzantine était le rouleau, écrit au recto et au verso, souvent avec des illustrations qui inter-

\footnotetext{
1243 Salaville, op. cit., I, 57; tropaire introduit par le patriarche Sergius en 624, Chronique Pascale ou Alexandrine, 1001.

1244 SALAVILLE, op . cit., 69.

1245 Kamateros, 345-352; Chronique Pascale, 989.

1246 GRONDIJS, op. cit., 78.

1247 Salaville, II, 93; Nicetas Stethatos, Contra Latinos, 1018.

1248 ANTOINE, archevêque de Novgorod, Le livre du pèlerin, 105.

1249 ForTESCUE, The Orthodox Eastern Church, 402; R. JANIN, Les Églises orientales et les rites orientaux, 46.
} 
rompent le texte et montrent les différents rites avec leur sens symbo-

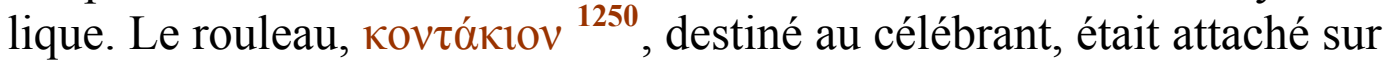
un cylindre de bois. Une peinture d'un rouleau montre le célébrant priant devant l'autel, dépliant un rouleau d'une main et le repliant de l'autre ${ }^{1251}$.

Les plus anciens rouleaux sont faits de papyrus, mais on n'en possède plus que des fragments, tels que l'anaphore de la liturgie de saint Marc à la Bibliothèque universitaire de Strasbourg ${ }^{1252}$. En revanche, les collections renferment plusieurs exemplaires en parchemin. On peut citer la bibliothèque du monastère Saint-Jean de Patmos, qui en possède vingt-neuf ${ }^{1253}$. Un exemplaire bien conservé et abondamment illustré est le rouleau du monastère de Lavra, qui contient la liturgie de saint Basile. Il a 7,65 $\mathrm{m}$ de long et est écrit en minuscule du début $\mathrm{du} \mathrm{XIV}^{\mathrm{e}}$ siècle. L'illustration comprend des initiales décoratives et 13 tableaux intercalés dans le texte, en interprétant à la fois la lettre et le sens symbolique : l'entrée du Christ dans l'église, la création et la chute de l'homme, la Nativité, la Cène, etc. ${ }^{1254}$.

L'office canonial. - Les clercs attachés à une église, comme les moines dans leurs monastères, étaient tenus de célébrer l'office quotidien ${ }^{1255}$. Dès le $\mathrm{VI}^{\mathrm{e}}$ siècle on y ajoutait les tropaires rythmiques dus aux mélodes. A l'origine, l'office était divisé en trois parties : mésonyktikon (matines), orthros (aurore), lykhnikos (jour), mais à partir du $\mathrm{VI}^{\mathrm{e}}$ siècle, après l'orthros on psalmodiait les petites heures, suivies de l'hespérinos (vêpres) et de l'apodeipnon (après-souper ou complies). En dehors de la psalmodie en antiphone, on lisait des passages de l'Ancien Testament, des actes des martyrs, des vies des saints et on chantait les cantiques (odes) de l'Ancien et du Nouveau Testament, accompagnés de tropaires ${ }^{1256}$.

\footnotetext{
1250 KAMATEROS, (en vers politiques), XC.

1251 BREHIER, Les peintures du rouleau liturgique de Lavra, A.I.K., Prague, 1939, fig. 1. — De même: Millet, Monuments byzantins de Mistra, pl. 84, 93 et 142; Millet et TALbot Rice, 1252 Byzantine Painting at Trebizond, 67 et s., pl. XXIV-XXV.

1252 Fragments sur papyrus de l'anaphore de saint Marc (éd. Andrieu et Collomp), R.S.R., VIII, 1928.

1253 KAMATEROS, loc. cit.

1254 BREHIER, loc. cit.

1255 C.J., I, III, 41, 10; Concile Quinisexte, canon 75, M.C., XI, 976.

1256 J. PARgOIRE, L'Église byzantine de 527 à 847, p. 104 et s.; Aigrain, Liturgia. Encyclopédie, 936.
} 
Les principaux livres utilisés pour l'office canonial étaient le Psautier, divisé en kathismata (sections liturgiques), les livres musicaux donnant des exemples d'offices pour chacun des huit tons (Oktoechos, fêtes des dimanches ; Paraklètiké, semaine ; Triodon, carême ; Pentékostarion, temps pascal), enfin les livres destinés aux lectures (leçons) : Ménées (propre des saints par mois) ; Synaxaires ou Ménologes, notices historiques sur les fêtes des martyrs et des saints, résumées pour le synaxaire quotidien. L'Horologion, de date plus récente que les livres précédents, contient l'ordinaire de l'office, le propre du temps, sans les cantiques des fêtes des saints ${ }^{1257}$.

Le calendrier liturgique. - L'Église byzantine se servait du calendrier julien, encore en usage dans les Églises orthodoxes, bien que ce soit à Constantinople que la réforme de ce calendrier ait été proposée pour la première fois par Nicéphore Grégoras à Andronic II ${ }^{1258}$.

L'année liturgique commençait, comme l'année civile, le $\mathrm{I}^{\mathrm{er}}$ septembre, jour de l'indiction. Elle était coupée par quatre carêmes : l'Avent (du 15 novembre à la vigile de Noël), le Grand Carême de 48 jours avant Pâques, des Apôtres (du lundi de la Pentecôte à la fête des Apôtres, le 28 juin), de l'Assomption (du I ${ }^{\mathrm{er}}$ au 14 août). Les fêtes étaient divisées en trois classes suivant leur importance. Le Synaxaire de Sainte-Sophie, composé de notices sur la fête célébrée chaque jour, montre l'usage de Constantinople ${ }^{1259}$. On y voit que les fêtes des saints de l'Ancien Testament sont plus nombreuses que dans le calendrier romain ${ }^{1260}$.

Mais surtout un grand nombre de fêtes furent ajoutées au calendrier pendant la période byzantine et parfois par des empereurs : la Purification (Hypapanti), créée par Justinien en $542^{1261}$, la Dormition de la Vierge, transportée par Maurice du 18 janvier au 15 août, acceptées par l'Occident ${ }^{1262}$. En 1122 Jean Comnène, victorieux des Petchénègues, crée une fête pour commémorer cet événement ${ }^{1263}$. La Fête de

1257 AIGRAIn, op. cit., 438; KATTENBUSCH, Lehrbuch der vergleichenden Konfessionskunde, t. I : Die orthodoxe anatolische Kirche, 482 et s.

1258 R. GuILland, Essai sur Nicéphore Grégoras, 10; NiCEPHORE GEGORAS, Histoire romaine, VIII, 13.

1259 Synaxaire de l'église Sainte-Sophie (manuscrit de Patmos, $\mathrm{X}^{\mathrm{e}}$ siècle).

1260 FORTESCUE, op. cit., 401; AIGRAIN, op. cit., 940.

1261 G. CEDRENOS, Synopsis, 700.

1262 TheOPHYLACTE DE SimOCATTA, Histoire, IV, 16.

1263 NiCETAS KhONIATES, Histoire, 4 (Bonn). 
l'Orthodoxie, créée en 843, célébrée le premier dimanche du Carême, commémore la défaite des iconoclastes et le rétablissement du culte des images ${ }^{1264}$. L'histoire même de Constantinople était rappelée par la liturgie : le 11 mai, anniversaire de sa dédicace ${ }^{1265}$, et, au cours de l'année, quatre anniversaires des attaques des Barbares, dont elle avait été miraculeusement sauvée : le 7 août (siège de 626 par les Avars), le 25 juin (siège de 678 par les Arabes), le 16 août (siège de 717-718 par le même peuple), le 5 juin (siège de 860 par les Russes) ${ }^{1266}$.

\section{Les fidèles}

Retour à la Table des Matières

La vie religieuse des fidèles était réglée en partie par des lois ecclésiastiques et civiles, mais surtout par des usages qui s'imposaient à tous.

Assistance à la liturgie dominicale. - Le fait de manquer la messe trois dimanches de suite entraînait, d'après le Quinisexte, l'excommunication pour les laïcs, la déposition pour les clercs ${ }^{1267}$. Le même concile défendait aux fidèles de s'agenouiller depuis les vêpres du samedi jusqu'à celles du dimanche, ainsi qu'à tous les offices de Pâques à la Pentecôte, car " prier debout, c'est honorer la Résurrection ${ }^{1268}$.

Bien des abus et des erreurs étaient redressés par ce concile. On vendait des comestibles ou d'autres denrées sous les portiques de l'église ${ }^{1269}$. Les femmes bavardaient pendant les offices ${ }^{1270}$. On détériorait les Livres saints pour les vendre à des parfumeurs, qui en faisaient des cornets ${ }^{1271}$. On pratiquait encore de vieux usages, comme de faire un repas dans l'église avant la communion du Jeudi saint ${ }^{1272}$. D'autres, de très bonne foi, apportaient à l'autel du lait et du miel ${ }^{1273}$

${ }_{1264}^{126}$ M.B.E.H. (Vie et mort de Byzance), éd. 1969, 105.

${ }^{1265}$ Frolow, La dédicace de Constantinople dans la tradition byzantine dans R.H.R., 1944, 61127.

1266 VASILIEV, The Russian Attack of Constantinople in 860.

1267 M.C., XI, 977 (canon 80).

1268 Ibidem, canon 90; PARGOIRE, L'Église byzantine de 527 à 847, p. 222 et s.

${ }^{1269} M$ M.C., XI, 976 et s., canon 76.

1270973 , canon 70

1271 Canon 68.

1272956 , canon 29.

1273969 , canon 57. 
ou des raisins, que le prêtre distribuait avec l'eucharistie ${ }^{1274}$. Mais le plus grand scandale était donné par ceux qui, prêtres ou laïcs, s'étaient installés avec leurs femmes dans les catéchumènes ou autres parties d'une église ${ }^{1275}$. Léon VI, qui a renouvelé ce décret, rappelle qu'il a fallu la fermeté de son père, Basile, pour faire exécuter la décision du concile ${ }^{1276}$.

Il semble bien que, dans les siècles suivants, on fit régner plus de décence dans les églises, comme le rapportaient les pèlerins d'Occident, édifiés de la tenue des fidèles ${ }^{1277}$.

Réception des sacrements. - Le baptême devait être administré exclusivement dans les baptistères, un païen ne pouvant se mêler à l'assemblée des fidèles. Le baptistère découvert à Doura-Europos montre qu'il en était ainsi au début du $\mathrm{III}^{\mathrm{e}}$ siècle. Depuis le $\mathrm{IV}^{\mathrm{e}}$ siècle, les baptistères étaient souvent des édifices indépendants, mais voisins de l'église cathédrale, bâtis en général sur des plans centrés (octogones, rotondes) rappelant l'architecture funéraire ${ }^{1278}$. Par contre, dans un grand nombre de villes, on avait continué à intégrer le baptistère dans le plan de l'église, avec laquelle il communiquait ${ }^{1279}$.

Quel que fût le plan, l'édifice était adapté à la liturgie du sacrement et comprenait essentiellement une salle où se faisaient les exorcismes, des vestiaires et la piscine dans laquelle avait lieu la triple immersion. Jusqu'à la fin du $\mathrm{IV}^{\mathrm{e}}$ siècle, les rites s'appliquaient surtout au baptême des adultes, conféré de préférence aux grandes fêtes. Un Samedi saint, où il fut l'objet d'un attentat dans son église, saint Jean Chrysostome avait baptisé 3000 catéchumènes et un grand nombre d'hommes et de femmes attendaient leur tour ${ }^{1280}$. Au VI ${ }^{\mathrm{e}}$ siècle, au contraire, les baptêmes d'adultes étaient plus rares. A cette époque, le baptême par infusion remplace souvent la triple immersion, mais il semble qu'il en était déjà ainsi au $\mathrm{V}^{\mathrm{e}}$ siècle, car Lemerle n'a trouvé aucune trace de piscine dans la basilique du Forum de Philippes ${ }^{1281}$. Au surplus, le baptême des adultes ne disparut jamais de Constantinople, où il était

\footnotetext{
1274956 , canon 28.

1275 985, canon 97; voir II. MONNIER, Les novelles de Léon le Sage, 20.

1276 LEON VI, Novelles (éd. et trad. Dam et Noailies, B.L., 1944) nov. 73 (250-51).

1277 Raoul GLABER, Historia sui temporis (éd. Prou), V, 1, 7, remarque, d'après les voyageurs, que les Grecs ne crachent pas dans les églises comme les Occidentaux.

1278 Symbolisme du baptême, mort et renaissance (cf. néophyte = nouveau-né).

1279 LASSUS, Sanctuaires chrétiens de Syrie, 217 et s.; LEMERLE, Philippes et la Macédoine orientale à l'époque chrétienne et byzantine, 335 et s., 439 et s.; D.A.C.L., I, 434 et s.

${ }^{1280}$ Lettre au pape Innocent, P.G., 17, 525.

1281 LEMERLE, op. cit., 337 et $\mathrm{s}$.
} 
conféré à des chefs barbares, à des hérétiques ${ }^{1282}$, à des Juifs. Après le baptême, le néophyte revêtu d'une robe blanche était conduit solennellement à l'église.

La confirmation a toujours été considérée en Orient comme la suite naturelle du baptême, le don suprême ${ }^{1283}$, conféré aux enfants comme aux adultes. Elle consiste dans l'onction, l'imposition de la main et le signe de la croix sur le front ( $\sigma \varphi \rho \alpha \gamma i ́$, consignatio). Elle avait lieu dans une salle attenante au baptistère ${ }^{1284}$ et était réservée à l'évêque, mais par nécessité, on dut donner ce droit aux simples prêtres ${ }^{1285}$.

Les pénitences publiques n'étaient plus en usage depuis le $\mathrm{IV}^{\mathrm{e}}$ siècle, mais la confession et les pénitences secrètes étaient obligatoires pour tous. On recherchait les moines et les ascètes comme directeurs de conscience, et des empereurs donnaient l'exemple de cette pratique ${ }^{1286}$, qui devint un monopole monastique. Deux traités sur le sacrement de pénitence, attribués à tort au patriarche Jean le Jeûneur (582-595), soutiennent qu'il appartient aux évêques et aux prêtres d'enseigner et aux moines de prêcher la pénitence et d'entendre les confessions. En 1274, Georges Akropolitès, représentant de Michel VIII au concile de Lyon, déclare que la rémission des péchés est un sacrement qu'un moine a seul le pouvoir de conférer ${ }^{1287}$.

Nous ne reviendrons pas sur les rites de la communion et du mariage qui ont été décrits déjà ${ }^{1288}$. L'évêque seul avait le pouvoir de conférer le sacrement de l'ordre par l'imposition des mains ${ }^{1289}$. L'extrême-onction était apportée aux malades, sans qu'ils fussent en danger de mort, afin de guérir les maux physiques et les défaillances de l'âme, suivant les termes d'un euchologe attribué au IV ${ }^{\mathrm{e}}$ siècle ${ }^{1290}$.

\footnotetext{
1282 L'Église reconnaissait le baptême des Nestoriens et des Jacobites, M.C., XI (Quinisexte), 984, canon 95.

1283 Clement D’AleXANDrie, Paedag., I, 16.

1284 LEMERLE, op. cit., 340-342.

1285 D.A.C.L., III, 1914, 2452 et s.

${ }^{1286}$ Maurice, Léon VI, Nicéphore Phocas, etc... PARGOIRE, L'Église Byzantine de 527 à 847, p. 94, 348 et 296.

1287 GRONDIJS, L'iconographie byzantine du Crucifié mort sur la croix, 99-100.

1288 Supra, p. 16 et 219.

1289 PARGOIRE, op. cit., 96

1290 D.A.C.L., V, 1922, 1028 et s.; JANIN, Les Églises orientales et les rites orientaux, 78.
} 
Formes de la piété. - Dans l'histoire de la piété byzantine le fait prédominant est l'action intense exercée par les moines sur les laïcs. Déjà $a u I^{\mathrm{e}}$ siècle on voit de hauts dignitaires mener la vie monastique sans cesser d'exercer leurs fonctions, un Gratissimus, praepositus sacri cubiliculi en 462, Un Jean Vincomalus, magister officiorum et consul en 453 : après les séances du Sénat auxquelles celui-ci avait assisté, il était reconduit à son monastère par de nombreux clients; là il se dépouillait de ses insignes pour endosser la mandya et se livrait aux plus viles besognes ${ }^{1291}$. A plus forte raison, après la victoire des Images, qui était en grande partie celle des moines, leur autorité ne fit que s'accroître et ce fut par leur action que se développèrent les deux dévotions caractéristiques du monde orthodoxe : le culte des saints et des reliques et la vénération des icônes.

\section{Le culte des saints et des reliques}

\section{$\underline{\text { Retour à la Table des Matières }}$}

Culte des martyrs. - A l'époque byzantine, le culte des martyrs avait franchi d'importantes étapes depuis les temps anciens, où il consistait en repas funéraires sur leurs tombes ${ }^{1292}$. Sous le nom de martyria (témoignages), on abrita leurs reliques dans des édifices funéraires aux plans variés, où l'on venait célébrer la liturgie à leur anniversaire ${ }^{1293}$. Puis, à partir $\mathrm{du} \mathrm{V}^{\mathrm{e}}$ siècle, le culte des martyrs pénétra dans les églises, tout en restant distinct de la liturgie ordinaire. On éleva des églises-martyria (rotondes, octogones), telles que la cathédrale d'Antioche, plusieurs églises de Syrie, à Constantinople les Saints-Apôtres de Justinien, les Saints Serge-et-Bacchus ${ }^{1294}$. En Palestine on vénéra comme témoignages (martyria) les lieux historiques de la vie de Jésus où s'étaient produites des apparitions divines ${ }^{1295}$; commémorées par des églises ou chapelles, ces théophanies étaient reproduites par des peintures dans leurs absides ${ }^{1296}$.

${ }^{1291}$ LASSUS, op. cit., 264-284 (vénération des ascètes syriens).

1292 A. GRABAR, Martyrium, I, 51.

1293 Ibidem, I, 147-203; LASSUS, op. cit., 120-161.

1294 GRABAR, op. cit., 1, 335-400 (Des martyria aux églises).

1295 Ibidem, I, 322-334.

${ }^{1296}$ Ibidem, II, 129-206. 
Le culte des reliques. - Commun à toute la chrétienté, le culte des reliques a donné lieu à Byzance à des manifestations extraordinaires et pris une telle importance, qu'il est devenu une affaire d'État, jusqu'à tenir une place dans les négociations avec les Musulmans ${ }^{1297}$. Nul n'a songé à mettre en doute leur authenticité. La littérature byzantine n'a jamais produit un ouvrage comparable au De pignoribus sanctorum de Guibert de Nogent, et le pillage éhonté des reliques de Constantinople par les croisés de 1204, resté l'un des griefs principaux des Grecs contre les Occidentaux, a contribué à rendre le schisme irréparable.

A Constantinople les reliques de la Vierge, patronne de la ville, avaient une importance considérable. A Sainte-Marie des Blachernes on conservait son linceul et sa tunique (maphorion) ${ }^{1298}$, à Sainte-

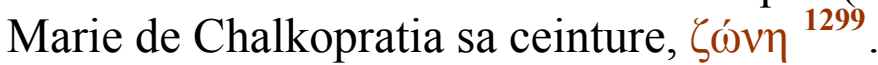

Ces reliques, regardées comme le palladium de la cité, étaient promenées sur les remparts chaque fois que Constantinople était assiégée et cette manifestation exerçait une action intense sur le moral des défenseurs ${ }^{1300}$.

Le culte de la Toute Sainte (Panagia) Mère de Dieu (Théotokos) alla en se développant: d'innombrables sanctuaires furent élevés en son honneur et pour conserver ses reliques ou ses icônes miraculeuses ${ }^{1301}$. La plus remarquable expression de son patronage est l'admirable mosaïque du vestibule de Sainte-Sophie, qui la montre trônant entre Constantin et Justinien, l'un offrant le modèle de la Ville, l'autre celui de l'église ${ }^{1302}$.

Reliques du Christ. - La plus vénérée de ces reliques était la Vraie Croix, que l'on avait rapportée de Jérusalem à Constantinople lorsque l'invasion arabe atteignit la Palestine ${ }^{1303}$. Conservée au Grand Palais, elle fut littéralement dépecée au cours des siècles, à cause de l'usage qui s'établit d'en envoyer des parcelles aux sanctuaires

1297 A propos de l'icône d'Édesse, voir p. 234-235.

1298 EBERSOLT, Sanctuaires de Byzance, 44 et s.

1299 Ibidem.

1300 Pendant le siège de 620 par les Avars, les Blachernes étant en dehors des murs, les reliques furent portées à Sainte-Sophie et rapportées aux Blachernes après la victoire. Sergius institua une fête commémorative de cet événement; elle est toujours célébrée. R.P.B., 280.

1301 FrolOw, art. cit., R.H.R., 1944, 93; EBERSOLT, op. cit., 61 et s.

1302 WhitTEMORE, The Mosaics of Haghia Sofia at Istanbul, II: Southern Vestibule (planches).

1303 Sebeos, Histoire d'Héraclius, 118; A. GARDNER, Theodore of Studium, his life and times, 290. 
d'Orient et d'Occident, aux monastères, aux princes étrangers. Cette pratique datait de loin, car en 569, à la prière de Radegonde, épouse répudiée de Clotaire, Justin II lui envoyait un fragment de la Vraie Croix, enchâssé dans un magnifique reliquaire, conservé au monastère de Sainte-Croix de Poitiers ${ }^{1304}$.

Depuis le $\mathrm{X}^{\mathrm{e}}$ siècle, ces parcelles étaient enfermées dans de riches reliquaires tout scintillants d'or et d'argent, d'émaux et de pierres précieuses, appelés staurothèques. Dans des cadres somptueux, la précieuse relique était disposée dans une cavité en forme de croix à double traverse ${ }^{1305}$. Le cadre, décoré de figures, était parfois muni de volets, ce qui faisait un triptyque. Nous avons eu déjà l'occasion de signaler la staurothèque de Limbourg-sur-Lahn sortie des ateliers du Grand Palais. La croix qui renferme la parcelle est entourée de 20 plaques d'or émaillé, figurant les hiérarchies célestes (au nom de Constantin Porphyrogénète et Romain, 948-959). Le couvercle, décoré d'une Deisis et d'ornements variés, porte le nom de Basile le Proèdre (963-985) ${ }^{1306}$. Par sa splendeur, cette staurothèque est le chefd'œuvre de ce genre de reliquaires ${ }^{1307}$.

L'importance attachée à la Vraie Croix était telle qu'en 924 Romain Lécapène, guéri d'une maladie, voulut faire don au monastère de Xéropotamou (Athos) d'une magnifique staurothèque, mais sur les réclamations du Sénat et du peuple de Constantinople, désireux de ne pas être privés des grâces dues à cette relique, le basileus ordonna qu'elle serait transportée à Constantinople tous les trois ans sous la protection d'un corps de soldats ${ }^{1308}$.

D'autres reliques de la Passion, la Couronne d'épines, le saint Sang, la sainte Lance étaient conservées au Grand Palais. L'empereur latin Baudouin II, pressé d'argent, vendit ces reliques au roi saint Louis, qui fit construire la Sainte-Chapelle de Paris pour les recevoir

\footnotetext{
1304 Gregolre de Tours, Historia Francorum, IX, 40; Gloria mart., 5; E. MolinIER, Histoire générale des arts appliqués à l'industrie, II : L'orfèvrerie, 40; EBERSOLT, Orient et Occident. Influences byzantines et orientales en France, 92, p1. su; FORTUNAT, Carmina, Appendix, II, 55-62; A.A., IV, 1, 277.

1305 La traverse supérieure figurant le titulus.

1306 BREHIER, La Sculpture et les Arts mineurs byzantins, 48, p1. 62; EBERSOLT, Sanctuaires de Byzance, 145 et $\mathrm{s}$.

1307 Staurothèques célèbres : Lavra (attribuée à Nicéphore Phocas), Maastricht (Vatican), Gran (Hongrie), DiEHL, op. cit., 42; MOLINIER, Histoire générale des arts appliqués à l'industrie, II : L’orfèvrerie, pl. 1.

1308 R.K.O.R., 600.
} 
(1243-1248) ${ }^{1309}$. Des fragments importants de la Vraie Croix étaient enchâssés dans un tableau-reliquaire creusé de trois cavités cruciformes : au-dessus, les quatre archanges en bustes et, au pied de la croix centrale, Constantin et sainte Hélène ${ }^{1310}$.

Et pourtant, malgré cette vente massive, on voit les églises de Constantinople conserver bien d'autres reliques de la vie de Jésus. Au Grand Palais on possédait le linge du lavement des pieds, le Linceul du Saint-Sépulcre, le manteau de pourpre et le roseau ${ }^{1311}$. Toutes ces reliques se trouvaient au monastère Saint-Jean de Petra au début du $\mathrm{XV}^{\mathrm{e}}$ siècle, et l'on y montrait aussi, enfermé dans un coffret d'or, le pain que Jésus donna à Judas et le fer de la Sainte Lance ${ }^{1312}$. La colonne de la Flagellation, qui se trouvait aux Saints-Apôtres à la fin du $\mathrm{XI}^{\mathrm{e}}$ siècle, était dans le trésor de Sainte-Sophie en 1439, ainsi que la sainte Lance. Ces reliques sont montrées au voyageur espagnol Peró Tafur par le despote Constantin Dragasès, le patriarche et le prieur de Sainte-Sophie, qui ont chacun une clef du trésor ${ }^{1313}$. On montrait même à l'église des Blachernes les corbeilles de la Multiplication des pains et à Sainte-Sophie les langes de Jésus ${ }^{1314}$ ! La crédulité des pèlerins n'était pas plus grande que celle du peuple grec lui-même.

Les reliques des saints. - Le culte des saints et de leurs reliques n'était pas moins fervent qu'en Occident. On leur demandait des grâces spirituelles et temporelles. Les récits de leur vie, de leurs exploits d'ascétisme, de leurs miracles ont donné lieu à une prodigieuse floraison de biographies et de panégyriques. La recherche de leurs reliques ressemblait à une véritable chasse. On se disputait les cadavres des ascètes, aussitôt après leurs derniers moments.

Ce fut ainsi qu'après la mort de saint Hilarion le Géorgien, qui vivait près de Thessalonique, en 880, l'empereur Basile, informé de ses vertus, voulut faire transporter son corps à Constantinople aussitôt une émeute éclata à Thessalonique, mais le gouverneur de la ville tint tête aux rebelles, parvint à enlever le corps

\footnotetext{
${ }^{1309}$ Bulle d'or de Baudouin II. RIANT, Exuviae sacrae, II, 135 et s.; GERARD DE SAINT QUENTIN EN L'ISLE, Translatio sanctae Corone, D.N.I.C. a Constantinopolitana urbe ad civitatem Parisiensem (éd. Miller, J.S., 1878), 295-302 et 389-403.

1310 EBERSOLT, Orient et Occident. Influences byzantines et orientales en France, II, 23.

1311 Id., Sanctuaires de Byzance, 28.

1312 Ibidem, 116-118 (d'après Buondelmonte et Clavijo).

1313 VAsiliev, Pero Tafur... and his visit to Constantinople, Trebizond and Italy, 104.

1314 AntoIne, archevêque de Novgorod, Le livre du pèlerin, 99-100; EBERSOLT, Sanctuaires de Byzance, 144.
} 
la nuit et à l'envoyer par mer à Constantinople, où il fut reçu en grande pompe par le basileus et le patriarche Photius (novembre 882) ${ }^{1315}$.

Constantinople était naturellement le principal centre des reliques des saints, conservées dans des châsses resplendissantes en forme de maisons à deux pignons avec toits à double versant ou d'églises à coupoles ${ }^{1316}$. Il y avait aussi des reliquaires en forme de chefs ou d'un membre quelconque, bras, main, pied, etc. Toutes ces variétés furent créées en Orient, avant d'atteindre l'Occident ${ }^{1317}$. Les encolpia ( $\gamma \kappa \circ \lambda \pi i ́ \alpha)$ étaient de petits reliquaires pectoraux.

Au culte des saints de l'Ancien Testament se rattachait la Verge de Moïse, conservée au Chrysotriclinium ${ }^{1318}$; à l'église des Blachernes, des reliques d'Isaïe; à la Nouvelle Église de Basile $\mathrm{I}^{\mathrm{er}}$, le prétendu manteau du prophète Élie, objet d'un culte fervent à Byzance ${ }^{1319}$.

Les temps apostoliques étaient représentés par les reliques des Saints Innocents ${ }^{1320}$ et par le chef de saint Jean-Baptiste, connu déjà aux $\mathrm{V}^{\mathrm{e}}$ et $\mathrm{VI}^{\mathrm{e}}$ siècles : il aurait été caché à Émèse pendant la persécution iconoclaste et fut découvert sous Michel III, apporté à Constantinople sous le patriarcat d'Ignace. Déposé au Grand Palais, puis au monastère de Stoudios, il devint une des reliques les plus célèbres de Constantinople ${ }^{1321}$.

Une église dédiée à saint Jean l'Évangéliste avait été construite par Constantin à l'Hebdomon et restaurée par Justinien ${ }^{1322}$. Une autre église lui était consacrée près de Sainte-Sophie : on y montrait une pierre de son tombeau, situé à Ephèse, où il attirait de nombreux pèlerins ${ }^{1323}$.

Constantinople fut la première ville où une église fut érigée en l'honneur des Douze Apôtres. L'édifice, fondé en 330 par Constantin

\footnotetext{
1315 Vie de saint Hilarion d'Ibérie, 236 et s.

1316 SCHLUMBERGER, Reliquaire en forme d'église, F.E.P.M., XII, 1905, pl. XIV.

1317 EBERSOLT, op. cit., 145.

1318 Ibidem, 22 et s.; ANTOINE, archevêque de Novgorod, op. cit., 98.

1319 EBERSOLT, op. cit., 29-30 fête du 29 juillet, voir p. 352).

1320 ANTOINE, op. cit., 99; EBERSOLT, 59.

1321 A.S.B., 24 juin, IV, 731-736; EBERSOLT, 79 et s.; Du CANGE, Traité historique du chef de saint Jean-Baptiste, Paris, 1665; EBERSOLT, Orient et Occident. Influences byzantines et orientales en France, II, 28, 80.

1322 M. R. DEMANGEL, Contribution à la topographie de l'Hebdomon, 30-32.

1323 EBERSOLT, op. cit., 83.
} 
et achevé sous Constance, qui y fit transporter le corps de son père, était au milieu d'une vaste enceinte entourée de portiques, avec des jardins et des thermes. L'église, incendiée pendant la sédition Nika (532), fut rebâtie par Justinien sous la forme d'une basilique en croix libre, couverte de cinq coupoles et inaugurée en 546. Les reliques des apôtres étaient placées sous un autel d'argent et, sous Constantin VII, on y ajouta leurs vêtements, qui y furent transportés en grande pompe. Les saints Grégoire de Nazianze, Jean Chrysostome, plusieurs empereurs et patriarches y étaient ensevelis ${ }^{1324}$.

Parmi les saints les plus vénérés se trouvait le protomartyr Étienne, dont le corps avait été retrouvé près de Jérusalem en 415. Ses reliques furent dispersées dans toute la chrétienté. Constantinople reçut sa main droite, placée par Pulchérie en 428 dans l'église Saint-Étienne du palais de Daphni, puis en 459 Eudokia rapporta de Jérusalem d'autres reliques du même saint ${ }^{1325}$.

Les martyrs de l'ancienne Byzance étaient peu nombreux ${ }^{1326}$, mais Constantinople accueillait les reliques des martyrs étrangers, comme celles de saint Laurent, apportées de Rome sous Théodose II ${ }^{1327}$, de sainte Euphémie, martyre à Chalcédoine sous Galère ${ }^{1328}$, des Quarante Martyrs de Sébaste en Petite-Arménie ${ }^{1329}$, des saints Serge et Bacchus, martyrs à Resafa (Sergiopolis), pour les reliques desquels Justinien fit construire la belle église qui porte leur nom ${ }^{1330}$.

Non moins célèbres étaient les reliques conservées dans certaines cités provinciales. Au premier rang il faut placer Thessalonique avec son culte de saint Démétrius, patron de la ville, bien que martyrisé à Sirmium sous Maximien ${ }^{1331}$. Il tenait une telle place dans la vie de la cité qu'on a vu en lui le successeur d'une divinité poliade, sans qu'on puisse fournir le moindre éclaircissement sur cette métamorphose

\footnotetext{
1324 A. GRABAR, Martyrium, I, 228 et s.; EBERSOLT, 30-43; VASILIEV, Imperial porphyry sarco1325 phagi, dans D.O.F., IV, 1948, 7-9.

1325 EBERSOLT, 7.

1326 Ibidem. 84-86.

1327 Ibidem, 87 et $\mathrm{s}$.

1328 A.S.B., septembre V, 247-283; LOPAREV, Vizantiiskiia Jitii Sviatuik, 36; EBERSOLT, 88 et s.

1329 EBERSOLT, 92.

1330 LASSUS, Sanctuaires chrétiens de Syrie, 208-212.

1331 A.S.B., oct. IV, 83 et s.
} 
d'un dieu païen en héros chrétien ${ }^{1332}$. La plus vaste église de la ville lui était dédiée ; de son tombeau découlait une huile miraculeuse qui guérissait les maladies, mais il était surtout le chef de guerre (hégémon), protecteur de la ville, qu'il avait sauvée maintes fois des assauts des Barbares. Il est le sauveur de la ville, le patron des soldats, des matelots et des voyageurs, " le soleil qui projette de brillants rayons; il est pour nous le soleil, la terre et la mer... ", s'écriait dans un sermon l'archevêque Isidore Glabas (1379-1393) ${ }^{1333}$.

Nous ne reviendrons pas sur le culte, déjà signalé, de saint Eugène à Trébizonde et de saint Jean l'Évangéliste à Éphèse.

Un des événements les plus curieux de l'histoire des reliques est la translation du corps de saint Nicolas, de Myre à Bari, en avril-mai 1087.

Le culte de saint Nicolas était déjà très répandu à Constantinople, dans tout l'Orient et en Occident. Son tombeau, placé à Myre dans l'absidiole d'un martyrium ${ }^{1334}$, attirait de nombreux pèlerins et la renommée de ses miracles était grande. Mais la ville, située près de la mer, avait été plusieurs fois en butte aux pillages des Sarrasins, lorsque l'évacuation d'une grande partie de l'Asie Mineure par les armées byzantines, après la bataille de Mantzikert (1071), rendit sa situation encore plus précaire. Les villes maritimes d'Italie qui avaient des relations de commerce avec l'Anatolie résolurent de mettre la précieuse relique en sûreté. Ce furent des matelots de Bari, où le culte de saint Nicolas était des plus prospères ${ }^{1335}$, qui, gagnant de vitesse des navires vénitiens, parvinrent à s'emparer des reliques du saint et à les rapporter triomphalement dans leur ville, où elles furent placées dans la crypte d'une nouvelle basilique, en présence du pape Urbain II, le $1^{\text {er }}$ octobre $1089^{1336}$.

Culte des saints guérisseurs (Hagiothérapie). - Comme en Occident, beaucoup de saints étaient invoqués pour le pouvoir, qu'on leur attribuait, de guérir certaines maladies. La guérison s'opérait, soit par l'attouchement des reliques (l'anneau de sainte Théophano trempé dans l'eau guérit de l'épilepsie la mère de son biographe) ${ }^{1337}$, soit,

1332 R.P. DELEHAYE, Les légendes grecques des saints militaires, 114; TAFRALI, Thessalonique au $X I V^{e}$ siècle, 131; DIEHL, Monuments chrétiens de Salonique, 61 et s.

1333 TAFRALI, op. cit., 134 et 135.

1334 GRABAR, Martyrium, I, 343.

1335 Où 4 églises lui étaient déjà dédiées. B. LEIB, Rome, Kiev et Byzance à lafin du XI siècle, 53.

${ }_{1337}^{1336}$ B. LEIB, op. cit., 51-74 (analyse critique des récits grecs, latins et russes de la translation).

${ }^{1337}$ Vie de sainte Théophano impératrice, première femme de Léon VI, « Monumenta Photiana », 1869; LOPAREV, op. cit., 71. 
comme nous venons de le voir, par l'huile qui découlait du corps des saints myrophores ou par celle des lampes qui brûlaient devant leurs tombeaux, soit par les sources miraculeuses qui jaillissaient dans leur martyrion ou à son voisinage. Avant le $\mathrm{VII}^{\mathrm{e}}$ siècle l'exemple le plus remarquable de l'utilisation d'une source de ce genre était le sanctuaire de saint Ménas sur le lac Maréotis près d'Alexandrie.

Saint Ménas, officier grec d'une légion, avait été décapité comme chrétien en 296 à Kotynon en Asie Mineure. Ses reliques furent apportées en Égypte et placées dans un martyrium construit à l'endroit où les chameaux, qui portaient son corps, s'étaient arrêtés. Son culte était très répandu à la fin $d u V^{e}$ siècle et l'empereur Arcadius fit construire une grande basilique près de son martyrium. Des monastères s'élevèrent dans le voisinage et une ville importante se forma autour d'eux et devint un grand centre de pèlerinage. Les fouilles de Kaufmann, en 1906, sur l'emplacement du village actuel, ont mis à jour une vaste crypte avec une citerne et l'inscription: "Prends l'eau de saint Ménas si tu veux faire cesser ton mal. » Une piscine était en relation avec la basilique, dans laquelle se trouvaient deux belles fontaines de marbre. Les pèlerins emportaient cette eau dans de petites ampoules (eulogies) de terre cuite, timbrées de l'icône du saint orant entre deux chameaux agenouillés. $\mathrm{Au} \mathrm{VI}^{\mathrm{e}}$ siècle le pèlerinage de saint Ménas était connu dans toute la chrétienté ${ }^{1338}$.

A Constantinople, au cours des fouilles françaises pratiquées en 1923 dans le quartier des Manganes, on a découvert dans l'enceinte du monastère du Saint-Sauveur la fontaine miraculeuse (ayasma,

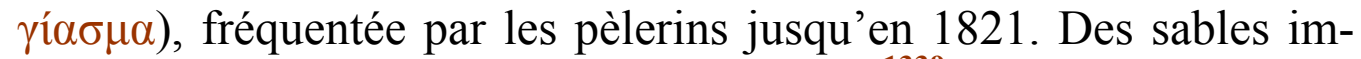
prégnés de son eau guérissaient les podagres ${ }^{1339}$. Un édifice hexagonal, entouré de larges et profondes absides avec une piscine centrale, dédié à la Vierge conductrice (Panagia Hodigitria) serait un ayasma du même genre plutôt qu'un baptistère ${ }^{1340}$.

La pratique païenne de l'incubation était toujours en usage. Des malades restaient couchés plusieurs jours dans certaines églises, soignés par un personnel de prêtres et d'infirmiers, qui avaient reçu une instruction médicale. Ces pratiques avaient lieu dans les sanctuaires des Saints Anargyres Cosme et Damien ${ }^{1341}$, médecins d'origine

${ }^{1338}$ Kaufmann, Der Menastempel und die Heiligtümer von Karm Abu Mina; D.A.C.L., XI, 1932, 324-398; GRABAR, Martyrium, I, 64 et s.

1339 Demangel et MAmboury, Le quartier des Manganes et la première région de Constantinople, 65 et s.

1340 Ibidem, 81-102.

${ }^{1341}$ Le surnom d'anargyres vient de ce qu'ils soignaient gratuitement les malades. Une miniature du Ménologe de Basile II (Vatican, gr. 1613) les montre recevant du ciel une trousse de chirurgien (Cumont, L'Adoration des Mages, Mém., Ac. Pontif. d'Archéol., 1932, pl. VII, 3). 
arabe, décapités comme chrétiens en 303. Leurs corps avaient été enterrés à Cyrus en Syrie, mais leur culte s'était propagé et plusieurs églises leur furent dédiées à Constantinople ${ }^{1342}$.

Enfin saint Michel était considéré aussi comme un saint guérisseur. Il était invoqué dans des sanctuaires ou martyria, construits sur les lieux où il passait pour être apparu : à Khonae en Phrygie, au Michaelion et à Sosthène sur le Bosphore, enfin dans la grotte du Monte Sant'Angelo en Italie. Le Michaelion était un martyrium circulaire attribué à Constantin et reconstruit par Justinien. On y célébrait la fête de l'Archange le 6 septembre ${ }^{1343}$.

\section{Le culte des icônes}

\section{$\underline{\text { Retour à la Table des Matières }}$}

Le culte des icônes, trait caractéristique de la confession orthodoxe, paraît avoir été, dès le moyen âge, plus fervent encore que celui des reliques, dont il est d'ailleurs indépendant ${ }^{1344}$. Nous avons vu qu'il était associé à la liturgie, surtout depuis la création de l'iconostase. Nous savons qu'il n'y avait pas de maison qui n'eût sa petite iconostase particulière. Enfin c'est un usage, qui date des temps byzantins, d'exposer chaque jour dans les églises, sur un pupitre

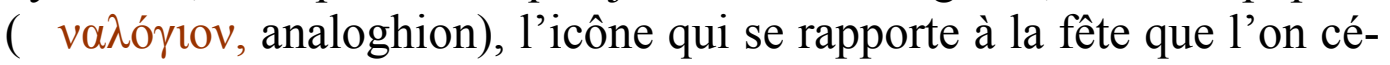
lèbre.

Origine des icônes. - Les plus anciennes icônes sont des portraits peints sur bois a tempera ou à l'encaustique. Elles dérivent des portraits funéraires égyptiens des époques hellénistique et romaine, que l'on plaçait sur les sarcophages contenant les momies. Ces portraits, retrouvés en grand nombre à Antinoé ou à Akhmin, ont un caractère individuel très marqué. Les défunts sont représentés de face, avec des

\footnotetext{
1342 Actes grecs des saints anargyres (éd. Dübner) et B.Z., 1908, 603; GRABAR, op. cit., II, 345; EBERSOLT, Sanctuaires de Byzance, 97 et s.

1343 EBERSOLT, op. cit., 99-101.

1344 GRABAR, op. cit., II, 351 (le culte des icônes aurait fait tort à celui des reliques).
} 
yeux agrandis fixés sur les spectateurs, et leurs regards intenses, qui vous poursuivent obstinément, semblent venir d'un autre monde ${ }^{1345}$.

Entre ce style et celui des plus anciennes icônes chrétiennes, il n'existe pas de différence. Ces icônes étaient à l'origine des portraits de martyrs, représentés tels qu'ils étaient avant leur supplice. Elles devinrent dans la suite des créations de peintres, mais elles ne cessèrent pas d'être regardées par les fidèles comme des portraits authentiques et c'était ce qui, à leurs yeux, en justifiait la vénération.

Mais l'icône a sa loi propre. Elle ne cherche pas comme la peinture à donner l'illusion de la réalité, mais à produire un effet d'ordre spirituel. Elle n'est ni réaliste, ni purement narrative, mais elle emprunte au réel les traits nécessaires à faire reconnaître un personnage ou une scène et, par là, elle se rattache à l'art historique. Elle recherche avant tout l'expression par le jeu des physionomies, la combinaison des lignes, des accessoires, des paysages : de la réalité, elle fait un symbole. C'est un art savant, tout en nuances, délicat et subtil. Son caractère religieux l'a rendu populaire, mais ce succès auprès des foules a favorisé sa cristallisation et sa décadence ${ }^{1346}$.

Les icônes regardées comme les plus antiques sont celles que Porphyre Ouspensky recueillit dans les monastères du Sinaï et qui furent conservées au Musée de l'Académie de Kiev. Une des plus belles est un portrait en bustes de deux époux martyrs, comme le montre la croix gemmée qui apparaît entre eux et dont les rayons se dirigent sur leurs têtes ${ }^{1347}$.

L'icône peinte à l'encaustique des saints Sergius et Bacchus, en costume de la garde impériale $\mathrm{du} \mathrm{VI}^{\mathrm{e}}$ siècle, montre la création de types d'âges et de professions variés. Un nimbe d'or entoure leur tête, qui se détache sur un fond vert bleuâtre. Entre eux on aperçoit une petite icône du Christ au nimbe crucifère ${ }^{1348}$.

\footnotetext{
1345 WulfF et AlPATOV, Dankmäler der Ikonenmalerei, 4; BREHIER, Les icônes dans l'histoire de l'art et la Russie, 150 et s.

1346 L. BREHIER, op. cit., 151 et s.

1347 WulfF et AlPATOV, op. cit., 8 (regardée comme du V $\mathrm{V}^{\mathrm{e}}$ siècle).

1348 Ibidem, 11, pl. 5; STRZYGOWSKI, Orient oder Rom, 124.
} 
L'icône religieuse est représentée par un portrait en pied de saint Jean-Baptiste, remarquable par son style vigoureux et la puissance d'expression du geste avec lequel il montre des icônes en médaillons du Christ et de la Vierge ${ }^{1349}$.

Icônes acheiropoiètes (non faites de main d'homme). $-\mathrm{Du} \mathrm{VI}^{\mathrm{e}}$ $\mathrm{au} \mathrm{IX}{ }^{\mathrm{e}}$ siècle, on possède à peine quelques fragments d'icônes, mais un grand nombre de portraits à fresque, en Égypte dans les chapelles de Baouit et dans plusieurs monastères. Plusieurs de ces portraits reproduisent des icônes, à la loi desquelles elles se conforment par leur frontalité, leurs teintes plates, leurs figures de face ${ }^{1350}$. Quelques débris provenant d'Égypte (Adoration des Mages, Nativité, etc.) montrent l'apparition de scènes historiques dans l'art des icônes dès le $\mathrm{VI}^{\mathrm{e}}$ siècle ${ }^{1351}$.

En outre c'est à cette époque que circulent des portraits du Christ et de la Vierge que l'on déclare authentiques d'après des textes apocryphes, tels que la lettre de Lentulus au Sénat romain, où il décrit la personne du Sauveur ${ }^{1352}$. C'est ainsi qu'au monastère de la Panagia Hodigitria, on vénérait une icône de la Vierge, envoyée de Jérusalem à Pulchérie par l'impératrice Eudokia, que l'on disait avoir été exécutée par saint Luc ${ }^{1353}$.

Mais sous Justinien ce furent des portraits du Christ, apportés à Constantinople de Cappadoce, que l'on vénéra comme acheiropoiètes. La principale de ces icônes venait de Kamouliana. Une païenne avait dit qu'elle ne croirait au Christ que si elle le voyait, quand elle aperçut son icône dans une pièce d'eau. On ne sait rien de cette icône que ce qu'en a dit saint Grégoire de Nysse, car elle fut probablement détruite par les iconoclastes ${ }^{1354}$.

\footnotetext{
1349 WulfF et AlpatOV, 20 et s., pl. 8; cf. 18, pl. 7.

1350 De GruneISEn, Sainte-Marie-Antique, 1097 et s.; D.A.C.L., V, 2022, fig. 4587; 2030, fig. 4591; ibid., III, 247-48, fig. 1284 et 1286.

1351 WulfF et Alpatov, 30-35.

1352 Guide de la Peinture (« Hermeneia ») trad. Didron : Manuel d'iconographie chrétienne, grecque et latine, 453, 2; G. DE JERPHANION, La Voix des Monuments, II, 9.

1353 TheOdORE LE LECTEUR, Histoire ecclésiastique (fragments), 165; découverte d'une icône semblable à Soumela, près de Trébizonde, en 1931 (Le Temps, 17 nov. 1931); JuGIE, dans B.N., V, 365 et s. (tropaire sur cette icône).

1354 Grabar, La Sainte Face de Laon, 22; DoBschütz, Christusbilder, I, 40 et s.; Saint GREGOIRE DE NYSSE (Homélies), atteste son existence à la fin du IV ${ }^{\mathrm{e}}$ siècle.
} 
Édesse, comme on l'a vu, possédait une lettre du Christ au roi $\mathrm{Ab}$ gar $\mathrm{V}$ : à la fin $d u \mathrm{~V}^{\mathrm{e}}$ siècle le bruit se répandit qu'on y conservait aussi son portrait acheiropoiète, et la légende attribuée à cette icône n'est qu'un développement de celle de la lettre.

Le roi Abgar invita Jésus à venir à Édesse, Le Sauveur refusa et lui envoya une lettre par son disciple Thaddée (Addai), qui convertit le roi et le peuple et fonda plus tard l'Église d'Édesse. D'autre part le roi avait chargé un peintre de faire le portrait du Christ, mais il ne put saisir les traits du Sauveur et avoua son impuissance. Alors Jésus saisit la toile et y imprima son visage.

Telle est la légende populaire, mais dans l'ouvrage, dit Doctrine d'Addaï, c'est l'envoyé d'Abgar qui fait le portrait du Christ et le porte à Édesse. On ne trouve aucune mention de cette légende avant Evagrios, qui écrit son Histoire vers $600{ }^{1355}$. Après son transfert à Constantinople, l'icône est appelée mandylion (mot arabe mandil, qui signifie serviette) ${ }^{1356}$. D'après Evagrios le mandylion, longtemps caché, fut retrouvé en 544, pendant le siège d'Édesse par les Perses et la ville lui dut son salut ${ }^{1357}$.

Quand Héraclius fait ses adieux au peuple à Sainte-Sophie avant de partir pour son expédition en Perse en 622, il tient à la main un étendard sur lequel est brodée une icône acheiropoiète du Christ ${ }^{1358}$.

La crise iconoclaste. - $\mathrm{Du} \mathrm{VI}^{\mathrm{e}}$ au $\mathrm{IX}^{\mathrm{e}}$ siècle la ferveur pour le culte des icônes augmenta à tel point, qu'on en arriva à des pratiques qui rappelaient le paganisme. Le prosternement ( $\pi \rho \circ \sigma \kappa v ́ v \eta \sigma ı \varsigma)$ n'était guère plus choquant devant une icône que devant le basileus, mais que dire de certaines excentricités : les cheveux de ceux qui entrent dans un monastère déposés devant des icônes, des prêtres grattant des icônes pour en faire tomber la poussière dans le calice et communier ainsi les fidèles, d'autres prenant des icônes comme parrains de leurs enfants ${ }^{1359}$.

1355 Evagrios, Histoire ecclésiastique, P.G., 86, 2, 2748.

${ }^{1356}$ L. BrehiER, Icônes non faites de main d'homme, 68, 77; Grabar, La Sainte-Face de Laon, 22 et $\mathrm{s}$.

1357 PROCOPE, B.P., II, 26, raconte ce siège et ne parle que de la lettre d'Abgar.

1358 GENESIOS, Le livre des Empereurs, P.G., 108 (I, 39); KOULAKOVSKY, Istoria Vizantii, III, 60.

${ }^{1359}$ R.K.O.R., 408 et s. (lettre de Michel II à Louis le Débonnaire en 824); Saint THEODORE LE STUDITE, Lettres, 961-963. 
Les histoires les plus extravagantes couraient sur les miracles des icônes, regardées comme des êtres vivants, proférant des paroles, versant des flots de sang lorsque des Juifs les percent d'une lance ${ }^{1360}$.

Doctrine théologique du culte des icônes. - Les attaques contre le culte des icônes obligèrent ses défenseurs à instituer une doctrine théologique qui justifiât et la fabrication et la vénération des icônes. Le traité De Imaginibus de saint Jean Damascène (vers 730) ${ }^{1361}$, inspira les décrets du concile de Nicée (787), qui prit le contre-pied du concile iconoclaste de 754 .

Dans sa $4^{\mathrm{e}}$ session il rassembla tous les passages bibliques et patristiques qui justifiaient le culte des images ${ }^{1362}$ et dans sa profession de foi $(\rho \circ \varsigma)$ il déclara :

Les représentations de la croix, de même que les saintes images, qu'elles soient faites avec des couleurs ou de la pierre, doivent être placées sur les vases, les habits, les murs, les maisons et dans les chemins... Plus on regardera ces images, plus on se souviendra de celui qu'elles représentent, plus on sera porté à les

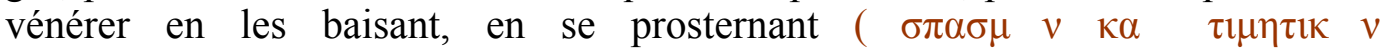
$\pi \rho \sigma\left(v_{v} \eta \sigma \iota v\right)$, sans leur témoigner cependant l'adoration véritable $(\tau v$ $\lambda \eta \theta v v \quad v \lambda \alpha \tau \rho \varepsilon i ́ \alpha v)$, qui ne convient qu'à Dieu seul, mais on leur offrira de l'encens et des lumières, comme on le fait pour la Sainte Croix et les saints Évangiles... Quiconque vénère une image, vénère la personne qu'elle représente ${ }^{1363}$.

Pendant la seconde période iconoclaste, cette doctrine fut rendue plus systématique et parfois dépassée. L'Antirrheticus du patriarche Nicéphore (806-815) établit la valeur des images et de tout 1'art religieux, qui est comme une prédication figurée : "La vue conduit mieux que l'oüe à la croyance », écrit-il, et s'appuyant sur la psychologie néoplatonicienne du pseudo-Denys l'Aréopagite, il montre que ce qui est placé sous les yeux s'imprime plus fortement dans l'âme et pénètre par la perception dans la partie affective. L'image ne s'adresse donc pas aux seuls illettrés, mais à tous ceux qui participent aux mystères ${ }^{1364}$.

${ }^{1360}$ Lettre des 3 patriarches d'Orient à Théophile sur les images (éd. Duchesne et Sakkelion, « Roma e l'Oriente », 1913), 283; GELZER, Die Legende von den heiligen Bildern, dans B.Z., 1901,477 et $s$.

1361 Saint Jean Damascene, Euvres, 1232-1284.

1362 M.C., XII, 1086; XIII, 130.

1363 M.C., XIII, 377 (7 octobre); SChWARZlose, Der Bilderstreit, 201 et s.; L. BrehIER, La querelle des images, 51-57.

1364 NICEPHORE, patriarche, Antirrhetici, III, 3, 380 et s. 
La lettre des trois patriarches d'Orient à Théophile (836) ajoute à cette apologétique de nouveaux arguments, en particulier le fait que le Verbe s'étant fait chair, il est légitime de figurer Jésus dans sa vie terrestre ; mais surtout les patriarches font état des icônes acheiropoiètes et miraculeuses, qu'ils énumèrent ${ }^{1365}$.

Ce sont: $1^{\circ}$ L'icône d'Édesse ; $2^{\circ}$ La Vierge de Lydda (Diospolis); $3^{\circ} \mathrm{La}$ Vierge de saint Luc ; $4^{\circ}$ La Vierge sculptée de saint Pierre à Ænea près de Lydda ; $5^{\circ}$ L'icône du Sauveur de Beyrouth, qu'un Juif perça d'une lance et dont le sang coula ; $6^{\circ}$ Une autre icône du Christ qu'un Juif perça de son épée et jeta ensuite dans le puits de Sainte-Sophie, d'où s'épanchèrent des flots de sang ; $7^{\circ}$ L'icône du Christ jetée à la mer par le patriarche Germain pendant la persécution de Léon III et qui fut portée par les flots jusqu'à l'embouchure du Tibre, d'où on l'apporta au pape Grégoire II, qui la déposa dans la basilique Saint-Pierre.

Mais Théodore Studite était allé encore plus loin. Félicitant le spathaire Jean d'avoir choisi pour parrain de son fils l'icône de saint Démétrius, il compare sa foi à celle du Centurion. L'enfant devient ainsi le fils spirituel du saint : "C'est le martyr lui-même, présent spirituellement, qui servait de parrain à l'enfant ${ }^{1366}$, doctrine intelligible seulement à la piété, ajoute-t-il, et inaccessible aux oreilles profanes. Pour lui la doctrine des icônes est indépendante de la théologie. C'est un fait que la personne du Verbe, en tant qu'elle se manifeste dans la nature humaine, est présente dans l'icône. Ainsi la présence réelle de la divinité serait identique dans l'icône du Sauveur et dans l'Eucharistie ${ }^{1367}$.

Après la victoire de l'orthodoxie (IX ${ }^{e}-X V^{e}$ siècle). - La victoire définitive des iconodoules se traduisit par un développement prodigieux de la fabrication et du culte des icônes, qui passa au premier plan dans les pratiques religieuses. La création des iconostases montre, comme on l'a vu, la place que prennent les icônes dans la liturgie. Le culte des icônes fait partie intégrante des dogmes de l'Église orthodoxe et les missionnaires byzantins l'introduisent dans tous les pays qu'ils convertissent au christianisme, en Bulgarie, en Serbie,

\footnotetext{
1365 Lettre des 3 patriarches..., 279 et s.

1366 Saint THEODORE LE STUDITE, Lettres, 961-963.

1367 GRONDIJS, Images de saints d'après la théologie byzantine du VIII s., A.C.E.B., VI, Paris 1948, tome II, 145-170. (En 1672 Dosithée, patriarche de Jerusalem, affirmait que les icônes ressemblantes n'ont pas besoin d'être consacrées.)
} 
dans les pays roumains et en Russie, où ils trouvent un terrain particulièrement favorable. Bien plus, les icônes, faciles à transporter, sont introduites en Italie et dans tout l'Occident, où elles exercent une action sur le développement de l'art et de l'iconographie religieuse ${ }^{1368}$.

En Orient de nouveaux devoirs incombent désormais aux artistes : faire de l'image regardée comme historique un symbole rempli d'idées, subordonner le naturalisme à la puissance d'expression et se tenir en étroit contact avec la doctrine de l'Église et la ferveur des fidèles, qui veillent jalousement sur la pureté des types. On écarte ceux qui ont une expression trop humaine, comme la Vierge allaitant l’Enfant ${ }^{1369}$.

La vogue des icônes acheiropoiètes n'a fait que s'accroître et leur culte connaît un triomphe éclatant avec la translation à Constantinople de l'icône d'Édesse, le mandylion, sous Romain Lécapène, à la suite des victoires de Jean Kourkouas en Orient (printemps de 943) et d'une longue négociation qui dura près d'un an. Ce fut le 15 août 944 que, Romain étant malade, ses deux fils et Constantin Porphyrogénète, après avoir porté solennellement l'icône autour de la Grande Muraille, la déposèrent à Sainte-Sophie, puis à l'église du Boucoléon, où se trouvaient les reliques de la Passion ${ }^{1370}$.

A partir de cette époque la réputation du Mandylion se répandit dans toute l'Europe. On le reproduisit dans les églises, en Cappadoce $^{1371}$, en Russie ${ }^{1372}$. On en fit surtout des copies, aussi vénérées que l'original, et l'une d'elles, conservée à Rome, est devenue célèbre sous le nom d'Image de sainte Véronique, dont il n'est pas question avant le début du XIV ${ }^{\mathrm{e}}$ siècle ${ }^{1373}$. Une des plus belles et des mieux conservées est la Sainte Face de la cathédrale de Laon, masque vraiment tragique, avec une inscription slavonne. On suppose qu'elle fut apportée par Jacques Pantaléon (le futur pape Urbain IV), nonce en

\footnotetext{
1368 L. BREHIER, L'Art chrétien. Son développement iconographique, 338 et s.

1369 WulfF et AlPATOV, Denkmäler der Ikonenmalerei, 46.

1370 Constantin VII Porphyrogenete, De imagine Edessa; Theophanes, Continuatus, 432 ; Steven Runciman, The Emperor Romanus Lecapenus, 248-250; VASILIEV, Vizantija i Arabui... za Vremja Makedonskoj dinastii, 253.

1371 JERPHANION, Les églises rupestres de Cappadoce, I, 399 et 475.

1372 GrabAr, La Sainte-Face de Laon, 16, 2; EBERSOLT, Fresques byzantines de Néréditsi, F.E.P.M., XIII, 1906.

1373 PERDRIZET, De la Véronique et de sainte Véronique, S.K., 1932; Dictionnaire des légendes du christianisme, 1202-1206.
} 
Pologne, d'où il revint en 1248, et donnée à sa sœur Sibylle, abbesse d'un monastère de Laon ${ }^{1374}$.

On vénérait aussi la Sainte Brique, apportée à Constantinople sous Nicéphore Phocas en 968 et sur laquelle la figure du Christ s'était imprimée après un contact avec le Mandylion d'Édesse ${ }^{1375}$. Enfin en 975 Jean Tzimiskès rapporta de sa campagne de Syrie l'icône de Beyrouth, citée plus haut, percée par un Juif et dont on voyait encore le sang au $\mathrm{XV}^{\mathrm{e}}$ siècle, d'après un pèlerin russe ${ }^{1376}$.

Les icônes, $I X-X V^{e}$ siècle. - Dès le $\mathrm{XII}^{\mathrm{e}}$ siècle on prit l'habitude de présenter les icônes dans des cadres précieux et bientôt on les cuirassa littéralement d'argent, rehaussé souvent de pierreries. Ces revêtements, $\theta$ prryía, ne laissent souvent voir que la figure et les mains du sujet. Cet usage est attesté avant $1204{ }^{1377}$. Dans les églises on tendait sous les icônes des voiles d'étoffes précieuses, cousues sur des toiles et auxquelles étaient attachées des croix pectorales ou de petites icônes ${ }^{1378}$.

Il ne reste pas beaucoup d'icônes que l'on puisse attribuer au $\mathrm{IX}^{\mathrm{e}}$ ou au début du $\mathrm{X}^{\mathrm{e}}$ siècle. Un exemplaire de cette époque est conservé au monastère de Vatopédi (Athos) et passe pour avoir appartenu à l'impératrice Théodora, épouse de Théophile (morte après 856). Elle représente en buste la Vierge de tendresse (Glykophilousa), tenant l'Enfant sur le bras droit, sa joue en contact avec celle de Jésus, son œil droit contre l'œil gauche de son fils qui regarde sa mère. L'expression maternelle s'accompagne d'une gravité triste. Les figures se détachent sur un fond jaune-orange, réservé pour faire place aux figures et aux plis du voile et du manteau ${ }^{1379}$.

\footnotetext{
1374 GRABAR, op. cit., 7-11; L. BREHIER, Icônes non faites de main d'homme, 72-74.

1375 Dite le Keramion, BREHIER, op. cit., 24 et s.; ROBERT DE ClARI, La conqueste de Constantinople, ch. 83.

1376 I.R.S.O.L., 205; EBersolt, Sanctuaires de Byzance, 20 et s.; DiEHL, Choses et gens de Byzance, I, 282 et $\mathrm{s}$.

1377 EBERSOLT, Les arts somptuaires de Byzance, III et s.

1378 FrolOw, La podea, dans B.N., 1938, 461.

1379 Mission Millet-Bréhier, 1930 (identification d'après l'inscription du cadre, au nom d'Anne Paléologue Cantacuzène, fin du $\mathrm{XIV}^{\mathrm{e}}$ siècle. Recueil des inscriptions chrétiennes de l'Athos (PARgoire et Petit, B.E.F.A., 91, 1904), n ${ }^{\circ}$ 76. Sur la rareté des icônes datées, voir P. LEMERlE, Sur la date d'une icône byzantine (Christ Pantocrator daté de 1357-1373), dans C.A., II, 129-132
} 
De l'époque des Comnènes, est la Vierge de Vladimir (Musée historique de Moscou), apportée de Constantinople à Souzdal par le prince André en 1155, l'un des chefs-d'œuvre de l'époque byzantine. On y retrouve le geste émouvant des deux joues l'une contre l'autre, mais la Mère se tient plus droite, son expression est plus triste. C'est la Vierge de pitié (Eléousa), qui prévoit le sacrifice sanglant, tandis que l'expression de tendresse de l'Enfant, qui cherche à consoler sa Mère, est vraiment touchante ${ }^{1380}$.

Cette icône est contemporaine de la renaissance artistique des $\mathrm{XI}^{\mathrm{e}}$ et $\mathrm{XII}^{\mathrm{e}}$ siècles et de la création du style monumental dans la décoration picturale, inspirée souvent par les modèles antiques. Cependant l'icône, bien que touchée par ce mouvement, qui lui donne plus de noblesse, conserve jusqu'au bout sa loi propre. Il suffit pour s'en rendre compte de comparer un même sujet, traité à la même époque par un peintre d'icône et sur une mosaïque murale : le thème de la Descente aux Limbes (Anastasis), sur une icône byzantine du XII ${ }^{\mathrm{e}}$ siècle $^{1381}$ et une mosaïque de l'église de Daphni. Dans les deux tableaux la composition a le même équilibre : les groupes de justes forment deux masses, avec Jésus entre eux. Mais, à Daphni, le Sauveur, vu de trois quarts, la croix à double traverse à la main, s'avance à grands pas, foulant aux pieds les portes de l'Enfer, sur lesquelles gît l'Hadès enchaîné, saisissant par la main Adam, qu'il tire d'un sarcophage. Sur l'icône, au contraire, Jésus est vu de face, les deux mains étendues. Adam sort seul du sarcophage et les trois prophètes, au lieu d'être vus en perspective, sont échelonnés à la droite du Christ et regardent le spectateur ${ }^{1382}$.

Dans la suite les transformations de l'art monumental se sont manifestées dans l'art de l'icône. C'est ainsi qu'à l'époque des Paléologues, elle acquiert la notion de l'espace ; ses paysages sont plus riches et on y trouve un sens plus réel du mouvement, mais elle n'en conserve pas moins ses traditions, la finesse de son dessin, le symbolisme de ses lignes et la recherche de l'expression ${ }^{1383}$. C'est en Russie que se trouve le chef-d'œuvre de cette école, la Trinité d'André Rou-

${ }^{1380}$ WulfF et Alpatov, Denkmäler der Ikonenmalerei, 62 et s.; L. BREHIER, Les icônes dans l'histoire de l'art et la Russie, 160, pl. XX.

1381 Musée de Leningrad.

1382 BREHIER, op. cit., 157 et s., fig. 52 et pl. XX.

1383 WulfF et Alpatov, op. cit., 128 et s. 
blev, « le Raphaël russe », formé aux méthodes de l'art byzantin. La Trinité est figurée, comme à Byzance à la même époque, par les trois anges de l'Hospitalité d'Abraham. Les trois figures, d'une délicatesse un peu féminine, sont disposées avec une symétrie qui n'est ni sévère, ni minutieuse, et l'inclinaison des têtes donne l'impression d'une conversation entre les trois anges ${ }^{1384}$.

A cette époque, non seulement l'art de l'icône a atteint son apogée, mais il se substitue dans la décoration des églises à l'art monumental dès le milieu du XIV ${ }^{\mathrm{e}}$ siècle. C'est en Crète, pays de nombreux peintres d'icônes, dont plusieurs ont émigré à Venise, qu'est née la nouvelle école. C'est là que naîtra au siècle suivant celui qu'on appellera le Greco ${ }^{1385}$.

Matière des icônes. - Les chefs-d'œuvre de l'icône que nous avons considérés ont été peints a tempera, suivant la tradition la plus ancienne, mais, depuis le $\mathrm{X}^{\mathrm{e}}$ siècle, on a fabriqué des icônes en d'autres matières : icônes en mosaïque avec des smalts d'une finesse extraordinaire, comme la Sainte Anne de Vatopédi, le Saint Georges du Louvre, etc. ${ }^{1386}$; icônes en relief, en marbre ${ }^{1387}$, en stéatite ${ }^{1388}$, en pierre dure ${ }^{1389}$, en terre cuite ${ }^{1390}$, mais elles n'eurent jamais la vogue des images peintes d'après les procédés antiques.

La dévotion pour les icônes. - Non seulement le culte des icônes n'avait rien perdu de sa ferveur au $\mathrm{XV}^{\mathrm{e}}$ siècle, mais dans la dévotion privée, il était la pratique essentielle et il tenait une place considérable dans le culte public. On peut en juger par les renseignements que les voyageurs, qui visitèrent Constantinople sous les Paléologues, Étienne de Novgorod en $1350{ }^{1391}$, Clavijo en $1403^{1392}$, Peró Tafur vers $1438^{1393}$, nous donnent sur la procession hebdomadaire de l'icône de Saint Luc. Au milieu d'un peuple immense et précédé d'un nombreux

\footnotetext{
${ }^{1384}$ L. BreHIER, op. cit., 167, pl. XXII; WulfF et Alpatov, 156-158 (Monastère de la Trinité Saint-Serge à Moscou), $1^{\text {re }}$ moitié du XV siècle.

1385 G. MiLLET, Recherches sur l'iconographie de l'Évangile..., 676-679.

1386 WulfF et Alpatov, 53-55.

1387 Catalogue de l'Exposition d'art byzantin de 1931, nº 576 (nombreux exemplaires connus).

1388 DIEHL, Choses et gens de Byzance, II, 524.

1389 Camée de Nicéphore Botaniatès, 1078-1081 (DE MELY dans F.E.P.M., VI, 195)

1390 GRABAR, Les influences orientales dans l'art des Balkans, 29.

1391 ETIENNE DE Novgorod, Pèlerinage à Constantinople, 119-120.

1392 P. MERIMEE, Étude sur les arts au Moyen Age, 334.

1393 VASIlieV, Pero Tafur, 106 (les 3 sources donnent le même jour, le mardi, mais dans l'espace d'un siècle des modifications ont été introduites dans la cérémonie).
} 
clergé, qui chantait des oraisons, un seul homme portait l'icône sur ses épaules, sans aucune fatigue, malgré la lourdeur de son poids. 


\section{Chapitre IX}

Superstitions, dissidents

\section{Superstitions}

$\underline{\text { Retour à la Table des Matières }}$

La déviation du sentiment religieux, qui se manifestait souvent dans le culte des reliques et des icônes, était due à la survivance de vieilles pratiques païennes, que le christianisme n'avait pas éliminées. A Byzance ces pratiques étaient innombrables, sans distinction de classe, dans la plus haute aristocratie comme dans le bas peuple. C'était en vain que les Pères de l'Église et les conciles tonnaient contre elles ${ }^{1394}$; les chrétiens les plus fervents y étaient attachés. Les empereurs, qui condamnaient la magie et l'assimilaient dans leurs lois à l'apostasie, avaient eux-mêmes une grande confiance dans l'astrologie et les prophéties ${ }^{1395}$. Des hommes aussi éminents que Psellos, Kéroularios, Nicétas Khoniatès croyaient à la vertu de la magie, aux présages, aux oracles ${ }^{1396}$.

Magie et sorcellerie. - La magie dérivait de la religion dualiste de 1'Iran ${ }^{1397}$. Parmi les Manichéens déportés en Thrace se trouvait la secte des Euchites (priants), qui pratiquait le culte de Satan, regardé comme fils aîné de Dieu, et de ses démons ${ }^{1398}$. La magie était l'ensemble des procédés qui permettaient de les évoquer, de les inter-

1394 Saint Jean Chrysostome, Homélies, P.G., XLVII (contre ceux qui observent la nouvelle lune, font des danses dans la ville, recherchent les enchantements).

1395 LEON VI, empereur, Novelles, nov. 65 (236-239).

1396 NicETAS KHONIATES, 23-24; CECONOMOS, La vie religieuse dans l'Empire byzantin au temps des Comnènes et des Anges, 80.

1397 Psellos, Un discours inédit, R.E.G., 1903-04, LXV, 77.

1398 Psellos, Timothée ou Dialogue sur les démons; WeLNFORFER, Die thrakischen Euchiten, dans B.Z., 1930, 177 et s. 
roger et de capter leurs services pour se venger d'autrui. Psellos, qui avait compilé tous les ouvrages de magie antique, divisait les démons en six espèces qui vivaient en six endroits, dans l'air, l'éther, le feu, la terre, l'eau, les souterrains ${ }^{1399}$.

Croyances populaires. - En fait la croyance à des êtres malfaisants, qui intervenaient sans cesse dans la vie des hommes, était universelle. Le peuple croyait à l'existence de Gello, démon femelle, ravisseuse d'enfants, dont elle suçait le sang. Des sorcières ailées absorbaient le fluide vital des nourrissons et l'on appelait $\gamma 1 \lambda \lambda o ́ \beta \rho \omega \tau \alpha$ les enfants ainsi atrophiés. Mais, contre ces dangers les mères avaient des formules d'exorcismes et invoquaient des saints spéciaux ${ }^{1400}$.

On amena un jour au tribunal d'un juge, père du patriarche Tarasios (784806), une misérable femme accusée d'avoir tué par magie des enfants à la mamelle en se glissant à travers les fissures des portes fermées d'une maison. Le juge, ne pouvant admettre cette version, acquitta l'accusée ; l'empereur, qui poursuivait les sorciers, évoqua la cause, mais fut obligé d'admettre le bien fondé de la sentence ${ }^{1401}$. En 717 les habitants de Pergame assiégée par les Arabes tuèrent une jeune femme sur le point d'accoucher avec sa progéniture, firent bouillir l'enfant dans un chaudron rempli d'eau et chacun des guerriers vint y tremper la main avant d'aller se battre. e crime monstrueux n'empêcha pas la prise de la ville ${ }^{1402}$.

On croyait aussi au mauvais œil ${ }^{1403}$ et le vieux nocher Charon était devenu un voleur nocturne ${ }^{1404}$.

Les sorciers et leurs rites. - Les plus anciennes sources relatives à ces pratiques, et postérieures à l'ère chrétienne, sont les tablettes magiques de plomb découvertes dans toutes les provinces de l'Empire, en particulier en Afrique et dans les pays grecs. Minuscules et étroitement enroulées, de manière à pouvoir être facilement glissées dans un vêtement, elles ont été étudiées avec une véritable sagacité par A. Audollent. Ces tabellae defixionum étaient destinées à nuire à un ennemi ou à un rival et à obliger les puissances surnaturelles à exécuter cette vengeance. Seuls, des sorciers de profession étaient capa-

\footnotetext{
1399 Swoboda, La démonologie de Michel Psellos, Brno, 1927, 7 et s.

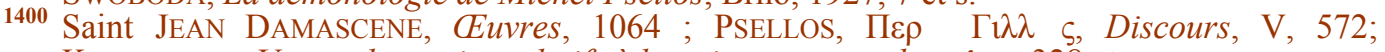
KOUKOULES, Usages byzantins relatifs à la naissance et au baptême, 328 et s.

1401 Vie de Tarasios, patriarche, 784-806, P.G., 98; LOPAREV, Vizantiiskiia Jitii Sviatuik, 100.

1402 NICEPHORE, patriarche, Breviarium, 53.

1403 Saint Jean Chrysostome, Homélies, hom. XII, 7, 105.

1404 JeAn le Geometre, Poésies, 940.
} 
bles de rédiger ces textes, d'après un vocabulaire spécial grec et latin, de dessiner la figure de la victime et celle du démon invoqué, Hécate, Perséphone, Mercure et le dieu égyptien Seth. Un grand nombre de ces tablettes ont été trouvées dans des tombeaux. On s'en servait pour écarter un rival en amour, gagner un procès, obliger un voleur à restituer. Les cochers de tous les hippodromes de l'Empire en faisaient grand usage pour triompher de leurs rivaux ${ }^{1405}$.

Les empereurs romains et byzantins n'ont jamais cessé de poursuivre les auteurs de ces sortilèges et le grand nombre des lois et aussi des actes conciliaires dirigés contre eux en montre suffisamment l'inefficacité.

C'est ce dont témoigne la vie de Sévère, patriarche d'Antioche (512-519). Étudiant à Beyrouth, il avait pour camarades des magiciens : l'un d'eux, Jean le Foulon, né à Thèbes en Égypte, ayant été dénoncé, eut beaucoup de mal à éviter le bûcher et dut brûler tous ses livres magiques ; cet incident eut pour résultat des perquisitions chez tous les étudiants suspects de magie et une rafle de leurs livres, dont on fit un immense bûcher ${ }^{1406}$.

Les chroniques de l'époque iconoclaste rapportent souvent des faits de ce genre. On voit, par exemple, les sorciers tenir ouvertement des assemblées sur une place de Constantinople malgré les édits de Constantin $\mathrm{V}^{1407}$. Plus tard, c'est l'empereur Nicéphore, violant la loi et apprenant de Pauliciens le moyen de venir à bout d'un patrice révolté, par des procédés magiques: un taureau est égorgé dans une fosse, pendant que le basileus broie à rebours dans un moulin un vêtement du révolté, en récitant des formules d'incantations ${ }^{1408}$. C'est enfin le patriarche Jean Hylilas (837-843), un Oriental, de son vrai nom Morocharzanios, versé dans tous les modes de sorcellerie ${ }^{1409}$. Il se serait fait aménager un laboratoire souterrain dans une maison située au-delà du Bosphore, appartenant à son frère, le patrice Arsarber et, par des procédés renouvelés des anciens (examen d'un foie, bassin et anneau, incantations, évocation des morts), il cherchait à prévoir l'avenir. On

\footnotetext{
1405 Defixionum tabellae (éd. Audollent, 1904).

1406 Vie de Sévère, patriarche monophysite d'Antioche, par Zacharie le Scolastique, II, 57-70; D.A.C.L., Magie, 1104-1105.

1407 Vie de saint Etienne le Nouveau, 1169.

1408 Theophanes Le Confesseur, Chronographie, P.G., 100, 789.

1409 Le même que Jean Grammatikos, précepteur de Théophile, connu par ses seuls ennemis.
} 
racontait que par ses pratiques, il avait envoûté des chefs de brigands qui désolaient l'Empire et obtenu leur disparition ${ }^{1410}$.

A toutes les époques la magie intervient dans la vie publique et privée de Byzance. Sous le patriarcat de Photius, des misérables creusent le tombeau d'un païen pour y trouver de l'argent et tuent un chien, qu'ils mangent, pour forcer la terre à rendre le trésor. Déçus et coupables de miarophagie (absorption d'aliments impurs), ils confessent leur faute et se voient infliger une pénitence ${ }^{1411}$.

A peu près au même moment, en 913, le basileus Alexandre, arrêté dans ses débauches par l'impuissance, se confie à des sorciers qui l'emmènent à l'Hippodrome et lui font allumer des cierges et brûler de l'encens devant des statues des signes du Zodiaque, couvertes de ses vêtements. Il meurt au retour de cette expédition ${ }^{1412}$.

$\mathrm{Au} \mathrm{XII}^{\mathrm{e}}$ siècle la sorcellerie sévit toujours, même à la cour de Jean Comnène, où l'impératrice Zoé, d'origine russe, a amené des sorciers de Kiev, auxquels elle se confie pendant une maladie mortelle et qui sont accusés de son trépas ${ }^{1413}$. Sous Manuel Comnène, les affaires de sorcellerie furent plus nombreuses que jamais et la répression devint moins sévère, mais la crédulité ne diminua pas. Le favori même du basileus, Alexis Axouch, fut accusé de vouloir le tuer, grâce au pouvoir qu'il avait de voler et de pénétrer dans les appartements. Il fut enfermé dans un monastère ${ }^{1414}$.

Andronic I ${ }^{\mathrm{er}}$ Comnène, Alexis III et surtout l'impératrice Euphrosyne étaient entourés de magiciens et d'astrologues ${ }^{1415}$. Au XIV siècle enfin Nicéphore Grégoras, Pachymère, Théodore Métochitès, représentants de l'élite intellectuelle, s'intéressaient à la divination, aux oracles chaldéens, aux énigmes de la Kabbale ${ }^{1416}$.

1410 Vie de saint Athanase l'Athonite, 172; GEORGES LE MOINE, Chronique universelle, 10251028; L. BREHIER, Un patriarche sorcier à Constantinople : Jean Hylilas, 832-842; BEYLIE, L'habitation byzantine, 106. Sur l'emploi du bassin et de l'anneau, BOUCHE-LECLERCQ, Histoire de la Divination dans l'Antiquité, I, 184 (d'après Psellos).

1411 R.P.B., 540.

1412 Vie de saint Euthyme, patriarche, XX, 10, 69.

1413 ECONOMOS, La vie religieuse dans l'Empire byzantin au temps des Comnènes et des Anges, 68 et $\mathrm{s}$.

1414 Nicetas Khoniates, Histoire, 187 et s.; Jean Kinnamos, Epitome, 265 et s.; Chalandon, Les Comnène, II, 219-228; ECONOMOS, op. cit., 78-80.

1415 ECONOMOS, op. cit., 82, 86, 96.

1416 R. GuILland, Essai sur Nicéphore Grégoras, 208 et s. 
La connaissance de l'avenir, voilà ce qui n'a jamais cessé de passionner Byzance.

\section{Amulettes. Exorcismes}

\section{$\underline{\text { Retour à la Table des Matières }}$}

Pour se protéger des maléfices on employait des amulettes et des talismans. Les mères les pendaient au cou de leurs enfants, entouraient leurs mains et leurs pieds d'une étoffe rouge, pendaient à leurs poignets des clochettes de métal, etc. ${ }^{1417}$. Les serpents qui surmontaient la colonne de Delphes à l'Hippodrome étaient regardés comme des talismans contre leurs congénères ${ }^{1418}$.

La vogue de ces pratiques ressort d'ailleurs du nombre considérable d'amulettes découvertes au cours des fouilles et recueillies dans les collections. Quelques-unes, des premiers siècles de l'ère chrétienne, proviennent de sectes gnostiques ${ }^{1419}$. Ce sont parfois des bracelets avec inscriptions et figurations chrétiennes, mais le plus souvent des médailles avec trous de suspension. On y trouve des formules contre le mauvais œil, avec invocation à Salomon, représenté chassant les démons ${ }^{1420}$, ainsi que des recettes contre les maux d'estomac, pour empêcher le vin de tourner (verset 8 du psaume XXXIV : goûtez et voyez combien doux est le Seigneur), contre les maladies des ânes, etc. Ces recettes prises dans des auteurs antiques sont extraites des Geoponika et Hippiatrika dédiés à Constantin Porphyrogénète. Il s'agit donc d'amulettes postérieures au $\mathrm{X}^{\mathrm{e}}$ siècle ${ }^{1421}$.

Une curieuse formule prophylactique est le carré magique, composé de cinq mots de cinq lettres chacun, qui peuvent se lire dans tous les sens et paraissent dénués de toute signification. Découvert sur des inscriptions païennes de Gaule,

\footnotetext{
1417 KOUKOULES, Usages byzantins relatifs à la naissance et au baptême, 326 et s.

1418 HAROUN-BEN-JAHJA (prisonnier de guerre), Récit, 222 (de même les chevaux de bronze qui surmontaient les carceres à l'Hippodrome).

1419 D.A.C.L., I, Abrasax, Amulettes.

1420 SCHLUMBERGER, Amulettes byzantines anciennes contre les maléfices et les maladies.

1421 Ibidem, et B.Z., 1893, 187-211; MiLLER, N.E.M., XXI, 2, 1-113.
} 
en lettres latines, vers $1837^{1422}$, on le retrouva en caractères grecs sur des ostraka et des papyrus chrétiens d'Égypte, accompagnés d'un autre carré et de formules déprécatoires destinées à guérir des maladies, avec l'invocation des trois démons Enouch, Barouch, Baroucha ${ }^{1423}$.

$\mathrm{CA} \mathrm{A} \Omega \mathrm{P}$
$\mathrm{A} \mathrm{P} \mathrm{E} \Pi \Omega$
$\mathrm{T} \mathrm{E} \mathrm{N} \mathrm{H} \mathrm{T}$
$\Omega \Pi \mathrm{E} \mathrm{PA}$
$\mathrm{P} \Omega \mathrm{T} \mathrm{A} \mathrm{C}$

$$
\begin{aligned}
& \alpha \lambda \varphi \alpha \\
& \lambda \varepsilon \omega v \\
& \varphi \omega \vee \eta \\
& \alpha v \eta \rho
\end{aligned}
$$

S A T O R

A R E P O

T E N E T

O P E R A

$\mathrm{R} O \mathrm{TAS}$

Plus récemment le Père de Jerphanion a découvert la même formule dans plusieurs chapelles rupestres de Cappadoce et, ce qui est étrange, les trois premiers mots sont donnés comme noms aux trois bergers sur les représentations de la Nativité $^{1424}(1424)$.

Le carré magique a été découvert encore à Doura-Europos (1932) et à Pompéi (1937) ${ }^{1425}$. Au début du XIV siècle, Manuel Moschopoulos, disciple de Maxime Planudés, donnant aux caractères du carré leur valeur numérale ${ }^{1426}$, étudia les moyens de construire des carrés semblables avec des nombres, mais sans leur attribuer une valeur magique $^{1427}$. Les explications tentées aujourd'hui (signe de reconnaissance des chrétiens ou des Juifs) n'emportent pas la conviction ${ }^{1428}$. Ce qu'on ne peut nier, c'est qu'il s'agit d'une formule prophylactique, créée dans un pays de langue latine, mais propagée en Orient comme en Occident et utilisée par les Juifs comme par les chrétiens. L’origine juive est la plus vraisemblable ; par contre la popularité du carré magique en Occident était encore grande à l'époque moderne ${ }^{1429}$.

\footnotetext{
${ }^{1422}$ Inscription de l'église de Rochernaure (Ardèche); B.S.A.F., 1874-77; M.S.A.F., LXIV, 1905, 41-68.

1423 G. DE JERPHANION, dans R.S.R., 1935, 188-225. Le carré est suivi des noms des 3 archanges et des 3 Hébreux dans la fournaise.

1424 Id., Les églises rupestres de Cappadoce, I, 158 (pl. 38, 1) et 189 (pl. 40-41), etc.

1425 Id., A.I.C.R., 24 mars 1937.

${ }^{1426}$ Les Grecs emploient encore aujourd'hui les lettres de l'alphabet comme chiffres.

1427 Traités sur les carrés magiques, texte et trad. TANNERY, dans A.A.F.G., XX, 1886, 263 et s.

1428 JerphaniOn, La Voix des Monuments, II, 38-94. D’après Cumont, rotas serait une allusion à la vision d'Ezéchiel.

1429 Servait à guérir les maux de dents et autres malaises. Utilisé encore au XIX ${ }^{\mathrm{e}}$ siècle dans le Massif Central.
} 


\section{L'Astrologie}

\section{$\underline{\text { Retour à la Table des Matières }}$}

Les origines. - L'astrologie, comme la magie, est en quelque sorte le résidu d'une ancienne religion d'origine chaldéenne, très répandue dans le monde gréco-romain à la fin de l'antiquité. Son dogme essentiel est la croyance à la solidarité, à la sympathie universelles ; les astres, qui sont des divinités, exercent leur influence sur les caractères des humains ${ }^{1430}$. Les astrologues constituent le thème généthliaque d'un enfant d'après la position des astres à sa naissance. Le caractère jovial est dû à la naissance sous le signe de Jupiter, auquel s'oppose celui de Saturne. Vénus favorise les amoureux, Mercure les gens d'affaires. Les révolutions des étoiles déterminent les destins des hommes et des choses ${ }^{1431}$. Après leur mort, les âmes traversent les différents cieux. La lune est une barque céleste, qui parcourt les douze signes du zodiaque, protège les marins et les pirates, mais elle est regardée aussi comme le séjour des morts ${ }^{1432}$. Le dogme de la sympathie universelle coïncidait avec les doctrines des stoïciens, qui contribuèrent à répandre l'astrologie dans les pays hellénistiques, puis dans le monde romain ${ }^{1433}$.

L'astrologie à Byzance. - L'astrologie fut d'abord aussi mal vue du pouvoir que la magie. Les empereurs, comme Honorius, et les conciles la condamnèrent, mais dès la fin $\mathrm{du}_{\mathrm{IV}}^{\mathrm{e}}$ siècle, des auteurs chrétiens essayèrent de concilier leur religion avec l'astrologie. D'ailleurs des traités comme le Compendium d'Héphestion de Thèbes (vers 380) ou le Dialogue d'Hermippos ( $\mathrm{V}^{\mathrm{e}}-\mathrm{VI}^{\mathrm{e}}$ siècle) ne font que reproduire des œuvres égyptiennes de l'époque des Lagides, comme celle d'Hermès Trismégiste, auteur supposé de livres sur la nature et l'influence des douze signes du zodiaque ${ }^{1434}$. Les manuscrits sont accompagnés de gloses des astrologues (mathematici) qui établissaient des horoscopes sur les conjonctions des astres. On y lit celui d'un

\footnotetext{
${ }^{1430}$ F. CUMONT, Les religions orientales dans le paganisme romain; BOUCHE-LECLERCQ, Histoire de l'Astrologie grecque.

1431 Cumont, Recherches sur le symbolisme funéraire des Romains, 280.

1432 Ibidem, 180 et $\mathrm{s}$.

1433 BOUCHE-LECLERCQ, op. cit., sur l'œuvre astrologique de Posidonius d'Aparnée; CuMONT, op. cit., 121 et s.

${ }^{1434}$ K. KRUMBACHER, Geschichte der byzantinischen Literatur, 627, 5.
} 
mime, dont le talent est favorisé par la constellation du Singe, ceux d'un baigneur, d'un pêcheur de thons, d'un danseur, de hauts fonctionnaires ${ }^{1435}$.

A Byzance l'astrologie est assimilée peu à peu à la vie courante et trouve grâce devant le pouvoir impérial. Du XII ${ }^{\mathrm{e}}$ siècle datent deux poèmes astrologiques, celui de Théodore Prodrome, dédié à Irène, épouse du sebastocrator Andronic, deuxième fils de Jean Comnène, et, un peu plus tard, celui de Jean Kamatéros, épikanikleiou ${ }^{1436}$, dédié à Manuel Comnène. A côté de ces compilations savantes, qui décrivent les planètes, le zodiaque, la conjonction et l'opposition des étoiles, il existait des traités populaires, à la portée de tous ${ }^{1437}$.

La doctrine. - Il résulte de ces traités que les astres ne sont plus considérés comme des dieux, mais ils ont reçu du Créateur certaines propriétés. De même que la pierre magnétique attire le fer, les astres agissent sur les hommes. Les sept planètes déterminent leur destin, mais d'autres influences peuvent modifier cette action. La puissance des planètes dépend de leur nature, de leurs associations ou aspects, de la maison du ciel qu'elles occupent au moment d'une naissance. Il y a 12 maisons du ciel, qui correspondent aux 12 signes du zodiaque. Chacune d'elles correspond à un âge ou à un aspect de la vie humaine: maladies, mariages, richesses, pouvoir impérial, etc.

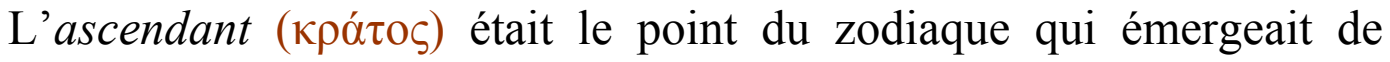
l'horizon au moment d'une naissance et qui permettait de déterminer l'horoscope d'un enfant ${ }^{1438}$. Il n'y avait là rien de bien nouveau. Toute cette doctrine déterministe, qui prédisait ce que serait la vie d'un homme dès sa naissance, avait été élaborée dans le plus grand détail à la fin de l'antiquité et continuait à avoir à Byzance le même succès qu'à Rome et à Alexandrie au temps des Césars.

La pratique. - Mais la consultation des astrologues n'était pas à la portée de toutes les bourses. Aussi, était-ce surtout l'aristocratie qui leur fournissait une clientèle et, en premier lieu, les empereurs. Par exemple en 792, Constantin VI, sur le point de livrer une bataille aux

1435 Cumont, L'Égypte des astrologues.

${ }_{1437}$ Sur cet office de porte-encrier, voir M.B.E.H. (Institutions).

1437 KrUMBACHER, op. cit., 760; Jean KAMATEROS, Sur le zodiaque, 1-39.

${ }^{1438}$ ECONOMOS, La vie religieuse dans l'Empire byzantin au temps des Comnènes et des Anges, 69-78. 
Bulgares, consulte les astrologues qui suivaient l'armée. L'un d'eux, Pancratos, lui promet la victoire : il subit une grande défaite et Pancratos se trouve parmi les morts ${ }^{1439}$. Inutile de dire que des échecs de ce genre ne désarmaient pas la crédulité publique.

Ce fut surtout au XII ${ }^{\mathrm{e}}$ siècle que l'astrologie fit fureur. Alexis Comnène lui était défavorable et lui reprochait de détourner les hommes de la confiance en Dieu, mais, s'il la déconseillait, il n'essaya jamais de la proscrire ${ }^{1440}$. Il est d'ailleurs intéressant de savoir ce que sa fille, Anne Comnène, pensait de l'astrologie. Elle la donne comme une science dont la découverte est récente et, son érudition est ici en défaut, que les anciens, Platon ou Manéthon, ignoraient. Elle reconnaît que cette science $(\pi \imath \sigma \tau \eta \dot{\mu \eta})$ a fait beaucoup de progrès sous le règne de son père et elle avoue qu'elle s'y est elle-même adonnée, mais,

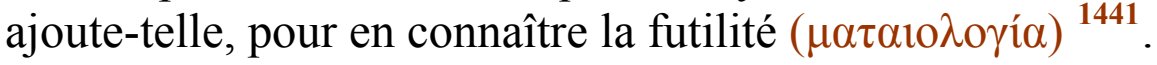

A la suite de ces réflexions, qui dénotent pas mal d'incertitude, elle donne quelques renseignements sur les principaux astrologues de son temps. Seth (probablement un Syrien, d'après son nom) avait prédit la mort de Robert Guiscard en 1085. Un Égyptien d'Alexandrie annonçait l'avenir avec les dés et sans se servir de l'astrolabe : le basileus l'exila à Rodosto, tout en pourvoyant à son entretien. Un autre Égyptien, Éleuthère, était aussi célèbre par ses prédictions. L'Athénien Katanagkès avait prédit une mort dans la famille impériale, mais ce fut le lion de la ménagerie du palais qui mourut. Une autre fois il annonça la mort d'Alexis, mais ce jour-là, ce fut la mère du basileus, Anne Dalassène, qui mourut. Alexis ne le chassa pas de Constantinople «parce que la fausseté de ses prédictions suffisait à en montrer la vanité ») ${ }^{1442}$.

Manuel Comnène, à la différence de son aïeul, avait la plus grande confiance dans l'astrologie, comme la plupart de ses proches et de ses courtisans ${ }^{1443}$.

Theophanes le Confesseur, Chronographie, 673 et s.

Anne Comnene, Alexiade, VI, 7 (II, 57 et s.); CECONOMOS, op. cit., 66 et s.

1441 Anne Comnene, op. cit., VI, 7 (II, 57-59); G. BuCKLER, Anna Comnena, 84-86; DieHl, La Société byzantine à l'époque des Comnènes, 59 et $\mathrm{s}$.

1442 Anne COMNENE, VI, 7 (II, 57-59); DIEHL, op. cit., 60.

1443 DIEHL, La société byzantine à l'époque des Comnènes, 68; DieHL et GuILland, L'Europe Orientale de 1081 à 1453, IX, 52 (DIEHL). 
En 1154, Manuel, en guerre avec le roi de Sicile, dirige contre lui une flotte commandée par son oncle Constantin l'Ange, mais ne le laisse partir qu'après avoir consulté ses astrologues. Le départ eut lieu au moment où ceux-ci s'aperçurent d'une erreur dans leurs calculs. Manuel aussitôt envoya à Constantin une galère rapide, avec l'ordre de rebrousser chemin, et la flotte ne repartit qu'après une observation minutieuse des étoiles. L'expédition échoua, Constantin fut fait prisonnier et Manuel dut conclure la paix avec Guillaume $\mathrm{I}^{\text {er } 1444}$. Le même basileus fit rédiger par le chroniqueur Michel Glykas une Défense de l'Astrologie contre un moine du Pantocrator, qui l'avait attaquée et traitée de sacrilège ${ }^{145}$. Lorsqu'il eut un fils en 1180 , il fit tirer son horoscope et, quand il s'agit de lui donner un nom, il se rappela une prédiction d'après laquelle il y aurait autant d'empereurs de la dynastie des Comnènes qu'il y a de lettres dans le mot $\alpha \mu \alpha$, aïma (sang, race). Il y avait eu déjà trois Comnènes : le nouveau-né serait le quatrième, si son nom commençait par un A : on l'appela donc Alexis ${ }^{1446}$. Un peu avant sa mort ses astrologues lui firent croire qu'il vivrait encore 14 ans et il en était persuadé pendant son agonie, tandis que le patriarche l'exhortait à penser à son salut ${ }^{1447}$.

Si Manuel, esprit brillant et très instruit, était aussi superstitieux, que dire de ses médiocres et incapables successeurs! Alexis III (11951203) était entouré d'un cortège d'astrologues, sans la permission desquels il n'aurait osé faire un pas et l'on a pu voir plus haut son aventure, lorsqu'il attendit des signes favorables pour se rendre du Grand Palais aux Blachernes ${ }^{1448}$.

$\mathrm{Au} \mathrm{XIV}$ siècle, Nicéphore Grégoras avait entrepris de rendre à l'astronomie scientifique la place qu'elle méritait et s'était occupé de la prédiction des éclipses ${ }^{1449}$, mais ce phénomène était regardé à Byzance comme un signe avant-coureur d'un événement important. Or Andronic II, qui avait demandé à Grégoras d'établir son pronostic, mourut le 13 février 1332, âgé de 74 ans et 74 jours après l'éclipse de soleil du 30 novembre $1331^{1450}$. La coïncidence fut remarquée. Nicéphore Grégoras n'en fut pas moins un des premiers Grecs du moyen âge à dénoncer la déformation de l'astronomie par les astrologues, d'où les rancunes qu'il amassa contre lui ${ }^{1451}$.

\footnotetext{
1444 Nicetas Khoniates, Histoire, 126 et s.; Chalandon, Les Comnène, II, 348; DieHL, La Société byzantine..., 68.

1445 KRUMBACHER, Geschichte der byzantinischen Literatur, 627; NICETAS KHONIATES, op. cit., 288 et $\mathrm{s}$.

1446 Nicetas KhONIATES, 220.

1447 DIEHL, op. cit., 69.

1448 Voir supra, p. 67.

1449 GuILland, Essai sur Nicéphore Grégoras, 275-279.

1450 NICEPHORE GREGORAS, Histoire romaine, IX, 14, p. 460.

1451 GuILLAND, op. cit., 279.
} 


\section{Oracles, voyants, explication des songes}

$\underline{\text { Retour à la Table des Matières }}$

On peut dire qu'à Byzance les superstitions étaient multiformes. Tous les moyens étaient bons pour connaître l'avenir: les dés, les grains de blé, l'inspection des cendres, l'aspect des icônes. «Il n'y manquait que le marc de café ${ }^{1452}$. »

Mais les prophéties n'étaient pas toujours inoffensives pour le pouvoir. Nombreux étaient ceux à qui des voyants, souvent respectables, prédisaient le pouvoir suprême, comme le patriarche Eutychios à Justin II trois ans avant son avènement ${ }^{1453}$, comme un moine à Léon l'Arménien et à Michel le Bègue ${ }^{1454}$. Un autre moine aurait prédit à Léon l'Arménien un règne de 72 ans, s'il supprimait de nouveau les images ${ }^{1455}$.

Théophile, qui avait un goût très vif pour les sciences occultes, faisait tirer le futur patriarche Méthodius de la prison où il l'avait fait enfermer comme iconophile et, à cause de sa sagesse, l'emmenait dans une expédition contre les Sarrasins. Peu après, une captive sarrasine lui prédit que son fils lui succéderait, puis que la maison des Martiniakoi occuperait le trône de longues années ${ }^{1456}$. Aussitôt le basileus força le chef de cette famille à se faire moine ${ }^{1457}$.

Léon VI, dont le caractère fantasque n'était pas sans analogie avec celui de Théophile, condamnait la magie, mais avait foi dans la divination et passait pour être luimême prophète, comme le montrent les oracles qui lui sont attribués. A son lit de mort il prédit à son frère Alexandre qu'il n'avait que treize mois à vivre ${ }^{1458}$.

\footnotetext{
1452 DieHL, La Société byzantine..., 66.

1453 Vie de saint Eutychios, patriarche, 2439; HAURY, dans B.Z., 1900, 345.

1454 THEOPHANES, Continuatus, 20 et s.

1455 Ibidem, 40 et $\mathrm{s}$.

1456 Théophano, première femme de Léon VI, était de cette famille.

1457 TheOPHANES, Continuatus, 129.

1458 KRUMBACHER, op. cit., 628, 3.
} 
Il va sans dire qu'un grand nombre de ces prédictions était imaginé après coup, comme le montre la précision avec laquelle Nicétas, évêque de Khonae en Phrygie, aurait dévoilé à Manuel Comnène tout ce qui se passerait sous son règne ${ }^{1459}$.

Recours au Jugement de Dieu. - Les adversaires des sciences occultes, mais qui voulaient connaître l'avenir, avaient recours au jugement de Dieu. Alexis Comnène, hésitant entre deux plans de campagne contre les Turcs, les rédigea sur deux tablettes qu'il fit placer solennellement, en présence du clergé et des chefs de l'armée, sur l'autel de Sainte-Sophie, puis il passa la nuit en prières. Le lendemain matin un prêtre saisit une des tablettes : c'était celle qui recommandait l'offensive contre les Turcs et dont le résultat fut la victoire de Philomelion (1095) ${ }^{1460}$.

De même, Andronic II, craignant pour les jours d'une fille nouvellement née (il en avait perdu plusieurs), alluma douze cierges en l'honneur des douze apôtres, chaque cierge recevant le nom d'un apôtre. L'enfant reçut le nom de Simonide, le cierge de saint Simon s'étant éteint le dernier ${ }^{1461}$.

Interprétation des songes. - Les songes tenaient une grande place dans les préoccupations des hommes. Nous avons dit ailleurs que, parmi les livres qu'un empereur emportait dans ses expéditions, figurait l'Oneirokritis (explication des songes) d'Artémidore, contemporain de Marc-Aurèle ${ }^{1462}$ (1462), ainsi qu'une « Explication des présa-

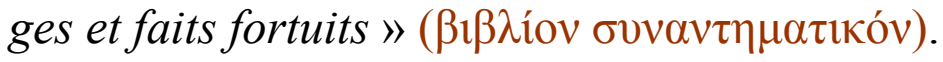

Il y avait toujours de bonnes âmes qui se disaient capables d'expliquer tous les songes. L'Arménien Vardan (Bardanès) fut exilé par Tibère III parce qu'il avait rêvé qu'il était basileus et, qu'après avoir consulté un solitaire, il s'en vanta devant un ami, qui le trahit ${ }^{1463}$.

1459 NiCETAS KhONIATES, Histoire, 284-286; ECONOMOS, La vie religieuse dans l'Empire byzantin au temps des Comnènes et des Anges, 86 et s.

1460 Anne COMNENE, Alexiade, X, 2 (II, 192); (ECONOMOS, op. cit., 13.

1461 PACHYMERE, Histoire, III, 32.

1462 M.B.E.H. (Institutions), éd. 1970, 300

1463 TheOphanes Le CONFESSEUR, Chronographie, 319; il devint empereur sous le nom de Philippicus. 
Plus dramatique aurait été le rêve de Léon l'Arménien, lorsqu'il tenait prisonnier au palais Michel le Bègue, accusé de complot. Ce rêve, dans lequel il vit le patriarche ordonner à Michel de le tuer, devait se réaliser dans la nuit même (24 au 25 décembre 824$){ }^{1464}$. Le Continuateur de Théophanes, qui raconte cette histoire, reconnaît la puissance de l'art divinatoire et la justesse de l'interprétation des songes, mais il y voit des œuvres démoniaques, qu'il faut bien se garder d'attiibuer à une inspiration d'origine divine ${ }^{1465}$.

Présages. - On attribuait aussi la même importance que les Romains aux présages, qu'une imagination dévoyée multipliait à plaisir. Au moment du débarquement de Bélisaire en Afrique (532), un soldat découvre une source en creusant des tranchées et c'est un présage de victoire ${ }^{1466}$. En juillet 811 , l'empereur Nicéphore pénètre-t-il en Bulgarie sous le signe du Chien, aucun présage ne pouvait être plus funeste et il est vaincu et tué ${ }^{1467}$. Des croix portées pas des clercs s'agitent-elles pendant une procession, Theodore le Sykéote prédit de grands désastres ${ }^{1468}$. Un pauvre loqueteux s'arrête à la porte d'un monastère, l'higoumène entend une voix qui lui dit : "Va ouvrir à l'empereur ! »Il n'en tient pas compte et se sent roué de coups. Alors il se décide à ouvrir, et c'est le futur empereur Basile qui entre ${ }^{1469}$.

Livres prophétiques. - Il existait dans la Bibliothèque impériale un livre qui prédisait les destinées de Byzance, avec des peintures représentant les empereurs. L'existence d'une élucubration de ce genre est attestée par des étrangers auxquels on l'a montrée ${ }^{1470}$. D'après Antoine, évêque de Novgorod, Léon Le Sage avait copié un livre pareil sur un rouleau qu'il découvrit dans le tombeau du prophète Daniel ${ }^{1471}$. Léon l'Arménien, qui craignait d'être assassiné par Michel le Bègue, consulta le livre des oracles et se vit changé en une bête fauve, qu'un chasseur s'apprêtait à transpercer le jour de Noël. Comme on était au 24 décembre, il refusa de faire grâce à Michel, mais on sait

\footnotetext{
64 Theophanes, Continuatus, 49.

Ibidem, 60.

Procope De Cesaree, De Bellis, III, XV, 35 (361).

TheOPHANES LE CONFESSEUR, P.G., CVII, 984.

A.S.B., avril III, 58; R.P.B., 278.

DIEHL, Figures byzantines, I, 157 et s.; de même NiCEPHORE GREGORAS, Histoire romaine, VIII, 5, 480-484.

1470 LUITPRAND, Relatio de legatione, 39.

1471 AnTOINE, archevêque de Novgorod, Le livre du pèlerin, 91.
} 
qu'il ne put échapper à son destin ${ }^{1472}$. Jusqu'aux derniers jours de Byzance les prophéties sur ses destinées pullulèrent ${ }^{1473}$ et ne firent qu'affoler la population au moment du danger suprême.

Intérieur d'un patriarche adepte des sciences occultes. - Malgré sa partialité, le Discours d'accusation, composé par Psellos contre le patriarche Michel Kéroularios, décrit en termes très vivants l'aspect que pouvait avoir l'intérieur d'un adepte des sciences occultes. Le patriarche aimait les objets rares et précieux et accueillait volontiers des marchands qui lui apportaient des fards, des aromates enchâssés dans l'or, des perles bien blanches, rondes ou allongées, une coupe de cristal diaphane, un vase de Thériclès « que rend plus beau une désignation nouvelle », ${ }^{1474}$ etc. Mais venaient ensuite les astrologues, puis des devins de grande réputation, à cause de leur pays, l'un illyrien, l'autre persan ${ }^{1475}$.

Parmi eux se trouvaient deux moines, Nicétas et Iohannès, qui avaient vécu longtemps en ermites sur une montagne de l'île de Chios. Ils traînaient avec eux une voyante, Dosithée, qui prédisait l'avenir ${ }^{1476}$ et semble avoir été hystérique. Accompagnée de ses deux protecteurs, elle donna au patriarche une séance qui le convainquit. Elle commençait par parler bas, prononçant des phrases entrecoupées, que les moines recueillaient comme des oracles ; puis, telle la Sibylle de Delphes, " ne pouvant supporter la densité de l'esprit », elle se soulevait de terre et décrivait le mouvement de l'univers, l'avenir du monde, la hiérarchie céleste. Par sa voix parlaient les prophètes, les martyrs, la Vierge, la Trinité en paroles incohérentes. On voyait les moines se transformer en animaux. Il s'agissait en fait d'imaginations autosuggestives. Les esprits étaient évoqués à la manière des spirites et Dosithée servait de médium ${ }^{1477}$.

Non seulement Michel Keroularios admit la vérité des prophéties, mais il prit les trois aventuriers sous sa protection, les produisit en public comme de rares phénomènes. Ils se mêlaient à sa suite jusque

\footnotetext{
1472 Theophanes, Continuatus, 149.

1473 Liste dans N.H., 1925, 97 et s.

1474 Potier corinthien (vases noirs à relief).

1475 PSELlOS, (Un discours inédit, éd. BREHIER, R.E.G., 1903-04), LXV, LXVI, 7, 76-79.

1476 Ibidem, IV-VII, 11-15.

1477 Ibidem, VIII-IX, 15-19; BREHIER, Le schisme oriental du XI siècle, 250 et s.; SWOBODA, La démonologie de Michel Psellos, 50 et s.
} 
dans le sanctuaire. Les livres où ils recueillaient leurs oracles furent examinés par le tribunal devant lequel le gouvernement de Théodora avait traduit les deux moines, et ils furent convaincus d'hellénisme et de chaldaïsme. Psellos lui-même, avec une mauvaise foi évidente, accusait le patriarche d'avoir adopté la philosophie néoplatonicienne ${ }^{1478}$, de rechercher la pierre philosophale ${ }^{1479}$ et de fréquenter ceux qui prédisaient l'avenir d'après l'inspection des omoplates d'animaux ${ }^{1480}$.

\section{Dissidents. Hérétiques}

\section{Retour à la Table des Matières}

En principe, aucune dissidence religieuse n'était tolérée dans l'Empire, et les hérétiques qui contrevenaient aux édits impériaux étaient punis de mort et même du bûcher. Dans la pratique, il n'en allait pas ainsi. Les juifs, très nombreux, avaient un statut légal et parfois les exigences de la politique extérieure obligeaient les empereurs et les patriarches à une certaine tolérance de fait. Ils ne renonçaient pas cependant à la propagande du christianisme : à côté des missions extérieures, il existait toute une œuvre de propagande pour convertir et baptiser les dissidents de toute catégorie.

Le paganisme. - Les deux précédents volumes du Monde byzantin ont décrit les mesures prises contre les païens et les hérétiques. Nous n'y reviendrons pas, mais nous chercherons à rassembler les témoignages sur la vie que pouvaient mener les dissidents immigrés dans l'Empire, sur leurs doctrines et leurs pratiques.

Le paganisme et les anciennes hérésies (nestoriens déjà réfugiés en Perse, jacobites, samaritains) ont disparu de l'Empire avec la conquête arabe. Nous avons vu quelles traces le paganisme avait laissées dans certaines fêtes publiques comme les Broumalia et, d'une manière inavouée, dans des pratiques superstitieuses. Par contre, il s'est réfugié

1478 Qu'il étudiait lui-même. Voir ch. XII.

${ }^{1479}$ Il avait lui-même dédié au patriarche un traité sur la manière de faire de l'or. Voir Ch. Ruelle, La Chrysopée de Psellos, R.E.G., 1889.

1480 Il lui avait aussi dédié un traité sur cette question. Voir SwOBODA, op. cit., 48 et s. 
dans la littérature et dans l'art, où il n'offre plus aucun danger. Un évhémérisme naïf, exposé au $\mathrm{VI}^{\mathrm{e}}$ siècle par Malalas, considère les dieux du paganisme, non plus comme des démons, mais comme d'anciens rois, adorés à cause des services qu'ils ont rendus aux hommes ${ }^{1481}$. La littérature savante est pleine de souvenirs et d'allusions mythologiques. Byzance a créé le merveilleux païen, qu'elle devait transmettre aux promoteurs de la Renaissance. Le néo-évhémérisme a produit des peintures de manuscrits qui montrent Zeus costumé en basileus et les statues des Olympiens juchées sur des colonnes ${ }^{1482}$.

Les hérésies nouvelles. - A partir du $\mathrm{IX}^{\mathrm{e}}$ siècle, apparaissent dans l'Empire des doctrines qui résultaient d'une contamination du christianisme avec des dogmes empruntés à d'anciennes religions orientales. Il y a là comme une renaissance du gnosticisme et surtout du vieux manichéisme du temps de saint Augustin, qui dérivait du dualisme persan, de la croyance à l'existence d'Ormuzd avec ses anges, d'Ahriman avec ses démons.

Les sectateurs de ces doctrines, pauliciens, athingans, bogomiles, rejetaient les dogmes de l'Église orthodoxe et prétendaient former des communautés séparées avec leurs dogmes, leur hiérarchie, leur culte, leurs livres sacrés, et se livraient souvent à une propagande audacieuse. Leur expansion dans la péninsule des Balkans et principalement dans les pays slaves, était due aux transports de populations orientales, imbues de ces doctrines, par les empereurs iconoclastes ${ }^{1483}$ et par Jean Tzimiskès, qui transporta aux environs de Philippopoli 2500 guerriers manichéens de Mélitène et de Théodosioupolis, renommés pour leur fanatisme et leur cruauté ${ }^{1484}$.

Pauliciens. - Les Pauliciens, fuyant les persécutions dont ils étaient l'objet, avaient émigré en territoire arabe sous Théophile et y avaient fondé un état théocratique qui fut détruit par Basile le Macédonien ${ }^{1485}$.

\footnotetext{
1481 HeSSELING, Essai sur la civilisation byzantine, 117-119.

1482 DieHL, Manuel d'Art byzantin, 630, fig. 304-306; du même : Choses et gens de Byzance, I, 497; BREHIER, La Sculpture et les Arts mineurs byzantins, pl. XCI.

1483 TheOphanes le CONFESSEUR, 422; NiCEPhORE, patriarche, Breviarium, 66, p. 62.

1484 Anne COMnENE, Alexiade, VIII, $3(111,179)$ a. 974.

1485 BURY, A History of the Eastern Roman Empire, 276.
} 
Nous connaissons leur doctrine par leur principal historien, Pierre de Sicile, que Basile le Macédonien envoya en ambassade à leur chef ${ }^{1486}$. C'est lui qui nous apprend que leur nom de Pauliciens vient d'un de leurs premiers apôtres, Paul, élevé dans la région de Samosate par une mère manichéenne ${ }^{1487}$.

La doctrine paulicienne n'est d'ailleurs qu'un néo-manichéisme, d'après lequel il existe deux principes. Le Père céleste en trois personnes a créé le Ciel et les anges; sa domination s'exerce sur le monde suprasensible. Le Créateur du monde visible, de la terre et des hommes est en même temps le dieu du mal. Le Sauveur est un ange, que le Père céleste a envoyé sur la terre pour combattre le mal. Il est né d'une femme, mais à laquelle on ne doit rendre aucun culte. Le terme de Théotokos (mère de Dieu) s'applique à la Jérusalem Céleste dans laquelle le Christ est entré par amour pour nous.

Les Pauliciens rejetaient le Baptême et la Cène, pensant que la parole du Christ est le seul moyen de communiquer avec lui, mais ils s'attachaient au sens et non à la lettre de l'Évangile. Ils regardaient le Crucifix comme une œuvre maudite. Christ seul est la vraie croix. Les prophètes et l'apôtre Pierre, serviteurs du dieu terrestre, n'ont aucune part au Salut.

Ils professaient que la seule Église Catholique était la communauté des vrais croyants. Leurs églises n'avaient aucun caractère de sainteté : elles étaient de simples lieux dc réunion destinés à la prière, $\pi \rho \circ \sigma \varepsilon v \chi \alpha i ́$. Ils n'avaient donc aucune hiérarchie ; leurs chefs, synekdêmoi, notarioi, ne se distinguaient des fidèles par aucun caractère extérieur ${ }^{1488}$.

La période la plus florissante de la secte coïnciderait avec l'apostolat de Sergius (801-835), qui, sous le nom de Tychikos, disciple de saint Paul, réorganisa la communauté et fit une vaste propagande en Asie Mineure et en Europe. Il y eut alors jusqu'à sept églises

1486 Pierre DE SicIle, Histoire des Manichéens, appelés aussi Pauliciens; H. GregoIre, Pour l'histoire des églises pauliciennes, Misc. J., II, 509 et s.; du même : Les sources de l'histoire ${ }_{1487}$ des Pauliciens dans B.A.B.L., XXII, 1936, 85-114.

1487 OBOLENSKY, The Bogomiles, 30-32.

1488 PierRe DE Sicile, Histoire des Manichéens, 1253 et s.; OBOLENSKY, op. cit., 38-43. 
pauliciennes, dont celle de Corinthe était regardée comme l'Églisemère, parce qu'elle avait été fondée par saint Paul ${ }^{1489}$.

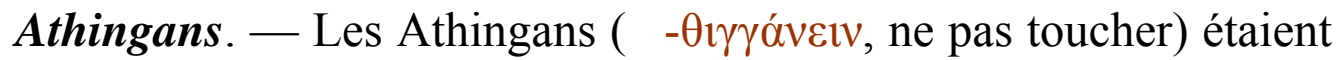
apparentés aux Pauliciens, mais, d'après leur nom même, regardaient comme une souillure le contact d'un grand nombre d'objets. Ils se seraient appuyés sur un verset d'une épître de saint Paul aux Colossiens, qui énumère les souillures légales, mais justement pour les tourner en dérision ${ }^{1490}$. Ils étaient surtout nombreux en Phrygie et Michel le Bègue (820-829) passait pour avoir fait partie de leur secte ${ }^{1491}$.

Les Bogomiles. - Des Pauliciens s'étaient réfugiés en Bulgarie à l'époque même où les Bulgares venaient de se convertir au christianisme orthodoxe (fin $\mathrm{IX}^{\mathrm{e}}-\mathrm{X}^{\mathrm{e}}$ siècle). De là une agitation et un effort de la jeune Église bulgare pour déterminer ces manichéens à se laisser baptiser. Le tsar Pierre demanda au patriarche Théophylacte une formule d'abjuration pour les nouveaux convertis. La réponse nous renseigne sur les doctrines qu'ils professaient : ce sont celles des Manichéens et des Pauliciens, qu'ils doivent abjurer, en condamnant formellement les apôtres et les chefs de la secte ${ }^{1492}$.

Ce fut dans ce milieu que naquit à cette époque l'hérésie des Bogomiles (de Bog, Dieu, mile, ami) ${ }^{1493}$. Son fondateur aurait choisi ce nom et aurait commencé son apostolat sous le tsar Pierre ${ }^{1494}$, et ses doctrines se répandirent bientôt de son principal centre, Philippopoli, dans toute la péninsule des Balkans et, au XII ${ }^{\mathrm{e}}$ siècle, jusqu'à Constantinople, où elle fut violemment réprimée par Alexis Comnène et ses successeurs ${ }^{1495}$. Les progrès des Bogomiles furent encore plus marqués en Bulgarie sous la dynastie des Asen et en Serbie sous Etienne Nemanja. Pourchassés et brûlés vifs en grand nombre dans ces deux pays, ils se réfugièrent en Bosnie et convertirent à leur foi le ban Koulin (1191-1204) et sa famille, ainsi que 10000 de ses sujets. Les Bo-

\footnotetext{
1489 Pierre de Sicile, op. cit., 1297; GREGOIRE, loc. cit., 102-104; OBOLENSKY, 35-37.

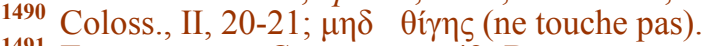

1491 Theophanes, Continuatus, 42; BURY, op. cit., 40, 1 et 78-79; D.H.G.E., V, 51.

1492 R.P.B., 789 (entre 940 et 950); OBOLENSKY, op. cit., 111-117.

1493 D.H.G.E., IX, 408; sur la fausse étymologie Dieu aide d'Euthymios Zigabenos, OBOLENSKY, 119 et $\mathrm{s}$.

1494 OBOLENSKY, app. II, 275 et s. (signale la confusion constante entre Bogomil, le fondateur et le pope Jérémie Bogomile).

1495 Anne Comnene, Alexiade, VI, 2,1 (II, 44-45); VIII, 7 (III, 181-182); Chalandon, Les Comnène, 22, 23, 635; Gesta Francorum et aliorum Hierosolymitanorum, 22-23.
} 
gomiles y organisèrent une Église, reconnue officiellement par le ban ${ }^{1496}$.

Nous ne connaissons la doctrine des Bogomiles que par leurs adversaires, le moine de Constantinople Euthymios Zigabenos, auteur d'une Panoplie dogmatique, composée par ordre d'Alexis Comnène ${ }^{1497}$, et par le Sermon contre les Hérétiques du prêtre bulgare Kosmas, prononcé après $9722^{1498}$.

Cette doctrine n'est qu'une nouvelle forme du système dualiste, une combinaison du manichéisme, du paulicianisme et de la vieille hérésie massalienne, dont on perd les traces au $\mathrm{V}^{\mathrm{e}}$ siècle, mais qui s'est perpétuée obscurément. On la retrouve chez les Orientaux immigrés en Thrace, qui portent au XI ${ }^{\mathrm{e}}$ siècle le nom d'Euchites (les priants). Le terme même de Massalien est un mot syrien qui signifie prier. La prière continuelle paraissait nécessaire pour résister au mal et obtenir la grâce, regardée comme préférable aux sacrements ${ }^{1499}$.

Les Bogomiles étaient d'ailleurs divisés en plusieurs sectes. Les Dragoviciens, à l'est, enseignaient un dualisme radical, analogue au marcionisme, et croyaient à l'éternité du mal. Au contraire dans la Bulgarie proprement dite, la doctrine de la Rédemption finale s'était greffée sur le dualisme. On y enseignait que Dieu avait deux fils, le Christ et Satanaël. Celui-ci est l'intendant infidèle de l'Évangile ${ }^{1500}$; il s'insurge contre Dieu mais, bien que vaincu par les anges, il conserve le pouvoir créateur, accomplit l'œuvre des Sept Jours, demande à Dieu pour l'homme l'étincelle de vie, puis est jaloux de sa creature et l'incite au mal. Alors Dieu envoie sur la terre l'Ange du Grand Conseil, dont il a fait son Fils. Le Christ s'incarne en apparence ${ }^{1501}$, s'attaque à Satanaël, brise sa puissance par sa victoire sur la mort. Satanael devenu Satan, $E l$, continue à lutter contre l'Esprit qui encourage les fidèles dans la bataille contre le mal. L'Esprit a d'abord

\footnotetext{
1496 HeSSELING, Essai sur la civilisation byzantine, IV, 518; G. MiLLET, La religion orthodoxe et les hérésies chez les Yougoslaves; OBOLENȘKY, The Bogomiles, 230 (Les bans protégeaient la secte suivant l'état de leurs rapports avec l'Église romaine.)

1497 EUThymios ZigaBenos, Panoplia dogmatike, 20 et s.

1498 Slovo na Eretiki, éd. Popruzhenko, Sofia, 1936, dans OBOLENSKY, 117-145.

1499 Millet, op. cit., 7; OBOLENSKY, 48-52. Ils s'autorisaient de PAUL, I Thess., V, 17, et récitaient le Pater sans interruption.

${ }_{1501}^{1500}$ Fliche et MARTIN, Histoire de l'Eglise, VI, 436 et s. (Luc, XIV, 20-26).

1501 Ancien docétisme jacobite du $\mathrm{VI}^{\mathrm{e}}$ siècle.
} 
inspiré les douze apôtres, puis les Bogomiles, qui l'ont reçu par l'imposition des mains ${ }^{1502}$.

C'est le seul sacrement qu'ils admettent et ils rejettent comme les Pauliciens le baptême, l'Eucharistie, le culte de la Vierge et des saints, les images et la croix ${ }^{1503}$. Ils ne connaissent pas de hiérarchie et ont à leur tête un did (aïeul), assisté de strainiks (administrateurs). Leurs églises n'avaient ni autels, ni cloches. Ils répudiaient le serment, avaient la haine du mariage, mais menaient une vie ascétique, qui comportait la pauvreté, le jeûne et la prière perpétuelle. Fuyant le voisinage des orthodoxes, ils se faisaient enterrer sur leurs propres terres ${ }^{1504}$.

Les doctrines des Manichéens, des Pauliciens, des Bogomiles sont à la fois des hérésies du mazdéisme et du christianisme. De l'un, elles adoptent sa solution du problème du mal, de l'autre les doctrines gnostiques des premiers siècles, qui se rapprochaient du dualisme iranien : le marcionisme, le massalianisme, le docétisme. La différence essentielle de ces vieilles hérésies avec l'orthodoxie est le refus d'admettre le dogme de l'Incarnation du Christ, ainsi que la réalité des souffrances de la Passion. La doctrine bogomile, au contraire, se présente comme une tentative suprême, pour réunir dans une synthèse monstrueuse le dualisme de l'Iran et le dogme de la Rédemption.

\section{Les Juifs}

$\underline{\text { Retour à la Table des Matières }}$

A la différence des hérétiques, les Juifs et les Musulmans qui habitaient le territoire de l'Empire possédaient un statut légal, à vrai dire assez précaire, mais jamais aboli sans retour.

Privilèges des Juifs. - Les juifs avaient des privilèges qui remontaient à Jules César et qui furent maintenus et renouvelés après les ré-

\footnotetext{
${ }^{1502}$ Cf. le consolamentum des Cathares.

${ }^{1503}$ Euthymios Zigabenos, Panoplia dogmatike, 1289; Fliche et MARTin, op. cit., VI, 436 et s.; OBOLENSKY, 207 et s.

${ }^{1504}$ MiLlET, op. cit., 12-16.
} 
voltes de 70 et de 135. Ils jouissaient des droits civils, de la liberté d'association, de la propriété de leurs synagogues, qui étaient souvent des édifices importants et d'une grande richesse, comme celles de Doura-Europos, d'Antioche, etc. ${ }^{1505}$.

Après le triomphe de l'Eglise, les chrétiens ne songèrent nullement à les détruire. On les regardait comme les témoins de la vérité de l'Ancien Testament et de la Messianité du Christ. Leur déchéance même démontrait la vérité des Évangiles. Cependant les faveurs accordées aux Juifs par Julien et son ordre de rebâtir le Temple de Salomon ${ }^{1506}$ déterminèrent, après sa mort, une réaction violente, qui aboutit aux lois prohibitives de Théodose II. Sans leur enlever la faculté d'exercer leur culte, on supprima leur organisation centrale ; ils furent exclus des fonctions publiques, mais non des charges fiscales ${ }^{1507}$. Les sévices exercés contre eux restèrent à peu près impunis, ils furent même expulsés de certaines villes et on les empêcha parfois d'exercer leur culte ${ }^{1508}$. Le gouvernement impérial finit par s'émouvoir de ces résistances, qui entraînaient les pires désordres, et contraignit les villes à infliger des pénalités à tous ceux qui troubleraient le culte hébraïque ${ }^{1509}$.

Tel fut le point de départ de la politique juive des empereurs byzantins, faite dans les siècles suivants d'une alternance de persécutions et de tolérance, ainsi qu'on a pu s'en rendre compte dans les deux volumes précédents du Monde byzantin. On a remarqué que lorsque l'empire était troublé, la surveillance des autorités se relâchait, mais dès que le pouvoir central redevenait puissant, il cherchait à rétablir l'unité religieuse en forçant les Juifs à se faire baptiser ${ }^{1510}$. Il en fut ainsi après la victoire d'Héraclius sur la Perse en 680, après celle de Léon III sur les Arabes en 723 et sous le règne réorganisateur de Basile I (874). Ces dates marquent trois tentatives de forcer les Juifs à renier leur foi. On peut remarquer d'ailleurs que, malgré cette contrainte, les Juifs furent mieux traités à Byzance qu'en Occident : ce

\footnotetext{
1505 D.A.C.L., VIII, 93 et s.

1506 Socrate, Histoire ecclésiastique, III, 20; SOZOMENE, Histoire ecclésiastique, V, 22; THEODORET, Histoire ecclésiastique, 15.

1507 ANDREADES, Les Juifs dans l'Empire byzantin, 23 et s. et M.D., I, 10; C.Th. XVI, 8, 13 (397), XVI, 18, 17 (404); L. DUCHESNE, L'Eglise au VI siècle, 281.

1508 Saint Cyrille les fait expulser d'Alexandrie.

1509 Nov.Th. 3 (3 janvier 438) = C.J.I., V, 7.

1510 F. Cumont, La conversion des Juifs, dans R.B.I., 1903, 1, 2.
} 
n'était pas toujours par la force, mais aussi par la persuasion, que l'on cherchait à les convertir au christianisme ${ }^{1511}$.

Colonies juives, $\mathbf{V I}^{e}-\mathrm{VII}^{e}$ siècles. - Avant l'invasion arabe de nombreuses colonies de marchands juifs étaient installées dans toute la Méditerranée et le long des frontières mésopotamiennes. A Antioche leur révolte qui se termine par le meurtre du patriarche Anastase (septembre 610) laisse supposer une colonie nombreuse, ainsi qu'à Édesse où, après le départ des Perses en 628, ils bravent le pouvoir impérial, et à Constantinople, où ils prennent une grande part à l'émeute du 28 septembre 641 contre le patriarche Pyrrhus ${ }^{1512}$.

Le prosélytisme juif hors de l'Empire. - Dans les époques troublées, les Juifs furent saisis d'une véritable ardeur de prosélytisme et ils envoyèrent des missions hors de l'Empire pendant la période iconoclaste. Un événement important fut la conversion au judaïsme du Khagan et des principaux chefs des Khazars. La date en est mal fixée. On doit écarter les sources juives qui la placent en 730, d'après une prétendue correspondance entre le Khagan et un ministre juif du califat de Cordoue, œuvre d'un faussaire. Les sources arabes comme Maçoudi indiquent le règne d'Haroun-al-Raschid (786-809) ${ }^{1513}$, mais un Occidental, Druthmar, moine de Corbie en 850, écrit que la conversion des Khazars est contemporaine du baptême de Boris (entre 862 et 866) ${ }^{1514}$. Vers 903 , un auteur arabe donne l'adoption du judaïsme par les chefs Khazars comme toute récente ${ }^{1515}$.

Les missionnaires juifs firent aussi des prosélytes en Crimée et dans la péninsule de Taman, où aurait été fondée une ville juive ${ }^{1516}$, ainsi que chez les Bulgares Noirs et les Turcs danubiens (Hongrois). Dans l'Empire même ils convertirent des Valaques du Pinde, dont

\footnotetext{
1511 Légendes slaves de Constantin et de Méthode, 200 et s.

1512 TheOdORE LE LECTEUR, Histoire ecclésiastique, 296; Fliche et MARTIn, Histoire de l'Église, V, 74; SEBEOS, Histoire d'Heraclius, 30.

1513 MARQUART, Osteuropäisehe und Ostasiatische-Strezfzüge, 4-8; Légendes slaves de Constantin et de Méthode, 168-170; PEETERS, Les Khazars dans la passion de saint Abo de Tiflis, dans A.B., 1934, 21-56; H. GREGOIRE, dans B.N., 1937, 225-236.

1514 VernadSKY, dans B.N., XV, 67-86, d'après DrUTHMAR, Expositio in Matthaeum, P.L., CVI, 1456.

1515 VERNADSKY, loc. cit., d'après Ibn-al-Fahiq.

1516 TheOPHANES LE CONFESSEUR, Chronographie, 357; Légendes slaves de Constantin et de Méthode, 171, 2.
} 
Benjamin de Tudèle vit au XII ${ }^{\mathrm{e}}$ siècle les descendants, qui portaient des noms hébreux et vivaient de brigandage ${ }^{1517}$.

La vie des colonies juives dans l'Empire. Tentatives de conversion des Juifs. - A la propagande juive chez les païens répondit la propagande chrétienne chez les juifs. Au lieu de détruire les juifs, Basile le Macédonien essaya de les gagner par la persuasion. Il institua des conférences contradictoires, dans lesquelles les Juifs auraient été mis en demeure, ou de prouver la vérité de leur religion ou de recevoir le baptême. On offrait à ceux qui se laissaient baptiser des exemptions d'impôts et des dignités. Vers 875-875, Basile aurait réussi à baptiser ainsi presque tous les Juifs de son empire, mais ces conversions étaient peu durables et beaucoup de membres du clergé les désapprouvaient. Un écrit anonyme rappela les règles établies par les conciles pour les conversions et son auteur s'indignait de la part importante qu'y prenaient des laïcs (les ministres de Basile) ${ }^{1518}$.

Une formule d'abjuration du judaïsme, imposée aux catéchumènes, serait peut-être une réaction contre ces pratiques. Elle offre le grand intérêt de nous montrer les usages et les croyances du peuple hébreu à cette époque.

Le converti doit déclarer qu'il agit librement, sincèrement, et non par crainte et en vue d'honneurs. Il jette l'anathème sur les hérésies juives (sadducéens, pharisiens), sur les livres postérieurs à l'Ancien Testament, le Talmud et surtout la Mischna. Il condamne la fête du Pourim célébrée chaque année à la mémoire de Mardochée et qui comportait la pendaison d'Aman à un gibet surmonté d'une croix ${ }^{1519}$. Même condamnation de la fête des cors, dont on faisait des sonneries le jour du nouvel an juif, de la commémoration de la destruction de Jérusalem, comportant un jeûne et la lecture des Lamentations de Jérémie. Répudiation de certaines croyances, comme la légende du $\mathrm{Ziz}^{1520}$, des pratiques magiques et des phylactères, versets de la Bible portés dans les vêtements. L'anathème était enfin prononcé sur les rabbins et sur le faux Messie attendu par les Juifs. Suivaient la profession de foi orthodoxe et les formules d'imprécations contre les relaps empruntées au Deutéronome ${ }^{1521}$.

${ }^{1517}$ Grousset, Histoire des Croisades et du royaume franc de Jérusalem, 273.

1518 Theophanes, Continuatus, 34; CumONT, loc. cit., 515, 3-5 et EuseBe DE Cesaree, Histoire ecclésiastique, 5-8.

1519 La date coïncidait avec le premier samedi du carême chrétien.

${ }^{1520}$ EUSENE DE CESAREE, op. cit., 10-11. Le Ziz, oiseau gigantesque qui, en ouvrant ses ailes, provoquait les éclipses de soleil.

${ }^{1521}$ Ibidem, première édition COTELIER, d'après un seul manuscrit, P.G., 1, 1456; édition critique de CuMONT, d'après 4 manuscrits qui contiennent aussi la formule d'abjuration imposée par Photius aux Manichéens en 870. 
Condition des Juifs ( $\boldsymbol{X}^{e}-\boldsymbol{X} V^{e}$ siècle). - Après le règne de Basile, Léon VI et plusieurs de ses successeurs publièrent des lois sévères contre les juifs relaps, mais dans la pratique on finit par les tolérer.

$\mathrm{Au} \mathrm{X}^{\mathrm{e}}$ siècle on créa un préposé aux affaires juives, qui fut souvent un évêque ${ }^{1522}$. Vers l'an mille Elie de Nisibe écrit que les Romains admettent les Juifs sur leur territoire, les protègent, leur permettent de célébrer leur culte et de construire des synagogues ${ }^{1523}$. Un siècle plus tard, Benjamin de Tudèle montre leur situation beaucoup moins bonne. Ils ne peuvent habiter dans l'enceinte de Constantinople, mais sont relégués à Péra, où le bas peuple les injurie et les maltraite. Ils étaient environ 1000 ouvriers en soie ou riches marchands. Aucun d'eux, sauf le médecin du basileus, ne pouvait monter à cheval ${ }^{1524}$.

Comme on l'a fait remarquer, cette hostilité date de la première croisade. Ce furent les croisés qui introduisirent l'antisémitisme à Byzance, où il fut d'ailleurs mitigé, où il ne fut jamais question d'expulsions en masse et encore moins de pogroms ${ }^{1525}$. On se contenta de parquer les Juifs en dehors des villes, comme nous l'avons déjà signalé à Sparte au $\mathrm{X}^{\mathrm{e}}$ siècle ${ }^{1526}$, et d'exiger d'eux la capitation spéciale, dite du didrachme, qui remontait à l'époque romaine et s'ajoutait aux impôts ordinaires; elle était toujours en vigueur au $\mathrm{XV}^{\mathrm{e}}$ siècle ${ }^{1527}$.

Les croisés de 1204 n'étaient pas plus favorables aux Juifs que les précédents et, le 6 juillet 1203, les Flamands de Baudouin, maîtres de la Tour de Galata, envahirent le quartier juif et l'incendièrent ${ }^{1528}$. Il n'en fut pas de même dans la suite et, loin de les persécuter, les empereurs latins permirent à la communauté juive de s'étendre sur la rive ouest de la Corne d'Or, en bordure du quartier vénitien. Ils continuaient à occuper cette position sous Andronic II, malgré les protesta-

\footnotetext{
1522 ZACHARIAE VON LINGENTHAL, Geschichte des griechisch-römischen Rechts, 382, n 1382.

1523 ANDREADES, Les Juifs dans l'Empire byzantin, 13, 8.

1524 BENJAMIN DE TUDELE, Voyages, 25 et s. (a.1172).

1525 ANDREADES, op. cit., 13.

1526 Supra, p. 127.

1527 ANDREADES, op cit., 13, 8; J. STARR, The Jewries of the Levant after the fourth Crusade, 4144 (établie par Vespasien, Suétone, Domitien, XII).

1528 StARr, op. cit., 25; Villehardouin, La Conquête de Constantinople, ch. 159 (quartier dit 1'Estanor).
} 
tions du patriarche Anastase ${ }^{1529}$, et ils fondèrent de nouvelles colonies dans les autres possessions latines ${ }^{1530}$.

Formes de la propagande chrétienne. - Les empereurs byzantins ne cherchaient pas à molester les Juifs, mais à les baptiser. On peut dire qu'à toutes les époques, depuis le $\mathrm{VII}^{\mathrm{e}}$ siècle, les efforts pour déterminer les Juifs à embrasser le christianisme furent ininterrompus. Des conférences contradictoires entre évêques et rabbins étaient parfois organisées. Une sorte de procès-verbal d'une de ces controverses, les Trophées de Damas, reproduit un colloque, qui eut lieu hors de l'Empire, entre un moine et un rabbin sous le règne d'un empereur Constantin, qui pourrait être Constantin IV, vers 681.

Cet ouvrage nous renseigne sur les méthodes apologétiques des deux parties qui discutent autour des textes de l'Ancien Testament et, surtout, des Prophètes. Il y eut quatre séances, la première secrète, les autres en présence d'un nombreux public, composé de Grecs, de juifs, de Musulmans, de Samaritains, qui intervenaient souvent dans le débat ${ }^{1531}$.

$\mathrm{Au} \mathrm{XII}{ }^{\mathrm{e}}$ siècle, l'auteur d'un traité d'alchimie, Pascalis Romanus, transcrit un dialogue entre un Juif et un chrétien appelé Anastasius Sinaiticus. "Pourquoi, demande le Juif, les chrétiens adorent-ils le bois de la croix ? - Pourquoi, riposte le chrétien, les Juifs adorent-ils le Livre de la Loi, revêtu de peaux d'animaux ${ }^{1532}$ ? »

On voit entrer dans l'administration impériale un Juif, Astaforte, que Manuel Comnène a ramené de Hongrie et qu'il charge d'établir un impôt sur les Francs qui habitent l'Empire ${ }^{1533}$.

$\mathrm{Au} \mathrm{XV} \mathrm{V}^{\mathrm{e}}$ siècle un Juif converti, devenu moine, est le père spirituel de Manuel II et son exécuteur testamentaire (1425) ${ }^{1534}$. En 1436, c'est Jean VIII qui prend lui-même la peine de disputer avec un Hébreu,

STARR, 26 et s.

Ibidem, 37-115.

1531 Les Trophées de Damas (éd. Bardy, P.O., XV, 2, 1920).

1532 HASKINS, dans B.N., 1924, 231 et s.

1533 Chalandon, Les Comnène, 277.

1534 Phrantzes, Chronique, II, 1; STARr, op. cit., 28. 
Zénon, qui, vaincu par les arguments du basileus, se fait baptiser sous le nom d'Emmanuel ${ }^{1535}$.

Vie intérieure des Juifs. - A la différence des colonies juives du Califat et des autres États arabes, celles de l'Empire n'avaient aucune organisation centrale, aucun organe commun. Etablis de préférence dans les villes ou dispersés dans des bourgades, les Juifs vivent dans des conditions assez différentes. Leur sort dépend des autorités locales et des habitants. Plusieurs sont serfs de monastères ${ }^{1536}$ et vivent de leur travail, mais la plupart du temps ils sont libres.

En Grèce, plusieurs de leurs colonies remontent au premier siècle de l'ère chrétienne. Saint Paul a prêché dans leurs synagogues, à Philippes, à Thessalonique, à Corinthe, à Athènes ; mais à l'époque byzantine, leur nombre s'est accru d'une manière considérable et ils sont représentés dans les plus petits centres au $\mathrm{X}^{\mathrm{e}}$ siècle ${ }^{1537}$.

La plupart des Juifs qui habitaient ces régions parlaient le grec, l'hébreu étant devenu une langue liturgique ${ }^{1538}$ et d'ailleurs Justinien n'avait-il pas exigé que les lectures de l'Ancien Testament, faites en hébreu dans les synagogues, fussent traduites en grec ? ${ }^{1539}$ On a retrouvé des glossaires judéo-grecs et même latins ${ }^{1540}$. Le sens des mots

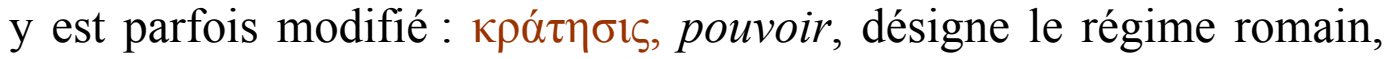
tandis que des mots nouveaux, d'origine barbare ou autre, sont introduits dans la langue ${ }^{1541}$.

La synagogue était le centre de la communauté et constituait, comme l'église des premiers siècles, une maison, comprenant plusieurs salles destinées aux divers offices. On connaît surtout celles de l'époque romaine par les fouilles ou les descriptions. La salle réservée au culte avait parfois la forme basilicale, avec de belles colonnades et des tribunes au-dessus des collatéraux. Leur ornementation était d'une grande richesse. On y voyait des pavements en mosaïque avec des animaux, des plantes, des symboles comme le chandelier à sept bran-

\footnotetext{
1535 PHRANTZES, op. cit., II, 2; STARR, 28.

1536 M.B.E.H. (Institutions); R.K.O.R., 892 (1049 Nea Moni de Chio).

1537 Giannopoulo, Communautés juives de la Grèce orientale, 187 et s. et t. VII, 253 et s.

1538 S. REINACH, dans M.Schl., 118 et s.

1539 C.I.C.I., nov. 146, 593.

1540 KouKoules dans B.Z., 1910, p. 422 et s.

1541 KRAUSS dans B.Z., 1893, p. 499 et s.
} 
ches et même des thèmes mythologiques, comme des Victoires ou le mythe d'Orphée ${ }^{1542}$. La découverte de la Synagogue de DouraEuropos, avec ses peintures qui illustrent les livres de l'Ancien Testament, datant du début du $\mathrm{III}^{\mathrm{e}}$ siècle, montre que les Juifs n'ont pas toujours condamné la reproduction de la figure humaine, qu'on retrouve dans certaines basiliques de Galilée de la même époque ${ }^{1543}$. Ce fut en Galilée que le patriarche Hanassi-Juda rédigea la Mischna, recueil de coutumes orales qui complétaient et interprétaient la Loi de Moïse. Aux $\mathrm{V}^{\mathrm{e}}$ et $\mathrm{VI}^{\mathrm{e}}$ siècles, époque de la rédaction du Talmud, les représentations figurées sont encore admises dans les synagogues ${ }^{1544}$.

Le culte nous est connu par la novelle de Justinien, citée plus haut, qui en réglemente minutieusement les détails, en se plaçant au point de vue de l'Église orthodoxe, que ce culte ne doit ni gêner, ni amoindrir. Ce fut ainsi que, plus tard, il fut décidé que les chants de la synagogue ne devaient pas être entendus des églises voisines ${ }^{1545}$. L'hébreu était autorisé pour ces chants, accompagnés du cor et de la trompette, ainsi que pour les prières, mais des punitions sévères menaçaient les rabbins qui refusaient de lire les textes du Pentateuque en grec. L'empereur allait même jusqu'à imposer pour ces lectures la Version des Septante ou celle d'Aquilée. Comme les Évangiles, le Pentateuque devait être divisé en péricopes, mais de manière à être lu entièrement en 5 ans. Le sermon qui suivait la lecture devait en être uniquement le commentaire. La Mischna et le Talmud étaient interdits ${ }^{1546}$. Il va sans dire que beaucoup de règles de cette législation tombèrent en désuétude.

Livres canoniques. - Le Talmud (enseignement) est une compilation de préceptes et de doctrines, due aux maîtres les plus réputés des $\mathrm{V}^{\mathrm{e}}$ et $\mathrm{VI}^{\mathrm{e}}$ siècles de notre ère. Il comprend deux parties : la Mischna (répétition) et la Guemara (compléments). Les écoles de Judée et de Chaldée eurent chacune leur Talmud distinct, avec des variantes.

\footnotetext{
1542 L. BREHIER, L'Art chrétien. Son développement iconographique, 19-20.

1543 DuMESNIL DE BuISSON, Les peintures de la Synagogue de Doura-Europos, Rome, 1939.

1544 BIKEMANN dans Syria, 1937, p. 221.

1545 JUSTER, Les Juifs dans l'Empire romain, leur condition juridique, économique et sociale, I, 362.

1546 C.I.C.I., nov. 146 (533); D.A.C.L., VIII, 127 et s.
} 
La Mischna est la plus ancienne codification des règles destinées à interpréter la Thora. Elle est divisée en six chapitres : Semences, Fêtes, Femmes, Dommages, Sacrifices, Purifications.

La Guemara n'est que le commentaire des chapitres de la Mischna. Celle de Jérusalem, rédigée à Tibériade vers 350 de notre ère, ne comprend que les trois premiers chapitres; celle de Babylone (vers 500) commente les 6 chapitres ${ }^{1547}$.

La Kabbale (tradition) représente le mysticisme et la gnose ; elle fut créée après la prise de Jérusalem, en 70, par Simon ben-Iokaï, qui, persécuté par les Romains, vécut douze ans dans une grotte de Galilée, à côté d'une source et d'un figuier, visité par les Anges, qui lui dictèrent le Zohar (livre de la Splendeur). Gracié par un pro-consul, il réinstalla son école à Safed, entouré de nombreux disciples. Après lui, sa doctrine se transmit par une série d'initiés et excita au XVI ${ }^{\mathrm{e}}$ siècle la curiosité des érudits occidentaux ${ }^{1548}$.

La Kabbale est en réalité une forme juive de la mystique néoplatonicienne. En face du Talmud, commentaire de la Loi, elle représente une mystique des nombres et des lettres, " qui sont les signes par lesquels la Sagesse se fait connaître aux hommes ». La méthode allégorique permet de voir dans chaque mot de la Loi un mystère sublime, tel que la hiérarchie des puissances et des anges, et de multiplier les intermédiaires entre Dieu et les créatures. Connue déjà de Philon d'Alexandrie, elle aurait été admise par les Esséniens, pour aboutir à un grossier panthéisme. Au moyen âge elle fut discréditée par les spéculations de deux juifs égyptiens, Isaac Israeli (845-940) et Sandja (892-942), qui déterminèrent la part de la raison et celle de l'inspiration dans la Loi, mais cette éclipse fut momentanée et la Kabbale redevint l'élément unique de la pensée juive ${ }^{1549}$.

Ce n'est là d'ailleurs qu'un aspect, et non le plus intéressant, des contacts de cette pensée avec la philosophie et de l'activité intellectuelle des juifs au moyen âge. Benjamin de Tudèle mentionne les assemblées, sortes d'académies. Les discussions engendraient les sectes.

\footnotetext{
1547 S. REINACH, Orpheus, 301-304 ; ABRAHAM, Jewish Life in the Middle Age, 1896.

${ }^{1548}$ Le Temps, 16 août 1936.

${ }^{1549}$ E. BREHIER, Histoire de la philosophie, II, 623; S. REINACH, op. cit., 289.
} 
A Constantinople notre voyageur en trouve deux qui se haïssent mutuellement : les Rabbanites, Disciples des Sages, qui admettent la tradition des rabbins et le Talmud, qu'ils préfèrent même à la Loi, et les Keraïtes qui s'en tiennent farouchement à la Loi, sauf quand le Talmud concorde avec elle. Pour 2000 Rabbanites il n'y avait que 500 Keraïtes et, dans la colonie de Péra, ils étaient séparés par un mur ${ }^{1550}$.

Les mouvements messianiques. - Quel que fût leur sort, les juifs byzantins se considéraient toujours comme opprimés et attendaient le Messie qui devait les délivrer des infidèles. Ils désignaient l'empereur par le terme de $B u z-U z$ (le méprisable oppresseur) ${ }^{1551}$.

Il était donc inévitable de voir apparaitre de temps à autre des illuminés ou des aventuriers, qui se donnaient comme le Messie attendu et provoquaient des soulèvements et des désordres. Un messie de ce genre apparut en Syrie sous Léon l'Isaurien et se dit le Christ, Fils de Dieu ${ }^{1552}$. Une curieuse lettre de la communauté juive de Thessalonique, découverte en Égypte, datée de 1096, annonce la résurrection dans cette ville du prophète Elie et les miracles qu'il accomplit, " dont témoignent Juifs et chrétiens ». Les habitants, qui détestaient les Juifs, leur témoignent brusquement toute sorte d'égards et les engagent à vendre leurs biens. Cette lettre donne des renseignements sur la croisade populaire qui traverse l'Empire byzantin et décrit les bandes d'Allemands, accompagnés de leurs femmes et de leurs enfants, avec tout leur avoir, se hâtant vers Jérusalem ${ }^{1553}$.

Activité extérieure des Juifs. - A la différence de leurs coreligionnaires occidentaux, les juifs byzantins ne faisaient pas le commerce de l'argent, mais exerçaient certaines industries et étaient surtout commerçants.

Benjamin de Tudèle (Aben Jonah), parti de Saragosse en 1165 pour visiter les communautés du monde juif, a été frappé par la prospérité des juiveries byzantines et en particulier de celle de Constanti-

${ }^{1550}$ BenJAmin de Tudele, Voyages, ch. 4; STARr, The Jews in the Byzantine Empire, 25 et s.

1551 Perles, dans B.Z., 1893. p. 569 et s.

1552 TheOPHANES LE CONFESSEUR, Chronographie, P.G., 108, 809 (à la veille de l'édit de Léon l'Isaurien contre les Juifs, en 722).

1553 KaUfmann, Ein Brief... liber messianische Bewegung... ans dem Jahre 1096 (B.Z., 1898, p. 83 et s.). 
nople ${ }^{1554}$. Il signale dans leur quartier des ouvriers en soieries, des commerçants et des médecins, dont l'un d'eux, Salomon, médecin de Manuel Comnène, protège ses coreligionnaires. Il retrouve des Juifs dans les manufactures de soie à Thèbes. A Thessalonique ils fabriquent des tapis et sont protégés par le clergé. Il voit des Juifs agriculteurs sur le Parnasse et d'autres, pasteurs dans la Grande Valachie (région du Pinde) ${ }^{1555}$. D'autres métiers sont plus singuliers. En Asie Mineure, ils sont employés comme bourreaux au XIII ${ }^{\mathrm{e}}$ siècle ${ }^{1556}$.

$\mathrm{Au}$ début du $\mathrm{XIV}^{\mathrm{e}}$ siècle la plupart des Juifs de Constantinople exerçaient les métiers de fourreurs et de tanneurs de peaux (pelamina, coria). Ils formaient une corporation sous le contrôle de l'État et y admettaient des Juifs sujets de Venise, qui n'étaient pas soumis à l'impôt juif. Brusquement, en 1319, Andronic II ordonna aux Juifs d'abandonner ces métiers, qu'il voulait réserver aux Grecs. Les Juifs sujets de l'Empire se soumirent, mais ceux de Venise ne tinrent aucun compte de cette ordonnance. Il fallut, pour les contraindre, les assiéger dans leurs ateliers, brûler leurs marchandises ou les jeter dans la Corne d'Or, enfin les expulser, en les condamnant à une forte amende. Les Grecs et les Juifs sujets du basileus reçurent l'autorisation de reprendre leur industrie. Il s'ensuivit entre Venise et Andronic une longue contestation, au sujet des indemnités réclamées par les Juifs vénitiens. Elle n'était pas encore terminée au moment où éclata la guerre civile entre Andronic II et son petit-fils (1320-1322) ${ }^{1557}$.

Mais, surtout, depuis de longs siècles, les Juifs prenaient part au commerce international entre l'Europe et l'Asie. L'Arabe IbnKhordâdbeh (fin $\mathrm{IX}^{\mathrm{e}}$ siècle) les montre, parcourant l'Orient et l'Occident, parlant la plupart des langues usitées dans le commerce et vendant des eunuques, des esclaves, de la soie, des pelleteries, des épées, notamment à Constantinople ${ }^{1558}$.

1554 Benjamin de Tudele, Voyages, 50-52; Andreades, Les Juifs dans l'Empire byzantin, 459; D.H.G.E., VII, 1344 et s.

1555 BenJamin De Tudele, ch. 4; ANdreades dans E.B., 1929, 28-29; W. Miller, Essays on the Latine Orient, 53.

1556 PACHYMERE, Histoire, 144-152.

1557 J. STARR, The Jews in the Byzantine Empire, 28-31.

1558 IBN-KHORDADBEH, Livre des routes et des royaumes (trad. Barbier de Meynard), 512; BRATIANU, Recherches sur le commerce génois dans la mer Noire au XIII siècle, 39. 
Et ce sont ces relations commerciales qui permirent entre les colonies du monde juif des communications régulières. Plusieurs documents attestent qu'une véritable solidarité régnait entre elles et qu'elles se soutenaient mutuellement lorsque l'une d'elles était en détresse.

Une lettre des Juifs d'Alexandrie à ceux de Madaura en Lydie, écrite vers 1030, annonce qu'ils cherchent à payer la rançon de ceux de Mastaura qui ont été pris par des pirates, mais qu'ils n'ont pas encore réuni les fonds nécessaires. Les captifs furent sans doute rachetés plus lard par les Juifs du Caire ${ }^{1559}$.

De même une lettre des Juifs de Nègrepont à la communauté de Rome, écrite vers 1300 , lui demande de supplier le pape d'intervenir auprès de Venise en faveur des Juifs, sujets des Lombards, dont la plupart sont serfs, afin d'obtenir une diminution de la taxe exorbitante qu'ils ne peuvent payer ${ }^{1560}$.

\section{Colonies musulmanes}

Retour à la Table des Matières

Dans la ville cosmopolite qu'était Constantinople, les Arabes tenaient une certaine place et, en vertu des traités conclus avec les califes, et plus tard les sultans turcs, les Musulmans pouvaient y pratiquer librement leur religion.

Les témoignages. - Le fait est attesté par de rares passages des chroniques byzantines et surtout par des voyageurs et géographes arabes venus à Constantinople, comme Ibn-Khordâdbeh (fin $\mathrm{IX}^{\mathrm{e}}$ siècle) ${ }^{1561}$, Haroun-ben-Jahja, prisonnier de guerre ${ }^{1562}$, Maçoudi au $X^{\mathrm{e}}$ siècle $^{1563}$, Edrisi, vers 1153, Aboul-Feda et Ibn Batoutah (XIV ${ }^{\mathrm{e}}$ siècle) ${ }^{1564}$.

\footnotetext{
1559 Th. REINACH, Un contrat de mariage du temps de Basile le Bulgaroctone, 118 et s.

1560 J. STARR, The Jewries of the Levant after the fourth Crusade, 48-59.

1561 IBN-KHORDADBEH, op. cit. 471 et s.

1562 HAROUN-BEN-JAHJA (prisonnier de guerre), Récit, 206 et 207.

1563 MAÇOUDI, Les prairies d'or, 311 et $\mathrm{s}$.

1564 EDRISI, Géographie, II, 425-444; ABOulfedA, Géographie, II, 315 et s.; EBERSOLT, Constantinople byzantine et les voyageurs du Levant, 42.
} 
Dans les chroniques il est parfois question des Musulmans qui habitent Constantinople ; par exemple ils prennent part à l'émeute contre Sclérène, la favorite de Constantin Monomaque ( 9 mars 1044) ${ }^{1565}$.

Mosquées de Constantinople. - En vertu des traités conclus avec les États musulmans, des mosquées et autres établissements cultuels, furent érigés à plusieurs reprises à Constantinople. On en trouve la première mention sous Léon l'Isaurien. En 717, après sa défaite devant la ville, Moslémah aurait obtenu de son vainqueur la permission de construire une sorte d'oratoire ${ }^{1566}$ qui existait encore deux siècles plus tard, car, après le traité conclu par la régente Zoé avec le calife Al-Maqtadir en 917, Nicolas le Mystique dément dans une lettre à ce calife que la mosquée ait été fermée ${ }^{1567}$.

Après son alliance avec le sultan seldjoukide Toghrul-beg, Constantin Monomaque fait élever une nouvelle mosquée et fournit tous les objets du culte musulman : la prière y était faite au nom du sultan ${ }^{1568}$.

Il n'est pas question de cette mosquée sous les Comnènes et les historiens arabes la considèrent comme disparue, sans que le culte ait cessé d'être célébré dans le palais du Magisdion. Au moment où Isaac l'Ange fait alliance avec Saladin, pendant la croisade allemande (1189), le sultan lui demande d'établir le rite sunnite au Magisdion. La mosquée est installée avec un minaret et un muezzin, puis l'ambassadeur turc fait la prière au nom du calife abbasside ${ }^{1569}$.

Il n'est plus question de mosquée avant la fin du XIV siècle et nous avons montré ailleurs comment en 1396 Bajazet exigea de Manuel II l'installation d'un cadi et la construction d'une mosquée, qui disparut après la bataille d'Angora ${ }^{1570}$.

Propagande chrétienne dans les colonies musulmanes. - Tout en cherchant à rallier les hérétiques à l'orthodoxie et à baptiser les Juifs, les empereurs byzantins s'attaquèrent à l'islam, qu'ils considé-

\footnotetext{
1565 G. CEDrenos, Synopsis, 761; BAR HeBraeus, Chronique syrienne, 245-248.

1566 Source unique : CONSTANTIN VII Porphyrogenete, De admintstrando imperio, ch. 21; NOMIKOS dans E.B., I, 199-209.

1567 NiCOLAS LE MYSTIQUE, patriarche, Correspondance, ép. 9, 309; R.P.B., 569.

1568 Au Magisdion en 1049. NomiKOs dans E.B., I, 204 et s.

1569 Remplace le rite chiite venu d'Égypte. NOMIKOS, loc. cit.

1570 Vie et mort de Byzance, 1969, p. 390; NomiKOS, E.B., I, 209.
} 
raient comme une hérésie dérivée de l'arianisme ${ }^{1571}$. Mais les difficultés étaient grandes : pour un prince seldjoukide, fondateur du monastère de Koutloumous (Athos) ou un Axouch converti par Alexis Comnène, qui en fit son grand-domestique ${ }^{1572}$, le nombre des chrétiens passés à l'islam l'emportait sur celui des musulmans devenus chrétiens.

La propagande commença par des traités d'apologétique, dont le premier est celui de saint Jean Damascène, qui possédait la langue arabe et se servait d'un texte du Coran. L'islam est pour lui l'hérésie la plus récente ${ }^{1573}(1573)$.

$\mathrm{Au} \mathrm{IX}{ }^{\mathrm{e}}$ siècle, Photius, Michel III et Basile font une place à l'islam dans le programme de leurs missions. Un Sarrasin aurait écrit à Michel III pour demander des explications sur certains dogmes. Une réponse très courtoise lui fut faite par Nicétas Byzantios, qui écrivit sous Basile I $^{\mathrm{er}}$ une réfutation du Coran ${ }^{1574}$ (1574).

Sous les Comnènes, Euthymios Zigabenos comprend l'islam dans sa Panoplia, en se servant des sources antérieures. Son ouvrage est suivi du récit d'une dispute, qu'il eut à Mélitène avec un Arabe ${ }^{1575}$. Dans son Trésor d'Orthodoxie, écrit à Nicée après 1204, Nicétas Khoniatès insère une formule d'abjuration dans laquelle le catéchumène doit condamner la sourate 12 du Coran : " Allah est le seul dieu olosphyre » (Dieu entier), que Manuel Comnène, pour faciliter les conversions, réussit à faire remplacer par une formule plus générale ${ }^{1576}$.

Dans la pratique tous ces efforts aboutissaient à la conversion des Turcs du Vardar et des Musulmans prisonniers de guerre, auxquels on offrait de nombreux avantages.

\footnotetext{
1571 GÜTERBOCK, Der Islam im Lichte der byzantinischem Polemik, 10.

1572 Chalandon, Les Comnène, 19.

1573 Saint JeAn Damascene, CEuvres, 764 et s.; GÜTERBOck, op. cit., 10; Dispute entre un Sarrasin et un chrétien, P.G., 96, 1336 et s.

1574 NiCETAS KhONIATES, Histoire, 807-842, 872 et s.; GÜTERBOCK, 24 et s.

1575 Euthymos Zigabenos, Panoplia dogmatike et P.G., 130, 1382 et s.; 131, 25 et s.; GÜTERBOCK, 34 et s.

1576 GÜTERbock, 37 et s.; Chalandon, Les Comnène, 661 et s.
} 
Comme il arrivait parfois pour d'autres sujets aussi graves, les réfutations de l'islam devinrent un simple exercice littéraire, comme le traité écrit par Jean Cantacuzène après son abdication. C'est un véritable roman dans lequel il met en scène son ami Archemenidès, musulman converti et moine sous le nom de Meletios. Un de ses compatriotes, Sampsatès d'Ispahan, lui écrit pour l'engager à revenir à l'islam, dont il cherche à lui montrer la supériorité sur le christianisme. Cette lettre, écrite en grec vulgaire, est évidemment supposée. A la demande de Meletios, Cantacuzène adresse à Sampsatès 4 apologies du christianisme et 4 discours sur les erreurs et les mensonges du Coran ${ }^{1577}$.

Peut-être en est-il de même du Dialogue que Manuel Paléologue prétend avoir eu, pendant sa captivité comme otage à Angora ${ }^{1578}$, avec son hôte, un muderris, professeur dans une médressé ${ }^{1579}$. La mise en scène est fort jolie. Toute la famille et plusieurs vieillards assistent aux entretiens. Le soir, après souper, Manuel s'assied près du foyer, ainsi que des membres de sa suite, et les discussions s'engagent avec l'aide d'un interprète. Manuel avait presque réussi à convaincre ses auditeurs après 26 entretiens, mais ils ne purent se résoudre à abjurer leur religion ${ }^{1580}$.

Le dernier traité apologétique du christianisme, adressé par un Byzantin aux Musulmans, fut celui que Gennadios, devenu patriarche de Constantinople, écrivit à la demande de Mahomet II, qui l'avait interrogé sur certains points de la religion chrétienne ${ }^{1581}$.

\footnotetext{
1577 Jean CANTACUZENE, Apologie contre l'Islam, 372 et s.

1578 Entre 1389 et 1391, M.B. (Vie et mort de Byzance), 1969, 379 et s.

1579 École théologique.

1580 MANUEL II PALEOLOGUe, CEuvres, 111 et s.

1581 R.P. JUGIE dans B.N., 1929, 295 et GERARD DE SAINT QueNTIN EN L'ISLE, Translatio sancte Corone..., t. 3, «morceau remarquable par sa logique».
} 


\section{LIVRE CINQUIÈME La vie intellectuelle}




\section{Chapitre X}

\section{La littérature byzantine}

Après avoir essayé de reconstituer la vie que menait la société byzantine, prise dans son ensemble, il faut en venir à son élite intellectuelle, aux littérateurs, aux penseurs, aux professeurs, aux artistes, dont l'œuvre, autant que nous pouvons la connaître, rend plus profonde notre connaissance du monde byzantin et de l'action qu'il a exercée pendant un millénaire.

\section{La vie intellectuelle et ses conditions}

C'est un fait certain que l'instruction fut très répandue à Byzance et, d'autant plus répandue, qu'elle menait aux honneurs, dans l'Église comme dans l'État. C'est ce qui explique que le champ de la littérature byzantine soit si vaste; il suffisait à un enfant de famille modeste d'être bien doué, pour qu'on lui fît faire des études, à des époques où, en dehors des monastères, les Occidentaux vivaient dans l'ignorance la plus complète.

Dans cette immense production littéraire de Byzance, tout n'est pas digne d'être admiré, il s'en faut de beaucoup, mais tout non plus ne mérite pas le mépris dont elle fut souvent l'objet; nous essaierons d'en donner la preuve.

Condition des lettrés. - Dans la société byzantine un lettré ne pouvait vivre uniquement de ses travaux, s'il n'était soutenu par un protecteur, haut dignitaire, prince ou princesse du sang, parfois 
l'empereur ou l'impératrice. Du moins le goût des hautes classes pour le savoir offrait aux auteurs des chances de subsister. Ce fut ainsi qu'au $\mathrm{XI}^{\mathrm{e}}$ siècle Michel Psellos, familier de Constantin Monomaque, puis de Constantin Doukas, devint, grâce à sa science et à son talent littéraire, un des grands personnages de l'État. Mais les essais de gouvernement des lettrés, au XI $\mathrm{XI}^{\mathrm{e}}$ siècle et, plus tard, à Nicée sous Théodore II Lascaris, furent, comme on le sait, très éphémères et exceptionnels dans l'histoire de Byzance. Ces savants privilégiés étaient d'ailleurs peu nombreux et les pensions servies aux gens de lettres par leurs nobles admirateurs ne devaient être ni régulières, ni suffisantes.

Bien que nous n'en soyons informés que par des écrits satiriques, il existait un prolétariat littéraire à Byzance. Sous le nom de Théodore Prodrome, dans un poème dédié à l'empereur jean Comnène ${ }^{1582}$, l'auteur raconte que, dans son enfance, son père lui vantait les avantages du métier de lettré :

Tel qui allait à pied sans chaussures est devenu un beau cavalier à la chevelure soignée, au costume magnifique, chaussé de souliers à la mode. Théodore apprit les lettres sans peine, mais il les maudit, car elles ne lui donnent même pas de pain. Son voisin, le savetier, fait à son nez des repas plantureux; son coffre est rempli de savoureuses provisions : dans celui du poète on ne trouve que des tablettes pour écrire et des sacs remplis de papier. Ne vaudrait-il pas mieux pour lui jeter bas son habit de lettré et se faire manœuvre ${ }^{1583}$ ?

Un autre bohème contemporain des Prodromes, Jean Tzetzès, un des philologues les plus remarquables du XII siècle, commentateur d'Homère et des principaux poètes grecs, dédiait en vain ses livres à Jean et à Manuel Comnène, à l'impératrice Irène, à un certain Kotertzès : il se plaint sans cesse de sa pauvreté et il tomba dans un tel dénûment qu'il vendit tous ses livres, sauf un Plutarque. "Ma bibliothèque, écrivait-il, c'est mon cerveau. Je n'ai plus mes livres qui souffrent cruellement de ma pauvreté ${ }^{1584}$. » De là, sans doute, en se fiant trop à sa mémoire, dont il vante la richesse, les erreurs grossières qu'il commet en faisant de Servius Tullius un empereur romain ou en confondant le Nil et l'Euphrate. Désolé de ne pas être apprécié à sa

\footnotetext{
1582 TheOdore Prodrome, Poèmes, 567.

1583 Ibidem, vers 1144: v $\kappa \beta \lambda \omega \tau \pi \alpha \pi \pi \alpha \delta$ เ $\alpha$ « « que je jette mon habit », nom d'un habit de coupe ecclésiastique porté par les lettrés.

1584 Jean Tzetzes, Euvres (éd. Pressel, 1851), Allégories 15, 87; KrumBACHER, Geschichte der byzantinischen Literatur, 526-536; DuchATEAU, Jean Tzetzès et ses études sur Homère, Chiliadès.
} 
valeur, de voir ses livres ignorés, il déclare qu'il n'a plus qu'un but : se procurer de quoi vivre et il se soucie des affaires publiques « autant que les geais, de la royauté et les aigles, des lois de Platon $»{ }^{1585}$.

Mais, formant un contraste avec ces gens de lettres besogneux, de hauts personnages s'adonnaient à la littérature et aux sciences : dans le haut clergé Georges Pisidès, diacre de Sainte-Sophie et chartophylax, historien des guerres d'Héraclius, et, sous les Comnènes, Théophylacte, archevêque d'Ochrida et Eustathe de Thessalonique ; parmi les grands dignitaires Théodore Métochitès, le grand-logothète d'Andronic II, le savant le plus qualifié de son temps. Même tradition chez les princes et princesses du sang depuis Athénaïs-Eudokia, épouse de Théodose II (421-460), jusqu'à Anne Comnène, pour ne citer que quelques exemples. Enfin deux empereurs, Jean Cantacuzène et Manuel Paléologue comptent parmi les plus grands écrivains de Byzance.

Les livres : matière et présentation. Le papyrus. - Byzance hérita des matières et des procédés usités dans l'antiquité pour la confection du livre. $\mathrm{Du} \mathrm{IV}^{\mathrm{e}}$ siècle à l'invasion arabe, les livres se présentaient comme des rouleaux de papyrus, préféré au parchemin. Le commerce du papyrus ne cessa pas d'ailleurs avec la perte de l'Égypte, mais il se dirigea surtout vers l'Occident ${ }^{1586}$; à Byzance il est encore employé pour les diplômes impériaux au $\mathrm{IX}^{\mathrm{e}}$ siècle ${ }^{1587}$. Tandis qu'à l'époque byzantine, le papyrus exigé pour les actes était un monopole d'État et devait porter sur le premier feuillet d'un cahier (protocole) l'estampille du comes sacrarum largitionum, il n'en était pas de même pour les livres, dont les éditeurs s'adressaient à des fabriques privées ${ }^{1588}$. Les feuilles de papyrus étaient plus longues que larges.

Le seul livre complet sur papyrus qui soit parvenu jusq'à nous est un recueil de sermons de saint Augustin, copié au VI ${ }^{\mathrm{e}}$ siècle, partagé entre la Bibliothèque Nationale de Paris (ancien fonds de SaintGermain-des-Près, partie découverte au XVI ${ }^{\mathrm{e}}$ siècle), et la Bibliothèque

\footnotetext{
1585 Jean Tzetzes, Chiliadès, 1, 77; DieHL, Figures byzantines, II, 140 et s.; Hesseling, Essai sur la civilisation byzantine, 328 et $\mathrm{s}$.

1586 Voir supra p. 175 et s.

1587 Lettre d'un basileus du IX siècle (trésor de Saint-Denis), M.B.E.H. (Institutions), 1970, 141.

1588 V. GARDTHAUSEN, Griechische Paläographie, 30-34; D.A.C.L., XIII, 1371 et s.
} 
de Genève ${ }^{1589}$. Par contre on a découvert et on découvre chaque jour un nombre prodigieux de fragments de l'Ancien Testament ${ }^{1590}$, des Évangiles canoniques, des logia ou sentences de Jésus, des recueils liturgiques, des papyrus magiques, etc. ${ }^{1591}$.

Certains de ces livres étaient illustrés de miniatures. On peut citer un fragment de rouleau d'un roman du premier siècle de l'ère chrétienne ${ }^{1592}$ et surtout les 49 fragments en 16 feuillets d'une chronique alexandrine en langue copte découverte à Gizeh. C'est une sorte d'almanach populaire qui contient les figures allégoriques des mois romains et juifs, des catalogues des prophètes, des rois de Rome, etc. et une chronique des événements de 382-393, qui présente la plus grande ressemblance avec la chronique latine dite le Barbarus Scaliger. Les peintures, des plus médiocres, sorte de gouache terreuse aux couleurs brillantes, sont placées sans ordre au milieu du texte ou en marge. On y voit l'histoire de David, le portrait du patriarche Théophile et un fragment de la destruction du Sérapeum ${ }^{1593}$.

Le parchemin. - Le parchemin, dont l'usage est originaire d'Asie, conserve son vieux nom ( $\pi \varepsilon \rho \gamma \alpha \mu \eta v o ́ \varsigma)$, rappelant Pergame, son principal centre de diffusion dans le monde antique. Les peaux de mouton, de veau (vélin), de bouc, de truie et, pour les manuscrits de grand luxe, d'antilope et de gazelle, étaient employées concurremment avec les papyrus, mais surtout dans les provinces d'Asie ${ }^{1594}$.

Constantin aurait fait copier sur parchemin les 50 Bibles destinées aux 50 églises qu'il avait fondées. Le plus ancien manuscrit sur parchemin de la Bible, le célèbre Codex Sinaiticus, découvert par Tischendorf au monastère de Sainte-Catherine du Sinaï (1844-1859), aujourd'hui au British Museum, date de la fin du IV siècle. Il est écrit sur quatre colonnes et, sauf quelques feuillets, d'une seule main ${ }^{1595}$.

589 OMONT dans B.E.C., 1918, 499-502

1590 Palimpseste syriaque d'Isaie daté de 459, découvert en 1910, au British Museum, par l'abbé — aujourd'hui cardinal Tisserand, R.B., 1911, 85-95.

1591 D.A.C.L., XIII, 394 et s.

1592 SIRARPIE TER NERSESSIAN, L'illustration du roman de Barlaam et Joasaph, 174.

1593 STRZYGOWSKY, Eine Alexandrinische Weltchronik, fragments de papyrus illustrés (Vienne 1906).

1594 GARDTHAUSEN, Griechische Paläographie, 39-40.

1595 Ibidem, 133. 
Dès cette époque on commençait à préférer le parchemin au papyrus, dont les feuillets minces et cassants se conservaient mal. A la fin $\mathrm{du} \mathrm{IV} \mathrm{V}^{\mathrm{e}}$ siècle, deux prêtres de Césarée (Palestine) entreprirent de renouveler une magnifique bibliothèque, fondée au $\mathrm{III}^{\mathrm{e}}$ siècle par saint Pamphile pour son école d'apologétique. Ils remplacèrent par des copies sur parchemin les livres sur papyrus qu'ils trouvèrent en mauvais état ${ }^{1596}$.

Les exemplaires de luxe des Livres Saints ou même des auteurs profanes représentent aussi une tradition antique : texte en lettres d'or ou d'argent sur parchemin pourpré, décoré de peintures ${ }^{1597}$. Citons parmi les plus célèbres la Bible d'Ulfilas (Codex Argenteus, Stockholm), la Genèse de Vienne, les fragments des Évangiles de Sinope (Paris), l'Évangéliaire de Rossano, qui représentent les chefs-d'œuvre des scriptoria des $\mathrm{V}^{\mathrm{e}}$ et $\mathrm{VI}^{\mathrm{e}}$ siècles. Ce fut en vain que des rigoristes, comme saint Jean Chrysostome et saint Jerôme, blâmèrent ce luxe, qui détournait les lecteurs de s'imprégner du sens des Évangiles, pour ne considérer que la somptuosité des livres. La recherche des beaux manuscrits, religieux et profanes, fut toujours en honneur à Byzance ${ }^{1598}$.

Le papier. - On distinguait le papier de coton et le papier de chanvre ou de lin, l'un et l'autre connus très anciennement des Chinois et transmis à l'Europe par les Arabes. Les plus anciens manuscrits arabes sur papier dateraient de la fin du $\mathrm{IX}^{\mathrm{e}}$ siècle, tandis qu'à Byzance le papier de coton (bombycinus) n'est employé que deux siècles plus tard ${ }^{1599}$ et qu'avant le XIII ${ }^{\mathrm{e}}$ siècle il ne paraît pas d'un usage courant ${ }^{1600}$. Au XIV ${ }^{\mathrm{e}}$ siècle au contraire les manuscrits en papier de coton sont nombreux.

La copie des livres. - A toutes les bibliothèques séculières ou monastiques étaient attachés des ateliers de copistes. A la différence de ce qui s'est passé en Occident jusqu'au XIII ${ }^{\mathrm{e}}$ siècle, ces copistes n'étaient pas exclusivement des moines, mais appartenaient à toutes

${ }_{1596}^{1596}$ Saint Jerome, Epist. CXI.

${ }^{1597}$ On s'explique mal l'opinion de Wickhoff qui croit ces livres exécutés pour des gens peu cultivés, princes barbares, grandes dames, etc. Voir B.Z., 1893, 214.

1598 Saint Jean Chrysostome, Homélies, hom. 22; P.G., 59, 107.

1599 GARDTHAUSEN, op. cit., 48-50 (plus ancien manuscrit en papier daté de 1095, Bibliothèque de Vienne).

${ }^{1600}$ Son emploi paraît plus précoce en Occident à cause du voisinage des Arabes d'Espagne et d'Afrique (chartes siciliennes, 1109), GARDTHAUSEN, 48-50. 
les professions. Des fonctionnaires, au $\mathrm{XI}^{\mathrm{e}}$ siècle un collecteur d'impôts, des notaires, des professeurs de l'Université augmentaient ainsi leurs maigres appointements ${ }^{1601}$. La plupart des manuscrits d'auteurs antiques sans souscription sortent d'ateliers séculiers, tandis que les moines-copistes indiquent en général leur profession : moine, pécheur, hiéromoine.

Un atelier de calligraphie, 4 Grecs et 3 Latins, fut attaché par Valens à la Bibliothèque de Constantinople ${ }^{1602}$. La copie des manuscrits était regardée dans les milieux intellectuels, à toutes les époques, comme une œuvre essentielle et salutaire. Parmi les copistes de marque, on citait l'empereur Théodose II ; Aréthas, professeur de philosophie à l'Université, archevêque de Césarée (Cappadoce), en 907, fit copier à ses frais les manuscrits d'Euclide, d'Aristide le Rhéteur, de Dion Chrysostome, de Platon. Ce sont ces copistes qui ont sauvé les œuvres de l'antiquité grecque. Un Demetrios Triclinos copie les poèmes d'Hésiode en 1316 (Marcianus, 464), des tragédies d'Eschyle (bibliothèque de Naples: II, F. 31) et les comédies d'Aristophane (Vaticanus 87). Quatre grandes bibliothèques (Vatican, Escurial, Ambrosienne, Laurentienne) se partagent les copies d'auteurs antiques exécutées de 1421 à 1436 par le diacre Georges Chrysococcès (Odyssée, Batrachomyomachie, Strabon, Xénophon, Plutarque) ${ }^{1603}$. En 1411, c'est un médecin, Démétrius Xanthopoulos, qui copie les œuvres de Sophocle, Euripide, Aristophane, Hésiode (aujourd'hui à Oxford-Bodléienne).

La copie était aussi importante dans les monastères, mais portait sur les Livres Saints, les œuvres des Pères de l'Eglise, les ouvrages spirituels. Retiré à Vatopédi après sa chute en 1355, Jean Cantacuzène fait exécuter plusieurs copies, dont les œuvres de saint Athanase, encore conservées à Vatopédi. Lui-même s'adonnait à la copie et l'on regarde comme un autographe le magnifique manuscrit de ses opuscules (Parisinus, 1242), avec son admirable portrait en basileus et en moine au frontispice ${ }^{1604}$.

1601 GARDTHAUSEN, op. cit.

1602 C.Th., XIV, 9, 2 (372)

1603 GARDTHAUSEN, 86 et $\mathrm{s}$.

${ }^{1604}$ H. BORDIER, Peinture des manuscrits grecs de la Bibliothèque Nationale, 238-242. 
L'édition des livres. - La forme du livre en papyrus était le rouleau ( $\beta \imath \beta \lambda$ ov, $\kappa \nu \lambda \imath v \delta \rho \alpha ́$, volumen). Le terme de tome désignait un rouleau d'un livre en plusieurs parties : nous l'employons encore. Pour lire, on déroulait le volume de la main droite et on l'enroulait au fur et à mesure de la main gauche : le papyrus était d'ailleurs écrit d'un seul côté ${ }^{1605}$.

Cette forme de rouleau était employée aussi pour le parchemin ${ }^{1606}$. Nous avons mentionné plus haut les rouleaux liturgiques illustrés. Plusieurs d'entre eux étaient couverts de peintures sans interruption: le rouleau de Josué (Vatic. gr. 431 bis), de 10 mètres de long, n'est qu'une épave d'une série de rouleaux, sur lesquels toute la Bible était illustrée. Il en est de même de la belle illustration de la prose Exultet... $\mathrm{du}$ Samedi saint, particulière aux églises de l'Italie méridionale ${ }^{1607}$.

En même temps que les rouleaux on éditait, sous le nom de codes (codex, codices), des feuillets, pliés en deux et groupés en cahiers de

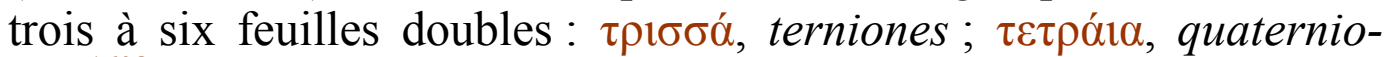
nes ${ }^{1608}$. L'usage du parchemin, plus lourd que le papyrus, rendait nécessaire, pour la commodité du relieur, la grosseur des livres. A l'origine on ne dépassait pas 360 feuillets ou 45 tetradia ${ }^{1609}$.

Les formats étaient très variables, parfois géants, parfois minuscules. Un évangéliaire du $\mathrm{X}^{\mathrm{e}}$ ou $\mathrm{XI}^{\mathrm{e}}$ siècle (Bibliothèque du Grand Séminaire de Strasbourg) mesure 15 centimètres sur 12 . Le texte est écrit en minuscules très nettes sans aucun ornement. C'est un volume destiné à l'usage manuel.

Il n'était pas rare d'éditer les œuvres complètes d'un écrivain célèbre. La Bibliothèque de Photius en cite plusieurs exemples ${ }^{1610}$. Suivant un usage antique, le portrait de l'auteur figurait sur son livre en frontispice. Nous venons d'en voir un exemple au début des Opuscules de Jean Cantacuzène. C'est de cette manière que s'est formée

1605 GARDTHAUSEN, 52 et $\mathrm{s}$.

1606 C.I.C.I., Digeste XXXIII, 52 : volumina sive in charta (papyrus) sive in membrana (parchemin); GARDTHAUSEN, 59; Th. BIRT, Die Buchrolle..., 318.

1607 BERTAUX, L'art dans l'Italie méridionale, 321 et $\mathrm{s}$.

1608 GARDTHAUSEN, 60 et s.

1609 Blake, Sur l'activité littéraire de Nicéphore $I^{e r}$, patriarche de Constantinople, dans B.N., XIV, 4 et s.; GaRdTHAUSEN, 62 et s.

1610 BLAKE, loc. cit., 4 et s. 
l'iconographie des quatre Évangélistes, dont les portraits précédaient souvent le texte ; ils étaient figurés soit en pied, soit assis devant un pupitre, avec à côté d'eux les instruments nécessaires à un scribe ${ }^{1611}$ $(\sigma \tau \alpha ́ \chi \omega \mu \alpha)$.

L'art de la reliure était déjà très développé à Byzance. On attachait les tetradia les uns aux autres et on les revêtait de plats; pour les grands formats on préférait le chêne, garni de cuir ou d'étoffe ${ }^{1612}$. Les plats de reliure des Évangéliaires et Livres Saints étaient souvent garnis de belles plaques d'ivoire et d'orfèvrerie, enrichies de pierres précieuses, d'émaux, de médailles. La plaque d'or du Louvre qui représente la Visite des Saintes Femmes au tombeau du Christ a certainement cette origine ${ }^{1613}$.

Un Évangéliaire du XIII ${ }^{\mathrm{e}}$ siècle (musée de Chicago) conserve sa reliure de la fin de l'époque byzantine. Elle consiste en deux plats de hêtre, couverts d'une peau de chevreau d'aspect brunâtre. Des cadres concentriques, ornés de palmettes, avec une roue entre deux losanges timbrés d'aigles, et des palmettes, placées obliquement aux angles, la décorent. Sur la couverture on lit le nom de Michel d'Andrinople (probablement le relieur), et l'année correspondant à $14666^{1614}$.

\section{Langue littéraire et parler vulgaire}

Retour à la Table des Matières

La коıv'́. - La langue des écrivains de Byzance n'est autre que la кoเví (langue commune), indépendante des anciens dialectes (dorien, éolien, ionien, attique), employée pendant les époques hellénistique et romaine. C'est la langue d'Aristote, de Polybe, de Plutarque, aux IV et $\mathrm{V}^{\mathrm{e}}$ siècles, de Julien, des Pères de l'Église, de Libanius, qui s'est prolongée jusqu'au $\mathrm{XV}^{\mathrm{e}}$ siècle, avec quelques tendances d'écrivains isolés, comme Lucien dans l'antiquité, Anne Comnène au moyen âge, à employer le dialecte attique ${ }^{1615}$.

1611 DALton, Byzantine Art and Archaology, 677.

1612 GARDTHAUSEN, 63 et $\mathrm{s}$.

1613 Ibidem, 64; L. BREHIER, La Sculpture et les Arts mineurs byzantins, pl. 57.

1614 H. R. WiLlOUghbY, Codex 2400 and its mniniatures(Rockefeller McCormick Mss., Chicago) et $A . K .$, XI, 1940, 21 et s

1615 A. MeILlet, Histoire de la langue grecque, 259; G. BuCKLER, Anna Comnena, 482 et s. 
Après les conquêtes d'Alexandre, le champ de la langue hellénique est devenu illimité. Bien que les idiomes indigènes, l'araméen, le persan (pehlvi), l'arabe se soient conservés, le grec est devenu la langue officielle des États et de l'administration des Diadoques et, par suite de la fondation de grandes bibliothèques ou d'écoles, la langue de la littérature et de la science. Enfin il a remplacé l'araméen comme langue internationale.

Et cette langue, c'était la אoıví grammaticalement fixée, enseignée dans les écoles, transmise par les écrivains, adoptée par les administrations centralisées et les commerçants.

Il en résulta que le grec devint la langue courante d'un nombre considérable d'étrangers, Syriens, Égyptiens, Arabes, Juifs, etc., que leur prononciation de cette langue acquise fut tout à fait variée et que l'intégrité de la langue fut menacée : sons différents, iotacisme, confusion des cas, négligences dans les conjugaisons, abandon de certains temps : l'optatif, le futur, l'infinitif. A côté de la langue écrite, dont les mots conservèrent leur orthographe, naquit une langue parlée de caractère populaire. Suivant les régions il se forma des dialectes, parlés dans l'usage courant et transcrits dans des actes sur papyrus ou des inscriptions, morceaux variés, parfois dénués de toute valeur littéraire ${ }^{1616}$.

Cet idiome vulgaire apparaît sur des papyrus du second siècle. Le grec du Nouveau Testament en relève beaucoup plus que de la кoıví ${ }^{1617}$. Il est employé dans certains chants d'église, dans la médecine, etc. ${ }^{1618}$.

Ainsi la langue littéraire de Byzance n'est pas celle de la conversation. C'est une langue artificielle qui n'est pas comprise du peuple et que les lettrés eux-mêmes ne parlent pas dans la vie courante. Nous en avons la preuve dans l'accès de colère que le patriarche Michel Kéroularios eut en 1059 contre Isaac Comnène et dont Skylitzès a repro-

\footnotetext{
1616 MeILLET, 260 et s.

1617 DeISSMAN, Die Sprache der griechischen Bibel, dans Theologische Rundschau, 1912, 339364.

1618 KRUMBACHER, Geschichte der byzantinischen Literatur, 787 et s.
} 
duit l'aspect trivial : « $\quad \sigma \varepsilon \quad \kappa \tau \imath \sigma \alpha, \varphi \circ \quad \rho \vee \varepsilon, \quad$ vó $\sigma \varepsilon$ $\chi \alpha \lambda \alpha \dot{\sigma} \sigma \omega »{ }^{1619} . \mathrm{j}$

En Occident la dégénérescence du latin a produit des langues nationales qui se sont développées et sont devenues des langues littéraires de grand style. Le latin lui-même, épuré à l'époque carolingienne, a été longtemps la langue internationale de la théologie, de la philosophie, de la science. En dehors même de la liturgie, il est resté la langue officielle de l'Église romaine. A Byzance l'évolution est très différente. La langue antique fut pendant mille ans la langue littéraire. Par un véritable amour-propre national, les Grecs de tous les temps ont tenu à la conserver comme le précieux héritage que leur a légué l'antiquité et qu'il faut préserver du contact des idiomes barbares ${ }^{1620}$.

La langue populaire en revanche ne cessa d'être méprisée des lettrés. Elle ne possède même pas de nom et ce sont des Occidentaux qui l'appellent la langue romaïque.

Évolution linguistique. - Mais, même avec le purisme le plus intransigeant, on ne parvient pas à fixer complètement une langue. La contamination redoutée se produit dès $\mathrm{le} \mathrm{VI}^{\mathrm{e}}$ siècle dans la Chronique de Malalas, au siècle suivant dans la Vie de saint Jean l'Aumônier d'Alexandrie, au $\mathrm{IX}^{\mathrm{e}}$ siècle dans la chronique de Théophanes, au $\mathrm{X}^{\mathrm{e}}$ dans les œuvres de Constantin Porphyrogénète ${ }^{1621}$. Des mots étrangers, latins, arabes, arméniens, etc., s'introduisent forcément dans la langue écrite.

La langue populaire n'en obtient pas davantage droit de cité. Au $\mathrm{XII}^{\mathrm{e}}$ siècle encore le patriarche Nicolas Muzalon fait jeter au feu une vie de saint écrite en grec vulgaire ${ }^{1622}$. D'autre part, la langue des lettrés ne conserve plus dans leur intégrité les règles de la grammaire antique.

1619 Cedrenos, Synopsis, 645; L. BrehIER, Le schisme oriental du XI siècle, 279. « Je t’ai élevé, brute, je te briserai. »

1620 Cf. le latin de Grégoire de Tours (Gelzer). Réflexion de saint Basile sur un barbarisme échappé au chambellan Démosthène : "Voici que nous avons un Démosthène illettré. 》

1621 KRUMBACHER, op. cit., 791 et s.

1622 Ibidem. 
La langue de Psellos. - Au milieu du $\mathrm{XI}^{\mathrm{e}}$ siècle a lieu une véritable réforme de la кoıví byzantine, dont Psellos (1018-1078) est le promoteur. Dans son poème sur la grammaire il recommande l'emploi de la кovví, c'est-à-dire du vocabulaire et des formes antiques et, dans son enseignement, il attachait une importance capitale à l'orthographe ${ }^{1623}$.

La langue qu'il écrit lui-même, d'après un bon juge en ces matières, Émile Renauld, conserve la tradition classique dans ses grandes lignes ; il affecte même souvent les formes attiques. Mais son exemple permet de constater la désorganisation partielle des déclinaisons et des conjugaisons dans la кovví byzantine. Dans les substantifs et les adjectifs, il admet à la fois des formes attiques et postérieures. Il supprime l'augment au plus-que-parfait et confond les conjugaisons ${ }^{1624}$. Sa syntaxe est plus correcte et il cherche à conserver à la langue sa pureté et sa précision par l'emploi de l'article et des locutions substantives, mais il n'évite pas toujours l'obscurité et, malgré ses efforts pour l'éviter, il subit parfois l'influence de la langue populaire. Il n'en a pas moins rendu à la koinè byzantine "quelque chose de l'abondance et de la souplesse des orateurs attiques $»{ }^{1625}$.

Psellos a fait école et prolongé l'emploi de la langue savante. Il a transmis à ses successeurs ses qualités et ses défauts. Anne Comnène s'est certainement inspirée de son exemple et, malgré son affectation de purisme, elle tombe dans des incorrections analogues et souvent plus graves ${ }^{1626}$.

Ce fut après l'invasion latine dans les pays grecs, après la croisade de 1204, qu'apparurent les premières œuvres importantes écrites en langue vulgaire, telles que la Chronique de Morée et au XIV ${ }^{\mathrm{e}}$ siècle les poèmes de Constantin Anagnostès ${ }^{1627}$, qui d'ailleurs écrivait aussi en koinè. Cependant le divorce entre les deux langues se prolongea jusqu'au terme de la vie de Byzance. Loin de faire la moindre concession aux démotiques, des lettrés comme Théodore Métochitès songeaient à

\footnotetext{
1623 E. RENAUld, Étude de la langue et du style de Michel Psellos; L. BREHIER, L'Enseignement supérieur à Constantinople dans la dernière moitié du XI siècle, 105.

1624 RENAULD, op. cit., 90, 324.

1625 Ibidem, 358.

1626 Anne Comnene, Préface d'Alexiade : CXli-CXliI; BuCKLER, Anna Comnena, 481-497.

1627 N. BANESCU, Deux poètes byzantins inédits (Bucarest, 1913).
} 
ramener la langue à la pureté antique. «Par la race et la langue, disaitil, ne sommes-nous pas les compatriotes et les héritiers des anciens Hellènes ${ }^{1628}$ ? »

L'admiration pour la langue de l'antiquité devait atteindre encore un plus haut degré chez les promoteurs de la renaissance de l'hellénisme au $\mathrm{XV}^{\mathrm{e}}$ siècle : un Jean Argyropoulos, un Pléthon, un Bessarion, qui pourtant, dans leur correspondance privée, se servaient de l'idiome si méprisé que parlaient leurs compatriotes ${ }^{1629}$.

\section{Caractères de la littérature byzantine}

Retour à la Table des Matières

La préférence des lettrés pour la langue antique a fixé les destinées de l'œuvre littéraire de Byzance, qu'on a justement définie la littérature d'Alexandrie transportée à Byzance, ajoutons continuée par Byzance $^{1630}$.

Byzance et Alexandrie. - Les caractères communs aux deux écoles sont nombreux : importance de la forme, à laquelle le fond est souvent sacrifié, quand il n'est pas simplement frivole; recherche du beau langage, emprunté aux grands auteurs; la pensée coulée dans un moule antique et incapable de s'exprimer simplement; même abus de la mythologie, simple preuve de mauvais goût chez les Alexandrins et, de plus, vrai contresens de la part de chrétiens. C'est ainsi que Théodore Hyrtakenos (XIV ${ }^{\mathrm{e}}$ siècle) compare sainte Anne à Niobé et qu'il fait intervenir la naissance de Pallas et celle de Bacchus dans le panégyrique d'un solitaire ${ }^{1631}$. A propos d'un livre qu'il a prêté au médecin Kalarchontès, qui ne le lui a pas rendu, Nicéphore Grégoras compare son ami à Denys le Tyran retenant Platon auprès de lui ${ }^{1632}$.

\footnotetext{
1628 DieHl et GuILland, L'Europe Orientale de 1081 à 1453, p. 412; DiEHL, Etudes byzantines, 398.

1629 BESSARION, Lettre au précepteur des enfants de Thomas Paléologue, dans N.H., 1908, 19 et s.

1630 K. DIETERICH, Geschichte der byzantinischen und neugriechischen Literatur, 4; PAUL LE Silentiaire, Poèmes, 23.

1631 ThEODORE HYRTAKENOS, Déclamations, V, 716

1632 Michel VIII Paleologue, [Autobiographie], ép. 75,105.
} 
Pastiche et plagiat. - Le pédantisme est le moindre de ces défauts : dans le pastiche, le mauvais goût se donne libre carrière.

Théodore Hyrtakénos, professeur de grammaire et de rhétorique (fin XIII ${ }^{\mathrm{e}}-\mathrm{XIV}^{\mathrm{e}}$ siècle), avait une telle connaissance de l'antiquité, qu'il ne pouvait, en quelque sorte, écrire une ligne sans en emprunter les termes à un auteur ancien. La tournure de ses phrases, son style, tout est calqué sur l'antique. Dans son Panégyrique de la Panagia on reconnaît des vers d'Homère, de Pindare, de Callimaque; dans la péroraison, l'invocation de l'auteur à la Vierge rappelle l'invocation à Artémis dans une hymne de Callimaque ${ }^{1633}$. Est-ce lui ou l'un de ses disciples qui composa cet étrange poème sur l'Annonciation, dans lequel chaque vers est emprunté, soit à l'Iliade, soit à l'Odyssée (exemple : Discours de l'Ange, V. 28-32). Réjouistoi, femme remplie de grâce : avant qu'un an soit révolu. $O d$. XI, 47. - Naîtra celui qui régnera sur tous les pays, $I l$. XIX, 104. - Des hommes qui sont de ton sang et de ta race, $I l$. XIX, 111. - Je te parlerai avec vérité et ne te cacherai rien, $O d$. $X I X, 269$. - Sa gloire sera très grande sous le ciel, $O d . I X, 264^{1634}$, etc.

La mythologie se retrouvait sur les jolis coffrets d'ivoire ciselés, qui montrent le petit dieu de la Richesse, le Ploutos d'Aristophane, entre Adam et Ève au travail ainsi que les travaux d'Hercule ou des Centaures ${ }^{1635}$. Les allusions mythologiques sont fréquentes, même dans les vies des saints: Nicolas le Studite est comparé aux champions des jeux Olympiques ${ }^{1636}$. L'histoire ancienne y tient aussi sa place: Élie le Nouveau, prêchant la pénitence et la vie honnête à Taormina, cite en exemples Epaminondas et Scipion ${ }^{1637}$. Saint Athanase de Méthone rappelle par sa sagesse les anciens législateurs $\mathrm{Za}$ molxis, Lycurgue, Solon, Clisthène, etc. Sa mort est aussi belle que celle de Socrate ${ }^{1638}$.

Certains pastiches dénotent une telle connaissance du vocabulaire et de la phrase des œuvres classiques, en particulier des dialogues satiriques imités de Lucien, qu'ils ont été insérés dans des manuscrits d'auteurs antiques ${ }^{1639}$.

C'est aussi d'Alexandrie que provient dans la littérature byzantine l'amour immodéré de l'éloquence, de l'amplification, de la dialecti-

\footnotetext{
1633 TheOdOre Hyrtakenos, op. cit., V, 716; NiCEPhORE GreGOrAs, Correspondance, 155.

1634 Dictionnaire des Légendes du Christianisme, 915 et s.

1635 BREHIER, Le coffret byzantin de Reims et les coffrets d'ivoire à rosettes. Coffret de Darmstadt.

1636 Vie de saint Nicolas le Studite, 3; LOPAREV, Vizantiiskiia Jitii Sviatuik, V.V., XVII, 186.

1637 Vie de saint Élie le Nouveau (Sicile, vers 900).

1638 LOPAREV, op. cit., 66.

1639 HASE, N.E.M., IX, 1813, 125.
} 
que : toute œuvre, qu'elle soit théologique, philosophique ou historique, se présente comme une démonstration. Verbeux et souvent obscurs à force d'abondance, sont les discours, les panégyriques, oraisons funèbres, etc. Le style épistolaire lui-même n'échappe pas à cette mode tyrannique.

Et aussi en poésie, à côté des longs poèmes, on aimait à Byzance comme à Alexandrie les pièces légères, les descriptions de paysages ou d'œuvres d'art, les épigrammes funéraires, amoureuses, païennes ou chrétiennes. C'est ce genre littéraire qui est le véritable trait d'union entre les deux écoles : comme on le verra plus loin, les Anthologies byzantines contiennent dans leurs recueils d'épigrammes plusieurs Anthologies hellénistiques.

La conservation de la littérature antique. - C'est aussi des Alexandrins, fondateurs de la philologie et de la critique littéraire, que les lettrés de Byzance ont reçu les procédés de conservation et d'exégèse de la littérature antique, la multiplication des copies et des éditions, leur conservation dans des bibliothèques. Celle de Constantinople devint bientôt la plus importante de l'Orient, tandis que se formait aussi une grande bibliothèque patriarcale comprenant, à côté des ouvrages ecclésiastiques, tout un fonds d'auteurs profanes. L'exégèse des livres antiques, le choix de chefs-d'œuvre nécessaires aux études, qui a hâté la disparition d'un nombre effrayant de manuscrits, la révision des copies par des correcteurs chargés d'assurer la pureté des textes, les gloses marginales, les commentateurs, les compilateurs ${ }^{1640}$ et faiseurs d'extraits, tout cela existait déjà à Alexandrie et probablement à Pergame, à Rome, à Carthage et dans tous les grands centres hellénistiques.

La forme et le fond. - Ce serait d'ailleurs se méprendre que de condamner comme un jeu artificiel cette littérature, dont le rôle historique fut immense. En laissant de côté les outrances et le mauvais goût de certains auteurs, on s'aperçoit que cette forme antique n'est qu'un habit somptueux qui revêt des pensers nouveaux. On songe à un XVII siècle plus pédant et plus précieux, mais reflétant son époque. La littérature byzantine, païenne par sa forme, est, en effet, chrétienne par

${ }^{1640}$ La Bibliothèque de Photius, Encyclopédies de Constantin Porphyrogénète. MontelaticI, Storia della Letteratura bizantina (324-1453), 1 et s. 
son inspiration. Ses premiers monuments sont les écrits des Pères de l'Église, dont l'action sur la pensée byzantine fut profonde, et c'est grâce à eux que l'apologétique tient une si grande place dans la littérature. La connaissance parfaite de l'Écriture Sainte était au moins aussi grande chez la plupart des lettrés que celle des textes antiques ; je n'en veux pour preuves qu'un Psellos, un Théodore Métochitès, un Nicéphore Grégoras et tant d'autres.

Mais ce n'est pas tout. L'intérêt que présente la littérature byzantine est dû à la richesse, à la variété de son inspiration. Loin d'être exclusive, la littérature savante a accueilli les récits exotiques, les légendes de l'Inde, de la Perse, de la Syrie, et même les cantilènes arabes qui transparaissent, comme on le verra, dans son épopée, et, dans les derniers siècles, les sources occidentales de certains poèmes.

Il faut même aller plus loin et concéder à la littérature byzantine une part assez grande d'originalité. Beaucoup d'auteurs ont su décrire en traits pittoresques la société de leur temps. Les pamphlets, les écrits satiriques eurent toujours un grand succès à Byzance. Certaines œuvres historiques, comme l'Alexiade ou les récits de Jean Cantacuzène, ont la valeur de mémoires personnels. Enfin une nouvelle poésie lyrique, longtemps ignorée des érudits, fut créée par les mélodes.

\section{Les œuvres : la prose, la rhétorique}

\section{$\underline{\text { Retour à la Table des Matières }}$}

Les genres littéraires sont ceux de l'antiquité, mais avec cette différence que, dans une large mesure, ils sont étroitement subordonnés aux règles de la rhétorique.

La rhétorique. - La rhétorique est l'art de bien dire. Elle est la codification de la méthode, des procédés observés chez les grands orateurs, pour émouvoir et convaincre leurs auditeurs, en s'adressant à leurs sentiments et à leur jugement. Sans doute l'éloquence suppose des dons naturels, mais ils ne servent à rien, s'ils ne sont pas dirigés suivant des règles qui sont de tous les temps. 
Tel est le point de vue des auteurs byzantins, adopté en Europe, de la Renaissance au Romantisme. L'éloquence était appliquée à Byzance à tous les genres littéraires, à la prose comme à la poésie, mais elle avait son genre propre : le discours, profane ou sacré, vaste domaine des rhéteurs.

Les règles et les genres. - C'est dans l'héritage de l'antiquité que Byzance a trouvé ce dangereux instrument. La rhétorique byzantine procède des méthodes, pour ainsi dire mécaniques, codifiées par un rhéteur du temps des Antonins, Hermogène ${ }^{1641}$, et par un de ses successeurs, Aphtonios ( III $^{\mathrm{e}}$ siècle). Dans leurs traités sur l'art oratoire (progymnasta), il n'est pas un seul procédé, une seule figure de pensée ou de style qui ne soit définie avec clarté, mais avec une abondance excessive. Ces programmes énumèrent tous les genres d'éloquence qui furent usités à Byzance, chacun avec ses règles particulières : éloquence d'apparat (panégyriques, oraisons funèbres), éloges, descriptions, $\kappa \rho \alpha ́ \sigma \varepsilon 1 \varsigma$, narrations, requêtes, etc. ${ }^{1642}$.

Telles sont les règles qu'appliquait le plus célèbre des rhéteurs de la fin de l'antiquité, Libanius d'Antioche (314-391), qui enseigna la rhétorique à Athènes, à Constantinople, à Nicée, à Nicomédie, enfin dans sa ville natale après 354 . Païen convaincu, ami et correspondant de l'empereur Julien, il montre à quelle réputation, à quels honneurs pouvait arriver un sophiste bien en cour ${ }^{1643}$.

Ce fut ainsi que se fixa pour plus d'un millénaire l'art oratoire de Byzance. Mais Libanius était païen : une école de rhétorique chrétienne fut fondée à Gaza au v $\mathrm{V}^{\mathrm{e}}$ siècle. Son directeur, Procope, contemporain d'Anastase, dont il prononça le panégyrique, de Justin et de Justinien, était en même temps théologien et remplaçait les exemples mythologiques par des allusions aux Livres saints. Bien qu'il ait passé toute sa vie à Gaza, sa réputation était grande et son successeur, Choricius, qui prononça son oraison funèbre, continua sa méthode, qui exerça la plus grande influence sur les rhéteurs et sophistes de Byzance. Cette éloquence prolixe, ampoulée, baroque, rappelle

${ }^{1641}$ Né à Tarse, professeur à 15 ans, fort goûté de Marc Aurèle, perd la mémoire à 25 ans. Sa Rhétorique, mise en vers par Tzetzès. KRUMBACHER, Geschichte der byzantinischen Literatur, 450 et s.; Rhetores graeci, éd. Walz, III, 670-686.

1642 Guilland, Essai sur Nicéphore Grégoras, 124.

${ }^{1643}$ LibaniUS D'ANTIOCHE, Discours. 
l'éloquence asiatique de l'antiquité, avec ses longues phrases, ses redondances, ses pointes : ce fut en grande partie celle de Byzance ${ }^{1644}$.

Les grands rhéteurs de Byzance. - Ils sont trop nombreux pour être cités tous ${ }^{1645}$. Devant les discours-fleuves de ceux qui sont imprimés, on est parfois découragé par la prolixité et le vide de leur développement. Mais dans la masse de ces sophistes, dont les productions ont souvent la valeur de bons devoirs d'écoliers, quelques grands noms émergent et montrent la continuation à Byzance des genres oratoires de l'antiquité.

$\mathrm{Au} I \mathrm{X}^{\mathrm{e}}$ siècle c'est Photius : la langue dc ses homélies a pu être comparée à celle d'Isocrate; sa connaissance de l'antiquité classique est prodigieuse, comme le montre sa "Bibliothèque », mais son éloquence n'est pas creuse; il sait émouvoir les foules et tirer des leçons des événements contemporains: ses deux homélies sur l'attaque des Russes contre Constantinople sont une des sources importantes de cet événement ${ }^{1646}$.

Photius est un homme d'action : son disciple Nicétas le Paphlagonien est un simple rhéteur. Son Panégyrique de saint Pierre et de saint Paul est un discours impersonnel, sans allusion historique et cherchant à se rapprocher du grec antique, tout en employant des tournures byzantines. La péroraison est une prosopopée, qui commence par le mot : $\mathrm{X} \alpha \quad \rho \varepsilon$ salut ${ }^{1647}$ !

Psellos est aussi un rhéteur de profession, mais son savoir est encyclopédique et sa personnalité domine le $\mathrm{XI}^{\mathrm{e}}$ siècle. Comme nous le verrons, il n'est pas un seul genre d'éloquence qu'il n'ait cultivé, depuis les plus graves jusqu'aux plus frivoles. C'est l'un des historiens les plus brillants de Byzance, mais, dans son respect pour les règles antiques, il se contente souvent d'allusions trop discrètes à des événements de grande importance ${ }^{1648}$.

\footnotetext{
1644 ChOricius DE GAZA, éd. Foerster; R. P. ABEL, Gaza au Ve siècle, d'après le rhéteur Choricius (R.B., 1931); KRUMBACHER, op. cit., 454 et s.

1645 K. KRUMBACHER, op. cit., reste la meilleure bibliographie.

1646 VASILIEV, The Russian Attack of Constantinople in 860, p. 90-94.

1647 Première édition et traduction A. VoGT dans O.C., 1931.

1648 Dans son oraison funèbre de Keroularios, il réduit le schisme avec Rome à une lutte entre les sièges (patriarcaux).
} 
Nicéphore Basilakès est l'un des rhéteurs les plus féconds du XII ${ }^{\mathrm{e}}$ siècle. Dans une sorte d'autobiographie, il dit qu' "il a puisé à l'étude de l'antiquité comme à une fontaine, mais qu'il n'a pas dédaigné de sacrifier aux Muses modernes ». Il avait cultivé surtout Platon et Marc Aurèle, mais s'était essayé dans tous les genres: discours à l'empereur Jean Comnène, aux princes du sang, au grand-domestique Jean Axouch, à côté des discours de Danaé à Zeus, de l'Hadès après la résurrection de Lazare, d'une jeune fille d'Édesse violée par un guerrier (éthopées), éloge du chien, etc. Il est l'un des rhéteurs les plus représentatifs de son temps ${ }^{1649}$.

Les empereurs eux-mêmes ne dédaignaient pas la rhétorique, comme en font foi les nombreux discours de Théodore II Lascaris (1254-1258) : éloges funèbres de son père et de Frédéric II, éloge de la ville de Nicée, discours pour la fête de l'Hymne Akathiste, où il rappelle les invasions russes. Disciple de deux fameux rhéteurs, Georges Akropolitès et Nicéphore Blemmydès, il avait une profonde admiration pour l'antiquité hellénique et s'était assimilé toutes les règles d'Hermogène. Son style correct, qu'on a rapproché de celui des Pères de l'Eglise, surchargé dans ses premières œuvres de fleurs de rhétorique, abusant de l'hyperbole, devint plus bref et plus concis dans ses dernières années ${ }^{1650}$.

Nicée avait été sous les Lascarides un centre de culture hellénique : sous les Paléologues on assiste à une véritable renaissance de la rhétorique. Plus que jamais on admire l'harmonie du langage et l'ampleur d'une période qui se développe et retombe avec grâce, comme les plis d'une draperie antique. L'éloquence suffit de nouveau à rendre un écrivain célèbre. Des hommes de la valeur de Nicéphore Grégoras prennent plaisir à se livrer à des exercices d'école, voire à rédiger des préambules de diplômes impériaux. L'éloquence d'apparat est aussi très recherchée. On avait pris l'habitude de prononcer l'éloge du basileus à certaines fêtes. Grégoras écrivit ainsi trois éloges d'Andronic II, dont un en dialecte ionien, un éloge d'Andronic III, et même celui d'un roi de Chypre, qui serait Hugue IV de Lusignan (1324-1360), ainsi que les oraisons funèbres d'Andronic II (1332), de Théodore

1649 NiCEPHORE BASILAKES, rhéteur du XII ${ }^{\mathrm{e}}$ siècle; KRUMBACHER, op. cit., 473-475; CHALANDON, Les Comnnène, 20, 640-642.

1650 THEODORE II LASCARIS, Euvres, 151-178. 
Métochitès (même année), de Xéné, mère d'Andronic III. Le canevas de tous ces éloges, véritable tissu de lieux communs, était traditionnel. Plus intéressantes sont les œuvres de polémique de Nicéphore Grégoras contre ses adversaires, mais ses vies de saints et ses sermons où le fond est sacrifié à la forme, sont aussi banals que ses éloges impériaux ${ }^{1651}$.

Dans le dernier demi-siècle de Byzance l'éloquence est représentée par quatre personnages également illustres: Manuel Paléologue (1350-1425), Gémiste Pléthon, Bessarion, Georges Scholarios. Le basileus Manuel II, d'une haute valeur intellectuelle et morale, s'occupait surtout de questions théologiques, mais composa plusieurs œuvres de rhétorique, les unes d'apparat, comme l'oraison funèbre de son frère Théodore $\mathrm{I}^{\mathrm{er}}$, despote du Péloponnèse, mort en $1407^{1652}$, les autres par plaisir, véritables exercices d'école, tels que le discours de Tamerlan à Bajazet vaincu et captif, antithèse banale, et d'ailleurs fausse, entre le puissant et pacifique souverain et l'ambitieux brouillon qui l'a provoqué et refuse de s'humilier devant son vainqueur ${ }^{1653}$.

Georges Gémiste Pléthon (1355-1450) est moins un rhéteur qu'un philosophe et un professeur, qui eut pour disciples à Mistra Bessarion et Georges Scholarios. Il enseignait cependant la rhétorique ${ }^{1654}$, mais l'intérêt que présentent les mémoires sur la réforme de l'État et de la Société adressés, l'un à Manuel II, l'autre au despote de Morée, Théodore II, est d'avoir créé un nouveau genre d'éloquence, l'éloquence politique. Nous reviendrons sur ses doctrines philosophiques.

Avant d'être l'élève de Pléthon, Bessarion, qui avait commencé ses études à Trébizonde, apprit l'art oratoire à Constantinople, où il suivit les cours de Chrysococcès en même temps que Filelfe ${ }^{1655}$. Ses discours ne représentent qu'une faible partie de son œuvre. Composés d'après les recettes traditionnelles, ils sont cependant plus vivants et plus riches en détails précis qu'on ne l'avait vu jusque-là. Sa monodie (discours funèbre) sur la mort de Manuel II (1425) suit pas à pas les

1651 CONYBEARE, Ananias of Shirak, 123-193.

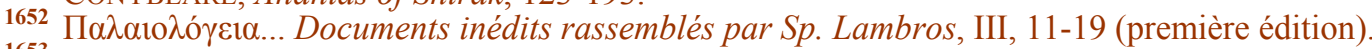

1653 MANUEl II PALeOlogue, Euvres (éd. Berger de Xivrey) et P.G., 156, 579-582.

${ }^{1654}$ Un des premiers travaux de Scholarios, fait sous sa direction, est un éloge de saint Léonce d'Achaïe, Documents inédits rassemblés par Sp. Lambros, II.

${ }^{1655}$ D.H.G.E., VIII, 1182-1198; H. VAST, Le cardinal Bessarion. 
péripéties dramatiques du règne de ce basileus et loue son amour des lettres et la protection qu'il accorda aux études ${ }^{1656}$. Il en est de même de son Éloge de Trébizonde qui, à côté de développements oratoires, renferme de nombreux détails historiques ${ }^{1657}$. Mais les discours qui ont fait sa réputation d'orateur sont ceux qu'il prononça aux conciles de Ferrare et de Florence (1438-1439) et son Encyclique aux Grecs lorsqu'il reçut en 1463 le vain titre de patriarche de Constantinople ${ }^{1658}$.

Avant de devenir un théologien et un redoutable polémiste, Georges Scholarios étudia la rhétorique et ses premières œuvres appartiennent au genre oratoire. Créé juge catholique des Romains ${ }^{1659}$, il faisait des conférences au Triclinium impérial tous les vendredis en présence $\mathrm{du}$ basileus et du Sénat ${ }^{1660}$. On a de lui une oraison funèbre du despote Théodore II Paléologue (1443) ${ }^{1661}$ et une monodie sur la mort de Marc, archevêque d'Éphèse, chef des adversaires de l'Union, où le polémiste transparaît sous l'orateur (1449) ${ }^{1662}$. Dès lors sa propagande contre l'Union se manifeste dans une série de lettres et de discours, dont les plus violents sont le Discours Apologétique adressé à Constantin XI, probablement en 1452, où il sait manier l'ironie, et la lettre adressée au despote Démétrius «Contre les adversaires du service divin et du dogme national et véritable », qui contient des détails historiques sur le retour du concile et le couronnement de Constantin Dragasès ${ }^{1663}$.

Les genres. - Les genres littéraires, qui sont le domaine propre de la rhétorique, énumérés dans les progymnastica, se ramènent dans la pratique à cinq classes :

$1^{\circ}$ Les panégyriques impériaux, dont on a déjà montré le caractère stéréotypé. Depuis le panégyrique de Trajan par Pline le Jeune jusqu'aux derniers Paléologues, aucun empereur n'en a manqué ${ }^{1664}$.

\footnotetext{
1656 Cardinal Bessarion, Euvres (trad. latine), 615-620. Première éd. grecque dans les Documents inédits rassemblés par Sp. Lambros, III, 284-290; VAST, op. cit., 21 et s.

1657 BESSARION, Éloge de Trébizonde.

1658 Id., Euvres (P.G., 141), 449-480, 531-614; VAST, op. cit., 30-32.

1659 Sur cette fonction M.B.E.H. (Institutions), 1970, 194 et s.

1660 Documents inédits rassemblés par Sp. Lambros, II, $\gamma$.

1661 Ibidem, II, 1-13.

1662 Ibidem, II, 28-39, 89-105.

1663 Georges Scholarios, (patriarche GenNADios), Euvres, IV.

1664 Le manuscrit $\Lambda 408$ de Vatopédi contient 34 panégyriques de Leon VI (éd. Akakios, 1868).
} 
$2^{\circ}$ Les oraisons funèbres ( $\pi \imath$ cópıı) d'empereurs, d'impératrices, de princes, de patriarches, de dignitaires, ont le même caractère. Toutes ces œuvres se ressemblent. Leurs auteurs ne se soucient pas de rassembler des détails biographiques qui soient précis : à part quelques exceptions, ils cherchent avant tout à répondre au questionnaire fixé par la tradition sur les vertus ou les exploits de celui qu'ils louent et noient les faits précis sous des allusions plus ou moins obscures. C'est ainsi que dans l'oraison funèbre que Léon VI prononça de son père, Basile $I^{\text {er }}$, pour rappeler la querelle entre Ignace et Photius, il parle « de la lutte entre les ministres de Dieu », il montre "des pontifes guerroyant contre des pontifes », Basile à son avènement ramenant la concorde dans l'Église etc. ${ }^{1665}$. Bien que dans ses oraisons funèbres, Psellos respecte toutes les règles traditionnelles du genre, il parvient, grâce à son talent, à faire revivre ceux dont il fait l'éloge, à retracer la carrière des trois patriarches qu'il a connus ${ }^{1666}$, à rappeler la méthode d'enseignement de Nicétas, "maître de l'Ecole Saint-Pierre ». Surtout, dans les éloges funèbres de sa mère et de sa sœur, on sent une émotion sincère, et les détails qu'il donne sur sa famille nous montrent ce qu'était un intérieur bourgeois de Constantinople au XI ${ }^{\mathrm{e}}$ siècle ${ }^{1667}$.

$3^{\circ}$ Les traités parénétiques, retraçant les devoirs des souverains, type de l'ouvrage de pure rhétorique, ont été recopiés de siècle en siècle, depuis celui du diacre Agapet, qui aurait été adressé à Justinien, jusqu'à celui de Manuel Paléologue ${ }^{1668}$.

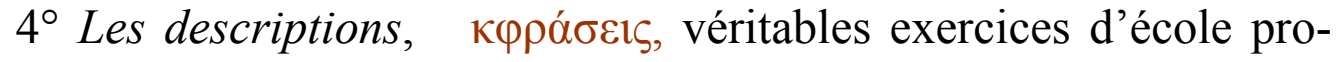
posés par les rhéteurs à leurs disciples. Les sujets étaient donc des plus variés : descriptions des fleuves célèbres, des mers, des montagnes, des monuments, des villes, etc. Certaines de ces descriptions sont fort jolies, mais il faut presque toujours chercher le modèle antique dont elles s'inspirent. Les plus brèves sont en général les plus personnelles.

1665 Edit. VOGT et HAUSSHERR dans O.C., 1932, 1-177.

1666 Michel Kéroularios, Constantin Lichoudès, Jean Xiphilin : PsEllos, Discours, Chronographie, Correspondance, IV, 304-462, V, 87-96.

1667 Psellos, op. cit., V, 3-87; DieHL, Figures byzantines, I, 290 et s.

1668 Sur ces traités M.B.E.H. (Les Institutions), éd. 1970, 56 et s. (introduits en Occident, encore en honneur en France sous Louis XIII). 
Dans une de ses lettres Démétrius Cydonès décrit le charme de Constantinople au printemps. C'est alors que la mer s'apaise et que les navigateurs, abordant de toute part, remplissent les marchés des produits des pays qu'ils ont visités. Les prairies, à l'intérieur de la ville ${ }^{1669}$ et les jardins commencent à fleurir et, sous peu, l'ombre des feuilles couvrira les petits sentiers, si bien que ceux qui les parcourent croiront que les avenues n'ont pas été ouvertes dans une ville, mais en pleine montagne ${ }^{1670}$.

Ce petit tableau qui nous montre le dépeuplement de Constantinople à la fin du XIV ${ }^{\mathrm{e}}$ siècle est pris sur le vif : c'est un témoignage précieux. On ne peut en dire autant de la description du printemps qui termine un discours de Léon VI et qui est d'ailleurs imitée d'un sermon de saint Grégoire de Nazianze. La périphrase y remplace les détails concrets. La mer "montre sa face terrible éclairée d'un doux sourire », les oiseaux sont "les habitants de l'air»; ceux qui sont migrateurs «viennent recevoir le droit de cité dans leur pays natal ${ }^{1671}$.

Plus artificiels encore sont les morceaux de bravoure, véritables jeux d'esprit comme l'apologie de la couleur verte par Théodore Prodrome ${ }^{1672}$ ou encore le «Discours de l'icône du protomartyr Étienne, vendue par des ecclésiastiques à des Vénitiens ${ }^{1673}$.

Une ekphrasis justement célèbre est la belle description que fit Manuel II d'une tapisserie qu'il vit au Louvre, lorsqu'il était l'hôte de Charles VI, et qui représentait l'éveil de la nature au printemps. Il montre le gazon qui semble se gonfler au souffle léger du zéphyr, les ruisseaux rentrant dans leur lit, les oiseaux perchés sur les arbres et dont le ramage annonce les temps meilleurs, les insectes remplissant l'air, les enfants cherchant à les attraper avec leur bonnet et s'ébattant dans les jardins fleuris ${ }^{1674}$.

$5^{\circ}$ L'épistolographie. L'art épistolaire lui-même était subordonné à la rhétorique depuis l'antiquité. Les rhéteurs avaient imaginé des modèles de lettres, qui devaient servir dans toutes les circonstances de la vie : remerciements, consolations, demandes, annonce d'une joie ou

\footnotetext{
1669 Écrit à une époque où une partie de la ville est devenue déserte. Voir supra, p. 75.

1670 DEMETRIUS KYDONES, Correspondance, ép. 44.

1671 Frolow, Deux églises byzantines d'après un sermon de Léon VI, dans R.E.B., III, 1945, 48.

1672 P.G., 133, 1007 et s.; TANNERY dans A.A.E.G., XXI, 1887, 107.

1673 Cod. Escurial. gr. Y, 10, f 342 (inédit).

1674 P.G., 156, 577-580.
} 
d'un malheur, etc. Il y avait des formules pour adresser des requêtes, pour écrire à un supérieur, à un ami, et cette rhétorique avait pénétré dans les chancelleries : c'est elle qui régnait dans les préambules des édits impériaux, chrysobulles, actes notariés, etc. ${ }^{1675}$. On attribuait à tort à Démétrius de Phalère vingt et un modèles de lettres qui se trouvent dans un manuscrit de Florence. Cette création est bien plus ancienne et était connue des anciens Grecs. Certaines lettres d'Isocrate adressées à Philippe sont de véritables traités de morale ou de politique destinés à la publication ${ }^{1676}$. Mais c'est surtout entre le $\mathrm{v}^{\mathrm{e}}$ et le $\mathrm{VII}^{\mathrm{e}}$ siècle que ces poncifs connaissent la vogue. Dans les œuvres des rhéteurs de cette époque, à côté de lettres réelles envoyées à des amis, figurent des lettres fictives adressées à des correspondants : imaginaires lettres d'amour d'Aristénète ( $\mathrm{VI}^{\mathrm{e}}$ siècle), lettres morales, de paysans, de courtisans, imaginées par Théophylacte de Simocatta ${ }^{1677}$.

Un manuscrit de Vienne, daté du $\mathrm{XI}^{\mathrm{e}}$ siècle, contient un grand nombre de lettres classées sous les rubriques d'exhortations, d'encouragements, de recommandations, etc., au nom de saint Jean Chrysostome, du patriarche Nicolas $I^{\mathrm{er}}$, de dignitaires et d'autres personnages. Beaucoup ne portent pas les noms de ceux qui les écrivirent ${ }^{1678}$. Ces exercices sophistiques se retrouvent, à côté de lettres réelles, dans les œuvres de Jean Tzetzès (entre 1118-1165) ${ }^{1679}$, de Nicéphore Chumnos, de Nicéphore Grégoras au XIV ${ }^{\mathrm{e}}$ siècle. Dans son précis de Rhétorique, le philosophe Joseph recommande d'éviter le ton oratoire et de rechercher celui de la narration. Il prône le style simple, tout en autorisant l'emploi d'ornements, de citations, surtout d'Homère, et comme modèles les Pères de l'Église, Libanius, Psel$\operatorname{los}{ }^{1680}$.

Les correspondances réelles. - Devant une lettre byzantine, il faut toujours chercher s'il s'agit d'un exercice sophistique ou d'une lettre authentique. Même dans ce dernier cas, sauf dans les lettres d'affaires, il est rare que l'auteur de la lettre ne sacrifie pas à la mode et ne reproduise pas quelques-uns des poncifs que lui ont appris les

\footnotetext{
1675 KRUMBACHER, Geschichte der byzantinischen Literatur, 452-454.

1676 A Alexandrie on vendait des recueils de lettres signées de noms illustres : Solon, Thémistocle, etc. SouIlHE, édit, de Platon, XIII, B.L., XIX et s.

1677 TzETZES, Vers inédits (éd. Petridès), 763 et s.

1678 Description de LAMBROS, N.H., 1925, 12 et s. (Cod. philol. gr. 342).

1679 Tzetzes, Euvres (éd. Pressel); Duchateau, Jean Tzetzès et ses études sur Homère.

1680 GuILland, Essai sur Nicéphore Grégoras, 259-261.
} 
rhéteurs. C'est ainsi qu'un esprit sérieux, comme l'était Nicolas Cabasilas, donne dans sa correspondance des renseignements sur ses études et sur les événements contemporains, mais son style est recherché et plusieurs de ses lettres, faites de phrases harmonieusement construites, sont des plus creuses ${ }^{1681}$.

Le seul fait qu'en dehors des correspondances officielles ou diplomatiques, comme celle du patriarche Nicolas le Mystique, de nombreux recueils de lettres figurent dans les œuvres des grands auteurs, comme Psellos, Michel d'Italie, Théodore II Lascaris, Nicéphore Grégoras, Bessarion, Georges Scholarios, etc., laisse supposer que dans la pensée de leurs auteurs, ces lettres étaient écrites pour être publiées, et c'est ce qui explique que, si pratique que soit leur objet, elles n'obéissent pas moins aux règles de la rhétorique. Ce n'est pas seulement, comme on l'a dit, par prudence, que les correspondants, au lieu de faire franchement le récit des événements, se contentent d'allusions si discrètes, qu'elles sont souvent difficiles à pénétrer. Assez rares sont ceux qui, comme Démétrius Cydonès, correspondant des plus grands personnages de la cour de Jean V et de Manuel II, ont laissé un tableau si vivant de leur temps, que leurs lettres sont des sources historiques, d'autant plus précieuses qu'elles sont sincères ${ }^{1682}$.

\section{L'histoire}

\section{$\underline{\text { Retour à la Table des Matières }}$}

Le genre littéraire le plus remarquable de la prose byzantine est le genre historique, qui est aussi un héritage de l'antiquité, mais adapté à un milieu nouveau, et cultivé sans interruption jusqu'à la chute de Byzance. Pendant dix siècles, de Procope à Phrantzès, grâce à la série de chroniques, d'histoires politiques, de biographies, de mémoires, conservés dans de nombreux et, la plupart du temps, excellents manuscrits, nous n'ignorons rien de l'histoire de Byzance. Chaque siècle a produit une chronique ou un historien. Il n'existe de lacune qu'entre la fin du VII ${ }^{\mathrm{e}}$ et le début du $\mathrm{IX}^{\mathrm{e}}$ siècle, période des invasions arabes et

${ }^{1681}$ Nicolas CABASILAS, Correspondance, 92-102; Monica WAgNer, A chapter of Byzantine Epistolography, D.O.P., IV, 1948, 121 et s. (Lettres de Théodoret, évêque de Cyr, 393-457).

1682 DEMETRIUS KYDONES, Correspondance, Introduction. 
des luttes iconoclastes. Les chroniques de cette période sont perdues, mais des œuvres postérieures en donnent la substance ${ }^{1683}$.

La valeur des monuments de l'histoire byzantine est d'autant plus grande qu'ils sont parfois les seuls à nous conserver des renseignements sur les nombreux peuples de toute race qui furent en contact avec l'Empire. Presque tous les peuples du Proche-Orient actuel, Russes, Bulgares, Yougoslaves, Hongrois, considèrent les sources byzantines comme le fondement de leur histoire nationale. Un historien des peuples turco-mongols déclare que, si l'on ne disposait pas de ces sources, on saurait peu de chose des migrations et de l'histoire primitive des peuples turcs ${ }^{1684}$.

Formation et éléments du genre historique. - L'histoire byzantine dérive d'abord des modèles antiques, Thucydide, Xénophon, Polybe. Elle en reproduit la langue, les procédés de composition, le style narratif, pour le récit d'une action, les discours (toujours refaits), qui résument une situation avant une action importante, militaire ou politique. Comme dans l'antiquité, la rhétorique a donc accès dans le genre historique, mais elle est contrebalancée par le souci qu'a l'historien d'être véridique et sincère. Il se trouve, d'ailleurs, que ceux qui écrivirent l'histoire de Byzance n'étaient pas toujours des professionnels, rhéteurs ou chefs d'école, mais des hommes d'action, pourvus d'une solide instruction et de postes élevés. Plusieurs avaient été témoins des événements qu'ils racontaient ou, à cause de leur situation à la cour, avaient pu s'entourer des meilleurs renseignements et même consulter des documents d'archives.

Faut-il rappeler Procope, secrétaire de Bélisaire, qu'il accompagne dans ses expéditions, Léon le Diacre qui assiste, comme clerc, aux guerres de Basile II contre les Bulgares, et tant d'autres, qui, tout en recherchant le style vigoureux et la forme élégante, tenaient à faire passer à la postérité tout ce qu'ils devaient à leur information personnelle?

1683 Gerland, Die Grundlagen der byzantinischen Geschichte dans B.N., 1933, 100 et s.; N. IORGA, Médaillons d'histoire littéraire byzantine dans B.N., 1925, 237 et s.; 1926, 17 et s.

${ }^{1684}$ MORAVCSIK, Byzantino-turcica, I : Die Byzantinischen Quellen der Geschichte der Turkvölker, 70. 
Dans ces histoires pragmatiques deux ordres de faits sont prédominants. C'est d'abord tout ce qui concerne l'empereur, la cour, le gouvernement de l'État, c'est ensuite l'histoire, en général très détaillée, des guerres, éléments venus de Rome. Ce furent des historiens comme Suétone, Tacite, Plutarque qui créèrent la biographie impériale, désignée à Byzance comme 1' $\sigma \tau$ opía, l'histoire proprement dite. L'empereur est au centre des événements et, après avoir décrit ses traits physiques, l'historien fait une étude psychologique de son caractère ${ }^{1685}$.

L'élément chrétien. - Malgré les liens qui les attachent à l'antiquité, les historiens de Byzance se placent au point de vue chrétien et créent deux genres nouveaux: l'histoire de l'Église, et la Chronique universelle. Le nom d'Eusèbe de Césarée (265-329) est attaché à l'un et à l'autre. Son Histoire de l'Église en dix livres va de la naissance du Christ jusqu'à la victoire de Constantin sur Licinius en $323^{1686}$. Traduite en latin et continuée par saint Jérôme pour l'Occident, à Byzance ce furent deux avocats de Constantinople qui en donnèrent la suite, Socrate de 305 439, Sozomène de 324 à 425 ; Théodoret, évêque de Cyrus (Syrie du nord) (393-457), d'après d'autres sources, la conduisit jusqu'en $427^{1687}$. Citons encore l'Histoire ecclésiastique d'Evagrios, avocat d'Antioche, qui va de 431 593 et a pour le $\mathrm{VI}^{\mathrm{e}}$ siècle la valeur d'une source générale ${ }^{1688}$, et celle de Nicéphore Kallistos Xanthopoulos, en dix-huit livres, qui s'arrête à la mort de Phocas (610). L'auteur, écrivain fécond du XIV ${ }^{\mathrm{e}}$ siècle, avait accès aux Archives Patriarcales et paraît avoir reproduit une Histoire anonyme du $\mathrm{X}^{\mathrm{e}}$ siècle, dont on possède des fragments ${ }^{1689}$.

Chroniques universelles. - La Chronique universelle est née de la nécessité d'introduire l'histoire sacrée, celle du peuple juif, d'après l'Ancien Testament, et celle de l'Église, dans l'histoire du monde, en établissant des synchronismes entre les chronologies des États de l'antiquité, archontes d'Athènes, fastes consulaires, etc., avec celles de la Bible et du christianisme. Un premier essai de ce genre était le

\footnotetext{
1685 HeSSELING, Essai sur la civilisation byzantine, 101 et s.; MORAVCSIK, op. cit., 72.

1686 EUSEBE DE CESAREE, Histoire ecclésiastique.

1687 SOCRATE, Histoire ecclésiastique; SOZOMENE, Histoire ecclésiastique; TZETZES, Euvres.

1688 EVAGRIOS, Histoire ecclésiastique.

1689 Nicephore Kallistos Xanthopoulos, Histoire de l'Église.
} 
Canon de saint Hippolyteé (martyrisé en 240$){ }^{1690}$; l'un des plus violents adversaires des chrétiens, Porphyre (233-304), avait fait le même travail pour l'antiquité païenne ; Eusèbe fit de l'Histoire des Hébreux le centre de l'histoire universelle en partant de la création du monde, suivant le récit de la Genèse. Dans sa Chronographie il reconstitua la

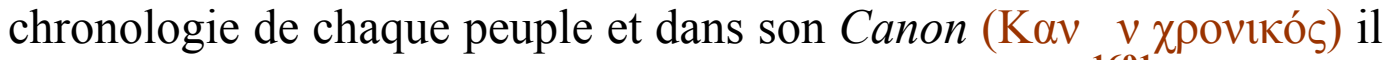
établit les synchronismes jusqu'au règne de Constantin ${ }^{1691}$.

Eusèbe créa ainsi l'Histoire universelle et montra, dans sa Préparation évangélique, que les révolutions sont l'effet d'un plan divin. Sa Chronographie fut le point de départ d'un nouveau genre historique très différent, à l'origine, de l'Histoire proprement dite et donnant, année par année, le récit des événements depuis la création du monde ${ }^{1692}$. Les chroniqueurs suivants reproduisent, sans y rien changer, les textes de leurs devanciers et se contentent de les continuer. Au IX ${ }^{\mathrm{e}}$ siècle, Georges le Syncelle pousse sa chronique jusqu'à 284 après Jésus-Christ; Théophanes la prend à cette date, l'amène jusqu'à la mort de Michel $\mathrm{I}^{\mathrm{er}}(813)$ et, dans la dernière partie, raconte des événements dont il est le contemporain; mais ceux qu'on appelle ses continuateurs sont en réalité des historiens, auteurs de biographies impériales depuis Léon l'Arménien jusqu'à la mort de Romain II : de 813 à 963.

Certaines de ces chroniques ont un aspect tout à fait populaire et ne s'adressent pas au même public. Telle est celle de Malalas, Syrien d'Antioche mal hellénisé, dont la langue annonce déjà le grec populaire et dont les allusions à l'histoire ou à la mythologie antiques sont pleines d'erreurs grossières ${ }^{1693}$. Il paraît avoir écrit pour un public ignorant. Les renseignements qu'il donne sur sa ville natale d'Antioche n'en sont pas moins intéressants et exposés sans aucun artifice de langage.

Cependant, il ne faut pas généraliser le cas de Malalas. Des auteurs de chroniques universelles comme Théophanes ${ }^{1694}$, et surtout comme

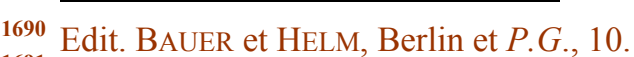

1691 EUSEBE DE CESAREE, Chronographie et Chronicon canonum quae supersunt.

1692 L'ère de Constantinople correspond à 5509 avant J.-C. et celle d'Alexandrie à 5503.

1693 Aurait vécu de 491 à 578; MORAVCSIK, op. cit., I, 184-191; HESSELING, op. cit., 116-120.

1694 ThEOPHANES LE CONFESSEUR, Chronographie (sur sa famille voir supra p. 31.)
} 
le patriarche Nicéphore ${ }^{1695}$, appartiennent à un milieu plus élevé que Malalas et parlent un grec correct, moins pur chez Théophanes. Loin de tomber dans le genre populaire, la chronique se rapproche de l'histoire et ne s'en distingue guère, lorsqu'elle est traitée au XI siècle par Skylitzès et au XII ${ }^{\mathrm{e}}$ par Zonaras, tous deux hauts dignitaires, pourvus d'une solide instruction.

Les grands historiens. - Parallèlement aux chroniques universelles les histoires des empereurs, traitées à la manière antique par des érudits, forment une série presque continue, des origines à la chute de Byzance.

A défaut de l'Histoire byzantine de Priscus, diplomate de métier, dont on ne possède plus qu'un fragment ${ }^{1696}$, la série s'ouvre avec Procope de Césarée, secrétaire de Bélisaire, qu'il accompagna dans la plupart de ses campagnes ${ }^{1697}$. Chargé de la rédaction des ordres du jour, des formations de combat, des correspondances, des rapports au basileus, il était bien placé pour rassembler les éléments d'une information étendue. C'est ce qui explique l'importance de ses renseignements sur la géographie des pays qu'il a traversés, sur l'ethnographie et la constitution politique des peuples avec lesquels il a été en contact : Vandales, Goths, Francs, Syriens, Arabes, Arméniens, Perses. Non seulement il a su observer et retenir, mais, grâce à sa solide instruction classique, il a présenté dans les huits livres de son Histoire des guerres, avec netteté, largeur de vues et d'une manière vivante, souvent saisissante, un magnifique tableau des entreprises militaires de Justinien.

Sa langue est toute classique, mais laisse voir déjà des dégradations de la syntaxe antique ${ }^{1698}$. Il emprunte souvent des expressions à Thucydide et à Hérodote et ses procédés de composition sont ceux de Polybe. Cependant son admiration pour ses modèles antiques ne

\footnotetext{
1695 NiCEPHORE, patriarche, Breviarium (806-815 déposé, mort en 829).

1696 PRISCUS PANITES, Excerpta de legationibus (le titre était Histoire de Byzance et des guerres contre Attila).

1697 PROCOPE DE CESAREE (De Bellis), chef de la chancellerie du général en chef et conseiller

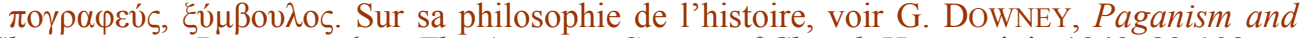
Christianity in Procopius dans The American Society of Church History, juin 1949, 89-102.

1698 KRUMBACHER, Geschichte der byzantinischen Literatur, 233-234.
} 
l'aveugle pas au point de lui faire travestir le fond même de ses récits $^{1699}$.

Son Histoire secrète, qui est bien de lui, est un pamphlet haineux, qui présente, comme plus tard Saint-Simon, l'envers d'un grand règne. Sous les exagérations, on sent la calomnie, la colère, mais peutêtre aussi la déception qu'a pu lui inspirer la manière dont la guerre contre Totila fut conduite ${ }^{1700}$.

Procope avait arrêté l'histoire des guerres à l'année 552. Agathias le Scholastique entreprit son achèvement, mais, mort à quarante-six ans, en 582, il ne put la mener que jusqu'en 558. Juriste et poète, auteur d'épigrammes, il est loin de disposer d'une information aussi sûre que Procope ${ }^{1701}$.

Un officier de la garde impériale, le protecteur Ménandre, continua l'histoire impériale, de 558 à l'avènement de Maurice (582), mais on ne possède plus de son œuvre qu'un fragment, important d'ailleurs, sur les premiers rapports des Avars et des Turcs avec Byzance ${ }^{1702}$. Un Grec d'Égypte, Théophylacte de Simocatta, ajouta à cet ensemble l'histoire du règne de Maurice (582-602). Haut dignitaire sous Héraclius, il disposait d'une bonne information, mais il est le type du rhéteur au style précieux, grandiloquent, encombré d'allusions mythologiques, auprès duquel le style de Procope et celui d'Agathias paraissent la simplicité même ${ }^{1703}$, mais il est le dernier historien de l'Empire romain universel, dont Maurice est le dernier représentant.

La grande lacune historiographique des temps iconoclastes est comblée par la Chronique de Théophanes et par les sept biographies

1699 Des médecins ont remarqué que sa description de la peste de Constantinople de 542 indique une tout autre maladie que la peste d'Athènes, décrite par Thucydide, à laquelle son texte fait songer. SOYKA, A.C.E.B., VI, Alger, 1939.

1700 DIEHL, Justinien et la civilisation byzantine au VI siècle, p. XII-XIII (les mêmes faits ressortent des deux ouvrages); BURY, History of the later Roman Empire, II, 420 (on ne trouve dans l'Histoire des guerres aucun éloge de Justinien).

1701 Agathias, Histoire. Style encore plus fleuri que celui de Procope. Auteur d'épigrammes. Anonyme, Philopatris, P.G., I, XXIII-XXIV.

1702 Menandre Le Protecteur, Fragments; KrUMBACHer, Geschichte der byzantinischen Literatur, 243 et s.; MORAVCSIK, op. cit., 1, 254-257.

1703 Theophylacte de SimocatTA, Histoire; Krumbacher, op. cit., 247-252; Moravcsik, I, 343 et $s$. 
impériales, de Léon l'Arménien à Romain II, considérées comme la continuation de Théophanes ${ }^{1704}$.

Une variété originale du genre historique est la Vie d'Euthyme, patriarche (907-912), par un moine du monastère de Psamathia ${ }^{1705}$. L'auteur n'a pas voulu écrire une œuvre hagiographique, mais ce qu'on pourrait appeler des Mémoires sur l'histoire de son temps, d'une importance capitale pour l'histoire de Léon VI et de ses conflits avec l'Église. Les traits de mœurs, les détails pittoresques, les dialogues animés, le récit des intrigues de la cour forment un tableau très vivant de la société byzantine à cette époque.

L'histoire impériale reprend, avec Léon le Diacre, à la mort de Constantin Porphyrogénète, pour se terminer à celle de Jean Tzimiskès (959-976). L'auteur, attaché au corps des aumôniers militaires pendant les campagnes de Basile II en Bulgarie, a vu la guerre de près. Historien de l'épopée byzantine et pourvu d'une bonne instruction classique, il fait alterner dans son histoire les récits de batailles, les discours, les tableaux de mœurs, qui composent un ensemble très coloré et très vivant ${ }^{1706}$.

La Chronographie de Michel Psellos en est la suite directe ${ }^{1707}$. Cette œuvre qui embrasse 12 règnes impériaux, de Basile II à la chute de Michel VII (976-1077), est l'une des plus importantes de l'historiographie byzantine. Rhéteur au savoir encyclopédique, parvenu aux plus hautes dignités et bien en cour sous la plupart des souverains, Psellos s'est moins soucié de l'histoire extérieure et des guerres que de la vie intérieure de Byzance et surtout des faits et gestes des hôtes du Palais Sacré, Constantin IX, Zoé, Sclérène, Théodora, etc. Il semble qu'il ait voulu, comme l'auteur de la Vie d'Euthyme, écrire l'histoire de son temps, mais avec cette différence qu'il met sans cesse en avant sa propre personne, sans oublier les succès qu'il avait auprès des souverains. On peut considérer son livre comme des Confessions

\footnotetext{
1704 THEOPHANES DE BYZANCE; Vie de saint Antoine le Nouveau.

1705 Vie de saint Euthyme, patriarche; LOPAREV, Vizantiiskiia Jitii Sviatuik, V.V., XVII, 202.

1706 LEON LE DIACRE, Histoires. Sur ses sources voir SJUZJUMOV dans V.O., II, 1916, 106-116.

1707 Comme le montre sa première phrase, qui reprend celle de Léon : "Donc le basileus Jean [Tzimiskès] termina ainsi sa vie. » PSELlos, Chronographie, I, I.
} 
ou des Mémoires personnels, et c'est ce qui lui donne, malgré la vanité de l'auteur, une grande valeur littéraire ${ }^{1708}$.

Haut fonctionnaire, ayant amassé une grande fortune qu'il employa en fondations utiles ${ }^{1709}$, Michel d'Attalie écrivit l'histoire de la période troublée qui marque la fin de l'époque macédonienne, l'avènement des Doukas et des Comnènes (1034-1079). Son récit dédié à Nicéphore Botaniatès permet de contrôler celui de Psellos : il est beaucoup plus impartial et plus sévère pour la politique d'abandon de Monomaque et de ses successeurs. Son témoignage est d'autant plus important qu'il a été le témoin des événements qu'il raconte ${ }^{1710}$.

A la demande de sa belle-mère Irène Doukas, le césar Nicéphore Bryenne, marié à Anne Comnène (1197), écrivit une sorte de chronique de famille, rappelant l'origine des Comnènes sous Basile II, ainsi que leur ascension, et justifiant l'avènement au trône d'Alexis I Comnène ${ }^{1711}$.

Ce fut à son instigation qu'Anne Comnène, exilée par son frère

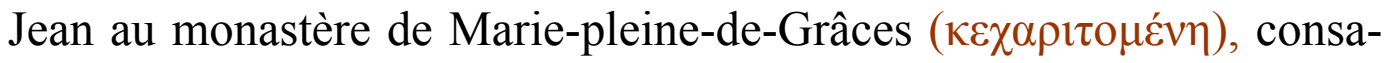
cra à la mémoire de son père une œuvre monumentale, qui tient à la fois du panégyrique, de l'histoire et des mémoires personnels. Le titre qu'elle lui donna ressemble à celui d'un poème : $\lambda \varepsilon \xi$ lós, l'Alexiade. On était en 1138 : Alexis Comnène était mort depuis 20 ans et la princesse était âgée de 55 ans. On peut supposer d'ailleurs qu'elle avait réuni déjà un dossier important, car elle n'écrit pas toujours d'après des souvenirs personnels. Elle avait douze ans en 1095 et elle n'a pu, à cet âge, noter elle-même les traits de caractère qu'elle attribue à Bohémond et aux chefs croisés. Elle a donc puisé son information auprès de témoins oculaires et parfois de leurs descendants. Les documents qu'elle rapporte in extenso montrent qu'elle eut accès aux Archives, impériales.

1708 PSELLOS, op. cit., Introd. I-LXXXVIII.

1709 M.B.E.H. (institutions), 1970, 433.

1710 MichEL D'ATTALIE, Histoire (avait accompagné Romain Diogène dans son expédition contre les Turcs et assisté à la bataille de Mantzikert en 1071); MORAVCSIK, op. cit., I, 258 et s.

${ }^{1711}$ Nicephore BryenNe, Histoire, MoravCSIK, I, 269 et s.; KRUMBACHER, Geschichte der byzantinischen Literatur, 271-276; CHALANDON, Les Comnène, I, Introd. V-VII. 
Son livre est donc précieux par les renseignements qu'il donne sur elle-même, sur sa famille, sur les guerres et la politique d'Alexis, sur la croisade. Cependant, malgré les déclarations retentissantes de sa préface, elle n'a pas la moindre impartialité et, si l'éloge perpétuel qu'elle fait de son père est en grande partie juste, elle passe sous silence tout ce qui regarde son frère et en particulier les intrigues auxquelles elle se livrait pour le priver du trône, pendant l'agonie de leur père.

On relève dans son livre des inexactitudes, de longs développements qui sentent la rhétorique, son affectation de purisme, souvent démentie par l'emploi de termes populaires et d'une syntaxe déjà déformée. En dépit de tous ces défauts, de son orgueil, de son pédantisme, l'Alexiade est certainement une des sources les plus importantes de l'histoire des Comnènes et l'une des œuvres littéraires les plus remarquables que Byzance ait produites ${ }^{1712}$.

La suite de l'Alexiade est due à des historiens qui n'ont certes pas le talent d'Anne Comnène, mais qui, par les fonctions élevées qu'ils exerçaient, ont été en partie des témoins oculaires des faits qu'ils racontent et ont pu disposer d'une bonne information. Jean Kinnamos, secrétaire intime de Manuel Comnène, l'a accompagné dans ses campagnes. Son Epitome comprend le règne de Jean Comnène (11181143 ) et celui de Manuel jusqu'en $1176^{1713}$. Nicétas Khoniatès, secrétaire impérial, duc du thème de Philippopoli en 1189 sous Isaac l'Ange, réfugié à Nicée en 1204, a décrit des événements auxquels il a

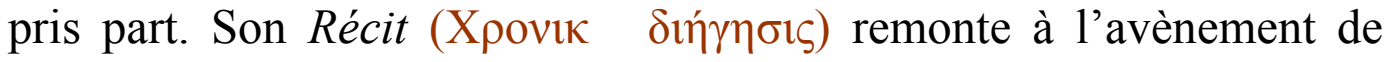
Jean Comnène, pour se terminer en 1206. Il a décrit en termes émus le sac de Constantinople par les croisés et prononcé plusieurs discours sur cet événement ${ }^{1714}$.

L'historien des empereurs de Nicée est Georges Akropolitès, grand logothète et précepteur de Théodore II Lascaris. Sa Chronique

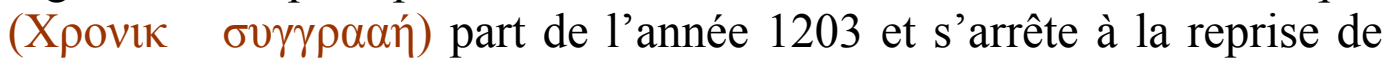

\footnotetext{
1712 Anne COMnene, Alexiade (Intr. Leib); Krumbacher op. cit., 274-279; ChAlAndon, I, Introd. VII-XXII; MORAVCSIK, I, 107-110. G. BUCKLER, Anna Comnena, 225 et s.

1713 Jean KinNAMOS, Epitome (éd. défectueuse); voir BABOS, Symbolae ad historiam textus Cinnami, Budapest, 1944. MORAVCSIK, I, 180-182.

1714 NiCETAS KHONIATES, Histoire; MORAVCSIK, I, 271 et s.
} 
Constantinople en $1261^{1715}$. L'histoire de la restauration de l'Empire est due aussi à un haut fonctionnaire, Georges Pachymère, dikaiophy-

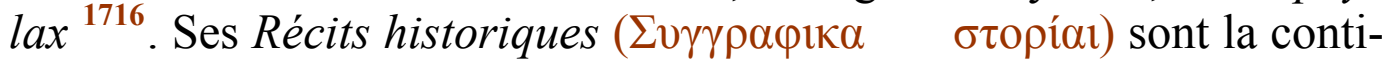
nuation de la Chronique d'Akropolitès de 1261 à 1308, comprenant le règne de Michel Paléologue (1261-1282) et les premières années d'Andronic II. D'une grande culture, il a composé des ouvrages de rhétorique, de physique, de philosophie, et il a eu un rôle littéraire important $^{1717}$.

L'histoire de l'Empire au XIV ${ }^{\mathrm{e}}$ siècle fut traitée par deux des hommes les plus illustres de leur temps, Nicéphore Grégoras et Jean Cantacuzène.

Nicéphore Grégoras est avant tout un savant, auquel aucune science de son temps, aucun genre littéraire n'étaient étrangers et, grâce à un esprit philosophique, il dominait les connaissances qu'il avait acquises. Sa vaste Histoire romaine en 37 livres prend les événements en 1204 pour les conduire jusqu'à 1359, quelques mois avant sa mort. La période de 1204 à 1320 est traitée sommairement en 7 livres, complétant et continuant la chronique de Pachymère. Par contre, 30 livres sont consacrés à son époque. Le développement qu'il donne à la querelle hésychaste, dans laquelle il a joué un si grand rôle, a la valeur de mémoires personnels. Il insiste sur les événements intérieurs, sur la guerre civile et néglige les faits extérieurs. Sa langue imite celle de Platon. Suivant l'usage de ses prédécesseurs, il emploie, pour suppléer au récit, les discours supposés qu'il considère comme « le miroir des actions », mais il cherche à faire connaître le caractère de ceux à qui il prête ces discours. Son ouvrage fut écrit en prison dans des conditions pénibles et il mourut sans pouvoir le mettre au point ${ }^{1718}$.

Les quatre livres d'Histoires de Jean Cantacuzène, qui donnent un récit des événements entre 1320 et 1356, furent écrits après son abdication et sont des Mémoires destinés à justifier ses actes et à combat-

\footnotetext{
1715 Georges AKropolites, Chronique; MorAVCSIK, I,137-139.

1716 Juge ecclésiastique, Archives de l'Athos Actes de Kutlumus, (éd. Lemerle), 21(27) et passim.

1717 PACHYMERE, Histoire; KRUMBACHER, op. cit.; renseignements importants sur l'histoire des Bulgares et sur les Mongols, MORAVCSIK, I, 148-150.

1718 NiCEPHORE GREGORAS, Histoire romaine; GuILland, Essai sur Nicéphore Grégoras, 228257; Krumbacher, 293 et s.; MoravcsiK, I, 275-277; N. IORGA, dans B.N., II, 293 et s.
} 
tre ses adversaires politiques. C'est ainsi qu'il attaque violemment Grégoras, qu'il protégea d'abord et qu'il abandonna pour des raisons politiques. Son histoire et celle de Grégoras racontent les mêmes événements, mais Cantacuzène oublie volontairement certains détails gênants pour sa réputation ${ }^{1719}$. En revanche son style est plus vivant et plus alerte. Il a pu se servir d'un journal de route et il insère dans son récit des documents intéressants ${ }^{1720}$.

$\mathrm{Au} \mathrm{XV} \mathrm{e}^{\mathrm{e}}$ siècle, deux historiens, Doukas et Phrantzès, ont laissé un récit de la fin de Byzance.

Doukas, figure énigmatique, qui, d'après ses renseignements, était au service de puissantes familles génoises de Galata, puis de Lesbos, a écrit une chronique populaire, d'Adam 1204. De cette date à 1359 il montre les progrès des Ottomans et suit leur histoire jusqu'en 1391. Il conte alors les règnes des trois derniers Paléologues et, après le récit de la prise de Constantinople, il suit les événements jusqu'à la conquête de Lesbos en 1462. Il est surtout l'historien des Turcs et c'est ce qui fait l'intérêt de son témoignage. Son style est exempt de rhétorique. Son instruction est moyenne et il compare des Turcs ou des Génois à des héros antiques, ce qui produit un effet un peu ridicule. Son vocabulaire est rempli de mots étrangers de toute provenance ${ }^{1721}$.

Georges Phrantzès, né en 1401, est, au contraire, un pur Hellène de Constantinople qui, après avoir fait de bonnes études, suivit la carrière des honneurs et occupa les premiers postes de ce qui était encore l'État byzantin, sous les derniers Paléologues. Il s'attacha surtout à Constantin, despote de Morée, qui devait être le dernier empereur de Byzance, et lui fut fidèle jusqu'au bout. Ce fut seulement en 1478, à l'âge de 77 ans, que, réfugié à Corfou, où il s'était fait moine, il écrivit, à la demande de ses amis, une Chronique en 4 livres, histoire de la dynastie des Paléologues depuis 1258 jusqu'à 1477. Le premier livre

\footnotetext{
1719 Jean CANTACUZENE, Histoire. Sur les divergences entre les deux historiens GuILLAND, Essai sur Nicéphore Grégoras, 251-255.

1720 Jean CANTACUZENE, IV, 5: texte en grec vulgaire des concessions faites par le sultan d'Égypte à Jean VI en 1349; M. CANARD dans Annales de l'Institut des Etudes Orientales de l'Université d'Alger, 1937; PARISOT, Cantacuzène, homme d'Etat et historien, 1845.

1721 DoukAs, Chronique universelle; KRUMBACHER, 303 et s.; MORAVCSIK, I, 126-128; TCHernousov dans V.V., XXI, 176 et s.; V. GRECU, Pour une meilleure connaissance de l'historien Doukas dans Mém. L.P., 128 et s.
} 
est un résumé des histoires antérieures, qui s'arrête à 1425. A partir de cette date, il écrit d'après ses souvenirs, ses notes, les documents qu'il a conservés. Il a participé lui-même aux événements qu'il raconte ou en a été le témoin oculaire ${ }^{1722}$.

L'Athénien Chalkokondylès, né vers 1432, représente la première génération byzantine ralliée au pouvoir ottoman. Dans ses Histoires qui vont de 1298 1463, c'est l'histoire de l'État turc qui occupe la première place, mais, fidèle aux traditions historiographiques de Byzance, il a pris pour modèles Hérodote et Thucydide ${ }^{1723}$.

Récits, souvenirs, biographies. - La littérature byzantine est riche en récits d'événements importants et en biographies, qui sont, en général, des sources de premier ordre, comme le récit de la prise de Jérusalem par les Perses en 634, dû à Antiochus le Stratège ${ }^{1724}$, ceux de la prise et du sac de Thessalonique, en 904, par des corsaires arabes (récit de Jean Kaméniatès), en 1185 par les Normands de Sicile (récit de l'archevêque Eustathe) ${ }^{1725}$. Citons encore le discours de Nicolas Mesaritès sur la tentative de Jean Comnène pour usurper le trône à la place d'Alexis III le 13 juillet $1201^{1726}$, plusieurs autobiographies de l'époque de Nicée de Nicéphore Blemmydès ${ }^{1727}$, du patriarche Grégoire de Chypre ${ }^{1728}$, de Michel Paléologue ${ }^{1729}$, et les Souvenirs ( $\pi$ o $\mu v \eta \mu v \varepsilon v ́ \mu \alpha \tau \alpha)$ de Sylvestre Syropoulos, grand ecclésiarque, sur le Concile de Florence ${ }^{1730}$.

1722 PhrantZes, Chronique (P.G., 156 et Papadopoulos); sur la chronique en grec vulgaire mise sous le nom de Phrantzès et qui n'est qu'un résumé de son histoire, fait au $\mathrm{XVI}^{\mathrm{e}}$ siècle, voir Papadopoulos, dans E.B., XV 87 et s., Gregoire, dans B.N. XII, 1937, 385 et MoravCSIK, $\mathrm{I}, 151$ et $\mathrm{s}$.

1723 Laonicos Chalkhokondyles, Histoire, (P.G., 159 et s éd. Darko, Budapest); MoravCSIK, I, 230 et $\mathrm{s}$.

1724 Antiochus le Stratege, Prise de Jérusalem par les Perses en 614 (connu seulement par des versions géorgiennes et arabes). — Voir PEETERS dans A.B., 1912, 304 et s.; 1920, 141 et s.

1725 Jean KAMENIATES, Sac de Thessalonique par les Arabes; KRUMBACHER, Geschichte der byzantinischen Ltteratur, I, 135; DUCHATEAU, Eustathe, archevêue de Thessalonique.

1726 MESARITES, Sur la tentative d'usurpation de Jean Comnène (inconnu des autres sources).

1727 NiCEPHORE BLEMMYDES [Autobiographie et oeuvres complètes] (1197-1272).

1728 GREGOIRE DE CHYPRE, Autobiographie.

1729 Dans le Typikon du monastère de St-Démétrius; trad. fr. dans CHAPMAN, Michel Paléologue, 1926, 167 et s.

1730 Syropoulos, Historia vera unionis non verae; JugIE, E.O., 38, 1939, 70 et s. 


\section{L'hagiographie}

Origines. - La biographie des saints a pour origine les Actes des martyrs (procès-verbaux de leur jugement, témoignages sur leur supplice). Elle devint, à partir du $\mathrm{IV}^{\mathrm{e}}$ siècle, un genre littéraire, soumis à des règles spéciales, dans lesquelles on reconnaît l'œuvre des rhé-

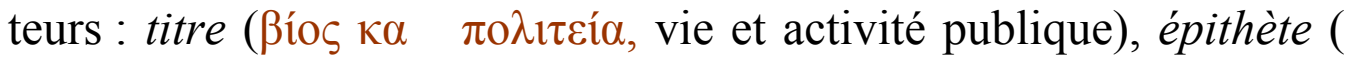

$v$ yíors $\pi \alpha \tau \quad \rho \quad \mu \quad v$, notre père d'entre les saints), préface, $p a-$ rents du saint, sa naissance, son nom, sa consécration dès sa naissance, sa situation de fortune, son éducation, ses exploits d'ascète, son histoire, les signes précurseurs et circonstances de sa mort, ses miracles, enfin la conclusion (comparaison fréquente avec les héros de l'Ancien et du Nouveau Testament) ${ }^{1731}$.

Tel est le schéma, presque obligatoire ; mais, au point de vue historique, il faut distinguer les vies écrites peu après la mort du saint, parfois par l'un de ses disciples, qui donne son nom ainsi que des détails sur sa famille, sa carrière, les circonstances dans lesquelles il a écrit la biographie de son maître ${ }^{1732}$, et, d'autre part, les panégyriques écrits longtemps après la mort du saint, purs exercices de rhétorique, composés parfois pour obtenir un grade universitaire ${ }^{1733}$. Les œuvres de la première catégorie donnent souvent des renseignements historiques précieux ou des détails vécus sur la société et les institutions ${ }^{1734}$. Les panégyriques sont de simples amplifications déclamatoires, du genre le plus banal, et sont dénués de valeur historique ou littéraire ${ }^{1735}$. Les recueils de Miracles, tenus à jour, comme ceux de saint Démétrius à Thessalonique, ont souvent, au contraire, une grande valeur, par les dates qu'ils donnent et les traits de mœurs qu'ils ont conservés.

\footnotetext{
1731 LopareV, Vizantiiskiia Jitii Sviatuik, V.V., 1910, 1-36; GuILland, Essai sur Nicéphore Grégoras, 173.

1732 LOPAREV, loc. cit., 36 et s.

1733 Voir ch. XIII : l'Enseignement.

1734 Par exemple les panégyriques écrits par Nicéphore Grégoras où il se montre «rhéteur dans toute l'acception du mot » (GuILLAND, op. cit., 174-192). Schéma analogue à celui des vies des philosophes du IV siècle, comme la vie de Proclus, par MARONIS DE TYR, O. SCHISSEL, Marinos von Neapolis und die neuplatonischen Tugenden.

1735 G. RouILLARD, L'administration de l'Égypte byzantine, 101-112.
} 
Valeur historique et littéraire. - La plupart des vies des saints, surtout celles de la première catégorie, étaient dues à des moines, soucieux de perpétuer la mémoire des ascètes, qui donnaient une réputation prestigieuse à leurs monastères, et d'encourager les vocations. La popularité même, dont jouissaient les moines, s'étendait à ces récits, qui formaient la lecture favorite de la société byzantine, surtout après le triomphe des images. Les vies de saints tiennent une place importante dans les catalogues de bibliothèques qui nous sont parvenus ${ }^{1736}$. En outre, malgré un plan stéréotypé, le charme de cette littérature était dû aux accents variés, aux méthodes les plus différentes qui s'y manifestaient, depuis l'observation précise de la réalité, jusqu'aux récits merveilleux, œuvres de pure imagination. Sans doute les vies des saints étaient avant tout des récits édifiants, mais pour mieux conquérir leurs lecteurs, les hagiographes présentaient sous une forme agréable la leçon qui s'en dégageait.

C'est ce qui explique la variété qui règne dans cette production; seuls nos romans peuvent en donner quelque idée peinture de la société, des mœurs des différentes classes, étude poussée et psychologie d'un caractère, récits d'aventures, contes fantastiques, tous les genres y sont représentés, tous les lecteurs suivant leur âge, leurs goûts, leur degré d'instruction, y trouvaient leur compte ${ }^{1737}$.

De certaines biographies qui font une large place à la peinture des mœurs, aux étapes de la carrière mondaine du futur saint, on pourrait tirer un tableau pittoresque du monde byzantin. Toutes les classes, toutes les conditions y sont représentées. La scène se passe quelquefois au Palais Sacré, où s'agitent les dignitaires de toute catégorie, dans les rues de Constantinople au milieu de la foule bigarrée, dans les provinces, où l'on pénètre dans des intérieurs bourgeois de petites villes, dans des exploitations rurales, dans des monastères. La vie de saint Hilarion le Géorgien (822-880), le récit de ses pèlerinages, de l'accueil hostile qu'il reçoit d'un higoumène, nous renseigne sur le monachisme errant, fertile en aventures, et sur la vie intérieure d'un monastère ${ }^{1738}$. Celle de saint Philarète le Miséricordieux, composée

\footnotetext{
1736 Comme celui de saint Jean de Patmos, XI ${ }^{\mathrm{e}}$ siècle, DieHL, Etudes byzantines, 321.

${ }^{1737}$ L. BREHIER, Le romantisme et le réalisme à Byzance [d'après les Vies des saints], 314 et s.; Bezobrazov, Contes byzantins dans V.O., 1915, 117 et. s.

${ }^{1738}$ Vie de saint Hilarion d'Ibérie, 236 et s.; LopAREV, op. cit., V.V., XVII, 56 (voir J.S., oct. 1916, 451 et s.).
} 
au début $\mathrm{du} \mathrm{IX}^{\mathrm{e}}$ siècle, décrit la vie d'un grand propriétaire foncier d'Asie, la coutume du concours de beauté, qui précédait le mariage de l'héritier du trône et la fortune prodigieuse des parents de celle qui avait été élue. Dans ce récit, écrit par un petit-fils de Philarète, il n'entre aucun élément merveilleux c'est une histoire réelle, qui aboutit au mariage de Constantin VI avec Marie d'Alanie en $788^{1739}$. La vie de saint Élie, martyrisé à Damas en 795, nous montre le destin tragique de l'esclave chrétien d'un riche marchand syrien, converti de force à l'islam et supplicié comme relaps ; la narration simple et sincère présente un tableau pittoresque de la vie qu'on menait en Syrie au temps d'Haroun-al-Raschid ${ }^{1740}$.

La vie de sainte Théodora de Thessalonique, écrite par son contemporain le prêtre Grégoire, nous introduit dans un monastère de moniales du $\mathrm{IX}^{\mathrm{e}}$ siècle et en montre les divers services et les occupations. L'intérêt du récit réside surtout dans le portrait que l'auteur trace de Théodora, dont il montre l'avancement progressif dans la vie religieuse. Veuve à 25 ans, elle accepte les plus basses besognes. Sa mère était déjà dans ce couvent, mais, pour les éprouver, la supérieure leur défend tout rapport et elles restent 15 ans sans se voir. Théodora supporte toutes les avanies : pour avoir déplacé la natte sur laquelle elle couche, dans la salle du chauffoir, elle se laisse condamner à passer la nuit dehors, exposée au vent, à la pluie, à la neige. Cette biographie, qui abonde en détails pittoresques, présente en même temps, avec beaucoup de délicatesse, la psychologie d'une sainte ${ }^{1741}$.

Récits d'aventures. - Enfin les aventures romanesques, les récits de pure imagination ne sont pas rares dans l'hagiographie, en particulier au $\mathrm{IX}^{\mathrm{e}}$ siècle. Parfois, comme dans les récits des Mille et Une Nuits, comme dans les romans picaresques, chaque personnage introduit dans le récit raconte ses propres aventures, et ces digressions, qui sont de véritables nouvelles, n'ont aucun rapport avec le sujet. Tel est, dans la vie de saint Nicolas le Studite (mort en 868), le récit d'un ermite, qui, étant scholaire dans la garde impériale, assista miraculeusement, sans y prendre part, à la défaite de Nicéphore I et au massacre

\footnotetext{
1739 Nomos Georgikos [Loi agraire], 134 et s.

1740 Vie de saint Elie, martyr à Damas, 36 et s.

1741 Vie de sainte Théodora de Salonique; Loparev, op. cit., et J.S., XV, 1917, 19-20; L. BREHIER, op. cit., 324 et s.
} 
de l'armée romaine par les Bulgares en 811, et vit l'endroit où il serait tombé, s'il avait participé à la bataille ${ }^{1742}$.

De tous ces récits, le plus merveilleux est la Vie de saint Théodore, archevêque d'Édesse, composée probablement en arabe dans un monastère mésopotamien. C'est un véritable roman, dans lequel se succèdent les digressions et les aventures : histoire du martyr Michel à Jérusalem, victime d'un roi et d'une reine de Perse venus en Palestine pour visiter le Saint Sépulcre ; histoire du stylite Théodose qui vivait depuis 95 ans sur une colonne des environs d'Édesse; conversion d'un calife de Bagdad par l'archevêque d'Édesse; nouveau récit fait au calife par le Stylite Théodose, qui lui décrit les merveilles de l'Inde et les ermites qu'il a vus sur les bords du Gange, réfugiés dans des amphores gigantesques couchées sur le côté, que les hommes d'autrefois avaient fabriquées ; massacre du calife qui déclare publiquement sa foi chrétienne ${ }^{1743}$.

Avec la Vie de Léon, évêque de Catane, on est en plein conte fantastique, dans lequel un mage, Héliodore, après avoir fait un pacte diabolique, se déplace à volonté en prononçant quelques mots. Il mystifie ainsi la population de Syracuse, assure la victoire de son neveu à l'Hippodrome, grâce à un cheval enchanté, etc. L'évêque arrive à lui passer son étole autour du cou et le conduit au bûcher ${ }^{1744}$.

Tout au contraire la Vie de Pierre, évêque d'Argos, mort vers 920, célèbre les exploits et les miracles d'un ascète, dont les trois frères et la sœur mènent sous sa direction la vie monastique à Constantinople. Son grand intérêt est de nous transmettre des faits historiques peu connus, contemporains de l'épiscopat de Pierre ; les incursions et les ravages des pirates arabes de Crète, l'occupation de la Morée pendant trois ans par un peuple barbare resté païen (probablement des tribus slaves au service du tsar Syméon), puis une terrible famine. L’évêque Pierre, averti miraculeusement de ces désastres, convertit les barbares

\footnotetext{
1742 Vie de saint Nicolas le Studite, 864 et s.; BREHIER, op. cit., 326-27.

1743 Vie de saint Théodore d'Édesse; LopAREV, op. cit., V.V., XIX, 41 et s.; J. GoulLLARD, Supercheries et méprises littéraires dans R.E.B., 1947, 137-157 (regarde cette biographie comme l'œuvre d'un faussaire qui se dit neveu de Theodore et évêque d'Émèse; il se vante d'avoir baptisé le calife); VASILIEV, The life of saint Theodore of Edesse, dans B.N., XVI, 1942-43, 165-225. (Théodore a réellement existé et a été en rapports avec Théodora et Michel III); sa vie, écrite en arabe, fut traduite en grec.

1744 Vie de Léon le Thaumaturge, archevêque de Catane ; BREHIER, op. cit., 331 et s.
} 
au christianisme et parvient à alimenter les populations de la péninsule ${ }^{1745}$.

Saint Pierre d'Argos fait partie d'un groupe de saints du Péloponnèse, dont les biographies, riches en traits de mœurs, nous renseignent sur les destinées de la péninsule au $\mathrm{X}^{\mathrm{e}}$ siècle. Nous avons déjà recueilli le témoignage de la vie de saint Nikon le Métanoïte sur Sparte ${ }^{1746}$; on peut y joindre ceux des biographes de saint Luc le Stylite (mort vers 949), de Marthe, abbesse de Monemvasia.

$\mathrm{Au} \mathrm{XI}{ }^{\mathrm{e}}$ siècle Syméon Métaphraste, magistros et logothète, entreprit de rassembler les vies des saints et de leur donner une forme plus littéraire, qui plairait au public lettré de Byzance. Une partie d'entre elles fut transcrite presque sans modification; d'autres furent remaniées en style noble. Cet ouvrage eut un grand succès ${ }^{1747}$, et Psellos prononça l'éloge funèbre de son auteur ${ }^{1748}$.

L'exemple de Métaphraste devait être funeste à l'hagiographie. Après le $\mathrm{XI}^{\mathrm{e}}$ siècle il y a encore des canonisations, d'ascètes, de fondateurs de monastères et même d'empereurs, comme celle de Jean Vatatzès le Miséricordieux ${ }^{1749}$. Les nouveaux saints trouvent des biographes, mais ce sont surtout des rhéteurs, qui préfèrent les ornements aux faits précis, le beau langage à l'histoire. L'hagiographie n'est plus qu'un exercice littéraire.

\section{Récits apocryphes. Romans}

Le goût des Grecs et des Orientaux pour les œuvres d'imagination explique l'immense succès des textes apocryphes, destinés à compléter les Écritures, à développer, à imaginer les détails, les épisodes de

\footnotetext{
1745 Vie de saint Pierre d'Argos, 163 et s.

1746 Vie de saint Nikon le Métanoïte, voir supra, p. 127 et s.; Vie de saint Luc le Stylite.

1747 KRUMBACHER, Geschichte der byzantinischen Literatur, 200-203; SYMEON METAPHRASTE, Sur les vies des saints (P.G., 114-116)

1748 Psellos, Discours..., IV, P.G., XCIV, 183-205. Sur l'époque de sa vie; Eustratiades dans E.B., 1933, 26 et s. (XI siècle); JuGIE dans E.O., 1923, 5-10 (2 ${ }^{\mathrm{e}}$ moitié du X $\mathrm{e}^{\mathrm{e}} \mathrm{s}$ ).

1749 Vie de saint Jean Vatatzès et A. HeISENBERG, Johannes Batatzes der Barmherzige; l'auteur est un moine qui donne quelques dates historiques, mais surtout par allusion.
} 
l'Ancien et du Nouveau Testament que le texte sacré passe sous silence ou raconte trop brièvement.

La plupart de ces apocryphes datent des premiers siècles de l'ère chrétienne et avaient été écrits en syriaque et en arabe, avant d'être traduits en grec; quelques-uns avaient été composés pour justifier une doctrine hérétique, ébionite ou marcionite. Ce qui nous intéresse surtout c'est la popularité dont les apocryphes du Nouveau Testament ont joui à Byzance, où non seulement ils étaient lus à toutes les époques ${ }^{1750}$, mais où ils inspiraient l'art religieux en général et, plus particulièrement, celui des monastères d'Orient (Cappadoce et autres régions), dont les thèmes furent adoptés à Constantinople et dans toute la Grèce au XIV ${ }^{\mathrm{e}}$ siècle ${ }^{1751}$. Loin d'être fixées comme les Évangiles canoniques, ces légendes continuaient à s'enrichir de nouveaux détails en pleine période byzantine. C'est ainsi que le Protévangile de Jacques, œuvre d'un chrétien hellénisant du second siècle, a reçu des additions au $\mathrm{V}^{\mathrm{e}}$ siècle, notamment la légende de Zacharie ${ }^{1752}$.

C'est par cet évangile, regardé par l'Église grecque comme canonique, que l'on connait les parents de la Vierge, sa jeunesse dans le Temple, ses fiançailles avec Joseph, l'âne et le bœuf de la crèche, qui se trouve dans une grotte, la montagne donnant asile à Elisabeth et à Jean pendant le massacre des Innocents, l'eau de l'épreuve bue par Marie et Joseph. Tous ces épisodes, gracieux ou tragiques, se succèdent dans les frises de peinture des églises archaïques, dans les monastères rupestres de la région d'Urgub ${ }^{1753}$.

Dans l'Évangile de l'Enfance, d'origine égyptienne, Jésus, malgré son jeune âge, guérit des possédés, ressuscite un de ses camarades qui s'est tué en tombant d'un toit, pétrit de la terre glaise et en fait des oiseaux auxquels il donne la volée. Un de ses camarades le bat et il pleure : c'est sa première rencontre avec Judas Iscariote. D'une grandeur épique est l'Évangile de Nicodème, dans lequel deux morts ressuscités racontent la Descente de Jésus aux Enfers, la délivrance d'Adam, des patriarches, des saints qui glorifient le Christ avec les

${ }^{1750}$ Ceux de l'Ancien Testament avaient moins de vogue (Livre d'Adam, Livre d'Hénoch, etc.) mais inspiraient parfois les artistes D.A.C.L., VI, 2245.

1751 Apocryphes de l'Ancien et du Nouveau Testament (Dictionnaire des), trad. Migne. Voir chap. XIV.

${ }_{1752}$ Protévangile de Jacques (éd. Amann), 99 et s. (Introd.).

1753 JeRPHANION, Les églises rupestres de Cappadoce, I, p. 269, pl. 65 et p. 75-80. 
prophètes. Saint Michel les introduit au Paradis, où ils sont accueillis par Hénoch et Elie, tous deux enlevés au ciel. Le thème iconographique de l'Anastasis (Résurrection), qui a produit des chefs-d'œuvre artistiques, n'est que l'interprétation figurée de cet évangile ${ }^{1754}$. C'est aussi un apocryphe qui a inspiré le thème de la Dormition (Koimesis) : les Apôtres réunis autour du lit funéraire de Marie, dont Jésus est venu chercher l'âme ${ }^{1755}$.

Ce n'est là, d'ailleurs, qu'un aperçu des apocryphes les plus célèbres. Le nombre prodigieux de ces textes s'accroît chaque jour par de nouvelles découvertes ${ }^{1756}$.

Romans en prose. - Le roman est un récit d'aventures, qui obéit à certaines traditions : il comporte un héros ou une héroïne, dont les amours sont contrariées et qui échappent à de multiples dangers, non par leur courage, mais grâce à l'intervention de protecteurs puissants ou de brigands généreux. Les caractères ne sont pas tracés et on ne voit pas si les auteurs sont païens ou chrétiens, bien que les héroïnes soient des modèles de vertu ${ }^{1757}$. Ce genre tout à fait romantique date de la fin de l'antiquité et a pu s'inspirer des contes égyptiens. On le retrouve à Byzance, où Héliodore, évêque de Trika en Thessalie sous Arcadius, écrivit l'Histoire Ethiopique ou les Amours de Théagène et de Chariclée ${ }^{1758}$, dont la traduction en français par Jacques Amyot (Paris, 1549, 1559, 1575, 1583) enchantait le jeune Racine à PortRoyal. Ce roman, dans lequel le héros et l'héroïne échappent successivement à la mort dans des circonstances merveilleuses, eut un grand succès à Byzance et, au XV $\mathrm{XV}^{\mathrm{e}}$ siècle, un grave personnage comme Jean Eugénikos, nomophylax de Trébizonde, composait une préface en vers ïambiques à l'œuvre d'Héliodore ${ }^{1759}$. Les Histoires de Leucippe et de Clitophon, d'Achille Tatius, sont de la même époque et de la même veine. La gracieuse et naïve pastorale de Longus, Daphnis et Chloé, est plus ancienne, mais a connu aussi le succès à Byzance. L'engouement de la société byzantine pour ce genre littéraire ne cessa

\footnotetext{
1754 Voir supra, icônes, p. 239.

1755 Au VI ${ }^{\mathrm{e}}$ siècle Grégoire de Tours connaît un Transitus Beatae Mariae importé de Syrie. — Von TISCHENDORF, Apocalypses apocryphae, 266-268; SINDING, Mariae Tod und Himmelfahrt, Copenhague, 1903.

1756 Évangile de Pierre, éd. Grébault, 1892, qui l'a découvert en 1886 à Alexandrie, etc., D.A.C.L., Apocryphes.

1757 HeSSELING, Essai sur la civilisation byzantine, 77.

1758 Socrate, Histoire ecclésiastique, V, 22, confirme l'attribution à Héliodore, de même PHOTIUS, Bibliothèque, cod. 73.

1759 KRUMBACHER, op. cit.,494.
} 
de se manifester par de nouvelles œuvres, mais on préféra les romans en vers, dont on voit déjà un exemple au $\mathrm{v}^{\mathrm{e}}$ siècle dans le Cyprien d'Antioche de l'impératrice Eudokia-Athénaïs (421-460). Son intérêt provient de ce qu'à la différence des œuvres précédentes, le christianisme intervient dans la donnée. Il s'agit d'un magicien qui abjure publiquement ses erreurs, se convertit au christianisme et devient évêque d'Antioche ${ }^{1760}$.

Barlaam et Joasaph. - Une œuvre étrange qui tient du roman et de l'hagiographie est la vie de Barlaam et de Joasaph, considérés comme des saints et fêtés le 27 novembre (calendrier romain) et le 26 août par les orthodoxes.

Ce récit nous transporte dans l'Inde, où le roi Abenner, grand persécuteur des chrétiens, apprend de ses astrologues que son fils Joasaph se convertira au christianisme. Pour démentir cette prédiction, le roi enferme Joasaph dans un palais merveilleux, où au milieu de plaisirs continuels, il ignorera la nécessité et l'instabilité des choses humaines. Mais le jeune prince s'ennuie dans cette cage dorée et le roi, inquiet, le laisse sortir : au cours d'une chasse, il rencontre un lépreux et un aveugle et, quelques jours après, un vieillard. Il interroge ses compagnons et apprend à connaître les misères de l'homme. Il y pense sans cesse, lorsqu'un ermite chrétien, Barlaam, déguisé en marchand, parvient à pénétrer jusqu'à lui. Après lui avoir raconté la parabole du semeur, il lui expose la foi chrétienne et le convertit, à la grande colère du roi, qui chasse Barlaam, mais ne peut empêcher Joasaph de se faire baptiser. Il lui donne alors la moitié de son royaume. Joasaph convertit son père et, après sa mort, se retire au désert où il rencontre Barlaam. Tous deux mènent la vie ascétique et, après leur mort, de nombreux miracles s'accomplissent sur leur tombe.

Dès la fin $\mathrm{du} \mathrm{XVI}^{\mathrm{e}}$ siècle un historien, Diégo Conto, avait constaté que la légende de Joasaph était un démarquage de celle du Bouddha, Gautama, fils d'un puissant roi, auquel des Brahmanes ont prédit qu'il serait plus tard un ascète. Son père l'enferme dans un palais, mais il en sort, rencontre en chemin la vieillesse, la maladie et la mort, s'enfuit au désert où il mène la vie d'un ascète, puis ayant compris le néant de toute chose, parvient à la vraie sagesse, au nirvanâ. La rédacteur chrétien a repris la plupart de ces traits et introduit dans la légende l'ermite Barlaam ${ }^{1761}$.

${ }_{1760}$ Eudociae Augustae carminum reliquiae (éd. Ludwich).

1761 Vie de Barlaam et Joasaph; SIRARPIE TER NERSESSIAN, L'illustration du roman de Barlaam et Joasaph et J.S., 1939, 42-45. 
On sait aujourd'hui que le texte grec, dont le plus ancien manuscrit, celui du monastère de Saint-Sabas de Jérusalem, date du XI ${ }^{\mathrm{e}}$ siècle, est une traduction d'une version géorgienne, exécutée par Euthyme, moine d'Iviron, mort en $1028^{1762}$. Nos connaissances s'arrêtent là, mais il a existé certainement des versions beaucoup plus anciennes, comme le montrent des allusions à des controverses théologiques, périmées au XI siècle (question monothélite, vénération des images, passages transcrits du traité de saint Jean Damascène sur la foi orthodoxe). Beaucoup de traits de mœurs et plusieurs apologues (le rossignol et le chasseur, l'homme fuyant la licorne) laissent supposer que la légende hindoue a été transmise par la Perse.

On ignore en quelle langue était l'archétype, mais il était tout au moins du VII ${ }^{\mathrm{e}}$ siècle et ne devait pas être grec, car aucune allusion n'est faite à cette légende dans la littérature byzantine avant le $\mathrm{XI}^{\mathrm{e}}$ siècle. Ce qu'on peut constater, c'est sa singulière fortune ; elle se répandit dans toute l'Europe et fut traduite dans toutes les langues ${ }^{1763}$. Le manuscrit illustré d'Iviron (fin $\mathrm{XII}^{\mathrm{e}}-\mathrm{XIII}^{\mathrm{e}}$ siècle) porte dans ses marges une traduction dans le français savoureux du début du XIII ${ }^{\mathrm{e}}$ siècle, œuvre de quelque clerc qui se trouvait parmi les croisés de $1204{ }^{1764}$.

\section{Pamphlets. Satires}

\section{$\underline{\text { Retour à la Table des Matières }}$}

Nous savons déjà que le despotisme impérial, malgré le respect officiel dont il était l'objet, n'en était pas moins exposé à une opposition, qui se traduisait parfois par des moqueries et des pamphlets ${ }^{1765}$. Quelques-uns de ces libelles ont une valeur littéraire et montrent l'esprit caustique des habitants de Constantinople. Mais même dans ces pièces, qui offraient à l'époque de leur composition un intérêt

\footnotetext{
1762 Vie de Barlaam et Joasaph, Introd. Zotenberg regardait le texte grec comme le plus ancien et le datait du VII ${ }^{\mathrm{e}}$ siècle, mais en 1888 Marr découvrit la version géorgienne du $\mathrm{X}^{\mathrm{e}}$ siècle.

1763 On en connaît 60 versions. SIRARPIE TER NERSESSIAN, op. cit., Introd. et bibliographie. Popularité de l'apologue de la Licorne. Nombreuses reproductions artistiques, par ex. au Baptistère de Parme.

1764 P. MeYer dans B.E.C. 1866; trad fr. de Jean de BILly Paris, 1578, reproduite dans le Dictionnaire des Légendes du Christianisme.

1765 M.B.E.H. (Vie et mort de Byzance), 1969, p. 51 et (Institutions), 1970, p. 152.
} 
d'actualité, l'imitation et même le démarquage de l'antique ne perdaient pas leurs droits.

Un auteur surtout était recherché pour ce genre de littérature. C'était Lucien, dont les lettrés admiraient le style, la verve, les bons mots, les ridicules prêtés aux despotes et aux grands hommes d'autrefois. Lucien était un des auteurs les plus lus à Byzance et l'imitation de ses œuvres était si littérale que des copistes insérèrent plusieurs pièces byzantines dans ses manuscrits ${ }^{1766}$.

Tel est le cas du dialogue intitulé Philopatris (le Patriote), qui met en scène des païens convertis, mais fait allusion à des événements du règne de Nicéphore Phocas: massacres en Crète, succès contre les Arabes, prochaine soumission de l'Égypte, danger d'une invasion de Scythes (Russes) écartée, mécontentement contre la sévérité du basileus et contre le clergé, qui refuse de laisser toucher aux biens d'église pour soutenir la politique de l'Empire. La date, regardée longtemps comme douteuse, peut être fixée à la fin du règne de Nicéphore Phocas (969) ${ }^{1767}$.

C'est aussi de Lucien que procèdent les Descentes aux Enfers, qui ouvraient un large champ à la raillerie. Celle de Timarion est précédée d'un voyage à Thessalonique, où il assiste à la fête de saint Démétrius. A son retour à Constantinople il est pris d'une crise violente, les

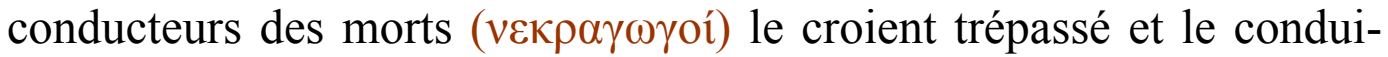
sent dans l'Hadès, où il trouve le décor classique de l'Enfer païen, mais il n'est pas mort (il n'a perdu qu'un élément de la bile). Cependant, il doit comparaître devant le tribunal de l'Hadès où, à côté de Minos, se trouvent Esculape, Hippocrate, d'autres médecins et l'empereur Théophile, assisté de son ange gardien. Il est naturellement renvoyé sur terre, mais il profite de sa visite pour lancer quelques brocards à ceux qu'il reconnaît. Il se moque du discours de Psellos, qui compare Constantin Monomaque au Roi-Soleil. Il retrouve son maître de rhétorique, qui avoue que la nourriture frugale des Enfers est plus favorable à sa santé que les copieux festins auxquels les empereurs

1766 Ed. HASE dans N.E.M. IX, 1813, 125.

1767 Id., avec LEON LE DiACRE, (Histoires) 459-461 dans P.G., 117; S. REINACH dans R.A., 1902,I. 
l'invitaient. Il voit les grands philosophes de l'antiquité, qui repoussent Diogène comme cynique et Jean l'Italien comme Galiléen ${ }^{1768}$.

Le Séjour de Mazaris dans l'Hadès est un pamphlet du début du $\mathrm{XV}^{\mathrm{e}}$ siècle, qui dévoile et stigmatise les intrigues dont la cour de Manuel II Paléologue est le théâtre et met en garde le basileus contre la bassesse des habitants du Péloponnèse. L'auteur suppose que, transporté aux Enfers, il y est accueilli par le rhéteur et secrétaire impérial Manuel Holobolos, auquel il raconte toutes les nouvelles de la cour. Son interlocuteur lui conseille de retourner sur la terre et de se retirer dans le Péloponnèse, où, dit-il ironiquement, il est aisé de faire fortune. Mazaris place son voyage dans l'Hadès en 1414 et il envoie à l'empereur ce pamphlet haineux, dans lequel les plus grands personnages sont couverts de boue, au moment où Manuel II va quitter le Péloponnèse, qu'il vient d'inspecter (entre octobre 1415 et mars 1416) ${ }^{1769}$.

$\mathrm{Au} \mathrm{XII}{ }^{\mathrm{e}}$ siècle, Théodore Prodrome composa plusieurs dialogues en prose à la manière de Lucien, qu'il démarqua sans vergogne, en représentant Zeus vendant à l'encan des hommes célèbres de la Grèce antique avec l'assistance d'Hermès ${ }^{1770}$.

Parfois des querelles privées se terminaient par des échanges d'écrits satiriques que leurs auteurs avaient soin de faire connaître au public. Psellos, dont la brillante fortune excitait la jalousie, était passé maître dans l'art d'invectiver ses adversaires, non d'ailleurs sans grossièreté. Ce sont des grenouilles qui coassent, des chiens qui aboient, des bûches qui leur donnent la réplique ${ }^{1771}$. Quand il quitta le monastère de l'Olympe, où il s'était réfugié, un moine, Jacob, composa un quatrain dans lequel il comparait le philosophe à Zeus, incapable de supporter le séjour de l'Olympe, où il est privé de ses belles déesses. En réponse, Psellos lui assena une longue satire, qui était une parodie du canon de la messe, les premières lettres de chaque verset formant

\footnotetext{
1768 TheOpHYlaCte DE SimoCATTA, Histoire, 144-146; KRUMBACHER, 467 et s.

1769 MAZARIS, Dialogos nekritos [Descente aux enfers]; TREU, Mazaris und Holobolos, dans B.Z., 1892, 86-97; sur le voyage de Manuel II dans le Péloponnèse, auquel il fait allusion: ZAKITHINOS, Le despotat grec de Morée, 168 et s.

1770 TheOdore Prodrome, Dialogues imités de Lucien, éd. Laporte du Theil.

1771 Psellos, Discours..., V, 168-170; RAMBAud, Etudes sur l'histoire byzantine, 141 et s.
} 
l'acrostiche: «Cet ivrogne de Jacob je le chante harmonieusement ${ }^{1772}$. »

Le basileus Théodore II Lascaris compte parmi les écrivains satiriques. On a de lui une Défense contre ceux qui voulaient le forcer à se

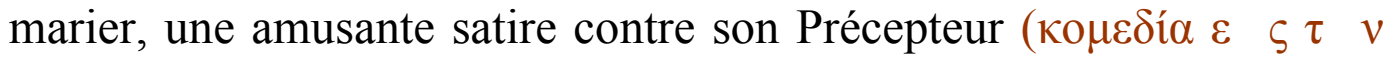
$\beta a \gamma 10 \quad \lambda \circ v a$ to ), une description plaisante de sa réception à Philadelphie par un notable drôlement accoutré, qui, juché sur un mulet, lui fait une harangue amphigourique ${ }^{1773}$.

Un spécimen de querelle entre deux érudits de haute valeur est, vers 1350, le pamphlet de Nicolas Cabasilas «Contre les élucubrations de Nicéphore Grégoras ». Il se moque des névralgies de Grégoras, de sa manie de citer pêle-mêle Esope, Homère, Aristophane, d'imiter la langue de Platon, de se donner l'air d'un prophète en citant les oracles chaldéens, de remplir sa maison d'appareils d'astronomie pour faire admirer sa science ${ }^{1774}$. Byzance connaissait déjà Vadius et Trissotin ${ }^{1775}$.

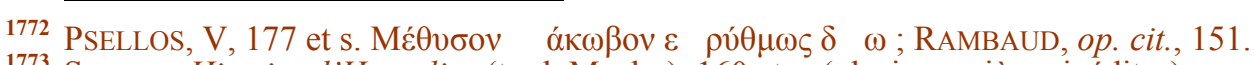

1773 SEBEOS, Histoire d'Heraclius (trad. Macler), 160 et s. (plusieurs pièces inédites).

1774 GuILlAND, Essai sur Nicéphore Grégoras, 170 (inédit).

1775 Cf. la polémique entre Nicéphore Chumnos et Théodore Métochitès sur leurs ouvrages respectifs (après 1321). Voir Ihor Sevšenko dans B.A.B.L., 1949, 473 et s.
} 


\title{
Chapitre XI
}

\author{
La poésie
}

\section{La poésie savante}

\section{$\underline{\text { Retour à la Table des Matières }}$}

La poésie savante est ce que la littérature byzantine a produit de plus médiocre. On ne peut lui attribuer aucune œuvre qui puisse être comparée aux chefs-d'œuvre des littératures occidentales du moyen âge. La raison de cette indigence est, chez ceux qui versifiaient, le manque de souffle poétique, l'absence de toute émotion sincère. En général, si certaines pièces ont un charme exceptionnel, c'est à un modèle antique qu'elles le doivent.

Avec ses règles immuables fixées par les anciens, la poésie était regardée comme un cadre commode pour traiter toute espèce de sujets : l'histoire, le droit, les sciences, le roman, les thèmes religieux. On mettait en vers l'Écriture sainte et souvent ce n'était qu'un procédé mnémotechnique. A côté de longs poèmes en plusieurs chants, la production poétique comprenait un nombre prodigieux de pièces de circonstance, réduites parfois à un quatrain ou même à un distique : éloges, monodies, épigrammes, etc., de la plus pure tradition d'Alexandrie.

La prosodie. - La métrique byzantine était fondée comme celle des anciens sur la quantité et la césure, mais, habitués à parler et même à écrire la langue vulgaire, les poètes avaient plus de respect superstitieux pour l'antiquité classique que de connaissance réelle de la prosodie, dont ils ne s'assimilaient pas toujours les règles. 
Rappelons qu'à ses origines, la poésie était chantée et que la quantité était le temps plus ou moins long que l'on mettait à prononcer une syllabe, d'où la distinction entre syllabes longues et brèves. On appelait pied $(\pi \circ v \zeta$ ) un groupe de syllabes contenant un temps fort, et mètre ( $\left.\mu \varepsilon^{\tau} \tau \rho \mathrm{v}\right)$, le groupe de deux temps forts, qui correspondait à une mesure.

Les pieds les plus usités dans la poésie byzantine étaient le trochée (longue et brève, - U), l'ïambe (brève et longue, $\mathrm{U}-$ ), le dactyle (longue et 2 brèves, - U U), le spondée (2 longues - - ). Comme mètres on employait surtout l'ancien trimètre ïambique, vif, léger, énergique, propre à l'art dramatique, comprenant en principe six ïambes, divisés en trois groupes de deux pieds : en fait, c'était simplement un vers de douze syllabes, car la plupart des poètes n'observaient la quantité qu'à la fin du vers et pour l'œil ; quelques-uns s'en abstenaient même tout à fait ${ }^{1776}$.

L'hexamètre dactylique d'Homère et de la poésie épique (Apollonius de Rhodes) était rarement employé. Par contre, le distique élégiaque, fait de l'alternance d'un hexamètre et d'un pentamètre, est en usage dans les hymnes ${ }^{1777}$. On trouve aussi le mètre anacréontique, vers ïambique de trois pieds et demi, dont le deuxième et le troisième sont nécessairement des ïambes ${ }^{1778}$.

Dans le vers politique, la quantité est complètement négligée ; il est construit $d$ 'après le rythme et l'accent tonique, mais se distingue de la poésie rythmique par la constance du même nombre de pieds dans tous les vers d'une même pièce. La dimension de ce mètre est d'ailleurs variable. Le plus usité est le vers de quinze syllabes, avec l'accent sur la deuxième syllabe du pied, et la césure après la huitième syllabe ${ }^{1779}$. Il est peu employé avant le $\mathrm{X}^{\mathrm{e}}$ siècle, mais se trouve déjà dans les acclamations des dèmes et les invectives contre Maurice ${ }^{1780}$.

\footnotetext{
1776 P. MAAS, Der byzantinische Zwölfsilber, dans B.Z., XII, 278; KRUMBACHER, op. cit., 648 et s.

1777 JeAn LE GeOMETRE, Poésies: "Hymne à la Vierge, » conclusion en trimètres iambiques; le pentamètre représente la nature humaine, l’hexamètre, la nature divine du Christ; KRUMBACHER, 734.

1778 Employé par Théodore Prodome.

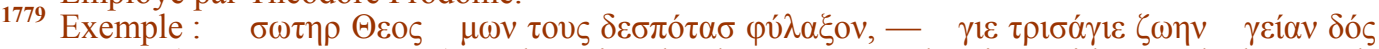

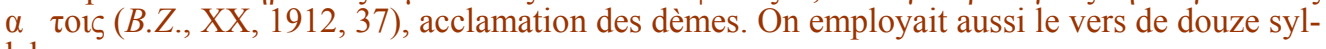
labes.

1780 P. MAAS, Metrische Akklamationen, dans B.Z., 1912, 31-35.
} 
Les genres. Poèmes didactiques. - Ce système artificiel fut appliqué à tous les genres, même à ceux qui comportent le moins le souffle poétique.

Georges Pisidès, diacre et chartophylax de Sainte-Sophie, contemporain d'Héraclius, a mis en vers le premier chapitre de la Genèse, L'œuvre des Sept Jours (Hexaemeron), 1900 trimètres ïambiques, en s'inspirant des commentaires des Pères de l'Église, de la Topographie chrétienne de Kosmas et, pour expliquer les phénomènes naturels, des œuvres d'Aristote et d'Elien ${ }^{1781}$. Il s'est servi du même mètre pour raconter l'histoire des campagnes d'Héraclius en Perse et, pour obéir à la loi du genre, a décoré ses récits de fleurs de rhétorique. Une invocation à la Trinité est suivie d'une digression sur Homère. Il compare Héraclius à Moïse, combattant un nouveau Pharaon, et à Héraklès, lorsqu'il renverse Phocas. Il jouit à Byzance d'une grande réputation et Psellos se demandait lequel, d'Euripide ou de Pisidès, était le plus grand poète.

Des poèmes allégoriques, dans lesquels des idées abstraites étaient personnifiées, ne sont pas rares. Un Miroir (Dioptra) du moine Philippe le Solitaire décrit en quatre chants et en 1700 vers les combats de l'Ame et du Corps ${ }^{1782}$. Au début du XIV ${ }^{\mathrm{e}}$ siècle, un Méliteniotès compose un poème de 3060 vers politiques Sur la Sagesse (E $\varsigma \tau \quad v$

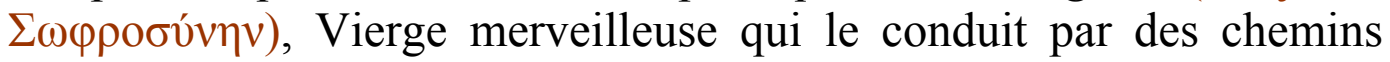
difficiles, défendus par des animaux fantastiques, jusqu'au château resplendissant que Dieu lui a donné pour demeure et dont aucun détail architectural ou ornemental ne nous est épargné. Sur les murs du parc on voit tous les dieux de l'Olympe avec leurs attributs et les héros de l'Ancien Testament. Le poète, au reste inconnu, a déversé dans son œuvre une immense somme de renseignements, dus à sa vaste érudition, mais ce poème indigeste est aussi froid que notre Roman de la rose, avec lequel il a beaucoup d'analogie ${ }^{1783}$. Ce genre d'exercices eut beaucoup de succès dans les derniers siècles de Byzance. La description allégorique des mois de l'année, inspirée de Théodore de Ga-

\footnotetext{
1781 Georges Pisides, Poèmes; KRUMBACHeR, 710 et s.

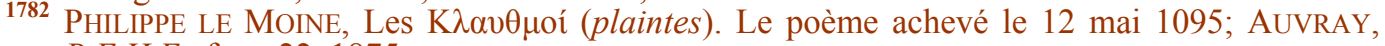
B.E.H.E., fasc. 22, 1875.

1783 Meliteniotes, Sur la Sagesse païenne; KRUMBACHER, 782-784.
} 
za, se trouve dans plusieurs manuscrits où les mois latins (ou attiques) sont représentés avec leurs attributs ${ }^{1784}$. Alexis Comnène a adressé à son fils Jean une sorte de testament politique en vers ïambiques ${ }^{1785}$. Théodore Métochitès a laissé vingt poèmes en hexamètres, adressés à des personnages de son temps et notamment à Nicéphore Grégoras ${ }^{1786}$.

Épigrammes et Anthologies. - L'épigramme, pièce assez courte pour être gravée sur un monument ou une œuvre d'art, était un des genres favoris de la poésie byzantine. Elle avait été très cultivée dans l'antiquité et elle devint un genre littéraire à Alexandrie où l'on prit plaisir à composer des épigrammes, sans qu'elles fussent destinées à être gravées ${ }^{1787}$. De là naquirent les anthologies, recueils d'épigrammes, tels que la Couronne de Méléagre de Gadara (Palestine), qui y inséra ses propres vers, presque tous érotiques, et ceux de trente-sept poètes, ses devanciers, d'Archiloque à ses contemporains ( ${ }^{\text {er }}$ siècle avant notre ère). Son exemple fut suivi à l'époque impériale romaine et c'est presque toujours par des compilateurs byzantins que nous connaissons ces recueils ${ }^{1788}$.

Ce genre fut accueilli avec faveur à Byzance et cultivé en particulier aux époques de renaissance littéraire, $\mathrm{au} \mathrm{VI}^{\mathrm{e}}$ siècle par l'historien de Justinien, Agathias de Myrina, qui pour la première fois classa les pièces par sujets ${ }^{1789}$ : épigrammes votives, descriptives, funéraires, anecdotiques, satiriques, amoureuses, bachiques. $\mathrm{Au} \mathrm{IX}^{\mathrm{e}}$ siècle, marqué par l'activité littéraire de Photius et de l'Université de Bardas, Constantin Céphalas, protopappas du Palais, composa avant 900 une nouvelle Anthologie ${ }^{1790}$. Une révision, édition revue et augmentée, en fut faite en 980, et c'est l'Anthologie palatine, qui doit cette épithète à

\footnotetext{
1784 Bibliothèque de Darmstadt, gr. 277, XVI ${ }^{\mathrm{e}}$ siècle, voir VolTZ dans B.Z., 1895, 547; de ThEODORE Prodrome, éd. Boissonade, N.E.M., XI, 1827, 181 et 182.

1785 Anne Comnene (Die Musen des Kaisers Alexios I), éd. Maas, B.Z., 1913, 348

1786 Guilland, dans B.N., 1926, 255 et s.; Treu Prog. Gymn., Potsdam, 1895.

1787 CouAt, La poésie alexandrine, 170-189. La plupart des poètes d'Alexandrie, Callimaque, Théocrite, etc. en ont composé.

1788 Anthologie grecque. I Anthologie Palatine, Introd., III-XXIII; Anthologia graeca epigramniarum Palatina cum Planudea; KRUMBACHER, Geschichte der byzantinischen Literarur, 725730 .

1789 Jusque-là classées par lettre alphabétique.

1790 Il n'en fut que l'éditeur. Anthologie grecque, XXV-XXXI.
} 
son unique manuscrit, le Codex Palatinus ${ }^{1791}$. Enfin sous les Paléologues, Maxime Planoudès (1260-1310) édita une Anthologie en sept chapitres qui correspondent à ceux de Céphalas et de l'Anthologie Palatine. Sa vogue éclipsa tous les recueils antérieurs ${ }^{1792}$.

L'Anthologie palatine comprend 3700 épigrammes, au total 22000 vers divisés en 15 livres : Epigrammes chrétiennes (1. I), statues des Thermes de Zeuxippe (1. II), inscriptions du temple d'Apollonis, veuve d'Attale, à Cyzique (1. III), prologues de Méléagre, Philippe, Agathias (1. IV), épigrammes amoureuses (1. V), votives (1. VI), funéraires (1. VII), ${ }^{1793}$, démonstratives (1. IX), exhortatoires (1. $\mathrm{X})$. Propos de table et plaisanteries $(\sigma v \mu \pi \mathrm{\sigma} \tau \kappa \kappa \alpha \quad \sigma \kappa о \pi \tau \iota \kappa \alpha ́)(1$. XI). Muse enfantine (1. XII). Sur différents mètres (1. XIII). Emblèmes, oracles (1. XIV). Miscellanaea (1. XV).

On voit que tout était matière à épigramme. Aux sujets antiques les Byzantins avaient ajouté les thèmes chrétiens, mais la loi du genre n'avait pas changé. Il s'agissait d'émettre sous une forme concise une pensée toujours banale, mais qui s'achevait par un trait plus ou moins frappant :

Il faut fuir l'Amour. Peine inutile : je n'échapperai pas, étant à pied, à un dieu ailé qui sans cesse me poursuit ${ }^{1794}$. Que personne ne tremble plus devant les traits de l'Amour, car le farouche Eros a vidé sur moi son carquois tout entier ${ }^{1795} \ldots A$ une coupe: Effleure ses lèvres qui distillent du miel, ô coupe; tu les as rencontrées, savoure-les; je ne suis pas jaloux de toi, mais je voudrais avoir ton sort ${ }^{1796}$.

C'est Stoudios qui a élevé cette belle demeure à Jean, le grand serviteur du Christ ; mais, bientôt il a trouvé la récompense de ses travaux en recevant les faisceaux consulaires ${ }^{1797}$.

Jeux d'esprit, jeux de société, madrigaux semblables à ceux qui charmaient nos Précieux du XVII ${ }^{\mathrm{e}}$ siècle, telle est la portée de cette lit-

1791 Découvert en 1606 par Claude Saumaise dans la bibliothèque de l'Électeur Palatin, transporté à Rome en 1622, à Paris en 1797, réclamé en 1816; mais le tome I fut renvoyé à Heidelberg, le tome II à Rome. Anthologie grecque, I, XXXVIII et s.

1792 Anthologie grecque, I, et s., édition princeps Jean Lascaris, Florence, 1494, d'après le manuscrit autographe de Planoudès Marcianus, gr. 481.

1793 Sur les épigrammes funéraires, supra p. 27.

1794 Anthologie grecque, II, 43, n 58 (du poète Archias, l'ami de Cicéron).

1795 Ibidem, II, 118, n 268 (de Paul le Silentiaire, VI ${ }^{\mathrm{e}}$ s.).

1796 Ibidem, II, 130, $\mathrm{n}^{\circ} 295$ (de Léontios, $\mathrm{VI}^{\mathrm{e}}$ s.).

1797 Ibidem, I, 14, n 4 . Inscription du monastère de Stoudios, qui fut consul avec Aetius en 453. 
térature. Un nombre considérable d'épigrammes n'est d'ailleurs pas entré dans les Anthologies, bien que signées de noms illustres comme le philosophe Léon, contemporain de Michel III (sur les grands philosophes; sur la Batrachomyomachie), comme l'empereur Léon VI (sur les mois des Romains), comme Jean Kyriotès le Géomètre ( $\mathrm{X}^{\mathrm{e}}$ siècle) (sur les auteurs antiques, les Pères de l'Église ; thèmes mythologiques, descriptions géographiques, épitaphes, événements contemporains du règne de Nicéphore Phocas, sujets chrétiens, etc.) ${ }^{1798}$. $\mathrm{Au} \mathrm{XI}^{\mathrm{e}}$ siècle Psellos ${ }^{1799}$, Christophoros de Mytilène ${ }^{1800}$, Jean, archevêque d'Euchaïta ${ }^{1801}$, Théophylacte d'Ochrida ${ }^{1802}$ cultivent ce genre. Au début du XIV ${ }^{\mathrm{e}}$ siècle un des auteurs d'épigrammes les plus féconds est Manuel Philès, d'É-phèse, disciple de Georges Pachymère, homme de lettres besogneux. Beaucoup de ses épigrammes sont des demandes de vivres, surtout de gibier, adressées à de grands personnages. Un événement tint une grande place dans sa vie : il fit partie d'une ambassade envoyée en Russie pour négocier le mariage d'une princesse impériale. Il prétend aussi avoir été en Perse, dans l'Inde et en Arabie. Ses descriptions d'œuvres d'art aujourd'hui perdues sont souvent précieuses ${ }^{1803}$.

On aimait aussi à composer des pièces que l'on attribuait à des personnages célèbres, en particulier aux Pères de l'Église ${ }^{1804}$. Non moins répandues étaient les énigmes ${ }^{1805}$, les tours de force comme les Karkinoi (écrevisses), vers lisibles indifféremment de droite à gauche et de gauche à droite ${ }^{1806}$, les vers-échos, dont chaque mot est plus long d'une syllabe que le précédent et dont le dernier mot d'un vers est le premier mot du précédent ${ }^{1807}$.

Toute cette littérature nous ouvre des jours sur les passe-temps érudits, qui supposaient une connaissance étendue de l'antiquité classique, auxquels se plaisait la société lettrée de Byzance. On est loin

\footnotetext{
1798 KRUMBACHER, op. cit., 731-735; SCHLUMBERGER, L'Épopée byzantine, I, 642.

1799 PSELlOS, Discours..., V.

1800 Christophoris de MYtilene, Poésies, éd. A. Rocchi, Rome.

1801 Jean MAUropous, archevêque d'Euchaïta, P.G., 120, p. 1039-1100.

1802 TheOPHYLACTE D’OChridA, Poèmes (éd. Mercati); KRUMBACHER, op. cit., 737-743.

1803 Manuel Philes, Poèmes; KrumBACHER, 774-780.

1804 Poème anacréontique du XII ${ }^{\mathrm{e}}$ siècle attribué à saint Grégoire de Nazianze. Voir G. MERCATI dans B.Z., 1908, 389 et s.

1805 Eustathe MAKREMBOLITES (éd. Treu).

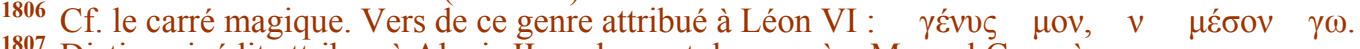

1807 Distique inédit attribue à Alexis II sur la mort de son père Manuel Comnène.
} 
d'ailleurs d'avoir imprimé les innombrables épigrammes encore enfouies dans les manuscrits ${ }^{1808}$.

Poésie de genre et de circonstance. - Beaucoup de poèmes, plus longs que les épigrammes, traitent de sujets analogues et sont la plupart du temps de simples exercices de rhétorique. Les vers d'Ignace, diacre de Constantinople et métropolite de Nicée, sur Adam, ont la forme d'un dialogue parfaitement symétrique entre trois personnages, chacun récitant trois vers à la fois ${ }^{1809}$. Un auteur fécond est le hiéromoine Michel Grammatikos, qui a laissé des vers sur toute espèce de sujets : sur la sobriété (en acrostiche alphabétique), sur la vanité de la mythologie, sur le Jugement Dernier, sur Abraham, ainsi que des invectives contre un ignorant devenu évêque ${ }^{1810}$. Des noms plus connus sont ceux de Jean Tzetzès ${ }^{1811}$, de Michel Khoniatès, archevêque d'Athènes ${ }^{1812}$, de son frère Nicétas ${ }^{1813}$, de Nicéphore Blemmydès ${ }^{1814}$, de Planoudès ${ }^{1815}$ et, au XV $\mathrm{XV}^{\mathrm{e}}$ siècle, de Jean Eugenikos ${ }^{1816}$, qui, auteurs d'ou-vrages plus importants, n'ont pas dédaigné ce genre de poésie; on a l'impression de morceaux improvisés, grâce à une excellente mémoire, d'où surgissaient à souhait les phrases et les expressions des antiques qu'ils n'hésitaient pas à s'approprier.

\section{La poésie rythmique}

\section{$\underline{\text { Retour à la Table des Matières }}$}

La poésie rythmique est la manifestation la plus originale du génie poétique des Grecs du moyen âge. Religieuse, populaire, dénuée de toute érudition antique, elle s'oppose à la poésie savante, aussi bien par ses thèmes que par sa métrique ${ }^{1817}$.

1808 Cod. Palat. gr. 367, XIV siècle, 50 pièces publiées par LAMBros, N.H., XVI, 400 et s.

1809 P.G., 117,1764 et s.; KRUMBACHER, op. cit., 716 et s.

1810 N.H., 1917; LEBEAU, Histoire du Bas-Empire, 786.

1811 Jean TZETZES, Vers inédits, 568 et s.; KRUMBACHER, 534.

1812 Michel KHONIATES, $\left(\mathrm{T} \sigma \omega \zeta \zeta^{\prime} \mu \varepsilon v \alpha\right)$ : élégie sur Athènes.

${ }^{1813}$ NiCETAS KhONIATES, Histoire. Sur les statues, P.G., 139.

1814 NiCEPHORE BLEMMYDES, [Autobiographie et oeuvres complètes], édit. Heisenberg. A Jean Vatatzès contre des calomniateurs; pièces de circonstance.

1815 PLANOUDES, Poèmes (idylles fantastiques).

${ }^{1816}$ KRUMBACHER, 495 et s.; éloge de Jean VIII, prologue aux Aethiopika d'Héliodore, etc.

${ }^{1817}$ E. Bouvy, Poètes et Mélodes. Origines du rythme tonique; KrUMBACHER, 655 et s. 
Sa prosodie. - Les poètes rythmiques ne se soucient plus de la quantité des voyelles, à laquelle l'oreille du peuple n'est plus sensible. Ses deux règles essentielles sont l'isosyllabie ${ }^{1818}$ et l'homotonie, l'observation de l'accent tonique. Dans une même pièce les vers sont inégaux. Le poète est guidé par le sentiment musical, qui commande seul la longueur des vers et leur groupement en strophes. Bien qu'il emploie la langue classique, surtout celle de la Bible des Septante, des Évangiles, des Pères de l'Église, il évite toute expression qui serait difficile à comprendre par le peuple. Cette poésie des mélodes, nom que l'on donne aux poètes rythmiques, n'est plus une distraction de lettrés, mais une littérature nationale.

Sa découverte. - Elle fut longtemps méconnue et prise pour de la prose, car elle était transcrite comme telle dans les manuscrits, les érudits de Byzance ne considérant comme des vers que la poésie qui observait la quantité. Ce fut l'un des plus savants liturgistes du XIX siècle, le cardinal Pitra, qui découvrit le rythme de ces hymnes dans un manuscrit de Saint-Pétersbourg ${ }^{1819}$ et ouvrit ainsi le champ à des recherches, qui ont permis la restitution de l'art des mélodes.

Forme des poésies rythmiques. - Elles sont nées de l'office canonial, qui consistait d'abord dans la psalmodie, mais qui avait pour base le chant alterné (antiphone). L'antiphone conduisit au tropaire, refrain intercalaire ou ritournelle musicale, introduite après chaque verset d'un psaume, sur laquelle on mit des paroles d'abord très courtes, puis tout un développement qui constitua d'abord une strophe, et bientôt un poème (ode). L'hirmos ( $1 \rho \mu$ ós) est la strophe-modèle, dont les autres reproduisent le schéma.

Le poème se présente sous deux formes : le Kontakion ou hymne, composé de plusieurs strophes égales, et le canon, réunion de plusieurs chants (8 ou 9), dont chacun a sa structure propre ${ }^{1820}$. A la fin de chaque strophe se trouve un refrain, púpviov, à l'origine une acclamation pieuse des fidèles. La rime est employée fréquemment. Enfir l'acrostiche est caractéristique de cette poésie : les première lettres

\footnotetext{
1818 KRUMBACHER, 655 et s. Toutes les syllabes, longues ou brèves, se valent et sont isochrones.

1819 Cardinal PITRA, Hymnographie de l'Eglise grecque (première publication de sa découverte, 1867, suivie des Analecta Sacra I, Paris et Rome, 1876, première édition des mélodes).

1820 D.A.C.L., II, 1905 et s.; KRUMBACHER, 695-697.
} 
de chaque vers sont reliées pour former un mot ou une phrase, tantôt l'alphabet, A- $\Omega$ ou $\Omega$-A, tantôt le nom de l'auteur, le titre de l'hymne, etc. ${ }^{1821}$. L'acrostiche fournit parfois des renseignements précieux.

Les origines. - Les origines de ces cantiques populaire sont antérieures à la Paix de l'Église : des hérétiques, comm le gnostique Bardesane d'Édesse (II ${ }^{\mathrm{e}}$ siècle), répandirent des hymnes de propagande et $\mathrm{y}$ associèrent le chant ; le défenseurs de l'orthodoxie leur empruntèrent ce procédé D'après saint Ephrem de Nisibe, Bardesane «offrit aux gens sains le poison amer dissimulé par la douceur ». Lui-même, retiré à Édesse (363-373), composa des hymnes contre les hérétiques en s'inspirant de la prosodie de Bardesane ${ }^{1822}$. C'est lui qui est le véritable créateur de la poésie ecclésiastique. Ses hymnes, écrites en syriaque et en grec, étaient chantées par des chœurs alternés. Les vers étaient de 4 à 10 syllabes et répartis en strophes, qui se terminaient par une pièce ou une doxologie. Il composa 75 variétés d'hymnes avec acrostiches ${ }^{1823}$. Son influence sur les mélodes est indéniable.

Romanos le Mélode. - Romanos n'est pas le plus ancien, mais le plus illustre des mélodes. Depuis la première édition de quelques-unes de ses œuvres parle cardinal Pitra ${ }^{1824}$, il a été l'objet d'un grand nombre de recherches et des découvertes ont montré que sa production poétique fut d'une fécondité prodigieuse. Il a célébré toutes les fêtes de l'année et la plupart des saints ${ }^{1825}$.

Il est né à Émèse, fut diacre à l'église de l'Anastasis de Beyrouth, vint à Constantinople sous Anastase et y vécut sous Justin et Justinien. Il faisait partie du clergé d'un monastère de la Vierge dite de Cyrus ; il $\mathrm{y}$ fut enseveli après sa mort et il est honoré comme un saint le premier octobre ${ }^{1826}$. D'après sa légende il passait la nuit de Noël dans l'église

${ }^{1821}$ KrumBaCher, Die Akrostichis in der griechischen Kirchenpoesie, B.Ak.W., 1904.

${ }^{1822}$ J. B. СНАВОТ, Littérature syriaque; Rubens DUVAL, La littérature syriaque, 11 (Ephrem, né à Nisibe en 306, d'une famille païenne, se convertit et, après la cession de Nisibe à la Perse (363), vint à Édesse où il occupa une chaire à l'École des Perses; il mourut en 373).

1823 Saint ÉPHREM, S. Ephraemi Syri opera; R. DUVAL, op. cit., 313.

${ }_{1825}$ Romanos le Melode, Analecta Sacra, I, 1876 (29 pièces).

1825 Ibidem. Les principaux travaux sont ceux de Krumbacher, qui avait préparé une édition, et d'Eustratiadès.

1826 P. MAAS, B.Z., XV, I et s. La Chronologie de Romanos relève les allusions à des événements du règne de Justinien. 
des Blachernes, quand la Vierge lui apparut en songe et lui octroya le don de la poésie mélodique ${ }^{1827}$.

Les hymnes de Romanos sont des Kontakia à strophes égales, dont la forme est simple, exempte de toute rhétorique, mais exprime une foi profonde, qui se traduit par la largeur de l'expression, par le caractère dramatique de certains épisodes, dans lesquels le mélode introduit des dialogues émouvants, comme celui de Marie et de Jésus sur la croix, enfin par des images grandioses qui sont souvent des paraphrases de la Bible ${ }^{1828}$.

Voici, par exemple le prélude du cantique de Noël :

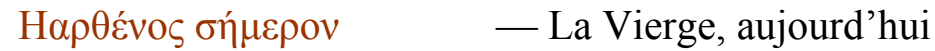

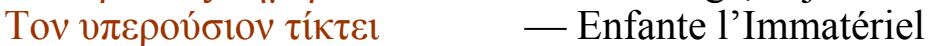

$$
\begin{aligned}
& \mathrm{K} \alpha \quad \gamma \quad \tau \quad \sigma \pi \hat{\lambda} \lambda \alpha i o v \text { Et la Terre, sa Caverne, }
\end{aligned}
$$

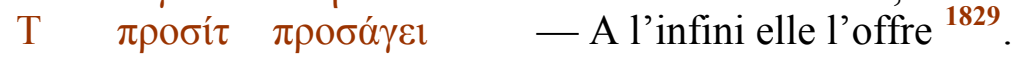

L'hymne sur le Jugement Dernier est remplie d'un souffle épique qui devait inspirer l'auteur du Dies Irae ${ }^{1830}$.

«Quand vous viendrez, Seigneur, - Sur la terre dans votre gloire - et que tremblera tout ce qui est. - Quand un torrent de feu se précipitera - devant votre tribunal, — quand s'ouvriront les Livres — et qu'au jour viendra ce qui était caché, — Oh ! délivrez-moi alors — de l'indestructible fournaise — et jugez-moi digne d'être placé — à votre droite — ô le plus juste des Juges ${ }^{1831}$.

Et qu'y a-t-il de plus gracieux, de plus entraînant que l'hymne pour l'Epiphanie :

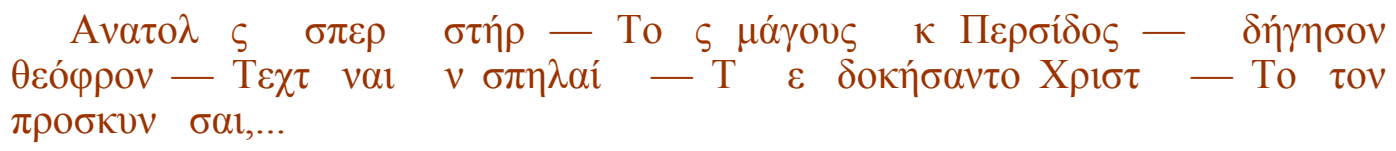

dont la légèreté du rythme ne peut se rendre dans une traduction :

1827 Eustratiades, Romanos le Mélode et ses ouvres poétiques, 255; Krumbacher, Geschichte der byzantinischen Literatur, 663.

1828 E. BOUVy, Poètes et Mélodes. Origines du rythme tonique, 361; KRUMBACHER, op. cit., 670 et s.; HESSELING, Essai sur la civilisation byzantine, 87-89.

1829 KRUMBACHER, 670.

${ }^{1830}$ Attribué au Franciscain Thomas de Celano (XIII ${ }^{\mathrm{e}}$ siècle).

${ }^{1831}$ Krumbacher, Studien zu Romanos, B.Ak W., 1898, II, 69, n III : Der Jüngste Tag. 
Comme l'astre du Levant, — de Perse a conduit les mages, — vers l'Esprit divin, - mettant au monde dans une caverne - le Christ consentant, - se prosterner devant lui, - des rois devant le roi... $\beta \alpha \sigma i \lambda \varepsilon$ s $\tau \quad \beta \alpha \sigma i \lambda \varepsilon{ }^{1832}$.

Mais il ne faut pas oublier que Romanos et les mélodes sont avant tout des musiciens, que les Kontakia sont faits pour être chantés et que c'est le vers qui doit se plier à la mélodie. Il en est résulté des fautes, dues à l'ignorance de la musique par les copistes des manuscrits ${ }^{1833}$.

Après Romanos. - Le mouvement, dont Romanos est le plus illustre représentant, ne se ralentit pas après lui, mais l'âge d'or de la poésie mélodique est essentiellement la période comprise entre la fin $\mathrm{du} \mathrm{VI}^{\mathrm{e}}$ siècle et celle du $\mathrm{X}^{\mathrm{e}}$ siècle. L'autorité de Romanos lui-même lui survécut, comme le montre l'Hymne Akathiste ${ }^{1834}$, que l'on chante le samedi de la cinquième semaine du Carême pour remercier la Vierge d'avoir sauvé Constantinople de l'assaut des barbares ${ }^{1835}$.

Cette hymne est divisée en 2 groupes de six strophes : groupe historique (de l'Annonciation à la Présentation), groupe mystique ou

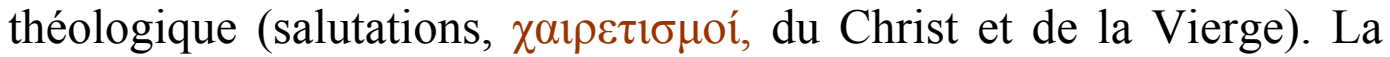
deuxième partie coïncide presque mot à mot avec un Kontakion de Romanos pour la Pentecôte; le mètre des versets est identique. De plus le premier prélude s'inspire de son hymne sur l'Annonciation, avec les mêmes salutations et le même refrain. Par sa forme élégante, par la profondeur du sentiment mystique et la beauté musicale des mots, l'Akathiste est unique dans la littérature byzantine ${ }^{1836}$.

L'hymne de Romanos pour Noël était chantée jusqu'au XII siècle par des chœurs alternés, à Sainte-Sophie et aux Saints-Apôtres, mais les hymnographes des $\mathrm{VIII}^{\mathrm{e}}$ et $\mathrm{IX}^{\mathrm{e}}$ siècles éliminèrent ses Kontakia des livres liturgiques pour y placer leurs propres œuvres ${ }^{1837}$. André, évêque de Gortyne en Crète, né à Damas en 660, fut clerc à Jérusalem,

1832 EUSTRATIADES, op. cit., 232.

1833 Ibidem, 187-189. Corrections d'après les Kontakia conservés dans les livres liturgiques en usage et inédits : Elpidio Mioni, Romano il Melode. Saggio critico e died inni inediti, Turin, 1937. (Voir la recension dans E.B., 1939, 438 et s.)

1834 Qui se chanta debout.

1835 AIgRAIn, Liturgia. Encyclopédie..., attribuée à tort au patriarche Sergius. Il s'agit des sièges de 626, 678 et 718 .

1836 Hymne Akathiste; Dom Placide de Meester. L'inno Akathisto, dans Bessarione, Rome, 1905; P. MAAS, dans B.Z., 1905, 643 et s.

1837 KRUMBACHER, Geschichte der byzantinischen Literatur, 671. 
puis à Constantinople où il apporta les coutumes liturgiques de Palestine. Musicien et mélode, il introduisit le canon ${ }^{1838}$ dans la poésie rythmique, qui acquiert ainsi plus de liberté et de fantaisie. Il composa aussi des idiomèles, strophes isolées et libres sur les fêtes de l'année. Il imita Romanos dans son Grand Canon de 250 strophes, mais il n'en a ni la simplicité ni l'élégance ${ }^{1839}$.

$\mathrm{Au} \mathrm{VIII}^{\mathrm{e}}$ siècle saint Jean Damascène et Kosmas, liés d'une étroite amitié, moines au monastère de Saint-Sabas, y cultivèrent la poésie religieuse $^{1840}$ et réussirent surtout dans la composition des canons. Ils prirent pour modèle les poésies de Grégoire de Nazianze. Leur style recherché s'oppose à la simplicité de Romanos. Jean joue la difficulté, en donnant à ses pièces des acrostiches composés de distiques; en outre, dans les canons de certaines fêtes, il observe la quantité des voyelles suivant les règles de la prosodie antique ${ }^{1841}$.

A l'époque iconoclaste la poésie mélodique est représentée par l'œuvre, longtemps inconnue, d'André l'Aveugle ${ }^{1842}$, et par les Studites Théodore ${ }^{1843}$, son frère Joseph, les frères $\gamma \rho \alpha \pi \tau o$, Théodore et Théophanes, l'hymnographe saint Clément ${ }^{1844}$, la poétesse Kasia ${ }^{1845}$. Toutes les hymnes de cette époque ont pour caractères communs le style recherché, le ton ampoulé, l'abus des épithètes. Certaines hymnes ne sont que des paraphrases versifiées de légendes hagiographiques en prose.

$\mathrm{Au} \mathrm{XI} \mathrm{I}^{\mathrm{e}}$ siècle il semble que le souffle poétique des mélodes se soit éteint, bien que la poésie rythmique soit encore cultivée dans les monastères, notamment à l'abbaye de Grottaferrata près de Rome. Contrairement à l'opinion de Krumbacher, qui place sa disparition à la

\footnotetext{
1838 Voir sa définition supra, p. 233.

1839 Andre le Melode, évêque de Gortyne (Crète), † 740, Canons; KrUMBACHER, op. cit., 165 et s.; S. VAILHE, Saint André de Crète, dans E.O., V, 378 et s.

1840 Saint Jean Damascene, Ceuvres, P.G., 96, 818-858; Kosmas, Poèmes mélodiques, 556-524.

1841 KrumbaCher, op. cit., 674 et s.; PAPADOPOUlOS-KERAMEUS dans B.Z., 1905 (pièce inédite de Kosmas sur saint Georges avec le nom de l'auteur dans l'acrostiche).

1842 Son œuvre retrouvée par EUSTRATIADES, E.B., 1923, 3 et s.; il vivait au VIII ${ }^{\mathrm{e}}$ siècle; D.H.G.E., II, 1637.

1843 Analecta Sacra, éd. Pitra, 1, P.G., 99, 1757 et s.

1844 A.S.B., avril, III, 796 et s. On connaît de lui neuf canons. S. PETRIDES, Office inédit de saint Clément, hymnographe, dans B.Z., XII, 571 et s.

1845 Krumbacher, 715 et s.; Dienl, Figures byzantines, I, 134 et s.; J. W. TILlyard, A musical Study of the hymns of Casia, B.Z., 1911.
} 
fin $\mathrm{du} \mathrm{XI} \mathrm{XI}^{\mathrm{e}}$ siècle, elle a survécu jusqu'à la fin de l'Empire ${ }^{1846}$. Non seulement elle a toujours figuré dans les livres liturgiques, mais elle a produit des œuvres nouvelles, qui portent les noms de Syméon Métaphraste (office pour le Vendredi Saint), de Manuel Holobolos (XIII ${ }^{\mathrm{e}}$ siècle), de Manuel Philès, de Nicéphore Kallistos, l'historien de l'Église ${ }^{1847}$, qui a retrouvé dans une certaine mesure le vocabulaire simple et la virtuosité des anciens mélodes.

\section{La musique byzantine}

\section{Retour à la Table des Matières}

Comme nous l'avons dit, les mélodes n'étaient pas seulement des poètes, mais essentiellement des musiciens. La composition musicale précédait celle du texte, subordonné au rythme. Ce fut seulement à la fin du IX ${ }^{\mathrm{e}}$ siècle que l'on commença à mettre de nouveaux textes sur des mélodies anciennes. L'étude de la musique byzantine est donc le complément nécessaire de celle de la poésie rythmique. La musique offre d'ailleurs l'un des aspects les plus caractéristiques du développement intellectuel et artistique du monde byzantin.

Malheureusement son étude est loin d'être achevée. Les manuscrits musicaux sont d'une interprétation difficile et les musicographes ne s'accordent pas sur la portée de leur témoignage.

Musicographes byzantins. - On ne peut tirer parti des traités des érudits byzantins sur la musique : ce sont la plupart du temps de simples plagiats d'auteurs antiques. L'étude de la musique théorique faisait partie du quadrivium et se rattachait aux sciences mathématiques. Les traités de Psellos sur la musique, ceux de Georges Pachymère et de Manuel Bryenne n'apprennent rien sur les compositions musicales réellement exécutées à Byzance ${ }^{1848}$.

\footnotetext{
1846 KRUMBACHER, 676-678.

1847 Son œuvre mélodique découverte par PAPAdopoulos-Kerameus, B.Z., 1902, 38, et M. JUGIE (NicEPhore Kallistos Xanthopoulos, Histoire de l'Église).

1848 KRUMBACHER, 289, 599.
} 
Il en va tout autrement d'un traité anonyme, dû à un habitant de Jérusalem, qui se qualifie de Hagiopolitès (citoyen de la Ville Sainte). Son traité est le livre de chant de l'Église de Jérusalem, qui contient les règles fixées par Kosmas. Il conserve de précieux fragments musicaux de l'antiquité grecque et c'est un des rares documents qui nous renseignent sur la musique profane. C'est surtout un traité théorique et pratique du chant liturgique, qui comprend une série d'extraits juxtaposés, sans ordre. La langue embarrassée trahit un Oriental ${ }^{1849}$

Caractères et origines. - Pas plus que la musique des anciens, la musique byzantine ne connaît l'harmonie ${ }^{1850}$. Elle est seulement mélodique et rythmique ; elle est faite pour le chant à l'unisson. Elle était toujours associée à la poésie, ainsi que la danse. Les instruments de musique, flûte ou lyre, ne servaient qu'à soutenir le chant et non à l'accompagner.

C'était la musique qui déterminait les tropaires et la strophemodèle, l'hirmos. Comme dans l'antiquité il existait 8 modes ou tons,

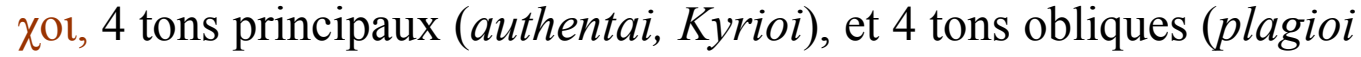
ou plagaux), qui portaient des noms antiques (dorien, phrygien, etc.), mais en différaient complètement. Des musicologues ont montré que la musique byzantine a rompu entièrement avec la musique de l'antiquité ; en pleine décadence, devenue un exercice de virtuosité.

L'Octoechos, livre d'office, comprenant 9 odes ajoutées au psautier, est attribué à tort à saint Jean Damascène. Il figure, en effet, en partie, sur un papyrus du vII ${ }^{\mathrm{e}}$ siècle. Il formait un canon récité, avec intercalation de tropaires. Le premier (l'hirmos) rappelait les prophéties et insistait sur l'identité du Père Céleste dans l'Ancien et le Nouveau Testament. La neuvième ode était le Magnificat ${ }^{1851}$. D'autre part, saint Jean Damascène et Kosmas employaient dans les hirmoi deux nouveaux tons moyens. Il y avait donc 10 tons, dont les noms proviennent de la notation, droite pour les tons-maitres, oblique pour les plagaux ${ }^{1852}$.

\footnotetext{
1849 Paris, gr., 360, fin XIII ${ }^{\mathrm{e}}$ siècle; A. GAStOUE (dans B.N., V, 1929, 349 et s.) en a montré l'importance.

1850 Notes entendues simultanément formant accord.

1851 Hoeg CARSTEN, Du nouveau sur la musique byzantine. L'Octoechos; GASTOUE, loc. cit., 354.

1852 Th. Gerold, La musique au Moyen Age. Musique liturgique byzantine, 49; H. TYLLARD, Handbook of the middle musical notation (distinctions des tons par des lettres grecques déformées, dites martyria, témoins).
} 
La mélodie byzantine se distingue de la mélodie antique par une plus grande richesse, qui est due à des influences syriennes. C'est ce qui ressort de sa parenté avec les mélodies ambrosienne et grégorienne, qui s'explique par des sources communes ${ }^{1853}$. On doit rappeler d'ailleurs que Grégoire le Grand, avant son avènement à la papauté, fut apocrisiaire du pape à Constantinople, où il put connaître la liturgie byzantine, et que, plus tard, sa réforme musicale lui attira le reproche d'imiter les Grecs. Le pape Sergius, d'origine syrienne, introduisit réellement dans la liturgie romaine des usages et des chants empruntés à Byzance ${ }^{1854}$.

Toujours est-il que la mélodie byzantine ne cessa d'être un art populaire et la preuve de sa vitalité, c'est qu'elle fut modifiée au cours des siècles. Un certain moine de l'Athos, Jean, dit Koukouzelis, ajoute aux mélodies des modulations qui prolongent les syllabes, à une époque où la voix humaine supplantait l'orgue et les instruments d'accompagnement ${ }^{1855}$.

La notation. - L'art des anciens mélodes étant exclusivement oral, la notation était inconnue. Le chef du chœur ponctuait la phrase musicale en indiquant les intervalles par des gestes de la main, de bas en haut indiquant l'élévation de la voix, de haut en bas son abaissement. C'est le système dit ekphonétique ${ }^{1856}$. C'est au IX ${ }^{\mathrm{e}}$ siècle qu'apparaissent dans les manuscrits musicaux les neumes (ve $\mu \alpha$, signe), notes proprement dites, adoptées aussi en Occident. Leur aspect est celui de lettres alphabétiques déformées ${ }^{1857}$. Les uns expriment les intervalles : somata, indiquant la répétition d'un son en montant ou en descendant; pneumata (esprits), sauts de plusieurs degrés (tierce, quarte, quinte). D'autres, hypostaseis ou aphones indiquent la durée de l'émission (points d'orgue). Ces signes servaient de secours aux

\footnotetext{
1853 G. Wellesz, Der Stand der Forschung auf dem Gebiete der byzantinischen Kirchenmusik, 735.

1855 EustratiADES, Jean Coucouzelis (E.B., 1938) d'après des manuscrits de Lavra. Né à Dyrrachium, chantre au Palais Impérial, puis moine à Lavra (XIV ${ }^{\mathrm{e}}$ siècle).

1856 Expression due à Isaac Tzetzès, frère du scoliaste, dans un traité sur la métrique de Pindare. $\mathrm{H}$. CARSTEN, La notation ekphonétique (voir E.O., 1939 (2), 243).

1857 J. THIBAUT, Origine byzantine de la notation neumatique de l'Église latine, 219; $\mathrm{H}$. TILLYARD, Handbook of the middle musical notation.
} 
chantres, mais ne donnaient pas les sons exprimés par les lettres indiquant les tons ${ }^{1858}$.

Musique profane. - L'Hagiopolitès distingue la musique profane, $\sigma \mu \alpha$, des chants d'église. Outre les huit tons, elle possède quatre tons moyens et quatre modulations (phtorai), véritables gammes nouvelles, qui se terminent dans un autre ton que celui du début. Elle a donc au moins seize échelles musicales à sa disposition ${ }^{1859}$.

Malheureusement elle est mal connue, bien qu'elle eût la même réputation que la musique religieuse : Mazaris rencontre dans l'Hadès un musicien célèbre du $\mathrm{XV}^{\mathrm{e}}$ siècle, Lampadarios, qui se plaint que son fils prostitue son talent en s'adonnant à la musique profane et en égayant les fêtes mondaines des riches débauchés de Constantinople ${ }^{1860}$. Les rares monuments de cette musique qui nous soient parvenus sont les acclamations rythmées des dèmes et aussi les chansons outrageantes qu'ils composaient contre les souverains. On classe dans la même catégorie les cantiques chantés au Grand Palais aux grandes fêtes de l'Église ${ }^{1861}$ (1861). Une chanson populaire de l'Hirondelle, chantée par les jeunes gens, décrit en vers heptasyllabes la naissance

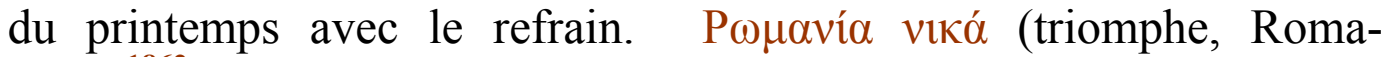
nie !) ${ }^{1862}$.

Instruments de musique. - Les orgues tenaient une grande place dans les cérémonies religieuses ou civiles. L'orgue était connu depuis une très haute antiquité, mais on attribuait à un Alexandrin du $\mathrm{III}^{\mathrm{e}}$ siècle avant notre ère, Ctéribios, l'invention de l'orgue hydraulique ${ }^{1863}$, très en vogue à Rome au $\mathrm{I}^{\mathrm{er}}$ siècle de l'Empire, où on le considérait surtout comme une curiosité ${ }^{1864}$.

L'orgue hydraulique fut remplacé à Byzance par l'orgue pneumatique, manœuvré au moyen de soufflets, qui faisaient passer l'air dans des tuyaux creux de longueur inégale et décroissante. On en possède

\footnotetext{
1858 Gerold, La musique au Moyen Age, 27 et s.; Wellesz, Der Stand der Forschung auf dem Gebiet der byz. Kirchenmusik, B.M, 1936, 731.

1859 Gastoue, B.N., V, 352 et s.

1860 MAZARIS, Dialogos nekrikos, 134

1861 P. MAAS, Metrische Akklamationen..., B.Z., 1912, 28.

1862 Ibidem, 43-45; Le Chant de l'Hirondelle (éd. Fabre).

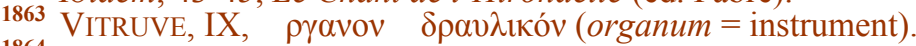

1864 D.A.C.L., VII, 1172 et s.
} 
une description précise dans un petit poème de l'empereur Julien, d'après lequel l'air était emmagasiné dans une outre en cuir. « Un virtuose habile, debout, laisse courir ses doigts agiles sur les touches qui font parler les flûtes et le jeu de leurs sauts délicats produit la mélodie $^{1865}$. » Deux orgues de ce genre sont sculptés sur le soubassement de l'obélisque de Théodose $\mathrm{I}^{\mathrm{er}}$ à Constantinople, aux deux bouts d'une file de danseurs ${ }^{1866}$. Ces orgues, connus en Occident à l'époque de saint Augustin, étaient oubliés au VIII ${ }^{\mathrm{e}}$ siècle et l'orgue, envoyé comme présent par Constantin V à Pépin le Bref en 757, excita une grande curiosité ${ }^{1867}$.

Les orgues byzantins étaient de tailles différentes et on distinguait le grand orgue, $\mu \varepsilon ́ \gamma 1 \sigma \tau$ ov $\rho \gamma \alpha v o v$, probablement fixe, et l'orgue ma-

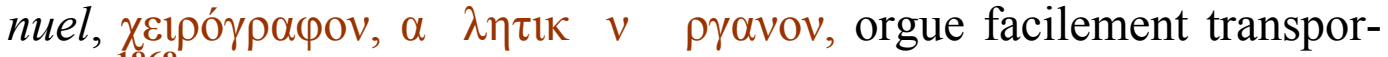
table ${ }^{1868}$. Lorsque Constantin et Irène font un voyage militaire sur la frontière de Thrace en 784, des organa figurent dans leurs bagages ${ }^{1869}$, et les dèmes ont leurs organistes attitrés, qui ont un rôle essentiel dans les réceptions et processions impériales ${ }^{1870}$.

Cependant l'orgue n'est pas un instrument d'accompagnement et on s'en sert presque exclusivement dans les cérémonies impériales. Nous avons vu que le chant liturgique n'est pas accompagné. Il possède les modes et les tons qui le guident, mais il n'en est pas de même de la musique instrumentale. L'orgue est un instrument d'orchestre, qui module souvent les chants religieux, par exemple le trisagion à l'Hippodrome, mais ne les accompagne pas ${ }^{1871}$.

$\mathrm{Au}$ festin offert en 946 par Constantin Porphyrogénète à des ambassadeurs sarrasins, des chœurs invisibles célébraient la gloire du basileus et de la Romanie. Ces voix mélodieuses étaient celles des chantres de Sainte-Sophie et des SaintsApôtres, dissimulés derrière un rideau de pourpre. Ils s'arrêtaient à chaque service et alors fusaient les accents des orgues aux tuyaux d'or et d'argent qui mettaient la joie aux cours des convives ${ }^{1872}$.

\footnotetext{
$1865 \overline{\text { JuliEN (empereur), Euvres, 214, n }}{ }^{\circ} 266$.

1866 D.A.C.L., 1189 , fig. 5931.

1867 R.K.O.R., 320; Annales Laurissenses Majores, 140 (reçu à Compiègne).

1868 D.A.C.L., VII, 1177 et s.

1869 THEOPHANES LE CONFESSEUR, Chronographie, 458-460.

1870 CONSTANTIN VII PORPhyRogenete, De caerimoniis aulae byzantinae, I, 8. (Se tiennent de chaque côté de la porte de Chalcé au moment où le basileus sort pour se rendre à SainteSophie).

1871 TIBAUT, La musique instrumentale chez les Byzantins, E.O., 1901-02, 347 et s.

1872 CONSTANTIN VII PORPHYROGENETE, op. cit., Bonn, 585.
} 
Un grand nombre d'autres instruments de musique à cordes ou à vent sont cités dans les textes ou figurés sur les monuments, comme la cithare, le luth à plusieurs cordes tendues contre une planche en forme de violon ${ }^{1873}$, le psalterion, la flûte, les olifants d'ivoire. Nous les connaissons assez mal ${ }^{1874}$.

\section{L'épopée}

Retour à la Table des Matières

Contrairement à ce qu'avait laissé supposer le caractère artificiel de sa littérature savante, Byzance a possédé une épopée nationale, dont les sources sont d'origine et de langue populaires.

Basile Digénis Akritas. - En 1872, Sathas découvrit dans un manuscrit de Trébizonde du XVI ${ }^{\mathrm{e}}$ siècle l'épopée des Exploits de Basile Digénis Akritas et fut frappé des rapports de ce poème avec les chansons populaires (tragoudia) de Chypre et des pays du Pont-Euxin.

Dans la suite on en découvrit plusieurs versions manuscrites, généralement récentes ${ }^{1875}$.

Ce sont des œuvres d'érudits de province, qui ont trouvé des dates historiques dans les chroniques et des expressions dans Homère, mais dont les sources principales sont les cantilènes ou tragoudia en langue populaire.

Le véritable sujet du poème est la lutte de l'Empire byzantin avec l'islam aux $\mathrm{IX}^{\mathrm{e}}$ et $\mathrm{X}^{\mathrm{e}}$ siècles et la défense des frontières par la milice spéciale des Akritai contre les Sarrasins et les Apélates, bandes de brigands vivant aux dépens des deux adversaires ${ }^{1876}$. L'immense effort

\footnotetext{
1873 Luth, ßópßıтov, cité dans Digenis Akritas. Voir H. GREGOIRE, dans B.N., VII, 296-299.

1874 H. WEISS, Kostümkunde. Geschichte der Tracht und des Geräthes im Mittelalter, II, 161 et s.; III, 1148

1875 Les exploits de Digenis Akritas, première édition Sathas-Legrand, 1872. Le plus ancien est celui de Grottaferrata (Cryptoferrat, $X^{\mathrm{e}} \mathrm{s}$.); les autres sont du XVI ${ }^{\mathrm{e}}$ s. (Escurial, Trébizonde) et du XVII ${ }^{\mathrm{e}}$ s. (Andros, Oxford et version en prose de Chio) ; S. BAUD-BOVY et H. GREGOIRE, Notes sur l'épopée byzantine, 249 et s.; éd. GreGOIRE, 1942: Digenis Akritas. The byzantine Epic in History and Poetry, New York, 1942.

1876 M.B.E.H. (Institutions), éd. 1970, 300.
} 
fait par Byzance pendant deux siècles pour reconquérir l'Orient et faire reculer l'islam, excita l'enthousiasme du peuple qui personnifia cette lutte dans la figure héroïque de Basile Digénis Akritas.

C'est donc dans la région des frontières de Cilicie et de Cappadoce, étendue au $\mathrm{X}^{\mathrm{e}}$ siècle jusqu'à l'Euphrate, qu'est née l'épopée byzantine. Une double ligne de postes, très rapprochés les uns des autres, garnissait la frontière. Les combats entre Akritai et Sarrasins, les razzias, les surprises étaient des événements quotidiens, d'où des aventures, des duels de chefs, des exploits extraordinaires.

Mais, à force d'être en contact, chrétiens et musulmans avaient fini par créer entre eux des relations de mutuelle sympathie et d'estime, dont les échanges périodiques de prisonniers sont un témoignage probant ${ }^{1877}$. Même vie aventureuse, même amour de l'or, même admiration pour les beaux coups d'épée, même lutte acharnée contre les Apélates, déserteurs, Klephtes, nuisibles à tous, même esprit chevaleresque. Toutes les conditions favorables à la naissance d'une épopée se trouvaient ainsi réunies. Du côté byzantin les stratèges des thèmes, éloignés de Constantinople, jouissaient d'une vie plus libre et d'une quasi-indépendance, sans que leur loyalisme vis-à-vis du basileus en souffrît, et c'est là un des traits bien caractéristiques de l'épopée de Digénis Akritas ${ }^{1878}$.

L'âge même de ses manuscrits montre que sa popularité a survécu longtemps au moyen âge : d'après la version de l'Escurial, des aèdes, pareils à nos jongleurs, la récitaient dans les assemblées des nobles ${ }^{1879}$.

Tel qu'il nous est parvenu, le poème comprend huit chants, divisés en trois parties, assez différentes de ton et d'esprit ${ }^{1880}$.

Les trois premiers chants, qui forment la première partie, sont consacrés aux parents de Digénis Akritas. Ce n'est certainement pas la

${ }_{1877}$ Sur ces échanges M.B.E.H. (ibid.), 259 et s.

1878 L. BREHIER, Un héros de roman dans la littérature byzantine, 1-10; RAMBAUD, Etudes sur l'histoire byzantine, 63-108; DIEHL, Figures byzantines, II, 291-319; HeSSELING, Essai sur la civilisation byzantine, 213.

1879 GrEgOIRE, Le tombeau et la date de Digénis Akritas (Aède s'adressant aux archontes), B.N., $1931,483$.

1880 Les exploits de Digénis Akritas (éd. Legrand); GREGOIRE, Digenis Akritas. The byzantine Epic in History and Poetry, 1942. 
partie la plus ancienne, car les exploits du père de Digénis, l'émir d'Édesse, qui enlève et épouse la fille du stratège Andronic Doukas, sont dans une certaine mesure un doublet des exploits de Digénis.

La deuxième partie, récit de ces exploits, représente le poème primitif, mais interpolé de digressions qui forment autant de morceaux distincts. Après l'explication de son nom, Digénis, issu de deux races, et un retour sur les exploits de son père, le poète célèbre ce que dans nos chansons de geste on appellerait les Enfances Digénis, son éducation, ses exploits merveilleux, son amour pour Eudokia, la fille d'un stratège qui fait décapiter les prétendants à la main de celle-ci. Mais Eudokia sera la fidèle compagne du héros, qui l'enlève : le père les poursuit avec ses gens, mais Digénis se défend avec un tel courage que le stratège émerveillé l'accepte pour gendre. Son mariage est célébré en grande pompe. Il délivre le pays des Apélates et sa réputation arrive bientôt jusqu'à l'empereur, avec qui il a une entrevue sur les bords de l'Euphrate (chant IV).

Le poème pouvait se terminer là et il en était peut-être ainsi d'abord, mais ce qui distingue la véritable épopée populaire, c'est qu'elle ne finit jamais. Une série d'épisodes distincts remplit les chants suivants et l'on a bien l'impression de poèmes juxtaposés. C'est d'abord le récit des amours de Digénis avec une jeune Arabe, que son ravisseur a lâchement abandonnée (chant V); puis Digénis retrouve Eudokia et la sauve des attaques d'un dragon, dont il tranche les trois têtes de son épée, et d'un lion, qu'il assomme de sa massue. On est au mois de mai, la nature est en fête. Digénis fait vibrer les cordes de son luth ; les sons, répétés par les échos des montagnes, attirent des Apélates qui veulent enlever Eudokia. Digénis les met en fuite, mais il est défié par trois brillants cavaliers. Digénis les renverse successivement et leur fait grâce de la vie. Ils se retirent en le bénissant ; mais furieux de leur défaite, ils lancent contre lui un ennemi de choix, Maximo l'Amazone, descendante des Amazones qu'Alexandre le Grand avait ramenées de l'Inde.

La lutte héroïque de Digénis contre Maximo forme un autre poème, remarquable par son caractère chevaleresque, qui fait songer à notre épopée courtoise, avec le merveilleux en moins. Maximo veut traverser l'Euphrate, mais Digénis la prévient galamment et s'élance à 
cheval dans le fleuve. Maximo s'élance sur lui : Digénis brise sa lance, fait sauter son épée et son casque. Prise de terreur, elle se prosterne à ses pieds, mais lui demande comme une faveur un nouveau duel, qui n'est pas plus heureux pour elle. Alors pour montrer qu'elle est domptée, elle s'offre à son vainqueur, qui ne peut résister à sa beauté.

Les exploits de Digénis sont terminés et la troisième partie (chants VII et VIII) le montre se reposant auprès d'Eudokia dans le palais merveilleux qu'il a fait bâtir sur les bords de l'Euphrate. Ses seuls exploits sont désormais cynégétiques : il étrangle les bêtes fauves sans aucune arme. Au retour d'une de ces chasses il prend un bain d'eau glacée et gagne un mal mortel, fin singulière pour un héros. La mort d'Eudokia en même temps que lui, le récit de leurs funérailles au milieu d'un peuple innombrable, les lamentations sur leur tombe terminent le poème et on ne peut se défendre de trouver cette fin un peu artificielle : elle n'a rien à voir certainement avec la version primitive.

Les caractères du poème. - Mais, même dans son état actuel, le poème de Digénis tranche par son originalité sur les autres productions littéraires de Byzance.

Ce sont d'abord les descriptions pittoresques qui forment aux événements un cadre brillant, par exemple l'arrivée triomphale de Digénis et de sa fiancée dans la maison du stratège : les trompettes sonnent, les tambours battent, les orgues d'argent jouent leurs plus beaux airs, les serviteurs poussent des acclamations. Les noces durent trois mois, pendant lesquels les festins se succèdent, tandis que les jeunes époux sont comblés de cadeaux : chevaux, léopards de chasse, faucons, icônes, armes, dont l'épée de Chosroès ${ }^{1881}$. La description du palais, digne des fées, de Digénis Akritas tient presque un chant entier $^{1882}$ : ce ne sont que marbres aux couleurs chatoyantes, sol d'albâtre poli comme une glace, triclinia resplendissants de mosaïques à fond d'or qui représentent les preux de l'antiquité païenne à côté de ceux de l'Ancien Testament, Achille à côté de Samson, David en face d'Alexandre le Grand ${ }^{1883}$.

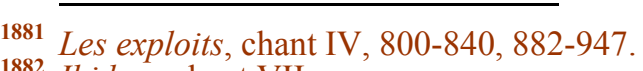

1882 Ibidem, chant VII.

1883 Cf. les preux et les preuses d'Occident. Y a-t-il eu contamination et de quel côté?
} 
Non moins remarquables sont les paysages qui montrent un réel sentiment de la nature.

C'est la verte prairie plantée d'arbustes variés, où Digénis dresse sa tente. Des roseaux dépassaient leur faîte ; une source fraîche jaillissait dans la prairie et formait mille ruisseaux. Les bois étaient remplis d'oiseaux de toute espèce. Suspendus aux branches des arbres, ils faisaient entendre leur ramage, tandis que des cygnes cherchaient leur vie dans les eaux, que des paons faisaient la roue au milieu des fleurs et que leurs plumes semblaient en refléter les nuances ${ }^{1884}$.

Ou bien c'est le désert de Syrie avec ses âpres solitudes et son horizon fuyant qu'interrompt la silhouette fantastique d'un palmier ${ }^{1885}$.

Il faut noter aussi l'accent de douceur et de jeunesse répandu sur le poème et ce sentiment de l'amour ingénu, dont on ne trouve guère d'autre exemple dans la littérature byzantine. Qu'y a-t-il de plus frais, de plus charmant que le dialogue entre Eudokia et Digénis dans leur première entrevue :

« Tu es descendu dans mon âme, dit Eudokia à sa fenêtre,... mais mon père le stratège passe des nuits à veiller à cause de toi... Prends garde de te mettre en péril à cause de moi,... car mon père est trop impitoyable pour t'épargner. - Penchetoi à ta fenêtre, répond Digénis, ô doux yeux de mon âme, afin que je voie ta beauté, afin qu'en mon cœur descende un amour infini de toi. Je suis jeune, tu le vois. Je ne connais pas la passion, j'ignore les chemins qui conduisent à l'amour, mais, si le désir de te posséder s'empare de mon âme, sache que quand bien même ton père le stratège et toute sa parenté et tous ses serviteurs se transformeraient en flèches et en épées étincelantes, nul d'entre eux ne pourrait m'atteindre ${ }^{1886}$.

Traits de caractères. - Un autre aspect original du poème c'est que ses personnages, à côté des traits héroïques communs aux épopées de tous les temps (conception du héros redresseur de torts, recherche des aventures et des grands coups), sont en même temps des Grecs de Byzance, qui ont tous les sentiments, toutes les préoccupations des sujets de Romain Lécapène ou de Nicéphore Phocas : le patriotisme (le terme de Romanie, qui revient souvent ${ }^{1887}$, montre l'éveil d'une conscience nationale), la fidélité au basileus et le respect de l'étiquette. Le héros, si jaloux de son indépendance, s'incline avec déférence devant la majesté impériale ; il demande au basileus de ve-

1884 Les exploits de Digénis Akritas, chant VI, 15-28.

1885 Ibidem, chant V, 19-29.

1886 Ibidem, chant IV, 320-339.

1887 Ibidem, chant I, 332 et chant IV, 1025. 
nir lui-même le voir sur les bords de l'Euphrate, car il craint que ses soldats jeunes et inexpérimentés ne profèrent en sa présence quelque parole contraire à l'étiquette. C'est bien là le souci d'un Byzantin, dont ne s'embarrassent guère un Ogier de Danemark ou un Guillaume au Court Nez ${ }^{1888}$.

La culture byzantine, le sentiment chrétien apparaissent en mainte circonstance. Le père d'Akritas fait un véritable cours de théologie à sa mère pour la convertir au christianisme ${ }^{1889}$. Digénis a un culte pour les saints guerriers, protecteurs des armées impériales, qu'il invoque avant de combattre; il a des scrupules peu habituels chez les héros épiques et se repent d'être sujet aux faiblesses humaines : le $\mathrm{V}^{\mathrm{e}}$ chant du poème est une charmante confession d'avoir succombé aux séductions de la princesse arabe qu'il avait arrachée à la mort.

Enfin l'élément byzantin est représenté par les réminiscences antiques que l'on rencontre à chaque instant. L'entrevue du père de Digénis avec sa femme et son petit enfant, avant son départ pour une expédition, rappelle les adieux d'Hector et d'Andromaque au $\mathrm{VI}^{\mathrm{e}}$ chant de l'Iliade ${ }^{1890}$ et deux longs passages, d'inspiration tout à fait païenne, glorifient la puissance de l'Amour qui triomphe des brigands les plus farouches ${ }^{1891}$.

Éléments et constitution du poème. - Notre brève analyse nous a montré dans le texte actuel des digressions, des contradictions, des redites. Le manque d'unité apparent pose le problème de la constitution du poème et de l'origine de ses éléments. Sathas, nous l'avons vu, avait déjà constaté que des épisodes du poème sont en rapport avec des chants populaires modernes et sont même passés dans la littérature russe par l'intermédiaire des Yougoslaves. Rambaud regarde comme sources du poème des chants populaires, qui se sont transmis oralement pendant neuf siècles et étaient forcément altérés quand ils ont été écrits pour la première fois au XIX ${ }^{\mathrm{e}}$ siècle ${ }^{1892}$. Enfin une plus vaste enquête a permis à Henri Grégoire de montrer que des cantilènes ac-

1888 Ibidem, chant IV, 988-1041; BREHIER, Un héros de roman dans la littérature byzantine, 20.

${ }^{1889}$ Les exploits de Digénis Akritas, chant III, 201-227; cf. la propagande chrétienne chez les Musulmans, supra, p. 332.

1890 Ibidem, chant II, 287-293.

1891 Ibidem, chant III, 1-8 et chant IV, 1-18.

1892 RAMBAUD, Études sur l'histoire byzantine, 89 et s. 
tuelles, indépendantes du poème, continuent de très anciennes cantilènes, dont l'auteur de Digénis Akritas a pu utiliser une partie ${ }^{1893}$. Aréthas, évêque de Césarée en Cappadoce (850-932), région où une partie du poème est localisée, mentionne des bateleurs paphlagoniens, qui vont de maison en maison, chanter les exploits des héros célèbres ${ }^{1894}$.

Ce texte précieux montre qu'il existait déjà des poèmes héroïques, ou tout au moins des cantilènes, à la fin $\mathrm{du}_{\mathrm{IX}} \mathrm{e}^{\mathrm{e}}$ siècle. Des cantilènes ou tragoudia, qui célébraient parfois d'autres héros que Digénis, renferment des traits historiques, noms de généraux, détails sur des armements et des méthodes de combat d'autrefois, qui attestent leur ancienneté. On peut citer le poème du Fils d'Andronic, dont la mère, enlevée par les Arabes, enfante dans sa prison un fils, de qui les exploits précoces rappellent ceux de Digénis enfant ${ }^{1895}$. Un thème semblable est celui de la Chanson d'Armouris, dont on a retrouvé plusieurs variantes à Chypre : un jeune héros délivre son père prisonnier des Sarrasins et gagne par sa vaillance l'estime d'un émir qui lui donne sa fille en mariage. Un détail historique est le passage de l'Euphrate par le héros Arestès, regardé comme un exploit miraculeux ${ }^{1896}$.

Le nombre des tragoudia, renfermant des détails plus ou moins déformés du poème de Digénis, et recueillis dans ces dernières années, est considérable : enlèvement d'Eudokia, mais à l'aide d'un luth magique, mort de Digénis, mais après un duel avec Charon ${ }^{1897}$. Certaines de ces variantes peuvent être anciennes ; d'autres seraient des altérations des cantilènes dont le poème serait sorti.

L'élément arabe. - Comme les Grecs, les Arabes avaient leurs chants épiques, qui célébraient les exploits de leurs émirs contre Byzance. On croit pouvoir reconnaître leur insertion dans les premiers chants du poème (exploits du père de Digénis). Les Arabes y sont

1893 GregorRe, Autour de Digénis Akritas, B.N., 1932, 287-302; du même : Digenis Akritas. The byzantine Epic in History and Poetry, VI-IX.

1894 GREGOIRE, Autour de Digésis Akritas, loc. cit., 290 et s.

1895 Rambaud, op. cit., 83; GregOIRE, loc. cit. Version du XVII ${ }^{\mathrm{e}}$ s., éd. Legrand, Collection de monuments..., XII, 1870, 1874.

${ }^{1896}$ Chansons recueillies par Mme Hedwige Lübke dans 4 villages de Chypre. Voir GREGOIRE dans B.N., XIV, 1939, 236 et s. (allusions historiques) et BAUD-Bovy, La chanson d'Armuris et la tradition orale, B.N., 1938, 249. 251.

${ }^{1897}$ RAMBAUD, Études sur l'histoire byzantine, 84-86; GREGOIRE B.N., VII, 296 et s.; Les exploits de Digénis Akritas, chant VIII, 283-288. 
montrés sous un jour favorable et on y lit l'énumération des villes prises par l'émir, père de Digénis, qui a soumis toute la Syrie et Koufa en Mésopotamie, ville sainte des Alides. Digénis lui-même combat moins les Arabes que les Apélates. D'autres faits de guerre arabes sont rappelés dans les diverses versions. Un roman turc reproduit un roman de chevalerie arabe et montre l'émigration dans l'Empire d'une tribu arabe de Mélitène, fait que l'on peut reconnaître dans l'établissement, dans un thème byzantin, du père de Digénis et de tous les siens ${ }^{1898}$.

Le fond historique. - De même que la Chanson de Roland, le poème de Digénis a un fond historique. Son héros a été identifié avec Panthérios, fils d'une Doukas et d'un émir arabe, devenu renégat par amour. Pantherios est un stratège célèbre de Romain Lécapène, qui le créa domestique des scholes d'Orient. En 941 il repoussa l'invasion des Russes et en 944 il força l'émir d'Édesse à livrer à l'Empire l'icône du Christ ${ }^{1899}$. Sa carrière ne correspond guère à celle de Digénis, mais ne peut-on en dire autant du comte des marches de Bretagne, devenu neveu de Charlemagne ? Les allusions au Mandylion d'Édesse dans toutes les versions du poème de Digénis, le fait que, dans le discours de la mère de l'émir à son fils, l'icône n'avait pas encore été transportée dans l'Empire, justifient l'identification de Digénis avec Panthérios.

D'autre part, Henri Grégoire a montré qu'un grand nombre de passages du poème sont empruntés à des chroniques et prêtent à Digénis les traits de certains personnages historiques ou correspondent à des faits réels. Il ne nie pas que Digénis Akritas ne soit un personnage imaginaire, symbole vivant de la valeur des Akritai, mais dont les aèdes auraient cherché à faire passer les exploits pour historiques ${ }^{1900}$.

C'est ce qui l'a conduit à rechercher la date de la version primitive, mais les nombreuses variantes et les contradictions des manuscrits rendent ce travail malaisé. Il a dû faire un examen critique des ver-

1898 Gregoire, A.C.E.B., IV, 1930, Athènes, 287 et s.; Id.. B.N., 1930, 328; M. CANARD Un personnage de roman arabo-byzantin (Congrès des Sciences Historiques, Alger, 1932) et B.N. 1932,615 et s.

1899 M.B.E.H. (Vie et mort de Byzance), 1969, 147; DiEHL, Dans l'Orient byzantin, 357; RUnCIMAN, The Emperor Romanos Lecapenus, 145; GREGOIRE, Digenis Akritas. The byzantine Epic is History and Poetry.

1900 GregOIRE, Autour de Digénis Akritas, 288 et s. et B.N., XV, 1945, 103. 
sions parvenues jusqu'à nous, dont je me contenterai de donner le résultat : d'une part, les manuscrits de Grottaferrata et de l'Escurial ont une origine commune, mais la version qui donne le tableau le plus fidèle de la société byzantine est celle de Grottaferrata; d'autre part, le groupe Andros-Trébizonde dénote une rédaction tardive et contient des épisodes nouveaux, comme l'horoscope d'Eudokia, mère de Digénis.

Le premier groupe est donc le plus ancien et, après y avoir relevé des allusions historiques, comme la lutte de Basile le Macédonien contre les Pauliciens, Grégoire date la version primitive du poème au plus tard de $900{ }^{1901}$. Elle aurait été rédigée en langue populaire. Ultérieurement, des lettrés remanièrent ce texte en langue savante. Le poème primitif ne devait comprendre que le récit des exploits du héros (chants IV, V, VI). Plus tard encore on y ajouta l'histoire de son père d'après des sources arabes (chants I à III) et la fin du héros (chants VII-VIII). Les différences notables entre les rédactions montrent que la légende de Digénis n'a jamais cessé de s'accroître d'épisodes nouveaux. Son souvenir n'a pas disparu et l'on montre encore son tombeau à l'endroit même où le fixe l'épopée, à Trosis sur l'Euphrate, non loin de Samosate ${ }^{1902}$. Il était hier encore le héros national des paysans d'Anatolie et des marins de l'Archipel.

\section{Poèmes chevaleresques}

\section{$\underline{\text { Retour à la Table des Matières }}$}

Après la croisade de Constantinople, il s'est développé, dans les mêmes régions d'Asie Mineure et des îles, tout un cycle de poèmes chevaleresques ou romans en vers, plus ou moins inspirés d'œuvres occidentales, surtout françaises ou italiennes. Leurs auteurs emploient la langue savante et le vers politique, mais leurs œuvres ont une allure

\footnotetext{
1901 Id., Le tombeau et la date de Digénis Akritas, 485.

1902 Ibidem, 499 et $\mathrm{s}$. A Trosis, première étape sur la route de Samosate à Germanicia (tombe d'un ancien roi de Commagène, aux colonnes garnies de chapiteaux ornés d'aigles); GREGOIRE, Digenis Akritas. The byzantine Epic in History and Poetry.
} 
populaire et montrent le goût de la société byzantine pour l'épopée ${ }^{1903}$.

Poèmes courtois. - On peut ranger sous cette rubrique ceux qui, par leur sujet, ont des rapports avec le cycle de la Table Ronde. Tel le Vieux Chevalier, abrégé d'un roman français en prose de la fin du VII ${ }^{\mathrm{e}}$ siècle, Gyron le Courtois. L'action se passe à la cour du roi Arthur ${ }^{1904}$.

Dans le poème de Belthandros et Chryzantza les personnages portent tantôt des noms français, tantôt des noms grecs ${ }^{1905}$. Même mélange dans le récit. Le fils du roi des Romains est reçu vassal du roi d'Antioche. Le Château d'Amour où est enfermée la princesse enchantée, délivrée par Belthandros, rappelle un thème de la poésie provençale, mais le mariage du héros est béni par le patriarche de Constantinople ${ }^{1906}$. Ce poème est un produit mixte d'une région occupée par des Français.

Callimaque et Chrysorrhoé est l'œuvre d'un prince Paléologue, Andronic, fils d'un cousin de l'empereur Andronic. Le sujet est la délivrance d'une princesse captive d'un dragon, au moyen d'un talisman. Le modèle français est particulièrement marqué dans Lybistros et Rhodamné (XIV siècle), où l'on trouve un autre Château d'Amour et des figures allégoriques qui forment la cour du dieu, auquel nul homme ne résiste ${ }^{1907}$.

Phlorios et Platziaphlora (Flore et Blanchefleur) (fin du XIV siècle) est une adaptation de la version italienne d'une légende provençale, qui montre l'amour d'un prince sarrasin pour Blanchefleur. Le conte, d'origine française, se trouve dans un des plus anciens et des plus exquis romans d'aventures écrit au XII ${ }^{\mathrm{e}}$ siècle ${ }^{1908}$. Enfin le $R o$ man de Bélisaire, calomnié auprès de Justinien, qui le fait aveugler, repose sur une légende occidentale, qui apparaît dans Grégoire de Tours et à Byzance, dans les Patria (fin du $\mathrm{X}^{\mathrm{e}}$ siècle) et dans les Chi-

\footnotetext{
1903 KRUMBACHER, Geschichte der byzantinischen Literatur, 854 et s.

$1904 \pi \rho \varepsilon \delta \beta \theta \zeta \pi \pi$ ó $\tau\rceil \zeta, 306$ vers non rimés, éd. von der HAGEN, Berlin, 1821.

1905 RoDOPHILE (Rodolphe), Belthandros (Bertrand) Chryzantza, nom grec.

1906 Edit. LEGRAND, B.G, V.; GIDEL, Etudes sur la littérature grecque moderne; KRUMBACHER, op. cit., 857 et s.; DIEHL, Figures byzantines, II, 321 et s.

1907 KrUMBACHER, 855 et s. 861 et s.; DIEHL, op. cit., II, 337 et s.

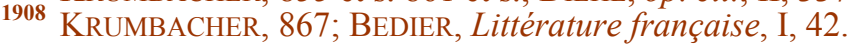


liades de Tzetzès ${ }^{1909}$. La plus ancienne version en 556 vers politiques date seulement du XV ${ }^{\mathrm{e}}$ siècle ${ }^{1910}$.

L'épopée antique. - Ce n'est pas par Homère que l'épopée antique a pénétré dans la littérature populaire, mais par les écrits fabuleux de Dictys de Crète et de Darès le Phrygien, arrivés d'Occident sous la forme d'une traduction de Dictys, composée sous Néron par L. Septimius et utilisée par Malalas dans sa chronique ${ }^{1911}$. Il existait d'ailleurs à Constantinople un récit en grec de la guerre de Troie sous le nom de Dictys ${ }^{1912}$.

Un poème anonyme du XIV ${ }^{\mathrm{e}}$ siècle intitulé La Guerre de Troie est une traduction presque littérale du Roman de Troie de Benoît de Sainte-Maure ${ }^{1913}$. Les mêmes anachronismes que dans les poèmes français se trouvent dans l'Iliade d'Hermoniakos dédiée au despote d'Epire Jean II (1323-1335). Achille y commande une armée de Hongrois et de Bulgares et les Troyens implorent la protection du prophète David ${ }^{1914}$. Il en est de même de l'Achilléide, qui semble originaire aussi de l'Épire et où l'on trouve un curieux mélange de coloris occidental et byzantin: des tournois, des apertises, les 12 chevaleries d'Achille, qui ressemblent à celles du roi Arthur, un palais avec une salle du trône, où l'on voit un platane d'or avec des oiseaux automates. Les exploits d'Achille enfant ressemblent à ceux de Digénis Akritas et il en est de même de sa mort prématurée ${ }^{1915}$.

La légende d'Alexandre le Grand, qui se trouve dans un manuscrit écrit en 1388, provenant de la bibliothèque du cardinal Bessarion, sous la forme d'un poème de 6117 vers politiques ${ }^{1916}$, dérive de l'histoire apocryphe du pseudo-Callisthène, qui remonte à l'époque alexandrine ${ }^{1917}$. La Bibliothèque de Sofia en possède une traduction

1909 Gregoire de TOURS, H.F., III, 32; BANDURI, Imperium Orientale site antiquitates Constantinopolitanae, 1, 1885; TZETZES, Chiliadès, III, 43 et s.

1910 Edit. Legrand, Bibliothèque Hellénique, I, 188; Richard SAlomon, Belisariana, dans B.Z., 1930,102 et $\mathrm{s}$.

1911 KRUMBACHER, 845.

1912 PATZIG, dans B.Z., 1892, 31 et s.

1913 Le poème de BENOIT, en 30000 vers octosyllabiques, date de 1116; SiSYPHE DE COS, [Poème de la guerre de Troyes], 231 et s.; GIDEL, Etudes sur la littérature grecque moderne, 197-229.

19148799 vers octosyllabiques, éd. Legrand, B.G.V., 1890.

1915 KrUmBACHER, 848; éd. SATHAS, A.A.E.G., 1879, 126 et s.; HAAG, Zur Überlieferungsgeschichte Vulgärdichtungen, dans B.Z., 1930, 113-120.

1916 Cod. Marcianus 408, éd. Legrand, B.G.V., 1881, et VeselovsKIJ, St-Pétersbourg, 1886.

1917 KRUMBACHER, 849 et $\mathrm{s}$. 
en serbe du $\mathrm{XV}^{\mathrm{e}}$ siècle, illustrée de peintures dérivées d'un original byzantin ${ }^{1918}$; et ce qui montre la popularité de cette légende, c'est que des épisodes en étaient reproduits sur des poteries où Alexandre portait le costume d'un empereur byzantin ${ }^{1919}$.

La Chronique de Morée ou Livre de la Conquête est le récit de la conquête du Péloponnèse par les chevaliers français et de la fondation de la principauté de Morée. Les deux versions grecques qu'on en possède ${ }^{1920}$ tiennent à la fois de l'histoire et de l'épopée. Elle sont en effet une source historique essentielle. Le récit s'arrête à l'alliance de Florence de Hainaut avec le despote d'Épire (1292). D'autre part, le ton et la description des mœurs féodales de la cour du prince de Morée, lui donnent l'allure d'un poème chevaleresque. La langue est le grec vulgaire, avec des termes byzantins entremêlés de mots français. L'auteur est défavorable à l'empire byzantin et à l'Église Orthodoxe : c'est certainement un Franc ou un gasmoul ${ }^{1921}$. La version française de cette chronique ${ }^{1922}$ coïncide entièrement avec la plus ancienne version grecque et l'on suppose qu'elles dérivent d'un prototype écrit en français ${ }^{1923}$ ou en dialecte vénitien ${ }^{1924}$.

\section{Poésie en langue populaire}

Retour à la Table des Matières

La langue populaire, parlée communément à Byzance dans toutes les classes de la société, n'a jamais produit une grande œuvre poétique, mais, comme nous l'avons vu, de petits poèmes, tragoudia, cantilènes, transcrits en langue savante, pour être englobés dans des œuvres de longue haleine, telles que la poésie rythmique ou l'épopée de Digénis Akritas.

\footnotetext{
1918 GRABAR. Les influences orientales dans l'art des Balkans, 108-133, pl. XII-XIV.

1919 XYNGOPOULOS, E.B., 1938, 207.

1920 Manuscrit de Copenhague (original) 9219 vers politiques; Paris, gr. 2898 (élaboration). Ed. parallèle des deux textes : Chronique de Morée. Version grecque Schmitt.

1921 KRUMBACHER, 833. Les Gasmouls, issus d'un mariage entre Français et Grecques.

1922 Chronique de Morée. Version française Jean Longnon. Introduction.

1923 A. ADAMANTIOU, op. cit., 516 et s. dans D.I.E.E.

1924 Chronique de Morée. Version française Jean Longnon, LXIII et s. (original entre 1305 et 1331).
} 
Cependant la poésie en langue populaire possède, surtout à partir du XII ${ }^{\text {e }}$ siècle, des genres assez variés, poèmes didactiques, satiriques, lyriques, proverbes, contes, etc., et a des tendances à devenir une littérature autonome, mais beaucoup plus semblable aux littératures en langues nationales de l'Occident, qu'à la littérature savante de Byzance. D'autre part, entre les productions des deux langues il n'existe pas de fossé profond : les mêmes auteurs écrivent en langue érudite et démotique et nous avons cité des exemples d'œuvres traduites d'une langue dans l'autre.

Poèmes didactiques. - Une sorte de traité de morale en vers, où sont reproduites les sentences d'un discours apocryphe d'Isocrate, paraît avoir été une lecture favorite des Byzantins, si l'on en juge par les 16 versions qui nous en sont parvenues. Echelonnées du XII ${ }^{\mathrm{e}}$ au $\mathrm{XVI}^{\mathrm{e}}$ siècle, elles permettent de suivre les transformations de la langue populaire et elles ont les mêmes caractères : une courte introduction, des conseils paternels d'une moralité douteuse, et beaucoup de verbiage. Une version est intitulée : Enseignement du roi Salomon à son fils Roboam ${ }^{1925}$. D'autres manuscrits attribuent l'œuvre à Alexis, fils aîné de Jean Comnène, mort avant d'avoir régné, en $1142^{1926}$. Enfin la version d'Oxford, assez indépendante des autres, porte le nom d'un auteur, Spaneas, qu'on a fini par donner à toutes les versions ${ }^{1927}$. Malgré sa faiblesse littéraire, le caractère byzantin se montre dans cette œuvre avec sa recherche de l'artifice et son mélange de dévotion et de frivolité. Des adaptations et traductions slaves attestent son succès jusqu'au XVIII ${ }^{\mathrm{e}}$ siècle.

Poèmes divers. - $\mathrm{Du} \mathrm{XII}^{\mathrm{e}}$ au XVI ${ }^{\mathrm{e}}$ siècle la langue vulgaire est employée dans les genres les plus variés : poème astrologique dédié à Manuel $\mathrm{I}^{\mathrm{er}}$ Comnène par Jean Kamateros, archevêque de Bulgarie $^{1928}$; poème anonyme écrit en 1392 sur la prise et le recouvrement de Constantinople $(1204-1261){ }^{1929}$; poésies de circonstance, éloges, canons, thrènes, etc. ${ }^{1930}$, et surtout parodies, pièces satiriques ou simplement plaisantes, œuvres de lettrés qui ne 1925 Edit. LEGRAND, B.G.V., 1880.

1926 Sur ce prince dont le portrait a été découvert dans la tribune méridionale de Sainte-Sophie Th. WhitTemore, The Imperial Portraits of the South Gallery (Haghia Sofia at Istanbul), 26.

1927 KrUMBACHER, 802 et s.; SCHMITT, Verfasser des Spaneas, dans B.Z., 1892, 316-322.

1928 JEAN KAMATERos Sur le zodiaque... (éd. Miller, N.E.M., 1872, 2, 46.112).

1929 Ed. BUCHON, Recherches sur la principauté de Morée, II, 335-367.

1930 JEAN, diacre d'Andrinople. Éloge de Jean VIII (1425), P.G., 158, 951 et s. Thrénes sur la prise de Constantinople, etc. 
plement plaisantes, œuvres de lettrés qui ne dédaignaient plus le langage parlé.

La Philosophie $d u$ père $d u$ vin est une parodie irréligieuse en 112 vers politiques, digne de « la Messe de l'Eunuque », qui tourne la liturgie en ridicule. Ces pièces, remplies d'obscénités, montrent que les milieux populaires de Byzance n'étaient pas plus raffinés que ceux qui, à la même époque en Occident, célébraient la Fête des Fous ou la Messe des Innocents ${ }^{1931}$.

D'autres pièces moins obscènes, mais au langage assez cru, ne sont pas rares : conseils à un vieillard qui épouse une jeune fille, description réaliste de la vie des courtisanes crétoises au $\mathrm{XV}^{\mathrm{e}}$ siècle dans l'Autobiographie d'Etienne Sachlikis ${ }^{1932}$, voyage aux Enfers où les nouveaux venus sont interrogés par les ombres sur ce qui se passe dans le monde ${ }^{1933}$; mais tous ces morceaux semblent pâles à côté de l'immense production mise sous le nom de Théodore Prodrome.

Les poèmes prodromiques. - Nous avons déjà rencontré la figure truculente de Théodore Prodrome et décrit son triste ménage et sa vie misérable d'auteur-parasite ${ }^{1934}$. Les manuscrits lui attribuent une masse considérable d'œuvres en vers et en prose, en langue populaire et en langue savante : pétitions, éloges, épithalames, œuvres religieuses et poèmes satiriques, qui l'ont rendu justement célèbre, mais cette production considérable, qui présente tant de contrastes, est-elle l'œuvre d'un seul auteur?

Les nombreuses pétitions et les poèmes satiriques parvenus sous son nom permettent de reconstituer la biographie d'un Théodore Prodrome, neveu d'un clerc byzantin, métropolite de Kiev, qui, au témoignage d'une chronique russe, reçut une excellente éducation, mais, par suite de son ivrognerie et de sa paresse, ne pouvait vivre de son métier d'homme de lettres. De là ses efforts pour trouver des protecteurs, qui pussent rémunérer en monnaie sonnante ses épîtres, ses épithalames, ses monodies funèbres. Il s'adressa aux deux empereurs Jean et Ma-

1931 KRUMBACHER, 809-811.

1932 Ibidem, 815 et s. (en dialecte crétois, dédié à un Français), véritable roman.

1933 Apokopos (repos du soir) KRUMBACHER, 818; éd. Legrand, B.G.V., 1881 (attaques contre l'avidité des moines).

1934 Ch. I ${ }^{\text {er }}$, p. 19-20. 
nuel Comnène, à un sébastocrator, à l'orphanotrophe Alexis Aristenos, à plusieurs princesses impériales. Il finit par recevoir de Manuel $\mathrm{I}^{\mathrm{er}}$ une prébende (charistikion) sur le monastère des Manganes ${ }^{1935}$, mais on ignore pour quelle raison il en fut privé et, de désespoir, il se fit moine sous le nom d'Hilarion. Loin de trouver le repos dans cette profession, il fut en butte aux persécutions de deux higoumènes, le père, et son fils, portant ce titre contrairement à la loi. Dans un poème adressé au basileus, il le supplie de le protéger contre ce couple tyrannique, qui le vexe de toutes les manières, lui impose les tâches les plus dures, rogne sur sa nourriture et lui inflige les pénitences les plus sévères à la moindre peccadille. Ces deux satrapes mènent une vie confortable, sont vêtus de riches habits, mangent les mets les plus recherchés et dépensent ainsi l'argent de la communauté, tandis que les moines pauvres, comme Hilarion, sont mal vêtus, dorment sur des nattes, ne prennent de bain qu'à Pâques et n'ont qu'une nourriture grossière, telle que le mélange infâme qu'on appelle par dérision le saint bouillon et qui ne ressemble guère aux poissons savoureux arrosés de vin de Chios, servis aux higoumènes ${ }^{1936}$.

Ce Ptochoprodrome, comme il s'intitule, sorte de Villon ou de Verlaine byzantin, n'est donc qu'un pauvre hère, toujours en quête d'argent, mais doué d'une verve amusante et spirituelle, qui lui assure le premier rang parmi les poètes en langue vulgaire. Or, beaucoup de manuscrits lui attribuent un nombre important d'œuvres en langue savante et de pure rhétorique. Ce sont des poèmes philosophiques, des poésies anacréontiques, des hymnes, des pièces sur les fêtes de l'Église, des poèmes astrologiques, des descriptions allégoriques des 12 mois et même des dialogues en prose imités de Lucien. C'est ce Prodrome que loue Eustathe de Thessalonique, qui vante sa connaissance de la littérature classique et sa forte instruction théologique.

Il y aurait donc eu deux Prodromes à peu près contemporains. Dans le manuscrit de Venise, qui contient les poèmes en grec vulgaire ${ }^{1937}$, le second Prodrome loue «l'écrivain illustre, l'hirondelle harmonieuse » qui fut « son ami et son précurseur», mais, quand il s'agit de faire le départ des poésies prodromiques entre les deux homonymes, il

\footnotetext{
1935 Sur le charistikion, M.B. (Institutions), 1970, p. 438.

${ }_{1937}$ Satire contre les higoumènes, 327 et s.

1937 Marc. gr. XI, 22 (XIII ${ }^{\mathrm{e}} \mathrm{s}$.).
} 
est impossible d'arriver à une solution satisfaisante. On a supposé sans beaucoup de preuves que l'un était mort en 1152 et l'autre en 1166 ; mais lequel des deux est le Ptochoprodrome et adressait des pétitions à Manuel Comnène ? Comme l'a dit Charles Diehl, «le second ressemblait au premier comme un frère » et tous deux passèrent leur vie à solliciter des secours et à se plaindre de leurs misères ${ }^{1938}$.

Ajoutons que parmi les œuvres en langue savante, attribuées par les manuscrits à l'un des Prodromes, se trouvent des pièces satiriques, dont la verve et parfois la crudité ne diffèrent pas du ton des poésies en langue vulgaire: L'ignorant ou le soi-disant grammairien ${ }^{1939}$, Contre une vieille débauchée ${ }^{1940}$, Contre les outrages faits à la raison ${ }^{1941}$, etc. Le problème est insoluble ${ }^{1942}$.

Folklore. Contes et légendes. - Des légendes originaires de l'Inde et transmises par l'intermédiaire de la Perse font partie du folklore européen et on en possède des versions en grec vulgaire. Telle est celle de Syntipas, dont la donnée rappelle les Mille et Une Nuits et dont le titre est une transcription de Sindbad ${ }^{1943}$. Le conte de Stephanitès et Ichnelatès, qui met en scène des animaux dissertant sur le gouvernement des princes, est d'origine bouddhique. Il fut traduit en pehlvi au VI ${ }^{\mathrm{e}}$ siècle et en arabe, sous le nom de Bidpaï au VIII'. La version en grec vulgaire fut composée vers 1080 par Syméon Seth, magistros et protosecrétaire, sur l'ordre d'Alexis Comnène ${ }^{1944}$. D'origine orientale est aussi le conte du Pauvre Léon (Ptochaleon), dont la sagesse impitoyable révèle à un prince que ses pierreries sont fausses, que sa fiancée est de mauvaise naissance et que lui-même n'est qu'un bâtard, mais, à chaque révélation nouvelle, les faveurs n'en pleuvent pas moins sur sa tête ${ }^{1945}$. Une Vie d'Esope, précédant ses fables, se trouve dans plusieurs manuscrits de Maxime Planoudès, qui l'a peut-être composée comme un recueil de sentences morales,

\footnotetext{
$1938 \overline{\text { DIEHL, Figures byzantines, II, } 135 \text { et s. }}$

1939 KRUMBACHER, 756 et s., n ${ }^{\mathrm{o}} 15$; textes dans P.G., 133, 1007 et s.

1940 Ibidem, $752, \mathrm{n}^{\circ} 4$.

1941 Ibidem, 752, n 6, P.G., 133, 1419.

1942 Papadimitriou, Theodor Prodromos, voir KuRTz dans B.Z., 1907 et V.V., X, 1902; KRUMBACHER, 760; MORAVCSIK, Die byzantinischen Quellen der Geschichte der Türkvölker, 326-328.

1943 (Le roman des Sept Sages), Syntipas (gr. v.) éd. Eberhard; KRUMBACHER, 891-895.

1944 Stephanitès et Ichnelatès, conte, éd. Silvestre de Sacy; KRUMBACHER, 895 et s.

1945 Edit. LEGRAND, A.A.E.G., 1872; GIDEL, Etudes sur la littérature grecque moderne, 385-400.
} 
mais s'est servi d'une rédaction qui procède de la Sagesse de Salomon et de la légende hébraïque d'Akir le Sage ${ }^{1946}$.

D'autre part, l'imagination populaire a travaillé sur des légendes du paganisme hellénique, comme celle de Charon, qui conserve son rôle de nocher dans les Descentes aux Enfers imitées de Lucien, mais qui revêt les figures les plus variées dans les tragoudia et les chansons populaires. Sous le nom de Charos, il se confond avec la Mort; il lutte contre Digénis Akritas, qu'il ne peut vaincre ; il devient Charon le ravisseur, le moissonneur, le vendangeur, le chasseur, qui ressemble au cavalier de l'Apocalypse. Christianisé, il est le messager de Dieu qui exhorte l'homme au repentir ${ }^{1947}$.

\section{Le théatre}

\section{$\underline{\text { Retour à la Table des Matières }}$}

On a déjà signalé la longue persistance du mime romain à Constantinople ${ }^{1948}$. L'existence d'un théâtre profane, de caractère essentiellement populaire, est donc hors de doute, mais on ne possède aucun texte de ces pièces, dans lesquelles l'improvisation laissée aux acteurs devait jouer un rôle capital.

Mais le peuple possédait-il aussi un théâtre religieux analogue à nos mystères dramatiques, constituant un genre littéraire avec ses lois propres ? La question, très contreversée, a été embrouillée par les théories et les contresens de Sathas, qui a discrédité l'opinion affirmative et fait la partie belle à ceux qui nient l'existence d'un théâtre byzantin. Il a confondu deux genres tout à fait distincts : le théâtre savant imité de l'antique et le théâtre religieux et populaire.

Le théatre savant. - A l'époque de la fondation de Constantinople, il $\mathrm{y}$ avait déjà longtemps que les représentations des tragédies classiques avaient cessé devant la vogue croissante des mimes, deve-

${ }^{1946}$ Edit. EBERHARD, Fabulae romanenses, Leipzig, 1872.

1947 MoravCSIK, Il Caronte bizantino dans S.B.N., III, 1931, 47-68; Hesseling, Charos, LeydeLeipzig, 1897.

1948 Supra, ch. IV, p. 97-98. 
nus à Alexandrie le seul genre dramatique vivant ${ }^{1949}$. On continua sans doute à écrire des pièces imitées des tragédies de Sophocle et d'Euripide, mais leur action dramatique est faible et les longs discours y tiennent la place principale. Mises au service de la prédication morale et philosophique, elles n'étaient pas faites pour être jouées mais, tout au plus pour être déclamées. Telles devaient être à Alexandrie les nombreuses tragédies attribuées à Lycophron (III siècle avant J.-C.), telles furent à Rome celles de Sénèque le philosophe.

Ce genre servit à la propagande judéo-chrétienne et à la polémique entre théologiens ${ }^{1950}$. Il fut naturellement adopté à Byzance, en particulier à l'époque iconoclaste par les défenseurs des images. De ce

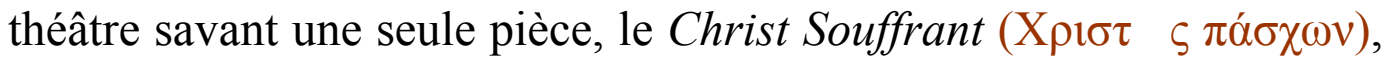
nous est parvenue. Elle est attribuée à tort à saint Grégoire de $\mathrm{Na}$ zianze et paraît être du $\mathrm{X}^{\mathrm{e}}$ ou du $\mathrm{XI}^{\mathrm{e}}$ siècle. C'est le récit dialogué de la Passion d'après les Évangiles canoniques et apocryphes, avec deux demi-chœurs de Galiléennes. Le rôle principal est tenu moins par le Christ que par la Vierge. La forme est d'autant plus près de l'antique, que sur les 2460 vers de la pièce, le tiers consiste en vers d'Euripide, d'Eschyle, de Lycophron, sans parler des emprunts à des tragédies perdues. Les seules Bacchantes ont donné 215 vers (paroles de Dionysos appliquées à Jésus) et Marie exprime sa douleur par les mêmes plaintes qu'Hécube pleurant sur ses enfants ${ }^{1951}$.

Le contraste est grand entre cette forme païenne et l'accent pathétique qui règne dans la pièce. Le cantique de la Vierge au pied de la croix semble inspiré de Romanos le Mélode ${ }^{1952}$. Les épisodes dans lesquels la Vierge intervient, sa présence sur le chemin du Calvaire, son dialogue avec Jésus au pied de la croix, ses lamentations sur le corps de Jésus (thrène) sont certainement en rapport avec les homélies de Georges de Nicomédie sur la Vierge de la Passion ${ }^{1953}$. Tous ces

\footnotetext{
1949 Découverte en 1891 des Mimes d'Hérondas (époque de Ptolémée Philadelphe, 285-247 av. J.C.). Voir WeIL dans J. S., 1891-1894. Réflexions intéressantes d'Eustathe de Thessalonique

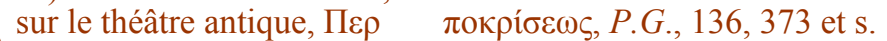

1950 LA PIANA, Le rappresentazioni sacre nella letteratura bizantina, 151-181.

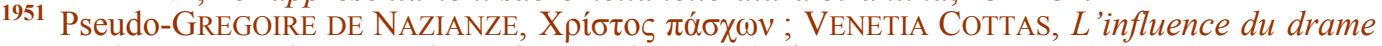
"Chrisros Paschôn » sur l'art chrétien d'Orient (voir J.S., 1932, 249-261).

1952 KRUMBACHER, 746 et s.; V. COTTAS soutient (op. cit., 225) que c'est Romanos qui s'est inspiré de la pièce.

1953 LA PIANA, op. cit., 58-60.
} 
épisodes sont en marge des Évangiles et donnent à la figure de la Vierge un aspect nouveau, celui de la Mère de Douleur ${ }^{1954}$.

Le théâtre religieux et populaire. - Des pièces comme le Christos Paschôn, œuvres de lettrés, ne pouvaient exercer aucune action sur le peuple, mais en face du théâtre savant il existait un théâtre religieux et populaire. Comme en Occident, il est né dans l'Église, dont la liturgie a par elle-même un caractère dramatique et, comme en Occident, il est sorti de l'homélie, qui a pris dès $l e \mathrm{IV}^{\mathrm{e}}$ siècle un aspect narratif, entrecoupé des dialogues, très courts, rapportés par les Évangiles (Gabriel et Marie dans l'Annonciation, Jésus et les sœurs de Lazare). Mais bientôt ces dialogues furent amplifiés par les prédicateurs, auxquels des interlocuteurs donnèrent la réplique. Ces dialogues finirent par devenir indépendants de l'homélie ${ }^{1955}$ et s'accompagnèrent des enrichissements de la liturgie au moyen des cantiques, des tropes, des hymnes populaires rythmées. Les dialogues conservés dans les homélies sont des fragments de tropes, commentés par les sermonnaires ${ }^{1956}$.

Il a donc existé à Byzance un drame sacré, mais qui n'a jamais cessé de dépendre de la prédication et de la liturgie. De plus, les homélies dramatiques, antérieures à l'époque iconoclaste, ne nous sont pas arrivées sous leur forme originale, mais ont été remaniées au $\mathrm{X}^{\mathrm{e}}$ siècle. On y reconnait aujourd'hui les parties dramatiques, dialogues, monologues, chœurs, mais noyées dans des commentaires plus ou moins verbeux. Des compilateurs recueillirent ce qui avait échappé aux iconoclastes et placèrent leurs compositions sous les noms des grands orateurs de l'époque patristique : saint Epiphane ${ }^{1957}$, Antipater de Bostra ${ }^{1958}$, Sophronius, patriarche de Jérusalem ${ }^{1959}$, André de Crète ${ }^{1960}$, etc.

\footnotetext{
1954 V. COTTAS, op. cit., 179 et s. (soutient à tort que la pièce était écrite pour être jouée). L'auteur du Christos Paschôn s'est inspiré de Georges de Nicomédie, qui a lui-même inspiré l'art religieux du XIV ${ }^{\mathrm{e}}$ siècle. Sur Georges de Nicomédie, chartophylax et ami de Photius (vers 860), Voir KRUMBACHER, 166.

1955 LA PIANA, op. cit., 34 et s. (J.S., XI, 1913, 357 et s.).

$1956 \mathrm{~V}$. COTTAS, Le théâtre à Byzance, 103-107.

1957 Éloge de la Sainte Mère de Dieu, P.G., 43, 486 et s.

1958 Sur le Précurseur, P.G., 85, 1764 et s.

1959 Sur l'Annonciation, P.G., 87 (3), 3218 et s.

1960 Sur la Nativité de la Vierge, P.G., 97, 805 et s.; LA PiAnA, op. cit., 68 et s.
} 
En réunissant les fragments ainsi conservés, La Piana est arrivé à restituer, dans leurs grandes lignes, deux trilogies. La première comprend des représentations du Baptême de Jésus, du Complot infernal contre le Christ, de la Descente aux Limbes et de la délivrance des patriarches. La seconde, aux lignes moins nettes, avait pour sujets la Jeunesse de la Vierge, l'Annonciation, le Complot des Démons contre le Messie, la Nativité, la Fuite en Egypte. Quelques épisodes de ces sujets traités dans les homélies montreront le caractère scénique des dialogues :

Dans la Descente aux Enfers, on montrait d'abord saint Jean Baptiste arrivant dans l'Hadès après son supplice et demandant à chacun des prophètes de répéter sa prédiction de l'avènement du Messie, premier exemple de la Procession des Prophètes, qui devait être en Occident le point de départ du théâtre religieux ${ }^{1961}$. En entendant ces paroles, le vieil Orcus, gardien des prisonniers, se trouble, mais Satan le rassure en lui révélant que Jésus est un homme sujet à la mort, puis il entre dans l'âme de Judas et lui persuade de trahir son Maître. Le forfait accompli, le diable revient dans l'Hadès triomphant et se moque des terreurs d'Orcus, qui rappelle la frayeur dont il fut saisi lorsqu'il entendit une voix toute-puissante appeler Lazare. Puis le Sauveur paraît, précédé de tous les ordres de la hiérarchie céleste, brise les portes, enchaîne le démon et délivre les patriarches. Un dialogue émouvant s'engage entre lui et Adam. La scène est transportée dans le Paradis, où le Bon Larron raconte comment les paroles de Jésus lui ont ouvert les portes du ciel $^{1962}$.

La Procession des Prophètes reparaît dans l'homélie du pseudo-Hésychius sur la Mère de Dieu, pour convaincre les Juifs de l'avènement du Messie. A ce prologue succèdent des dialogues animés, dans le ciel entre Dieu et l'ange Gabriel, à Nazareth entre Marie et Gabriel, puis entre Marie et Joseph, qui accable la Vierge de reproches et exprime ses soupcons en termes des plus réalistes, qui rappellent le mime. On assiste enfin à un complot des démons, qui, ne pouvant tenter Marie, la feront condamner comme adultère par le tribunal des Juifs et, s'ils échouent, inciteront Hérode à faire périr le Christ ${ }^{1963}$.

La présentation même de ces épidoses dramatiques avait un caractère poétique qui les rapprochait de la poésie rythmique. L'homélie sur l'Annonciation, attribuée à saint Proclus patriarche de Constantinople (434-446), est tout entière en prose rythmée, mais se distingue par plusieurs traits de la poésie des mélodes, notamment par l'emploi

\footnotetext{
1961 E. MALE, L'art religieux du XII siècle en France (d'après un sermon attribué à saint Augustin), 141-144.

1962 LA PIANA, op. cit., 79-97.

1963 Ibidem, 100-105.
} 
constant de la rime et l'absence de l'hirmos (strophe modèle), le type étant varié suivant les exigences du dialogue et de l'action ${ }^{1964}$.

Aux homélies étudiées par La Piana, il faut ajouter les six homélies sur la Vie de la Vierge du moine Jacques de Kokkinobaphos $\left(\mathrm{XI}^{\mathrm{e}}\right.$ siècle) et surtout le témoignage de leur illustration, dans les deux beaux manuscrits du Vatican (gr. 1162) et de Paris (gr. 1208), de la première moitié du XII ${ }^{\mathrm{e}}$ siècle et sortis du même atelier, comme le montre la concordance presque complète de leurs peintures ${ }^{1965}$.

Le texte de ces homélies sur la Nativité et la jeunesse de la Vierge suit les données du Protévangile de Jacques, mais en y ajoutant beaucoup d'autres détails, qui coïncident parfois avec ceux d'homélies antérieures ou d'apocryphes syriaques sur la vie de la Vierge ${ }^{1966}$, ou même lui appartiennent en propre, comme l'assistance de Marie aux couches d'Élisabeth et le ton très libre avec lequel elle parle du vieillard, en désignant saint Joseph.

Ainsi, à côté du Protévangile, l'homéliste a utilisé d'autres sources, beaucoup plus riches en détails pittoresques. Mais ces détails, qui supposent déjà une action dramatique, sont séparés par d'interminables amplifications oratoires. Au contraire, les peintures des deux manuscrits forment une série de scènes bien liées et présentées dans un ordre logique. Bien plus, le texte du moine Jacques ne coïncide pas toujours avec l'illustration. Le peintre est beaucoup plus complet que l'homéliste. Par exemple l'Échelle de Jacob, peinte au début du sermon sur la Nativité, n'est pas mentionnée dans le texte, mais la comparaison entre Marie et cette figure biblique se trouve dans plusieurs homélies. L'assistance des douze vieillards d'Israël à la naissance de Marie, le splendide cortège de la Présentation de la Vierge au Temple, auquel viennent se joindre les soixante anges qui gardent le trône de Dieu, et bien d'autres scènes pittoresques, appartiennent exclusivement à l'illustration.

1964 Ibidem, 128 et s., édition critique et reconstruction métrique en 50 épisodes, 203-275; MILLET, Recherches sur l'iconographie de l'Évangile... 612 (refuse d'y voir un dialogue dramatique).

1965 Homélies sur la Vie de la Vierge, de J. de Kokkinobaphos (P.G., 127).

1966 BREHIER, Les miniatures des Homélies du moine Jacques et le théâtre religieux à Byzance. (F.E.P.M., XXIV, 1921). 
La suite des peintures représente donc une action dramatique dont la Vierge, instrument du mystère de l'Incarnation, forme le centre, et qui se développe avec une véritable ampleur, depuis les Offrandes de Joachim repoussées, jusqu'à la proclamation de l'innocence de Joseph et de Marie par le Sanhédrin. Le caractère scénique des tableaux ressort de la vivacité de l'action. Les personnages se démènent et courent plus qu'ils ne marchent. Comme dans une pièce à grand spectacle, on voit se succéder les cortèges solennels, les festins, les foules, les apparitions célestes (le trône de Dieu) ou infernales (les justes dans les limbes). Les moments de l'action sont indiqués par le nombre des tableaux consacrés à un seul événement : sept pour la Présentation au Temple, huit pour l'Annonciation. Les protagonistes sont peu nombreux ; on les reconnaît à leur type et à leur costume qui sont invariables ${ }^{1967}$; autour d'eux se meut tout un peuple de figurants et probablement de choristes : les suivantes d'Anne et Elisabeth, les sept vierges de la Présentation, les douze phylarques d'Israël, les huissiers du Temple et la foule des israélites, qui intervient aux moments décisifs de l'action. Les décors sont de deux sortes : les uns, très simples, se réduisent à quatre : la maison de Joachim, l'intérieur du Temple avec l'autel des holocaustes, la maison de Joseph à Nazareth et celle d'Élisabeth. Les autres ont un aspect irréel et nous transportent au milieu des épisodes de l'Ancien Testament, au ciel devant le trône de Dieu, dans les limbes où les justes attendent la venue du Messie. Existait-il une machinerie qui permettait, comme dans les mimes, de faire passer des tableaux fantastiques sous les yeux des spectateurs? C'est ce qu'on peut supposer ${ }^{1968}$.

Tel était le cadre de ce drame, dont notre illustration permet, par son unité et ses coupures si nettes, de reconstituer la suite. Il y avait d'abord un prologue (la Conception de Marie), puis six parties, véritables actes: la Nativité de Marie, sa Présentation au Temple, l'Annonciation, la Visite à Elisabeth, l'Accusation et l'innocence reconnue ${ }^{1969}$.

${ }^{1967}$ Marie; ses parents, Joachim et Anne; le grand prêtre Zacharie; sainte Elisabeth; saint Joseph; l'ange Gabriel. Personnages accessoires : les quatre fils de Joseph, le scribe du Temple.

1968 BREHIER, op. cit., 19-22.

1969 Ibidem, 24-27, tableau de la pièce et des décors. 
Il est difficile d'assigner à cette pièce une date précise, qui ne peut être qu'antérieure au $\mathrm{XI}^{\mathrm{e}}$ siècle. Du moins un certain nombre de traits dénotent chez leur auteur une connaissance sérieuse de l'étiquette du Palais Sacré. La présence des douze phylarques à la naissance de Marie, le cortège de la Présentation, réglé comme une procession impériale, les salutations cérémonieuses des personnages nous rapprochent de Constantinople et de l'époque où, d'après Luitprand, les représentations dramatiques étaient encore en vogue à Byzance ${ }^{1970}$.

Ce qui est certain, c'est que le drame religieux avait fini par constituer un genre littéraire distinct, avec ses lois propres et sa tradition. Sans aucun lien avec la littérature antique, assez analogue par ses origines et son caractère romantique à nos mystères occidentaux, il représente, au même titre que l'hymnographie et l'épopée, l'effort tenté par les Grecs pour créer une littérature adaptée à leurs aspirations nationales.

Les destinées du drame religieux. - Un certain nombre de témoignages montrent qu'à la fin $\mathrm{du} I \mathrm{X}^{\mathrm{e}}$ et $\mathrm{au} \mathrm{X}^{\mathrm{e}}$ siècle, on célébrait à l'intérieur des églises des jeux dramatiques à certaines fêtes. Telle était la fête du prophète Élie, célébrée le 20 juillet dans la Nouvelle Église du Palais, qui lui avait été dédiée par Basile $\mathrm{I}^{\mathrm{er}}$. Ce jour-là, d'après l'auteur de la Vie de sainte Théophano, on allait chercher des vêtements somptueux dans les églises «pour habiller le saint prophète ${ }^{1971}$. Comme il ne pouvait être question d'habiller une statue, le rôle d'Élie était tenu par un acteur, peut-être un clerc, dont l'enlèvement au ciel était figuré d'une manière quelconque, au témoignage de Luitprand, qui assista le 20 juillet 968 aux jeux scéniques célébrés à cette occasion ${ }^{1972}$; d'après le Livre des Cérémonies, la fête durait deux à trois jours et comportait des chants, des danses, des acclamations, des processions et une course de chevaux ${ }^{1973}$. Le même texte mentionne des jeux scéniques, $\theta 0 \mu \varepsilon \lambda 1 \kappa \quad \pi \alpha i ́ \gamma v i \alpha$, à certaines fêtes (Dormition, Nativité de la Vierge, Épiphanie) célébrées par le

\footnotetext{
${ }^{1970}$ LuITPRAND, Relatio de legatione, 31, 353 et s.

1971 Vie de sainte Théophano, impératrice, première femme de Léon VI, éd. Hergenrbther (« Monumenta Photiana », 1869) et Kurtz; LOPAREV, Vizantitskiia Jitii Svtatuik, XVII, 71.

1972 LUITPRAND, Relatio de legatione, 31, 353 et s.

1973 CONSTANTIN VII PORPhYROGENETE, De caerimoniis aulae byzant. II, 759 et s.
} 
clergé. Les diacres représentaient des anges et venaient dans ce costume prendre part au banquet impérial ${ }^{1974}$.

Ces divertissements ne ressemblent guère aux thèmes dramatiques des homélies. Comme on le voit, les rôles n'étaient pas tenus par des acteurs professionnels mais par des clercs, et tout se passait à l'intérieur des églises. Le caractère scénique de ces jeux n'en était pas moins accusé, car ils étaient interrompus par des intermèdes profanes. Skylitzès, dans sa chronique, accuse le patriarche Théophylacte (933956) d'avoir pris l'initiative de cette coutume, qui existait encore de son temps (fin du $\mathrm{XI}^{\mathrm{e}}$ siècle), et d'avoir toléré à l'intérieur de SainteSophie des farces grotesques et indécentes ${ }^{1975}$.

Les témoignages postérieurs ne nous montrent pas de grands changements dans ces coutumes. Une constitution d'Andronic II étend au mois d'août tout entier les fêtes célébrées en l'honneur de la Dormition, mais il y est question de vigiles en l'honneur de la Vierge dans les églises qui lui sont dédiées, d'un mystère célébré à Sainte-Sophie « comme dans un firmament terrestre ou un second ciel » ${ }^{1976}$ et, à la fin du mois, des chants d'allégresse à l'église des Blachernes. Une seule allusion y est faite à des auditions de chant et à des spectacles «qui permettent de voir les choses et de les comprendre mieux que par la lecture $\gg{ }^{1977}$.

La tradition de jeux scéniques célébrés dans les églises aux grandes fêtes ne fut donc pas interrompue. C'est ainsi que le jeu des trois Hébreux dans la fournaise est mentionné au $\mathrm{X}^{\mathrm{e}}$ siècle par le typikon de Sainte-Sophie ${ }^{1978}$, par Eustathe de Thessalonique au XII ${ }^{\mathrm{e}}$ siècle ${ }^{1979}$, et était célébré toujours au XV $\mathrm{XV}^{\mathrm{e}}$ siècle. Bertrandon de La Broquière assista à cette représentation à Sainte-Sophie et ce "mistère », comme il l'appelle, dura tout un jour, détail précieux qui suppose un jeu com-

\footnotetext{
$1974 \mathrm{~V}$. COTTAS, Le théâtre à Byzance, 86 et s.

1975 G. CEDrenos, Synopsis, 68; COTTAS (L'influence du drame "Christos Paschôn » sur l'art chrétien d'Orient, 256) fait de Théophylacte l'organisateur d'un théâtre religieux sur lequel on n'a aucun renseignement.

1976 Il s'agit du mystère liturgique et non d'un mystère dramatique, sens que n'a jamais eu le mot

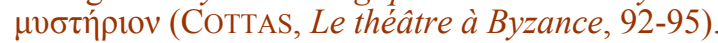

1977 P. G., 1106; COTTAS, op. cit., 96.

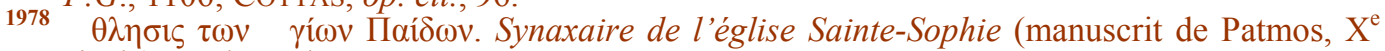
siècle), 17 décembre.

1979 Eustathe De ThessaloniQue, Opuscula, P.G., 136, 296 et s.
} 
pliqué ${ }^{1980}$. D'après la description qu'en donne Syméon de Thessalonique ${ }^{1981}$ et celle d'un manuscrit d'Iviron daté de $1457^{1982}$, c'était le seul jeu où figuraient les Hébreux. Ils étaient enfermés, non dans une fournaise, mais au milieu des cierges, levant leurs bras et leurs yeux vers le ciel, d'où descendait un ange sous la forme d'un mannequin. Les enfants chantaient alors le cantique d'actions de grâce et dansaient en mesure ${ }^{1983}$.

Mais dans sa description, Syrnéon de Thessalonique insiste sur la différence entre ces jeux, célébrés dans les églises, et par des clercs, et les mystères occidentaux, qu'il trouve anticanoniques. Il leur reproche, non sans mauvaise foi, leurs accessoires profanes, tels que la colombe du Saint-Esprit; il s'indigne de voir figurer les personnages sacrés par des laïcs indignes et même par des femmes et il justifie l'usage grec de confier les rôles de la Vierge et du Christ à des prêtres ou à des moines, à cause de leur pureté ${ }^{1984}$.

Ainsi, au $\mathrm{XV}^{\mathrm{e}}$ siècle, les Grecs avaient oublié les liens qui rattachaient l'origine de leurs jeux scéniques à ceux de l'Occident. Le théâtre religieux de Byzance, né dans l'église, retourna dans l'église, après avoir produit des œuvres qui tendaient à former un genre littéraire accessible au peuple. En Occident, au contraire, le théâtre religieux sortit de l'église et devint, à partir du $\mathrm{XIV}^{\mathrm{e}}$ siècle surtout, un genre littéraire indépendant. Ses directeurs, ses auteurs, ses acteurs furent des laïcs. Jamais le théâtre religieux de Byzance ne parvint à une telle autonomie, mais ce serait se méprendre que de nier son existence.

A vrai dire, c'est dans une seule province, l'île de Chypre, que l'on trouve un théâtre analogue à celui de l'Occident. Un manuscrit du Vatican contient un véritable livre du metteur en scène, qui indique la manière de représenter neuf épisodes de la Passion, avec des fragments de dialogues sur lesquels les acteurs pouvaient improviser ${ }^{1985}$.

1980 Bertrandon de la BroquiERE, Le Voyage d'Outre-mer, 155 et s.

1981 SYMEON DE THESSALONIQUE, Euvres, 113.

1982 Cod. 1120 daté de 1457, contient les séquences musicales composées pour ce jeu, MiLLET, Recherches sur l'iconographie de l'Evangile..., 613.

1983 Ibidem, 613, se refuse à y voir un jeu scénique.

1984 COTTAS, Le théâtre à Byzance, 99 et s.; LA PIANA, Le rappresentazioni sacre nella letteratura bizantina, 277 et $\mathrm{s}$.

1985 Cod. Palat. gr. 367, XIV siècle, découvert en 1916 par Lambros (N.H., 1916, 381 et s.), publié de nouveau par A. VoGT, Etudes sur le théâtre byzantin, 623 et s. 
Mais le manuscrit du XIV ${ }^{\mathrm{e}}$ siècle provient de Chypre et l'auteur du scénario est Constantin, primicier des notaires. Comme on l'a fait remarquer, Chypre appartenait alors à la dynastie des Lusignan et était devenue une véritable colonie française. Le texte du Palatinus montre simplement une imitation des mystères français en grec populaire. On a d'ailleurs la preuve que cette tentative eut un plein succès, comme en témoignent plusieurs pièces en dialecte chypriote des $\mathrm{XV}^{\mathrm{e}}$ et $\mathrm{XVI}^{\mathrm{e}}$ siècles, dont un curieux Mystère d'Abraham ${ }^{1986}$.

Retour à la Table des Matières

${ }^{1986}$ S. BAUD-Bovy, Sur un «Sacrifice d'Abraham » de Romanos et sur l'existence d'un théatre religieux à Byzance, 321 et $\mathrm{s}$. 


\section{Chapitre XII}

\section{La philosophie et les sciences}

\section{La philosophie et le dogme}

\section{$\underline{\text { Retour à la Table des Matières }}$}

Comme toute la culture intellectuelle de Byzance, le mouvement philosophique est lié étroitement à la tradition antique. Son existence même a été mise en doute et son étude est peu avancée. Un grand nombre de textes qui témoignent de son importance sont encore inédits et, parmi les autres, très peu ont été pourvus d'éditions critiques. Le titre de philosophe, porté par un grand nombre de personnages, n'était, on le verra, qu'un grade universitaire, obtenu après une épreuve purement littéraire.

L'existence d'une pensée autonome, occupée des problèmes qui concernent l'univers et la destinée de l'homme, n'en est pas moins incontestable. Devenus chrétiens, les Grecs n'avaient pas répudié entièrement la pensée antique. Ils avaient conscience de la supériorité que ce magnifique héritage leur donnait sur les Occidentaux et ils employaient volontiers cette pensée antique, quand elle n'était pas contraire aux dogmes, pour présenter leur foi sous une forme cohérente.

C'est en comparant la pensée byzantine à la pensée latine, que l'on saisit le mieux son originalité. La patristique grecque est très différente de celle de l'Occident. Les Grecs ont un goût marqué pour l'intuition métaphysique, qui révèle la place occupée par l'homme dans l'ordre universel. L'âme risque de s'abîmer dans la contemplation de cet ordre. Rien de pareil en Occident, où saint Augustin met 
l'accent sur l'activité pratique dans les relations de l'homme avec Dieu.

A Byzance, les philosophes, clercs ou laïcs, qui agitent ces problèmes, sortent de l'Université impériale : en Occident les universités sont fondées par les papes et recrutent leurs professeurs dans les ordres monastiques. A Byzance, au contraire, la spiritualité des moines est tournée uniquement vers le mysticisme ${ }^{1987}$. On a d'ailleurs remarqué qu'en Occident le terme de catholique est synonyme d'universel et embrasse tous les peuples du monde. En Orient, être catholique signifie être en union ou en communion avec un ensemble ${ }^{1988}$.

Ainsi la philosophie byzantine est la manifestation de la pensée chrétienne, qui s'efforce de s'appuyer sur la tradition hellénique, soit par le raisonnement et la démonstration (écoles platonicienne et aristotélicienne), soit par l'intuition du divin et la contemplation (mysticisme néoplatonicien).

Dans l'histoire millénaire de la pensée byzantine, on constate deux positions assez différentes. Du $\mathrm{IV}^{\mathrm{e}}$ au $\mathrm{IX}^{\mathrm{e}}$ siècle elle est subordonnée au dogme et n'a d'autre objet que de parvenir à l'intelligence de la révélation. A partir de la fin du $\mathrm{IX}^{\mathrm{e}}$ siècle, au contraire, on commence à étudier la philosophie pour elle-même, et son indépendance du dogme s'accroît au point d'aboutir au néo-paganisme de Pléthon, repoussé par l'Église, qui reste fidèle à la scolastique orthodoxe, conciliation entre le dogme et la pensée hellénique.

Première période (IV $\boldsymbol{V}^{e}-\mathbf{I} \boldsymbol{X}^{e}$ siècle). - Au moment où commence l'histoire de l'Empire d'Orient, du $\mathrm{IV}^{\mathrm{e}}$ au VI siècle, l'enseignement philosophique est donné dans les écoles supérieures, tantôt exclusivement païennes (Université d'Athènes avec Proclus, 410-485), tantôt chrétiennes (école de Gaza avec Enée, vers 450-534, et Procope, rhéteur et philosophe, $\mathrm{VI}^{\mathrm{e}}$ siècle). En dépit des édits impériaux, le néoplatonisme païen est encore puissant, mais il devient de plus en plus une

${ }^{1987}$ Émile BreHIER, Histoire de la philosophie, I, L'Antiquité et le Moyen Age, et TATAKIS, La philosophie byzantine, préf. par E. BREHIER.

1988 SWIETLINSKI, La conception sociologique de l'œecuménicité dans la pensée religieuse russe contemporaine, Paris, 1938; E. BREHIER-TATAKIS, La philosophie byzantine, VII, 1. (Cf. le Katholikon, église principale d'un monastère où tous les moines se réunissent, les jugescatholiques des Romains, juges suprêmes, etc.). 
religion, avec son culte et sa liturgie, et cherche, depuis Maximien et julien, à s'organiser sur le modèle de l'Église ${ }^{1989}$. L'avenir ne lui appartient plus. De son côté, la pensée chrétienne part de la révélation comme d'un fait primordial, que la raison doit interpréter pour atteindre la seule vraie raison, qui est Dieu.

A vrai dire la philosophie chrétienne ne se distingue guère de la théologie et l'on sait quelles luttes soulevèrent au $\mathrm{V}^{\mathrm{e}}$ siècle les deux méthodes opposées de l'interprétation des Écritures, celle de l'École d'Alexandrie (interprétation allégorique d'Origène) et celle de l'École d'Antioche (exégèse rationaliste et interprétation grammaticohistorique de Théodore de Mopsueste, 350-428) ${ }^{1990}$.

Un des philosophes les plus remarquables de la fin du VI ${ }^{e}$ siècle est Jean Philoponos d'Alexandrie, professeur à l'Université, où il commentait les œuvres d'Aristote. Païen, il se convertit au christianisme, qu'il trouve plus favorable à la spéculation. Sans être un pur péripatéticien (il compare Aristote à Platon), il se sert de la Logique d'Aristote et de ses Catégories, instrument merveilleux pour raisonner juste en partant d'un principe donné, dans ses exégèses du dogme chrétien. Dans son livre sur l'Eternité $d u$ Monde, dirigé contre Proclus, il disserte moins en théologien qu'en savant et déclare que Platon fut inspiré par Moïse. Dans son commentaire de la Genèse (De opificio mundi), il a recours à Aristote pour prouver que l'âme humaine et les anges sont incorporels. D'autre part, en appliquant à la Trinité la doctrine d'Aristote sur les substances et les espèces faites d'individus distincts, il tomba dans l'hérésie trithéiste, en soutenant que le Père, le Fils et l'Esprit sont trois personnes distinctes ${ }^{1991}$. Il n'en exerça pas moins une grande influence et fut un des précurseurs de la scolastique orthodoxe ${ }^{1992}$.

Diffusion des écrits du pseudo-Denys. - Un événement d'une portée considérable fut la diffusion des œuvres d'un néoplatonicien converti au christianisme, présentées sous la nom prestigieux de De-

${ }^{1989}$ Patria, éd. Preger, 229, 14. Au V e siècle congrès tenus, à cet effet, à Constantinople par les professeurs d'Athènes, Béryte, Alexandrie, sous un portique bâti par Constantin.

1990 E. BREHIER-TATAKIS, op. cit., 9-11.

1991 L. DuCheSne, L'Église au VI $I^{e}$ siècle, 342 et s.; MASPERO, Histoire des patriarches d'Alexandrie, 202.

1992 E. BREHIER-TATAKIS, op. cit., 39-50. 
nys, le seul membre de l'Aréopage que saint Paul ait pu convertir ${ }^{1993}$. Bien que la supercherie ait été découverte la première fois que son autorité fut invoquée par des évêques monophysites aux conférences d'union réunies par Justinien à Constantinople, en $533{ }^{1994}$, « on ne peut dire combien d'idées néoplatoniciennes passèrent sous le couvert de son nom, dans la mystique chrétienne ${ }^{1995}$. Dans sa Hiérarchie céleste et dans sa Hiérarchie ecclésiastique il s'agit des êtres capables de recevoir la révélation, rangés par ordre, depuis les Trônes jusqu'au dernier des fidèles. Ses autres ouvrages, Des noms divins, la Théologie mystique et deux autres perdus, formaient un cours complet de théologie. Bien qu'il prétende tirer toute sa philosophie de l'Écriture, il est imprégné des idées de Proclus ${ }^{1996}$.

Dès le milieu du VI ${ }^{\mathrm{e}}$ siècle Jean de Skythopolis publiait le premier commentaire du pseudo-Denys, mais ce fut surtout Maxime le Confesseur qui incorpora ses doctines à la vie spirituelle de Byzance ${ }^{1997}$. Désormais le néoplatonisme inspire la théologie mystique, « qui, d'après le pseudo-Denys lui-même, ne démontre pas la vérité, mais la fait voir à nu sous les symboles et y fait pénétrer sans raisonnement l'âme altérée de sainteté et de lumière ${ }^{1998}$. Dieu étant audessus de tout, l'intelligence ne peut atteindre son essence. Le seul moyen de s'en approcher est de nier tout ce qu'on peut en dire. L'extase est la seule voie qui conduise jusqu'à "Celui qui dépasse tout $\gg$.

La spiritualité monastique produisit à cette époque plusieurs doctrines mystiques. Celle de Maxime le Confesseur, qui mourut pour sa foi (580-662), est la première manifestation de l'influence diony-

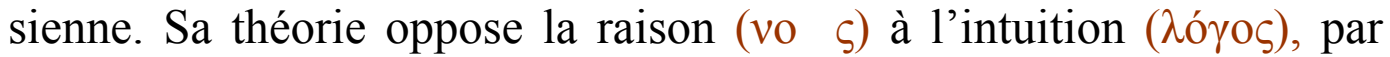
laquelle l'âme s'unit à Dieu. C'est par l'ascèse, mais accompagnée de l'amour qui sépare l'intelligence de toutes les pensées et, par la grâce

\footnotetext{
1993 Acta Apost., XVII, 34.

1994 Fliche et MARTin, Histoire de l'Église, VI, 449 et s.; DuCheSne, L'Eglise au VI siècle, 160162.

1995 E. BREHIER, Histoire de la philosophie, I, 518.

1996 Pseudo-DENYS L'AREOPAGITE; E. BREHIER, op. cit., 519-521.

1997 E. BREHIER-TATAKIS, 73-90.

1998 Pseudo-Denys L'Areopagite, epist. IX, 1, P.G., 3, 1105; E. Brehier-TAtAKis, op. cit., 25; sur la tentative pour identifier le Pseudo-Denys avec Sévère, STEFANOU dans E.O., 1932, 446.
} 
divine, à condition d'effacer de l'âme tout raisonnement, que l'on arrive à vivre en Dieu ${ }^{1999}$.

Avant Maxime, le mysticisme de saint Jean Climaque (vers 525605) est, au contraire, indépendant du pseudo-Denys et en diffère par son caractère plus pratique que spéculatif. L'Echelle, $\kappa \lambda i \mu \alpha \xi$, titre de son livre, dont on lui a donné le nom, est le symbole des efforts progressifs que l'on doit faire (détachement intérieur, retraite du monde, etc.), pour parvenir à l'impassibilité (apatheia) ou à l'hésychia (quiétisme), mort de l'âme et de l'intelligence. D'après lui, la méditation de la mort, que Platon conseille au philosophe, doit être la principale occupation du moine ${ }^{2000}$.

Ce livre eut un succès prodigieux et devint la lecture favorite des moines. Il fut traduit dans les principales langues de l'Europe.

Formation de la Scolastique Orthodoxe. - A cette époque le mysticisme, fruit d'un lointain Orient, ne sortait pas des monastères. Les clercs séculiers, élevés dans l'admiration de l'humanisme hellénique, ne cessaient de chercher la vérité par le raisonnement et la démonstration. Léonce de Byzance (485-542), défenseur du concile de Chalcédoine, a contribué par sa dialectique à l'établissement définitif de l'orthodoxie. Ses démonstrations ont parfois la forme de théorèmes. Il fut un des premiers à utiliser la Logique d'Aristote, et malgré ses dénégations, le Commentaire de Porphyre sur les Catégories. Son aristotélisme est d'ailleurs tout formel. C'est un instrument pour raisonner juste. Il s'est aussi servi de Platon et des néoplatoniciens. Il se réfère même au pseudo-Denys, mais c'est aux Pères de l'Église qu'il doit la formation de sa pensée. Il peut être considéré, avec Jean Philoponos, dont il a déjà été question, comme le fondateur de la scolastique byzantine, mais, à la différence du philosophe alexandrin, il est resté strictement orthodoxe ${ }^{2001}$.

L'œuvre de tous ces penseurs aboutit à la fin du VIII siècle à la magistrale synthèse de saint Jean Damascène: La Source de la

1999 E. Brehier-TATAKis, 7678; Fliche et MARTin, op. cit.,. V, 161 et s., 173 et s.

2000 E. BREHIER-TATAKIS, 5358; P. HeNRY, Les églises de la Moldavie du nord, des origines à la fin $d u X V I^{e}$ siècle, atlas (figuration de l'Échelle dans la peinture religieuse).

2001 E. BREHIER-TATAKIS, 71 et s.; BURY, History of the later Roman Empire, II, 375 et s.; KRUMBACHER, Geschichte der byzantintschen Literatur, 54-57. 


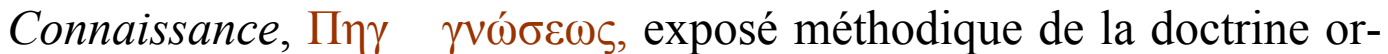
thodoxe, définie par les Pères de l'Eglise et les conciles ${ }^{2002}$. Damascène n'est ni philosophe, ni savant, mais théologien. Il connaît très bien la philosophie grecque, mais elle ne l'intéresse qu'en vue de l'élucidation du dogme. La vérité est donnée par la révélation : il reste à trouver les moyens humains de la saisir.

La Source de la connaissance. - L'ordonnance du livre annonce l'intention de rendre inutile la philosophie $d u$ dehors pour lui substituer la théologie. La première partie, Chapitres philosophiques, donne les définitions précises de l'Être, de la Substance, des Hypostases, d'après Aristote, Porphyre et Ammonios, parfois par l'intermédiaire de Léonce de Byzance. Ce sont en fait les postulats nécessaires à la construction théologique.

La deuxième partie, Sur les hérésies, en énumère cent d'après saint Epiphane, Théodoret, etc. L'auteur expose lui-même les trois hérésies récentes : celles des Musulmans, des Iconoclastes, des Aposchites ${ }^{2003}$.

La troisième partie, Chapitres dogmatiques. Exposé de la Foi Orthodoxe, est la plus complète et comprend cent chapitres. C'est un essai d'exposé complet des dogmes, depuis celui de l'existence de Dieu jusqu'à celui de la Résurrection finale. Près de la moitié des chapitres est consacrée à la Christologie. Suivant sa déclaration : " Je ne dirai rien qui soit de moi », il emprunte tout son exposé aux Pères de l'Église et aux théologiens jusqu'à Maxime le Confesseur. Il ignore la littérature antérieure au concile de Nicée ${ }^{2004}$.

L'Exposé de la Foi Orthodoxe est devenu le livre dogmatique par excellence et l'arsenal apologétique de l'Eglise d'Orient. Le dogme y était fixé une fois pour toutes. Il n'y avait plus de place, semblait-il, pour la philosophie. Telle fut la question qui se posa aux générations suivantes.

\footnotetext{
2002 Saint Jean Damascene, Euvres, P.G., 94, 429 et s.; Krumbacher, 68 et s. ; E. BrehierTATAKIS, 105 et $\mathrm{s}$.

2003 E. BREHIER-TATAKIS, 113

2004 KRUMBACHER, 68; HARNACK, Précis de l'histoire des dogmes, trad. CHOISY, 1893, 244-246.
} 


\section{La philosophie autonome}

\section{$\underline{\text { Retour à la Table des Matières }}$}

L'alliance de la pensée byzantine avec le platonisme, l'aristotélisme et surtout le néoplatonisme, entraîna au point de vue religieux des sacrifices dont les orthodoxes ne se rendirent pas compte ${ }^{2005}$. C'est ce qui explique que la philosophie, chassée de la discussion théologique par l'Exposé de la Foi Orthodoxe, ne tarda pas à reparaître, mais cultivée cette fois pour elle-même et non plus en fonction du dogme.

Photius, philosophe. - Cette tendance apparaît déjà dans l'enseignement donné à l'Université réorganisée par Théophile et en 863 par Bardas ${ }^{2006}$. Son chef, Léon le Mathématicien, et Photius, son disciple, furent accusés d'enseigner les sciences profanes et durent se justifier. Photius s'intéressait spécialement à la logique et à la dialectique, dont il composait des traités à l'usage de ses élèves. Il s'occupait dans ses cours des catégories, du genre, de l'espèce, d'après Porphyre, Ammonios et Damascène. Il traitait des Catégories d'une manière plus détaillée qu'Aristote et discutait le problème du nominalisme et du réalisme. Dans sa hardiesse, il allait jusqu'à soutenir que les discours pyrrhoniens sont utiles, sous certaines réserves, à ceux qui cultivent la dialectique ${ }^{2007}$. A Platon, il préférait Aristote, dont il trouvait la philosophie plus divine, fondée sur la nécessité logique. Dans Platon, et à travers les néoplatoniciens, il voyait surtout les mythes ${ }^{2008}$.

La philosophie de Psellos. - Psellos considère la rhétorique et la philosophie comme inséparables et moins comme une fin en soi que comme un instrument d'éducation : la plupart de ses ouvrages philosophiques sont des réponses aux questions qui lui étaient posées. Il a donc été avant tout un professeur de philosophie, mais il n'en a pas moins accentué le mouvement qui tendait à rendre la pensée philoso-

\footnotetext{
2005 E. BREHIER-TATAKIS, 97.

2006 Voir ch. XIII : Enseignement, p. 383.

2007 E. BREHIER-TATAKIS, 132.

2008 Ibidem, 132 et s. Cependant son disciple Aréthas de Césarée est platonicien.
} 
phique autonome et on peut dire que c'est de lui que date son émancipation.

D'après Psellos l'enseignement doit donner les fondements de la pensée philosophique au moyen de la Logique et de la Physique d'Aristote. C'est là le stage préparatoire à la métaphysique.

Par contre, pour étudier la métaphysique, ce n'est plus Aristote, mais Platon, Plotin, Proclus, qui permettront de s'élever à la connaissance, et ce n'est pas seulement de la pensée grecque qu'il s'agit, mais de celle de l'Orient, de l'Égypte, de la Chaldée, de la Syrie. Pour la première fois les philosophes hellènes sont regardés comme les précurseurs du christianisme: la méthode allégorique, telle que l'employait Philon d'Alexandrie, permet les rapprochements ${ }^{2009}$.

L'ambition de Psellos était de tenter une vaste synthèse de toutes les disciplines, en y comprenant même les sciences occultes, qu'il s'était donné la peine d'étudier et qu'il condamnait d'ailleurs sous le nom de chaldaïsme ${ }^{2010}$. Sa métaphysique part de la causalité et du déterminisme universel. Chaque être, chaque phénomène a sa cause, et l'on remonte ainsi jusqu'à Dieu, cause première, mais qui agit par l'intermédiaire de la nature de chaque être, de chaque phénomène ${ }^{2011}$.

Mais si tout a sa raison d'être, il s'en faut de beaucoup que toutes les causes soient connues de nous et beaucoup échappent à notre raisonnement. C'est ainsi que « tout le divin ne nous est pas abordable et toute la nature ne peut être saisie par la raison ».

Au-dessus de la raison, c'est l'intelligence (vo $\varsigma)$ qui atteint les choses directement, sans démonstration, par l'intuition.

De même on peut ressembler à Dieu par les vertus politiques (dans les rapports avec nos semblables), par les vertus purgatives (ascèse), par les vertus contemplatives et théurgiques (extase, hésychia). Mais la vie contemplative est le fait de la partie impassible de l'âme, réservée pour la vie future et inaccessible à la raison. On doit préférer pour

\footnotetext{
2009 Ibidem, 162-169.

2010 Bien qu'il reproche à Keroularios et à Jean Xiphilin de les pratiquer.

2011 E. BREHIER-TATAKIS, 176.
} 
la vie d'ici-bas la partie passible de l'âme, qui forme, avec le corps, l'homme politique et social ${ }^{2012}$.

Psellos avait puisé tous ces principes dans la philosophie de Platon et surtout de Proclus.

« Je me suis dirigé, écrit-il, vers Plotin, Porphyre et Jamblique, pour m’arrêter à l'admirable Proclus, comme dans un vaste port. C'est lui qui m'a fourni la science et de justes idées ${ }^{2013}$. »

Aux reproches de Xiphilin, qui admirait au contraire Aristote et l'accusait d'hellénisme, Psellos répondait qu'il restait fidèle à la doctrine chrétienne et qu'au surplus, il ne faisait que suivre l'exemple des Pères de l'Église, en utilisant Platon pour la défense des dogmes. Si Platon lui paraît préférable, c'est parce qu'il est le plus grand génie que le monde ait connu, le seul qui ait atteint les limites extrêmes de la pensée, le seul dans lequel on puisse voir le précurseur du christianisme par sa doctrine de la justice et de l'immortalité de l'âme et parce qu'il a compris que tout ne dépend pas du raisonnement, mais que par l'intelligence il s'est élevé jusqu'à l'Un ${ }^{2014}$.

Ainsi Psellos regarde Platon comme un théologien, qui est arrivé à ordonner nos connaissances sur le monde intelligible. Il est de ce fait le promoteur du mouvement platonicien qui, par Pléthon et Bessarion, s'est propagé dans l'Italie de la Renaissance. On peut croire que cette admiration pour Platon lui fut inspirée par Jean Mauropous, le futur évêque d'Euchaïta, dont il fut le disciple, et qui, dans une épigramme, supplie le Christ d'épargner Platon et Plutarque, si proches par leur doctrine de la loi de l'Évangile ${ }^{2015}$. C'était l'époque où le prince Grégoire Magistros (1044-1058) traduisait les œuvres de Platon en arménien ${ }^{2016}$.

La déviation de la doctrine de Psellos. Jean l'Italien. - Élève et successeur de Psellos dans son enseignement, vers 1077, Jean l'Italien continua à enseigner la philosophie d'Aristote, de Platon, des néoplatoniciens et surtout la dialectique. Il était lui-même un dialecticien

\footnotetext{
2012 Ibidem, 181.

2013 E. BREHIER, Histoire de la philosophie. L'Antiquité et le Moyen Age, 627.

2014 Ibidem, I, 627 et s.; E. BREHIER-TATAKIS, 184-187.

2015 Jean MAUropous, archevêque d'Euchaïta, P.G., 120, 1156; E. BreHIER-TATAKIS, 161 et s.

${ }^{2016}$ LANGLOIS, Vie et écrits du prince Grégoire Magister, dans J.A., $6^{\mathrm{e}}$ s. XIII, 11-17.
} 
consommé et triomphait dans toutes les disputes, si on en croit Anne Comnène, qui en fait un portrait quelque peu caricatural ${ }^{2017}$.

Comme autrefois le pseudo-Denys, Psellos avait trouvé moyen d'introduire une part de la doctrine néoplatonicienne dans le christianisme, mais il lui avait donné un sens nouveau, qui en faisait une pensée chrétienne. Il rejetait tout ce qui était contraire au dogme, la métempsycose de Platon, les supplices des âmes dans les Enfers, les extases de Plotin, les monstruosités de Proclus et même le démon de Socrate. Le procès d'hérésie qui fut intenté à Jean l'Italien sous Michel VII et Alexis Comnène (1077-1082) montre que Jean l'Italien, allant plus loin que son maître, enseignait les doctrines néoplatoniciennes presque dans leur intégralité, en les associant à l'exégèse des dogmes chrétiens.

D'après la liste des accusations portées contre lui, il enseignait les doctrines néoplatoniciennes sur l'âme humaine, le ciel, la terre, les créatures, et préférait leurs opinions à celles des Pères de l'Église. Il croyait à l'éternité de la matière et des Idées platoniciennes ainsi qu'à la métempsycose; il niait les miracles du Christ, de la Vierge, des saints ; il considérait les lettres profanes comme dépositaires de la vérité et non comme un simple instrument d'éducation intellectuelle ${ }^{2018}$. D'après la profession de foi qu'il présenta, il croyait à l'Un incréé, et incompréhensible, suivant Plotin, sans le nommer Dieu.

Italos a donc achevé d'émanciper la philosophie de la théologie, mais en renversant les termes, en faisant dépendre l'explication du dogme chrétien de la métaphysique néoplatonicienne. Il a tenu une place importante dans cette résurrection de l'hellénisme, qui devait aboutir après plus de trois siècles aux doctrines de Pléthon et qui lui valut, à l'avènenement des Comnènes, un grand succès et de nombreux disciples ${ }^{2019}$.

La suite d'Italos. - La plupart des disciples d'Italos traduits devant le concile furent acquittés, à l'exception de Nil, de Léon de Chal-

\footnotetext{
2017 Anne COMnene, Alexiade, V, 8 (II, 34-40).

2018 ECONOMOS, La vie religieuse dans l'Empire byzantin..., 25-29: E. BREHIER-TATAKIS, 213 et s.; Th. OUSPENSKY, Le procès d'hérésie de Jean Italos (I.R.I., 897, II).

2019 E. Brehier-TAtakis, 214 et s.; CEconomos, op. cit., 24; Anne Comnene, Alexiade, V, 8 (II, 37, 39).
} 
cédoine, d'Eustratios de Nicée. Celui-ci commentait Aristote, non sans émettre des opinions personnelles, et en se servant de la forme syllogistique pour comprendre la philosophie néoplatonicienne dans un esprit chrétien et prouver la vérité du christianisme par des arguments rationnels. On s'étonnera d'autant moins que ses ouvrages aient excité l'intérêt des Scolastiques occidentaux ${ }^{2020}$, qu'il enseignait la même doctrine plotinienne des hypostases qu'Abélard quelques années plus tard à Paris ${ }^{2021}$.

Époque de Nicée et des Paléologues. - Après la catastrophe de 1204 la philosophie dominante est la scolastique orthodoxe, appuyée sur la scolastique occidentale et opposée au néoplatonisme, qui cherche à assurer l'autonomie de la pensée et qui devient le néopaganisme de Pléthon. Puis scolastiques et néoplatoniciens se heurtent à la pleine expansion du mysticisme, sous la forme de la doctrine hésychaste ${ }^{2022}$.

A Nicée, Nicéphore Blemmydès (1197-1272) enseignait la philosophie et eut pour disciples Georges Akropolitès, qui devint grand logothète, et le futur empereur Théodore II Lascaris. Strictement orthodoxe, il se servait de la Logique et de la Physique d'Aristote. Les commentaires qu'il publia sur ces ouvrages d'après Porphyre devinrent le manuel favori des philosophes byzantins. Il renonça à une carrière qui eût été brillante, en se faisant moine (1235), et en refusant le patriarcat de Constantinople. Attiré par la question des universaux, il chercha à concilier le réalisme et le nominalisme, en supposant que les genres et les espèces résident dans la pensée de Dieu avant d'être formés ici-bas par les êtres. Dans l'enseignement qu'il donnait dans son monastère, il s'occupait de l'éducation et dressait le portrait du souverain idéal, roi-philosophe «qui sera tout à tous,... vrai Dieu sur la terre $\gg{ }^{2023}$.

Théodore II Lascaris, à qui ce portrait était dédié, devait à son éducation classique une grande admiration pour le passé hellénique et était aussi instruit dans le domaine de la philosophie que dans ceux de

\footnotetext{
2020 Ses commentaires, traduit en latin, furent utilisés par Albert le Grand et saint Thomas d'Aquin. E. BREHIER-TATAKIS, 216 et s.; DrAESEKE dans B.Z, V, 320 et s.

2021 E. BREHIER, Histoire de la, philosophie. L'Antiquité et le Moyen Age, 590, 628.

2022 E. BREHIER-TATAKIS, La philosophie byzantine, 231.

2023 NiCEPHORE BLEMMYDES [Autobiographie et œuvres consplètes]; E. BREHIER-TATAKIS, op. cit., 232-235.
} 
la mathématique et de la physique. Ses Six discours de la communion naturelle montrent une pensée très hardie, qui envisage la nature

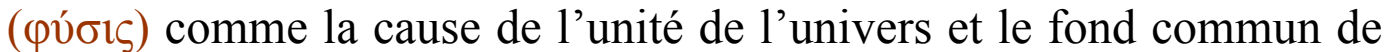
tous les êtres ${ }^{2024}$.

La philosophie d'Aristote domine toujours la pensée byzantine à la fin du XIII et au début du XIV ${ }^{\mathrm{e}}$ siècle. L'historien Georges Pachymère en écrit un exposé synthétique ${ }^{2025}$. Le moine Sophonias en publie des paraphrases, qui donnent d'un côté le texte du philosophe et en face, les scolies et les amplifications ${ }^{2026}$. Nicéphore Chumnos, épikanikleiou sous Andronic II, dirige des attaques contre Platon et les néoplatoniciens, ainsi que contre les aristotéliciens trop zélés ${ }^{2027}$. Ce qui fait le fond de ces discussions c'est toujours la question de la matière, de la substance et celle des universaux.

Philosophie, sciences et humanisme. - Théodore Métochitès (1260-1332), grand logothète d'Andronic II, n'a pas créé de système philosophique, mais, doué d'un savoir encyclopédique et d'une vaste culture, il représente le philosophe humaniste auquel les problèmes métaphysiques sont familiers. Il a la même admiration pour Platon et Aristote, et son attitude à leur égard est la même que celle de Psellos, mais il est loin d'admettre toutes leurs opinions. Son principal ouvrage, Miscellanea, est une sorte d'encyclopédie philosophique. Il y condamne la métaphysique d'Aristote et lui préfère Platon, dont il admire surtout la théorie des mathématiques. Après avoir passé en revue tout les grands mathématiciens de l'antiquité, il conclut que la mathématique, science exacte par excellence, conduit à l'intelligence de la réalité. Le nombre est en effet la nature primordiale de tous les êtres ${ }^{2028}$.

Théodore Métochitès avait aussi un goût marqué pour l'astronomie, qu'il contribua à épurer en la libérant de l'astrologie ${ }^{2029}$. Ce parfait humaniste ose condamner la vie solitaire et contemplative, qui conduirait à la destruction de l'humanité. Fin psy-

\footnotetext{
2024 Sebeos, Histoire d'Heraclius, 158 et s; E. Brehier-TATAKIS, 236-239; P. G., 140, 1266.

2025 Paraphrase du pseudo-Denys : E. BREHIER-TATAKIS, 229.

2026 Ibidem, 246.

2027 P.G., 140, 1397-1526; E. BREHIER-TATAKIS, 247 et s.

2028 E. BREHIER-TATAKIS, 249256; GuILlAND, Essai sur Nicéphore Grégoras, 6 et s.

2029 Voir § Astronomie, p.376.
} 
chologue, il remarque qu'il est absolument impossible à l'homme d'être impartial dans ses jugements. S'il lui arrive de saisir une pensée objective, il est incapable de la reproduire telle qu'il l'a reçue ${ }^{2030}$.

Disciple de Théodore Métochitès, Nicéphore Grégoras (12951360) n'a, pas plus que son maître, tenté de fonder un système philosophique, mais, excellent humaniste comme lui, il fut attiré par les études scientifiques et par la philosophie de Platon, qu'il imita dans ses dialogues. Frappé par la finalité dans la nature, il accepta la théorie platonicienne de l'âme du monde, en fait par l'intermédiaire de Plotin, et il chercha à expliquer les réactions du monde céleste sur le monde terrestre autrement que par la fatalité des stoïciens ; afin de ménager le libre arbitre de l'homme, il les attribua à la volonté divine ${ }^{2031}$.

Sur la connaissance, Grégoras préfère la méthode a priori, qui consiste à descendre du général au particulier, mais il repousse la méthode syllogistique d'Aristote et en fait une critique sévère. Il admet d'ailleurs qu'il soit nécessaire d'aller du particulier au général, à condition que l'expérience soit contrôlée par la raison. D'autre part, la raison n'est pas infaillible et ne peut par ses propres forces pénétrer jusqu'à la réalité des choses. Il abandonne ainsi la dialectique platonicienne, qui permet de s'élever des apparences sensibles à l'Idée suprême. C'est, comme on l'a remarqué, l'attachement à sa foi chrétienne qui l'amène à douter de l'infaillibilité de la raison ${ }^{2032}$.

Telle était la position de Grégoras, lorsqu'un représentant de la scolastique d'Occident, Barlaam, né à Seminara en Calabre, Grec de naissance, mais non de langue, vint en Grèce en 1328, apprit le grec à Thessalonique et vers 1330 partit pour Constantinople, où il gagna la faveur de Jean Cantacuzène qui le chargea d'enseigner la théologie au monastère du Sauveur. Sûr de lui-même et confiant dans sa méthode syllogistique, il osa provoquer à une dispute publique Nicéphore Grégoras, dont la réputation l'offusquait. Mal lui en prit : il ne put répondre aux attaques de Grégoras et fut obligé d'avouer son ignorance ; son adversaire acheva de l'accabler, en lui montrant que les syllogismes étaient le refuge des esprits médiocres. Ainsi bafoué publique-

\footnotetext{
2030 TheOdore Metochites, Miscellanea, 498.

2031 GuILland, op. cit., 149.

2032 Ibidem, 204 et s.
} 
ment, Barlaam repartit pour Thessalonique, d'où il se réfugia au Mont Athos. Mais là il se trouva dans un milieu mystique, hostile aux études classiques et à la scolastique. Toujours outrecuidant, il ne put s'empêcher de railler les pratiques des hésychastes et déclencha ainsi la longue lutte qui allait troubler l'Église et l'État. La philosophie humaniste et scolastique se heurtait au courant mystique, qui n'avait cessé de se développer dans les monastères ${ }^{2033}$.

\section{Mystiques et humanistes}

$\underline{\text { Retour à la Table des Matières }}$

Le courant mystique avant l'hésychasme. - Pendant que s'affrontaient scolastiques et rationalistes, platoniciens et péripatéticiens, le mysticisme continuait à fleurir dans les monastères suivant la tradition de Maxime le Confesseur. La vie contemplative, en dehors des œuvres et de tout raisonnement, peut seule procurer le calme et permettre de saisir le divin. Telle est la doctrine de Syméon le Nouveau qui, sentant que l'intuition mystique est incompatible avec la vie du monde, abandonna ses études de philosophie et entra au monastère de Stoudios (950-1022), où il eut pour maître Syméon l'Eulabès, mort en 986, et pour disciple Nicétas Stethatos (Pectoratus). Connu surtout par son Traité des azymes, qui fut une des causes du schisme ${ }^{2034}$, Nicétas a écrit de nombreux ouvrages mystiques presque tous inédits. Il se faisait gloire de son ignorance des sciences profanes. Dans ses «Chapitres pratiques» il définissait les trois degrés qui, selon lui, permettaient de parvenir à l'apatheia (impassibilité) ${ }^{2035}$.

La querelle hésychaste. - La crise de la discipline monastique au temps des Comnènes et des Anges ${ }^{2036}$ n'était guère favorable à la vie contemplative. Cependant elle s'était conservée dans certains monastères $^{2037}$, en particulier en Palestine et au Sinaï. Ce fut un moine du

\footnotetext{
2033 E. BREHIER-TATAKIS, 265; GUILLAND, 16 et s.; OUSPENSKY, Le mouvement philosophique et théologique au XIV siècle, dans Z.M.N.P., 1892, 279 et s.; JUGIE dans E.O., 1940, 100 et s.

2034 NicetAs Stethatos, Contra Latinos; L. BREHIER, Le schisme oriental du XI siècle, 94 et s.

2035 E. BREHIER-TATAKIS, La philosophie byzantine, 140-152; KRUMBACHER, Geschichte der byzantinischen Literatur, 152-155.

2036 M.B.E.H. (Institutions), éd. 1970, 447-449

2037 E. BREHIER-TATAKIS, op. cit., 153.
} 
Sinaï, Grégoire, qui introduisit au Mont Athos l'hésychia et la méthode d'oraison des Orientaux. Le moine, selon lui, doit chercher le lieu du cœur où sont concentrées les puissances de l'âme, en fixant son nombril, le menton appuyé sur la poitrine, en respirant à peine et en invoquant Jésus sans interruption : il obtiendra ainsi l'union immédiate avec Dieu ${ }^{2038}$. Les adeptes de cette méthode d'oraison racontaient qu'ils apercevaient une grande lumière qui les remplissait d'une joie ineffable : on y vit la lumière incréée de Dieu, distincte de son essence, telle qu'elle apparut aux apôtres sur le Thabor ${ }^{2039}$.

Telle est la doctrine que Barlaam découvrit à l'Athos et dont il entreprit de démontrer la fausseté, non sans lancer force lazzis contre la méthode d'oraison des hésychastes. Il attaqua en particulier leur chef, Grégoire Palamas, et ce fut de la riposte de celui-ci que naquit la querelle qui divisa les théologiens en deux partis irréconciliables, à la veille de la guerre civile. Nous ne reviendrons pas sur les péripéties de cette lutte, d'autant plus néfaste pour l'Empire, que la position du pouvoir, sur une question qui eût dû rester strictement religieuse, varia suivant les hasards de la politique. Ce qui nous intéresse ici c'est le conflit des deux doctrines ${ }^{2040}$.

La portée de leur désaccord est immense et dépasse le cadre théologique. C'est une lutte entre la culture universitaire, attachée à la tradition classique, et la spiritualité monastique, qui n'a que haine et mépris pour la science du dehors et confond hellénisme et paganisme. D'un côté, les scolastiques comme Barlaam et les humanistes comme Nicéphore Grégoras, de l'autre tous les moines et leur chef, Palamas, persuadés que seule l'hésychia, le quiétisme, est le degré suprême de la vie chrétienne.

Barlaam estime qu'on peut prouver la vérité du christianisme par le raisonnement, en prenant comme point de départ la pensée des anciens Grecs. Toute tendance mystique est pour lui une source d'erreur. Comme on l'a fait remarquer, il dépasse la scolastique admise jusquelà par les orthodoxes et il fonde une nouvelle scolastique, qui s'inspire

2038 GregorRe Le Sinaïte, Sur l'hésychia et la méthode d'oraison, 1237; E. BreHIER-TATAKIS, op. cit., 261.

2039 Saint Matthieu, XVII, 2; E. Brehier-TATAKIS, 262 et s.; GuILland, Essai sur Nicéphore Grégoras, 23-25.

2040 Guilland, op. cit., 2354; BarlaAm, Correspondance. Traités, P.G., 151. 
librement de celle de l'Occident. C'est la cause de son dissentiment avec Grégoras ${ }^{2041}$, mais ce qui le choquait le plus chez les Hésychastes, c'était la lumière incréée, véritable matérialisation de Dieu. Il regardait la contemplation du divin comme une connaissance à laquelle on ne pouvait arriver qu'après avoir étudié la sagesse de Pythagore, de Platon, d'Aristote. Qui connaît la sagesse connaît la vérité, qui connaît la vérité connaît Dieu. L'homme ne peut donc voir l'essence divine et ne peut percevoir Dieu que dans ses manifestations, telles que la lumière du Thabor, créée et vue par des yeux corporels ${ }^{2042}$.

Toutes ces, propositions étaient pour Grégoire Palamas autant de blasphèmes, mais il voulut opposer à ses adversaires une théorie positive de la contemplation. D'après lui, le chemin qui mène à Dieu passe par l'intelligence. Or, l'intelligence n'est pas extérieure au corps, erreur enseignée par les païens, mais elle est dans notre sentiment corporel ; quand nous voulons la purifier, c'est dans le cœur qu'il faut la rassembler. La foi est une vision du cœur, parce qu'elle dépasse les facultés intellectuelles de notre âme. La contemplation fournit la preuve la plus éclatante que Dieu existe :

C'est seulement quand la lumière remplit notre cœur, que le vrai homme va à son vrai travail, monte sur les montagnes éternelles, voit l'invisible et entre dans la région du miracle ${ }^{2043}$.

Palamas essaya enfin de justifier le caractère incréé de la lumière du Thabor par la distinction réelle, en Dieu, entre l'essence et l'opération, théorie subtile et obscure qui revient à dire que, seuls ceux qui sont secondés par la grâce, voient Dieu de leurs propres yeux ${ }^{2044}$.

Ainsi entre les deux positions, toute conciliation était impossible. La doctrine hésychaste, produit de l'Asie mystique, répugnait au fond à l'hellénisme et surtout à l'humanisme. Elle dut sa victoire temporaire à la popularité des moines et à des raisons politiques, mais elle

2041 E. BREHIER-TATAKIS, 264, remarque que les adversaires des Hésychastes étaient des aristotéliciens.

2042 BARLAAM, loc. cit, 718 et s.; E. BREHIER-TATAKIS, 265 et s.

2043 GrEgolRe PALAMAS, éd. Sophokles, 298 et s.; BREHIER-TATAKIS, 272 et s. compare cette position (sentir la vérité par le cœur) à celle de Pascal.

2044 E. BREHIER-TATAKIS, 274276; GOUILLARD, Autour du palamisme, dans E.O., 1938, 424-464 et 1939,130 et s. (Terminologie mystique). 
devint dans la pratique l'apanage d'une minorité d'ascètes, qui vivaient dans des skites (ermitages), autour des grands monastères.

Le mysticisme de Nicolas Cabasilas. - Nicolas Cabasilas, dont on connaît assez mal la biographie, était un partisan de Jean Cantacuzène qui l'employa pendant la guerre civile (1341-1355). Il se retira au monastère des Manganes. Ses deux livres, Sur la vie en Jésus et Explication de la Divine Liturgie, font époque dans l'histoire du mysticisme, presque au même titre que l'Imitation de Jésus-Christ. Adversaire de Nicéphore Grégoras, il déclara les écrits de Palamas irréprochables, mais il n'en fit aucun état et, en condamnant la vie d'anachorète, il se sépare nettement des hésychastes. Son mysticisme est à la portée de tous et se rattache à la tradition de Syméon le Nouveau et de Maxime le Confesseur. Son style est simple et souvent lyrique avec des réminiscences d'auteurs classiques. Non seulement il ne condamne pas la science, mais il trouve que les saints à qui elle a manqué sont incomplets ${ }^{2045}$.

\section{Pléthon et le néo-platonisme}

Pléthon. - Le dernier demi-siècle de Byzance est marqué par le triomphe de l'humanisme et par son expansion en Italie et dans tout l'Occident. Le principal représentant de ce mouvement est Georges Gémiste, qui changea son nom en celui de Pléthon ${ }^{2046}$. Né à Constantinople, où il fit ses études ${ }^{2047}$, il séjourna à la cour musulmane d'Andrinople ${ }^{2048}$, puis se retira à Mistra, où il dirigea une école de philosophie sous la protection du despote Théodore II Paléologue. Sa

2045 Nicolas Cabasilas, Explication de la Divine Liturgie, P.G., 150, 498-725; du même : Correspondance, 96 et s.; E. BREHIER-TATAKIS, 227-281; La Vie en JésusChrist, de Cabasilas, édit, par BROUSSALEUX en 1932.

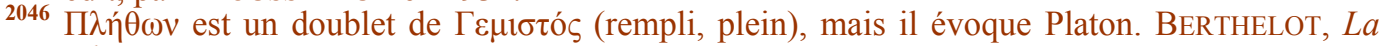
Chimie au Moyen Age, 810, 99-184.

2047 On ignore la date de sa naissance; celle de sa mort n'est pas certaine (date vraisemblable 1452, d'après JuGIE dans E.O., 1935, 160 et s).

2048 Elle y était installée depuis 1362, M.B.E H. (Vie et mort de Byzance), ed. 1969, 369. 
réputation était telle que des étudiants de Constantinople, comme Bessarion, vinrent suivre ses cours ${ }^{2049}$.

Patriote avant tout, il semble considérer les institutions de Byzance comme une déviation de l'hellénisme et y voit la cause de ses défaites. Le seul remède selon lui consisterait dans une réforme profonde de l'État, de la Société, de l'Éducation, par un retour aux traditions abandonnées. Ce fut dans ce sens qu'il adressa deux mémoires, l'un à Manuel II sur les causes du malaise social et politique (1416-1418), l'autre vers 1425 au despote Théodore, dans lequel il préconise des réformes, aussi utopiques par leur caractère que par le moment critique où se trouvait Byzance ${ }^{2050}$. Entier dans ses opinions, il se déclara opposé à l'union des Églises au concile de Florence, où Jean VIII l'avait emmené comme conseiller, parce que, pour lui, l'Union et la Croisade, loin d'être des remèdes, précipiteraient l'hellénisme dans une nouvelle servitude ${ }^{2051}$.

Avec une logique imperturbable Pléthon comprenait la religion dans sa réforme. Le christianisme n'est pas pour lui un principe d'union et il y voit une décadence de la pensée hellénique. C'est dans cette pensée, représentée par Platon et les néoplatoniciens, qu'il trouve la vérité absolue. Pendant son séjour à Florence, où il était l'objet d'une véritable vénération, il aurait dit à Georges de Trébizonde que bientôt toute la terre embrasserait une religion qui ne serait ni le christianisme, ni l'islam, mais qui ne différerait pas de l'ancien paganisme ${ }^{2052}$.

Le Traité des lois. - Il traça le programme de cette religion dans son livre Des lois, dont il emprunta le titre à Platon et qui fit scandale. Georges Scholarios le dénonça comme un livre païen ${ }^{2053}$. Défenseur d'Aristote contre Platon, il avait eu déjà une polémique avec Pléthon, dont les attaques contre Aristote lui paraissaient dirigées contre

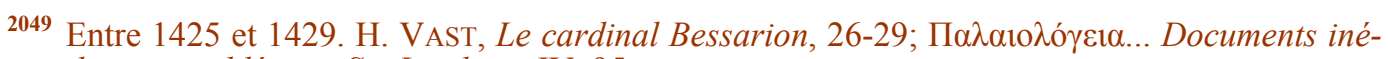
dits rassemblés par Sp. Lambros, IV, 95 et s.

2050 DieHL, Manuel d'Art byzantin, 175-180; Documents inédits..., III, 260 et s.; GEORGES Gemiste (Plethon), Discours et ouvres diverses, p. 6., 160.

2051 Milton V. Anastos, Pletho's Calendar and Liturgy, 185 et s.; E. Brehier-Tatakis, 284.

2052 Milton V. AnAstos, op. cit., 185 et s.; E. BrehIER-TATAKIS, 284 et s.; BörJE KNÖS, Gémiste Pléthon et son souvenir, B.L. (Lettres d'humanité, 1950, 113 et s.).

2053 Lettre à l'impératrice veuve de Manuel II, Documents inédits rassemblés par Sp. Lambros, II, 19-23. 
l'Église. Non seulement il avait écrit un livre contre lui ${ }^{2054}$, mais, devenu patriarche sous le nom de Gennadios, il fit brûler le manuscrit des Lois, dont il aurait épargné une partie (qui nous est parvenue), afin de pouvoir justifier sa sentence ${ }^{2055}$.

Le Traité des lois était un exposé dogmatique, plus théologique que philosophique. Il y pose des principes, d'après lesquels il légifère, sans les justifier. Il ne cite généralement pas ses sources, mais on peut deviner qu'il est familier avec la philosophie de Psellos et surtout, parmi les néoplatoniciens, de Proclus. L'ouvrage comprenait un code de réformes, sociales, politiques, morales, religieuses. Il s'agit d'assurer à l'homme son bonheur, mais il faut d'abord connaître l'homme, ce qui n'est possible que si l'on sait quelle place il occupe dans l'univers.

L'univers de Pléthon comprend des êtres divins, pures intelligences, qui résident au ciel, et des êtres composés d'une âme et d'un corps, qui habitent en dedans du ciel. Tout l'univers émane de la pensée de Zeus, le premier principe, et lui est coéternel : il procède de lui par un lien de causalité et non dans le temps. Zeus ne peut donc modifier en rien sa volonté. Il est soumis comme l'univers au déterminisme le plus rigoureux. Tout se rattache à la volonté de Zeus, mais par le lien inflexible de la fatalité, de l'Heimarmèné (ce qui échoit). Les natures des êtres sont classées d'après l'ordre de leur génération. Poseidon, fils aîné de Zeus, préside à l'ensemble de la création, ses frères aux éléments, Héra au nombre et à la multiplication des êtres, les dieux inférieurs aux lois de l'Être. A mesure que l'on descend dans la hiérarchie, les attributions sont de moins en moins générales, car, d'après la théorie platonicienne des Idées, le général embrasse le particulier.

Après la sphère des dieux, viennent les génies, les démons, les âmes sans corps, immortelles comme les dieux, mais faillibles, enfin les hommes, composés d'une âme et d'un corps, qui doivent s'efforcer d'être semblables aux dieux. Ceux-ci représentent des Idées, mais sont

\footnotetext{
${ }^{2054}$ Documents inédits (Lambros), 24 et s.; GeOrges Scholarios, (patriarche Gennadios), Euvres complètes, IV; M. JugIE, La polémique de Georges Scholarios contre Pléthon, dans B.N., $\mathrm{X}, 1935,517-530$.

2055 MILTON V. ANASTOS, op. cit., 188; BÖRJE KNÖS, op. cit., 124-132.
} 
des personnes et non des abstractions. Il en résulte que la philosophie de Pléthon est, comme celle de Jamblique et de Proclus, une religion avec son culte et sa liturgie ${ }^{2056}$. Pléthon soutenait que cette doctrine venait de Zoroastre et avait été professée par Pythagore et Platon ${ }^{2057}$.

Le premier chapitre des Lois, intitulé le culte des dieux, contient un calendrier des fêtes, inspiré des calendriers grecs de l'antiquité, comportant un compromis entre le cycle lunaire de 12 mois de 29 jours $1 / 2$ et l'année solaire de 365 jours $1 / 4$, avec un mois intercalaire pour combler l'écart entre les deux cycles ${ }^{2058}$.

A l'ancienne Grèce, Pléthon emprunte la fête des Noumenia, qui était célèbrée au commencement de chaque mois en l'honneur de Zeus ou d'une autre divinité locale ${ }^{2059}$. Son calendrier comportait ainsi 70 à 75 fêtes annuelles, réglées sur le cours de la lune ${ }^{2060}$. Des prières (en prose), accompagnées d'hymnes en hexamètres dactyliques, étaient récitées cinq fois par jour ${ }^{2061}$.

Le néoplatonisme. - C'est ainsi que Pléthon se donnait l'illusion de ressusciter le passé, de renouer la tradition au moment où elle avait été rompue, après la mort de Julien et l'exil de Proclus. Cependant, en dépit de son hostilité contre les sophistes (nom donné par lui aux chrétiens), il ne trouva rien de mieux, quand il s'agit de régler les rites de sa liturgie, que d'emprunter les pratiques dans lesquelles il avait été élevé l'usage de commencer la célébration d'une fête la veille du jour où elle tombe (vigile), ainsi que les attitudes de la prière, faite à genoux, les bras et les yeux levés au ciel $^{2062}$.

Ce n'est pas ce projet romantique qui a valu à Pléthon le respect et la réputation dont il a joui parmi ses contemporains. On a vu surtout en lui le défenseur de Platon, l'adversaire d'Aristote et de la scolasti-

\footnotetext{
2056 E. BREHIER-TATAKIS, 301-305.

2057 Milton V. AnASTOS, 190 et s.; sur les rapports de la religion de Pléthon avec l'Islam (Scholarios accusait Pléthon d'avoir été instruit de la religion musulmane par le Juif Isaac); M. V. ANASTOS, 190 et 270-294: réfutation de la thèse de Täschner dans la revue Der Islam, 1929.

2058 M. V. AnASTOS, 193-200 (on ignore le cycle adopté pour le mois intercalaire). Quelques détails dans THEODORE DE GAZA, P.G., XIX, 1168 B.

2059 M. V. ANASTOS, 238-241.

2060 Ibidem, 242-245 et 251 le 8 du mois (premier quartier) consacré à Poseidon, le 15 (pleine lune) à Athèna.

2061 Ibidem, 252 et s.

2062 Ibidem, 255-260.
} 
que. Pendant son séjour à Florence, il avait engagé Cosme de Médicis à fonder une Académie platonicienne ${ }^{2063}$. Le projet n'avait pas abouti, à la mort de Cosme en 1464, mais l'installation du cardinal Bessarion en Italie apporta une aide puissante aux platoniciens. Bessarion, malgré ses divergences religieuses avec son maître, ne l'abandonna jamais, s'occupa de ses enfants après sa mort et écrivit un traité «Contre les calomniateurs de Platon » ${ }^{2064}$. L'année même où ce traité était publié en 1479, l'Académie platonicienne était fondée à Florence par les soins du chanoine Marsilio Ficino (1433-1499), admirateur enthousiaste de Platon, dont il faisait l'éloge jusque dans sa chaire $^{2065}$.

\section{Les sciences}

$\underline{\text { Retour à la Table des Matières }}$

Byzance hérita de la tradition scientifique des anciens, mais, comme la philosophie, les sciences étaient étudiées dans les commentaires des auteurs antiques, Pythagore, Euclide, Ptolémée, etc. Cette étude elle-même n'était pas désintéressée. On considérait celle des sciences exactes comme une préparation à la philosophie. Par exemple, suivant la doctrine de Platon, les mathématiques purifiaient l'esprit en l'habituant à considérer les incorporels; elles le rendaient apte aux études de philosophie et même de théologie. C'est ainsi que saint Basile, étudiant à Athènes, prenait de l'astronomie, de la géométrie, de l'arithmétique ce qui lui était nécessaire pour s'élever à la contemplation des choses divines, $\varepsilon v \quad \sigma \varepsilon \beta \varepsilon \quad v^{2066}$.

Classification des sciences. - On s'en tenait aux sept arts libéraux de Varron, mais le programme était moins étroit que celui de l'Occident. Le Trivium concernait l'art littéraire et oratoire. Le Quadrivium ( $\tau \varepsilon \tau \rho \alpha \kappa \tau \varsigma \tau \vee \mu \alpha \theta \eta \mu \alpha ́ \tau \omega v$ ) comprenait les sciences exactes arithmétique, géométrie, musique, astronomie, confondue

\footnotetext{
2063 Ibidem, 185 (d'après Marode Ficin, préface à sa traduction de Plotin).

2064 Cardinal BeSsARION, Euvres (trad. lat.); édit, grecque Mohler, Paderborn, 1927. Bessarion regardait Pléthon comme le Grec le plus sage qu'on eût vu depuis Platon, dont il aurait semblé la réincarnation, si on avait cru à la métempsycose.

2065 M. V. ANASTOS, 185 et s.

2066 Saint Gregoire de NAZIAnZE, Homélies, or. 43, P. G., 36, 528.
} 
souvent avec l'astrologie. Bien d'autres disciplines, histoire naturelle, physique, chimie ne trouvaient aucune place dans cette classification et étaient associées sous le nom de physique. Le terme de mathemata avait aussi un sens assez général et s'appliquait à l'ensemble des sciences.

Le plan d'études d'Olympiodore comportait cinq degrés qui permettaient de s'élever jusqu'à la philosophie : logique, physique, éthique, mathématique, métaphysique ${ }^{2067}$. On retrouve à peu près le même plan aux IX ${ }^{\mathrm{e}}, \mathrm{XI}^{\mathrm{e}}$ et $\mathrm{XII}^{\mathrm{e}}$ siècles ${ }^{2068}$. Anne Comnène a lu les traités d'Aristote et les dialogues de Platon, mais a mûri son esprit par l'étude du quadrivium ${ }^{2069}$. Vers 1310 Nicolas Cabasilas, le futur mystique, tout en poursuivant ses études de théologie, a appris les sciences profanes et, en particulier, l'astronomie ${ }^{2070}$.

Mathématiques et astronomie. Période ancienne. - La plupart du temps les mêmes savants cultivent les deux sciences et il n'y a pas d'interruption entre ceux de la fin de l'antiquité et les contemporains de Justinien et d'Héraclius. Alexandrie demeure longtemps la métropole scientifique de l'Empire. Les professeurs de son Université, au $\mathrm{IV}^{\mathrm{e}}$ siècle Théon, au $\mathrm{V}^{\mathrm{e}}$ Malchos et Diophante, au VI Jean Philoponos, commentent les Éléments d'Euclide, l'Arithmétique de Nicomaque de Gérasa et 1'Almageste de Ptolémée ${ }^{2071}$. Synésius, évêque de Cyrène, invente un astrolabe plus complet que tous ceux qui avaient été construits jusque-là ${ }^{2072}$. Philoponos écrivit un Traité de l'Astrolabe et une Théorie du Monde d'après laquelle l'élément primordial est la monade, qui est une et se multiplie par sa propre révolution. Il admet la génération spontanée, mais en reconnaissant que Dieu a inséré dans la matière les germes qui s'y développeront. De ses extraits et commentaires des antiques on tira un manuel, usité dans les écoles byzantines et même en Occident ${ }^{2073}$.

\footnotetext{
2067 Commentarii in Aristotelem graeci, XII, 1, 9, 31; O. SCHISSEL, Marinos von Neapolis und die neuplatonischen Tugenden, B.N.I., I, 1928, p. 55 et 112.

Ibidem, 53 et s.

Anne Comnene, Alexiade, Préface, I, 31.

${ }^{2070}$ NicOlas CABASILAS, Correspondance, 98 et s.

2071 KRUMBACHER, Geschichte der byzantinischen Literatur, 620 et s.; sur Philoponos, E. BREHIER-TATAKIS, La philosophie byzantine, 48.

${ }^{2072}$ DruOn, Synésius; 1859, 22.

2073 De opificio mundi, E. BREHIER-TATAKIS, 48 et, s.
} 
$\mathrm{Au} \mathrm{VII}^{\mathrm{e}}$ siècle c'est encore d'Alexandrie que vient le maître ménique de l'Université de Constantinople, Étienne, qui enseigne les sciences du quadrivium, mais un autre mathématicien, Tychikos, a une telle renommée que l'Arménien Ananias de Schirak vient suivre ses cours pendant 8 ans ${ }^{2074}$.

Presque tous les astronomes avaient encore une grande confiance dans l'astrologie. Un auteur, chrétien anonyme avait cherché à la concilier avec le dogme ${ }^{2075}$. Un traité «Sur les premiers jours de la Lune » plaçait « la naissance » d'Adam le premier jour de cet astre. Les astrologues antiques, Manéthon, Vettius Valens, etc., étaient naturellement utilisés par leurs successeurs. Les manuscrits astrologiques de Florence donnent une anthologie de leurs écrits et une liste des astrologues du $\mathrm{VI}^{\mathrm{e}}$ siècle ${ }^{2076}$. Sous Héraclius un livre sur l'Art mathématique, d'Étienne d'Alexandrie, n'est qu'un exposé et un éloge de l'astrologie ${ }^{2077}$.

Du XIII au $X V^{e}$ siècle. - On n'aperçoit pas beaucoup de changement dans les travaux scientifiques des $\mathrm{XI}^{\mathrm{e}}$ et $\mathrm{XII}^{\mathrm{e}}$ siècles ${ }^{2078}$. Sous les Paléologues, au contraire, on constate un intérêt croissant pour les sciences exactes et une curiosité universelle des lettrés, qui élargissent le champ de leurs recherches. Ils ne se contentent plus de commenter des textes, mais ils se livrent à des observations de la nature, s'intéressent aux travaux des Arabes, soumettent les données de leurs devanciers à la critique et risquent des hypothèses nouvelles ${ }^{2079}$.

A Nicée, Nicéphore Blemmydès adresse un poème astronomique au basileus Jean Vatatzès à l'occasion de la mort de l'impératrice Irène (1241), mise en relation avec l'éclipse de soleil du 3 juin $1239^{2080}$. Un traité inédit du même auteur a pour titre Le Ciel et la Terre, le Soleil, la Lune, le Temps et les jours ${ }^{2081}$.

\footnotetext{
2074 COnyBeare, Ananias of Schirak (d'après son autobiographie), dans B.Z., 1897, 572 et s.

2075 HermipPos, Dialogues sur l'astrologie, éd. Kroll, Leipzig.

2076 Catalogus codicum astrologorum graecorum, codd. Florentini, B.Z., 1899, 139; CUMONT dans R.B.I., 1897, 1-12.

2077 E. BREHIER-TATAKIS, 242; CUMONT, loc. cit. (liste d'astrologues).

2078 KRUMBACHER, op. cit., 622.

2079 E. BREHIER-TATAKIS, 240.

2080 NiCEPHORE BlEMMYDES [Autobiographie et œuvres complètes]. Première éd. BuRY, dans B.Z., X, 1901, 418-424.

2081 Paris, gr. 854.
} 
Maxime Planoudès (1260-1310), dans des scolies aux livres d'arithmétique de Diophante, explique les opérations intermédiaires, que cet auteur ne donne pas, et emploie pour la première fois dans ses calculs le zéro ( $\tau \zeta \dot{i} \varphi \rho \alpha)$, emprunté aux Hindous, ainsi que les chiffres arabes. Le zéro était déjà usité en Occident, en particulier en Italie, dans les comptes commerciaux ${ }^{2082}$. Ce qui est nouveau c'est de voir Planoudès appliquer au commentaire d'un auteur du $\mathrm{VI}^{\mathrm{e}}$ siècle une pratique commerciale usitée de son temps ${ }^{2083}$.

A la même époque Nicéphore Chumnos étudie l'origine de la grêle et des vents et cherche pourquoi l'air en mouvement est froid, en réfutant les théories des «sages d'autrefois » ${ }^{2084}$; Manuel Moschopoulos écrit un traité sur la quadrature du cercle ${ }^{2085}$, et un médecin de Trébizonde, Grégoire Chionadès, qui a voyagé en Perse avec son confrère Georges Chrysokokkès, traduit en grec les livres persans d'astronomie et de mathématiques. Chrysokokkès lui-même donne une édition commentée de la Syntaxis des Perses (1346) ${ }^{2086}$.

L'astronomie, vraiment scientifique et libérée des rêveries astrologiques, fut introduite à Constantinople par Théodore Métochitès, dont on a signalé plus haut la tournure d'esprit encyclopédique et philosophique. Il arriva à l'astronomie par l'étude de la musique théorique, l'harmonique, dont relèvent les mouvements harmonieux des astres. Il cherche à introduire à Constantinople cette science qui, dit-il, purifie l'esprit, en le détachant de la vaine agitation du monde. Il a conscience qu'elle était en sommeil et que, par ses efforts, il l'a ranimée ${ }^{2087}$. Dans ses ouvrages encore inédits ${ }^{2088}$, il passe en revue tous ses devanciers en particulier Ptolémée, et en donne une étude critique. Il a lutté surtout contre les préjugés tenaces qui discréditaient l'astronomie, confondue communément avec l'astrologie. Il soutient d'ailleurs, contre certains hommes d'église, que l'astronomie n'a au-

\footnotetext{
2082 A Florence l'emploi du zéro fut d'abord interdit aux marchands. (Ordonnance de la Seigneurie en 1299).

2083 E. TANNERY, Les chiffres arabes dans les manuscrits grecs, B.A., 1886.

2084 KRUMBACHER, 479.

2085 E. TANNERY dans A.A.E.G., XX, 1886

2086 E. BREHIER-TATAKIS, 243; KRUMBACHER, 622 et s.; M ${ }^{\text {gr }}$ ChrYsAnTHOS, op. cit., 332-339.

2087 TheOdore Metochites, Miscellanea (éd. Müller-Kiessling, 253. Préface : " de quelques charbons sous la cendre, s'est élevée une flamme puissante »; E. BREHIER-TATAKIS, 253.

2088 Seule la Préface aux éléments a été éditée par SATHAS, B.M.Ae., I, LXXXV-CXI.
} 
cun rapport avec la foi, mais n'est qu'une connaissance méthodique d'êtres créés ${ }^{2089}$.

Disciple de Théodore Métochitès, Nicéphore Grégoras, dont nous avons mentionné les doctrines philosophiques, a laissé une œuvre scientifique importante, mais en grande partie inédite. Ses travaux font suite à ceux de son maître, qu'il s'agisse de l'arithmétique de Nicomaque, dont il glose les commentaires, des harmoniques (il complète les Harmoniques de Ptolémée et écrit un opuscule sur les rapports ou intervalles musicaux comparés à ceux des planètes); enfin de l'astronomie, qu'il défend comme Théodore Métochitès contre ceux qui la confondent avec l'astrologie. Il admet cependant que l'astronomie permet de connaître l'influence des astres, et en particulier de la lune, sur la terre et les hommes ${ }^{2090}$. Il va même jusqu'à croire, comme Ptolémée, que la position des astres permet de prédire la destinée de l'homme (thème généthliaque) ${ }^{2091}$.

Son langage souvent très mordant à l'égard des charlatans qui abusaient de la crédulité humaine, lui fit de nombreux ennemis.

Un de ces imposteurs avait prédit à Anne de Savoie la mort prochaine de Jean Cantacuzène, alors en pleine révolte (1341). Grégoras le confondit facilement, mais l'impératrice lui fut désormais hostile ${ }^{2092}$.

Parmi ses travaux astronomiques, il en est deux qui manifestent un véritable progrès : la prédiction des éclipses et le projet de réforme du calendrier. Après avoir écrit un commentaire de la Grande Syntaxe $^{2093}$ de Ptolémée, il s'intéressa au calcul des éclipses du soleil et de la lune et ne tarda pas à le mettre en pratique. A des contradicteurs fallacieux qui lui demandaient s'il pouvait aussi retrouver les dates des éclipses d'autrefois, il rappela les plus importantes, depuis celle de 448 sous Théodose II ${ }^{2094}$.

\footnotetext{
2089 TheOdore Metochites, op. cit., 252-254; GuILland, Essai sur Nicéphore Grégoras, 7 et s.

2090 GuILLAND, op . cit., 278; il connaît l'action de la lune sur les marées.

2091 D'après le Genethlialogikon de Ptolémée.

2092 NiCEPHORE GREGORAS, Histoire romaine, XIV, 8, 721; GuILlAND, 278 et s.

2093 Syntaxis $=$ ordre, composition.

2094 NicephORE GregOrAS, Correspondance, 134, prédit une éclipse pour le 30 nov. 1331.
} 
Son traité sur 1'Astrolabe, plus complet que celui de Philoponos, paraît avoir eu un grand succès, si l'on en juge par le nombre des manuscrits qui l'ont conservé. Suivant la méthode indiquée par Ptolémée, il montra la manière d'établir l'astrolabe sur un planisphère et de représenter les cercles concentriques ${ }^{2095}$.

Mais son œuvre la plus originale fut son traité Sur la date de Pâques, qu'il présenta à Andronic II en 1324 et qu'il inséra dans son Histoire. Il y signale l'erreur du calendrier julien, qui donne à l'année 365 jours un quart, d'où les troubles apportés dans le calendrier ecclésiastique $^{2096}$ : la fête de Pâques n'était plus fixée d'une manière immuable. Grégoras proposait de la rendre fixe, de manière qu'elle fût célébrée le même jour dans toute la chrétienté. Andronic II qui approuvait la réforme n'eut pas la hardiesse de l'ordonner ${ }^{2097}$.

Après Grégoras, le plus grand astronome de Byzance fut Théodore Méliténiotès, qui était vers 1361 grand sacellaire et chef de l'École

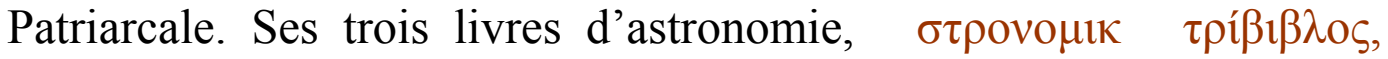
forment une encyclopédie, dont les sources sont les travaux de Ptolémée, de Théon et des astronomes persans, qu'il connaissait par des traductions. Dans sa préface il fait l'éloge de l'astronomie et déclare qu'après la théologie, elle est le meilleur chapitre de la philosophie, qui nous élève au-dessus des choses visibles. Elle a pour unique objet la prévision des mouvements des corps célestes, mais toute autre prévision est vaine. Ainsi les saines doctrines de Métochitès avaient fini par triompher, mais l'astronomie byzantine n'avait pu sortir du cadre de Ptolémée, pas plus d'ailleurs que l'Occident avant Galilée ${ }^{2098}$.

Sciences naturelles et appliquées. - En marge du quadrivium, certaines sciences étaient cultivées en vue de leur application pratique. Il y eut à Byzance des inventeurs comme l'architecte de SainteSophie, Anthémius de Tralles, qui avait imaginé une machine à vapeur et des jeux de miroirs inspirés des miroirs incendiaires d'Archimède, mais qui n'utilisa ses inventions que pour mystifier un

\footnotetext{
95 GUILLAND, 279-282.

2096 La fraction réelle est de 24 secondes, 22166.

2097 GUILLAND, 282-284. La question avait été agitée en Occident au XIII ${ }^{\mathrm{e}}$ siècle.

2098 TheOdore Meliteniotes, Astronomike tribiblos, P.G., 149; E. BreHiER-TAtakis, La philosophie byzantine. Sur les théories retardataires, explications de Phrantzès sur les tremblements de terre, les comètes, etc. Phrantzes, Chronique, IV, 7 (P.G., 156, 950 et s.).
} 
voisin avec lequel il était en procès ${ }^{2099}$. Par contre, l'invention du feu grégeois par le Syrien Callinicus fut appliquée immédiatement à la guerre et l'on sait quelle fut son efficacité dans les guerres navales ${ }^{2100}$.

L'alchimie, dite la science sacrée, n'était pas non plus une science désintéressée, mais reposait sur la croyance à la transmutation des métaux. On avait observé que les gisements d'or contenaient souvent de l'argent, que les minerais d'argent étaient mélangés de plomb et de cuivre : on en concluait que les métaux avaient une vie souterraine et que, par une lente évolution, ils atteignaient le stade le plus parfait, c'est-à-dire l'or. Les alchimistes cherchaient donc un agent tel que la pierre philosophale, qui pût hâter cette transmutation ${ }^{2101}$.

Le terme de chimie $\chi 0 \mu \varepsilon \quad \alpha$ (mixture) apparaît au $\mathrm{IV}^{\mathrm{e}}$ siècle ${ }^{2102}$ et, plus tard, des copistes y ajoutent le préfixe arabe al. L'alchimie était sous le patronage de Saturne et plusieurs astrologues étaient en même temps alchimistes. Le plus ancien alchimiste grec est Zozime, de Panopolis en Égypte (fin du IV ${ }^{\mathrm{e}}$ siècle), mais beaucoup de traités d'alchimie furent mis sous des noms illustres : Démocrite, Théophraste, Moïse, et même Justinien et Héraclius. Au v siècle, Olympiodore, qui fit partie d'une ambassade à Attila et avait parcouru l'Égypte et la Nubie, prétendait que toute la science alchimique était exposée en hiéroglyphes sur les murs du temple d'Isis à Philé. L'alchimie ne cessa d'être cultivée à Byzance, et au XI $\mathrm{e}^{\mathrm{e}}$ siècle, dans sa Chrysopée, Psellos étudiait les recettes qui permettaient de faire de l'or ${ }^{2103}$.

Histoire naturelle. - Les livres de zoologie, de botanique, de minéralogie n'eurent jamais à Byzance une valeur scientifique. Leurs auteurs recherchaient surtout les faits merveilleux ou se plaçaient au point de vue pratique. Par exemple, au $\mathrm{V}^{\mathrm{e}}$ siècle Timothée de Gaza décrivait les animaux de l'Inde d'après Ctésias et Arrien ${ }^{2104}$. Sous le

\footnotetext{
2099 DIEHL, Justinien et la civilisation byzantine au VI siècle, 473 et s.; KRUMBACHER, Geschichte der byzantinischen Literatur, 621-624.

${ }^{2100}$ M.B.E.H. (Institutions), éd. 1970, 331 et s.

2101 M. Berthelot, La Chimie an Moyen Age, 3 vol., 1893, et R.D.M., 1893; Houllevigue dans le Journal des Débats, 3 nov. 1941; KrUMBACHER, op. cit., 632-634. E. GILSON (Le Monde, 30 nov. 1949) montre la continuité entre les travaux des alchimistes et la chimie atomique.

2102 KRUMBACHER, 632; Alchimistes grecs, éd. Berthelot et Rulle, (papyrus de Leyde, fin III ${ }^{\mathrm{e}}$ au IV siècle).

2103 RuELLE, La chrysopée de Psellos dans R.E.G., 1889, 260 et s.

2104 KRUMBACHER, 631 et $\mathrm{s}$.
} 
nom de Physiologus, une description des animaux réels ou fantastiques, remontant au deuxième siècle de l'ère chrétienne, avait une vogue extraordinaire à Byzance, comme le montrent les manuscrits illustrés de cet ouvrage. On y ajouta des commentaires qui donnaient à chaque animal un aspect symbolique et religieux; la plus ancienne version grecque est celle de Georges de Pise, chartophylax vers $630^{2105}$. En revanche des traités sur les faucons sont destinés aux chasseurs et leur objet est exclusivement utilitaire.

Géographie et voyages. - Les ouvrages de géographie comprennent : $1^{\circ}$ de simples itinéraires avec évaluation des distances : tel est le Périple de la Grande Mer (Méditerranée) d'un anonyme, qui décrit des voyages d'Alexandrie aux Colonnes d'Hercule, l'un en suivant la côte d'Afrique, l'autre par Constantinople et la côte européenne ; il évalue les distances en stades ${ }^{2106}$.

$2^{\circ}$ Des descriptions du monde empruntées à des auteurs antiques. Tels sont les extraits de l'ouvrage géographique d'un inconnu dans un manuscrit astrologique. On y trouve des fragments de cosmologie d'origine antique, la description des 12 grandes montagnes de la terre, des quatre mers, du fleuve Océan, au-delà duquel est le Paradis, des sept climats, et des dissertations sur la cause des tremblements de terre, la nature des eaux thermales, les quatre parties du ciel et les aventures de navigateurs inconnus autrement ${ }^{2107}$. De même au XIII ${ }^{\mathrm{e}}$ siècle, le Manuel de géographie (Géographie synoptique) de Nicéphore Blemmydès est en grande partie une paraphrase de Denys le Périégète ${ }^{2108}$; mais dans un autre ouvrage, il a étudié le volume de la terre et affirmé sa sphéricité ${ }^{2109}$.

$3^{\circ}$ Les récits de voyageurs et de navigateurs, la plupart du temps des commerçants, tels que Kosmas Indikopleustès, auteur de la Topographie chrétienne, que nous avons signalée à propos des relations commerciales avec l'Inde ${ }^{2110}$.

\footnotetext{
2105 StrZYGOWsKi, Der Bilder Kreis des griechischen Physiologus, B.A., II, 1890.

2106 Fin du IV siècle, G.G.M., I, 427-454.

2107 DelatTe, Geographika dans B.Z., 1930, 511-518.

2108 NiCEPHORE BLEMMYDES, éd. Heisenberg.

2109 KRUMBACHER, 446 et s.; G.G.M., II, 458 et s.

2110 Supra, ch. VII, p. 170.
} 
Un témoignage intéressant montre qu'au XIV ${ }^{\mathrm{e}}$ siècle la boussole, $\mu \alpha \gamma \vee \eta \tau 1 \kappa \quad \pi v \xi i \xi \mu$, était connue à Byzance ${ }^{2111}$. Les cartes géographiques étaient sans doute d'un emploi courant, comme en témoigne l'envoi à l'empereur Julien par Alypius, vicaire de Bretagne, d'une carte accompagnée de vers ïambiques (350). Une nomenclature des provinces et des villes de l'Empire, comme le Synekdemos d'Hiéroclès ( $\mathrm{VI}^{\mathrm{e}}$ siècle), suppose l'emploi d'une carte. Un savant de Trébizonde, Georges Ameroutzès, établit sur un peplum pour Mahomet II une carte du monde d'après la géographie de Ptolémée avec les noms des pays en caractères arabes ${ }^{2112}$.

La Médecine. - La médecine byzantine se rattache aux grands médecins de l'antiquité, surtout à Hippocrate et à Galien et aussi à l'Asclépiade Hérophile, né vers 300 avant notre ère ${ }^{2113}$, et à Pédianos Dioscoridès (premier siècle de notre ère), dont l'ouvrage en 24 livres fut réédité luxueusement pour la princesse Julia Anicia, morte en $524^{2114}$.

Cependant la pratique obligea les médecins à tenir compte de l'expérience, mais ils cherchèrent à l'adapter aux théories anciennes d'Hippocrate (théorie des humeurs et des tempéraments) et de Galien (emploi des électuaires comme la thériaque, composée de 20 à 60 substances). Le résultat de cette science, surtout livresque, fut le manque de découvertes et d'hypothèses fécondes. Le travail médical fut limité au diagnostic, à la connaissance des symptômes et au traitement pharmaceutique ${ }^{2115}$.

Les manuscrits médicaux, tels que celui de Bologne, renferment des fragments d'œuvres de médecins célèbres des $\mathrm{IV}^{\mathrm{e}}$ et $\mathrm{V}^{\mathrm{e}}$ siècles ${ }^{2116}$. On cite Oribase de Pergame (325-400), médecin favori de Julien, qu'il accompagna dans ses expéditions. Il avait composé une encyclopédie médicale en 70 livres, qui était une compilation d'Hippocrate et de

2111 Introduite par les navigateurs italiens, mentionnée par Marc ANGE dans Eros, poème sur l'Amour ( $x i v^{\mathrm{e}}$ siècle), édit. Lambros, N.H., 1923, 273 et s.

$2112 \mathrm{M}^{\mathrm{gr}}$ ChRYSANTHOS, op. cit., Athènes, 1933, p. 322.

2113 Qui disséqua le premier un cadavre humain.

2114 J. EBERSOLT, La Miniature byzantine, 9 et s.

2115 F. BRUNET, Euvres médicales d'Alexandre de Tralles, I, 100 et s.

2116 Bibliothèque universitaire de Bologne, 362, XIV siècle; ZERVOS dans A.C.E.B., III, Athènes, 1930. 
Galien avec paraphrases ${ }^{2117}$. Jacques le Psychestre (le rafraîchissant), ami et confident de Léon $\mathrm{I}^{\mathrm{er}}$ devait son surnom au régime végétarien, accompagné de bains froids et de purgations qu'il prescrivait aux hommes d'affaires, bureaucrates et intellectuels ${ }^{2118}$.

Le médecin le plus remarquable du $\mathrm{VI}^{\mathrm{e}}$ siècle, Alexandre de Tralles, appartenait à une famille de savants. Son père, Étienne, et son fils furent médecins; il avait pour frères Anthémius, l'architecte de Sainte-Sophie, Métrodore rhéteur, Olympios jurisconsulte et Dioscore médecin ${ }^{2119}$. Lui-même fit ses études à Alexandrie et dans d'autres villes. Il entreprit de nombreux voyages en Arménie, en Thrace, à Corfou, en Afrique, à Rome, en Gaule, en Bretagne, en Espagne ${ }^{2120}$. Son œuvre médicale se trouve dans de nombreux manuscrits, dont l'un, du IX ${ }^{\mathrm{e}}$ siècle, au Mont-Cassin, atteste la renommée qu'il ne cessa d'avoir au moyen âge ${ }^{2121}$.

Alexandre de Tralles s'y révèle comme un praticien, observateur consciencieux, ami de l'ordre, de la clarté, de la logique. Comparant entre elles les théories de ses prédécesseurs, il adopte celles qui se rapprochent le plus de ses observations. Il réduit au minimum les questions de pure doctrine. Pour ses explications, il a recours tantôt à l'humorisme, tantôt au simple empirisme. Il cherche d'abord à se rendre compte de l'état du malade, puis à le soulager et à le guérir. Dans ses ouvrages il parcourt la thérapeutique entière, y compris l'oculistique ${ }^{2122}$.

«Il a fait de la thérapeutique une étude clinique qui n'est inféodée à aucune secte médicale, qui met en œuvre toutes les ressources, non seulement de la matière médicale, mais aussi de l'hygiène, de l'alimentation, des agents physiques et mécaniques... Il manie les régimes alimentaires, le régime lacté, les sels, les alcalins, les eaux minérales et thermales, l'opothérapie, la lumière, les climats, d'une façon empirique, mais en se proposant de les approprier avec précision au but à atteindre. La saignée, la purgation, la révulsion, la cautérisation sont légitimées par l'état évident de l'organisme et non par des hypothèses, même logiques, dérivées des théories humorales ${ }^{2123}$.»

\footnotetext{
2117 ZERVOS, loc. cit.

2118 F. BRUNET, op. cit., 95 et s.

2119 Ibidem, 4 et $\mathrm{s}$.

2120 Ibidem, 14-23 (suppose qu'il fut médecin des armées de Bélisaire).

2121 Ibidem, I, 48-60 et 62-76. Apprécié des médecins arabes, trad. en latin, en arabe, en hébreu.

2122 Ibidem, I, 94-98.

2123 Ibidem, 294 et s.
} 
Malheureusement, cette tendance à préférer l'expérience aux théories anciennes ne persista pas dans les œuvres médicales. Paul d'Égine, chirurgien et accoucheur du temps d'Héraclius, a laissé encore un manuel inspiré d'Oribase avec des observations nouvelles ${ }^{2124}$. Dans la suite la médecine est considérée avant tout comme une science théorique, dont l'étude complétait celles du quadrivium et de la philosophie. Des savants comme Nicéphore Blemmydès, Holobolos et d'autres moins connus ont fait des études médicales ${ }^{2125}$. Par réciprocité, des actuarioi (médecins impériaux) sont en même temps des savants de premier ordre. Nous avons eu l'occasion d'indiquer les initiatives des médecins de Trébizonde, qui traduisirent en grec les ouvrages persans de mathématiques et d'astronomie ${ }^{2126}$. Ce fut un service du même ordre que rendirent certains actuarioi des $\mathrm{XIII}^{\mathrm{e}}$ et $\mathrm{XIV}^{\mathrm{e}}$ siècles en introduisant à Byzance la médecine et la pharmacie des Arabes. Nicolas Myrepsos compila des recettes arabes en 48 chapitres. Son livre, introduit en Occident, fut reconnu au XVII siècle comme Codex pharmaceuticus de la Faculté de Médecine de Paris. Sous Andronic III l'actuarios Jean dédia au mégaduc Apokaukos un livre dans lequel il réfutait les doctrines de Galien et exposait celles des Arabes, ainsi que des observations personnelles ${ }^{2127}$.

Mais on peut se demander quel était le sort des malades en face de théoriciens qui défendaient leur système favori. Le récit que fait Anne Comnène de la mort d'Alexis I ${ }^{\mathrm{er}}$ est significatif : les médecins appelés à son chevet ne s'entendaient pas. "Chacun diagnostiquait différemment et préconisait un traitement conforme à son diagnostic. » Aucun d'eux ne put expliquer la cause de l'oppression du basileus : finalement on le saigna, ce qui l'affaiblit davantage sans le soulager ${ }^{2128}$.

Pour le commun des mortels les praticiens avaient à leur disposition des aide-mémoire thérapeutiques ${ }^{2129}$, mais à côté de la médecine

\footnotetext{
Ibidem, 98 et $\mathrm{s}$.

F. FUCHS, Die höheren Schulen von Konstantinopel im Mittelalter, 61; REY, La maturité de la pensée scientifique en Grèce, E.H., (S.C., 3), 1949, 453.

2126 Supra, p. 375-376.

2127 KRUMBACHER, 615.

2128 AnNe COMnENE, Alexiade, XV, 11 (III, 232 et s.). - Cf. le traitement de Jean Vatatzès après une attaque d'apoplexie (février 1255) : PACHYMERE, Histoire, I, 23 et s.; NiCEPHORE GREGORAS, Histoire romaine, II, 8.

2129 JEANSELME dans M.D.J., 147-170.
} 
scientifique, les pratiques de magie devaient être très répandues. Un manuscrit de Bologne est rempli de formules médicales à côté de formules magiques, de mots étrangers de caractère magique, de sigles chimiques ${ }^{2130}$.

$\underline{\text { Retour à la Table des Matières }}$

${ }^{2130}$ LamBros, N.H., 1921, 29-39. 


\section{Chapitre XIII}

\section{L'enseignement}

Sans aucune interruption, les écoles publiques de la fin de l'antiquité ont continué leur activité dans l'Empire d'Orient et des écoles semblables ont été créées à Constantinople.

Plusieurs traits originaux: caractérisent ces fondations. Le plus important est la séparation de l'enseignement profane de tradition païenne et de l'enseignement religieux, le premier organisé par l'État, le second par l'Église.

$\mathrm{Du} \mathrm{IV}^{\mathrm{e}}$ au XV $\mathrm{XV}^{\mathrm{e}}$ siècle il existe à Constantinople une Université impériale qui se rattache à la tradition hellénistique et romaine (fondations des Lagides à Alexandrie, de Marc-Aurèle à Athènes). On y enseigne les belles lettres, les sciences et la philosophie, mais non la théologie. Des écoles provinciales du même genre étaient entretenues par les municipalités et il y avait aussi des écoles privées.

L'enseignement religieux était le monopole de l'École patriarcale, dont les maîtres appartenaient au clergé de Sainte-Sophie et qui se rattachait aux écoles d'apologétique fondées aux II ${ }^{\mathrm{e}}$ et $\mathrm{III}^{\mathrm{e}}$ siècles dans les grandes métropoles, à Rome, à Carthage, à Antioche, à Alexandrie, à Édesse, etc.

Enfin des écoles, organisées dans les monastères, étaient réservées aux novices.

Un autre trait commun à tous ces enseignements, c'est que leur objet n'était nullement désintéressé. L’Université impériale formait des juristes et des fonctionnaires capables de rédiger des actes en langage correct et suivant les règles de la logique, d'où la place tenue par la 
rhétorique et la dialectique dans son enseignement. Les évêques étaient recrutés souvent parmi ses professeurs et ses étudiants. L'école patriarcale était avant tout une école d'apologétique et de propagande chrétienne. Les écoles monastiques se proposaient d'éliminer de l'enseignement toute trace d'hellénisme païen et formaient le terrain le plus favorable à l'éclosion du mysticisme, en opposition violente avec l'enseignement classique.

\section{L'enseignement public jusqu'aux iconoclastes}

$\underline{\text { Retour à la Table des Matières }}$

A Constantinople, le point de départ de l'enseignement public fut 1'Université fondée par Constantin au Capitole en 330. Ses professeurs étaient en partie des païens, comme Libanius, qui y fut appelé par Constance, et Thémistius, dont l'enseignement commença en 344 et qui fut Préfet de la Ville sous Théodose $\mathrm{I}^{\text {er }}{ }^{2131}$. Un grammairien, Evanthius, mort en 360, y fut remplacé par l'Africain Charisius ${ }^{2132}$.

L'Université de Théodose II. - La fondation de Théodose II au Capitole est donc une réorganisation et un agrandissement de celle de Constantin. L'édit du 26 février $425^{2133}$ crée un auditorium qui comprendra 31 chaires, 16 grecques et 15 latines : Grammaire (10 grecques, 10 latines); Rhétorique (5 grecques, 3 latines); Philosophie (une seule chaire, grecque); Droit (2 chaires latines). Les candidats au professorat passeront un examen devant le Sénat. Ils auront un traitement annuel, et après 20 ans de services deviendront comtes de premier ordre. Enfin cet auditorium aura le monopole de l'enseignement public. En fait, parmi les professeurs se trouvaient plusieurs Hellènes (païens) ${ }^{2134}$ et l'enseignement resta bilingue jusqu'à la fin du VII ${ }^{\mathrm{e}}$ siècle.

${ }^{2131}$ L. BREHIER, Notes sur l'Enseignement supérieur à Constantinople, B.N., 1926 (73-94) et 1927-28 (13-28); F. FuCHS, Die höheren Schulen von Konstantinopel im Mittelalter, I et s.

${ }^{2132}$ Chronique de saint Jérôme, 360; FUCHS, op. cit., 2.

${ }^{2133}$ C.Th., XIV, IX, 3 (1).

2134 Ammonios, Olympiodore, Leonas, etc., auxquels est accordé le titre de comes $I^{\text {mi }}$ Ordinis (C.Th., VI, XXI, 1), Pamprepios (AsmUS dans B.Z., 1913, 336 et s.). 
L'enseignement public, ainsi réorganisé, survécut, d'une manière quelconque, à sa fondation jusqu'aux derniers jours de Byzance. Malheureusement il n'existe aucune source qui nous permette de reconstituer son histoire pendant ce millénaire. Du moins, sa réorganisation à plusieurs reprises par des lois impériales, montre que cet établissement a parfois périclité et s'est trouvé comme en sommeil. Sa résurrection périodique en est d'autant plus remarquable. Jamais les empereurs n'ont cessé de s'intéresser à l'enseignement supérieur et d'en faire le véritable foyer de l'hellénisme.

Comme l'a montré Fuchs ${ }^{2135}$, à défaut de sources qui nous informent directement, les détails donnés par les biographies profanes ou religieuses sur l'éducation des futurs saints et des hommes de toute condition, permettent d'établir des recoupements et des rapprochements qui nous renseignent sur la vie scolaire et les programmes d'enseignement. Bien que beaucoup de points soient douteux, on arrive ainsi à reconstituer l'histoire des écoles de Constantinople dans ses grandes lignes.

L'enseignement public en province. - Dernière venue parmi les grandes Universités d'Orient, celle de Constantinople ne tarda pas à les éclipser par l'illustration de ses maîtres et la qualité de son enseignement.

A Alexandrie la Mouseia Akademia ${ }^{2136}$ enseignait le trivium, le quadrivium, la philosophie, le droit, la médecine. Aux IV et $\mathrm{V}^{\mathrm{e}}$ siècles beaucoup de ses maîtres étaient païens ou monophysites. Nous avons déjà signalé l'intérêt de l'enseignement de Philoponos, l'un de ses maîtres les plus connus.

L'Université de Beyrouth était célèbre surtout par son École de droit, mentionnée dès le $\mathrm{III}^{\mathrm{e}}$ siècle. Aux $\mathrm{IV}^{\mathrm{e}}$ et $\mathrm{V}^{\mathrm{e}}$ siècles, sous le nom d'Auditoria elle se trouvait dans les dépendances de la cathédrale ${ }^{2137}$. Elle était particulièrement prospère $a u \mathrm{~V}^{\mathrm{e}}$ siècle et ses maîtres, renommés pour leur science juridique, avaient reçu le titre pompeux de maîtres ocuméniques ${ }^{2138}$.

\footnotetext{
2135 FUCHS, 1 et $\mathrm{s}$.

2136 L'Académie des Muses.

2137 Construite avant 449. P. Collinet, Histoire de l'École de droit de Beyrouth, 63 et s.

2138 COLlinet, op. cit., 130-156.
} 
A l'Université d'Athènes, le régime qui datait de Marc Aurèle ${ }^{2139}$, s'était à peu près maintenu au $\mathrm{V}^{\mathrm{e}}$ siècle, mais les quatre chaires de philosophie avaient de moins en moins d'élèves ${ }^{2140}$. C'était la chaire de rhétorique qui attirait les plus nombreux auditeurs ${ }^{2141}$. Elle était fréquentée par des étudiants comme Basile de Césarée, Grégoire de Nazianze, en même temps que par le futur empereur Julien. Plutarque, fils de Nestorius, renouvela véritablement l'enseignement public d'Athènes, en y fondant la troisième école néoplatonicienne, indépendante de l'État et en même temps centre de paganisme. L'un de ses disciples et successeurs, Proclus, ne se contentait pas de faire cinq leçons chaque jour, mais champion du polythéisme, il avait introduit dans son école une religion secrète, tirée des oracles chaldéens, avec sa liturgie aux rites multiples et sa morale sévère. Il mourut en 485, après avoir formé des disciples qui furent les derniers néoplatoniciens ${ }^{2142}$.

L'Enseignement public sous Justinien. - L'impartialité relative, montrée jusque-là par l'État, cessa avec Justinien, qui interdit l'enseignement aux hérétiques, aux Samaritains et aux païens ${ }^{2143}$, puis en 529 ordonna la fermeture de l'École néoplatonicienne d'Athènes, qui déclinait depuis la mort de Proclus et était devenue une sorte de monastère païen ${ }^{2144}$. Quelques-uns de ses maîtres, dont le plus intransigeant était Damascius, s'exilèrent volontairement en Perse, où ils furent bien accueillis par Chosroès, mais ne purent s'accommoder aux nouvelles conditions de vie dans lesquelles ils se trouvèrent. Ils regagnèrent l'Empire, mais dans le traité qu'il conclut avec Justinien en 532, le roi de Perse obtint la promesse qu'ils ne seraient ni maltraités ni obligés d'embrasser le christianisme ${ }^{2145}$.

2139 Dion Cassius, Pseudo-Codinus, De officialibus palatii, 31; Petit De Julleville, L'École d'Athènes (1868), 4.

${ }^{2140}$ L'Académie (Platoniciens), le Lycée (Aristotéliciens), le Portique (Stoïciens), le Jardin (Épicure).

2141 «Il n'y a plus à Athènes que des marchands de miel » (sophistes), disait Synésius. Cité par HERTZBERG dans son Histoire de l'hellénisme, éd. franç. III, 440.

${ }^{2142}$ O. SCHISSEL, Marinos von Neapolis und die neuplatonischen Tugenden, 51; MARINOS DE TYR, Vie de Proclus, ch. VIII, 40.

2143 C.I.C.I., C.J., I, V, 18 et XI, 10 (en grec et non daté).

2144 Jean MALALAS, Chronographie, XVIII, 451; J. B. BURY, History of the later Roman Empire, I, 369 et s.; DIEHL, Justinien et la civilisation byzantine au VI siècle, 562.

2145 GÜTERBOCK, Byzanz und Persien, 41 et s.; DieHL, op. cit., 564; BURY, op. cit., I, 370. 
D'autre part, l'attention de Justinien se porta surtout sur la réorganisation des études de droit. L'édit de 529 avait supprimé, en même temps que l'école philosophique, la Faculté de droit, créée à Athènes au $\mathrm{V}^{\mathrm{e}}$ siècle ${ }^{2146}$. Par la constitution Omnem adressée à huit professeurs de droit, dont quatre de Beyrouth (16 décembre 533), l'empereur ne conserva que trois Facultés de droit, celles de Constantinople, de Beyrouth et de Rome (qui appartenait encore aux Ostrogoths) ${ }^{2147}$. On sait quelle part importante les maîtres cecuméniques de Beyrouth prirent à la rédaction du Corpus Iuris ${ }^{2148}$. Leur école dépassait en importance celle de Constantinople et il semble que l'intention de Justinien ait été de rendre de plus en plus étroits les rapports entre les deux centres juridiques. Malheureusement, le 16 juillet 551 un tremblement de terre accompagné d'un raz de marée et d'un incendie détruisit Beyrouth et son Université. L'École de droit, transportée à Sidon, disparut avant la conquête arabe ${ }^{2149}$.

L'occupation de Rome par Totila (546-554) ${ }^{2150}$ ruina ses institutions scolaires. Sans doute après sa reprise, la première pensée de Justinien fut d'y reconstituer l'enseignement, en rétablissant l'annone donnée aux grammairiens, rhéteurs, médecins et jurisconsultes ${ }^{2151}$, mais l'état de la Ville était si misérable que son Université ne put vraisemblablement reprendre vie. Par la force des choses Constantinople se trouva donc l'unique centre d'études juridiques de l'Empire.

Organisation de l'enseignement. - Justinien porta les études de droit de 4 à 5 ans. Les étudiants de première année perdirent leur surnom de Dupondii, qui leur attirait des brimades et reçurent celui de Iustiniani ${ }^{2152}$. Ceux des quatre années suivantes étaient qualifiés successivement d'Edictales, Papinianistae, Lytae, Prolytae ${ }^{2153}$. Les brimades et les tours joués aux professeurs, usage invétéré, étaient interdits sous les peines les plus sévères ${ }^{2154}$. On a peu de renseignements

\footnotetext{
2146 Jean MALALAS, loc. cit.

2147 C.C.C.I., préface du Digeste.

2148 M.B.E.H. (Institutions), éd. 1970, 144-146.

2149 Agathias, Histoire, 1360 et s.; Michel LE Syrien, édit. Chabot, II, 247; Collinet, Histoire de l'École de droit de Beyrouth, 55-58.

2150 Voir M.B.E.H. (Vie et mort de Byzance), éd. 1969, 39.

2151 C.I.C.I., Code, alias constitutiones (Pragmatique Sanction, 22), 13 août 554.

2152 C.I.C.I., préface du Digeste.

2153 COLlineT, op. cit., 99; Vie de Sévère, patriarche monophysite d'Antioche, par ZACHARIE LE SCOLASTIQUE (éd. et lead. Kugener).

2154 M. KugENER, Les brimades aux $I V^{e}$ et $V^{e}$ siècles (Liège, 1905), 345 et s.
} 
sur la Faculté de droit de Constantinople, dont l'importance ne fit que s'accroître. Une épigramme de l'Anthologie Palatine, due probablement à Agathias, fait allusion à la basilique dans laquelle l'école de droit était installée. ${ }^{2155}$

De Justinien aux iconoclastes. - Après la mort de Justinien, les renseignements sur l'enseignement public sont rares et obscurs. Fuchs et d'autres historiens ont vu dans le prologue de l'ouvrage historique de Théophylacte de Simocatta la preuve que l'enseignement, malmené par Phocas, aurait été restauré au Palais Impérial par Héraclius. Il s'agit en fait d'un dialogue entre la Philosophie et l'Histoire exilées du palais et rappelées par le grand archiereus et proèdre de la terre entière $^{2156}$, simple allusion aux désordres du règne de Phocas et au rétablissement de l'État par Héraclius, dont le titre d'archiereus (pontife) n'est pas un fait exceptionnel ${ }^{2157}$.

En réalité quelques allusions permettent de supposer que l'enseignement public n'a cessé de fonctionner après Justinien. Tibère

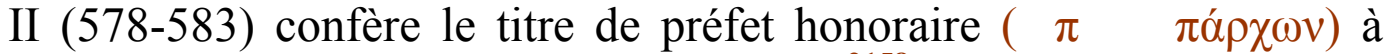
l'un de ses maîtres, le physicien Zacharias ${ }^{2158}$. La langue latine y était enseignée encore à la fin du VII ${ }^{\mathrm{e}}$ siècle par Paul de Byzance, commentateur de Lucain ${ }^{2159}$, mais on peut supposer que son cours n'attirait pas beaucoup d'auditeurs, car Grégoire le Grand, apocrisiaire à Constantinople (579-585) se plaint d'y trouver difficilement des interprètes capables de traduire en grec des documents latins ${ }^{2160}$.

L'existence de l'Université de Constantinople sous Héraclius est certaine : elle porte le nom de Pandictatorion et l'empereur y appelle un professeur d'Alexandrie, disciple de Philoponos, Étienne, qui y

\footnotetext{
2155 Anthologia graeca epigrammatum Palatina cum Planudea, IX, 66; BANDURI, Imperium Orientale sive antiquitates Constantinopolitanae, I, 147; FUCHS, Die höheren Schulen von Konstantinopel im Mittelalter, 8 (cette basilique serait la basilique civile de Théodose II au Capitole).

2156 THEOPHYLACTE DE SimocatTA, Histoire, 20 et s.

${ }^{2157}$ M.B.E.H. (Institutions), 1970, 346; FuCHS, op. cit., 9 et G. MorAVCSIK, Byzantino-turcicci, 65 , concluent à tort qu'il s'agit du patriarche Sergius.

2158 MENANDRE LE PROTECTEUR, Fragments, 255, fr. 56.

2159 FUCHS, op . cit., 6.

2160 Lettre à Narsès, JUGIE, Le Schisme byzantin, 41.
} 
enseigne la philosophie et le quadrivium. Il porte le titre de maître œcuménique, créé, comme on l'a vu, à Beyrouth ${ }^{2161}$.

La légende de Léon l'Isaurien, incendiaire. - L'Université de Théodose II s'est donc maintenue sans interruption jusqu'aux iconoclastes et aurait été détruite par Léon l'Isaurien qui, ne pouvant gagner les professeurs à ses doctrines, fit entasser des matériaux inflammables autour de l'édifice où ils enseignaient et brûler en même temps l'édifice, les professeurs et la bibliothèque.

Cette tradition est certainement apocryphe ${ }^{2162}$. Les écrits contemporains ignorent cet événement. Comment supposer que ce crime monstrueux ait pu passer inaperçu d'un saint Jean Damascène, et du biographe de saint Étienne le Nouveau? Comment admettre qu'au IX ${ }^{\mathrm{e}}$ siècle les professeurs-martyrs n'aient pas été canonisés en même temps que tous ceux qui avaient souffert pour la cause des images?

A vrai dire le récit de cet incendie ne se trouve que dans deux sources postérieures : la Vie du patriarche Germain, écrite dans le premier quart du IX ${ }^{\mathrm{e}}$ siècle ${ }^{2163}$, et un chapitre des Patria (Antiquités de Constantinople), qui date de 995 environ ${ }^{2164}$. D'après ces textes, qui ne sont pas toujours d'accord, il existait près de la Citerne Impériale ${ }^{2165}$ une Université, Didaskaleion okoumenikon, qui remontait à Constantin et comprenait, d'après la Vie de Germain, douze, d'après les $\mathrm{Pa}$ tria, seize professeurs, dirigés par un maître œcuménique ; les empereurs les appelaient parfois à faire partie de leur conseil et ne prenaient aucune mesure importante sans les consulter. Détail curieux, ces maîtres portaient l'habit monastique ${ }^{2166}$ et, d'après les Patria, donnaient à la fois l'enseignement profane et théologique ${ }^{2167}$. Ce dernier détail en particulier est en contradiction avec tout ce que nous savons de l'histoire de l'enseignement public. On pourrait admettre tout au plus

\footnotetext{
2161 E. BREHIER-TATAKIS, La philosophie byzantine, 50; KRUMBACHER, Geschichte der byzantinischen Literatur, 430, 621. Le titre est le même que celui des professeurs de Beyrouth, sans avoir aucun rapport avec le titre du patriarche.

${ }^{2162}$ L. BREHIER, Notes sur l'Enseignement supérieur à Constantinople, 1927, 13-28; FUCHS, 9-16.

2163 Reproduite dans la Chronique universelle de GEORGES LE MOINE (IV, 742).

2164 BANDURI, op. cit., I, 12.

2165 Aujourd'hui Jara-Batan-Seraï, non loin de l'Octagone. L'Université y aurait été transportée depuis 414 ans (en 587, sous Maurice), fait inconnu des autres sources.

2166 Détail commun aux deux sources, ce qui n'implique pas qu'ils fussent des moines d'origine.

2167 L. BREHIER, op. cit., 17.
} 
le transfert de l'Université, du Forum de Constantin à l'Octagone, suivant la tradition recueillie par les Patria.

Toutes les Chroniques et Histoires postérieures reproduisirent, en les mélangeant, les deux récits apocryphes, dont il faut chercher l'origine à l'époque de la deuxième prohibition des icônes par Léon l'Arménien en $815^{2168}$. Il n'en est que plus important de constater que les deux chroniques le mieux informées du $\mathrm{IX}^{\mathrm{e}}$ siècle ignorent totalement l'incendie de l'Université et le martyre de ses professeurs. Le patriarche Nicéphore dit, sans plus, que l'instruction commença à décliner sous Anastase II (713-716), donc avant Léon III ${ }^{2169}$. Théophanes accuse seulement Léon III d'avoir tari la source du savoir et détruit «le pieux enseignement» donné depuis Constantin: de l'incendie, pas un mot ${ }^{2170}$.

On peut aller plus loin et montrer que non seulement l'Université n'a pas été incendiée par Léon l'Isaurien, mais qu'elle a même continué à fonctionner sous les iconoclastes ${ }^{2171}$. Le patriarche Tarasios (784-806), proto-asecretis sous Irène, avait enseigné la prosodie antique à son biographe le diacre Ignace. Son enseignement portait sur les sept arts libéraux et la philosophie ; il le donnait avant 780, c'est-àdire sous Constantin V et Léon IV ${ }^{2172}$. Le futur patriarche Nicéphore fit ses études à la même époque et parcourut le même cycle ${ }^{2173}$. Plus tard, sous Léon l'Arménien, Constantin Kasymatas, fils d'un prêtre interdit, après avoir exercé le métier de cordonnier, devint professeur de droit dans sa vieillesse. A la suite d'accusations, il se réfugia dans un monastère, en devint higoumène, puis évêque de Syllaeon. En 815 il fut chargé par Léon l'Arménien de rassembler avec Jean le Grammairien les textes contraires à la vénération des icônes ${ }^{2174}$.

\footnotetext{
${ }^{2168}$ La Vie de Germain peut se rattacher à la campagne anti-iconoclaste représentée par les Anitrrhetici de Nicéphore.

2169 NICEPHORE, patriarche, Breviarium, II, 742.

2170 Theophanes le CONFESSEur, Chronographie, 405. Le pieux enseignement serait celui de l'École Patriarcale.

2171 On ne cite aucun professeur parmi les martyrs des images.

2172 Vie de Tarasios, patriarche, P.G., 98, 1385 et s.

2173 Vita Nicephori, P.G., 100, 49-57 et Breviarium de NICEPHORE.

2174 Vie de Léon l'Arménien (Anonyme), P.G., 108, 1025.
} 


\section{La restauration de l'enseignement public $I X^{e}-X^{e}$ siècle}

Malgré ces exemples, la période iconoclaste, y compris le règne de Constantin VI et d'Irène, avec ses troubles, ses révolutions militaires, ses persécutions, ne pouvait pas être favorable au développement de l'instruction. Un empereur comme Michel le Bègue (820-829) savait à peine lire son nom, mais fit donner par Jean Grammatikos une instruction de choix à son fils Théophile, et ce fut Théophile qui restaura l'enseignement public ${ }^{2175}$.

Créations de Théophile. - Entre 830 et 838, en effet, ce basileus découvrit à Constantinople Léon le Mathématicien, qui donnait une instruction privée à quelques disciples et l'établit, d'abord à l'église des Quarante-Saints, puis au palais de la Magnaure, et en fit le chef de l'Enseignement public ${ }^{2176}$.

Né vers 800 dans un bourg thessalien, Léon apprit la grammaire et la prosodie à Constantinople, mais ce fut en province, à l'île d'Andros, qu'un savant l'initia à la philosophie, à la rhétorique, à l'arithmétique. Revenu sur le continent, il alla de monastère en monastère, fréquentant les bibliothèques, et parfois il se retirait dans les montagnes, plongé dans ses méditations ${ }^{2177}$. Il apprit ainsi toutes les sciences $\varepsilon \quad \varsigma \quad \kappa \rho o v$, d'une manière exhaustive, et, dès qu'il eut commencé à enseigner à Constantinople, sa réputation ne tarda pas à se répandre. Un de ses élèves, à qui il avait appris la géométrie, devenu le secrétaire d'un stratège, fait prisonnier dans une bataille par les Arabes, échut comme esclave à un émir Mamoun, versé dans les sciences helléniques et surtout savant géomètre. Le prisonnier l'ayant appris, lui fit savoir qu'il connaissait aussi cette science. Mamoun le mit à l'épreuve et, surpris de la justesse de ses réponses, voulut savoir quel était son maître. Dès qu'il le sut, il envoya le Grec à Constantinople avec une lettre dans laquelle il invitait Léon à venir enseigner dans le califat. Ayant reçu la lettre, Léon crut prudent de la remettre au logothète Théoktiste ${ }^{2178}$, et ce fut de cette manière que l'empereur Théophile apprit l'existence de Léon : il le détermina à rester à Byzance ${ }^{2179}$.

\footnotetext{
2175 Theophanes, Continuatus, P.G., 109, 64, 84.

2176 Ibidem, P.G., 109, 206; GEORGES LE MOINE, Chronique universelle, P.G., 109, 868.

2177 FuChS, Die höheren Schulen von Konst., 18; TheOPHANES, Continuatus, P. G., 109, 205.

2178 Sur Théoktiste, logothète du drome, M.B.E.H. (Vie et mort de Byzance), 1969, 105 et s.

2179 THeophanes, Continuatus, P.G., CIX, 200-206. Sur l'étude du grec à Bagdad, FuchS, op. cit., 18.
} 
Pour mieux le retenir, Théophile le fit sacrer archevêque de Thessalonique, mais il devait être déposé, comme iconoclaste, sous la régence de Théodora, par le patriarche Méthodius ${ }^{2180}$.

L'Université de Bardas. - C'est à tort qu'on a regardé l'Université organisée par le césar Bardas en 863 comme une création nouvelle. Après la mort de Théophile, le logothète Théoktiste continua à veiller sur sa fondation universitaire. Il rappela de Thessalonique Léon le Mathématicien qui, bien que déposé comme archevêque, reprit son enseignement, au palais de la Magnaure vraisemblablement ${ }^{2181}$. Il y eut comme disciple le futur apôtre des Slaves, Constantin, et probablement comme collègue Photius. Constantin apprit d'eux la dialectique et la philosophie et, ses études terminées, fut nommé, grâce à Théoktiste, bibliothécaire de Sainte-Sophie, puis « fut chargé d'enseigner la philosophie aux indigènes et aux étrangers ${ }^{2182}$.

Ce fut seulement en 863 , sept ans après le meurtre de Théoktiste, que Bardas fit sa réforme ${ }^{2183}$. Elle consista, semble-t-il, à concentrer l'enseignement publie à la Magnaure, à en donner la direction, avec la chaire de philosophie, à Léon le Mathématicien et à créer pour ses disciples les chaires de géométrie, d'astronomie, de grammaire, occupées respectivement par Théodore, Théodegios et Kometas ${ }^{2184}$.

Persistance de l'Université de Bardas. - L'historien Génésios, qui appartenait au cercle des savants réunis autour de Constantin Porphyrogénète, montre la continuité entre l'Université de Bardas et celle de son temps ${ }^{2185}$.

Léon le Mathématicien vivait encore sous Basile $\mathrm{I}^{\mathrm{er}}$. On ignore à quelle époque il cessa d'enseigner, mais un disciple de Photius, qui fut aussi le sien, Aréthas, métropolite de Césarée, semble avoir écouté

\footnotetext{
2180 Theophanes, Continuatus, P.G., CIX, 206; GeOrges le MoIne, Chronique universelle, P.G., 109, 868; TAFRALI, Thessalonique, des origines au XIV siècle, 274 et s.

2181 F. DVORNIK, Les légendes de Constantin et de Méthode vues de Byzance, 39-45.

2182 Légendes slaves de Constantin et Méthode, 4; Dvornik, op. cit., 352 et s.; J. B. BURY, A History of the Eastern Roman Empire, 439, affirme sans preuve que Léon avait abandonné l'enseignement officiel. Photius a donné d'abord un enseignement privé (lettre au page Nicolas en 861, M. C., XVI, 409 D), puis, d'après les Légendes slaves de C. et M., a été le collègue de Léon.

2183 DVORNIK, op. cit., 83; FUCHS, op. cit., 18 et s.

2184 TheOdore Prodrome, Poèmes, VII, P.G., 109, 200,208.

2185 Genesios, Le Livre des Rois, Bonn, 98; Saint TheOdore LE Studite, Lettres, 21.
} 
une de ses leçons sur le VI livre d'Euclide ${ }^{2186}$. Aréthas lui-même, qui vivait encore en 932, enseigna la philosophie et eut pour disciple $\mathrm{Ni}$ cétas le Paphlagonien, dont la réputation de savant parvint jusqu'à l'empereur Léon VI, qui le fit rechercher pour le récompenser ${ }^{2187}$.

Nous avons là une preuve de l'intérêt que les souverains ne cessaient de porter aux études. Léon VI réorganisa l'enseignement du droit, qui comprit désormais deux classes de professeurs : les didaskaloi, chargés de donner l'instruction générale, enkyklios paideusis ${ }^{2188}$, nécessaire aux futurs juristes, et les paidodidaskaloi nomikoi, professeurs de droit proprement dit, qui avaient à enseigner les 40 titres du Prochiros Nomos de Basile et les 60 livres des Basiliques. Les deux groupes de professeurs faisaient partie de la corporation des notaires et formaient avec eux le collège électoral qui choisissait les titulaires des chaires ${ }^{2189}$.

$\mathrm{Au} \mathrm{X}^{\mathrm{e}}$ siècle Constantin Porphyrogénète est le véritable représentant de l'éducation encyclopédique que l'on donnait dans les écoles ${ }^{2190}$. Si l'on en croyait les préfaces d'ouvrages qui lui sont adressées, il aurait relevé l'enseignement, qui se mourait sous le gouvernement de Romain Lécapène ${ }^{2191}$. Il y a là quelque exagération. La vérité est qu'il développa l'enseignement par son activité personnelle, en s'efforçant de recruter les professeurs les plus savants et en rassemblant autour d'eux des étudiants ${ }^{2192}$ dont il s'occupait lui-même et qu'il admettait dans son palais et à sa table. Il choisissait parmi eux les hauts fonctionnaires et même des évêques ${ }^{2193}$. Toutes les disciplines étaient représentées dans cette Université, mais il semble, qu'avec la rhétorique, on y étudiait surtout les sciences pratiques, quadrivium, droit et médecine ${ }^{2194}$.

\footnotetext{
${ }^{2186}$ KRUMBACHER, Geschichte der byzantinischen Literatur, 622.

2187 Vie de saint Euthynle, patriarche, XVI, 1-5 et 56.

$2188 \gamma \kappa v ́ \kappa \lambda$ เo $\pi \alpha \dot{\delta} \delta \varepsilon v \sigma 1 \varsigma$, propédeutique, instruction élémentaire et générale. FUCHS, op. cit., 4150; Livre du Préfet, I, 2 (exigée des notaires).

2189 FuCHS, 23; The Cambridge Medieval History, IV: The Eastern Roman Empire, 716 (Colline); sceau d'un professeur de droit du Xe siècle, SCHLUMBERGER, dans R.N., 1905, 26.

2190 Sur son instruction personnelle, M.B.E.H. (Vie et mort de Byzance), 1969, 153 et s.

${ }^{2191}$ FUCHS, 21 et s.; RAMBAUD, L'Empire grec au X'e siècle. Constantin Porphyrogénète, 79.

${ }^{2192}$ Georges CEDRENOS, Synopsis, II, 326.

2193 TheOPhanes, Continuatus, 14, 461. L'un de ces étudiants était le futur basileus Nicéphore Phocas.

2194 RAMBAUD, op. cit., 70.
} 
L'organisation du Porphyrogénète subsistait encore sous Jean Tzimiskès (969-976), comme le montre l'invitation adressée par ce basileus à Pantaléon, chef des docteurs arméniens, à venir disputer avec les philosophes et les savants de Constantinople ${ }^{2195}$. Depuis la fondation de Théophile vers 830, l'enseignement impérial avait été ininterrompu pendant près d'un siècle et demi.

L'organisation scolaire. - Quelques témoignages, malheureusement rares, nous renseignent sur son organisation.

Le choix même des locaux montre la sollicitude des empereurs pour l'enseignement. Sous Théophile, c'est l'église des QuaranteSaints ${ }^{2196}$, puis le palais de la Magnaure ${ }^{2197}$ qui reste le centre de l'Université. D'après une glose de l'Anthologie Palatine, un enseignement était donné au début du $\mathrm{X}^{\mathrm{e}}$ siècle dans les dépendances de la Nouvelle Eglise de Basile le Macédonien ${ }^{2198}$.

Une peinture du manuscrit de Skylitzès de Madrid montre une de ces écoles, dans une salle décorée d'arcades et de colonnes : à gauche des élèves ( $\mu \alpha \theta \eta \tau \alpha i ́)$ sont assis autour d'une longue table garnie de livres ouverts; au haut bout siège le maître qui fait un geste oratoire. A droite, d'autres disciples, debout, un livre à la main, s'entretiennent

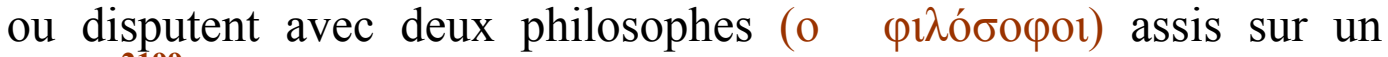
trône ${ }^{2199}$.

Les enseignements étaient classés hiérarchiquement : au sommet les chaires magistrales, thronoi didaskalikoi, puis des assistants, maîtres de conférence, o $\quad v \tau \quad \sigma v v \varepsilon \delta \rho \varepsilon i ́ \alpha \tau$ o $\delta i \delta \alpha \sigma \kappa a ́ \lambda o v$ (assesseurs ou assistants d'un professeur), grade qui pouvait être conféré à un bon étudiant ${ }^{2200}$. Le directeur, véritable recteur de l'Université, était toujours le professeur de philosophie ${ }^{2201}$. Sous le Porphyrogénète les ti-

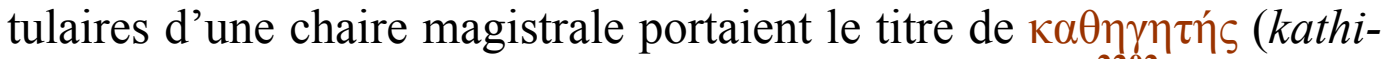
gitis, directeur) et avaient droit à des costumes officiels ${ }^{2202}$.

\footnotetext{
2195 MATHIEU D’ÉDESSE, Chronique, 380; FuCHS, 22.

2196 Les quarante martyrs de Sébaste. EBERSOLT, Le Grand Palais de Constantinople, 123.

2197 Le palais de la Magnaure servait aux réceptions solennelles des ambassadeurs étrangers.

2198 Anthologie grecque. I, Anthologie Palatine, VII, 429 (t. V, 38).

2199 BEYLIE, L'habitation byzantine, 103.

2200 FuCHS, 21 (d'après la Vie de saint Athanase, fondateur de l'Athos).

2201 Léon le Mathématicien sous Bardas, Constantin le protospathaire sous Constantin VII.

2202 RAMBAUD, op. cit. 70; THEOPHANES, Continuatus, 14, 446.
} 
Leurs rapports avec les étudiants étaient parfois difficiles. Par exemple, sous Romain Lécapène, un étudiant de Trébizonde, Abraamios, vient achever son instruction à Constantinople. Élève d'Athanase, en même temps professeur et recteur de l'Université (Koinos didaskalos), il fait des progrès si rapides et acquiert une telle autorité sur ses condisciples, que ceux-ci l'élisent professeur et obtiennent du basileus la ratification de leur choix ${ }^{2203}$. Il en résulte que les étudiants se portent en masse au cours d'Abraamios et qu'Athanase se trouve réduit à quelques auditeurs. Par égard pour son maître, Abraamios veut lui renvoyer ses disciples, mais ceux-ci refusent de le quitter. Ni le recteur, ni le basileus luimême ne peuvent faire cesser la grève. L'enseignement d'Abraamios est alors transporté dans un lointain local : les étudiants le suivent. Excédé, Abraamios, qui menait déjà la vie d'un ascète, abandonne sa chaire et se fait moine. Sous le nom d'Athanase, il devait réorganiser les couvents de l'Athos ${ }^{2204}$.

Sur les exercices et les grades scolaires, nous apprenons que certaines épreuves étaient destinées à obtenir un grade. Il en était ainsi d'une version des Actes des 42 martyrs d'Amorium, due à Sophronios d'Amorium, plus tard archevaque de Chypre, que, d'après sa préface, il dut lire dans une salle d'audition (akroaterion) ${ }^{2205}$.

Le titre de philosophe paraît avoir été un de ces grades. Il est porté par Léon le Mathématicien, par un de ses disciples du même nom ${ }^{2206}$, par Constantin, futur apôtre des Slaves, par l'empereur Léon VI, par Nicétas le Paphlagonien, qui ont vécu à la même époque. Il correspond en réalité à notre mot docteur et évoque la sagesse, terme synonyme de science.

La lecture et le commentaire des auteurs anciens tenaient déjà une grande place dans l'instruction générale (enkyklios paideusis) et l'enseignement littéraire s'acheminait vers l'humanisme. Ignace, diacre et skeuophylax (conservateur du trésor) de Sainte-Sophie, mettait en vers les fables d'Ésope ${ }^{2207}$. Constantin Cephalas, protopappas du Palais en 917 et principal rédacteur de l'Anthologie Palatine, aurait

\footnotetext{
2203 DIEHL, Choses et gens de Byzance, 14 et s.

2204 Sous le nom d'Athanase, futur fondateur de Lavra; Vie de saint Athanase l'Athonite (éd. Petit), 29, 19; FUCHS, 21; M ${ }^{\text {gr }}$ ChrYSANTHOS, op. cit., 345 et s.

2205 LOPAREV, Vizantiiskiia Sviatuik, V.V., XVII, 78-80 (version $\Delta$ ).

2206 FUCHS, 20.

2207 KRUMBACHER, Geschichte der byzantinischen Literatur, 716 et s.
} 
expliqué à la Nouvelle Église une épigramme tirée de la Couronne de Méléagre ${ }^{2208}$.

\section{De Constantin Monomaque à la conquête franque}

$\underline{\text { Retour à la Table des Matières }}$

L'éclipse de l'Université. - Après Jean Tzimiskès, on n'a plus aucun témoignage sur l'existence d'un enseignement public avant l'année $1045^{2209}$. Basile II, esprit supérieur, mais avant tout guerrier et homme d'action, ne paraît avoir eu ni le temps, ni le désir de s'intéresser aux études. Psellos s'étonne que, sous le règne d'un empereur qui méprisait ainsi la science, il y ait eu tant de rhéteurs et de philosophes remarquables. L'instruction fut même assez répandue. Des hommes tels que l'empereur Romain Argyre (1028-1034), qui possédait une culture grecque et latine ${ }^{2210}$, ou Michel d'Attalie, qui regarde Constantinople comme la métropole du savoir ${ }^{2211}$, avaient reçu une instruction étendue. De jeunes provinciaux continuaient à venir terminer leurs études dans la ville impériale, mais seules, des écoles privées dispensaient alors la science.

Les écoles privées. - Vers 1028, Jean Mauropous, venu de Claudiopolis en Cilicie, ouvrit à ses risques et périls une école à Constantinople. On ignore comment il s'était instruit lui-même, mais il avait un savoir encyclopédique. Le métier était dur et, dans des vers adressés à sa maison, il se plaint d'avoir passé bien des jours et des nuits à parler ${ }^{2212}$. Son école comptait plusieurs didaskaloi et il ne demandait aucune rétribution à ses élèves. L'enseignement était surtout oral et consistait en discussions entre maîtres et élèves. Il n'y régnait pas toujours un ordre parfait et le rôle de Mauropous consistait surtout à imposer son arbitrage, en redressant les vues des uns et des autres, ce qui

\footnotetext{
${ }^{2208}$ Anthologie grecque, I: Anthologie Palatine, V, 38, nº 429 (d'après la glose de cette épigramme, supra, p. 320).

2209 Anne COMnENE, Alexiade, V, 8 (1I, 33).

2210 PSELlOS, Chronographie, I, 29 (I, 18).

2211 Ibidem, III, 2 (I, 32).

2212 Michel D’ATtAliE, Histoire, II, 8 et s., p. 23.
} 
finissait par l'épuiser. " Je pâlissais, dit-il, au milieu des écritures et des lectures ${ }^{2213} »$.

Son plus brillant disciple fut Psellos. Auparavant il avait eu d'autres maîtres, mais qui exigeaient de fortes rétributions de leurs élèves; il dut interrompre ses études pour chercher une occupation lucrative et pouvoir les continuer ${ }^{2214}$. Il trouva enfin l'école de Mauropous, où il acheva son éducation. Il s'y lia avec Constantin Likhoudès, juriste renommé, que Michel V prit comme ministre, avec Nicétas Byzantios, Jean Xiphilin de Trébizonde, Jean Patrikios. Ces étudiants, déjà âgés et dont plusieurs étaient pourvus d'emplois, se donnaient un enseignement mutuel en échangeant leurs connaissances, mais Psellos, qui enseignait la philosophie à Patrikios, les dominait par son érudition ${ }^{2215}$.

Ces maîtres privés donnaient à leurs disciples une instruction solide, mais incomplète. Il manquait à leurs efforts un peu plus de cohésion et une idée directrice. L'avènement de Constantin Monomaque allait mettre fin à cette situation.

La restauration de l'enseignement public. - Par son passé et son caractère frivole, cet empereur ne semblait guère destiné à cette tâche, mais « il recherchait la science ou plutôt ceux qui la professaient... Lui-même y goûtait du bout des doigts » ${ }^{2216}$. En réalité il se plaçait surtout à un point de vue politique et administratif: il voulait que l'État fût gouverné par des lettrés, par opposition à l'aristocratie militaire qu'il redoutait ${ }^{2217}$. Le haut enseignement redeviendrait, suivant la pensée même qui avait déterminé sa création et ses réformes successives, une pépinière d'administrateurs et d'hommes d'État.

Il était donc urgent de réorganiser avant tout les études juridiques. La novelle de 1045 créa un nomophylax (gardien de la loi), conservateur de la Bibliothèque juridique (textes du Corpus juris), directeur de l'École de droit. Placé à un rang élevé dans la hiérarchie impériale,

\footnotetext{
2213 Jean MAUropous, Correspondance inédite, éd. de Lagarde, 23-31; L. BREHIER, L'Enseignement supérieur à Constantinople dans la dernière moitié du XI siècle, 100 et s.

2214 E. RENAULD, Étude de la langue et du style de Michel Psellos, 407 et s.

2215 Psellos, op. cit., T, XII-XIII, sur Patrikios; du même Discours, V, 88 (amitié avec Nicétas).

$2216 \kappa \rho$, $\mu$ óv $\delta \alpha \kappa \tau u ́ \lambda$, ZONARAS, Epitome, III, 617.

2217 L. BREHIER, op. cit., 103 et s.
} 
dignitaire inamovible, pourvu d'un traitement annuel de 4 livres et de divers avantages, il devait l'emporter sur tous les juristes et ne pas craindre les travaux attachés à un office si grand. Jean Xiphilin, illoustrios et juge de 1'Hippodrome, fut le premier titulaire de cette charge ${ }^{2218}$.

Constantin IX installa l'École de droit ( $\delta 1 \delta \alpha \sigma \kappa \alpha \lambda \varepsilon$ ov $\tau \quad v$ vó $\mu \omega v)$ au monastère de Saint-Georges des Manganes. Les études étaient gratuites pour tous ; les étudiants riches pouvaient offrir des présents aux professeurs, mais sans prétendre au moindre privilège. Les rangs étaient attribués suivant le mérite. La sanction des études était le certificat délivré par le nomophylax et qui était exigé de tous les candidats aux fonctions de notaires ou d'avocats ${ }^{2219}$. L'assiduité la plus grande était recommandée aux étudiants, mais ils avaient des vacances, qui étaient les mêmes que celles de la Faculté de philosophie et ils célébraient le 25 octobre la fête de leurs patrons, les saints notaires Markianos et Martyrios, en organisant de joyeux cortèges, qui n'étaient pas toujours exempts de quelques désordres ${ }^{2220}$.

La Faculté de philosophie. - On ne connaît pas l'acte de fondation de la Faculté de philosophie, qui fut créée en même temps que la Faculté de droit et eut pour directeur Psellos, qui reçut le titre de

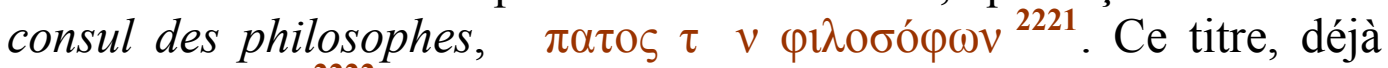
porté avant lui ${ }^{2222}$, n'en est pas moins une nouveauté au $\mathrm{XI}^{\mathrm{e}}$ siècle : au-dessus de ceux qui ont reçu, comme on l'a vu, le grade de philosophe ${ }^{2223}$, est créé un dignitaire, qui tient dans la hiérarchie impériale une place analogue à celle du nomophylax. Le consul des philosophes est donc le chef d'un ordre, qui comprend les érudits les plus distingués de Byzance, les philosophes du Sénat, qui leur confère ce titre. «Moi aussi j'occupe un trône élevé non moins que le tien », écrit Psellos au patriarche Kéroularios ${ }^{2224}$.

\footnotetext{
${ }^{2218} \overline{\text { R.K.O.R., 863. Le texte est dans les } œ u v r e s ~ d e ~ M a u r o p o u s, ~ q u i ~ a ~ d u ̂ ~ r e ́ d i g e r ~ l a ~ n o v e l l e ~: ~ C o r-~}$ respondance inédite, 195-202; L. BREHIER, 105; MiChel D'ATTALIE, Histoire, 21.

2219 FUCHS, Die höheren Schulen von Konst., 25 et s.; L. BREHIER, op. cit., 110-112.

${ }^{2220}$ Jean MAUROPOUS, op. cit., 199; ChristOPHOROS DE MYTILENE, Poésies, 136; FuChS, op. cit., 2221 MiCHEL D’ATTALIE, op. cit., 21.

2222 FUCHS, 29; ZACHARIAE VON LINGENTHAL, Geschichte des griechisch-römischen Rechts, III, 29.

2223 Voir supra, p. 393.

${ }^{2224}$ PSELlOS, Chronographie, V, 509 (thronos désigne une chaire magistrale).
} 
La Faculté de philosophie, que Psellos appelle le Gymnase,

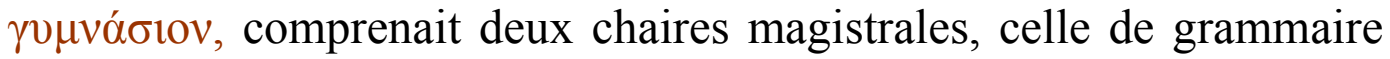
confiée à Nicétas et celle de philosophie occupée par Psellos. D'après l'éloge funèbre qu'il prononça de Nicétas, les deux enseignements se donnaient sous le même toit, à l'église Saint-Pierre ${ }^{2225}$.

Psellos nous a laissé un tableau très vivant du fonctionnement de ces écoles. Très avant dans la nuit le maître prépare la leçon du lendemain. Dès l'aube il est dans ses livres, puis se rend au gymnase. En chemin il rencontre un étudiant, ses livres dans un pli de sa robe et repassant sa leçon tout haut. A l'entrée du professeur les bons élèves se lèvent et imposent silence à leurs camarades. Le professeur gagne sa chaire et, son menton appuyé sur sa main, inspecte ses disciples assis sur des bancs. Il y a des retardataires; d'autres ont oublié le jour de la leçon ou ne viennent pas les jours de pluie. La leçon peut enfin commencer, après que le maître a épanché sa bile contre les écoliers paresseux. L'enseignement consistait dans les réponses aux questions posées par les élèves, suivant la méthode platonicienne. Psellos avait du mal à obtenir que ce fût sur des problèmes déterminés et non au hasard. Les élèves écrivaient sur des tablettes ou parchemins sur leurs genoux. Ils faisaient aussi des travaux écrits, dont le professeur critiquait le plan, les transitions, les expressions ${ }^{2226}$. D'une très grande bonté, Psellos prenait à part ceux qui avait du mal à suivre les leçons et allait jusqu'à aider de ses deniers des étudiants peu fortunés ${ }^{2227}$.

Les programmes d'enseignement. - La méthode d'enseignement consistait toujours en commentaires des auteurs anciens, mais d'une manière plus variée. Le premier cycle comportait l'étude de la grammaire ou orthographe, dirigée par Nicétas, qui la regardait comme le fondement de la science. Il faut d'ailleurs se rendre compte que le terme de grammaire était beaucoup plus compréhensible qu'il ne l'est couramment. C'était un enseignement complet de connaissances variées, qui avait pour base la lecture des chefs-d'œuvre de la littérature antique ${ }^{2228}$. Il comprenait l'étude de l'alphabet et de son invention par Cadmus ${ }^{2229}$, des dialectes anciens, de la phonétique (ton et accents), de la syntaxe (rôle des propositions subordonnées dans la phrase, pronoms et particules), vocabulaire, mots usuels et sens différents (sémantique). Ces recherches étaient complétées par une explication des

\footnotetext{
2225 Id., Discours, V 87; FuCHS, 28.

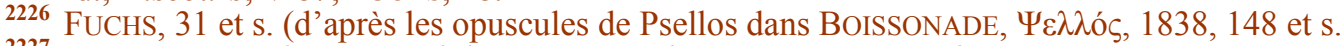

2227 W. Fischer, Iohannes Xiphilinos, Patriarch von Konstantinopel, $5,2$.

2228 On peut en rapprocher nos classes de grammaire dans notre enseignement secondaire.

${ }^{2229}$ La légende de Cadmus est le symbole de l'invention de l'alphabet par les Phéniciens, que les recherches récentes attribuent à une haute antiquité.
} 
auteurs grecs, non seulement grammaticale, mais littéraire et même allégorique.

Les poèmes homériques tenaient une grande place dans ces lectures ${ }^{2230}$. Nicétas y trouvait des allégories morales. Arès enchaîné figurait la passion retenue par la puissance des discours. La patrie chère aux prisonniers de Circé est la Jérusalem céleste, dont nous éloignent les délices trompeuses du plaisir qui nous transforment en bêtes. A côté d'Homère les poètes grecs et surtout les auteurs lyriques dont les vers avaient un sens moral, Archiloque, Pindare, etc., fournissaient aussi des textes d'explication ${ }^{2231}$.

Psellos s'était réservé la tâche la plus lourde. Nous savons déjà le sens compréhensif qu'il donnait à la philosophie, qu'il ne séparait pas de la rhétorique ${ }^{2232}$ dont il n'existait à l'école Saint-Pierre aucune chaire spéciale. Il était donc rhéteur et philosophe, mais l'importance de son enseignement provenait de ses efforts pour former des humanistes et pour concilier la morale païenne avec le christianisme. Il exhortait ses élèves à étudier les auteurs profanes dans l'intérêt même de la connaissance de la religion chrétienne ${ }^{2233}$.

Sans revenir sur les doctrines philosophiques de Psellos, il est nécessaire d'indiquer les éléments du programme encyclopédique de son enseignement. Au cours de rhétorique il joignait ceux de cosmographie et géométrie, de ce qu'il appelle la métaphysique, comprenant la logique formelle, la cosmologie (formation de l'univers et des corps solides, le premier principe immatériel, la nature du discours philosophique, la valeur morale des nombres). La musique théorique (substance des rythmes, nature de leur beauté, leur conformité à la vie de l'âme), la dialectique, qui étudiait la démonstration par les syllogismes et les sophismes, la psychologie (étude de l'âme, question de sa substance et de son immortalité, de ses rapports avec le corps), l'astrologie elle-même s'ajoutaient à ce vaste programme ${ }^{2234}$. Il est d'ailleurs peu vraisemblable qu'il ait pu, même en plusieurs années, exposer systématiquement un pareil amas de connaissances, mais il est probable qu'il s'agit du programme des nombreuses questions qui pouvaient être traitées ou discutées à son cours.

\footnotetext{
2230 Psellos, Discours, V, 14. C'était le premier livre mis entre les mains des écoliers.

2231 Ibidem, V, 90 et s.; L. BREHIER, L'Enseignement supérieur à Constantinople..., 105 et s.

2232 Supra, p. 361.

2233 BOISSONADE, op. cit., 151-153.

2234 PSELlOS, op. cit., V, 54 et s. (oraison funèbre de sa mère); L. BREHIER, op. cit., 107-109.
} 
L'époque des Comnènes. - L'Université de Constantin Monomaque dura sans interruption jusqu'en 1204, mais non sans heurts. On ne peut accepter l'assertion d'Anne Comnène d'après laquelle son père fit refleurir les études, qu'il trouva délaissées à son avènement ${ }^{2235}$. La vérité est que dix ans de guerre civile (1071-1081) et la disgrâce de Psellos (1077) ont pu détourner de l'enseignement l'attention du pouvoir impérial; mais ce qui prouve la continuité de la fondation de 1045, ce sont les listes de consuls des philosophes et de gardiens des lois (nomophylakès) depuis Psellos et Jean Xiphilin jusqu'à la fin de l'Empire ${ }^{2236}$. Alexis Comnène n'a modifié en rien l'organisation de l'Université et sa seule fondation scolaire est un orphelinat, à la fois hospice et maison d'éducation, situé autour de l'église des Saints Pierre et Paul. Destiné à des enfants, cet établissement était dirigé par un proèdre (président). On y donnait l'enseignement élémentaire (enkyklios paideia) et le basileus se plaisait à venir inspecter et interroger ses pupilles ${ }^{2237}$.

L'événement capital de l'histoire universitaire à cette époque fut le droit de surveillance des études, donné à l'Église. Alexis Comnène, dit sa fille, ne cessait d'encourager les étudiants, mais il leur recommandait de faire passer la connaissance des Livres Saints avant la culture hellénique ${ }^{2238}$, et c'est là un son nouveau. Le basileus était effrayé des hardiesses de Jean l'Italien ${ }^{2239}$. Après son procès d'hérésie et sa condamnation en 1082 la défiance envers l'enseignement philosophique augmenta. A partir du règne de Manuel Comnène, les dignités de consul des philosophes et de nomophylax furent régulièrement conférées à des diacres de Sainte-Sophie ${ }^{2240}$. Le patriarche n'exerce cependant aucune autorité sur l'Université et Théodore Prodrome oppose les professeurs de l'École Patriarcale ( $\tau$

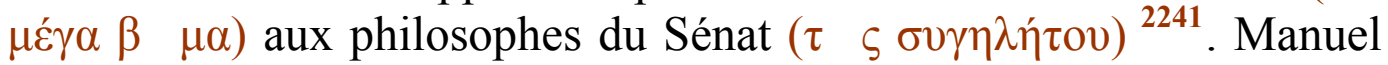
Comnène n'en opéra pas moins une réforme profonde de l'Université, en y installant un enseignement exclusivement aristotélicien. C'est ce

\footnotetext{
AnNe Comnene, Alexiade, 11, $9(11,38)$.

FuCHS, op. cit., 26 et s., 35 et 50-51.

Synopsis Chronike ad a. 1261 (éd. Sathas), VII, 178 et s.; ANNE Comnene, Alexiade, II, 9 (II, 38-39).

2239 Successeur de Psellos comme consul des philosophes.

${ }^{2240}$ FUCHS, op. cit., 50.

${ }^{2241}$ Ibidem, 47.
}

${ }^{2238}$ Ibidem. 
que montre la leçon d'ouverture de Michel d'Anchialos, le futur patriarche, nommé consul des philosophes et président de la Faculté de philosophie. Il y loue Manuel d'avoir remis la philosophie en honneur, mais il retranchera «ce qui est pourri » (le néoplatonisme) et enseignera la logique, la dialectique, la physique, la métaphysique, l'astronomie, la météorologie, d'après le système d'Aristote ${ }^{2242}$.

Cependant, la philosophie exceptée, il n'y eut aucun changement dans l'enseignement des autres matières. Eustathe, archevêque de Thessalonique, professeur à l'Université, y enseignait les lois $d u$ rythme et de l'harmonie (musique), l'étymologie des noms, les antiquités (histoire et civilisation helléniques), l'éloquence ${ }^{2243}$. Il eut pour disciples Michel Khoniatès et son frère Nicétas, originaires de Khonae en Phrygie, d'une famille aisée. Leur père les envoya faire leurs études à Constantinople où, avant de suivre le cours d'Eustathe, ils eurent pour maîtres Jean et Isaac Tzetzès, probablement professeurs de grammaire et chefs d'une école privée ${ }^{2244}$. A cette époque un procédé pédagogique très répandu était la schédographie. Sur une tablette, schedos $(\sigma \chi \varepsilon \dot{\varepsilon} \delta \mathrm{s})$, l'élève écrivait le passage d'un auteur pour en faire une analyse grammaticale, comprenant l'étude des flexions, de l'étymologie, du sens des mots. On avait d'ailleurs composé de nombreux vocabulaires des auteurs classiques, comme l'Abrégé de schédographie du sage Longibardos. Les mots étaient groupés suivant leur sens (mythologie, géographie, costume, etc.). Dans un autre manuel les exemples classés par lettre alphabétique étaient présentés en 907 vers politiques, analogues à ceux du Jardin des Racines grecques de l'excellent Claude Lancelot :

$v \alpha \xi \pi \alpha \rho \chi \varepsilon 1 \beta \alpha \sigma 1 \lambda \varepsilon v ́ \sigma, \quad v \alpha \sigma \sigma \alpha \quad \delta \varepsilon \sigma \pi \operatorname{lí}^{2} \alpha \eta$
(Anax signifie basileus, anassa la despoina) $^{2245}$, etc.

Ces méthodes d'enseignement, assez semblables à celles qu'ont connues tous ceux qui ont reçu de nos jours une bonne éducation clas-

${ }^{2242}$ Ibidem, 50 et s. Élu patriarche en 1170. Sa nomination comme consul des philosophes a dû avoir lieu au moment du Concile des Blachernes de 1157, qui condamna les derniers néoplatoniciens. ChalANDON, Les Comnène, 641 et s.; ECONOMOS, La vie religieuse dans l'Empire byzantin au temps des Comnènes et des Anges, 30 et s.

${ }^{2243}$ MiCHEL KHONIATES (T $\sigma \omega \zeta$ ל́ $\mu \varepsilon v \alpha$ ), éd. Lambros, P.G., 140 et 341.

2244 Ibidem, 140 et 363; DuchatAUX, Eustathe, archevêque de Thessalonique, 143 et s.

2245 KRUMBACHER, Geschichte der byzantinischen Literatur, 590 et s.; ANNE COMNENE, Alexiade, XV, 7 (III, 218), traite cet exercice de futilité; FUCHS, op. cit., 44-49; sur les manuels en usage, FESTA, Longibardos, dans B.N., 1931, 101-122 et B.Z., 107, 143-153. 
sique, expliquent la connaissance parfaite que les lettrés de Byzance avaient des auteurs grecs et le magnifique développement de l'humanisme qui en fut la conséquence.

\section{L'enseignement public à Nicée et sous les Paléologues}

\section{Retour à la Table des Matières}

La conquête de Constantinople et de l'Empire par les Occidentaux entraîna la disparition des écoles publiques, mais la première pensée des empereurs de Nicée fut de les réorganiser. Et il y a quelque chose de touchant à voir ces réfugiés, obligés de défendre pied à pied des lambeaux de territoires au milieu d'ennemis redoutables, trouver le temps de créer des écoles, qui devaient être, dans leur pensée, un centre de ralliement pour tous les Hellènes.

Sous les empereurs de Nicée. - Sous Théodore $\mathrm{I}^{\mathrm{er}}$ on constate l'existence d'écoles municipales à Nicée, à Brousse, à Smyrne, à Scamandros ${ }^{2246}$. Jean Vatatzès (1222-1254) fonde des bibliothèques publiques dans toutes les villes de ses possessions et sauve ainsi une grande partie des richesses littéraires de Byzance ${ }^{2247}$.

Le même empereur ordonne aux archontes et gouverneurs des villes d'allouer dans le budget municipal un salaire aux professeurs qui enseignent la médecine, les mathématiques et la rhétorique ${ }^{2248}$.

Quant aux professeurs de philosophie et de droit, poursuit l'édit, vu leur mépris de ce qui touche à la matière et à l'argent, ils enseigneront gratuitement, mais pourront accepter une rétribution de leurs élèves ${ }^{2249}$.

\footnotetext{
2246 NiCEPHORE BLEMMYDES [Autobiographie et œuvres complètes], éd. Heisenberg.

2247 Synopsis Chronike ad a. 1261, 519; J. B. PAPADOPOULOS, Théodore II Lascaris, 10.

2248 Synopsis minor dans ZACHARIAE VON LINGENTHAL, Geschichte des griechisch-römischen Rechts, II, 203.

2249 Le « désintéressement des philosophes » était devenu une clause de style, un lieu commun depuis un édit d'Antonin le Pieux cité par Modestinus (III ${ }^{\mathrm{e}}$ siècle) et dans UlPIEN, Dig.L., V, 8 ; HerzoG, Urkunden zur Hochschulpolitik der römischen Kaiser, Séances de l'Académie de Berlin 1935, 994; FUCHS, op. cit., 35.
} 
Jean Vatatzès lui-même fonde une école de philosophie à Nicée sous la direction d'Hexapterygos, qui meurt en 1238, et qu'il remplace par le savant le plus remarquable du temps, Nicéphore Blemmydès.

Né à Constantinople en 1198 et fils d'un médecin, Blemmydès avait fait de fortes études, mais, par suite de la désorganisation qui suivit la conquête latine, avait dû aller de ville en ville pour arriver à acheverson instruction ${ }^{2250}$. Après quelques années, sur l'invitation du basileus, il ouvrit lui-même une école à Smyrne. A l'école de Nicée, où il enseigna dix ans (1238-1248), il eut comme élèves Georges Pachymère, le futur empereur Théodore II Lascaris et Georges Akropolitès, qui avait commencé ses études avec Théodore Hexapterygos ${ }^{2251}$, et il exerça sur eux une action profonde. Puis, épris de la vie solitaire, Nicéphore Blemmydès quitta Nicée et fonda à Éphèse un monastère, dont il prit la direction. Il y adjoignit une école, mais réservée aux moines et aux novices ${ }^{2252}$.

Ce départ inopiné fut désastreux pour l'enseignement public, d'ailleurs insuffisant et suivi par un très petit nombre d'élèves. Monté sur le trône en 1254, Théodore II essaya de relever les études. Il dota de livres nouveaux les bibliothèques des villes en recommandant aux autorités de les prêter à tous ceux qui voudraient s'instruire ${ }^{2253}$. Il adjoignit une école de grammaire et de rhétorique à l'église qu'il avait fondée en l'honneur de saint Tryphon ${ }^{2254}$, mais il n'y entretenait que six boursiers et la brièveté de son règne empêcha ses projets d'aboutir. Les troubles qui suivirent sa mort désorganisèrent l'enseignement. Georges de Chypre ${ }^{2255}$, rebuté par l'école franque de son pays et désireux de s'instruire, n'ayant pu pénétrer dans l'école de Blemmydès à Ephèse, vient à Nicée où, lui avait-on dit, il y avait un si grand nombre de savants qu'on s'y croyait dans l'ancienne Athènes. Sa déception fut grande, quand il n'y trouva que des maîtres de grammaire et de rhétorique, dont l'enseignement était superficiel et terre à terre.

\footnotetext{
2250 Nicephore Blemmydes : FuChs, 5; PApAdopoulos, Théodore II Lascaris, 10. Il étudie la grammaire à Brousse quatre ans, la médecine à Smyrne, l'arithmétique, la géométrie, 1'astronomie à Scamandros (Troade), en 1220.

2251 GeOrges AKropolites, Chronique, éd. Heisenberg, 32.

2252 KURTZ dans B.Z., 1896, 394 et s.

2253 R.K.O.R., 1847; GEORGES AKROPOLITES, op. cit., I, 297.

2254 FUCHS, 55.

2255 Le futur patriarche Grégoire II KYPRIOS (1283-1289).
} 
Depuis la démission de Nicéphore Blemmydès, l'enseignement de la philosophie et des sciences avait disparu des écoles publiques ${ }^{2256}$.

L'odyssée et les tribulations de Georges de Chypre montrent l'enthousiasme pour l'instruction qui animait la jeunesse. A 9 ans, il est envoyé par ses parents à Nicosie, où un maître franc lui enseigne la grammaire latine et la logique d'Aristote. L'accent étranger du maître l'empêche de le comprendre. A 15 ans, il revient dans son pays, découragé. C'est alors qu'il demande à ses parents à partir pour Nicée, mais ceux-ci le trouvent trop jeune pour un pareil voyage. Après deux ans de tiraillements, il s'embarque clandestinement pour Saint-Jean d'Acre et passe de là à Éphèse. Après son échec pour entrer à l'école de Blemmydès, il part pour Nicée en plein hiver par un chemin pénible et y arrive au bout de six mois. On est en 1260 ; l'empereur, qui est alors Michel Paléologue, va partir pour investir Constantinople. Georges le suit en Thrace, dans l'espoir d'obtenir de lui une bourse pour terminer ses études, mais, n'ayant rien obtenu, il est obligé de revenir à Nicée, dénué de ressources, n'ayant pas de quoi subsister trois jours de suite. Sa constance est enfin récompensée et, après un séjour bref dans les écoles de Nicée, il peut gagner Constantinople vers 1264 et suivre pendant 7 ans les cours de Georges Akropolitès ${ }^{2257}$.

Michel Paléologue et les études. - Rentré à Constantinople, Michel Paléologue avait d'autres soucis que celui de la protection des études. Lui-même avait reçu une éducation plus politique et militaire que classique. Il faut ajouter que sa politique de restauration et de défense exigeait des sommes énormes et laissait peu de ressources pour l'enseignement.

Mais c'était une tradition bien établie qu'un basileus dût s'intéresser aux études. Michel ne voulut pas se dérober à ce devoir, mais il ne fit aucune création nouvelle. Il rétablit l'Orphelinat SaintPaul d'Alexis Cornnène et son école de grammaire ${ }^{2258}$. L'initiative de la création d'une école de haut enseignement est due au grandlogothète Georges Akropolitès. Michel Paléologue, l'ayant su, le déchargea de ses fonctions administratives, afin qu'il pût consacrer tout son temps à ses élèves et le nomma professeur de philosophie aristotélicienne ${ }^{2259}$.

${ }^{2256}$ Gregorre De Chypre, Autobiographie, P.G., 142, 20 et s. et LAMEere, La tradition des manuscrits de la Correspondance de Grégoire de Chypre, 176 et s.

2257 Ibidem, 186 et $\mathrm{s}$.

2258 PACHYMERE, Histoire, IV, 14

2259 GREGOIRE DE ChYPRE, 134 et P.G., 142-181 (éloge de Michel VIII). 
Nous avons vu que Georges de Chypre fut l'élève d'Akropolitès pendant sept ans (1264-1271), mais on ignore où se donnait l'enseignement et rien n'indique que le professeur ait été appointé. L'enseignement portait sur la philosophie d'Aristote, sur la géométrie d'Euclide, sur l'arithmétique de Nicomaque ${ }^{2260}$.

Georges Akropolitès mourut en 1282, la même année que Michel VIII. Il avait cessé son enseignement, mais on ignore à quelle date. D'autre part, Georges de Chypre fut aussi professeur, ses études terminées. A-t-il succédé à Akropolitès ? On n'en sait rien et il n'en dit rien dans son autobiographic. On connaît du moins plusieurs de ses élèves: Théodore Mouzalon, futur grand-logothète, et Nicéphore Chumnos, qui exprimait plus tard son admiration pour l'enseignement qu'il avait reçu de lui ${ }^{2261}$.

Michel Paléologue avait donc rétabli l'enseignement à Constantinople, mais d'une manière très modeste et à peu près sans bourse délier ${ }^{2262}$.

L'Université d'Andronic II. - L'obscurité qui règne sur la politique scolaire, au temps de Michel VIII, cesse avec l'avènement d'Andronic II. L'enseignement prend alors un développement magnifique, que ni les guerres civiles, ni les querelles religieuses ne peuvent arrêter. C'est pendant cette période que l'humanisme byzantin, générateur de la Renaissance, prend son essor.

Sans qu'on sache quand et comment elle s'est reconstituée, il existe de nouveau une Université impériale, organisée sur un plan bien défini. Voici le témoignage d'un musicien célèbre, Jean Koukouzélis, né à Dyrrachium, qui, après avoir reçu l'instruction élémentaire dans sa ville natale, vint suivre à Constantinople les cours de l'École impériale ( $\varepsilon \varsigma \sigma \chi 0 \lambda \varepsilon$ ov $\beta \alpha \sigma \iota \lambda \iota \kappa o ́ v$ ) et y apprit la musique, la philosophie, la calligraphie ${ }^{2263}$. Le nom officiel de cette école, le Musée, rappelait la tradition d'Alexandrie ${ }^{2264}$.

\footnotetext{
2260 Ibidem, 184; FuCHS, 56.

2261 KRUMBACHER, Geschichte der byzantinischen Literatur, 476 et s. ; FUCHS, 58.

2262 Ses dépenses paraissent avoir eu pour seul objet l'orphelinat Saint-Paul. PACHYMERE, Histoire, IV, 14.

2263 S. EUSTRATIADES, Jean Koukouzelis, dans E.B., 1938, 5 et s.

2264 TheOdORE HyRTAKENOS, Déclamations. Lettres, V, 738.
} 
C'est par la correspondance de Théodore Hyrtakénos, qui y fut professeur, que l'on connaît l'organisation de cette Université. Elle était placée sous l'autorité du grand-logothète, qui fut d'abord Théodore Métochitès. Le professorat était considéré comme une charge (liturgie), dont le titulaire ne pouvait s'affranchir sans le consentement impérial. En contrepartie, le grand-logothète versait aux professeurs un traitement et ils recevaient des indemnités, payées d'ailleurs sans régularité, des parents de leurs élèves : pour la première fois le haut enseignement cessait d'être gratuit, mais le traitement officiel était luimême très aléatoire. Dans ses lettres au grand-logothète et même à l'Empereur, Théodore Hyrtakénos se plaint sans cesse de l'irrégularité des paiements ${ }^{2265}$. II se plaignait aussi de la conduite du fils de Théodore Métochitès qu'il avait pour élève et qui préférait s'amuser dans les rues au lieu de venir au cours ${ }^{2266}$.

En même temps les anciens grades universitaires reparaissaient. Celui de philosophe était conféré à Joseph professeur au Musée, à son disciple, le médecin Zacharie, à Nicéphore Grégoras, peut-être après sa dispute avec Barlaam ${ }^{2267}$. Le titre de consul des philosophes, conféré à des clercs, était resté en usage ${ }^{2268}$. Vers 1310 Nicolas Cabasilas prenait part à un concours, en vue duquel il composait un éloge de saint Démétrius : le jury était présidé par le consul des philosophes ${ }^{2269}$.

L'Université était donc reconstituée, mais on ignore dans quel local se donnait son enseignement. On se demande même si les chaires étaient concentrées dans un seul édifice. Ce qui semble résulter du témoignage des sources, c'est que chaque professeur enseignait dans un local particulier, parfois même à son domicile. Devant l'imprécision des sources il est difficile de savoir si les écoles, auxquelles est attaché le nom d'un professeur, comme Planoudès, Théodore Métochitès, Grégoras, sont publiques ou privées.

\footnotetext{
2265 Ibidem, VI, 35-47; FUCHS, 58-59.

2266 THEODORE HYRTAKENOS, op, cit., V, 728 et VI, 35. Le jeune homme préférait l'équitation aux études.

2267 GUILlAND, Essai sur Nicéphore Grégoras, 18; FUCHS, 60.

2268 Pseudo-CodinUs, De officialibus palatti, P.G., 157 (Bonn, 211); FUCHS, 52.

2269 Nicolas CABASILAS, Correspondance (GuILLAND, B.Z., 1930, 96-102), 98.
} 
Par exemple l'école de Maxime Planoudès (1260-1310), grammairien, éditeur de la dernière Anthologie, traducteur en grec des poètes latins, bien qu'établie dans un monastère, devait être rattachée à l'Université, comme le montrent et son organisation, comportant des assistants, et les fonctionnaires qui en sont sortis ${ }^{2270}$.

D'autre part, Nicéphore Grégoras, après avoir acquis une réputation de savant, ouvre une école, sur l'insistance de ses amis, au monastère de Chora, rebâti par Théodore Métochitès, dans la petite mai-

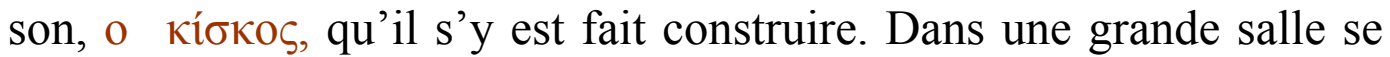
trouvent sa chaire, ses livres et ses instruments de travail : il y a bientôt de nombreux disciples, auxquels il donne un enseignement encyclopédique ${ }^{2271}$. Il s'agit bien là d'une école privée, qui est fermée en 1328 après la disgrâce de Théodore Métochitès, rouverte en 1330 après la dispute avec Barlaam, supprimée définitivement par Jean Cantacuzène, victorieux d'Anne de Savoie (1347). Une école libre ne pouvait donc subsister qu'avec la tolérance du pouvoir.

La dernière Université de Byzance. - Dès la fin du XIV ${ }^{\mathrm{e}}$ siècle il se produisit un changement profond dans l'organisation scolaire. L'initiative de la réforme est due à Manuel II Paléologue (1391-1425), l'un des écrivains les plus remarquables de son époque, érudit, dialecticien, théologien, styliste au courant des finesses du dialecte attique ${ }^{2272}$. Ses voyages en Occident, dont les résultats politiques furent si médiocres, eurent au contraire une grande importance dans le domaine intellectuel. Les Grecs qui accompagnaient le basileus et Manuel lui-même apprirent à connaître les Occidentaux. Le basileus eut des discussions théologiques avec les docteurs de Sorbonne et apprit à estimer leur érudition. De retour dans ses États, il correspondit avec les lettrés dont il avait fait la connaissance et chercha à les attirer à sa cour. La période de répit pour l'empire, qui suivit la bataille d'Angora, lui permit de réorganiser l'enseignement public. Byzance lui dut sa dernière Université.

\footnotetext{
${ }^{2270}$ FUCHS, 59 et $\mathrm{s}$.

2271 GUILland, Essai sur Nicéphore Grégoras, 13-15; NiCEPHORE GREGORAS, Correspondance, 94 (ép. 51); FUCHS, 63 et s.

2272 Supra, p. 291.
} 
Au lieu d'écoles séparées, de caractère indéterminé, tous les enseignements furent réunis dans le même édifice. Le nom officiel resta le même, mais avec l'addition d'une épithète caractéristique, Katholikon Mouseion, que Filelfe, qui en avait été l'élève, traduisit par Universitas litterarum et scientiarum, publicus discendi ludus ${ }^{2273}$. Le local choisi pour abriter l'Université était un hôpital fondé par le kral serbe Ourosch II Miloutine, adjoint au monastère de Saint-JeanBaptiste $^{2274}$.

Ce choix, qui paraît étrange, peut s'expliquer par une raison d'économie, mais aussi par l'importance qu'avaient prise les études médicales. Plusieurs professeurs comme Georges Chrysococcès étaient en même temps rhéteurs et médecins ${ }^{2275}$; d'autre part, la riche bibliothèque du monastère du Précurseur était à la disposition des professeurs : en 1406 l'un d'eux, Jean Chortasménos, fait relier un manuscrit de Dioscoridès de cette bibliothèque par ordre du Nosokomos ${ }^{2276}$.

Suivant la tradition ancienne, l'Université dépendait directement du Sénat, qui en conférait les grades, mais au XV $\mathrm{X}^{\mathrm{e}}$ siècle, le Grand Logothète n'en est plus le directeur depuis la réforme judiciaire d'Andronic III ${ }^{2277}$, c'est l'un des quatre juges-généraux qui exerce cette fonction. Sous Jean VIII (1425-1448) son titulaire est Georges Scholarios, juge catholique des Romains, membre du Sénat, secrétaire du basileus et professeur (didaskalos) au Mouseion impérial, où il enseigne la philosophie. Nous avons déjà signalé son activité et ses conférences hebdomadaires devant l'empereur et le Sénat. Disgracié par Jean VIII après le concile de Florence, Scholarios fut remplacé par Jean Argyropoulos, prêtre séculier. Vers 1434, il avait enseigné le grec à l'Université de Padoue. Revenu à Constantinople en 1444, il ouvrit une école privée, mais Jean VIII le nomma juge-général, professeur impérial et président du Mouseion ${ }^{2278}$.

Une précieuse peinture d'un manuscrit d'Oxford représente Jean Argyropoulos dans l'exercice de ses fonctions de professeur au Musée. Assis dans sa chaire,

\footnotetext{
2273 François Filelfe, Cent dix lettres (éd. Legrand), a. 1448, Lettre à Bessarion; FuCHS, 72.

2274 Sur cette fondation vers 1296, M.B.E.H. (Vie et mort de Byzance), 1969, 340. Ce Xénon, situé non loin du monastère de Chora, était à la fois hôpital et hospice.

2275 FUCHS, 72.

2276 Titre du médecin en chef de l'hôpital; FUCHS, 70 et s.

2277 M.B.E.H. (Institutions), 1970, 194 et .

2278 FUCHS, 70 et s.
} 
large trône au dossier circulaire, sa figure se détache sans perspective sur un fond d'édifices qui, d'après l'épigraphe du folio, représente l'hospice du Kral. Dans une pose familière, une jambe croisée sur l'autre, il tient de la main droite un sceptre fleuronné et de la gauche un livre ouvert, qu'il montre à ses auditeurs, le visage de trois quarts, encadré d'une barbe courte, tendu dans leur direction, avec un regard expressif. II est vêtu d'une ample robe à larges manches, boutonnée par devant et laissant à découvert le cou et la gorge. Il est coiffé d'un étrange bonnet très haut, composé de larges tuyaux en saillie par devant et qui font songer à une lourde étoffe froncée ou à une couronne de métal ${ }^{2279}$.

Les professeurs étaient recrutés la plupart du temps parmi les anciens élèves du Mouseion. Ils étaient en général laïcs, parfois prêtres séculiers, mais jamais moines. Leur situation sociale était assez élevée, comme le montrent leur place dans la hiérarchie et les missions importantes, en particulier les ambassades qui leur sont confiées, comme celle de Manuel Chrysoloras, envoyé en 1397 à Venise par Manuel II. N'oublions pas qu'à cette époque les négociations comportaient des échanges de longs discours.

Le recrutement des étudiants était très varié. Ils représentaient toutes les classes de la société. Beaucoup venaient des provinces, où ils avaient reçu l'instruction élémentaire, et appartenaient à des familles modestes, comme Bessarion, dont les parents exerçaient un métier manuel à Trébizonde ${ }^{2280}$. D'autres venaient de la haute bourgeoisie, comme Michel Apostolis, né à Constantinople vers 1422 d'un père fortuné, mais qui mourut ruiné. Dénué de ressources, Michel se fit copiste de manuscrits et parvint à suivre les cours de Jean Argyropoulos. Il fut lui-même professeur, se maria deux fois et eut plusieurs enfants. Prisonnier des Turcs en 1453, il fut libéré et gagna l'Italie où il fut bien accueilli par Bessarion, qui lui accorda une pension ${ }^{2281}$.

D’une famille aisée de Thessalonique, où cependant les écoles ne manquaient pas, Nicolas Cabasilas, âgé de vingt ans, vint terminer ses études à Constantinople. Son père, qui voulait faire de lui un savant, exigeait d'être renseigné presque journellement sur son travail et ses

\footnotetext{
${ }^{2279}$ Cod. Barocc. Oxford, 87, f $\mathrm{f}^{\mathrm{O}} 35 \mathrm{a}, \mathrm{XV}^{\mathrm{e}}$ siècle. Manuscrit des Catégories d'ARISTOTE. Reproduction dans N.H., X, 1913, 127. L'inscription en épigraphe donne les noms d' «Argyropoulos enseignant à l'hospice du Kral » et de cinq de ses auditeurs presque tous médecins.

2280 H. VAST, Le cardinal Bessarion, 3-5; D.H.G.E., III, 1031-1032 et VIII, 1181-1199; Michel Apostolis, Correspondance, éd. Legrand (B.H.L., 1885, II, 234-259).

2281 Michel APOSTOLIS, loc. cit.
} 
progrès. Le malheureux étudiant avait peine à concilier les exigences paternelles avec ses devoirs d'écolier et finit par tomber malade ${ }^{2282}$. Des étudiants pauvres recevaient des bourses impériales (basilika sitérésia), mais, si l'on en croit Marc d'Éphèse, elles étaient généralement mal payées.

Étudiants occidentaux. - De tout temps, des Orientaux, Arméniens, Géorgiens, Slaves, étaient venus s'instruire à Byzance ; l'événement d'une grande portée, de la fin du XIV siècle, est l'affluence des Occidentaux, en majeure partie des Italiens, désireux d'apprendre le grec et de pouvoir lire les auteurs antiques. Au XV siècle un séjour à Constantinople était le complément d'une bonne éducation $^{2283}$. C'est ainsi que Guarino de Vérone, tout en expédiant les affaires commerciales de son patron Paul Zane, apprend le grec avec Manuel Chrysoloras, qui lui a offert l'hospitalité dans sa maison. Il fit de rapides progrès et acquit une telle réputation de savant, que sa société fut recherchée par des nobles et même par des princes de la maison impériale ${ }^{2284}$.

Cet exemple excita une véritable émulation parmi les Italiens. Vers 1421, le Sicilien Aurispa vendait ses habits à Constantinople pour pouvoir acheter des livres grecs, et plus tard il enseigna le grec à Florence et à Bologne ${ }^{2285}$. Ce furent ces disciples des derniers professeurs de Byzance qui enseignèrent le grec à leur tour à leurs compatriotes, apportèrent en Italie d'innombrables manuscrits et devinrent les véritables initiateurs de la Renaissance.

L'un des plus brillants de ces humanistes est François Filelfe, fils d'un artisan de Tolentino, né en 1398. En 1419, il devint secrétaire du bayle vénitien de Constantinople et suivit les cours de Jean Chrysoloras ${ }^{2286}$ dont il épousa la fille. Après la mort de son beau-père en 1425, il fut le disciple de Georges Chrysococcès en même temps que Bessarion et quitta Constantinople en 1427. Il emportait de nombreux ma-

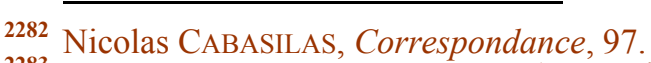

2283 Aeneas Sylvius Piccolomini (Pape Pie II), Correspondances, 705 : « Nemo Latinorum satis videri doctus poterat, nisi per tempus Constantinopoli studuisset. »

2284 GUARINO DE VERONE, éd. De Rosmuni: Vita e disciplina di G. Veronese e dei sui discepoli, 1, 3 et s.; FUCHS, 69.

2285 FUCHS, 72.

2286 Neveu de Manuel Chrysoloras. FuCHS, 69.
} 
nuscrits qu'il avait fait copier ou achetés ${ }^{2287}$. Très vaniteux, il daubait volontiers sur l'enseignement qu'il avait reçu à Constantinople et prétendait que, l'enseignement de son beau-père excepté, il avait tout appris par lui-même ${ }^{2288}$. Par contre il continuait à correspondre avec les Grecs qu'il avait connus et vantait à l'un d'eux le charme (eudaimonia) qu'il avait éprouvé « à Byzance » ${ }^{2289}$. Bien plus, après le concile de Florence, il confia à Jean VIII son fils, JeanMarius, pour achever ses études au Mouseion impérial ${ }^{2290}$. Le jeune homme suivit les cours de Jean Argyropoulos, avec lequel Filelfe ne cessa d'être en correspondance $^{2291}$.

Les études. - Le programme d'études s'est assoupli et, bien que les arts libéraux, menant à la philosophie, en constituent toujours le fond, c'est avec un tout autre esprit qu'ils sont étudiés. Nous avons déjà signalé l'élargissement du programme philosophique et la résurrection du platonisme. L'enseignement littéraire se propose désormais avant tout de former des humanistes, ce qui veut dire qu'il ne s'agit pas seulement de prendre dans l'antiquité classique les éléments qui permettaient de mieux comprendre les Livres Saints et la littérature chrétienne. Désormais la littérature antique est étudiée pour ellemême, pour la beauté de sa forme, la richesse de sa langue, la hauteur et la pureté de sa morale qui s'adresse à tous les hommes et qui leur propose les exemples de vertu, de courage, de désintéressement les plus beaux qu'un homme ait jamais pu concevoir. A cette aurore de la Renaissance, on ne discerne plus les contradictions qui peuvent exister entre cette morale, souvent altière, et celle de l'Évangile.

Telle était la doctrine qui régnait dans l'enseignement de l'Université impériale, aussi bien que dans l'école de Pléthon à Mistra. Il en résultait que l'exercice essentiel proposé aux étudiants était la lecture et le commentaire des auteurs antiques. Il semble que jusqu'au XIV ${ }^{\mathrm{e}}$ siècle cet exercice ait été surtout pratiqué dans les classes de grammaire : désormais il pénètre dans le haut enseignement et l'on

\footnotetext{
${ }^{2287}$ H. VAST, Le cardinal Bessarion, 17; Fr. FILELFE, Cent dix lettres (éd. Legrand), nº 64, 112 (de Milan, 31 oct. 1464)

2288 FUCHS, 69.

2289 Fr. FILELFE, op. cit., $\mathrm{n}^{0}$ 11, 28 (de Sienne, 1436).

2290 Ibidem, $\mathrm{n}^{\mathrm{O}} 15,37-39$ (Gianmarino avait $14 \mathrm{ans}$ ).

2291 Ibidem, n ${ }^{\circ}$ 24, 50-52 (de Milan, 13 avril 1441), recommande à Argyropoulos son élève, Perleone, qui achevait ses études à Constantinople.
} 
constate que des choix étaient faits dans les œuvres des anciens et reproduits à l'usage des écoles ${ }^{2292}$.

Le témoignage le plus remarquable que nous possédions sur la méthode d'explication des auteurs antiques est celui de Guarino de Vérone, qui décrit ainsi celle de Michel Chrysoloras ${ }^{2293}$.

« Le maître faisait d'abord lire à haute et intelligible voix le texte à expliquer, ce qui permettait d'en mieux comprendre le sens et de saisir l'harmonie du style. Puis chaque période était examinée séparément au point de vue des mots : leur place dans la phrase, leur signification, leur choix, leur propriété. Si le sens d'une période demeurait obscur, il fallait, avant d'aller plus loin, éclaircir le passage à force d'examen et de réflexion. Le sens de la phrase établi, l'élève devait la ruminer et en profiter pour augmenter ses connaissances et améliorer son style. Les passages les plus élégants, les bons mots, les sentences utiles à la conduite de la vie devaient se fixer dans la mémoire. Il était bon de relire le passage à haute voix le soir avant de dormir et le répéter au réveil. »

Il est inutile d'insister sur l'excellence de cette méthode que Guarino pratiquait lui-même dans son enseignement ${ }^{2294}$ et qui ne diffère pas beaucoup de celle que l'on emploie dans l'enseignement classique depuis le XVI ${ }^{\mathrm{e}}$ siècle ${ }^{2295}$. Alors qu'au XI $\mathrm{XI}^{\mathrm{e}}$ siècle l'explication des auteurs était surtout grammaticale ou allégorique ${ }^{2296}$, au XV siècle elle est purement littéraire et morale. Ajoutons que l'on se servait dans l'enseignement de la méthode directe. Le grec savant était la seule langue parlée dans les écoles, et plus tard Michel Apostolis reprochait aux professeurs de grec d'Italie de faire leur cours en latin; il attribuait à l'abandon de la méthode directe, pratiquée au Mouseion byzantin, la difficulté avec laquelle les Italiens apprenaient le grec ${ }^{2297}$.

La rhétorique. - Les nouvelles méthodes d'explication des auteurs classiques avaient eu une répercussion sur l'enseignement de la rhétorique. Sans doute on étudiait toujours les traités théoriques d'Aphtonios et d'Hermogène, mais les applications qu'on en faisait,

2292 P. MAZON, Eschyle, B.L., 1931 : les manuscrits d'Eschyle montrent des groupements de trois pièces (par exemple Prométhée, Sept contre Thèbes, Perses), dans plusieurs manuscrits et dans le même ordre; ces choix dateraient de l'époque d'Hadrien.

2293 GUARINO DE VERONE, op. cit., I, 79-114 (lettre écrite en 1429 à Nicolas d'Este, qui lui avait demandé d'être le précepteur de son fils).

2294 Ibidem, 5 (d'après son disciple Jean Panniono).

2295 Voir PORTEAU, Montaigne et la vie pédagogique de son temps, 1935, 121 et s.

2296 L'enseignement de Nicétas : supra, p. 397.

2297 Discours aux Italiens sur l'enseignement de la langue grecque (1472); H. NoIRET, Lettres inédites de Michel Apostolis..., B.E.F.A., LIV, 1889, 143 et s. 
soit dans les déclamations, soit dans les exercices écrits (progymnas$t a$ ), étaient moins abstraites et plus vivantes.

C'est ainsi que Nicéphore Grégoras avait à traiter le sujet suivant : «Les Lacédémoniens et les Thébains marchent sur Platées : les Platéens leur envoient des députés pour leur montrer qu'il n'y a aucune raison de se faire la guerre. » Restituer le discours des Platéens. Ce sujet classique, tiré de Thucydide (II, 1-6), figurait dans les Exercices préparatoires de Théon d'Alexandrie, mais Grégoras le traita à sa manière. En prenant les divers themes de développement indiqués par Hermogène, il fit preuve de connaissances historiques. L'argument, montrant que les luttes intestines des Grecs livreraient le pays aux barbares, pouvait être une allusion aux discordes de son temps ${ }^{2298}$.

Parfois ces travaux écrits donnaient lieu à des concours. Sur l'ordre de son père, Nicolas Cabasilas rédigea ainsi un éloge de saint Démétrius et il espérait que sa composition serait la mieux notée par le jury, que devait présider le Consul des philosophes; mais sa lecture souleva l'indignation parce qu'il avait écrit que Démétrius, le patron de sa ville natale, était plus grand que saint Jean-Baptiste ${ }^{2299}$. Au Xv ${ }^{\mathrm{e}}$ siècle Georges Scholarios avait un professeur qui, laissant les sentiers battus, faisait traiter par ses élèves des sujets nouveaux. Ce fut ainsi qu'il écrivit un éloge d'un saint obscur, Léon d'Achaïe, peut-être à l'époque où il suivait les cours de Pléthon à Mistra ${ }^{2300}$.

Nous ne pouvons énumérer les témoignages innombrables qui montrent la vitalité des écoles du dernier siècle de Byzance. Nous avons pu du moins nous rendre compte de l'importance que les empereurs attachaient à leurs prospérité. Si leurs fondations scolaires n'ont pu survivre à la conquête turque, leurs efforts n'auront pas du moins été inutiles au développement intellectuel de l'Europe. Les derniers professeurs de l'Université byzantine furent les maîtres des premiers humanistes de l'Occident.

\footnotetext{
2298 GuILland, Essai sur Nicéphore Grégoras, 129; autre exemple, NiCEPHORE GrEGORAS, Correspondance, 349.

2299 Nicolas CABASILAS, Correspondance, 98; texte dans P.G., 150.

${ }^{2300} \Pi \alpha \lambda \alpha 10 \lambda o ́ \gamma \varepsilon 1 \alpha . .$. Documents inédits rassemblés par Sp. Lambros, p. p. $1 \delta$ '1є’, 169-172.
} 


\section{L'école patriarcale}

$\underline{\text { Retour à la Table des Matières }}$

En face de l'Université impériale, destinée uniquement à l'enseignement des sciences et disciplines profanes, il existait une école supérieure de théologie, placée sous l'autorité du patriarche, dont l'objet était de former des clercs et des théologiens. Il n'y a pas longtemps qu'on est parvenu à distinguer les deux établissements et à mieux interpréter les témoignages qui montrent l'intervention d'un patriarche dans une question scolaire ou la nomination d'un professeur. Il ne s'agit pas là, comme on le croyait, d'une subordination temporaire de l'Université à l'Église, mais de l'administration d'un institut autonome et distinct de l'Université ${ }^{2301}$.

Conformément aux décrets des conciles, chaque diocèse possédait une école épiscopale plus ou moins importante ${ }^{2302}$.

Il en était ainsi à Constantinople, mais on ne possède aucun témoignage sur les débuts de cette école patriarcale, qui parait n'avoir joué aucun rôle dans les querelles dogmatiques des $\mathrm{V}^{\mathrm{e}}$ et $\mathrm{VI}^{\mathrm{e}}$ siècles. Il est possible qu'elle ait été éclipsée par les centres d'études théologiques qu'étaient les grands monastères, comme celui des Acémètes, dont la riche bibliothèque était célèbre ${ }^{2303}$.

Le premier document qui fasse allusion à l'École Patriarcale est l'autobiographie du computiste arménien Ananias de Schiraq (VII siècle) : il raconte qu'il voyagea avec un diacre du patriarche byzantin et de jeunes clercs, qu'il avait recrutés en Arménie, pour les faire instruire à Constantinople ${ }^{2304}$.

A vrai dire, $\mathrm{c}^{\prime}$ est surtout à partir $\mathrm{du} \mathrm{IX}^{\mathrm{e}}$ siècle que l'on connaît bien l'École Patriarcale. Les documents d'archives la distinguent nettement de l'Université. Des souscriptions à des diplômes montrent, d'un côté

${ }^{2301}$ La distinction a été faite pour la première fois par Fuchs, Die höheren Schulen von Konstantinopel im Mittelalter, 35-41; L. BREHIER, L'enseignement classique et l'enseignement religieux à Byzance, 41 et s.

${ }^{2302}$ Par exemple celle de Corinthe, N. VeIS, Manuel Makros dans E.B., 1925, 125 (XII ${ }^{\mathrm{e}}$ siècle).

${ }^{2303}$ MARIN, Les moines de Constantinople... jusqu'à Photius, 401; M.C., VII, 679 et s.; D.A.C.L., I, 307 et s. (possédait tous les actes des conciles).

${ }^{2304}$ Conybeare, Ananias of Shirak, B.Z., 1897, p. 572 et s.; HeisenBerg, B.Z., 1897, croit à tort que ce texte atteste la mainmise du patriarche sur l'Université. 
le consul des philosophes et les professeurs dépendant du Sénat ( $\pi$

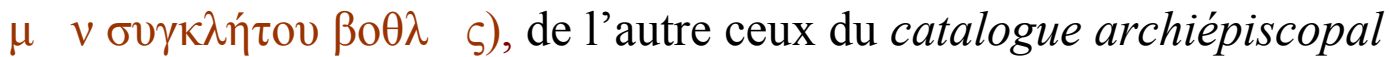

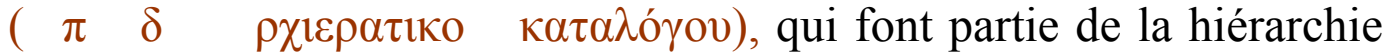
patriarcale. Les philosophes du Sénat s'opposent toujours aux maîtres de la Grande Église ${ }^{2305}$. Et, sans aller plus loin, l'enseignement théologique est interdit aux laïcs par le concile Quinisexte (692), ce qui confirme l'existence d'un enseignement religieux ${ }^{2306}$.

Organisation de l'École patriarcale. - La direction appartenait au Professeur cecuménique. Il est inexact que l'épithète d'œcuménique soit destinée à montrer sa dépendance du patriarche. Nous avons vu que ce titre qui signifie universel était usité au $\mathrm{VI}^{\mathrm{e}}$ siècle à l'École de droit de Beyrouth ${ }^{2307}$. Le didaskalos acuménique, en même temps recteur et professeur principal, était chargé de l'exégèse de l’Évangile ${ }^{2308}$.

Comme le maître œcuménique, tous les professeurs étaient des diacres de Sainte-Sophie, et avaient un rang défini dans la hiérarchie des dignitaires patriarcaux ${ }^{2309}$. Le programme des études comprenait d'abord l'enseignement général, enkyklios paideia, que l'Église a toujours exigé des futurs clercs : on l'appelait l'enseignement de la porte,

$\theta v \rho \alpha ́ \theta \varepsilon v$ бофí $\alpha, \pi \alpha 1 \delta \varepsilon i ́ \alpha$, qu'il fallait franchir avant de pénétrer dans le sanctuaire. Il consistait dans l'étude élémentaire de la grammaire, de la rhétorique et même de la philosophie. Deux maîtres, portant le titre de $\mu \alpha i ̈ \sigma \tau \omega \rho$ (maïstor), donnaient cet enseignement : le maître des rhéteurs et le maître des philosophes ${ }^{2310}$. Ils avaient probablement d'autres maîtres sous leurs ordres, comme le montre une allusion d'Anne Comnène aux grammairiens du catalogue sacré ${ }^{2311}$.

En dehors de leurs fonctions professorales, les maîtres des rhéteurs étaient les orateurs de la cour et prononçaient des discours d'apparat devant le basileus au jour de l'an et aux grandes fêtes ${ }^{2312}$.

\footnotetext{
2305 FuCHS, 47 et s. A la fin du XV siècle Argyropoulos dit, dans ses Discours (éd. Lambros), que l'enseignement dépend, soit du basileus, soit de l'Église.

2306 Canon 64

2307 FUCHS, 37; voir supra, p. 385.

2308 FUCHS, 36 (leçon inaugurale de Michel do Thessalonique, XII ${ }^{\mathrm{e}}$ siècle); souscription aux actes du Concile des Blachernes de 1165 de Nicolas, maître de l'Évangile, P.G., 140, 256.

2309 M.B.E.H. (Institutions), 1970, 396 et s.

2310 L. BREHIER, L'enseignement classique et l'enseignement religieux à Byzance, 49.

2311 ANNE COMNENE, Alexiade, XV, 7 (III, 218).

2312 FUCHS, 41; L. BREHIER, op. cit., 50.
} 
L'enseignement théologique comportait trois maîtres, qui portaient le titre de didaskalos. C'était d'abord le professeur de l'Évangile, en même temps recteur. Venaient ensuite le professeur de l'Apôtre, chargé de l'exégèse des Épîtres, et le professeur du Psautier ${ }^{2313}$. Ces fonctions se maintinrent jusqu'au $\mathrm{XV}^{\mathrm{e}}$ siècle, comme le montre le tableau des offices patriarcaux du pseudo-Codinus. On y voit même un quatrième exégète : le rhéteur interprète des Écritures (probablement l'Ancien Testament) ${ }^{2314}$.

L'École patriarcale constituait donc une véritable université, et la théologie mise à part, son enseignement ne différait pas beaucoup de celui de l'Université impériale. On a la preuve que des étudiants fréquentaient les deux établissements ${ }^{2315}$, dans lesquels régnait la même ardeur pour les études antiques. Les professeurs de théologie euxmêmes étaient au $\mathrm{XII}^{\mathrm{e}}$ siècle de parfaits humanistes : quelques-uns d'entre eux, comme Michel Italikos, professeur œcuménique, n'hésitaient pas à introduire dans leur enseignement des matières qui n'avaient rien à voir avec les Écritures, comme les mathématiques, la philosophie, la littérature antique. C'est seulement après avoir parcouru ce long cycle que Michel Italikos abordait enfin au «port de l'Évangile » ${ }^{2316}$.

L'établissement des Saints-Apôtres. - Ce vaste domaine, embrassé par l'enseignement encyclopédique de Michel Italikos, nous aide à comprendre la nature du curieux établissement, décrit par Nicolas Mésaritès, installé dans les dépendances de l'église des SaintApôtres ${ }^{2317}$.

Le patriarche Jean Kamatéros (1199-1206) dirigeait cet institut, dont l'originalité consistait en l'absence de professeurs et de cours réguliers. Des jeunes gens, des adultes de tout âge, des vieillards, y passaient leur temps en discussions et en controverses sur les matières de l'enseignement. Il y avait deux sections : l'une occupait le narthex

\footnotetext{
${ }^{2313}$ L. BREHIER, op. cit., 51; condamnation de Nicéphore Basilakès, professeur de l'Apôtre, en 1156; ChalANDON, Les Comnène, 640 et s.

2314 Pseudo-CoDINUS, De officialibus palatii, I, 5, 28.

2315 Démétrius, frère de Théophylacte d'Ochrida, élève du maître æecuménique Nicétas et du consul des philosophes Théodore, THEOPHYLACTE D'OCHRIDA, Correspondance, 436, 509 et 536; FUCHS, 48

2316 FuChS, 37-39; dialogue Xenedemos de Theodore Prodrome, dans A.A.E.G., 1887, 11 et s.

2317 Nicolas MeSARITES, Chronique, II, 90-96.
} 
(peribolos), qui formait la façade de l'église et faisait deux retours d'angle qui enveloppaient les façades latérales ${ }^{2318}$; l'autre disposait des portiques de l'atrium ( $\pi \rho \circ \alpha v ́ \lambda 1 \alpha)$ qui précédait la façade de la basilique. La première section était celle des grammairiens, des rhéteurs et des dialecticiens; dans la seconde on s'occupait de physique, de médecine, d'arithmétique, de géométrie, de musique. Les étudiants s'assemblaient "comme des moineaux autour d'une source", s'interrogeant mutuellement sur la question à l'ordre du jour, chacun soutenant son opinion avec opiniâtreté. Des paroles vives s'échangeaient et dégénéraient en disputes : quand la mesure était dépassée, les adversaires s'en remettaient à l'arbitrage du patriarche et se réconciliaient en assistant ensemble « au sacrifice non sanglant».

Heisenberg vit dans cet institut un établissement de l'Université Impériale, placée sous la dépendance du patriarche, et la plupart des historiens adoptèrent cette interprétation ${ }^{2319}$. Elle ne peut en réalité s'appuyer sur aucun témoignage et on ne trouve aucun texte qui place l'Université sous l'autorité patriarcale. On remarquera que les controverses portaient sur les matières enseignées par Michel Italikos, et les étudiants qui se réconciliaient après avoir assisté à la messe sont manifestement des clercs. Qu'il y ait eu parmi eux des étudiants et même des professeurs de l'Université, ce n'est pas impossible, mais les deux institutions n'en demeuraient pas moins distinctes. Le patriarche Jean Kamatéros, érudit de grande valeur, avait été maître des rhéteurs, avant son avènement au patriarcat. On peut supposer qu'il voulut infuser une vie nouvelle à l'Ecole patriarcale en instituant ce séminaire, qui fut une des créations scolaires les plus originales de Byzance ${ }^{2320}$.

Sous les Paléologues. — L'École patriarcale, désorganisée comme l'Université par la conquête latine, fut reconstituée en 1266 par le patriarche Germain, qui obtint de Michel VIII l'autorisation de nommer Michel Holobolos, ancien secrétaire impérial, rhéteur et professeur, puis maître des rhéteurs et directeur de l'Ecole Patriarcale ${ }^{2321}$. Il redevint, comme les anciens rhéteurs, l'orateur attitré de la cour impé-

\footnotetext{
2318 Ce plan est reproduit à Saint-Marc de Venise.

2319 J'avais moi-même accepté cette interprétation dans B.N. 1926, 77.

2320 FUCHS, 53; L. BREHIER op. cit., 55 et s.

2321 PACHYMERE, Histoire, IV. 14, 730 (occupa cette fonction six ans); FuCHS, 58. Dans sa requête à Michel VIII le patriarche fait valoir l'obligation de former des clercs. Voir TREU dans B.Z., 1896,543 et $\mathrm{s}$.
} 
riale ${ }^{2322}$. Sur les successeurs d'Holobolos on est mal renseigné avant le milieu du XIV ${ }^{\mathrm{e}}$ siècle. L'école patriarcale a pour chef à cette époque Théodore Méliténiotès, qui porte le titre pompeux de didaskalos des didaskaloi $^{2323}$. Il eut pour successeur Joseph Bryenne, né à Mistra, moine en Crète, qui vint à Constantinople en 1396 et entra au monastère de Stoudios. Réputé pour sa science et son éloquence, il gagna la faveur de Manuel II, fit partie du conseil impérial et devint le prédicateur officiel de la cour. Sous sa direction l'École Patriarcale retrouva une grande prospérité. Installée chez les Studites, elle compta jusqu'à 30 professeurs. Joseph Bryenne était lui-même exégète de l'Évangile, mais bien qu'avant tout théologien, il enseignait aussi les sciences profanes ${ }^{2324}$. Chargé par Jean VIII des négociations relatives à l'Union religieuse, il n'attendait rien de la croisade occidentale et refusait toute concession dogmatique. Il préféra renoncer à sa mission, regagna la Crète vers 1436 et mourut avant le concile de Florence ${ }^{2325}$.

Avant la chute de Constantinople, le dernier directeur de l'École patriarcale fut sans doute Mathieu Kamariotès. Il eut Georges Scholarios comme élève et continua à exercer ses fonctions après 1453, avec le titre de rhéteur de la Grande Église, porté désormais par tous ses successeurs ${ }^{2326}$.

Malheureusement nous connaissons mal la nature de l'enseignement donné à l'École Patriarcale sous les Paléologues. L'humanisme paraît y avoir pris le pas sur la théologie. Cependant il y eut aux $X V^{\mathrm{e}}$ et $\mathrm{XV}^{\mathrm{e}}$ siècles de nombreux théologiens. La polémique contre des Latins tient une grande place dans leurs ouvrages, mais elle est loin d'être exclusive. Les traités d'exégèse, d'apologétique, d'ascétisme et la littérature mystique y sont représentés; mais ce n'était pas à l'École Patriarcale, c'était au fond des cloîtres que toutes ces œuvres étaient élaborées.

2322 KRUMBACHER, Geschichte der byzantinischen Literatur, 770 et s.

${ }^{2323}$ FUCHS, 73 et s. Interprète de l'Évangile, dont il écrit un commentaire, P.G., 149, 881 et s., ainsi qu'un traité : Sur la sagesse païenne (MELITENIOTES).

2324 D'après Marc d'Ephèse, son disciple au Mouseion des Studites. PAPADOPOULOS-KerameUs,

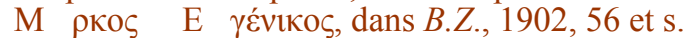

2325 FuCHS, 73 et s. D.H.G.E., X, 1938, 993 et s.; en relations avec les humanistes italiens, se trouvait à Florence en 1425, DEMETRIUS KYDONES, Correspondance, 264.

${ }^{2326}$ KRUMBACHER, op. cit., 451; FuCHS, 75 et s.; N. IORGA, Byzance après Byzance (Bucarest, 1935), 98. 


\section{Les écoles monastiques}

\section{Retour à la Table des Matières}

Les écoles monastiques étaient opposées par leur esprit et leurs programmes d'enseignement à l'Université et même à l'École patriarcale.

L'instruction des moines. - L'étude de l'antiquité païenne paraissait indispensable au plus grand législateur du monachisme byzantin, Basile de Césarée ${ }^{2327}$. Tous les Pères de l'Église étaient d'accord avec lui et plus tard un Jean Damascène, un Théodore de Stude étaient imbus des mêmes principes. Sans parler des professeurs et des érudits attirés par la vie monastique, nous avons pu constater qu'à toutes les époques il se trouvait des moines parmi les humanistes.

Mais nous savons que, d'une part, la législation de saint Basile représente un effort pour adapter le cénobitisme oriental au génie hellénique, et que, d'autre part, le monachisme byzantin ne tarda pas à se modeler sur les instituts monastiques de Palestine, de Syrie et d'Égypte ${ }^{2328}$.

Or, l'idéal du moine oriental, c'est l'ascétisme le plus dur, le mépris du monde et de la science humaine, l'élan mystique vers Dieu, qui mène au repos spirituel, à l'hésychia, au quiétisme. Plus près du peuple que le clergé séculier, recrutés en grande partie dans le peuple et souvent illettrés ${ }^{2329}$, les moines ne pouvaient avoir la moindre considération pour l'instruction raffinée de l'Université. Ils ne voyaient dans la littérature antique que son caractère païen et sa mythologie, qu'ils regardaient comme démoniaque.

C'est ce qui explique le malentendu qui régna à toutes les époques entre les moines, même instruits, et les humanistes. Les sciences pro-

\footnotetext{
2327 Saint BASILE DE CESAREE, Aux jeunes gens sur la manière de tirer profit des lettres helléniques (éd. F. Boulenger), Introduction.

2328 M.B.E.H. (institutions), 1970, 480 et s.

${ }^{2329}$ Exemple de saint Joannice le Grand qui apprit à lire à 41 ans: Vie de saint Joannice le Grand, A.S.B., nov. II.
} 
fanes sont pour eux les sciences $d u$ vestibule, de la porte, $\quad \theta v ́ \rho \alpha \theta \varepsilon v$

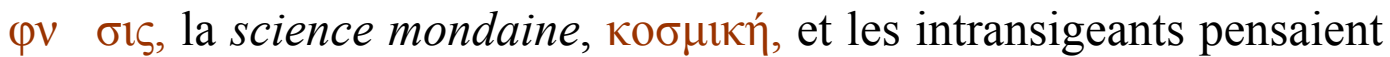
que c'était une perte de temps de s'y attarder avant d'aborder la vraie

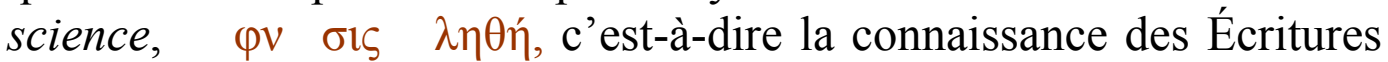
et des ouvrages ascétiques. Le biographe du patriarche Nicéphore (806-815) compare la science profane à Ismaël, fils de l'esclave, la science sacrée à Isaac, l'héritier légitime ${ }^{2330}$.

Les vies des saints, œuvres des moines, sont remplies d'allusions désobligeantes pour les sciences helléniques et ceux qui les cultivent. Le biographe de saint Jean le Psichaïte, higoumène d'un monastère de la Vierge, qui souffrit pour la cause des images sous Léon l'Arménien (815-820), le montre dans sa jeunesse plongé dans l'étude des Écritures et en profite pour faire une critique en règle du plan d'études de l’Université impériale.

Jean, disait-il, possédant la vraie science, n'avait besoin ni des minuties grammaticales, ni de connaître le bavardage d'Homère ou l'art d'atteler des chars, ni des mensonges des rhéteurs... Il ne faisait cas, ni des syllogismes, ni des sophismes, "qui ne sont que des toiles d'araignées ». L'astronomie, la géométrie, l'arithmétique, il les considérait comme des choses qui n'ont pas d'existence, mais il avait surtout un grand mépris pour Platon, qui « pareil aux serpents, rampe dans la boue des passions » ${ }^{2331}$.

Ainsi ce sont toutes les matières du trivium et du quadrivium qui sont condamnées sans appel. Bien plus, c'est la tradition de Basile le Grand, des Pères de l'Église, de saint Jean Damascène, qui est reniée sans remords. On ne se contentait pas d'ailleurs de vilipender l'enseignement : ceux qui le donnaient n'étaient pas à l'abri des attaques, même après leur mort.

Après la mort de Léon le Mathématicien, dont le nom, comme nous l'avons vu, est à l'origine de la rénovation universitaire, un de ses anciens disciples, Constantin, publia contre lui des vers venimeux, dans lesquels il était accusé d'apostasie et d'hellénisme. «Il avait abandonné le Christ pour les dieux de la Grèce. » Un chœur de chrétiens lui annonçait qu'il serait précipité en enfer avec Socrate, Platon, Aristote, Chrysippe, Épicure. Le scandale fut grand dans les cercles lettrés, qui accusèrent Constantin d'impiété et de parricide. Il répondit par un nouveau poème, dans lequel il en appelait au Christ, unique source de vérité ${ }^{2332}$.

${ }^{2330}$ L. BREHIER, L'enseignement classique et l'enseignement religieux à Byzance, 59-61.

2331 Légendes slaves de Constantin et Méthode (trad. Dvornik), 29 et s.

2332 P.G., 107, 61 et s.; BURY, A History of the Eastern Roman Empire, 440 et s.; FuCHS, 18 et s. 
Cette lutte entre les lettrés et les moines a duré pendant tout le moyen âge, et loin de se ralentir, est devenue de plus en plus âpre dans les derniers siècles de Byzance : l'histoire de l'Université nous a déjà permis d'en percevoir les échos. Un article du Synodikon, qui rappelle les anathèmes prononcés par le concile de 1082 contre Jean l'Italien, condamne ceux qui se livrent aux études helléniques autrement que pour leur instruction et tiennent comme des vérités les vaines doctrines des anciens ${ }^{2333}$. Dans sa lutte contre Barlaarn, Grégoire Palamas va plus loin et blâme son adversaire « d'être attaché follement à la vanité des études helléniques », en considérant les auteurs païens comme des auxiliaires de la théologie ${ }^{2334}$. La lutte d'idées prit un aspect tragique lorsqu'elle aboutit aux tortures infligées à Nicéphore Grégoras et aux insultes prodiguées par des moines à sa dépouille mortelle ${ }^{2335}$.

L'enseignement dans les monastères. - Cet éloignement des moines pour l'humanisme ne prouve nullement qu'ils aient renoncé à tout travail intellectuel. La règle de saint Basile leur faisait un devoir de se livrer à l'étude, de copier des manuscrits et d'instruire les novices. Il existait donc une école, plus ou moins bien organisée, dans chaque monastère, mais elle était réservée exclusivement aux enfants que leurs parents engageaient dans la vie monastique, et souvent à l'âge le plus tendre. Le concile de Chalcédoine (451) avait interdit de recevoir des enfants laïcs (pueri saeculares) dans les écoles monastiques, comme l'avait permis saint Basile. Il faut croire que cette prohibition tomba souvent en désuétude, car on la trouve renouvelée à plusieurs reprises ${ }^{2336}$.

C'est surtout par des textes hagiographiques et des typika qu'on a quelques renseignements sur les études des novices. L'enseignement religieux y tenait la place principale. Aux illettrés on faisait apprendre le Psautier par cœur ${ }^{2337}$. Les novices devaient lire les Écritures et les œuvres des Pères de l'Église, des livres de morale pratique et les vies de saints, production la plus importante de la littérature monastique.

\footnotetext{
2333 CECONOMOs, La vie religieuse dans l'Empire byzantin au temps des Comnènes et des Anges, 2 27; L. BREHIER, op. cit., 67.

GUILLAND, Essai sur Nicéphore Grégoras, 23-30.

Ibidem, 39-44, et 53-54.

Vie de saint Antoine le Nouveau (éd. Papadopoulos-Kérameus), 186-207.

L. Brehier, op. cit., 63 et s.; Michel D’AtTAlie, Diataxis, 14 (même interdiction).
} 
Cependant l'instruction religieuse elle-même eût été impossible sans l'acquisition d'un minimum de connaissances élémentaires, qu'on ne pouvait trouver que dans les ouvrages des anciens. L'instruction générale, enkyklios paideia, précédait donc dans les écoles monastiques l'enseignement religieux proprement dit. Par exemple, Michel le Syncelle (fin VIII ${ }^{\mathrm{e}}$-IX ${ }^{\mathrm{e}}$ siècle), qui avait reçu une instruction complète avant d'entrer au monastère de Saint-Sabas près de Jérusalem, fut chargé par son higoumène de l'éducation de deux moines orientaux, arrivés nouvellement: Théodore et Théophanes, âgés, l'un de 22, l'autre de 25 ans. Michel les tonsura et leur apprit la grammaire, la philosophie et la poésie; Leurs progrès furent rapides ${ }^{2338}$.

Cette méthode d'éducation était générale à cette époque. Le futur higoumène de Stoudios, Nicolas, né en Crète en 793, entre comme novice à 10 ans dans ce monastère. L'higoumène, qui n'était autre que saint Théodore le Studite, le bénit et le conduit à l'école attenante au couvent, où il trouve d'autres enfants de son âge, avec lesquels il se délecte à la lecture des vies des saints ${ }^{2339}$.

Le typikon du monastère de Petritzos près Philippopoli, fondé en 1083 par Grégoire Pakourianos, montre l'organisation d'une école monastique destinée à six boursiers de naissance géorgienne. Un prêtre-moine expérimenté sera chargé de les instruire dans les lettres sacrées, $\tau \quad \varepsilon \rho \quad \gamma \rho \alpha ́ \mu \mu \alpha \tau \alpha$ jusqu'à ce qu'ils soient capables d'être eux-mêmes ordonnés prêtres ${ }^{2340}$.

Les bibliothèques monastiques. - A défaut de renseignements plus abondants sur ces écoles, les détails qui nous sont parvenus sur les bibliothèques monastiques, leurs catalogues et parfois leurs livres de prêts, peuvent jeter quelque lumière sur les préoccupations intellectuelles des moines. Les conclusions qu'on en peut tirer confirment ce que nous savons des écoles. Alors que la bibliothèque patriarcale de Constantinople possédait un grand nombre d'auteurs classiques et jusqu'à des textes, aujourd'hui perdus, de Ménandre, les bibliothèques monastiques dont on a retrouvé les catalogues, celle de Petritzos

\footnotetext{
2338 Vie de Michel le Studite (éd. Schmitt), 228-231.

2339 Vie de Nicolas le Siudite, P.G., 105, 540 et s.; L. BREHIER, 65.

2340 Typikon de Grégoire Pakourianos (Monastère de Petritzos), éd. L. Petit, 50 (ch. 31).
} 
d'après le typikon cité plus haut, celle du monastère de Michel d'Attalie (vers 1077), celle de Saint-Jean de Patmos (d'après un catalogue dressé en 1201) renfermaient des ouvrages liturgiques, des textes et des commentaires des Écritures et des Pères de l'Église, des vies de saints et des manuels destinés à l'enseignement élémentaire. Sur les 330 ouvrages (267 sur parchemin, 63 sur papier de coton) de la bibliothèque de Patmos, on compte 124 livres liturgiques (dont 12 évangiles), 13 recueils de livres isolés de l'Ancien Testament, 116 manuscrits des Pères de l'Église et des vies de saints (dont 7 de saint Basile). Les livres profanes étaient des manuels de grammaire et de médecine, ou des lexiques. La littérature antique était représentée par deux manuscrits d'Aristote et les œuvres de Josèphe, celle de Byzance par le roman de Barlaam et Joasaph, regardé d'ailleurs comme une œuvre édifiante, et par les chroniques du patriarche Nicéphore et de Skylitzès ${ }^{2341}$.

Aucun témoignage n'est plus éloquent que ce catalogue. On s'explique ainsi comment l'enseignement théologique, exclu de l'Université impériale, médiocrement représenté à l'École patriarcale, ait trouvé asile dans les monastères. A la culture antique étudiée pour elle-même, les moines opposaient une culture exclusivement chrétienne et ne demandaient à l'antiquité païenne que des leçons de grammaire et de rhétorique.

Retour à la Table des Matières

2341 DieHL, Etudes byzantines, 307-336. 


\section{Chapitre XIV}

\section{L'art byzantin}

Aux créations intellectuelles de Byzance s'ajoute un essor artistique, qui permet d'évoquer sa civilisation dans tout son éclat et de saisir le mieux l'originalité de son génie.

Mais, s'il existe incontestablement un art qui a régné dans l'Empire byzantin, il est difficile de lui assigner des limites dans le temps et dans l'espace. Pas plus que sa littérature, l'art de Byzance n'est une création nouvelle : il continue une tradition. D'autre part, il déborde au-delà des frontières de l'Empire et ne possède pas une véritable unité d'inspiration. C'est en essayant de reconstituer le milieu artistique dans lequel il apparaît, que l'on peut définir le mieux ses caractères et délimiter son domaine.

\section{Au berceau de l'art byzantin}

\section{$\underline{\text { Retour à la Table des Matières }}$}

Ses sources. - L'art hellénistique, qui régnait dans l'Empire romain et même au-delà de ses frontières, dans l'État hindou du Gandhara, en Afghanistan, en Bactriane, avait pris un caractère abstrait et cosmopolite, qui convenait à toutes les races, à toutes les religions. Son décor mythologique était susceptible d'interprétations symbolistes, qui variaient avec les doctrines. C'est ainsi que le mythe d'Orphée se trouve dans des cimetières chrétiens et des synagogues juives, que le même type sculptural de l'orateur est attribué au Christ enseignant et au Bouddha ${ }^{2342}$.

${ }^{2342}$ L. BREHIER, L'Art chrétien. Son développement iconographique, 50 et s. 
D'autre part, dans l'Orient asiatique, l'hellénisme propagé dans les États fondés par les successeurs d'Alexandre le Grand n'était qu'un vernis superficiel, qui n'avait pas entamé les traditions millénaires de la Mésopotamie et de l'Iran ${ }^{2343}$. La résurrection de la Perse et la fondation de l'État des Sassanides en 227 eurent pour résultat un recul de la puissance romaine. En même temps la restauration de la religion des mages, l'apparition d'une langue nationale, le pehlvi, firent du nouvel État un centre de résistance à l'hellénisme.

Les conséquences de cette révolution ethnique et politique devaient se faire sentir dans le domaine de l'art. Du $\mathrm{III}^{\mathrm{e}}$ au $\mathrm{V}^{\mathrm{e}}$ siècle on peut suivre la déchéance de l'art hellénistique et la renaissance de l'art oriental, avec le retour à d'anciennes conventions : la frontalité, la hiérarchie des tailles, la perspective inverse, la symétrie des compositions, la conception géométrique des corps, qui entraîne parfois la stylisation des formes vivantes. L'art grec était l'art humain par excellence : l'art oriental recherche le surhumain ${ }^{2344}$; c'est un art purement décoratif qui vaut par la richesse de la matière, la variété de la couleur, le hiératisme de la composition.

Les monuments de Doura-Europos, tous antérieurs à la prise et à l'abandon de la ville par les Perses en 260 et la plupart datés des premières années du $\mathrm{III}^{\mathrm{e}}$ siècle, démontrent l'existence d'un art étranger à la tradition hellénique, dans lequel on note déjà des traits que l'on retrouve dans l'art byzantin ${ }^{2345}$.

Il est d'ailleurs remarquable que, dans les nombreux sanctuaires des religions pratiquées à Doura, qu'il s'agisse du temple des dieux palmyréniens, du baptistère chrétien ou de la synagogue, les procédés de composition des peintures soient les mêmes. A la liberté du dessin, à la composition habile de l'art grec, les peintres de Doura préfèrent le réalisme, la ressemblance physique, la composition symétrique, la rigidité des personnages, les attitudes solennelles. Voyez par exemple le Sacrifice du tribun au temple des dieux palmyréniens, avec la file mo-

\footnotetext{
${ }^{2343} \mathrm{~V}$. CHAPOT, Les destinées de l'hellénisme au-delà de l'Euphrate, M.S.A.F., 1904.

${ }^{2344}$ Avec les Sassanides réapparaissent les sculptures rupestres de dimensions colossales, L. BREHIER, De l'art antique à l'art médiéval. Art roman, 363 et s.

2345 Dumesnil De Buisson, Les peintures de la Synagogue de Doura-Europos. Préface de G. Millet.
} 
notone des soldats, dont la taille va en diminuant, tous tendant le bras du même geste, tous la tête de face au lieu de regarder l'autel. On note enfin dans les peintures de Doura deux traits encore inconnus du premier art chrétien : la composition narrative et le sens dogmatique des sujets, par exemple au baptistère une sorte de concordance des deux Testaments, la chute de l'homme et le Bon Pasteur au-dessus de la piscine baptismale ${ }^{2346}$.

Les peintures de Doura, simple ville de province, nous montrent l'art nouveau, devenu à son tour cosmopolite, qui se répandit dans les provinces orientales, surtout dans l'intérieur des terres, au centre de l'Anatolie et en Syrie, moins touchées par l'hellénisme que les grandes cités maritimes d'Antioche, d'Alexandrie, de Carthage.

L'apparition de l'art byzantin. - L'art byzantin n'est pas né à date fixe. Au moment de la fondation de Constantinople, le même art hellénistique et orientalisant règne dans le monde romain tout entier. La liberté accordée par Constantin à l'Église, ses victoires, qui lui permettent de rétablir l'unité de l'Empire et de fonder une dynastie, sont des événements d'une importance capitale, dont la répercussion fut immédiate dans le domaine artistique. Des palais, des basiliques civiles, des arcs de triomphe, des églises et même des temples furent élevés dans tout l'Empire. Autant que l'on peut en juger, ce nouvel art impérial devait manquer d'originalité. Constantin n'hésita pas à dépouiller des monuments anciens pour enrichir ses créations et légua ce vandalisme, érigé en système, à ses successeurs byzantins. Des monuments, comme l'arc de triomphe dédié à l'empereur par le Sénat romain après sa victoire sur Maxence ${ }^{2347}$, montrent la dégradation de l'art classique. Les figurines trapues, aux gestes stéréotypés, de la proclamation impériale et du congiarium rappellent le Sacrifice du tribun du temple de Doura-Europos. Les reliefs de l'arc de triomphe de Galère à Thessalonique ${ }^{2348}$, ceux de la base de l'obélisque de Théodore $\mathrm{I}^{\mathrm{er}}$ à Constantinople ${ }^{2349}$, témoignent de la décadence du bas-

\footnotetext{
2346 F. CUMOnt, Fouilles de Doura-Europos (1923); L. BreHIER op. cit., J, 356; SESTON, L'église et le baptistère de Doura-Europos (Gand, 1937).

2347 Ch. PICARD, La Sculpture antique. Origines de la sculpture byzantine, II, 471 (date et identifications discutées).

2348 Ibidem, 469.

2349 Ibidem, 477 et s. Érigé en 401 par Proclus, préfet du Prétoire. Voir supra, p. 87; L. BREHIER, La Sculpture et les Arts mineurs byzantins, pl. V.
} 
relief pittoresque; le groupe de porphyre de la Tétrarchie ${ }^{2350}$ montre le degré de barbarie atteint par la statuaire.

Ce fut seulement au $\mathrm{VI}^{\mathrm{e}}$ siècle que, grâce à l'action personnelle de Justinien, Constantinople devînt le centre d'une école artistique indépendante, que l'on peut appeler l'art byzantin. Cet art s'est manifesté progressivement depuis la fin du IV siècle, mais c'est bien Justinien qui lui a donné son essor par les constructions grandioses et luxueuses qu'il a dû entreprendre pour rebâtir les édifices incendiés pendant la sédition Nika en 532. Son activité ne s'est pas bornée à la Nouvelle Rome et l'on sait, par le Traité des édifices de Procope, qu'il a couvert de ses constructions toutes les provinces de l'Empire. Jamais Byzance ne devait revoir un pareil prince bâtisseur.

Dans les éléments qui constituent ce nouvel art impérial, l'Orient a la plus grande part. Les maîtres d'œuvre, Anthémius de Tralles, Isidore de Milet, sont des Asiatiques. Les mêmes plans, les mêmes formes, appliqués par eux aux palais comme aux sanctuaires, proviennent de l'Orient : basiliques à coupole, coupoles sur pendentifs couvrant des plans barlongs, carrés, octogonaux ; décoration des murs par des placages de marbre ou de mosaïques; somptuosité de l'ornementation et recherche de la couleur sur les pavements, dans les lambris de marbre nuancé, dans les mosaïques à fond d'or, sur lesquelles se détachent les thèmes décoratifs ou les personnages avec un véritable relief.

C'est à l'Orient aussi que l'on doit les nouvelles techniques de la sculpture. Depuis le $\mathrm{IV}^{\mathrm{e}}$ siècle la sculpture décorative substituait au modelage une technique impressionniste qui suggérait le relief par des contrastes d'éclairage. Les motifs étaient mis en pleine lumière par tous les trous d'ombre, creusés au trépan, dont ils étaient cernés. Les sarcophages dits d'Asie Mineure (IV siècle), décorés de statues qui se détachent sur des fonds ainsi travaillés, les chapiteaux dits théodosiens, du $\mathrm{V}^{\mathrm{e}}$ siècle, dont les feuilles d'acanthe, déchiquetées par le trépan, ont un aspect épineux et sec, représentent cette technique qui montre l'abandon progressif de la sculpture dans l'espace.

${ }^{2350}$ Ch. PICARD, op. cit., II, 190 (provient d'Alexandrie); BREHIER, pl. II. 
Depuis la fin du $\mathrm{V}^{\mathrm{e}}$ siècle une technique plus raffinée produit des contrastes encore plus marqués entre la lumière et l'ombre : c'est la sculpture ajourée, dont l'ornement, découpé comme un grillage, ne tient plus à son support que par les extrémités. Le chef-d'œuvre de cette technique est l'ornementation intérieure de l'église SainteSophie, rebâtie par Justinien (532-537). Elle règne sur les chapiteaux de marbre en forme de cratères, enserrant les monogrammes de Justinien et de Théodora; elle s'étale en larges surfaces entre les arcades, formant un vrai fouillis de feuilles d'acanthe, interrompu par des disques de marbre polychrome (omphaloi). On retrouve la technique ajourée dans le beau décor de l'église des Saints-Serge-et-Bacchus et dans toute la Méditerranée, en Égypte, en Afrique, en Italie, où des chapiteaux en marbre de Proconnèse, décorés ainsi dans les ateliers byzantins, étaient exportés au $\mathrm{VI}^{\mathrm{e}}$ siècle $^{2351}$.

La première manifestation de l'art byzantin correspond donc à une nouvelle poussée de l'esthétique iranienne vers l'Occident. Cependant la tradition hellénistique, toujours vivante à Byzance, a empêché son art d'accepter aveuglément tous les apports de l'Orient. En architecture il ne connaît ni l'arc brisé, ni l'arc outrepassé, ni la coupole ovoïde sur trompes d'angle, ni les revêtements de briques émaillées ${ }^{2352}$ et il adopte peu la basilique voûtée en berceau. Dans les arts du dessin, l'art byzantin continue à reproduire la figure humaine et lui conserve sa réalité, au moment où elle est de plus en plus stylisée et même éliminée, en Orient comme en Occident.

C'est cette double hérédité qui donne à l'art byzantin son originalité et son charme : son aspect d'ailleurs varie au cours des siècles, suivant que prédomine l'une ou l'autre de ces influences.

\footnotetext{
2351 L. BREHIER, op. cit., 11-13, pl. VI et VII; du même : Etudes sur l'histoire de la sculpture byzantine, et Nouvelles recherches sur l'histoire de la sculpture byzantine.

2352 A. GRABAR, Les influences orientales dans l'art des Balkans, 7-51 (tradition achéménide transmise aux peuples en contact avec l'Iran, comme les Bulgares avant leur migration, MORAVCSIK, Die byzantinischen Quellen der Geschichte der Türkvölker, I, 50 et s.).
} 


\section{Les destinées de l'art byzantin}

\section{$\underline{\text { Retour à la Table des Matières }}$}

Loin d'avoir été immobile et uniforme, suivant la réputation que lui avait faite Didron au temps du romantisme ${ }^{2353}$, l'art byzantin n'a cessé de se renouveler au cours des siècles, grâce à de nombreuses initiatives, dues parfois aux princes, ou aux particuliers, mécènes, fondateurs de monuments, clients de marque des ateliers d'art décoratif. Nous ne connaissons guère cette production artistique d'un millénaire que sous son aspect religieux, mais, si on veut en mesurer la puissance et l'étendue, il faut comprendre dans son étude les œuvres profanes, sur lesquelles nous ne sommes plus guère renseignés que par des textes et des miniatures.

L'histoire de l'art byzantin est comme un reflet de l'histoire politique de l'Empire. Les deux bouleversements subis par Byzance, le premier au temps des iconoclastes, le second après la croisade de 1204 , ont désorganisé sa production artistique. Mais ces deux crises furent des points de départ du renouvellement de l'art, au $\mathrm{X}^{\mathrm{e}}$ siècle sous la dynastie macédonienne, au XIV ${ }^{\mathrm{e}}$ siècle sous les Paléologues.

Ces deux âges d'or, comme on les appelle, ainsi qu'auparavant le règne de Justinien, furent pour l'art byzantin des périodes d'apogée. Loin de se ressembler, les monuments de ces trois âges diffèrent par leur inspiration, par leur technique, par leur style. Ce sont trois aspects originaux du même art.

Mais ce n'est pas seulement dans le temps que se manifeste la variété d'aspects de l'art byzantin. Des traditions régionales ont déterminé la formation de véritables écoles d'art dont l'originalité s'affirme, soit dans les monuments d'architecture, soit dans les arts plastiques.

Tout d'abord Constantinople est devenue sous Justinien le véritable foyer de l'art byzantin. La présence de la cour impériale et l'ouverture de chantiers, tels que ceux de Sainte-Sophie et des autres construc-

2353 Guide de la Peinture (Hermeneia), trad. Didron. Manuel d'iconographie chrétienne, grecque et latine. Introduction écrite en 1845. 
tions de Justinien, y ont attiré les maîtres d'œuvre et les techniciens les plus renommés. Il en fut ainsi à toutes les époques et particulièrement $\mathrm{du} \mathrm{X}^{\mathrm{e}}$ au XII ${ }^{\mathrm{e}}$ siècle. A côté des ateliers privés, ceux du Grand Palais exerçaient une sorte de prééminence sur la production. C'est de là que sortaient, comme nous l'avons vu, les chefs-d'œuvre les plus somptueux d'art décoratif, qu'on admire encore dans les grandes collections : étoffes historiées, émaux cloisonnés, manuscrits luxueux, etc. C'est par Constantinople que l'art byzantin s'est propagé hors des frontières de l'Empire. A plusieurs époques, ses maîtres ont porté au loin, en Italie, en Sicile, à Venise, en Serbie, en Russie, dans les pays du Caucase, les méthodes de construction et d'ornementation élaborées sur le Bosphore.

Mais si puissant que fût son rayonnement, Constantinople n'était pas l'unique foyer d'art. Avant le règne de Justinien, des églises et des palais du nord de l'Italie: San Lorenzo de Milan (fin du IV e siècle) avec sa coupole octogonale reposant sur des colonnes intérieures, San Nazaro dans la même ville, sur plan cruciforme, ne doivent rien à l'art de Constantinople ${ }^{2354}$. Ces plans se retrouvent à Ravenne, l'octogone au baptistère des Orthodoxes (entre 449-452) et à Saint-Vital (époque de Théodoric), le plan cruciforme (en croix libre) au mausolée de Galla Placidia (avant 450) ${ }^{2355}$. En même temps, on continuait à construire dans la même ville des basiliques de type hellénistique et à employer au $\mathrm{V}^{\mathrm{e}}$ siècle les mosaïques murales à fond d'azur d'un charme si pénétrant, technique usitée en Italie depuis l'ère chrétienne ${ }^{2356}$ et constituant ainsi une tradition régionale. Il existe une vraie parenté entre cet art de Ravenne et celui des villes d'Istrie (cathédrales de Parenzo et de Trieste, églises de Pola et d'Aquilée). Et ce n'est pas par un simple hasard que le Christ de la mosaïque absidale de Saint-David de Thessalonique a une ressemblance frappante avec le Bon Pasteur gardant son troupeau, au mausolée de Galla Placidia : c'est la même expression majestueuse avec le même geste souverain ${ }^{2357}$. Il y a donc là un groupe de monuments construits aux $\mathrm{V}^{\mathrm{e}}$ et $\mathrm{VI}^{\mathrm{e}}$ siècles par des ateliers attachés aux mêmes traditions, orientale et hellénistique, ce qui est le propre d'une école d'art.

\footnotetext{
2354 DIEHL, Manuel d'art byzantin, I, 128.

2355 Id., Ravenne (Villes d'art célèbres, 1903), 20-22, chap. II et V.

2356 L. BREHIER, Les mosaïques à fond d'azur, R.E.B., III, 20 et s. (exemples les plus anciens à Herculanum et à Ostie).

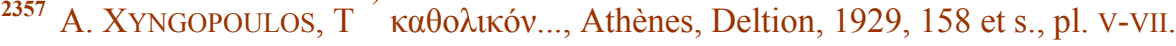


L'école grecque. - La tradition orientale, réfractaire à l'action de Constantinople, a continué, après le $\mathrm{VI}^{\mathrm{e}}$ siècle, son expansion vers l'Occident. Son influence s'est particulièrement exercée dans l'île de Chypre, en Grèce et en Macédoine. A Thessalonique, l'église SainteParaskévi (Eski Djouma) rappelle une basilique syrienne par ses deux étages de baies ouvertes, par ses vastes tribunes garnies de colonnes élancées qui supportent des arcades, par son magnifique éclairage (deux rangs de fenêtres formant file continue au rez-de-chaussée), par le retour d'angle de sa colonnade à l'ouest ${ }^{2358}$.

La basilique voûtée d'Anatolie, avec nef éclairée au-dessus des bas-côtés, se trouve à Serres et à Castoria au $\mathrm{XI}^{\mathrm{e}}$ siècle, tandis qu'à Sainte-Sophie d'Ochrida, à la même époque, la nef est aveugle et prise sous le même toit que les collatéraux ${ }^{2359}$. Des églises en croix libre avec pignons aigus, comme la Petite Métropole d'Athènes, couverte d'une coupole centrale et construite en marbre pentélique, rappellent les églises arméniennes ${ }^{2360}$.

Un autre groupe original est celui des églises dont la coupole, au tambour octogonal, s'appuie sur huit piliers par l'intermédiaire de niches ou trompes d'angle. Ce procédé iranien, encore archaïque au Saint-Sauveur de Milo, est celui des belles églises de Hosios Loukas ( $\mathrm{X}^{\mathrm{e}}$ siècle) (Phocide), de Daphni ( $\mathrm{XI}^{\mathrm{e}}$ siècle), de Sainte-Sophie de Monemvasia (XIII ${ }^{\mathrm{e}}$ siècle) ${ }^{2361}$.

Le même contraste entre les deux écoles se manifeste à l'extérieur des édifices. A la place des arcatures, des gradations de relief, des pignons curvilignes de l'école de Constantinople, la Grèce préfère les surfaces unies, les lignes droites, les angles nets ${ }^{2362}$.

\footnotetext{
2358 Notes de voyage 1930; DIEHL, Monuments chrétiens de Salonique, 35-52.

2359 MILLET, L'Ecole grecque dans l'architecture byzantine; W. RAMSAY et miss BELL, The thousand and one Churches.

2360 Millet, op. cit., 42, 107, 113, 191 et s.

2361 Panagia Gorgopigo, A. STRUCK, Die mittelbyzantinische Kirchen, A.M., 1906, 79 et s. On trouve aussi la basilique voûtée à nef unique de type mésopotamien: SOTIRIOU, La belle église d'Egine dans E.B., 1925, 43 et s.; A. XYNGOPOUlos, Basiliques orientalisantes de Laconie dans E.B., 1927, 343 et s. MiLlet, op. cit., 105-118.

2362 MiLLET, 141-179.
} 
L'art des monastères rupestres. - En décrivant les institutions monastiques, nous avons signalé dans la région volcanique d'Urgub en Cappadoce les curieuses colonies de moines, installées à l'intérieur des dykes de tuf, affouillés, et comprenant des églises et des monastères, dont les parois, les voûtes, les piliers ont été littéralement sculptés dans la roche, sur le modèle des constructions maçonnées ${ }^{2363}$. Des instituts analogues furent fondés par des ermites au mont Latros sur le golfe Latmique, en Thessalie aux Météores, et dans les régions désertiques de la Calabre, mais aucun n'atteint l'importance du groupe cappadocien.

L'identité des résultats obtenus par les mêmes procédés d'affouillement, en réservant dans le roc les masses destinées à être sculptées en piliers, en colonnes, en arcs, en berceaux, en coupoles, ou à former des pièces de mobilier (autels, clôtures, iconostases des églises, bancs et tables des réfectoires), montrent que nous sommes en présence d'ateliers monastiques, qui travaillèrent pendant quatre siècles environ avec les mêmes méthodes, suivant une même tradition. Si l'on ajoute à l'œuvre des architectes celle des moines qui couvrirent de fresques les surfaces rupestres, on n'hésitera pas à voir dans ce groupe d'ateliers monastiques les éléments d'une école artistique. Sans doute il s'agit d'un art populaire, parfois même maladroit et grossier. Les constructions ne sont pas régulières, les nombreuses inscriptions sont remplies de fautes, les peintures sont ternes, les dessins maladroits. Cette école cappadocienne - on ne peut lui donner un autre nom — n'en tient pas moins sa place dans l'histoire de l'art byzantin.

Elle y représente la part de l'Orient, mais avec un apport régional qui en augmente l'intérêt. L'architecture des églises les plus anciennes est en effet parente de celle du groupe voisin de Lycaonie dans le Hassan-Dagh : nef rectangulaire sans bas-côtés, couverte d'une voûte en berceau ou d'un plafond, terminée par une abside en arc outrepassé, le plus souvent sans pilastres ni arcs doubleaux. Ce type rudimentaire s'est enrichi au cours des âges d'éléments nouveaux, d'origine orientale à l'époque archaïque (nef transversale à trois absides, église à deux nefs communiquant par des arcades, plan en croix libre à cou-

${ }^{2363}$ M.B.E.H. (Institutions de l'Empire byzantin), 1970, 443 et s.; JERPHANION, Les églises rupestres de Cappadoce, I, 43-66 et R.A., 1927, 1-47. 
pole centrale entre quatre berceaux), à une époque plus récente (fin du $\mathrm{X}^{\mathrm{e}}-\mathrm{XI}$ siècle) trahissant un apport étranger, qui ne peut venir que de Constantinople. Telles sont les églises à croix inscrites dans un carré avec coupole centrale et colonnes, qui rappellent l'église en croix grecque $^{2364}$, mais qui conservent l'élément régional qu'est l'arc outrepassé.

Les fresques iconographiques qui recouvrent toutes les surfaces disponibles et constituent à peu près le seul ornement de ces églises, dérivent de la même tradition orientale que l'architecture. Leur technique est très simple. Le peintre traçait à l'ocre rouge la silhouette des personnages, les traits de leur visage, les grands plis de leurs draperies; le modelé était obtenu avec des teintes claires, où dominaient les tons gris, rouges et jaunes d'ocre ; le bleu est rarement employé. Dans les églises archaïques, cette peinture est entièrement narrative. Son programme consistait à disposer en longues frises et en plusieurs registres la vie de Jésus, partagée en trois cycles : l'Enfance, les Miracles, la Passion. Certaines théophanies, l'Ascension, les Visions apocalyptiques (celles-ci inconnues de l'art de Constantinople) ${ }^{2365}$ sont réservées pour les absides et les coupoles. Des portraits de prophètes, de saints remplissent les intervalles laissés libres. Les portraits de donateurs ne sont pas rares. Les inscriptions sont nombreuses.

Le style est assez gauche. La tradition de la peinture syrienne revit dans les conventions enfantines, dans le réalisme des figures, dans l'emploi fréquent des apocryphes, dans le sentiment dramatique qui anime en particulier les épisodes de la Passion. D'ailleurs ce sont les attitudes expressives des personnages, la vie intense de leur regard, la noblesse de leurs gestes et le mouvement dont les scènes sont animées, qui donnent à cette peinture un véritable charme ${ }^{2366}$.

Les peintures des églises à colonnes, à partir de la fin du $\mathrm{X}^{\mathrm{e}}$ siècle, manifestent l'influence de l'art de Constantinople. Le décor se présente dans un cadre monumental. La vision apocalyptique est remplacée, à la Nouvelle Eglise de Toqalé (fin du $\mathrm{X}^{\mathrm{e}}$ siècle), par la Cruci-

2364 Sur ce plan, trop compliqué pour une église monolithe, voir p. 435.

2365 L. BREHIER, Les visions apocalyptiques dans l'art byzantin (Ext. de Aria si arheologia, Bucarest, 1930).

${ }^{2366}$ Par exemple à l'église de Qeledjiar, dont les peintures sont remarquables par leur expression JERPHANION, op. cit., I, 25, pl. IV. 
fixion, suivie de la Déposition de Croix et de la Résurrection ${ }^{2367}$. Dans l'abside nord de l'église de Taghar (début du XIII ${ }^{\mathrm{e}}$ ), le buste colossal du Pantocrator apparait dans un riche décor d'entrelacs et surmonte une Crucifixion ${ }^{2368}$. La Dormition de la Vierge est figurée plusieurs fois ${ }^{2369}$. L'imitation de la mosaïque murale et le caractère liturgique et théologique des thèmes sont visibles. Ce qui est nouveau surtout, c'est l'entente de l'effet décoratif, l'adaptation du décor à l'architecture et, dans les tableaux, une certaine recherche du cadre (édifices, arbres, rochers), plus marquée que dans les églises archaïques ${ }^{2370}$.

\section{Les créations de l'art byzantin}

Retour à la Table des Matières

Le tableau sommaire des destinées de l'art byzantin nous a donné les preuves de sa vitalité, de sa variété, de son activité créatrice. Les maîtres de cet art, pénétrés de l'harmonie des œuvres antiques et de la magnificence orientale, réussirent à fondre ces éléments opposés dans une vaste synthèse, en s'assimilant les apports exotiques, en les adaptant à leur goût et à leur milieu. C'est par là qu'ils sont vraiment des créateurs et, sans pouvoir entrer ici dans le détail de leurs créations, il est nécessaire de montrer quel usage ils firent des procédés techniques légués par leurs devanciers et de rappeler quelques-uns des chefsd'œuvre qui représentent le mieux leur génie d'invention.

Ces maîtres byzantins, on voudrait les connaître et c'est tout juste si on sait les noms de plusieurs d'entre eux, grâce à des signatures recueillies sur des inscriptions ou dans des manuscrits enluminés et aussi par quelques anecdotes qui, d'ailleurs, ne concernent pas leurs œuvres. Mais quelle était leur origine, quelle éducation ils ont reçue, quelles furent les étapes de leur carrière, il faut se résigner à l'ignorer.

Ibidem, I, 345, pl. 84, 2.

Ibidem, II, 191, pl. 168, 1 (Deisis dans l'abside orientale).

Ibidem, Qeledjlar, I, 250, pl. 60, 3; Toqalé, Nouvelle église, 357, pl. 83, 1 et s.

Ibidem, I, 299, 378. 
C'est par leurs œuvres que l'on peut savoir quelque chose de leur tempérament et de leur personnalité ${ }^{2371}$.

Architecture. - L'école de Constantinople emploie la brique, exceptionnelle en Asie Mineure et en Syrie, et, suivant un procédé venu de Rome, l'alternance des assises de moellons et de briques. Par contre, à la différence des voûtes romaines, berceaux et coupoles, en matériaux lourds assemblés par un ciment indestructible, les voûtes byzantines sont en briques creuses ou en matériaux légers, pierre ponce, pouzzolanes et jarres de terre cuite noyées dans le mortier ${ }^{2372}$.

Cette construction en briques exige des revêtements intérieurs, et même parfois extérieurs, de marbres et de mosaïques. Les carrières des marbres les plus variés, de la blancheur la plus pure jusqu'aux nuances les plus délicates, étaient abondantes dans l'Empire et Constantinople disposait des carrières de Proconnèse. Les empereurs n'en conservèrent pas moins l'habitude de leurs prédécesseurs romains, en puisant sans discrétion dans les ruines antiques pour enrichir leurs fondations.

La Grande Église Sainte-Sophie. — L'église de Justinien, qui a pu traverser quatorze siècles, représente l'effort le plus puissant qu'aient jamais fait les maîtres byzantins, mais c'est aussi la première œuvre où se manifeste l'originalité de leur art. Sans ses dépendances aujourd'hui disparues ${ }^{2373}$, elle occupe une superficie de 10000 mètres carrés avec 77 mètres de longueur sur $72,70 \mathrm{~m}$ de largeur. La coupole actuelle, rebâtie en 562 et moins hardie que la première, qui s'écroula en 558, ne s'élève pas moins à 54 mètres du sol pour un diamètre de 32 mètres, dépassant en hauteur celle du Panthéon de Rome (43 mètres) et les voûtes de nos cathédrales gothiques ${ }^{2374}$.

Un édifice aussi grandiose, jamais égalé à Byzance, n'est pas né spontanément, mais il est comme l'épanouissement d'une série de créations architecturales, dont le point de départ est la basilique hellé-

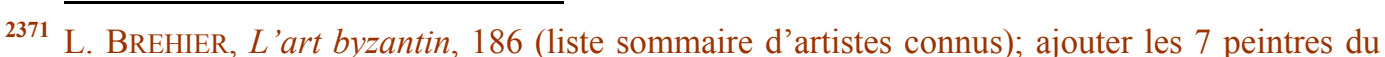
Ménologe de Basile II, DIEHL, Manuel d'art byzantin, 632.

${ }^{2372}$ L. BREHIER, op. cit., 72-76; DEMANGEL et MAMBOURY, Le quartier des Manganes et la première région de Constantinople, 148 et $\mathrm{s}$.

${ }^{2373}$ EBERsolT, Sainte-Sophie de Constantinople, étude de topographie d'après les "Cérémonies », 1910.

2374 Amiens : 44 mètres; Beauvais : 48 mètres. 
nistique à colonnes. On ignore qui eut le premier l'idée d'interrompre la file des colonnes par de gros piliers, sur lesquels furent bandés les grands arcs qui supportèrent une coupole sur pendentifs. Les plus anciens exemples de cette disposition se trouvaient en Asie Mineure (basilique de Mériamlik en Cilicie, construite sous Zénon, 474-491) ${ }^{2375}$, et en Macédoine orientale dans la basilique de Direkler à Philippes, contemporaine de Justinien ${ }^{2376}$.

Il est vraisemblable qu'avant de se mettre au service de cet empereur, les maîtres d'œuvre de Sainte-Sophie, Anthémius de Tralles et Isidore de Milet, avaient construit des basiliques à coupole. Ce mode de construction n'avait certainement pas de secret pour eux, mais les proportions grandioses qu'ils adoptèrent firent de leur œuvre une création nouvelle, qui porte la marque de personnalités puissantes.

Dans les exemples antérieurs de ce plan, la coupole est construite en avant de l'abside, juxtaposée en quelque sorte à la basilique à colonnes. Les architectes de Sainte-Sophie la montèrent au milieu de l'édifice, dont toutes les parties lui furent subordonnées ${ }^{2377}$. Elle couvre entièrement la nef, considérablement élargie. A l'est et à l'ouest, deux demi-coupoles la contrebutent; au nord et au sud, elle est limitée par deux grands arcs sous lesquels s'étagent la grandiose colonnade, qui la sépare des bas-côtés, et les arcades, par où prennent jour les vastes tribunes. Aux quatre angles de la nef, des exèdres, reliées aux bas-côtés et à l'étage des tribunes, achèvent de donner au plan son caractère d'élégance. L'abside à trois pans, couverte d'une demicoupole, s'ouvrait directement sur la nef. On a pu comparer cette immense enceinte, faite pour contenir tout un peuple, à celle de l'Hippodrome.

La décoration architecturale a autant d'importance pour l'histoire de l'art que sa construction. Nous en avons déjà montré les caractères essentiels.

\footnotetext{
2375 P. LEMERLE, Philippes et la Macédoine orientale à l'époque chrétienne et byzantine, 472 et s. On a cru longtemps que le plus ancien type était Sainte-Sophie de Salonique, DIEHL, Monuments chrétiens de Salonique, 117 et s., qui est regardée aujourd'hui comme de l'époque iconoclaste.

2376 LEMERLE, op. cit., 485 et s.

2377 Ibidem, 474 et s.
} 
$V I^{e}-V_{I I}{ }^{e}$ siècle. - Si exceptionnelle que soit la « Grande Église », elle est loin d'avoir épuisé l'activité des architectes de Justinien, ainsi que leur imagination créatrice. Chacune des églises construites à cette époque a un plan particulier. L'église Sainte-Irène, reconstruite en 564, montre une modification de la basilique à coupole, qui annonce le plan en croix grecque : les grands arcs de sa coupole, placée en avant du chœur, se prolongent par des berceaux ${ }^{2378}$. L'église ou martyrion des Saints-Apôtres, réservée aux sépultures impériales, fut rebâtie entre 536 et 546 sur un plan en croix libre comportant cinq coupoles ${ }^{2379}$. L'église dédiée aux saints Serge-et-Bacchus (527-536) est un octogone inscrit dans un carré irrégulier, avec un double étage de colonnes entre les piliers et une coupole hémisphérique, qui se raccorde à l'octogone par des fuseaux alternativement droits et côtelés. Les parties droites de l'octogone alternent avec des exèdres, dont les voûtes en cul-de-four contrebutent la coupole ${ }^{2380}$. Le plan triconque apparaît à Saint-André-de-Krisis (Hodja Mustapha) : une coupole centrale est accostée au nord et au sud de deux demi-coupoles, qui couvrent les deux bras du transept, terminés par deux absides ${ }^{2381}$.

L'église en croix grecque. - Après une période pendant laquelle la production artistique semble tarie, et qui correspond au temps des iconoclastes, l'art religieux s'enrichit d'une nouvelle création d'un grand avenir, le plan en croix inscrite, dit en croix grecque. Ce type d'église est l'une des principales manifestations de l'originalité byzantine. Au lieu de faire porter le poids de la coupole centrale sur de massifs piliers qui encombrent la nef, la poussée est reportée sur les murs latéraux, au moyen des quatre voûtes en berceau qui prolongent les grands arcs et dessinent à l'extérieur la croix grecque, que surmonte la coupole établie sur un haut tambour. Des galeries moins élevées garnissent les quatre angles et forment les bas-côtés, parfois couverts de coupoles aveugles et précédés d'un narthex, qui fait souvent retour d'angle sur les façades latérales et se termine par des absidioles qui accostent l'abside principale à 3 pans.

2378 Ibidem, 473 et s.; EBERSOLT et THIERS, Les églises de Constantinople, 53 et s.; il y a désaccord sur la date de la coupole, qui serait postérieure au tremblement de terre de 741 .

2379 DiEHL, Manuel d'art byzantin, 178 et s.

2380 EBERSOLT et THIERS, op, cit., 21-51.

2381 Ibidem, 73-90. 
Les archéologues ne sont pas d'accord sur l'origine de ce plan, que l'on a cherché à rattacher aux édifices cruciformes de l'Orient et qui semble plutôt une création des architectes de Constantinople. La disposition des coupoles de Sainte Irène de Constantinople paraît en être la première tentative.

Tel est le plan de l'église du Myrélaion, fondée à Constantinople par Romain Lécapène ${ }^{2382}$ (920-944), avec un des premiers exemples de coupole élevée sur un tambour cylindrique et de l'amincissement des piliers qui la soutiennent. $\mathrm{Au} \mathrm{XI}{ }^{\mathrm{e}}$ siècle, à Kilissé-djami de Constantinople, à l'église de la Vierge-des-Chaudronniers de Thessalonique ${ }^{2383}$, une svelte coupole se dresse sur un haut tambour à deux étages de baies et les grands arcs reposent sur de simples colonnes, qui sont des étais et non des organes de butée.

Le type est allé en s'affinant sous les Comnènes et les Paléologues. Les coupoles sont de plus en plus sveltes, mais leur diamètre se rétrécit et elles deviennent de simples lanternes. A Constantinople au monastère du Pantocrator (1124), deux belles églises en croix grecques sont reliées par une chapelle funéraire ${ }^{2384}$.

Avec l'église en croix grecque apparaît une innovation importante, l'ornementation extérieure des églises, qui semble avoir été assez pauvre avant le $\mathrm{XI}^{\mathrm{e}}$ siècle. A Thessalonique, au $\mathrm{XII}^{\mathrm{e}}$ siècle SaintPantelcimon, au XIII ${ }^{\mathrm{e}}$ les Saints-Apôtres sont d'exquises et petites églises, dont l'extérieur est orné avec élégance. Les baies des tambours échancrent les coupoles par une ligne molle et ondulée; les frontons curvilignes des façades ne sont que les amortissements des voûtes en berceau et les absides sont décorées de dessins variés, dus à une combinaison de briques et de marbre ${ }^{2385}$.

Monastères de l'Athos. - Les monastères de l'Athos forment comme de petites villes entourées d'une enceinte fortifiée, avec une grosse tour carrée en forme de donjon. Au centre des édifices, la grande église (catholikon) est bâtie en croix grecque, mais combinée

\footnotetext{
2382 Boudroum-djami actuel, EBERSOLT et THIERS, 137 et s., pl. 32 et 33.

2383 Ibidem, 147 et s.; DIEHL. Monuments chrétiens de Salonique, 153 et s., pl. L-LIII (datés par une inscription de 1028).

2384 EBERSOLT et THIERS, 183-208, pl. XLII-XLVIII.

2385 DIEHL, op. cit., 167 et s., 189 et s., pl. LIV-LVII et LXII-LXVIII.
} 
avec le plan triconque, dont les absides secondaires sont occupées par les stalles des moines. Cette salle cruciforme est couverte d'une coupole et précédée d'un double narthex ou d'un large vestibule, la liti. Le type en croix grecque, assez lourd à Lavra (fin du $\mathrm{X}^{\mathrm{e}}$ siècle), s'est affirmé à Iviron, à Vatopédi et surtout à Chilandar, fondation serbe de 1197, dont l'extérieur est orné d'une riche combinaison de briques. Parmi les autres bâtiments il faut signaler les grands réfectoires en forme d'églises, avec une petite abside où se trouvait la table de l'higoumène, et les immenses cuisines, couvertes de coupoles surmontées de lanternes ajourées pour laisser passer la fumée des foyers ${ }^{2386}$.

L'école de Mistra. - Sous les Paléologues, dans l'architecture comme dans les autres arts, il se produit comme un retour vers le passé et dans les églises reparaissent d'anciens modèles, combinés ingénieusement avec le plan en croix grecque. A Mistra, devenue la capitale du Péloponnèse impériale, on adopta les solutions les plus variées. A l'église des Saints-Théodores (avant 1296), la croix grecque est couverte par une coupole qui repose sur des trompes d'angle par l'intermédiaire d'un tambour à 16 pans. Ou bien l'allongement du bras occidental transforme la croix grecque en croix latine, à la Péribleptos, à l'Evanguelistria, à Sainte-Sophie (XIV siècle). A l'ancienne Métropole consacrée à saint Démétrius (début du même siècle, mais remaniée plus tard), ainsi qu'à la Pantanassa (début du $\mathrm{XV}^{\mathrm{e}}$ siècle), l'église a la forme d'une basilique à colonnes au rez-dechaussée, mais prend au premier étage celle d'une croix grecque, avec la coupole centrale contrebutée par des voûtes en berceau et de petites coupoles dans les angles de la croix. A la Pantanassa, une élégante loggia à arcades est adossée à un clocher, percé de plusieurs étages de baies et d'allure toute occidentale ${ }^{2387}$.

Ce compromis entre la tradition de l'École grecque et celle de Constantinople se retrouve à Arta, capitale des despotes d'Épire, dans l'église de la Panagia Parigoritissa (fin du XIII ${ }^{\mathrm{e}}$ siècle) ${ }^{2388}$, ainsi que dans les églises de Trébizonde ${ }^{2389}$.

\footnotetext{
${ }^{2386}$ Millet, L'École grecque dans l'architecture byzantine, 57, 62, fig. 26, 124 et s., 182 et s.; DIEHL, Manuel d'art byzantin, 754.

2387 Millet, op. cit.; du même : Monuments byzantins de Mistra, pl. 15-41; DIEHL, Manuel d'art byzantin, 769 et $\mathrm{s}$.

2388 MILLET, L'École Grecque dans l'architecture byzantine, 98 et s., 196 s.; DIEHL, op. cit., 771.

2389 Millet, Les monastères et les églises de Trébizonde, 446 et s.; DIEHL, op. cit., 768 et s.
} 
L'ornement sculpté. - On connaît déjà la transformation de la sculpture monumentale sous l'action de l'Orient et la création du relief impressionniste ${ }^{2390}$. Poussés par la logique de leur conception ornementale, les sculpteurs firent une place de plus en plus restreinte au relief modelé. A l'art arabe, à la mode sous Théophile, ils empruntèrent la sculpture-broderie, qui consiste à reproduire sur le marbre et la pierre les thèmes et les ornements tissés ou brodés sur les étoffes précieuses : animaux adossés ou affrontés devant l'arbre de vie, palmettes, spirales et jusqu'aux points de broderie, jusqu'aux caractères coufiques des inscriptions de certains tissus musulmans ${ }^{2391}$. Ce genre de sculpture fut adopté particulièrement dans l'École grecque. Aux $\mathrm{XIV}^{\mathrm{e}}$ et $\mathrm{XV}^{\mathrm{e}}$ siècles elle couvre de ses galons de passementerie les chapiteaux, les entablements, les jambages et chambranles de portes des églises de Mistra et d'autres régions du monde grec ${ }^{2392}$.

En même temps que la sculpture-broderie, les maîtres byzantins adoptèrent une autre technique musulmane, la sculpture champlevée, qui consiste à réserver les motifs d'ornement sur un fond légèrement creusé et rempli d'un mastic sombre; le décor s'enlève en clair sur le fond obscur. Le modelage est éliminé, la technique est celle des émaux ciselés. C'est aux $\mathrm{X}^{\mathrm{e}}$ et $\mathrm{XI}^{\mathrm{e}}$ siècles que le procédé apparaît en Grèce (corniches et chapiteaux de Saint-Luc en Phocide, de Daphni, des églises d'Athènes), et à Venise (chapiteaux des colonnes intérieures de Saint-Marc). Il est encore employé au XV siècle à Mistra, où il est combiné parfois avec la sculpture-broderie ${ }^{2393}$.

Les techniques plus anciennes, comme la sculpture ajourée et le bas-relief lui-même, ne furent jamais abandonnées. On a cru à tort qu'après la querelle des images, la sculpture iconographique avait été écartée des églises byzantines. A vrai dire, elle a perdu son caractère monumental et n'a pas produit de grands ensembles. Elle orne les corniches sculptées provenant de clôtures de chœur, les chancels et les panneaux de marbre qui servaient de murs d'appui aux tribunes ou

\footnotetext{
2390 Supra, p. 424.

2391 L. BREHIER, L'art byzantin, 128 et s.; du même : La Sculpture et les Arts mineurs byzantins, 16-20, pl. X.

2392 Id., Études sur l'histoire de la sculpture byzantine (Missions scientifiques, 3, 1911), 34 et s. et Nouvelles recherches sur l'histoire de la sculpture byzantine (Missions scientifiques, 9, 1913), 18 et s., 55 et s.

2393 Id., Etudes sur l'histoire..., 80-83; du même : Nouvelles recherches..., 57-61.
} 
aux ambons. Des archivoltes du musée d'Athènes, garnies de statuettes en haut-relief, ont pu servir de cadres à une icône de la Nativité, dont les épisodes se succèdent dans leur courbe ${ }^{2394}$. Il existe même des icônes sculptées. Les plus répandues sont des Vierges orantes, debout, regardées parfois comme miraculeuses, mais la plupart des types iconographiques de Madones ont été reproduits ainsi ${ }^{2395}$. D'autres icônes en relief représentent des anges, des saints et des épisodes de l'histoire évangélique ${ }^{2396}$.

La sculpture historiée devait à plus forte raison décorer les monuments civils ${ }^{2397}$, et l'on voit par là combien il serait injuste de passer sous silence cet aspect de l'art byzantin qui atteste que ses maîtres, loin d'être asservis complètement aux techniques orientales, avaient conservé le sens de la tradition hellénique. C'est ce que montrerait encore mieux l'étude des beaux ivoires ou des pierres dures sculptées des $\mathrm{X}^{\mathrm{e}}$ et $\mathrm{XI}^{\mathrm{e}}$ siècles dans lesquels revit véritablement la beauté antique ${ }^{2398}$. C'est enfin ce qui ressort des monuments de la mosaïque et de la peinture.

Arts de la couleur. Mosaïque murale. - La mosaïque murale est devenue dans l'art byzantin le complément naturel des placages de marbres. Nous connaissons déjà son origine romaine et quelques-uns de ses chefs-d'œuvre. Détachées sur le fond uniforme, les figures et les scènes, au coloris éclatant, mais harmonieux, prennent un singulier relief. La mosaïque recherche le même effet d'impressionnisme que la sculpture.

Les maîtres byzantins n'en ont créé ni la technique ni même le style, mais ont maintenu le dessin correct de la figure humaine et ont

\footnotetext{
2394 L. BREHIER, Les voussures à personnages sculptés du Musée d'Athènes dans M.Schl., 425 et s.; XYNGOPOULOS, Reliefs franco-byzantins d'Athènes, 69 et s.

2395 L. BREHIER, La sculpture iconographique dans les églises byzantines, 21; du même: La Sculpture et les Arts mineurs byzantins, 17 et s.; DIEHL, Manuel d'art byzantin, 651-654.

${ }^{2396}$ L. BREHIER, La Sculpture et les Arts mineurs byzantins, pl. X, XI, XV.

2397 Id., Les mosaïques à fond d'azur (R.E.B., III, 20 et s.), 7; du même : La Sculpture et les Arts mineurs byzantins, pl. XIV.

2398 Exemple : le triptyque des Apôtres, partagé entre les musées de Vienne, Dresde, Venise, au nom d'un despote Constantin, Schlumberger, Mélanges d'archéologie byzantine, 337; DIEHL, Manuel d'art byzantin, 660-671; L. BREHIER, La Sculpture et les Arts mineurs byzantins, pl. XXXI, coffrets, pl. XXXII et s.
} 
su adapter leurs œuvres à l'effet de splendeur qui convenait à la décoration des palais et des églises ${ }^{2399}$.

A l'époque de Justinien ce sont surtout les sanctuaires de l'école de Ravenne qui ont conservé les chefs-d'œuvre de cet art. A Constantinople il n'est plus représenté que par la splendide décoration du narthex de Sainte-Sophie ${ }^{2400}$, longue galerie divisée en 9 compartiments de voûtes d'arêtes, que séparent de larges bandeaux d'ornements géométriques. Au centre de chaque voûte, dans une gloire circulaire se détache le chrismon sur fond d'or, et dans les lunettes, sauf dans celle du centre ${ }^{2401}$, apparaît une grande croix pattée. Ce décor se rattache au symbolisme triomphal, qui fait de la Croix le symbole de la victoire perpétuelle de l'empereur ${ }^{2402}$. On peut lui comparer celui de Sainte-Paraskévi de Thessalonique, où le tranchant des arcades est orné du monogramme du Christ et, sur fond d'or, de beaux vases cannelés, bleus d'azur, d'où s'échappent des enroulements de feuillages, parmi lesquels volent des oiseaux ${ }^{2403}$.

Dans la même ville on a pu sauver de l'incendie de 1917 une partie du décor en mosaïque de la basilique de Saint-Démétrius, consistant en tableaux votifs, de dates et de factures différentes, offerts par des fidèles en reconnaissance des grâces obtenues du saint. L'aspect est celui d'icônes agrandies. On y voit parfois saint Démétrius dans son somptueux costume civil d'officier impérial ${ }^{2404}$, entouré de fidèles, hommes, femmes, vieillards, enfants, véritable galerie de portraits aux physionomies individuelles, qui contrastent avec les portraits conventionnels de Démétrius et, sur d'autres tableaux, de la Vierge et des anges. Sur l'un des piliers, le saint apparait, dominant deux fondateurs de sa basilique, les bras passés autour de leur cou. L'un, en costume de dignitaire civil, serait Léonce, préfet d'Illyricum au $\mathrm{v}^{\mathrm{e}}$ siècle, l'autre, l'évêque qui restaura l'église sous Héraclius ${ }^{2405}$.

\footnotetext{
2399 Sur la mosaïque profane DieHL, op. cit., 225 et s., 400 et s.

2400 Restauré et recouvert par Fossati en 1841, décapé et restauré de nouveau par le Prof. Thomas Whittemore en 1931-32, Th. WhitTEMORE, The Mosaics of Haghia Sofia at Istanbul.

2401 Remplacé par le basileus aux pieds du Christ.

2402 M.B.E.H. (Instit.), 1970, 53. WHITTEMORE, op. cit., planches.

2403 DIEHL, Monuments chrétiens de Salonique, 52 et s., pl. VIII-XII.

2404 Tunique blanche brodée aux épaules, ceinture étroite, chlamyde décorée d'un large clavas de pourpre, attachée par une fibule d'or. Dans les portraits postérieurs, il porte le costume de 2405 guerre.

2405 DIEHL, op. cit., 94-113, pl. XXVII-XXXIV; A. GRABAR, Martyrium, II, 86-89.
} 
C'est entre le $\mathrm{X}^{\mathrm{e}}$ et le XII ${ }^{\mathrm{e}}$ siècle que l'on peut placer l'âge d'or de la mosaïque murale, qui coïncide avec la période de la prospérité et des victoires de l'Empire. Jamais les empereurs et les particuliers n'avaient disposé de telles richesses, jamais les fondations n'atteignirent un pareil luxe, jamais l'autorité impériale n'avait joui d'un tel prestige. L'art de la mosaïque, cette tapisserie brillante, tendue pour l'éternité, s'est renouvelé. Sa technique s'est affinée; son coloris est plus harmonieux ; son style a acquis une fermeté, une beauté incomparables, qui rappellent parfois l'antique.

Pendant ces trois siècles, sans parler des monuments profanes, il n'est guère d'église de l'Empire et des pays voisins qui n'ait reçu une riche ornementation en mosaïques. On savait déjà que c'était à Constantinople qu'il fallait chercher le foyer de ce mouvement. C'est ce que les beaux travaux du professeur Whittemore à Sainte-Sophie ont confirmé, en mettant à jour quelques-uns des chefs-d'œuvre qui devaient faire école dans les provinces.

C'est sans doute à Constantinople, après la victoire des images, que des théologiens élaborèrent la nouvelle ordonnance des thèmes iconographiques dans les églises. A l'art narratif et historique se substitua le symbolisme, qui associe les figures et les épisodes de l'art sacré à la liturgie ${ }^{2406}$.

Sous la coupole le Tout-Puissant (Pantocrator) plane dans un arc-en-ciel, entouré des prophètes ou des apôtres. Sur l'arc triomphal est dressé le trône du Jugement, chargé des instruments de la Passion et gardé par des anges. Dans la conque de l'abside, la Vierge, figure de l'Église, offre le sacrifice et parfois, audessous d'elle, se déroule la Communion des Apôtres, tandis que, sur les murs du chœur, les Grands Prêtres hébreux et les Pères de l'Église semblent participer à la liturgie. Parfois, sur les pendentifs de la coupole et, régulièrement, sur les murs du transept et de la nef, sont figurés les épisodes des Évangiles qui correspondent aux 12 grandes fêtes du Christ: Annonciation, Nativité, Épiphanie, Présentation, Baptême, Transfiguration, Lazare, Rameaux, Crucifiement, Résurrection, Ascension, Pentecôte ${ }^{2407}$. Il y a là, comme on le voit, un choix très restreint de fêtes, mais ce sont celles qui ont le plus de signification commémorative et liturgique. Cette ordonnance est complétée par les portraits des martyrs et des saints qui figurent

${ }^{2406}$ MILlET, Recherches sur l'iconographie de l'Évangile aux XIV $V^{e}$ XV $V^{e}$ et XVI siècles, 16-40; du même : L'art byzantin, dans Histoire de l'Art de A. MICHEL, 184 et s.; L. BREHIER, L'art byzantin, I, 421 et s.; du même : L'Art chrétien. Son développement iconographique, 136-146.

2407 Millet, op. cit. : Khairetisinos, Gennesis, Theophaneia, Hypapanti, Baptisis, Metamorphosis, Egersis Lazarou, Baiophoros, Staurosis, Anastasis, Analepsis, Pentekoste. 
dans le calendrier liturgique, et quelquefois le Jugement Dernier occupe le mur occidental ${ }^{2408}$. Au-dessus de l'entrée principale la Vierge et le Précurseur intercèdent auprès du Christ trônant (Deisis). Un cycle des Fêtes de la Vierge, de sa Nativité à sa Dormition, peut décorer le narthex ${ }^{2409}$.

Cet ordre est loin d'être immuable, bien que cette méthode de décoration laisse peu de place à la fantaisie. Les compositions sont simples et claires, les personnages peu nombreux ; le paysage et le mobilier sont indiqués sobrement. Et pourtant les artistes ont accepté ces entraves qui restreignaient la part de leur invention, mais leur talent s'est manifesté dans la vérité des figures qui, sans être des portraits, laissent voir souvent les caractères ethniques des étrangers, Arméniens ou Turcs, immigrés dans l'Empire. Leurs œuvres valent surtout par la variété pittoresque des costumes aux tons éclatants, par la beauté de la draperie et la dignité des gestes, qui impliquent l'étude de l'antique ${ }^{2410}$.

Parmi les œuvres nombreuses de ces époques il faut mettre au premier rang les mosaïques de Sainte-Sophie restaurées par Whittemore, qui représentent les ateliers de l'école de Constantinople.

C'est d'abord dans la lunette du narthex qui surmonte la Porte Royale, le Christ assis sur un trône impérial, adoré par un basileus, agenouillé, le dos horizontal, les mains suppliantes ${ }^{2411}$, que, d'après sa figure, on identifie à Léon VI (886-912). Le Christ, aux traits sévères, bénit et tient un livre ${ }^{2412}$. En buste, dans des médaillons, l'Ange et la Vierge de l'Annonciation accostent le trône ${ }^{2413}$. Bien qu'il y ait quelques sécheresses dans les draperies du Christ, on devine un artiste familiarisé avec l'antique. Le portrait du basileus est d'une vérité saisissante et peut être rapproché des belles figures qui ornent le manuscrit de saint Grégoire de Nazianze, exécuté pour Basile le Macédonien ${ }^{2414}$.

\footnotetext{
2408 DIEHL, Venise (Villes d'Art célèbres). La basilique de Torcello.

2409 Par exemple à Daphni.

2410 MILLET, Le Monastère de Daphni, chap. III à VIII.

2411 WhitTEMORE, The Mosaics of Haghia Sofia at Istanbul, I, Narthex, 14, et s. pl. XII-XXI; attitude, toujours actuelle, de la metanoia (pénitence).

2412 Inscription. Trad. : « Je suis la Lumière du monde. »

2413 Sur le sens de ces mèdaillons, OsIECZKOWSKA, La mosaïque de la Porte Royale à SainteSophie, dans B.N., 1934, 43-83.

2414 Paris, gr. 510, frontispice.
} 
Des œuvres d'art remarquables décoraient la Nouvelle Église, construite par ce prince au Grand Palais. Les mosaïques découvertes à Sainte-Sophie peuvent nous en donner une idée. Dans le vestibule méridional situé dans l'axe du narthex, une délicieuse Madone, au costume bleu améthyste nuancé, tient sur ses genoux un Enfant aux traits expressifs, vêtu de drap d'or. Aux côtés du trône où siège la Vierge, deux grandes figures en pied, Constantin offrant le modèle de la Ville Impériale, Justinien celui de Sainte-Sophie. Des ombres vertes sous les figures témoignent d'une répulsion pour les tons noirs et d'un effort pour rendre lumineuses et légères les ombres elles-mêmes ${ }^{2415}$.

Dans la tribune sud, au-dessus du sanctuaire, il existait une chapelle privée, dans laquelle les empereurs se rendaient à certains jours. C'est à cet endroit qu'ont été découverts deux tableaux représentant des empereurs et des impératrices en prières (deisis) et tenant à la main des offrandes, d'une part, Constantin IX et Zoé (1042-1050), devant le Christ trônant, de l'autre, Jean II Comnène, l'impératrice Irène et leur fils Alexis (associé au trône en 1122, mort un an avant son père en 1142), en présence d'une Madone ${ }^{2416}$. Il s'agit de portraits officiels et de poses stéréotypées. Les empereurs tiennent à la main une grosse bourse (apocombion), les impératrices un rouleau de parchemin (donations à la Grande Église). Il y a cependant entre les deux panneaux des différences de style assez marquées. Constantin et Zoé se tournent vers le Christ au visage ascétique, tandis que Jean Comnène et Irène sont vus de face. Seul le portrait d'Alexis est vraiment expressif et donne l'impression de la ressemblance, avec son visage bilieux, ses cheveux bruns lustrés, ses lèvres minces, ombragées d'un léger duvet ${ }^{2417}$.

Sainte-Sophie n'a pas encore révélé tous ses secrets. Des découvertes de grandes figures de saints, de portraits d'empereurs et de patriarches, et de la Madone entre des anges, qui occupe l'abside, attendent encore leur publication. Cependant nos connaissances sont déjà suffisantes pour nous permettre de saisir les liens qui rattachent les ensembles connus à l'École de Constantinople.

\footnotetext{
2415 Whittemore, The Mosaics of Haghia Sofia et Istanbul, II, Southern Vestibule, 57 et s. et planches, 30 et s. (date probable d'après les inscriptions entre 975 et 1000).

2416 Id., ibid., III, The Imperial Portraits of the South Gallery.

2417 Ibidem, 26 et pl. I (en couleur). La partie inférieure des mosaïques a disparu.
} 
$\mathrm{Du} \mathrm{XI}^{\mathrm{e}}$ siècle date la belle Madone de l'abside de Chiti (île de Chypre), entre les deux archanges Michel et Gabriel aux ailes en plumes de paon, le sceptre et le globe crucifère à la main ${ }^{2418}$.

Le magnifique ensemble de Saint-Luc en Phocide date du début de ce siècle et comprend un cycle liturgique complet. L'esprit monastique s'y manifeste par le type du Pantocrator à la figure morose, longue et amaigrie, qui rappelle le Christ des offrandes de Constantin IX et Zoé, par l'importance donnée aux ascètes parmi les portraits de saints, enfin dans la plus ancienne représentation connue du Christ en croix figuré mort ${ }^{2419}$.

Les mosaïques de Sainte-Sophie de Kiev exécutées sous Iaroslav, entre 1047 et 1054, sont dues à des maîtres byzantins. Particulièrement remarquables sont le Pantocrator de la coupole, entouré d'anges et de prophètes, la grande Panagia orante de l'abside et la Communion des Apôtres. L'ange de l'Annonciation est figuré sur un pilier à l'entrée du chœur et Marie, filant la pourpre, sur celui qui est en face $^{2420}$. On retrouve cette disposition dans le chœur et aussi dans le narthex du catholikon de Vatopédi (Athos). Dans le Déisis du narthex de ce même édifice, une Vierge au manteau bleu pâle galonné d'or et le Précurseur, dont l'himation vert est jeté sur une tunique jaune, sont aux côtés du Christ aux draperies striées d'or et de pourpre ${ }^{2421}$.

Un des plus beaux ensembles de mosaïques est celui de la petite église de Daphni, sur l'antique Voie Sacrée, entre Athènes et Éleusis ${ }^{2422}$. Tout un monde de figures et de scènes remplit cet espace restreint. Des maîtres de premier ordre, coloristes délicats élevés dans l'admiration des chefs-d'œuvre de l'antiquité, ont donné de l'iconographie sacrée l'interprétation la plus noble et la plus majestueuse que présente l'art byzantin. Par la souplesse et l'élégance du dessin, par la richesse du coloris aux bleus profonds, aux rouges éclatants rehaussés de traits d'or, par la clarté et parfois la fantaisie pittoresque de leurs compositions, ils dépassent d'une manière surprenante

\footnotetext{
2418 Th. SCHMITT, Panagia Angeloktistos [Chypre] pl. IV-VIII.

2419 DieHL., Manuel d'art byzantin, 513-516.

2420 Ibidem, 524, fig. 250.

2421 Millet, Les monuments de l'Athos, I, Les peintures (1927), pl. IV, 1.

2422 Id., Le Monastère de Daphni.
} 
tous leurs confrères contemporains. Des tableaux comme celui de la Descente aux Limbes (Anastasis), comme la Crucifixion où le corps du Christ, vivant sur la croix, décrit une courbe harmonieuse, comme l'Adoration des trois Mages, qui se pressent au pied du trône de la Vierge, sont empreints d'une majesté souveraine éloignée des compositions stéréotypées de l'art officiel ${ }^{2423}$.

Nous ne pouvons que citer les autres ensembles qui dérivent de la même source et sont remarquables aussi par l'élégance du dessin et la richesse des couleurs : les mosaïques du Nouveau Monastère (Nea Moni), de Chios, dues à la munificence de Constantin Monomaque ${ }^{2424}$; les plus anciennes mosaïques de Saint-Marc de Venise, œuvre des maîtres byzantins de la fin du $\mathrm{XI}^{\mathrm{e}}$ et de la première moitié du $\mathrm{XII}^{\mathrm{e}}$ siècle ${ }^{2425}$; les ensembles de mosaïques des basiliques siciliennes construites par les rois normands et leurs ministres à Cefalù (11311148), à Palerme (Chapelle Palatine 1129-1143, La Martorana, due à Georges d'Antioche), à Monreale, à Messine ${ }^{2426}$.

Dans ces vastes monuments le programme liturgique est noyé au milieu d'épisodes historiques. Des cycles de la Genèse, inspirés d'anciennes Bibles illustrées, décorent les coupoles du narthex de Saint-Marc de Venise, les nefs de la Chapelle Palatine de Palerme et de la basilique de Monreale ${ }^{2427}$. Une magnifique composition, figurant la vie de saint Jean-Baptiste, avec un pittoresque Festin d'Hérode, orne le Baptistère de Saint-Marc de Venise (XIII ${ }^{\mathrm{e}}$ siècle) ${ }^{2428}$.

\section{La rénovation artistique sous les Paléologues}

Retour à la Table des Matières

Le pillage de Constantinople par les croisés de 1204 et l'établissement de la domination franque sur la plus grande partie de

\footnotetext{
2423 P. Muratoff, La peinture byzantine (1928), pl. XCIII-CIV; DIEHL, op. dr., 524-526; p. LEMERLE, Le Style byzantin, 85 et s.

2424 DIEHL, op. cit., 518 et s.

2425 Ibidem, 537-541; du même: Venise (Villes d'art célèbres).

2426 DIEHL, Manuel d'art byzantin, 548 et s.; du même Palerme et Syracuse (V.A.C.).

2427 DIEHL, Manuel d'art byzantin, 541-543; du même: Palerme et Syracuse; MurATOFF, La peinture byzantine, pl. CXI-CXIII.

2428 DiEHL, Manuel d'art byzantin, 804 et s.
} 
l'Empire désorganisèrent les ateliers d'art. Cependant, loin de disparaître, l'art byzantin ressuscita sous une nouvelle forme et, loin d'être épuisé, il manifesta sa vitalité par de nouvelles créations.

Il semble qu'au lendemain de la restauration de Michel Paléologue, les maîtres byzantins aient cherché à rassembler toutes les traditions, tous les procédés, toutes les méthodes les plus anciennes dont le souvenir avait survécu à la catastrophe. Comme l'a si bien dit Gabriel Millet, l'art byzantin, et, en particulier, la peinture monumentale, remonta à ses sources ${ }^{2429}$.

Mais une transformation profonde résulta de cette élaboration. L'art somptueux de la période précédente était l'expression de la société byzantine et satisfaisait son goût de la pompe, de la hiérarchie rigide, du symbolisme abstrait. L'art des Paléologues, au contraire, emploie des techniques moins coûteuses, et il semble qu'il ait retrouvé dans les anciens modèles le secret de la vie et du mouvement, des effets pittoresques, de l'émotion pathétique. S'il emploie des matériaux moins somptueux, ce n'est pas toujours pour un motif d'économie, justifié par la situation de l'Empire. Il y a dans cette simplicité un certain raffinement esthétique. La loi du nouvel art est de tout sacrifier au style, qui résulte des jeux savants des couleurs et des lignes. Désormais, à la simplicité des matériaux, correspond la richesse du style ${ }^{2430}$.

On aurait cependant tort de croire que les sujets des Paléologues avaient entièrement renoncé à la somptuosité des œuvres d'art. Cependant si la richesse de la matière était réservée à de petits monuments, on la rencontre aussi dans les placages et les pavements de marbre précieux ainsi que sur les mosaïques murales de certaines églises.

La mosaïque murale. - Actuellement le seul ensemble connu décore les deux narthex de l'église de Chora (Kahrié-Djami) à Constantinople. Ces mosaïques furent exécutées au début du XIV ${ }^{\mathrm{e}}$ siècle aux frais de Théodore Métochitès, et il s'est fait représenter lui-même au tympan de la Porte-Royale qui donne accès dans l'église, dans le riche

${ }^{2429}$ MiLlet, Recherches, sur l'iconographie de l'Evangile..., (1916).

${ }^{2430}$ L. BREHIER, La rénovation artistique sous les Paléologues et le mouvement des idées, 2 et $\mathrm{s}$. 
costume de grand-logothète, offrant au Christ le modèle de l'église qu'il a restaurée ${ }^{2431}$.

Les deux cycles qui se déroulent, dans le narthex intérieur : la Jeunesse de la Vierge et l'Enfance de Jésus, dans le narthex extérieur, les Miracles du Christ, montrent le nouveau point de vue de l'art, qui est redevenu narratif. Le dogme y tient cependant sa place, comme il résulte du décor des deux coupoles du narthex intérieur: dans l'une la Vierge entourée des rois de Juda, ses ancêtres, dans l'autre le Christ au milieu des patriarches et des chefs des tribus d'Israël.

Ce qui est surtout nouveau c'est le style, c'est la noblesse et la beauté des figures, la douceur exquise de celle de Marie, la bonté qui ressort de celle de Jésus, dont les traits réguliers n'ont plus rien de commun avec ceux de l'ascète amaigri du temps des Comnènes. Toute rigidité est exclue des attitudes, élégantes et naturelles. Dans des compositions libres et variées les peintres ont reproduit minutieusement tous les détails que donnent les évangiles apocryphes sur la jeunesse de la Vierge : citons l'Annonciation à sainte Anne dans le parc verdoyant aux eaux jaillisantes, la Nativité de la Vierge, la Distribution de la pourpre au milieu d'un décor d'architecture antique avec les trois vieillards majestueux trônant dans une large exèdre, puis Marie s'avançant timide, modeste, dans son long voile, formant contraste avec les vierges qui l'accompagnent, véritables figures antiques, à la chevelure opulente retenue par un léger ruban, drapées avec majesté dans leurs manteaux aux plis harmonieux. Non moins admirable est le Recensement devant le légat Quirinus, vue en quelque sorte instantanée du moment où Marie, suivie de Joseph et de plusieurs Juifs, s'avance modestement pour être inscrite sur le rôle que déroule le greffier du gouverneur siégeant dans sa chaire.

Aux fonds d'or sur lesquels se détachaient les figures on a substitué de vrais paysages, garnis d'édifices de style hellénistique, des plus gracieux et des plus variés. Ces architectures, naturellement conventionnelles, n'en donnent pas moins à une scène un caractère plus vivant $^{2432}$.

${ }^{2431}$ DieHL, Etudes byzantines, 396 et s.; Th. SCHMITT, Kahrié-Djami, pl. LVII-LVIII.

${ }^{2432}$ DIEHL, Manuel d'art byzantin, 793-804; MURATOFF, La peinture byzantine, pl. CCXXXIICCXXXVIII; EBERSOLt: R.A.A.M., 1929 (découverte en 1929 d'une Dormition au-dessus du 
Les mosaïques de Kahrié-Djami ne sont pas les seules qui aient été créées au XIV siècle. A Constantinople même, à Fétiyé Djami, on voit encore dans la coupole la figure d'un majestueux Pantocrator, et des travaux en cours permettent de découvrir sous le badigeon un cycle narratif assez analogue à celui de Kahrié-Djami ${ }^{2433}$. Des mosaïques murales ont été découvertes en 1930 dans l'église des Saints-Apôtres de Thessalonique sur le mur occidental. Ce sont de grandes figures de saints et les fragments d'une Dormition qui se détachent, ce qui est très rare, sur un fond formé de smalts bleus et rouges ${ }^{2434}$.

La peinture murale. - D'un caractère plus libre et plus populaire que la mosaïque, la peinture murale n'avait pas cessé d'être cultivée. Les deux techniques se trouvaient parfois dans le même édifice, mais, dans ce cas, les fresques étaient reléguées dans les dépendances des églises, comme à Sainte-Sophie de Kiev. De la fin du XI ${ }^{\mathrm{e}}$ au XIII ${ }^{\mathrm{e}}$ siècle les seuls ensembles importants de peinture murale que l'on connaisse se trouvent en Cappadoce, dans les pays slaves des Balkans et en Russie ${ }^{2435}$.

A partir du XIII siècle au contraire, c'est, nous l'avons vu, la mosaïque murale qui est exceptionnelle. La fresque est devenue le décor favori des églises. Selon la même doctrine que les mosaïstes, les peintres ressuscitent l'art narratif et historique. Désormais des récits détaillés de l'Évangile forment dans l'église de vastes cycles. La peinture a cessé d'être exclusivement le cadre approprié aux pompes de la liturgie. Elle prend un développement prodigieux, partant du sol pour atteindre les voûtes, en formant plusieurs registres; au XVI siècle elle couvrira même les murs, à l'extérieur des églises moldaves. L'iconographie sacrée tient une telle place dans la vie religieuse qu'elle se substitue à l'art ornemental et envahit le mobilier et jusqu'aux étoffes liturgiques.

$\mathrm{Au} \mathrm{XIV}{ }^{\mathrm{e}}$ siècle cet art était dans sa prime jeunesse, encore éloigné des poncifs et traité par des peintres de grand talent, que l'on connaît

portail de la nef); WhitTEMORE, L'état actuel de recherches dans le monastère de Chora à Constantinople.

2433 Notes de voyage, 1910; DiEHL., op. cit., 803.

${ }^{2434}$ Ibidem, 804 et s., fig. 398 et s.

${ }^{2435}$ Millet, 586 et s.; EBersolt, Fresques byzantines de Néréditsi (voir p. 466 et s.). 
malheureusement fort mal. Que la production soit inégale, c'est ce qu'on ne pouvait éviter avec un programme aussi chargé. Cette époque n'en est pas moins celle des grandes créations.

L'art nouveau s'efforce avant tout de donner l'illusion de la vie et de la réalité. Ses fonds de paysage sont des tableaux pittoresques, chargés d'architectures légères ou de paysages romantiques de rochers. Au lieu de quelques personnages de caractère symbolique, des foules entières figurent dans la vie de Jésus, aux moments indiqués dans les Évangiles.

A Daphni 2 apôtres, 4 juifs et 4 enfants entourent Jésus à son entrée à Jérusalem. A la Peribleptos, de Mistra, un flot de Juifs, aux manteaux bigarrés, se porte au devant du Sauveur que suit la foule de ses disciples ${ }^{2436}$.

Dans la même église un thème d'un caractère épique, la Divine Liturgie, permet, bien que la peinture soit détériorée, de saisir tous les caractères de cette nouvelle décoration.

Au centre, le Christ au large nimbe crucifère, vêtu du sakkos patriarcal broché d'or, l'omophorion semé de croix sur la poitrine, est assis devant une table d'autel drapée et abritée par un baldaquin. De chaque côté s'avance vers lui une procession d'anges, qui portent sous des voiles des instruments liturgiques ou, dans les mains, des cierges et des encensoirs. Un ruban blanc attache leurs cheveux roux ; les chairs aux ombres verdâtres sont d'une coloration très chaude, qui font valoir les tons clairs de leurs robes. Le tracé de leurs ailes vertes à revers bleu détermine sur un fond d'un bleu intense des silhouettes décoratives du plus grand effet ${ }^{2437}$.

Ce thème de la Divine Liturgie est sorti des commentaires de l'Épître aux Hébreux, dans laquelle saint Paul oppose le sacerdoce du Christ, à la fois prêtre et victime, au sacerdoce de l'Ancienne Loi (Hébr., V-VIII et IX, 11-12) ${ }^{2438}$. D'autre part, le service des diacres réservé aux anges vient des commentaires du pseudo-Denys ${ }^{2439}$. Ce sujet convient surtout à une abside et à une coupole, mais il fut représenté d'abord sur de petits objets, sur une boîte à reliques du trésor de Latran, sans la participation des anges ${ }^{2440}$, dont on voit au contraire la procession de chaque côté d'un autel sur la patène en ophite de Pul-

\footnotetext{
2436 Millet, Le Monastère de Daphni, 163, fig. 65; du même: Monuments byzantins de Mistra, pl. 120.

2437 Millet, Monuments byzantins de Mistra, pl. 113 et s.; MURATOFF, op. cit., pl. XLVII.

2438 Saint Jean Chrysostome, Homélies, hom. I, 6 (P.G., 49, 380), hom. 17 (P.G., 63, 129).

2439 Théodore, évêque d'Andida, P.G, 40, 417 et s.

$2440 \mathrm{Ph}$. LAUER, Le trésor du « Sancta Sanctorum » à Rome, 66, pl. IX.
} 
chérie au monastère de Xéropotamou (Athos) ${ }^{2441}$. La « liturgie de l'autre monde ${ }^{2442}$ se retrouve à Mistra dans une coupole aveugle de Sainte-Sophie ${ }^{2443}$ et elle est souvent reproduite dans les églises du Mont Athos et des pays slaves et roumains.

Origines de cette iconographie. - Un thème à la fois théologique et empreint d'un sentiment pathétique comme celui de la Divine Liturgie, se rattache à la tradition de l'art syrien et palestinien, plus dramatique et pittoresque que l'art, imprégné d'hellénisme, de Constantinople. C'est cette iconographie syrienne, conservée dans les monastères d'Orient, qui fournit des sujets aux peintres d'églises depuis le XIII ${ }^{\mathrm{e}}$ siècle. Les peintures de Mistra montrent la même iconographie,, traitée dans le même esprit, la même recherche du mouvement, de la vraisemblance, de l'émotion dramatique, le même emploi des évangiles apocryphes, la même fidélité à des conventions naïves, comme la taille des personnages variant suivant leur importance, la perspective inverse et en hauteur. Par exemple la gloire qui enveloppe le Christ dans la Descente aux Limbes, de règle dans les peintures des églises de Cappadoce, est supprimée à Saint-Luc et à Daphni et reparaît à Mistra.

A vrai dire, cet art monastique et populaire n'avait jamais disparu et coexistait dans les églises de province avec l'art impérial de Constantinople. Les fresques signalées plus haut dans certaines églises antérieures au XIII ${ }^{e}$ siècle nous en ont donné la preuve. Tel est l'art qui s'est imposé à l'école de peinture de Constantinople sous les Paléologues et qui a produit les deux ensembles des mosaïques de KahriéDjami et les peintures de Mistra.

Il existe une relation évidente entre ce mouvement artistique et le mysticisme des Hésychastes, qui s'est répandu dans la société byzantine. En même temps qu'ils reproduisent les épisodes de l'histoire sacrée, les peintres illustrent les cantiques et même les prières, comme les 24 stations de l'Hymne Akathiste, qui apparaissent pour la pre-

\footnotetext{
2441 Regardée comme une œuvre du XII $^{\mathrm{e}}$ siècle. DIEHL, op. cit., 673, fig. 335.

2442 Poésie de saint Sava, Millet, L'ancien art serbe. Les Églises, 19.

2443 Millet, Monuments byzantins de Mistra, pl. 131, 2.
} 
mière fois à la Pantanassa de Mistra et sont reproduites dans la plupart des églises orthodoxes ${ }^{2444}$.

La part de l'hellénisme. - Mais si les sujets sont populaires, la technique savante et raffinée se rattache à la tradition hellénistique, complétée par des observations directes. La peinture a retrouvé l'espace et la perspective linéaires. Ses architectures et ses accessoires ne ressemblent plus à des coulisses plates mais prennent un aspect cubique. Les draperies elles-mêmes se gonflent suivant les mouvements des personnages. Ceux-ci ne paraissent plus en files régulières sur la même surface, mais tous les détails, objets et figures sont disposés suivant une vision optique dans des plans différents. La peinture n'est plus un simple décor, elle reproduit la vie ${ }^{2445}$.

Le portrait. - Une autre découverte de cet art, c'est celle de l'homme, au physique et au moral. Là aussi l'art antique a servi de guide, mais les peintres ne se sont pas bornés à l'imiter : à côté de l'homme idéal des anciens, ils savaient représenter fidèlement leurs contemporains. Le portrait a toujours tenu une place importante dans l'art byzantin, comme d'ailleurs dans la littérature. Presque tous les historiens ont retracé les traits physiques et moraux des personnages de premier plan. Les peintres, de leur côté, ont su rendre l'extérieur, le tempérament et la psychologie de leurs modèles, qu'il s'agisse de souverains, comme Justinien et Théodora, ou de particuliers, comme les donateurs ou fondateurs d'églises.

Dans le narthex du Brontochion à Mistra, Théodore I (mort en 1407) s'était fait représenter, d'une part dans son magnifique costume de despote, d'autre part, suivant l'usage de son temps, en moine, revêtu de la mandya. Le portrait du despote est malheureusement mutilé ; celui du moine est à peu près intact. La robe sombre et le fond grisâtre font ressortir le visage rose et lumineux, encadré d'une barbe rousse. L'expression est pleine de finesse et de bonté ${ }^{2446}$.

C'est au frontispice d'un manuscrit que se trouve un des plus beaux portraits byzantins, celui de Jean VI Cantacuzène après son abdication en 1355, en basileus et en moine. Sans parler du contraste pittoresque entre les deux costumes, les deux visages ont les mêmes

\footnotetext{
2444 L. BREHIER, La rénovatien artistique sous les Paléologues et le mouvement des idées, 4 et s.; LEMERLE, Philippes et la Macédoine orientale à l'époque chrétienne et byzantine, 89. 2445 SOTIRIOU dans Hellenika 1928, 100 et s.

2446 Millet, Portraits byzantins, 450 et s.; L. BREHIER, Le portrait dans l'art byzantin, 344-349.
} 
traits : la forte arcade sourcilière ombrée, qui exprime l'énergie, les yeux vifs et l'expression méditative accusée par la moustache tombante, encadrant une lèvre légèrement relevée, et la longue barbe grisonnante à deux pointes ${ }^{2447}$.

Le coloris. - Enfin la réforme artistique s'est étendue à la palette. Les peintres ne se contentent plus de traits calligraphiés cernant des teintes plates. En découvrant l'espace, ils ont appris à connaître la lumière et ses jeux sur les surfaces colorées. Leur art est tout en nuances et ils combinent les couleurs de manière à obtenir des tons variés et des dégradations de teintes, qu'on ne pouvait réaliser avec des cubes de mosaïque. Il est clair que ce n'est pas en imitant les modèles antiques, mais par leur travail personnel, qu'ils sont parvenus à ces résultats.

Peintres et humanistes. - La rénovation de l'art qui s'est produite sous les Paléologues est donc un aspect de la Renaissance intellectuelle. Si le programme de peinture religieuse dérive de l'iconographie monastique, son exécution porte la marque de l'humanisme. L'idéal des peintre est le même que celui des humanistes. Ce qu'ils recherchent c'est la beauté et la noblesse, l'expression de la vie, la perfection du travail.

Les écoles de peinture. - Ce qui achève de montrer la fécondité de cet art et la personnalité de ses maîtres, c'est que la différence de leur éducation et de leurs tempéraments s'est manifestée par la création d'écoles de peinture avec leurs traditions distinctes, leur style et leurs procédés particuliers. On admet d'ailleurs que ces écoles ont été créées à Constantinople et se sont installées ensuite dans les provinces. Leur existence est un fait incontestable, mais leur origine et leur histoire sont pleines d'obscurité ${ }^{2448}$.

L'expression d'école du Palais, à laquelle on rattache les mosaïques de Kahrié-Djami, les beaux manuscrits de Cantacuzène et divers chefs-d'œuvre de plusieurs techniques, ne paraît pas très heureuse et

2447 GrABAR, Miniatures byzantines de la B.N. (agrandi 3 fois et demie); L. BREHIER, Le portrait dans l'art byzantin, 342 et s.

${ }^{2448}$ DIEHL, Manuel d'Art byzantin, 788; L. BReHIER, La rénovation artistique sous les Paléologues... 9-10. 
on ne voit pas la nécessité de nommer ainsi des œuvres, dont l'exécution ne doit rien à une initiative impériale.

L'école macédonienne a décoré les églises des villes de Macédoine, conquises sur 1'Empire par les princes serbes Miloutine et Douschan ${ }^{2449}$. Elle est caractérisée par les longues frises de scènes ininterrompues, que séparent en plusieurs registres de larges bandeaux décoratifs. Elle a travaillé au Mont Athos et rafraîchi d'anciennes peintures ${ }^{2450}$. Des signatures de peintres grecs ont été découvertes à Nagoritčino et Lesnovo. Les fresques sont largement traitées sans minutie. On y trouve la recherche de la vie, du mouvement, la tendance au réalisme, mais on a remarqué ses rapports avec la peinture italienne. On y voit les mêmes draperies souples et naturelles, les mêmes attitudes, les mêmes accents de tendresse que dans l'école siennoise ${ }^{2451}$.

On fait cependant venir cette école de Constantinople, mais on ne peut en donner aucune preuve : ce n'est qu'une présomption. Ce qui est certain, c'est que ce sont des fonds de paysages hellénistiques que l'on trouve dans ces peintures et ce détail suffit à montrer l'indépendance de cette école vis-à-vis de la peinture italienne.

L'école crétoise. - Vers 1350 apparaît une autre manière; ce n'est pas en Crète, comme le ferait supposer son nom, mais à Mistra, dans les peintures de la Péribleptos, dont quelques-unes ont déjà été décrites. Le nom viendrait de ce qu'avant l'exploration de Mistra, cette école n'était guère connue que par Théophane le Crétois et ses disciples, qui travaillèrent au Mont Athos au milieu du XVI siècle. Naturellement on fait venir cette école de Constantinople, sous prétexte que Mistra est une colonie de la Ville Impériale, mais la conjecture n'est pas plus certaine que pour l'école macédonienne. Le principal argument serait qu'un peintre de l'école crétoise, Théoplane le Grec, travaillait à Novgorod en 1378, puis à Moscou, où il eut pour disciple André Roublev, mais rien n'indique que ce maître se soit formé à Constantinople plutôt qu'à Mistra ${ }^{2452}$.

\footnotetext{
2449 Millet, Recherches sur l'iconographie de l'Évangile..., 630 et s. (Nagoričq, 1317; Gračaniča, avant 1321; Ljuboten, 1327)

2450 Millet, Les monuments de l'Athos. A Chilandar et, au XVI siècle, au Protaton, à Vatopédi.

2451 DIEHL., La peinture byzantine, pl. LII et LIV.

2452 MiLlET, Recherches sur l'iconographie de l'Evangile, 69 et s.
} 
Le succès de cette école fut prodigieux et, dès la dernière moitié du $\mathrm{XIV}^{\mathrm{e}}$ siècle, elle se substitua en Serbie à l'école macédonienne. Alors que les peintures de cette école, disposées en frises, avaient un caractère d'enseignement, accusé par de nombreuses inscriptions, les peintures de l'école crétoise se présentent dans des cadres séparés. C'est une succession de tableaux isolés, dont chacun forme un tout, une petite œuvre d'art, une icône.

La peinture crétoise, comme l'a montré Millet, n'est que la peinture d'icônes appliquée à la décoration architecturale. Elle se rapproche des icônes par sa disposition, par son esprit, par ses procédés techniques. Or l'icône n'est pas faite pour donner l'impression de la vie réelle, mais pour produire sur ceux qui la contemplent un effet d'ordre moral et religieux. Elle met le fidèle en contact avec le monde suprasensible. De là son absence de réalisme, ses figures idéalisées et expressives tournées vers le spectateur. On voit par là toute la différence d'esprit qui règne entre l'école macédonienne, historique, narrative, réaliste, et l'école crétoise, mystique et idéaliste.

Mais, loin de compromettre la perfection technique de la peinture monumentale, cette nouvelle manière l'a au contraire augmentée. A la large technique décorative de la fresque, la peinture crétoise oppose la minutie, la finesse du dessin, la délicatesse du style, qui s'efforce de rendre l'expression morale des personnages, la somptuosité du coloris, les couleurs intenses qui font la beauté des icônes, du XIV au XVI siècle, le cramoisi foncé, le brun-rouge, le lilas foncé, et surtout l'effet chatoyant de deux couleurs combinées, l'une dans l'ombre, l'autre dans la lumière ${ }^{2453}$. Les raffinements de la peinture de chevalet sont appliqués à la décoration monumentale. C'est ainsi que le modelé des visages est fait de couches menues, de lignes parallèles minces et serrées et c'est par là que les peintures de la Péribleptos se distinguent de celles des autres églises de Mistra.

Ainsi après la victoire des Hésychastes la mystique byzantine triomphe, mais s'accommode de la pensée antique. Byzance retrouve sa vraie figure, à la fois mystique et lettrée ${ }^{2454}$.

2453 N. P. KONDAKOV, Ikonografiia Bogomateri, 92-94.

2454 MiLleT, op. cit., 683. 


\section{Manuscrits historiés et arts somptuaires}

\section{$\underline{\text { Retour à la Table des Matières }}$}

L'activité des maîtres de Byzance ne s'exerça pas dans le seul domaine de l'art monumental. Comme on le constate dans les productions des écoles de grand art, des objets luxueux de dimension très variable, portails, pièces de mobilier, parure, vaisselle précieuse, etc., portent la marque du style usité à chaque époque. Ces œuvres d'art comblent les lacunes de la connaissance que nous avons de l'art monumental et achèvent de nous révéler la fécondité artistique de Byzance $^{2455}$.

On a déjà présenté les plus belles de ces œuvres dans le cadre même pour lequel des artistes les avaient créées ou dans leurs centres de fabrication. On se contentera d'en dresser un tableau d'ensemble et de compléter certains détails.

Manuscrits historiés. - $\mathrm{Au}$ premier rang il faut placer l'illustration des manuscrits qui complète notre connaissance de la peinture murale, dont elle fut si souvent la source. On a montré plus haut ses origines, les méthodes d'illustration des rouleaux et des livres sur papyrus ou parchemin, ainsi que les éditions de grand luxe des Livres Saints ${ }^{2456}$.

Les peintres de manuscrits reproduisaient la plupart du temps des modèles anciens, dérivés de prototypes traditionnels, mais ils interprétaient ces sources à leur fantaisie et les adaptaient à la technique et au style de leur époque. Chaque espèce d'ouvrage avait son illustration traditionnelle, mais traitée différemment suivant les temps et les goûts des peintres.

A partir $\mathrm{du} \mathrm{X}^{\mathrm{e}}$ siècle le courant profane est en relation étroite avec le développement des études classiques. Des manuscrits des Cynégétiques, poème attribué à Oppien, montrent des copies directes de mo-

\footnotetext{
2455 EBERSOLT, Les arts somptuaires dc Byzance (étude historique d'ensemble).

2456 Supra, p. 280; EBersolt, La Miniature byzantine; DIEHL, La peinture byzantine, 39-49, pl. LXXIX et $\mathrm{s}$.
} 
dèles hellénistiques ${ }^{2457}$ (Venise, $\mathrm{X}^{\mathrm{e}}$ siècle, reproduit au XV ${ }^{\mathrm{e}}$ ). Il en est de même dans un manuscrit des Idylles de Théocrite (Paris, XIV ${ }^{\mathrm{e}}$ siècle), où le dieu Pan apparaît à l'auteur sous la forme d'un bouc ${ }^{2458}$.

La mythologie pénétrait même dans les manuscrits religieux, comme on le voit dans un manuscrit des Homélies de Grégoire de Nazianze, dans lequel les allusions du sermonnaire au paganisme sont illustrées d'épisodes mythologiques ${ }^{2459}$, On possède plusieurs variantes de l'illustration de cet ouvrage. La plus belle est celle du manuscrit de Paris (Bibliothèque Nationale, gr. 510), exécutée vers 880 pour Basile $\mathrm{I}^{\mathrm{er}}$, représenté avec sa famille au frontispice. Les thèmes en sont empruntés à la biographie du saint, à l'histoire de l'empereur Julien et de saint Basile, à des épisodes de la Bible et de l'Évangile, comme l'admirable vision d'Ezéchiel, où l'on retrouve les fonds bleus et roses de la peinture antique et jusqu'au cadre élégant de l'original chrétien, probablement une peinture alexandrine du IV ${ }^{\mathrm{e}}$ siècle ${ }^{2460}$.

Parmi les libres enrichis de peintures, ce sont surtout les textes des Écritures qui nous sont parvenus. On ne connaît pas de Bible byzantine complète, mais seulement le recueil des huit premiers livres, l'Octateuque, dont on possède six exemplaires illustrés des $\mathrm{XI}^{\mathrm{e}}$ et $\mathrm{XII}^{\mathrm{e}}$ siècles, qui reproduisent dans le plus grand détail les peintures d'un ancien rouleau, analogue au rouleau de Josué ${ }^{2461}$. Un exemplaire du Livre des Rois, illustré d'après une source analogue, a été découvert à la bibliothèque Vaticane ${ }^{2462}$. On constate dans ces œuvres l'affaiblissement du style antique, dont la liberté d'allure disparaît. Le style se rapproche de plus en plus de l'art monumental officiel.

Le livre de l'Ancien Testament illustré le plus fréquemment est celui des Psaumes, dont on distingue deux éditions : les psautiers à frontispices, dits aristocratiques, dont les tableaux, peints à pleine page, illustrent la vie de David et les cantiques (odes), et les psautiers à il-

EBERSOLT, La Miniature byzantine, 58, pl. LXV.

2458 Ibidem, 58, pl. LXIII-LXIV (Théocrite offrant à Pan les poèmes de l'Autel et de la Flûte).

2459 Ambrosienne, IX ${ }^{\mathrm{e}}$ siècle; DIEHL, Manuel d'art byzantin, 626-629, fig. 300-303.

${ }^{2460}$ DieHL, op. cit., 621-623, fig. 297-299; Millet, L'Art byzantin dans l'Histoire de l'Art de A. Michel 241-243; EBersolt, La Miniature byzantine, XX et XXI, pl. XIV-XV; D.A.C.L., VI, 1667-1711.

2461 DIEHL, op. cit., 616-620, fig. 293-296; Th. OusPENSKY, L'Octateuque de la Bibliothèque du Sérail à Constantinople, album; EBERSOLT, op. cit., 31 et s., pl. XXVIII et s.; MILLET, Les octateuques byzantins dans R.A., 1910, II.

2462 J. LASSUS, Les miniatures byzantines du «Livre des Empereurs », M.A.H., 1928. 
lustration marginale, dits monastiques. Les exemplaires de la première catégorie furent commandés par des empereurs ou de hauts personnages : le plus beau est celui de la Bibliothèque Nationale de Paris (gr. 139, $\mathrm{X}^{\mathrm{e}}$ siècle). Ses peintures somptueuses nous ramènent aux plus beaux temps hellénistiques, avec ses paysages pompéiens, comme celui de David gardant ses troupeaux, ses belles figures allégoriques, qui viennent tout droit d'Alexandrie. Le style cérémoniel y est représenté par le portrait de David en empereur byzantin entre Sophia et Prophetia $^{2463}$.

Très différente est l'illustration des psautiers monastiques. Elle suit le texte pas à pas et en fait un commentaire imagé, plein de fantaisie, presque toujours indépendant de la tradition iconographique. On y remarque des traits satiriques et de curieuses allusions à la persécution des iconoclastes. Les plus anciens exemplaires, comme le Psautier Chloudov de Moscou et celui du Pantocrator (Mont Athos), datent du $\mathrm{IX}^{\mathrm{e}}$ siècle. Le British Museum en possède un autre, écrit au monastère Saint-Jean de Stoudios en $1066^{2464}$. Les miniatures placées dans les marges sont de simples vignettes qui se détachent, sans autre fond, sur le parchemin du manuscrit. Le dessin, exécuté à la plume, est revêtu de couleurs, en général peu brillantes. Ces psautiers, dont certains exemplaires datent des $\mathrm{XIV}^{\mathrm{e}}$ et $\mathrm{XV}^{\mathrm{e}}$ siècles, représentent un art plus libre que l'art officiel. Leurs figures, pleines de caractère, dénotent un esprit d'observation et une recherche de réalisme qui va jusqu'à la caricature.

L'illustration des Évangiles n'a plus le même aspect somptueux qu'au VI siècle. Elle est faite d'une succession de petits tableaux, tantôt dans la marge (Paris, $119, \mathrm{x}^{\mathrm{e}}$ s.), tantôt au milieu du texte (Paris, $74, \mathrm{XI}^{\mathrm{e}} \mathrm{s}$.), d'un caractère anecdotique, dû à la reproduction probable d'anciens rouleaux ${ }^{2465}$. Un modèle plus luxueux est celui de l'Évangéliaire à frontispices ornés des portraits des Évangélistes, avec en tête de chaque Évangile la figuration d'une grande fête, méthode qui correspond à celle qui est employée dans la décoration des églises

\footnotetext{
${ }^{2463}$ H. BuChtAl, The miniatures of the Paris Psalter, pl. I-XIV (dimensions des originaux).

${ }^{2464}$ DiEHL., op. cit., 379-384, fig. 182-184; 614-616, fig. 291 et 292. L'origine monastique du psautier Chloudov est discutable. Voir MALICKIJ dans M.O., II, 235 et s. et MARES, A.C.E.B., VI, Alger, 218 et s.

${ }^{2465}$ H. OMONT, Evangiles avec peintures byzantines du XI siècle; MILLET, Recherches sur l'iconographie de l'Évangile, 590-592; DIEHL., op. vit., 626 (copié à Constantinople sur un exemplaire de la Bibliothèque impériale).
} 
du IX ${ }^{\mathrm{e}}$ au XII ${ }^{\mathrm{e}}$ siècle ${ }^{2466}$. Souvent les têtes de chapitres consistent en bandeaux ornés de dessins géométriques, de feuillages et d'arabesques. Les canons de concordance sont d'abord en simples arcades, puis le décor s'enrichit, les bases des colonnes se compliquent, les fûts imitent les veines de marbre, et le décor zoomorphe règne sur les chapiteaux ${ }^{2467}$. Parfois, au lieu d'une arcade, les colonnes supportent un entablement composé d'un large bandeau en rectangle coupé par un gâble; sa surface est couverte d'ornements géométriques qui imitent des pavements de mosaïques et, au-dessus, s'agitent des figurines, chasse au léopard, paons s'abreuvant à une fontaine, etc., d'un style d'une exquise fantaisie ${ }^{2468}$.

De l'époque des Paléologues date le magnifique manuscrit Rockefeller de Chicago, qui contient le Nouveau Testament, sauf 1'Apocalypse. Il fut orné vers 1265 dans le scriptorium impérial du palais des Blachernes, en même temps que le Coislin 200 de la Bibliothèque Nationale de Paris, et les deux manuscrits furent envoyés en don à Saint Louis par Michel Paléologue en $1269^{2469}$. Ses peintures assez détériorées, disposées en tableaux au milieu du texte, se rattachent au style hellénistique, mais avec des détails iconographiques qui rappellent la Cappadoce ${ }^{2470}$.

Parmi les autres livres religieux illustrés il faut mentionner les $M e ́-$ nologes, résumés des vies de saints disposées dans l'ordre du calendrier liturgique. Le plus bel exemplaire, qui est aussi un des plus anciens, est le Ménologe du Vatican, copié et orné pour Basile II dans les dernières années du $\mathrm{X}^{\mathrm{e}}$ siècle par 8 peintres, qui ont signé chacun leur œuvre personnelle. Au-dessus du texte, les portraits des saints et les scènes de martyres se détachent sur des fonds d'architectures antiques d'une grande variété ${ }^{2471}$.

Nous avons signalé en leur temps les curieux manuscrits illustrés des Homélies du Moine Jacques ${ }^{2472}$.

${ }^{2466}$ DieHL, 626; Paris, gr. 70, daté de 964; Iviron, Evang. $n^{\circ} 1$, fig. 235 et s.

2467 EBERSOLT, op. cit., 44, pl. XXX-IX et s.

2468 Parés, gr. 64, EBERSOLT, pl. XLII et s.

${ }^{2469}$ H. R. WILloughBY, Codex 2400 and its miniatures (The Art Bulletin, Chicago, XV, 1, 1933 p. 1-74). Il a dû être porte par Jean Vekkos au vamp devant Tunis. Voir M.B.E.H. (Vie et mort de Byzance), 1969, 325.

${ }^{2470}$ Deux frontispices à pleine page (Moïse-David) et 90 tableaux.

2471 DieHL, Manuel d'Art byzantin, 632-635, 11g. 306-308; EBERSOLT, La Miniature byzantine, 35 et s., pl. XXXIII et s.

2472 Supra, p. 349 et s. 
Techniques variées. - De même, les créations variées des autres techniciens ont été déjà envisagées à propos de l'usage qui en était fait dans la société byzantine. Cependant, afin d'en montrer toute l’importance, il est nécessaire de les rappeler.

Ce sont d'abord les icônes peintes, dont on a décrit les plus belles et indiqué la place considérable que leur culte, toujours vivant, tenait à Byzance ${ }^{2473}$. C'est ensuite le travail des métaux, les trésors d'argenterie, mobilier liturgique et vaisselle d'or et d'argent ${ }^{2474}$, les portes de bronze incrustées d'argent, importées de Constantinople en Italie $^{2475}$, les revêtements somptueux d'émaux ${ }^{2476}$ et les créations exquises des orfèvres et des bijoutiers ${ }^{2477}$. La taille, la gravure et la sculpture des pierres dures, comme la stéatite, l'albâtre, l'ophite, etc., sont représentées par les objets les plus divers : calices à monture d'orfèvrerie du trésor de Saint-Marc de Venise, icônes de stéatite, camées, etc. ${ }^{2478}$.

La technique du relief est celle de la sculpture sur bois (meubles, portraits, coffrets, iconostases) ${ }^{2479}$ et surtout sur ivoire. La série des ivoires byzantins ne conserve pas seulement un art délicieux, mais, de plus, c'est un des plus précieux répertoires de monuments qui permettent de suivre les variations des techniques et des styles ${ }^{2480}$. Terminons enfin par l'industrie somptueuse des étoffes tissées et brodées, ainsi que des tapisseries, qui achève de donner à la civilisation byzantine son caractère de magnificence ${ }^{2481}$.

Retour à la Table des Matières

Supra, p. 232 et s.

2474 Supra, p. 171, 190, 211.

2475 Supra, p. 183,

2476 Supra, p. 191.

2477 Supra, p. 49, 191.

2478 Supra, p. 192, 240.

2479 Supra, p. 38, 192, 286.

2480 Supra, p. 39, 192, 286.

2481 Supra, p. 185-190. 


\section{Chapitre XV}

\section{L'expansion de l'art byzantin}

\section{Retour à la Table des Matières}

Une école d'art aussi puissante que celle de Byzance ne reste jamais enfermée dans des frontières politiques, à plus forte raison quand ces frontières varient aussi souvent au cours des âges que celles de l'Empire byzantin.

Mais cette expansion se présente sous deux formes que l'on confond trop souvent. Tantôt les maîtres d'un pays, architectes, peintres, etc., viennent travailler dans un pays étranger : il s'agit d'une importation. Tantôt les maîtres d'une région imitent l'art d'un pays étranger avec plus ou moins de fidélité, et c'est alors que l'on peut parler d'une influence.

Les causes d'une influence sont parfois politiques, par exemple aux $\mathrm{V}^{\mathrm{e}}$ et $\mathrm{VI}^{\mathrm{e}}$ siècles, lorsque l'Empire byzantin était entouré d'États barbares, dont les chefs admiraient sa civilisation. Mais, dans son histoire millénaire, l'expansion artistique de Byzance trouva ses bornes en Orient dans l'art musulman, importé d'ailleurs en Afrique, en Espagne, en Sicile. D'autre part, après une longue enfance, l'art de l'Occident affirma son originalité et son pouvoir créateur en face de Byzance.

\section{Les importations}

\section{$\underline{\text { Retour à la Table des Matières }}$}

Il faut d'abord mettre à part les territoires de l'Empire situés en Occident, l'Afrique, l'Italie, dans lesquels on reconnaît les œuvres de maîtres envoyés de Constantinople ou venus des pays d'Orient, 
Égypte, Syrie, Perse. Nous avons vu par l'exemple de Ravenne combien ces deux origines sont difficiles à distinguer.

En Gaule, à l'époque mérovingienne, parmi les objets qu'importaient les marchands syriens, dont les colonies étaient si florissantes ${ }^{2482}$, se trouvaient de nombreux objets d'art fabriqués en Orient : les tissus de soie, les ivoires, pyxides ${ }^{2483}$, boucles de ceintures, comme celle de saint Césaire qui montre les gardes endormis au pied du Saint-Sépulcre et s'apparente aux diptyques consulaires et aux plus beaux ivoires byzantins ${ }^{2484}$. L'argenterie d'Antioche est représentée par des missoria et des vases sacrés, décrits dans des textes où il est question d'objets d'or, de filigranes, et enrichis d'émaux ${ }^{2485}$.

Des monuments importants furent élevés à la même époque dans les régions occupées par les Wisigoths. A Toulouse, l'église décagonale de La Daurade, dédiée à la Vierge (Sancta Maria deaurata), qui existait encore en 1761, était décorée de mosaïques à fonds d'or et d'argent, qui représentaient la vie de Jésus, disposée en trois registres, avec des emprunts aux textes apocryphes : c'est déjà le programme des fresques cappadociennes, exécuté vraisemblablement dans le troisième quart du $\mathrm{v}^{\mathrm{e}}$ siècle ${ }^{2486}$. C'est aussi à la région wisigothique que l'on doit les peintures du Sacramentaire de Gellone, dont l'origine orientale ne laisse pas de doute et se trahit, dans le texte par des mots grecs transcrits en caractères latins, et dans l'illustration presque entièrement zoomorphe, par la prédominance de la faune des pays chauds, lions, serpents, gypaètes, perroquets au plumage éclatant. Les Évangélistes y ont des corps d'hommes, avec la tête de l'animal qui correspond à leur symbole ${ }^{2487}$.

(2432) Supra, p. 175

${ }^{2483}$ L. BREHIER, Ivoires chrétiens de la région de Brioude (Almanach de Brioude, XX, 1939, p. 19 et s.).

${ }^{2484}$ Id., L'art en France, des invasions barbares à l'époque romane (1930), 36 (saint Césaire, archevêque d'Arles, 501-542).

2485 Ibidem, 37.

${ }^{2486}$ R. REY, Le sanctuaire paléochrétien de La Daurade à Toulouse. L'église démolie en 1761, mais on a plusieurs descriptions des mosaïques en manuscrits. Helen WoODRUF, The Iconography and Date of the Mosaics of La Daurade, dans The Art Bulletin, Chicago, XIII, 1, 1931, 80-114.

2487 Paris, lat. 12048 (provient de l'abbaye de Saint-Guilhem le Désert), L. BreHIER, L'art en France..., 67 et s. 
Ce n'est pas à l'art byzantin, mais plutôt à celui de l'Iran et de l'Égypte copte, que l'on doit le style géométrique des manuscrits irlandais, dans lesquels la faune et l'homme lui-même deviennent de simples épures. Les rapports de cet art avec l'art arabe sont parfois saisissants ${ }^{2488}$.

En Italie, après la restauration de l'autorité impériale par Justinien, de nombreux Grecs et Syriens s'établirent à Rome et y formèrent une colonie importante qui donna des papes à la chrétienté. Elle comptait certainement de nombreux maîtres-d'œuvre et artistes.

Ce furent eux qui construisirent et décorèrent de mosaïques plusieurs basiliques au $\mathrm{V}^{\mathrm{e}}$ siècle, comme celle de Sainte-Agnès-hors-lesMurs, où la jeune martyre, vêtue du costume somptueux des impératrices byzantines, occupe (premier exemple) le milieu de l'abside. Ce furent aussi des maîtres de Constantinople qui exécutèrent les mosaïques de l'oratoire de Saint-Venance au palais de Latran et celles de l'oratoire du pape Jean VII, dans la basilique de Saint-Pierre ${ }^{2489}$, qui possédait un véritable cycle iconographique et était dédié à la ViergeReine.

Puis, fuyant la persécution iconoclaste, un grand nombre d'artistes, architectes, peintre d'icônes, parmi lesquels des moines, se réfugièrent à Rome qui devint le principal centre de la résistance aux iconoclastes.

La décoration de l'église Sainte-Marie-Antique du Forum, presque entièrement due à des Grecs, en est le témoignage. Construite sous Jean VII vers 705-707, elle fut ornée de fresques, exclusivement iconographiques, entre 741 et $792^{2490}$. Non seulement les inscriptions en grec dominent, même pour désigner des martyrs romains et certains papes, mais les saints d'Orient, les Pères grecs tiennent une large place dans la décoration. Sur le mur du collatéral nord, le Christ, bénissant à la grecque, trône entre deux théories de saints, les uns grecs, les autres romains. C'est vraiment l'église des icônes, dont un grand nombre sont reproduites sur les murs. La participation de peintres sy-

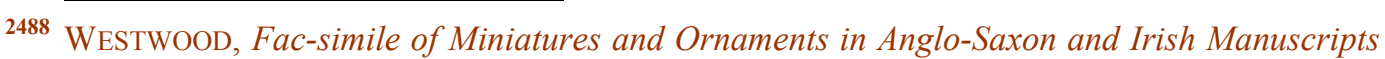
(Londres, 1868); L. Brehier, De l'art antique à l'art médiéval, dans H.G.A., II, Art roman, 55 et $\mathrm{s}$.

2489 L. BREHIER, L'Art chrétien. Son développement iconographique, 130-133.

${ }^{2490}$ De GruneISEN, Sainte-Marie-Antique (Rome, 1911); D.A.C.L., V, 2006 et s. (portraits des papes Zacharie (741-752), Paul I ${ }^{\mathrm{er}}$ (757-767), Adrien I ${ }^{\mathrm{er}}$ (772-795) et de son oncle le primicier Théodote avec sa famille. 
riens à cet ensemble ressort du type syrien du Christ en croix, vêtu du long colobium ${ }^{2491}$.

Nous avons signalé la magnifique expansion de l'art de Constantinople en Italie, et le travail des maîtres grecs aux monastères du Mont Cassin, à Amalfi et dans l'Italie Méridionale, à Saint-Marc de Venise et en Sicile sous les rois normands, de la fin du $\mathrm{X}^{\mathrm{e}}$ au XII ${ }^{\mathrm{e}}$ siècle. Ce sont bien là des importations, comme celles qui étaient l'objet d'un commerce actif à cette époque entre Constantinople et l'Italie ${ }^{2492}$.

\section{Les influences (Occident)}

$\underline{\text { Retour à la Table des Matières }}$

Les importations sont des faits certains : les influences, les inspirations sont plus difficiles à saisir. L'art byzantin de Constantinople, antérieur au $\mathrm{XIII}^{\mathrm{e}}$ siècle, qui employait des techniques de luxe et conservait la tradition hellénique, avec son style savant et délicat, ne pouvait être assimilé par des maîtres dont l'instruction était sommaire, les ressources médiocres et les moyens techniques rudimentaires. L'art des écoles orientales, plus simple, moins luxueux, plus réaliste et plus vivant leur convenait beaucoup plus et ce fut celui qui eut le plus de succès en Occident, mais les deux tendances furent parfois associées sans aucun souci d'unité.

L'art carolingien. - A première vue, le mouvement de la Renaissance carolingienne ne doit rien à Byzance et lui est même hostile. Les doctrines du concile de Nicée de 787 sur le culte dû aux icônes ne furent pas admises dans l'empire franc et furent attaquées assez violemment aux conciles de Francfort (794) et de Paris (825). Les Occidentaux s'en tenaient à la doctrine de saint Grégoire le Grand, d'après laquelle l'art religieux n'avait que la valeur d'un enseignement ${ }^{2493}$.

Cependant les lettrés de l'entourage de Charlemagne poursuivaient le même but que ceux de Byzance: revenir à l'antiquité classique dans la langue, dans la littérature, dans l'art religieux. Le véritable ini-

\footnotetext{
2491 DE GRUNEISEN, op. cit., pl. XXXVII; L. BREHIER, op. cit., 133.

${ }_{2492}$ Supra, p. 181 et s.

2493 L. BREHIER, La querelle des images, 58-62.
} 
tiateur de ce mouvement était le moine anglo-saxon Alcuin, directeur de l'école fondée à York par l'archevêque Egbert, mort en 766. Non seulement on y enseignait le latin et le grec, mais, à côté des livres religieux, sa bibliothèque possédait la plupart des auteurs classiques, dont les manuscrits avaient été rapportés de Rome ${ }^{2494}$.

Alcuin représentait donc la tradition érudite, qui, par un Bède le Vénérable et un Benoît Biscop, remontait à un Byzantin authentique, Théodore de Tarse, moine de Cilicie. Instruit dans les deux langues classiques, celui-ci vint à Rome, où il se trouvait en 668, fut sacré par le pape Vitalien archevêque de Cantorbéry et chargé de réorganiser l'église d'Angleterre, fondée sous Grégoire le Grand. Théodore s'acquitta admirablement de sa mission et, entre autres mesures, fonda dans les monastères des écoles de culture classique ${ }^{2495}$.

Ce fut en 782 qu'Alcuin, sur l'invitation de Charlemagne, vint se fixer en France et dirigea l'École du Palais, point de départ et centre de la Renaissance des lettres classiques.

Or, dans le programme de réforme d'Alcuin, l'art tenait une place importante. Dans les principaux monastères furent créés des ateliers de peinture et d'autres techniques, ainsi que des scriptoria dans lesquels on copiait et on enluminait des manuscrits sacrés et profanes.

Nous n'avons pas à étudier cet art, mais à chercher ce qu'il doit à Byzance ${ }^{2496}$. On ne voit pas que des maîtres grecs soient venus travailler en France : c'est par d'autres voies que l'influence byzantine s'est exercée sur l'art, probablement par l'intermédiaire de Rome et des régions wisigothiques.

Le grand service que l'art byzantin a rendu à l'Occident est d'avoir déterminé ses maîtres à revenir au traitement naturaliste de la figure humaine, supprimée dans les arts musulmans, stylisée ou étouffée par les entrelacs de l'art irlandais. Sans doute les peintres d'Occident ont pu copier directement l'antique, mais c'est à l'imitation de l'art by-

94 D.H.G.E., II, 30-39.

2495 FliChE et MARTIN, Histoire de l'Église, V, 317-329.

2496 L. BREHIER, L'art en France, des invasions barbares à l'époque romane, 112-206 et 208; D.A.C.L., III, 658 et s. 
zantin qu'ils ont reproduit d'une manière vivante les portraits des Evangélistes, des rois en Majesté entourés parfois de figures allégoriques, des saints, des évêques, etc. ${ }^{2497}$. La Sagesse (Sophia Sancta) assise, un livre ouvert sur les genoux (Bible d'Alcuin), est toute byzantine. Le Christ enseignant de l'Évangéliaire de Charlemagne, par la beauté de ses draperies et l'impression idéaliste qui se dégage de sa figure imberbe, encadrée de longs cheveux, semble une création des maîtres hellénistiques du premier art chrétien ${ }^{2498}$.

L'iconographie religieuse a dans la peinture des manuscrits un caractère narratif et même anecdotique, qui indique l'influence de l'iconographie syrienne. On constate cette parenté par l'aspect dramatique que prend le récit de la Passion. Ce n'est pas par un simple hasard que le thème douloureux de la Déposition de croix apparaît, pour la première fois, presque en même temps sur un Évangéliaire d'Angers et dans une peinture cappadocienne ${ }^{2499}$. L'abbaye de SaintGall paraît avoir été un centre important d'influences byzantines, comme le montrent les manuscrits illustrés qui datent de l'abbatiat de Grimald (841-872), ainsi que les ivoires attribués au moine Tuotilo (fin $\mathrm{IX}^{\mathrm{e}}-\mathrm{X}^{\mathrm{e}}$ siècle) ${ }^{2500}$. Un Évangéliaire de cette époque contient une description, en latin mêlé de grec, des peintures d'un exemplaire byzantin des Quatre Évangiles. C'est un véritable Guide de la Peinture qui montre de quelle manière l'influence de l'art byzantin pouvait s'exercer en Occident ${ }^{2501}$.

C'est enfin en grande partie à l'art byzantin que les peintres carolingiens ont emprunté leur somptueuse ornementation, l'emploi de l'or et de l'argent sur fond pourpré dans les titres et, avant tout, leurs magnifiques canons évangéliaires d'une si belle fantaisie. C'est grâce à l'art byzantin que le style monumental des temps hellénistiques reparait dans l'art occidental (thèmes de la Fontaine de vie du frontispice de l'Évangéliaire de Godescalc et dans celui de l'Évangéliaire de

A. BOINET, La miniature carolingienne (1913).

D.A C.L., III, 707 et 833.

MiLlet, Recherches sur l'iconographie de l'Évangile, 463; DE JERPHANION, Les églises rupestres de Cappadoce, I, 318, Pl. 85, 4; Angers, Bibliothèque Municipale, 24 ( $\mathrm{XI}^{\mathrm{e}}$ siècle); BREHIER, op. cit., 171-175.

2500 L. BREHIER, op. cit., 192 et s.; D.A.C.L., V, 173 et s.

${ }^{2501} \mathrm{~S}$. BERGER, De la tradition de l'art grec dans les manuscrits latins des Evangiles, 146-148; L. BREHIER, 176-178. 
Saint-Médard de Soissons ${ }^{2502}$, de l'Édifice symbolique de l'Église dans le même manuscrit, de l'Adoration de l'Agneau dans la Bible d'Alcuin) ${ }^{2503}$.

L'influence byzantine s'est exercée sur les autres techniques de l'époque carolingienne (architecture, ivoires, etc.) mais d'une manière moins nette que sur la peinture ${ }^{2504}$.

Époque romane. - Cette influence reparaît en Allemagne à la fin $\mathrm{du} \mathrm{X}^{\mathrm{e}}$ siècle, après le mariage du futur Otton II avec une princesse byzantine, Théophano, fille de Romain II, en 972. Il est vraisemblable que la nouvelle souveraine amena avec elle plusieurs de ses sujets, parmi lesquels des peintres, chargés de faire des portraits, ainsi que des spécimens des arts somptuaires de son pays. Bien que la tradition de l'art carolingien n'ait pas été interrompue au $\mathrm{X}^{\mathrm{e}}$ siècle dans les pays germaniques, on relève des influences byzantines dans l'iconographie des manuscrits religieux ornés pour Egbert, archevêque de Trêves (977-993) ; des ivoires provenant de l'abbaye de Lorsch sont des copies d'originaux byzantins. L'illustration de l'Évangéliaire d'Otton III reproduit certainement un modèle syrien ${ }^{2505}$.

Dans la seconde moitié du $\mathrm{X}^{\mathrm{e}}$ siècle s'ouvrit en Languedoc l'atelier d'orfèvrerie de l'abbaye de Conques. Parmi les ex-voto de toute époque qui ornent la célèbre statue d'or de Sainte-Foy, se trouve un plat de reliure en argent, provenant d'un évangéliaire byzantin. Les autels portatifs et reliquaires exécutés dans cet atelier au $\mathrm{XI}^{\mathrm{e}}$ siècle sont décorés d'émaux cloisonnés qui, malgré une différence de technique, sont une imitation certaine des émaux byzantins ${ }^{2506}$.

Ce ne furent pas moins des orfèvres occidentaux qui créèrent la technique nouvelle et originale de l'émaillerie champlevée au début $\mathrm{du} \mathrm{XII}^{\mathrm{e}}$ siècle, en Limousin d'une part, dans la région rhénane de

\footnotetext{
${ }^{2502}$ D.A.C.L., III, 711, fig. 2635. Même modèle sur l'Évangéliaire arménien d'Etschmiadzin, copie faite en 989 d'un original du VI e siècle. - STRZYGOWSKI, Der Dom zu Aachen, 20-22.

2503 BoINET, op. cit.; D.A.C.L., III, fig. 2654 (thème répété sur l'Évangéliaire de Saint-Emmeran de Munich).

2504 LEITSCHUH, Geschichte der Karolingischen Malerei (Berlin, 1894); STRZYGOWSKI, op. cit.

2505 DIEHL, Manuel d'art byzantin, 723-725; G. LEINDINGER, Das sogenannte Evangeliarium Kaiser Otto III (Crucifixion syrienne avec long colobium).

${ }^{2506} \mathrm{E}$. MOLINIER, Histoire générale des arts appliqués à l'industrie. II, L'orfèvrerie, 117; Bouillet, L'église et le trésor de Conques, 29 et s.
} 
l'autre ${ }^{2507}$. Cette invention marque une véritable émancipation de l'art occidental, mais, dans leur composition et leur style, les pièces sorties de ces ateliers conservent le souvenir des modèles byzantins, soit dans l'iconographie religieuse, soit dans les ornements.

C'est ce qu'on remarque en particulier dans l'émaillerie rhénane et mosane, sur les œuvres conservées au musée du Cinquantenaire de Bruxelles, sur le support du chef de saint Alexandre, dû à Godefroy de Claire, sur l'autel portatif de Stavelot (1165), où les figures de saints et les scènes de martyres font songer à l'iconographie du Ménologe de Basile II ${ }^{2508}$. Sur l'ambon de l'abbaye de Klosterneubourg (Autriche) les scènes tirées de l'Ancien et du Nouveau Testament se déroulent en 51 tableaux émaillés, œuvre de Nicolas de Verdun ${ }^{2509}$.

Il résulte des faits ainsi rassemblés que l'art byzantin eut surtout en Occident un rôle d'initiation. Ce fut le désir de créer un art sacré aussi somptueux qui poussa les ateliers occidentaux à imiter l'art de Byzance. Or, cette imitation fut superficielle et ne nuisit en rien à l'originalité de l'art occidental. Ce ne sont pas les techniques byzantines qui sont imitées, mais les thèmes décoratifs et l'iconographie religieuse, transcrits souvent dans une autre technique que celle du modèle. C'est ainsi que deux animaux affrontés sur un tissu sont sculptés en ronde bosse sur la corbeille d'un chapiteau ${ }^{2510}$, que tel épisode de la Vie de Jésus dans une peinture cappadocienne reparaît, parfois avec des inscriptions analogues, dans une sculpture romane ${ }^{2511}$.

L'art roman est entièrement indépendant de l'art byzantin et c'est à tort que l'on s'obstine à lui rattacher les églises à files de coupoles sur pendentifs du sud-ouest de la France. Ces églises sont à nef unique et emploient l'arc brisé, inconnu à Byzance. Quand elles n'ont pas été restaurées au XIX ${ }^{\mathrm{e}}$ siècle, on s'aperçoit que leurs pendentifs sont composés d'assises en encorbellement disposées entre les grands arcs. Il en était ainsi à Saint-Front de Périgueux avant la restauration

\footnotetext{
${ }^{2507}$ L. BREHIER, Le Style roman (1941), 73-77; C. de BORCHGAVE, De l'influence des arts orientaux dans nos régions au Moyen Age (Bull. Soc. Archéol., Bruxelles, 1948).

2508 L. BREHIER, De l'art antique à l'art médiéval, II, Art roman, 142-145.

2509 Id., Le Style roman, 75-77.

2510 Id., Les thèmes décoratifs des tissus d'Orient et leur imitation dans la sculpture romane, dans Etudes du Musée National d'Alger, 1945.

2511 Id., Les épisodes de la Passion dans la sculpture romane d'Auvergne, dans G.B.A., juillet 1925 , p. 64-67.
} 
d'Abadie en 1855. On ne peut nier que le plan de cette église rappelle celui de Saint-Marc de Venise, mais d'après le projet primitif, elle devait être prolongée à l'ouest et recevoir le plan en croix latine, qui est celui de la cathédrale d'Angoulême ${ }^{2512}$.

Ce n'est pas de ce côté, mais bien plutôt dans la peinture murale, que l'on constate des influences byzantines. Deux écoles de peinture ont décoré les églises romanes : l'école aux fonds clairs, aux teintes neutres et pauvres, au dessin schématique, mais ferme et vigoureux, rappelle les peintures cappadociennes ; mais ses maîtres ont des tempéraments variés, la gravité du maître du Liget, la fougue du peintre de Vicq, qu'on ne trouve guère en Cappadoce; l'école aux fonds bleus, au coloris varié, au dessin plus poussé, présente des rapports avec les fresques italiennes et byzantines de la même époque ${ }^{2513}$.

C'est à l'abbaye de Cluny, véritable capitale de l'art roman, qu'apparaît ce style. Dans le chœur de la grande abbatiale, consacrée par Urbain II en 1095, un Christ colossal, semblable à un Pantocrator byzantin, se détachait sur un fond d'or ${ }^{2514}$. Cette œuvre a disparu, mais on peut se représenter l'effet qu'elle produisait, grâce à une vision semblable du Christ au manteau de pourpre retrouvé dans l'abside de l'église de Paray-le-Monial ${ }^{2515}$, et surtout dans le prieuré clunisien de Berzé-la-Ville, construit entre 1100 et 1120.

Dans l'abside de l'église, apparaît dans une gloire un Christ géant, vêtu d'une robe blanche et d'un manteau de pourpre violette, sur le fond d'azur semé d'étoiles d'or. Entouré d'apôtres et de saints, il tend à saint Pierre le rouleau de la Nouvelle Loi. L'expression triste du visage rappelle certaines figurations byzantines. Dans les écoinçons de l'étage d'arcades qui règne sous la conque, les Vierges Sages, en bustes, portent le costume des princesses byzantines, le diadème perlé, la tunique brodée, les lourds pendants d'oreilles. L'ensemble forme une composition brillante, chargée d'ornements perlés et de rinceaux, mais les attitudes sont raides et les visages peu expressifs ${ }^{2516}$.

D'autres œuvres de la même école ornent des sanctuaires du Velay (cathédrale du Puy), de l'Auvergne (tribune de Saint-Julien de

\footnotetext{
2512 Id., Les églises d'Aquitaine à coupoles et l'origine de leur architecture (J.S., 1927).

2513 BERTAUX, L'art dans l'Italie méridionale, 250-267; JERPHANION, Le cycle iconographique de Sant'Angelo in Formis, dans B.N., I, 341 et s.

2514 Décrit par André Lenoir qui vante « la fraîcheur de la peinture à l'œuf », H. FocILLON, Peintures romanes des églises de France, 52.

2515 Prieuré de Cluny : son église est comme une réduction de la grande Abbatiale.

2516 MerCIER, Les Primitifs français. La peinture clunysienne en Bourgogne, 23-79.
} 
Brioude), du Languedoc (chapelle Saint-Michel de Rocamadour, avec peintures extérieures), de Catalogne. Elles représentent l'imitation la plus caractérisée que l'art roman ait faite d'une technique byzantine ${ }^{2517}$.

Epoque gothique. - Comme dans la période précédente, c'est surtout dans l'iconographie religieuse et dans les arts somptuaires que se manifeste du XIII ${ }^{\mathrm{e}}$ au XV $\mathrm{XV}^{\mathrm{e}}$ siècle l'influence de l'art byzantin. Les icônes, les reliques rapportées d'Orient dans de somptueux reliquaires, surtout après le pillage de Constantinople en 1204, les tissus luxueux achetés sur les marchés byzantins achevèrent de familiariser les Occidentaux avec les richesses de Byzance ${ }^{2518}$.

On a remarqué la place que tient l'iconographie byzantine dans la statuaire et les vitraux des églises gothiques, en particulier les effigies ou les légendes des saints, dont une église possédait les reliques ${ }^{2519}$.

Mais ces influences paraissent bien superficielles si l'on considère la maîtrise, la puissance de l'art occidental. Loin de laisser entamer son originalité par des influences étrangères, c'est sur le domaine même de Byzance qu'il s'implante, en Syrie, à Chypre, en Grèce ${ }^{2520}$.

A vrai dire, à l'époque gothique, c'est l'Italie qui est le véritable champ de bataille entre l'art de Byzance et celui de l'Occident. C'est par son intermédiaire que l'art pathétique et pittoresque de Byzance éveille en Occident une nouvelle conception de l'art religieux. Mais, peut-on dire, cette imitation n'est pas un esclavage. Le cycle de peintures de la Chapelle de l'Arena à Padoue est symbolique à cet égard ${ }^{2521}$. L'iconographie de la vie de Jésus est toute byzantine, mais le génie de Giotto déborde ce cadre avec une telle puissance, qu'elle fait d'un poncif maintes fois reproduit, une création nouvelle. Ce n'est plus Byzance qui sert de guide.

\footnotetext{
2517 FOCILLON, op. cit., 51-57; L. BREHIER, Le Style roman, 64-65.

2518 EBERSOLT, Orient et Occident. Influences byzantines et orientales en France, II, 22-35.

2519 Ibidem, 81 et s. (par exemple à la cathédrale de Chartres).

2520 R. GROUSSET, Histoire de l'Orient latin. L'art roman et l'art gothique, dans H.G.M.A., IX, 1945; G. HILL, History of Cyprus, III : The fine arts, 117 et s.

${ }^{2521}$ Peinte par Giotto, 1305-1306; MILLET, Recherches sur l'iconographie de l'Évangile, 684-687; P. TOESCA, Storia dell'Arte Italiana, I, Turin, 1927, p. 914-1020.
} 


\section{Les influences (Orient)}

\section{$\underline{\text { Retour à la Table des Matières }}$}

L'influence de l'art byzantin s'est exercée plus profondément dans les pays d'Orient étrangers à l'hellénisme, surtout, comme il est naturel, dans ceux qui avaient reçu de Byzance des importations artistiques en même temps que le christianisme.

Art arabe. - L'art arabe à ses débuts, sous les Ommiades, fut tributaire de l'art byzantin. En Syrie le château de Qoçair' Amrah (première moitié du VIII siècle) est décoré de fresques, danseuses, musiciens, portraits de style hellénistique, telles qu'on pouvait en voir dans les palais byzantins ${ }^{2522}$. A Damas, dans la mosquée des Ommiades (ancienne église Saint-Jean-Baptiste), on a découvert des mosaïques murales de style tout pompéien. Ce sont des architectures légères, parfois irréelles, dans un cadre de verdure, parcs délicieux ombragés de grands arbres et arrosés de ruisseaux qui retombent en cascades. On n'y voit aucun être animé et ce serait l'œuvre d'artistes appelés de Constantinople ${ }^{2523}$. Enfin par son plan octogonal et son ornementation en mosaïques, la Coupole du Rocher (dite Mosquée d'Omar) à Jérusalem est un martyrion purement byzantin ${ }^{2524}$.

Art chrétien jacobite. - Cette subordination du premier art arabe à Byzance disparut sous les califes abbassides, avec la brillante renaissance des arts de l'Iran. La tradition de l'art chrétien se maintint sans doute dans les communautés jacobites de Syrie et de Mésopotamie, mais dans un décor tout musulman. Deux évangéliaires jacobites en langue syriaque, illustrés en Haute-Mésopotamie ${ }^{2525}$, montrent dans les tableaux de la vie du Christ un pittoresque mélange de traits byzantins et musulmans. Le Christ, la Vierge, les Apôtres, vêtus de leurs costumes traditionnels, sont entourés de personnages habillés de

${ }^{2522}$ DieHL, Manuel d'art byzantin, 345; DALton, Byzantine Art and Archaeology, 278-282; STRZYGOWSKI, Amra und seine Malereien, dans Z.B.K., 1908.

${ }^{2523}$ Eustache de LOREY, Les mosaïques du VIII ${ }^{e}$ siècle dans la mosquée des Omneyades à Damas (Cahiers d'art, IV, 1929), 7 et s.

2524 DIEHL, op. cit., 344; GRABAR, Martyrium, I, 289 (renferme la pierre d'Abraham).

2525 JeRPHANION, Les Miniatures du manuscrit syriaque n' 559 [achevé le 2 mai 1220 au monastère de Mar-Mattaï, près de Mossoul] de la Bibliothèque Vaticane, Introduction, et Brit. Museum, Syr. add. 7170 (entre 1216 et 1220); H. Buchthal, The painting of the Syrian Jacobites in his relations to byzantine and islamic Art, dans « Syria », 1939, 136-150. 
caftans, coiffés de turbans, au milieu d'architectures, de mobiliers, de paysages qui rappellent les miniatures musulmanes du même temps ${ }^{2526}$. Les mêmes traits ethniques sont attribués aux personnages sacrés, au Christ, aux Apôtres, comme aux Juifs : type arabe ou arménien au nez fort et busqué, type mongol aux yeux bridés, à la grosse tête, aux pommettes saillantes. Même caractère dans les attitudes (Caïphe assis, jambes croisées sur un divan, comme un cadi rendant la justice, Hérode trônant comme un sultan, ses soldats couverts de l'armure de la garde turque des califes), dans les fonds d'architecture (coupoles bulbeuses, murs aux menons fleurdelisés).

Mais à ce décor musulman correspond une iconographie toute byzantine, division tripartite de la vie de Jésus et ordonnance semblable des thèmes qui correspondent aux grandes fêtes. Les compositions attestent une véritable intrusion byzantine dans ce milieu d'art islamique. Les thèmes sont traités suivant les formules qui règnent à Byzance jusqu'au milieu du XIII siècle. C'est l'époque où l'iconographie en usage à Constantinople est introduite dans les églises rupestres de Cappadoce, où, suivant la chronique de Bar Hebraeus ${ }^{2527}$, une reine du pays fait venir deux peintres de Constantinople pour orner de fresques une église grecque, où les manuscrits illustrés dans les monastères de Grande Arménie et de Cilicie offrent des exemples de la version dite alexandrine des épisodes de la vie de Jésus ${ }^{2528}$. Mais cette dernière expansion de l'art byzantin en Orient devait se heurter à la résistance des traditions indigènes. Les Arméniens, comme les chrétiens Jacobites de Mésopotamie, pouvaient bien emprunter des thèmes iconographiques à Byzance, mais ils les interprétaient suivant leur génie national.

\footnotetext{
${ }^{2526}$ Par exemple celles des Séances de Hariri, Paris, arab. 6094 (a. 1221) et Hariri Schefer, Paris, arab. 5847 (a. 1237).

2527 BAR HeBraEus, Chronique syrienne (éd. et trad. Abeloos).

2528 Sur cette version MILLET, Recherches sur l'iconographie de l'Évangile, 564-568. — S. TER Nersessian, Manuscrits arméniens illustrés.., des Pères Mekhitaristes à Venise. Paris, 1937.
} 


\section{Péninsule des Balkans}

$\underline{\text { Retour à la Table des Matières }}$

Bulgarie. - Les Bulgares établis en Mésie au VII ${ }^{\mathrm{e}}$ siècle y apportèrent un art d'origine iranienne, caractérisé par des reliefs rupestres de dimensions colossales, une orfèvrerie barbare et des édifices aux murs revêtus de céramique émaillée. Leur conversion au christianisme introduit chez eux l'art byzantin, qui resta prédominant jusqu'à la conquête des Turcs : les églises bulgares, d'ailleurs mal conservées, en reflètent les diverses tendances sans beaucoup d'originalité. L'un des monuments les plus remarquables est l'église à double étage de Boïana, construite en 1259, dont le cycle iconographique de fresques et les beaux portraits des fondateurs et des souverains annoncent l'art plus libre qui va régner sous les Paléologues ${ }^{2529}$.

Serbie. - En Serbie au contraire, les maîtres byzantins trouvèrent une tradition indigène apparentée à l'art roman. Les églises de Rascie élevées au XII ${ }^{\mathrm{e}}$ siècle par Etienne Nemanja et son fils, saint Sava, sont à nef unique, surmontée d'une coupole qui s'appuie sur un massif carré ; une ornementation sculptée d'origine lombarde décore les fenêtres et les portails ${ }^{2530}$. Mais ce sont des maîtres byzantins qui couvrent de peintures l'intérieur de ces églises de Rascie: Stoudenitsa, Zitcha, Gradats. Dans le narthex de Zitcha les beaux portraits des fondateurs de l'État serbe accueillent les visiteurs. Les thèmes iconographiques sont ceux de l'art monastique de Cappadoce ${ }^{2531}$.

Puis au XIV ${ }^{\mathrm{e}}$ siècle, Miloutine et Étienne Douschan, conquérants de la Macédoine, veulent célébrer leurs victoires par des fondations grandioses et appellent de Constantinople des maîtres, qui construisent la grande église du monastère serbe de Chilandar au Mont Athos (vers 1300), la cathédrale de Prizrend (1307-1315), les églises de Nagoritchino (1312-1313), de Gratchanitsa (avant 1321). Des voiévodes imitent l'exemple des souverains (fondation de Lesnovo en 1341).

${ }^{2529}$ GraBAR, La peinture religieuse en Bulgarie (1928); du même : L'église de Boïana.
${ }^{2531}$ Millet, L'ancien art serbe. Les Églises (1919).
Ibidem, 89 et s.; N. OKUnEV, Monumenta artis Serbicae (Prague, 1928-32), III, 1-4. 
Dans toutes ces constructions apparaissent les procédés et les plans de l'école de Constantinople, les appareils décoratifs, les baies géminées et trilobées, les corniches de briques en dents de scie, le plan en croix grecque, mais les travaux ont été dirigés par des architectes serbes, qui ont interprété la tradition byzantine suivant leur génie national : narthex et sanctuaire inclus dans le corps principal de l'église, coupoles plus hardies, qui rompent l'équilibre savant des édifices grecs.

L'église de Nagoritchino se développe en longueur, celle de Gratchanitsa dresse vers le ciel une construction pyramidale : des hautes toitures de ses nefs s'élancent deux croix grecques superposées, couronnées par la coupole élancée, tandis qu'entre les bras de la croix inférieure, quatre coupoles secondaires complètent l'effet d'ascension échelonnée qui appelle l'aspect des églises de Rascie $^{2532}$.

Après la bataille de Kossovo la nationalité serbe se reconstitue dans la région des deux Morava et atteint la vallée du Danube par la possession de Belgrade. Ce n'est plus l'influence de Constantinople qui domine, mais celle de l'Orient. Le plan usuel redevient la nef unique des églises de Rascie, mais modifié par l'adoption du chœur tréflé des églises de l'Athos avec coupole centrale ${ }^{2533}$. La sculpturebroderie de l'Orient envahit le décor architectural ${ }^{2534}$.

Peinture murale. - Nous savons déjà que les églises fondées par les princes serbes en Macédoine furent décorées par une école dite macédonienne ou gréco-slave ${ }^{2535}$, remarquable par la netteté du dessin, l'éclat et la pureté des couleurs, l'harmonie de la composition. Mais dans l'église de Nagoritchino, où on a trouvé la signature du peintre grec Eutychios et la date de 1317, les thèmes iconographiques ne sont pas disposés en frises, mais forment des tableaux séparés.

C'est une école de peintres, d'un esprit assez différent, qui a travaillé à l'église de Lesnovo (Macédoine serbe), construite sous Étienne Douschan, de 1341 à 1349, par le despote Oliver, de nationalité grecque. Le coloris est plus sombre que celui de l'école macédo-

\footnotetext{
2532 Millet, op. cit., 97-120.

${ }^{2533}$ Ibidem, 152 et s.; L. BREHIER, L'art serbe et l'art roumain au Moyen Age, dans Starinara, Belgrade 1925 (en serbe) et dans R.S.E., 1926 (en français).

2534 Ibidem, 170 et s., 185-189.

2535 OKUNEV dans M.O., I, 2, 224.
} 
nienne. Le dessin est parfois hardi, mais souvent faible. Le cycle des Grandes Fêtes orne la partie centrale, tandis que d'autres cycles, des Miracles et de la Passion, sont très détaillés. Les sujets rares et compliqués, conformes aux goûts monastiques, sont particulièrement recherchés. C'est de la même école que relèvent les peintures des monastères de Marko et de Mateič ${ }^{2536}$.

\section{Pays roumains}

\section{Retour à la Table des Matières}

Les principautés roumaines, la Valachie et la Moldavie, pays de grand passage et d'invasions, ont reçu des influences nombreuses et variées, mais distinctes dans chacune des deux provinces. L'art valaque, le dernier venu dans les pays voisins de Byzance, n'a connu d'abord l'art byzantin que par l'intermédiaire des moines serbes qui essaimaient au-delà du Danube au XIV ${ }^{\mathrm{e}}$ siècle et importaient leur architecture nationale: les églises de Rascie à nef unique ${ }^{2537}$. Ce fut seulement après la création, par le patriarche de Constantinople, d'une métropole en Valachie (1359) ${ }^{2538}$, que le prince Alexandre fit construire, dans sa nouvelle capitale d'Argès, une église dédiée à saint Nicolas avec le concours de maîtres byzantins ${ }^{2539}$. Le plan est en croix grecque, comprenant le narthex, la nef couverte d'une coupole que contrebutent au nord et au sud les berceaux des bas-côtés, et le sanctuaire à trois absides. Par contre, la coupole à seize pans, sur tambour cylindrique, émerge d'un massif carré d'origine serbe ${ }^{2540}$.

Mais l'œuvre des maîtres byzantins apparaît surtout dans le bel ensemble de fresques narratives qui tapissent l'intérieur de l'église. Les épisodes de l'Enfance du Christ ont les plus grands rapports avec les mosaïques de Kahrié-Djami. Ce sont les mêmes sujets, dont quelquesuns, assez rares, comme le Recensement devant Quirinus, les mêmes

\footnotetext{
2536 Ibidem, 257 et s.; PetKovič, La peinture serbe du Moyen Age, I, pl. 120-131; OKUnEV, Monumenta artis Serbicae, III, 5-11 et IV, 8-10.

2537 IORGA et BALŚ, L'art roumain (Paris, 1922); BALŚ, Influence du plan serbe sur le plan des églises roumaines, dans M.O., I, 277-294.

2538 M.B.E.H. (Institutions), 1970, 378-379.

2539 Curtea Domneasca din Argeś, Bucarest, 1947, B.C.M.I. (œuvre collective); TAFrALI, Monuments byzantins de Curtea de Argeś (Sofia, 1927).

2540 GHIKA-BuDEŚTI, Evolutia Architecturii in Muntenia (Bucarest, 1947), I.
} 
attitudes, les mêmes fonds de paysages. Il n'y a de variantes que dans les costumes (hommes d'armes à cottes de mailles devant le trône d'Hérode), et dans le style qui est moins ferme ${ }^{2541}$.

Ce premier contact avec l'art de Byzance devait être fécond. Bien que l'architecture serbe ait continué à se développer en Valachie (monastère de Cozia, 1387) et ait même atteint la Moldavie ${ }^{2542}$, l'influence byzantine survécut dans l'art valaque à la chute de Constantinople et s'étendit à toutes les techniques, icônes, sculpture sur bois, arts somptuaires, non sans mélange d'ailleurs avec les apports de l'Orient asiatique ${ }^{2543}$.

L'art de la Moldavie semblait devoir être réfractaire à toute influence byzantine. Son architecture indigène ne connaissait d'autres matériaux que le bois et la brique. De Hongrie et de Pologne lui vint l'art gothique flamboyant et, au point de vue religieux, ses princes hésitèrent longtemps entre le catholicisme romain et l'orthodoxie byzantine. Ce fut par l'iconographie et les arts somptuaires que l'art byzantin pénétra en Moldavie et que des cycles de peintures murales couvrirent l'intérieur et même l'extérieur de ses églises ${ }^{2544}$. Une visite au monastère de Poutna (Bucovine), fondé par l'un des plus grands souverains qui aient régné en Roumanie, Etienne le Grand (1457-1504), permettait naguère d'admirer, dans un merveilleux trésor, une accumulation de vases sacrés, d'objets liturgiques, d'étoffes brodées, au milieu d'un ruissellement de perles et de pierres précieuses, œuvre des derniers artistes qui possédaient encore le secret des techniques de Byzance ${ }^{2545}$.

\footnotetext{
${ }^{2541}$ IORGA et BALŚ, op. cit., 11 et s.

${ }^{2542}$ BALŚ, loc. cit., $277-294$.

${ }^{2543}$ N. IORGA, Les arts mineurs en Roumanie (Bucarest, 1934); STEFANESCU, La peinture religieuse en Valachie et en Transylvanie (Paris, 1932).

$2544 \mathrm{P}$. HenRY, Les églises de la Moldavie du nord, des origines à la fin du XVI siècle (Paris, 1930); StefanesCU, L'évolution de la peinture religieuse en Bucovine et en Moldavie (Paris, 1927).

2545 O. TAFRALI, Le trésor byzantin et roumain du monastère de Poutna (Paris, 1925).
} 


\section{Russie}

\section{$\underline{\text { Retour à la Table des Matières }}$}

Nous avons vu que l'art byzantin avait été importé en Russie avec le christianisme ; dès le milieu du XI ${ }^{\mathrm{e}}$ siècle, Sainte-Sophie de Kiev et sa décoration de mosaïques servent de modèle à de nombreuses constructions, dues à des Grecs au service des grands princes. Déjà cependant des Russes sont initiés à l'architecture et bâtissent des églises en bois, qui imitent plus ou moins les plans byzantins : croix grecque avec abside saillante, coupole remplacée par un toit pyramidal. Mais ce sont des architectes de Constantinople qui construisent les églises de Tchernigov $(1131,1169)$, dont les coupoles élancées forment le principal élément décoratif ${ }^{2546}$. De 1045 à 1052, le fils du grand prince Iaroslav fait construire à Novgorod une cathédrale, placée comme celle de Kiev sous le patronage caractéristique de sainte Sophie $^{2547}$. Des peintres indigènes, comme le moine Alympii (fin du XI siècle), se forment à l'école des maîtres byzantins ${ }^{2548}$.

Après l'invasion des Mongols, qui ruina Kiev (1240), la suprématie politique passa à Novgorod, république commerçante en relations avec le monde germanique ${ }^{2549}$, avec Constantinople et les pays du Caucase. Une puissante école d'art s'y développa, encore byzantine d'inspiration ; mais on y voit déjà se manifester l'originalité du génie russe dans la simplification des plans d'églises et la forme bulbeuse donnée aux coupoles ${ }^{2550}$.

$\mathrm{Au} \mathrm{XI}$ e siècle, de la colonisation russe dans la vallée de la Volga, naît la principauté de Souzdalie, avec ses villes importantes (Souzdal, Vladimir, Iaroslav). L'art de cette région subit d'autres influences que celle de Constantinople. Les églises sont construites en pierre et reçoivent à l'extérieur une décoration sculptée, parfois exubérante, comme la célèbre frise iconographique de la cathédrale Saint-Georges

\footnotetext{
2546 L. REAU, L'art russe, des origines à Pierre le Grand (1921), 110 et s.

2547 Marque d'allégeance envers le patriarcat de Constasitinople dans tous les pays rattachés à Byzance. L. BREHIER, op. cit., 124 et s.

2548 Ibidem, 109-111.

2549 Agrégée à la Hanse.

${ }^{2550}$ L. REAU, op. cit., 128-133. Les inscriptions en grec deviennent plus rares.
} 
de Iouriev-Polski (1230-1234) ${ }^{2551}$, page de sculpture-broderie, avec figures de saints sous des arcs en accolade, qui ne peut avoir pour auteur qu'un maître arménien.

Les Mongols ruinèrent, en 1238, les villes de Souzdalie et ce fut Moscou qui recueillit leur héritage. La ville médiocre, mentionnée pour la première fois en $1147^{2552}$, remplaça Vladimir comme capitale politique et religieuse. Le grand prince Ivan Kalita (1328-1340) ${ }^{2553}$ bâtit sur le Kremlin la cathédrale de la Dormition; saint Serge fonda le monastère de la Trinité (Troïtaki) ${ }^{2554}$. Mais ce fut seulement après la prise de Constantinople que Moscou devint la véritable capitale de la Russie. Le mariage d'Ivan III avec Sophie Paléologue en fit la nouvelle Byzance, la troisième Rome, mais les architectes italiens amenés par la nouvelle tsarine allaient entraîner l'art russe vers de nouveaux destins ${ }^{2555}$.

Écoles de peinture. - A la différence de l'architecture, la décoration picturale des églises russes a continué à montrer son attachement aux modèles byzantins. Du XII ${ }^{\mathrm{e}}$ au XV $\mathrm{XV}^{\mathrm{e}}$ siècle, à l'activité architecturale des écoles de Novgorod et de Souzdalie, correspondit une école de peinture dont les maîtres, Grecs ou Russes formés à leur école, ont reproduit dans les églises les cycles liturgiques et narratifs de la peinture byzantine ${ }^{2556}$.

A défaut des peintures disparues de Sainte-Sophie de Novgorod, on voit que celles de l'église voisine de Néréditsi (1199) et surtout celles de la cathédrale de Vladimir, fondée en 1194, se rattachent à l'art de l'époque des Comnènes. A Néréditsi, la multitude des personnages aux figures régulières, la majesté des frises de saints, la splendeur de la coupole, au sommet de laquelle le Christ occupe le centre d'une sphère portée par six anges en plein vol, et les cycles narratifs de la vie de Jésus, évoquent le décor d'un sanctuaire byzantin ${ }^{2557}$.

\footnotetext{
2551 Ibidem, 219 et s.; ROMANOV dans M.O., II, 54 et s.

2552 RAMBAUD, Histoire de Russie, 159.

2553 Ibidem, 163-167.

2554 L. REAU, op . cit., 228 et s. Les cathédrales du Kremlin furent rebâties à la fin du XV siècle.

2555 RAMBAUD, op . cit., 200-203; L. REAU, L'art russe, des origines à Pierre le Grand, 232-248.

2556 L. REAU, op. cit., 168 et s.

2557 EBERSOLT, Fresques byzantines de Néréditsi, F.E.P.M., XIII, 1906, p. 1-23; L. REAU, op. cit., $170-172$.
} 
Très supérieures par leur style sont les fresques de Vladimir, dégagées du stuc en 1918. Le coloris est riche et harmonieux; les visages sont modelés en bleu-vert. Un Jugement Dernier montre les Apôtres assis sur des trônes avec des anges derrière eux. Les têtes sont vivantes et énergiques; au lieu de leurs draperies traditionnelles, ils portent le costume ecclésiastique ${ }^{2558}$.

$\mathrm{Au} \mathrm{XIV}{ }^{\mathrm{e}}$ siècle, époque d'apogée de l'art de Novgorod, les peintures de ses églises sont en rapport avec l'art de Kahrié-Djami et de Mistra. L'œuvre des peintres grecs est mentionnée dans les chroniques et l'on attribue à l'un d'eux, Théophane, les peintures de l'église de la Transfiguration ${ }^{2559}$. Il eut pour disciple le célèbre André Roublev (1370-1430?), originaire de Pskov, qui alla travailler à Vladimir et à Moscou, mais les décors qu'il y exécuta ont péri par le pinceau des restaurateurs. On ne connaît plus de lui que l'icône de la Trinité déjà signalée ${ }^{2560}$.

Arts somptuaires. - Les peintures des manuscrits et des icônes, comme la peinture murale, attestent l'influence byzantine sur l'art russe. Dans les manuscrits, le style arménien avec ses décors d'entrelacs et d'ornements géométriques se substitue souvent aux thèmes byzantins. L'Évangile d'Ostromir, écrit à Novgorod en 1056, par le diacre Grégoire, ressemble à un travail byzantin, avec ses portraits des Évangélistes et des vignettes qui ont les tons d'un émail ${ }^{2561}$. Une curieuse habitude est celle des frontispices monumentaux des manuscrits religieux, qui représentent la coupe transversale d'une église à plusieurs coupoles. Ce n'est d'ailleurs que l'imitation des frontispices de certains manuscrits byzantins ${ }^{2562}$. Un des plus anciens exemples de ce décor, dans un manuscrit russe, est daté de $1073^{2563}$. $\mathrm{Au} \mathrm{XII}{ }^{\mathrm{e}}$ siècle, le motif s'altère et devient irréel. Deux siècles plus tard, il est métamorphosé en ornement oriental, garni d'entrelacs, de mons-

\footnotetext{
${ }^{2558}$ L. REAU dans M.O., II, 68 et s.

2559 L. REAU, L'art russe, des origines à Pierre le Grand, 173-175. Sur les travaux attribués à Théophane le Grec, NEKRASOV, Les frontispices architecturaux dans les manuscrits russes..., M.O., II, 271.

2560 AlPATOFF, La Trinité dans l'art byzantin et l'icône de Roublev (Paris, 1927), regardée communément comme représentant l'École de Moscou.

2561 Passe pour le plus ancien manuscrit russe à miniatures. Bibliothèque de Léningrad.

2562 Voir supra et L. BREHIER, Les miniatures des Homélies du moine Jacques et le théâtre religieux à Byzance, F.E.P.M., XXIV, 1921 : frontispice des deux manuscrits de ces Homélies, Vatic. gr. 116 et Paris, gr. 1208, XII siècle.

2563 NEKRASOV, Les frontispices architecturaux dans les manuscrits russes, 253.
} 
tres, de coupoles bulbeuses, d'arcs en accolade; puis à la fin du XIV siècle, Théophane le Grec remet en honneur le style hellénique et dessine des coupes de Sainte-Sophie de Constantinople, qui excitent l'admiration de ses contemporains et sont reproduites dans des manuscrits russes du XV $\mathrm{Xv}^{\mathrm{e}}$ siècle ${ }^{2564}$.

Les icônes pénétrèrent en Russie dès la conversion de saint Vladimir, qui en enleva plusieurs de Kherson pour orner ses églises ; mais avec les icônes importées de Constantinople, il en vint beaucoup d'Orient, et il se forma une école de peintres d'icônes dans les monastères russes ${ }^{2565}$. En s'inspirant des traditions byzantines, ils manifestèrent certaines tendances originales, un effort de simplification dans le modelé des figures et une subordination des personnages à un ensemble. L'adoption de l'iconostase acheva de préciser cette nouvelle interprétation. En 1386, Athanase, higoumène d'un monastère voisin de Moscou, fit venir de Constantinople sept grandes icônes représentant la Deisis, deux archanges, les saints Pierre et Paul. Cet ensemble devint le motif central d'une iconostase ${ }^{2566}$. Jusque-là il n'y avait aucune liaison entre les figures, qui regardaient toutes le spectateur : désormais elles se tournent vers le Christ, unies dans la même prière.

$\mathrm{Au} \mathrm{XIV}$ siècle le style Paléologue fit sentir son influence sur l'icône russe : dès sa formation, Moscou et Novgorod rivalisèrent pour appeler des maîtres byzantins et importer des icônes, mais l'assimilation du nouveau style ne fut pas la même. A Novgorod ce furent des modèles des provinces orientales qui pénétrèrent. A Moscou, par suite des rapports entre les princes et le clergé de Constantinople, l'influence de l'art Paléologue se fit sentir directement ${ }^{2567}$. Il en résulte de grandes différences entre les icônes sorties des ateliers de Moscou, comme la Trinité de Roublev, et celles de Novgorod. Le même sujet d'origine byzantine, traité par les deux écoles, est instructif à cet égard. Il s'agit du miracle hebdomadaire de la Vierge des Blachernes à Constantinople. L'icône moscovite reproduit les coupoles élancées, beaucoup plus byzantines que russes ; les figures sont bien groupées, le geste large d'André le Fou, qui se retourne vers ses disci-

Ibidem, 272-281.

2565 WulfF et AlPATOV, Denkmäler der Ikonenmalerei (Dresde, 1925), 84.

2566 Ibidem, 92 et s.; L. BREHIER, Les icônes dans l'histoire de l'art et la Russie, 165 et s.

2567 WulfF et AlPatov, op. cit., 151. C'est à ce moment que Théophane le Grec vient en Russie 
ples pour leur montrer l'apparition de la Vierge, est des plus expressifs. Les mêmes détails sont reproduits sur l'icône novgorodienne, mais traités dans un tout autre esprit. A la clarté qui émane de l'apparition et illumine les assistants, se substitue une peinture plate. Les figures, moins bien groupées, ont des gestes monotones et peu expressifs. Les architectures à coupoles bulbeuses sont russes. Cette icône représente une ancienne tradition, tandis que celle de Moscou est conforme au style Paléologue ${ }^{2568}$.

Retour à la Table des Matières

2568 Ibidem, 55 et s., fig. 55; L. BREHIER, op. cit., 168 et s., fig. 55 et s. 


\section{Conclusion}

\section{Retour à la Table des Matières}

Au terme de nos études sur le monde byzantin, l'enquête que nous avons entreprise sur la civilisation, qui eut Constantinople pour foyer principal pendant un millénaire, ne démentit pas nos conclusions précédentes.

La société byzantine était européenne par ses institutions familiales, par son attachement aux traditions antiques, comme le culte des morts, par sa langue et sa culture helléniques. Elle n'en avait pas moins emprunté à l'Orient quelques-uns de ses traits les plus caractéristiques : la réclusion des femmes, les modes vestimentaires, la coiffure des deux sexes, le goût de la parure, des couleurs éclatantes, des étoffes somptueuses, des bijoux, des perles, des pierreries. C'était de l'Asie que venaient les supplices cruels, les superstitions, la magie, l'astrologie, les doctrines manichéennes qui mettaient l'orthodoxie en péril.

Il en résultait que les Orientaux immigrés dans l'Empire ne s'y trouvaient pas dépaysés et adoptaient assez facilement les mœurs de leur nouvelle patrie. Il en était d'ailleurs de même des Grecs qui parcouraient l'Orient, soit pour s'y fixer (il y eut pas mal de renégats à certaines époques), soit pour leur commerce, soit comme diplomates, soit, comme le trop fameux Andronic Comnène, pour y chercher des aventures. Des échanges continuels d'hommes, d'idées, de produits, d'inventions avaient lieu entre Byzance et les pays asiatiques : nous en avons cité de nombreux exemples. 
Et pourtant ce qui frappe dans cette société mixte, c'est que la part de l'Europe l'emporte sur celle de l'Asie. Si les femmes sont confinées dans le gynécée, la maison familiale ne ressemble pas aux logis orientaux entourés de hautes murailles, mais a sur la rue de larges ouvertures. L'art byzantin, asiatique par ses origines, s'est transformé grâce aux inspirations puisées dans l'étude des chefs-d'œuvre de l'antiquité grecque. Si la poésie rythmique a été transmise à Byzance par la Syrie, les thèmes traités par les mélodes exaltent la puissance de l'Empire et la protection divine accordée au basileus. De même, l'épopée de Digénis Akritas a reçu dans une certaine mesure son inspiration de chants arabes, mais le cadre qu'elle décrit et les sentiments qu'elle exprime viennent de Byzance. La dette de ses auteurs vis-à-vis de l'Orient n'est guère plus lourde que celle de Corneille envers l'Espagne.

Et, si l'on veut apprécier la place que la civilisation byzantine tient dans l'histoire du monde, c'est sa culture intellectuelle, entièrement hellénique et européenne, qu'il faut surtout considérer. C'est grâce à ses écrivains, aussi bien à ses grammairiens qu'à ses penseurs, que la langue hellénique s'est conservée. Byzance fait figure, au moyen âge, d'une nouvelle société hellénistique, mais plus riche d'inspirations que celle d'Alexandrie. Nous avons essayé de déterminer la part immense qui lui revient dans la renaissance de l'humanisme occidental. C'est un fait incontestable qu'avant la chute de Byzance, des Italiens sont venus s'initier à la connaissance des chefs-d'œuvre de l'antiquité classique auprès des derniers maîtres de l'Université Impériale, dont quelques-uns, comme Chrysoloras, furent appelés à enseigner le grec en Italie.

Si importants cependant que soient ces échanges, c'est après 1453 que Byzance a vraiment mis l'Occident en possession de son héritage intellectuel. Pendant la dernière moitié $d u \mathrm{XV}^{\mathrm{e}}$ siècle et le premier tiers du XVI ${ }^{\mathrm{e}}, 1^{\prime}$ hellénisme fit littéralement la conquête de l'Europe. Fuyant la domination turque, les derniers lettrés de Byzance apportaient avec eux leurs trésors de nouveaux manuscrits et leur érudition. Jusque-là le grec n'était encore enseigné que dans quelques villes d'Italie. Il n'y eut pas désormais un seul pays qui ne voulût posséder une chaire de grec. Les fondations se présentaient sous des aspects variés qui rappe- 
laient la liberté des fondations byzantines et contrastaient avec la rigidité des règlements universitaires.

Ce furent surtout des réfugiés qui donnèrent les premiers cet enseignement et formèrent les plus célèbres représentants de l'humanisme occidental, un Reuchlin, un Erasme, un Guillaume Budé, auditeurs d'Hermonyme de Sparte à Paris en 1478. Reuchlin suivit aussi les cours de Jean Argyropoulos, le plus éminent des derniers professeurs de l'Université Impériale, réfugié en France en 1456 et pourvu d'une chaire à Rome.

Mais le centre de cette propagande hellénique était le palais du cardinal Bessarion à Rome. Véritable providence de ses compatriotes sans ressources, il les tirait de la misère et les recommandait aux princes et aux évêques. Il présidait l'Académie fondée par Nicolas $\mathrm{V}$, où Théodore de Gaza, Georges de Trébizonde rencontraient le Pogge et Laurent Valla et où s'échangeaient parfois des propos d'une singulière hardiesse. Le legs de la riche bibliothèque du cardinal à la Seigneurie de Venise en 1467 fut le dernier service que cet illustre représentant de Byzance rendit à la cause de l'humanisme.

Après la mort de Bessarion en 1472, le mouvement ne se ralentit pas et ce fut la première génération des hellénistes occidentaux qui en prit la direction. En 1515, sur les conseils d'Erasme, le pape Léon X fondait à Rome un gymnase hellénique. En 1519, le grec était enseigné à Cambridge, à Oxford, dans les Pays-Bas, où un mécène créait à Louvain le Collège des Trois Langues (latin, grec, hébreu), en France, où le roi François $\mathrm{I}^{\mathrm{er}}$ appelait l'un des derniers Grecs réfugiés, JeanAndré Lascaris, et dressait avec lui les plans d'un Musaeon (en souvenir de l'Université byzantine), qui allait dans la suite devenir le Collège de France. Le même prince réunit à Fontainebleau une bibliothèque qui comptait en 1542 un fonds de 546 manuscrits grecs.

Mais depuis longtemps l'imprimerie augmentait la diffusion des auteurs grecs et les préservait d'un nouveau naufrage. Des Grecs réfugiés furent les premiers correcteurs des textes grecs imprimés, d'abord à Rome, puis à Milan, où Jean Lascaris imprima sa Grammaire Grecque (1476-1480) et où l'historien Chalkokondylès publia en 1488 la première édition des Poèmes d'Homère. Il eut pour auxiliaire et disci- 
ple Alde Manuce 1'Ancien, qui alla fonder sa célèbre imprimerie à Venise, mais ne put l'exploiter qu'à partir de 1515. En France les éditions grecques étaient la spécialité de l'Imprimerie Royale, fondée par François $\mathrm{I}^{\mathrm{er}}$ en 1539 et dirigée par Robert Estienne.

Si l'on veut bien réfléchir à la portée de ce vaste mouvement de pensée qui a changé la face du monde, on sera obligé d'avouer qu'il est lié étroitement à l'œuvre intellectuelle de Byzance et que l'érudition occidentale vit depuis le $\mathrm{XV}^{\mathrm{e}}$ siècle sur les travaux des philologues byzantins. On peut dire que dans la chaîne continue qui relie les penseurs des temps modernes à ceux de la Grèce ancienne, il y aurait un singulier hiatus si Byzance n'avait sauvé de la destruction les trésors de la civilisation antique et lutté pendant mille ans pour les conserver à l'humanité.

Fin du texte 


\section{Table des références bibliographiques}

Retour à la Table des Matières

\section{ABRÉVIATIONS}

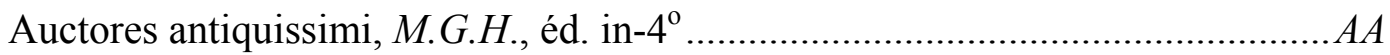

Annuaire de l'Association des Etudes grecques .......................................AAEG

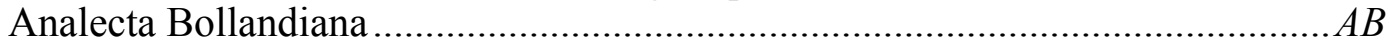

Almanach de Brioude ................................................................................... $\mathrm{ABr}$

Art Bulletin (The). Chicago ........................................................................ABull

Actes des Congrès internationaux des Études byzantines (1924-1948, VII Ses-

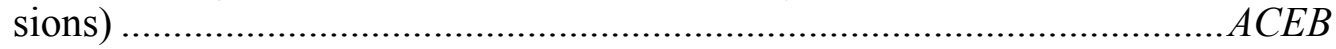

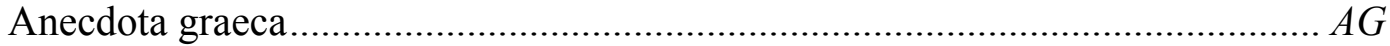

Annales d'histoire économique..............................................................AHE

Académie des Inscriptions et Belles-Lettres, Comptes rendus des séances .....AICR Annales de 1'Institut Kondakov, Prague .............................................................AIK Annuaire de l'institut de philologie et d'histoire orientale de l'Université de Bruxelles...................................................................................................

Archives de l'Orient chrétien de l'institut des RR. PP. Assomptionnistes...AIOChr

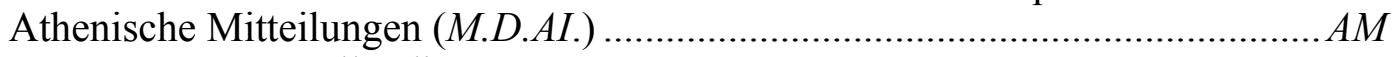

Acta Sanctorum Bollandiana ................................................................... ASB

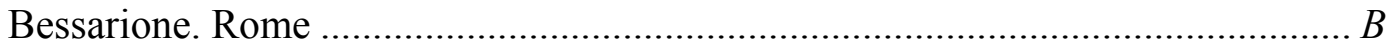

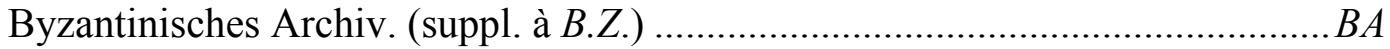

Bulletin de l'Académie de Belgique. Classe des Arts ...................................BABA

Bulletin de l'Académie de Belgique. Cl. des Lettres...................................... $B A B L$

Bulletin archéologique du Comité des Travaux Historiques ....................... BACTH Bayerische Akademie der Wissenschaften, philosophische-philologische Klasse

Bulletin de Correspondance Hellénique .......................................................BCH

Buletinul Comisiunii Monumentelor Istorice. Bucarest ................................ BCMI

Bibliothèque de l'École des Chartes ............................................................ BEC

Bibliothèque de l'École Française d'Athènes.............................................BEFA

Bibliothèque de l'École Française de Rome ............................................... BEFR

Bibliothèque de l'École des Hautes Etudes ...............................................BEHE

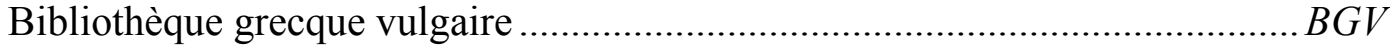

Bulletin de la section historique de l'Acad. Roumaine................................BHAR

Bibliographie Hellénique (Legrand) .......................................................... BHL

Bulletin de l'institut Français d'Archéologie orientale. Le Caire ..................... BIFC 


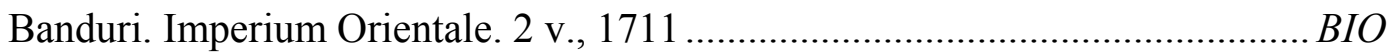

Belles-Lettres (Les). Editions Guillaume Budé .............................................. $B L$

Bibliotheca Medii Aevi............................................................................. BMAe

Byzantion. Bruxelles....................................................................................

Byzantinisch.-Neugriechische Jahrbücher ................................................... BNI

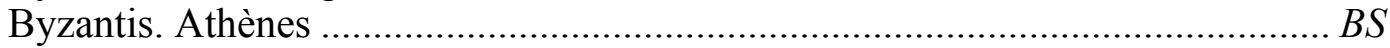

Bulletin de la Société des Antiquaires de France......................................... BSAF

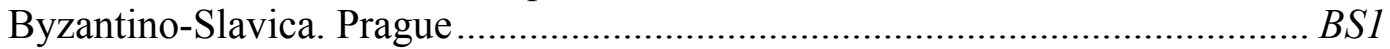

Byzantinische Zeitschrift .......................................................................... BZ

Correspondant (Le). Paris ..................................................................

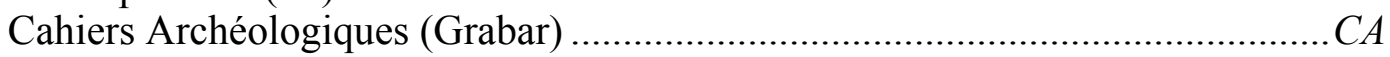

Collection byzantine de l'Association Guillaume Budé............................... $C B B$

Corpus Bruxellense historiae byzantinae.................................................. CBHB

Classiques de 1'Histoire de France au moyen âge .........................................CHF

Corpus iuris civilis Iustiniani, éd. Schœll (Code = C.J.; Digeste $=$ Dig.; Institutes

$=$ Inst $;$ Novelles $=$ Nov. $)$.................................................................... CICI

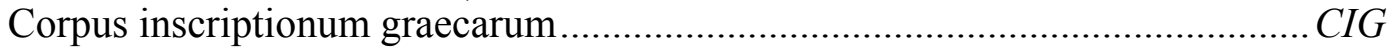

Corpus inscriptionum latinarum .......................................................................

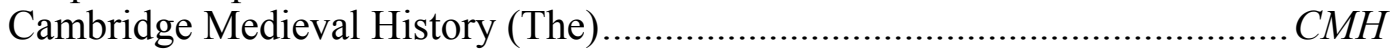

Corpus Scriptorum historiae byzantinae Bonnae, 1828-1878 ..................... CSBB

Corpus Scriptorum historiae byzantinae (Byzantine du Louvre, 1648-1819) . CSBL

Corpus Scriptorum ecclesiasticorum latinorum (Académie de Vienne, Autriche.....

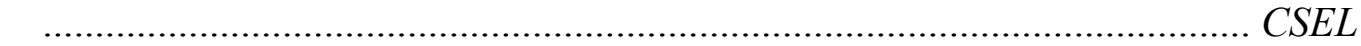

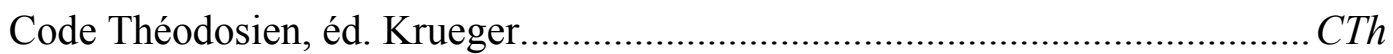

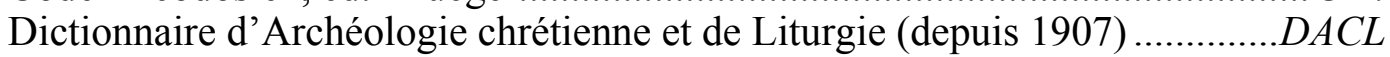

Du Cange. Glossarium ad scriptores mediæ et infimæ græcitatis, 1688 ......... DGG

Du Cange. Glossarium ad scriptores mediæ et infimæ latinitatis, éd. de 1883 .DGL

Dictionnaire d'Histoire et de Géographie ecclésiastiques (depuis 1912) .......DHGE

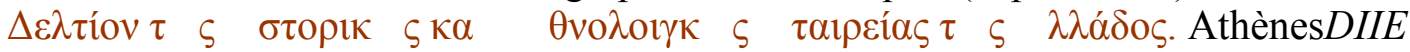

Dumbarton Oaks Papers. Washington ...........................................................DOP

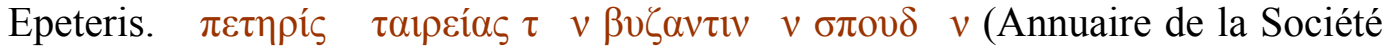

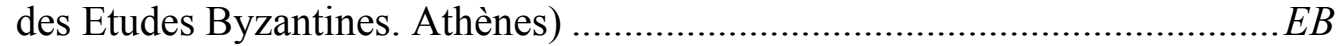

Évolution de 1'Humanité (L') (H. Berr.)........................................................ EH

Échos d'Orient (RR. PP. Assomptionnistes) ................................................E EO

Encyclopédie théologique (Migne) .............................................................

Fondation Eugène Piot. Monuments et mémoires publiés par l'Académie des Inscriptions.

FEFM

Fragmenta historicorum graecorum. éd. Muller (C.) 5 v. Paris, 1870, $2^{\mathrm{e}}$ éd. 1883

Gazette des Beaux-Arts.

FHG

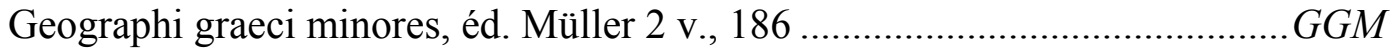

Histoire de l'Art Byzantin (Ch. Diehl) .......................................................... HAB

Historiens des croisades (Recueil des) ........................................................HC

Histoire générale de l'Art (G. Huisman)......................................................HGA

Histoire générale (Glotz). Histoire ancienne .............................................HGHA

Histoire générale (Glotz). Moyen Age........................................................ HGMA

Itinera Hierosolymitana, C.S.E.L. 39 .......................................................IH 
Izviestiia Rousskago Archeologitcheskago Instituta v'Konstantinopol (Bulletin de

l'Institut Archéologique russe de Constantinople) ..........................................IRI

Itinéraires russes (Société de l'Orient latin).............................................IRSOL

Journal asiatique ......................................................................................

Journal of Hellenic Studies .......................................................................... JHS

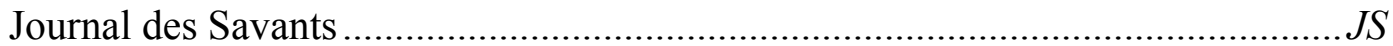

Langlois. Collection des historiens anciens et modernes d'Arménie, 2 v., 18671869

LHA

Mélanges d'archéologie et d'histoire (École Française de Rome) .....................MAH

Mélanges Bidez, Bruxelles .......................................................................MB

Monde Byzantin (Le) Vie et Mort de Byzance, éd. 1969; Les Institutions, éd. 1970

(L'Évolution de l'Humanité)..................................................................

Mansi (J. D.) Sacrorum Conciliorum amplissima collectio, 1759-1798, 31 v ....MC

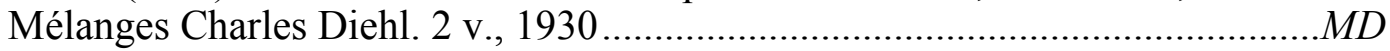

Mitteilungen des deutschen archäologischen Instituts........................................

Mélanges de l'École Roumaine en France......................................................ERF

Monumenta Germaniae Historica. Scriptores.............................................

Mélanges Nicolas Iorga. Paris, 1933 ..............................................................

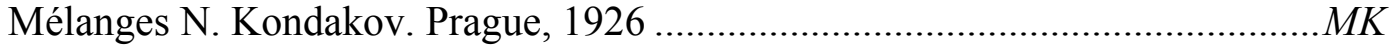

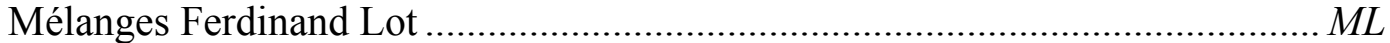

Miklosich et Müller. Acta et diplomata graeca medii aevi. 6 v. Vienne, 1860-1890

.MM

Mélanges F. Ouspensky. L'art byzantin chez les Slaves, 2 tomes en 4 vol. 19301932

$M O$

Mélanges Sir A. W. Ramsay, Manchester, 1923 ..............................................

Mémoires de la Société des Antiquaires de France ..........................................MSAF

Mélanges G. Schlumberger, 1924...............................................................Schl

Missions Scientifiques (Rapports, nouvelle série)..........................................Scien

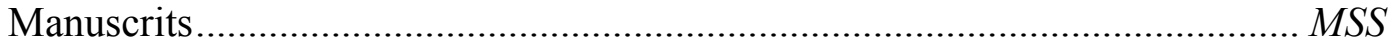

Mélanges Joseph Strzygowski ........................................................................

Mélanges de l'Université Saint-Joseph de Beyrouth ...........................................

Mémorial Louis Petit. Bucarest, 1948 ..................................................... MemLP

Miscellanea G. de Jerphanion, 2 v., Rome, 1947 ..............................................

Notices et extraits des manuscrits de la Bibliothèque Nationale .......................NEM

Neos hellenomnemon (Sp. Lambros, Athènes, 1904-1930) ..................................

Orientalia Cristiana periodica. Rome. Institut Pontifical des Études Orientales . OC

Patrologiae cursus Migne. Series graeco-latina .............................................. $P G$

Patrologiae cursus Migne. Series latina …………………………………... $P L$

Patrologia Orientalis (Graffin et Nau) ...........................................................PO

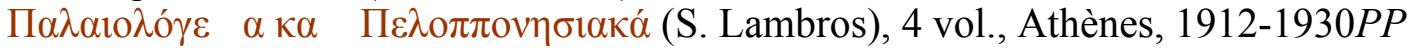

Revue Archéologique..............................................................................RA

Revue de l'Art (ancienne Revue des arts anciens et modernes) ..................... RAAM

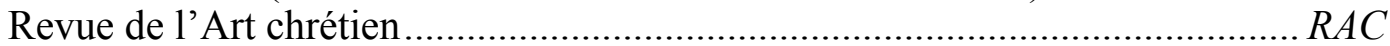

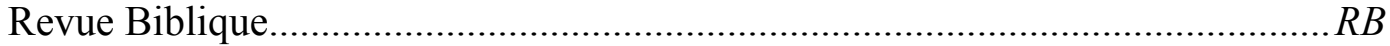

Revue belge de l'Instruction Publique ..........................................................

Revue belge de Philosophie et d'Histoire .........................................................

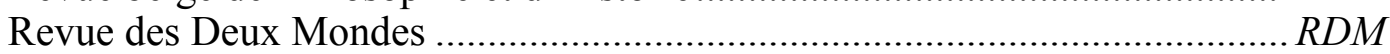

Revue des Etudes Byzantines (suite des E.O. depuis 1943) .......................... REB 


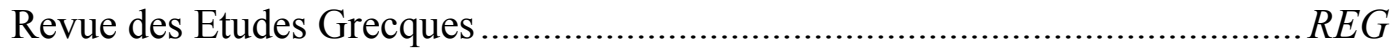

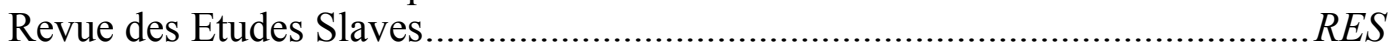

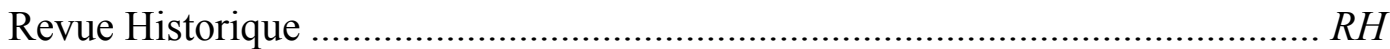

Revue d'Histoire ecclésiastique (Louvain) ..................................................... RHE

Recueil des Historiens des Gaules et de la France........................................ RHF

Revue de l'Histoire des religions......................................................... RHR

Revue internationale de l'Enseignement Supérieur..........................................RIE

Rerum italicarum Scriptores (Muratori) ……….......................................... RIS

Regesten der Kaiserurkunden des oströmischen Reiches (F. Dölger)............ RKOR

Revue de Numismatique .......................................................................... RN

Revue de l'Orient Chrétien ......................................................................ROC

Revue de l'Orient Latin ........................................................................ ROL

Regestes des actes du Patriarcat byzantin. I. Actes des patriarches (V. Grumel)

Revue d'histoire et de philosophie religieuses de la Faculté de théologie protes-

tante de l'Université de Strasbourg ...................................................... RPPS

Revue des Questions Historiques............................................................... $R \mathrm{RH}$

Revue historique du Sud-Est européen, Bucarest ..........................................RSE

Revue des Sciences Religieuses............................................................RSR

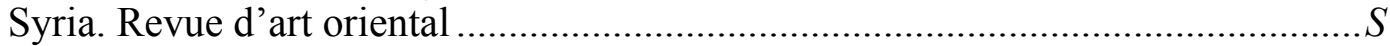

Studi bizantini e neocilenici. Rome (S.G. Mercati) ......................................SBN

Seminarium Kondakovianum. Prague .......................................................... $S K$

Société Orthodoxe de Palestine ................................................................... SOP

Speculum. A Journal of mediaeval Studies, published by the Mediaeval Academy

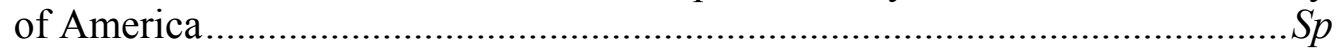

Scriptores rerum langobardicarum. M.G.H., in- $4^{\circ}$...................................... SRL

Traditio. Studies in ancient and mediaeval History, Thought and Religion. New

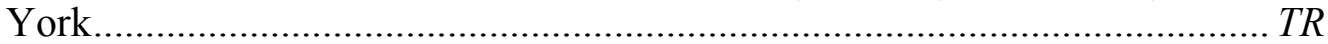

Travaux de l'Académie nationale de Reims ................................................TAR

Villes d'art célèbres (H. Laurens) .................................................................. VAC

Vizantiskoe Obozriénié (Revue Byzantine). Hegel. Iouriev, 1914-1915 ............ VO

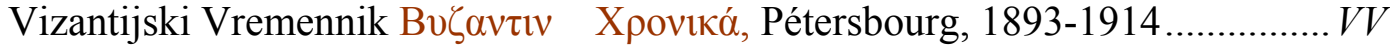

Zeitschrift für bildende Kunst. Vienne ....................................................... ZBK

Zachariae von Lingenthal. Geschichte des griechisch-römischen Rechts, $3^{\mathrm{e}}$ éd.,

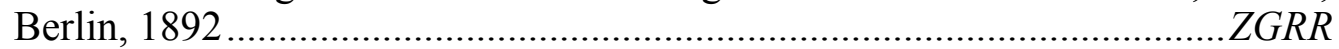

Zhurnal ministerzva narodnago prosveshcheniya (Journal du Ministère de l'Inst.

Pub.), Pétersbourg

$Z M P N$

\section{SOURCES CONSULTÉES}

ABOUlfEDA, Géographie, XIV ${ }^{\mathrm{e}}$ s., trad. fr. Reinaud (M.), 2 v., 1848.

Aснмет, veıрокрıєıкóv (clef des songes), vers 820, éd. Rigault, Paris, 1603.

Actes grecs des saints anargyres, éd. Dübner (voir Maas, B.Z., 1908, 603).

Actes des 42 martyrs d'Amorium, éd. Vasiliev, Pétersbourg, 1898.

Aeneas Sylvius Oiccolomini (1405-1464), (le pape Pie II), Correspondances,

Fontes rerum austriacarum, 4 v., Vienne, 1909-1918. 
Agathias, Histoire (552-558), P.G., 88.

Agnellus, Liber Pontificalis Ecclesiae Ravennatis, éd. Holder-Egger, S.R.L., 1878.

Alchimistes grecs, éd. Berthelot et Ruelle, 1880.

AleXANDre le SCRIBE, Voyage à Constantinople, 1393, I.R.S.O.L., 161 ss.

AleXANDre De Tralles, médecin, $\mathrm{VI}^{\mathrm{e}}$ s., éd. Putschmann, Vienne, 1873.

AleXis Comnene (Die Musen des Kaisers Alexios I), éd. Maas, B.Z., 1913, 348.

ANDre LE MElode, évêque de Gortyne († 740), Canons, P.G., 97,1305-1444.

Annales Laurissenses Majores, M.G.H.S.S, I.

AnNe Comnene, Alexiade, éd. et trad. Leib, C.B.B., 3 v., 1937-1946.

Anonyme, Periplus maris Erythraei, éd. Criddle, Londres, 1879.

Anonyme, Philopatris, éd. Hase, P.G., 117.

Anonyme russe, Description de Constantinople, I.R.S.O.L., 225 ss.

Anonyme, Totius orbis descriptio, G.G.M., II, 520.

Anonyme, Vie de Léon l'Arménien, P.G., 108.

Anthologia graeca epigrammatum Palatina cum Planudea, éd. Stadtmüller, 3 vol., Leipzig, 1894-1906 et Dübner-Cougny, 2 v., 1864-1877.

Anthologie grecque, I Anthologie Palatine, éd. et trad. Waltz, (P.), B.L., 19281948, 6 vol. publiés.

Antiochus le Stratege, Prise de Jérusalem par les Perses en 614, éd. Vincent et Abel, Jérusalem Nouvelle, II, 2, 926.

ANTOINE, archevêque de Novgorod, Le livre du pèlerin, I.R.S.O.L.

Apocryphes de l'Ancien et du Nouveau Testament (Dictionnaire des) trad. franç. Migne, E.T.M., 23, 2 v., 1856.

ApostOLIS (Michel), 1422-1480, Correspondance, éd. Legrand, B.H.L., 1885, 11, 234-259.

Archivio Veneto (Morozzo, Documenti...), Venise 1940.

рүчролои́ $\lambda \varepsilon 1 \alpha$. Discours et lettres de Jean Argyropoulos, éd. Lambros, Athènes, 1910.

Aristote, Commentaria in Aristotelem graeca, éd. Académie de Berlin, 23 v., 1883-1891.

Asterius, évêque d'Amasée (fin IV s. s.), Homélies, P.G., XL, 163-178.

Athonskie Dokument, éd. Bezobrazov, V.O., I.

Athos (Actes de l'), dans V.V. (suppl.) XII, 1905, Esphigmenou. - XIII, 1907, Zographou. - XX, 1913, Philotheou - XVII, 1910-1912 Chilandar et Supplem. ad acta gr. Chil., Acad. de Ljubljana, 1948, 90.

Athos, Meyer, Die Haupturkunden der Athoskloster, Leipzig.

Athos (Archives de l') (G. Millet), I. Actes de Lavra, éd. G. Rouillard et P. Collomp, 1945. II. Actes de Kutlumus, éd. P. Lemerle, 1945.

BANDURI, Imperium Orientale sive antiquitates Constantinopolitanae, 2 v., Paris, 1711.

BAR-Hebraeus, Chronique syriaque, éd. et trad. Abbeloos, 3 v., Louvain, 18721877.

BARlaAM, (XIV s. s.), Correspondance. Traités, P.G., 151.

Barlaam et Joasaph (Vie de), éd. Boissonade, P.G., 96 et Zotenberg (avec trad. franç. dans N.E.M., XXVIII, I, 1887).

BASILE (Saint), Aux jeunes gens sur la manière de tirer profit des lettres helléniques, éd. et trad. Boulenger (F.), B.L., 1935. 


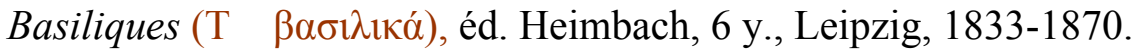

Belthandros et Chryzantza, éd. Legrand, B.G.V., I.

BENJAmin De Tudele ( $\dagger$ 1173), Voyages, trad. franç. Baratier, Paris et Amsterdam, 2 v., 1734.

Bertrandon de la Broquiere, Le Voyage d'Outre-mer, éd. Schefer, 1892.

BESSARION (cardinal), Euvres, P.G., 141 (incomplet et insuffisant; bibliographie dans D.H.G.E., VIII, 1935, 1196-1199).

BeSSARION, Éloge de Trébizonde, éd. Lambros, N.H., XIII, 1916, 145-204.

CABASILAS (Nicolas), Correspondance (Guilland, B.Z., 1930, 96-102).

- Explication de la Divine Liturgie. Introduction et trad. Salaville, Lyon, 1943; texte dans P.G., 150, 368-492.

CANTACUZENE (Jean), Histoires, P.G., 153-154.

- Apologie contre l'islam, P.G., 154, 372 ss.

Catalogus codicum astrologorum graecorum, 3 v., Bruxelles, 1898-1901.

CEDREnos (Georges), Synopsis, P.G., 121-122.

Chalkondyles (Laonicos), Histoires, P.G., 159 et éd. Darko, Budapest, 2 v., 1922-1927.

Chant (Le) de l'Hirondelle, éd. Fabre. Le polyptyque du chanoine Benoît Lille, 1889.

CHORICIUS DE GAZA, éd. Foerster, Leipzig, 1929.

Christophoros de Mytilene, Poésies, éd. Antonio Roechi, Rome, 1887, et Kurtz, Leipzig, 1903.

Chronique de Morée. Version grecque, éd. Th. Schmitt. Londres, 1904.

- Version française, éd. Longnon, S.H.F., 1911.

Chronique Pascale (ou alexandrine), P.G., 92.

Chrysoloras (Manuel), Correspondance, P.G., 156.

Claudiani carmina, éd. Jesp, 2 v., Leipzig, 1879.

ClaviJo, Historia del gran Tamerlan, Madrid, 1779. Sur son ambassade, MERIMEE (P.), Histoire des Arts au moyen age, 305 ss.

CoDInUs (Pseudo), De officialibus palatii, P.G., 157.

Constantin VII Porphyrogenete, [De administrando imperio], P.G., 113.

- De caerimoniis aulae byzantinae, éd. Reiske, 1751-1754. P.G., 112. Texte, traduct. et comment. A. VoGT, 2 v., C.B.B., 1939-1940 (inachevé).

- [De thematibus], P.G., 113.

- De imagine Edessa, P.G., 113, 444 ss.

Constantin, évêque de Tios (Paphiagonie), IX ${ }^{\mathrm{e}}$ s., avant 837. Discours sur l'invention des reliques de sainte Euphémie, A.S.B., sept. 247 ss.

CORIPPUS, In laudem Justini, éd. Partsch, A.A., III, 2.

Critobule D’ImBros, De rebus gestis Mechemetis II, éd. Müller, F.H.G., V, 1870.

DANDOLO, Chronicon Venetum, R.I.S., XII.

Defixionum tabellae..., éd. Audollent, 1904.

Demetrius Kydones, Correspondance, éd. et trad. franç. Cammelli, C.B.B., 1930.

DenYs L'Areopagite (Pseudo), P.G., 3-4.

Digénis Akritas (Les exploits de), éd. Legrand, B.G.V., VI, 1892 (mss. de Grottaferrata).

Doukas, Chronique universelle, P.G., 157. 
EDRISI, Géographie, trad. Jaubert (PA.), 1840.

EPHREM (Saint), éd. Mercati (S.G.), S. Ephraemi Syri opera I, Rome, 1915.

ÉtIENNE De Novgorod, Pèlerinage à Constantinople (vers 1350, I.R.S.O.L., 115 SS.

EudE DE DeuIL, De Ludovici VII profectione in Orientem, P.L., 185, 1205 ss. M.G.H.S.S., XXVI, 60-73.

Eudociae Augustae carminum reliquiae, éd. Ludwich (A.), Berlin, 1193.

EUSEBE DE CESAREE, I. Chronographie. II. Chronicon canonum quae supersunt, P.G., 19.

- Histoire ecclésiastique, éd. et trad. Graphs.

Eugenikos (Jean), Discours sur la parure féminine, E.B., 1931, 42 ss.

Eustathe MakKemBolites, éd. Treu, Breslau, 1893 (v. B.Z. 111,172-177).

Eustathe De Thessalonique, Opuscula, éd. Tafel., P.G., 136-137.

- Prise de Thessalonique par les Normands, 1185, P.G., 136, 10-40.

Euthymios Zigabenos, Panoplia dogmatike, P.G., 130, 20-1360.

Evagrios, Histoire ecclésiastique, P.G., 86 et éd. Bidez-Parmentier, Leipzig, 1886.

Filelfe (François), Cent dix lettres de F., éd. Legrand, 1892.

Formule d'abjuration du judaïsme (fin IX ${ }^{\mathrm{e}}$ s.), éd. Catcher, 1672, PG., 1, 1456.

FouCHER DE CHARTRES, Gesta Francorum Hierusalem expugnuntium, H.C., Occ., III, 311 ss.

GENESIOS, Le livre des Empereurs, P.G., 108.

Georges Akropolites, Chronique, P.G., 140 et éd. Heisenberg, 2 v., Leipzig, 1903.

Georges de Chypre, Descriptio orbis Romani, éd. Geizer, Leipzig, 1890.

Georges Gemiste (Plethon), Discours et æuvres diverses, P.G., 160.

Georges le Moine, Chronique universelle, P.G., 109 et éd. de Boor, 2 v., Leipzig, 1904.

Georges Pisides, Poèmes, P.G., 92.

GeORges Scholarios (patriarche GenNADIOS), Euvres complètes, éd. L. Petit et Jugie, 8 y., 1927-48.

Gerard De St-Quentin-EN-L'Isle, Translatio sancte Corone D. N. I. C. a Constantinopolitana urbe ad civitatem Parisiensem, éd. Miller, J.S., 1878.

GERMAIN (Pseudo), Histoire ecclésiastique, P.G., 98.

Gesta Francorum et aliorumn Hierosolymitanorum, éd. et trad. Bréhier (L.), C.H.F., 1924.

Gregoire De ChyPre, Autobiographie, P.G., CXLII et Lameere, La tradition des mss. de la correspondance rie G. de Ch., Bruxelles, 1937.

Gregoire de Nazianze(Saint), Homélies, P.G., 36 ss.

- Illustration du mss., Paris gr. 510 (IX ${ }^{\mathrm{e}}$ s.) dans D.A.C.L., VI, 1925, fig. 5411-5451.

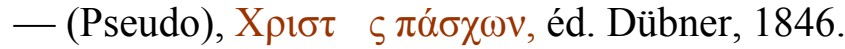

Gregoire De Nysse (Saint), Homélies, P.G., 44.

Gregoire PALAMAS, P.G., 150-151.

Gregoire Le SinAïte, Sur l'hésychia et la méthode d'oraison, P.G., 150 (vers 1330).

Gregoire De Tours, Euvres, éd. Krusch, S.R.M., t. T, Hanovre, 1885; Historia Francorum, éd. Omont et Collon, 2 v., 1886.1893. 
Guarino de Verone, éd. Rosmini (C. de), Vita e disciplina di Guarino Veronese e dei sui discepoli, Brescia, 2 v., 1805-1806.

[Guide de la Peinture] (Hermeneia), trad. fr. Didron, Manuel d'iconographie chrétienne, grecque et latine, 1845.

GuILlaume D’APUlie, Geste Roberti Wiscardi, M.G.H.S.S., IX, 239 ss.

GUILlAUME DE TYR, Historia rerum in partibus transmarinis gestarum, H.C., Occ., I.

HAROUN-BEN-JAHJA, prisonnier de guerre, Récit. Voir Marquant, 206 ss.

HeRMiPPos, Dialogues [sur l'astrologie], V ${ }^{\mathrm{e}}-\mathrm{VI}^{\mathrm{e}}$ s., éd. Kroll, Leipzig, 1895.

HiEROCLES, Synekdemos, P.G., 113 et éd. Honigmann, C.B.H.B.

HiEROPHILE [Calendrier de régimes], éd. Jeanselme, M. Schl., 217 ss.

Hippolyte (Canon de Saint), éd. Bauer et Helm, Berlin.

Homélies sur la Vie de la Vierge, de Jacques de KoKKInOBAPHOS, P.G., 127, 554700.

Hymne Akathiste, P.G., 92, 135-148 et éd. dom Placide de Meester, B., 1905.

IBn Batoutah, Voyages (XIV ${ }^{\mathrm{e}}$ s.), éd. et trad. Defrémery et Sanguinetti, 2 v., Paris, 1854.

IBN KORDADBEH, Livre des routes et des royaumes (fin $\mathrm{IX}^{\mathrm{e}} \mathrm{s}$.), trad. franç. Barbier de Meynard, J.A., 1865.

Icônes (Légendes des), éd. Gelzer (H.), Der Codex 80 der theologischen Schule von Haiki $\left(\mathrm{XV}^{\mathrm{e}} \mathrm{s}\right.$.) und die Legende von den heiligen Ikonen, B.Z., 1901, 477 SS.

IGNACE DE SMOLENSK, Pèlerinage, 1389-1405, I.R.S.O.L., 129 ss.

Inscriptions (Recueils d'), HANTON, Lexique explicatif du recueil des inscriptions chrétiennes d'Asie Mineure, B.N., 1927, 53-136.

- Gregoire (H.), Miettes d'histoire byzantine, M.R., 1923.

— Id., Notes d'épigraphie byzantine, R.P.B.H., 1922.

- Id., Inscriptions historiques byzantines, B.N., 1921

- Id., Notes épigraphiques, B.N., 1933, 49 s.

- Jullian (C.), Inscriptions chrétiennes de Bordeaux.

— LE BLANT, Inscriptions chrétiennes de la Gaule, 2 v., 1856 et 1865.

MerCATI (S.G.), Note d'epigrafia bizantina, B., 1921.

- Id., Epigraphica, Rome, 1925.

Millet (G.), Inscriptions byzantines de Mistra, B.C.H., 1899 et 1906.

- Millet, PARgoire et Petit, Recueil des inscriptions chrétiennes de l'Athos, B.E.F.A., 91, 1904.

Jean Chrysostome (Saint), Homélies, P.G., 50, 507 ss.

JeAn Climaque (Saint), L'Echelle, P.G., 88.

JeAn Damascene (Saint), Euvres, P.G., 94.

- Poèmes, P.G., 96, 818-858.

JEAN D'ÉPHESE, Histoire de l'Église, éd. Land, Anecdota syriaca, II, 1868.

- Vie des bienheureux orientaux, trad. latine Douwen et Land, Amsterdam, 1889.

Jean le Geometre, Poésies, P.G., 141.

Jean Kamateros, Sur le Zodiaque..., éd. Miller, N.E.M., 1872, 2, 46-112.

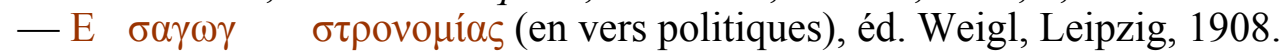

JeAn Kameniates, Sac de Thessalonique par les Arabes (904), P.G., 109, 519653. 
Jean Kinnamos, Epitome, P.G., 133.

JeAn Mauropous, évêque d'Euchaïta, P.G., 120.

- Correspondance inédite, éd. P. de Lagarde, Gbttingen, 1881.

JoRDANIS, De origine actibusque Gothorum, éd. Mommsen, A.A., V, 1, 1882.

JuLIEN, empereur, Euvres, éd. Bidez, 2v., Bruxelles, 1924 et 1932.

KeKaumenos, Strategikon ou Logos nouthetitikos, éd. Vasilievsky, Récits d'un grand seigneur byzantin du XI siècle, Z.M.N.P., 1881, $2^{\mathrm{e}}$ éd., Pétersbourg, 1896.

Kosmas IndiKopleustes, Topographie Chrétienne, P.G., 88.

- [Illustration] Stornajolo, Le miniature della Topografia Cristiana, Milan, 1908.

Kosmas, évêque de Malouma, Poèmes mélodiques, P.G., 98, 456-524.

Légendes du christianisme (Dictionnaire des), E.T.M., XIV, 1859.

Légendes slaves de Constantin et Méthode vues de Byzance, trad. franç. Dvornik, 339-393.

LEON VI, empereur, Novelles, éd. et trad. Dam (A.) et Noailles (R.), B.L., 1944.

- Discours et auvres diverses, P.G., 107.

- Oraison funèbre de Basile I, éd. Vogt et Hausherr, O.C., XXVI, 1932.

LEON LE DiACRE, Histoires, P.G., 117.

LEONCE DE BYZANCE, P.G., 86.

[Lettre des 3 patriarches d'Orient à Théophile sur les images] éd. Duchesne et Sakkelion, Roma e l'Oriente, 1913.

LiBANIUS, Discours, éd. Fœrster, 12 v., Leipzig, 1903-1927.

Liturgies: Brightmann, Liturgies Eastern and Western, Oxford, 1885, t.I.

- Anaphores (Les) des liturgies de saint Jean Chrys. et de saint Bas., éd. et trad. dom F.-J. Moreau, 1927.

- Fragments sur papyrus de l'anaphore de saint Marc, éd. Andrieu (M.) et Collomp (P.), R.S.R., VIII, 1928.

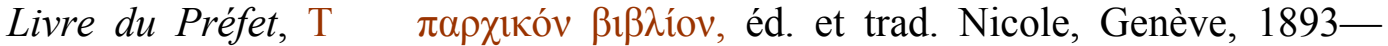
1894.

LUITPRAND, Antapodosis (= Ant.); Relatio de legatione (= Leg.), M.G.H.S.S., III. Lydos (Jean), De mensibus, éd. Wuensch, Leipzig, 1898.

MAÇOUDI, Les prairies d'or, éd. et trad. Barbier de Meynard, 2 v., 1861-1863.

Malalas (Jean), Chronographie, P.G., 97.

MANASSES, Synopsis Historike, P.G., 127.

- $\quad \kappa \varphi \rho \alpha \sigma i \varsigma ~ \kappa v v \eta \gamma \varepsilon \sigma i ́ o v ~ \gamma \varepsilon \rho \alpha ́ v \omega v$ (chasse au faucon), $1^{\text {re }}$ éd. Kurtz., V.V., 1905, 79-88.

- Monodie sur la sébaste Théodora, V.V., 1900, 630.

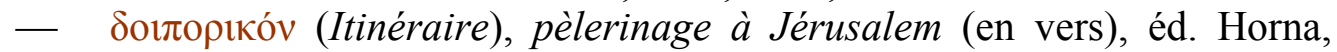
B.Z., XIII, 1904, 313 ss.

Manuel II Paleologue, Euvres, éd. Berger de Xivrey, Mémoires A.J., XIX, 2, $1853,1-201$.

—Éloge funèbre du despote Théodore I (1407), $1^{\text {re }}$ éd. Lambros, P.P., III, 1119.

Marcellinus Comes, Annales, éd. Mommsen, A.A., IX, 2, 1894.

MATHIEU D’ÉDESSE, Chronique (952-1136), trad. Dulaurier, Bibl. Hist. Armén., 1858.

MAXime Le Confesseur, P.G., 90-91. 
MaZARIS, Dialogos nekrikos (Descente aux Enfers), éd. Hase, N.E.M., 1813, 131 SS.

Meliteniotes, Sur la Sagesse païenne, N.E.M., XIX, 1858.

Menandre Le Protecteur, Fragments, éd. Müller, F.H.G., IV.

MeSARITES, Chronique, éd. Heisenberg (Apostelkirche, 90-96), Leipzig, 1908. -

Sur la tentative d'usurpation de Jean Comnène (1201), éd. Heisenberg, Wurzbourg, 1907.

Messe de l'Eunuque (XIII ${ }^{\mathrm{e}}-\mathrm{XIV}^{\mathrm{e}}$ s.), éd. Legrand, B.G.V., 1881, 28-47.

Metochites (Théodore), Poésies inédites. Voir Guilland (R.), B.N., 1926, 265 ss.

MIChEl D’AtTAlie, Histoire, éd. Bekker, C.S.B.B., 1883.

- Diataxis, éd. Nissen (W.), Die Diataxis des M.A., léna, 1894.

MICHEL KhONIATES ( $\mathrm{T} \quad \sigma \omega \zeta$ ó $\mu \varepsilon v \alpha$ ), éd. Lambros, Athènes, 1879.

- Monodie sur Eustathe de Thessalonique, P.G., 140.

MIChel VIII PALEOLOGUe [Autobiographie], dans Typikon de saint Démétrius, éd. Troïtski, Pétersbourg, 1885; trad. Chapman, 167-177.

NiCEPHORE BASILAKES, rhéteur, XII ${ }^{\mathrm{e}}$ s., éd. et trad. Vogt, O.C., 1931.

NICEPHORE BLEMMYDES [Autobiographie et œuvres complètes], éd. Heisenberg, Leipzig, 1896.

NiCEPHORE BRYENNE, Histoire, P.G., 127.

NiCEPHORE GREGORAS, Histoire romaine, P.G., 148-149.

- Correspondance, éd. et trad. Guilland (R.), C.B.B., 1927.

Nicephore Kallistos Xanthopoulos, Histoire de l'Église, P.G., 165.

- Poésies rythmiques, B.N., 1929, 357-390.

NiCEPHORE, patriarche, 806-815, Breviarium, éd. de Boor, Leipzig, 1886.

- Antirrhetici, P.G., 100.

Nicetas Khoniates, Histoire, P.G., 139-140.

- Trésor de l'Orthodoxie, P.G., 139.

Nicetas Stethatos, Contra Latinos, P.O., 120.

NiCOLAS LE MYSTIQUE, patriarche, Correspondance, P.G., 111.

Nomos Georgikos (Loi agraire), éd. Ferrini, B. Z., 1898, 558-571 et (edizione critica), Milan, 1929; Ashburner, J.H.S., 1904 ; Pantchenko, I.B.I., IX, 1904.

NotARAs (Lucas), Correspondance avec Georges Scholarios, éd. Lambros, P.P., II, 182 ss.

Notitia Urbis Constantinopolitanae, éd. Seeck (dans Not. dignitat.), 253 ss.

Octateuque (L') du Sérail à Constantinople, voir Ouspensky, I.R.I., XII, 1907 et album.

Office inédit en l'honneur de Nicéphore Phocas, éd. L. Petit, B.Z., 1904, 398 ss. OPPIEN DE Cilicie, Les Halieutiques. Les Cynégétiques, trad. fr. Bourquin, 1877.

PACHYMERE, Histoire (1261-1308), P.G., 143-144.

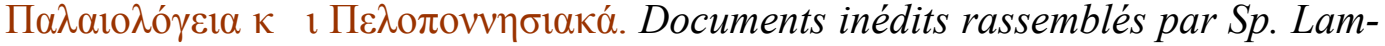
bros, 4 v., Athènes, 1912-1930.

PALladius, Historia Lausiaca, P.G., 65.

PANTECHNES, archevêque de Philippopoli, La chasse à l'once, trad. Miller, A.A.E.G., 1872-1873.

Papyrus. Greek Papyri in the British Museum, éd. Kenyon et miss Bell, Londres, 1893.

— The Oxyrhyncus Papyri, éd. et trad. Grenfell et Hunt, Londres, 1898. 
- Papyrus littéraire d'Aphrodite, éd. Jean Maspero, B.Z., 1910, 1 ss.

- Papyrus de Théadelphie, éd. Jouguet, 1911.

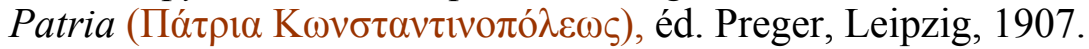

Paul le Silentiaire, Poèmes, trad. ital. Veniero, Catane, 1906.

PAulin DE Nole, Epistolae, P.L., 61.

Pegolotti (Francesco Belducci), Practica della Mercatura, dans H., I, 482.

Philes (Manuel), Poèmes, éd. Miller, 1855, 2 v.

Phrantzes (Georges), Chronique, P.G., 156 et PAPAdopoulos (J.-B.), Leipzig, 1935.

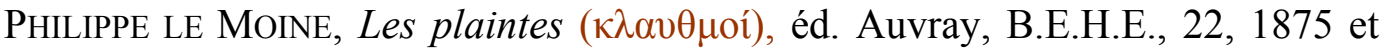
P.G., 127.

PIERRE DAMIEN, Institutio monialis, P.L., 145.

PIERRE DE SiCILE, Histoire des Manichéens appelés aussi Pauliciens, P.G., 104, $1240 \mathrm{ss}$.

Planoudes, Poèmes, éd. Holtzinger, Vienne, 1893.

PRISCUS PANITES, Excerpta de legationibus, éd. de Boor, Berlin, 1893.

Procope de Cesaree, De Bellis, 1. VII (= B.), Anecdota (= An.), De Adificiis (= Aed.), éd. Haury, 6 v., Leipzig, 1905-1913.

PRocope DE GAZA, Discours, P.G., 87, 2816.

Protévangile de Jacques, éd. Amann (E.), 1910.

Proverbes, Krumbacher (K.), Sammlung byzantinischen Sprichwörter, Munich, 1887.

PSEllos, Discours, Chronographie, Correspond., éd. Sathas, B.M.Ae., IV et V, 1874-1876.

- Chronographie, éd. et trad. Renauld (E.), 2 v., C.B.B., 1928.

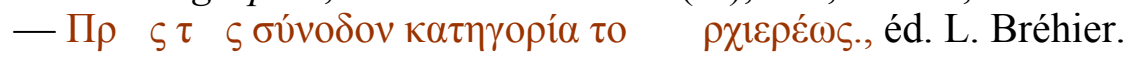

- Un discours inédit de Psellos, R.E.G., 1903-1904 (et à part),

- Timothée ou dialogue sur les démons, P.G., 122.

- Scripta Minora, éd. Kurtz-Drexl.

Ptocho-Léon, Contes, éd. Legrand, A.A.E.G., VI, 1872.

RaOUl Glaber, Historia sui temporis, éd. Prou, 1886.

Rhetores graeci, éd. Waltz, Stuttgart, 1832-36, 9 v.

ROBERT DE ClARI, La conqueste de Constantinople, éd. Lauer, 1924.

Romanos Le Melode, $1^{\text {re }}$ éd., Pitra, Analecta sacra, Rome, 1876; éd. partielles :

Eustratiadès, E.B., XV, 1909,182-255; Krurnbacher, B.Ak.W., 1899-1902;

Maas, B.Z., 1906.

Satire contre les higoumènes, trad. fr. Jeanselme et OEconomos, B.N., 1924, $317-$

339; éd. Legrand, B.G.V., 1, 1880.

SEBEos, Histoire d'Héraclius, trad. Macler, 1904.

Silviae Etheriae peregrinatio (vers 396), éd. Geyer, I.H.

SiSYPHE DE COS [poème de la guerre de Troie], Patzig (E.), B.Z., 203, 231-257.

SOCRATE, Histoire ecclésiastique, P.G., 67.

SOZOMENE, Histoire ecclésiastique, P.G., 67.

Stephanitès et Ichnelatos, conte, éd. Silvestre de Sacy, N.E.M., IX-X, 1813.

Strabon, Geographica, éd. Müller (C.) et Dübner (F.), 2 v., 1853-1858. Coll.

Didot.

SUIDAS, Lexikon, éd. Bekker, Berlin, 1854.

SymeOn Metaphraste, Sur les vies des saints, P.G., 114-116. 
SYMEON (ps.) magister, Chronique, P.G., 109.

SyMEON DE TheSSALONIQUe, Euvres, P.G., 155.

Synaxaire de l'église Sainte-Sophie (mss. de Patmos, $\left.X^{e} s.\right)$, éd. Delehaye, A.S.

B., novembris.

Synopsis Chronike ad a. 1261, éd. Sathas, B.M.Ac., VII, 1894.

Syntipas (gr. y.), éd. Eberhard, Leipzig, 1872.

SYropoulos, Historia vera unionis non verae, éd. R. Creyghton, La Haye, 1660.

TAFUR (PERO), Travels and Adventures, 1435-1439, éd. et trad. angl., Malcom Letts, New York, 1926.

Testament de saint Grégoire de Nazianze, P.G., 37, 389 ss. et trad. Martroye, M.S.A.F., 1923.

Testament de Théodore Karabas (1314), éd. Bezobrazov, V. 0., 1915,70 ss.

THEMISTIUS, Orationes, éd. Dindorf.

THEODORE HyRTAKENOS (vers 1328-1341), Déclamations, lettres, éd. Laporte du Theil, N.E.M., V-VI, 1798-1800.

TheOdore II LASCARIS, Euvres (en partie inédites). Textes et trad. dans J.B.

PAPADOPOULOS, Théodore II Lascaris, 1908, p. 158-178.

THEODORE LE LECTEUR, Histoire ecclésiastique (fragments), P.G., 165.

Theodore Meliteniotes, Astronomike tribiblos, P.G., 149.

TheOdore Metochites, Miscellanea, éd. Müller-Kiessling, Leipzig, 1821.

- Poèmes, éd. Treu, Potsdam, 1895.

Theodore Prodrome, Poèmes, éd. et trad. Miller, R.A., 1874 (2), 361 ss.

- Poèmes prodromiques, éd. Hesseling-Pernot.

- Dialogues imités de Lucien, éd. Laporte du Theil, N.E.M., VIII, 2.

TheOdORE LE STUDite (Saint), Lettres, P.G., 99.

THEODORET, Histoire ecclésiastique, P.G., 82.

THEOPHANES DE BYZANCE, F.H G., IV.

Theophanes le CONFESSEur, Chronographia, éd. de Boor, Leipzig, 1885, 2 y.

TheOPHANES Continuatus, P.G., 109.

TheOPHYlacte (archev. d'Ochrida), Correspondance, P.G., 126, 307 ss. (Voir

B.N., 1938, 253 ss.)

- Poèmes, éd. Mercati (S. G.), Studi bizantini, 1924.

Theophylacte De SimocatTA, Histoire (582-602), éd. de Boor, Leipzig, 1887.

- Correspondance, éd. Hercher (Epistolographi graeci), 1873.

Timarion, Sur ses maux, éd. Hase, N.E.M., IX, 2, 1813 (2), 144-246.

Trophées (Les) de Damas, éd. G. Bardy, P.O., XV, 2, 1920.

Typikon de Grégoire Pakourianos (monastère de Petritzos), éd. Petit (L.), V.V., XI, 1904.

Tzetzes, CEuvres, éd. Pressel, Tübingen, 1851.

- Vers inédits, éd. Petridès, B.Z., XII, 568 ss.

Vie de saint Antoine le Nouveau (Olympe), éd. Papadopoulos-Kerameus, S.O.P.,

LVII, 1907.

- de saint Athanase l'Athonite, éd. Petit, A.B., XXV, 1906.

— de saint David de Salonique, éd. Vasiliev, T.R., IV, 1946, 117-147.

- de saint Élie, martyr à Damas, éd. Loparev, V. V.,XIX, 36-41.

- de saint Élie le Nouveau (Sicile, vers 900), éd. A.S.B., août III, 489 ss.

- de saint Étienne le Nouveau, P.G., 100, 1069 ss.

- d'Eutychios,patriarche († 582), P.G., 86. 
- de saint Euthyme, patriarche, éd. de Boor, Berlin, 1888.

- de sainte Geneviève (425-513), S.R.M., III, 226 ss.

- de Germain, patriarche (715-730), P.G., 98.

— de saint Hilarion d'Ibérie, éd. Peeters, A.B., 1913, 236 ss.

- de saint Jean l'Aumônier, par Léonce de Neapolis, éd. Geizer (H.), Fribourg, 1893.

- de Jean Vatatzès, empereur (1222-1254). Voir Heisenberg, B.Z., XIV, 1905, 160.

- de saint Joannice le Grand, A.S.B., nov. II.

- de Léon le Thaumaturge, archevêque de Catane, A.S.B., février III, 223235.

— de saint Luc le Stylite († 979), éd. Vogt, A.B., 1909.

— de Michel le Syncelle, éd. Th. Schmitt, I.R.I., 1906, 228-231.

- de Nicolas le Studite, P.G., 105, 864 ss.

— de saint Nikon le Métanoïte, $1^{\mathrm{re}}$ éd., Lambros, N.H., 1906, 128 ss.

— de saint Philarète le Miséricordieux, éd. et trad. Fourmy et Leroy, B.N., IX, 1934, 85-170.

- de saint Pierre d'Argos, éd. Vasiliev, T.R., V, 1948, 164-191.

- de Porphyre (ap. Eunape, Vitae Sophistarum, éd. Boissonade et Wyttenbach, Amsterdam, 1882) (vers 375).

- de saint Porphyre de Gaza, par Marc le Diacre, éd. Grégoire (H.) et Kugener, B.L., 1930.

- de Sévère, patriarche monophysite d'Antioche, par Zacharie le Scolastique, éd. et trad. Kugener, P.O., II, 1903.

— de Tarasios, patriarche, 784-806, P.G., 98, éd. Heikel, Helsingfors, 1889.

- de sainte Théodora de Salonique, éd. Kurtz, Pétersbourg, 1902; Loparev, V.V., XIX, 87 ss.

— de saint Théodore d'Edesse, éd. Pomjalovsky, Pétersbourg, 1892 (voir B.Z., L, 632).

— de saint Théodore le Sykéote, A.S.B., avril III.

- de saint Théodore Tiron, $1^{\text {re }}$ éd. Sigala, E.B., 1925.

— de saint Théophanes le Confesseur, P.G., 115 (Voir Krumbacher, Byz. Litt., 347).

- de saint Théophanes (panégyrique), par Saint Théodore le Studite, A.B., 1912, 11-23 (éd. van den Vorst).

- de sainte Théophano, impératrice, $1^{\text {re }}$ femme de Léon VI, éd. Hergenroether (Monumenta Photiana, 1869) éd. Kurtz, Pétersbourg, 1898.

Villehardouin, La Conquête de Constantinople, éd. Faral, C.H.F., 2 v., 19381939.

YAhYA D’AnTIOCHE, Chronique universelle, éd. et trad. fr. Vasiliev, P.O., XVIII, 5, 1924.

ZONARAS, Epitome, P.G., 124-125.

Zosime, Histoire, éd. Bekker, C.S.B.B.

Zosime Le DiACre, Pèlerinage, 1419-1421, I.R.S.O.L., 204 ss. 


\title{
OUVRAGES ET TRAVAUX CONSULTÉS
}

\author{
OUVRAGES D'ENSEMBLE
}

$1^{\circ}$ HISTOIRES POLITIQUES ET SOCIALES

Cambridge Medieval History (The), IV, The Eastern Roman Empire (717-1453), Cambridge, 1923.

DieHL (Ch.) et MARÇAIS (G.), Le monde oriental de 395 à 1081, H.G.M.A., III, 1936.

— et GuILland, L'Europe Orientale de 1081 à 1453, H.G.M.A., IX, 1946.

- Les grands problèmes de l'histoire byzantine, 1943.

GELZER (H.), Byzantinische Kulturgeschichte, Tubingen, 1909.

HESSELING (D. C.), Essai sur la civilisation byzantine, 1907.

IORGA (N.), Histoire de la vie byzantine, 3 v., Bucarest, 1934.

KOULAKOVSKY, Istoria Vizantii, 3 v. (inachevé), Kiev, 1910-1915.

KRAUSE, Die Byzantiner des Mittelalters in ihrem Staats.Hof- und Privat-leben..., Halle, 1869.

KRUMBACHER (K.), Geschichte der byzantinischen Literatur, $2^{\mathrm{e}}$ éd., Munich, 1897 [fondamental].

LEBEAU, Histoire du Bas-Empire, édition revue par Saint-Martin, 1924, 21 v.

MARQUART, Osteuropäische and Ostasiatische Strefzüge, Leipzig, 1909.

MoraVvcsiK (G.), Byzantino-turcica. I. Die byzantinischen Quellen der Geschichte der Türkvölker. II. Sprachreste dec Türkvölker in den byzantinischen Quellen, Budapest, 2 v., 1942-1943 [excellent instrument de travail].

Ostrogorsky (G.), Geschichte des byzantinischen Staates, Munich, 1940.

RunCIMAN (St.), Byzantine Civilisation, Londres, 1933; édition française, Paris, 1934.

STEIN (E.), Geschichte des spätrömischen Reiches, I,Vienne, 1928; II,Paris, 1950.

VASILIEV (A.), Histoire de l'Empire byzantin, 2 v., 1932.

ZACHARIAE VON LINGENTHAL, Geschichte des griechisch-römischen Rechts, Berlin, $3^{\mathrm{e}}$ éd., 1892.

\section{$2^{\circ}$ MONOGRAPHIES}

BURY (J. B.), History of the later Roman Empire, 2 v., Londres, 1923.

- A History of the Eastern Roman Empire (802-867), Londres, 1912.

- The imperial administrative System in the ninth Century, Londres, 1911.

Chalandon (F.), Les Comnène. I... Alexis Comnène. II, Jean II et Manuel, 1900 et 1912.

Cognasso (F.), Partiti politici e lotte dinastiche in Bizanzio alla morte di Manuele Comneno. R. Accad. di Torino, 1912.

COURET, La Palestine sous les empereurs grecs, 1869.

DIEHL (Ch.), Justinien et la civilisation byzantine au VI siècle, 1901.

— La Société byzantine à l'époque des Comnènes, 1929. 
DvorniK (F.), Les Slaves, Byzance et Rome au IX siècle, 1926.

- Les légendes de Constantin et de Méthode vues de Byzance, 1933.

GARDNER (Alice), Theodore of Studium, his life and times, Londres, 1909.

Grousset (R.), L'empire des Steppes, 1939.

- Histoire des Croisades et du royaume franc de Jérusalem, 3 v., 19341936.

Holmes, The age of Justinian and Theodora, 2 v., Londres, 1907.

IORGA (N.), Byzance après Byzance, Bucarest, 1935.

LAURENT (Joseph), L'Arménie entre Byzance et l'islam, 1919.

- Byzance et les Turcs seldjoucides dans l'Asie Occidentale jusqu'en 1081, Nancy, 1919.

LOMBARD (A,), Constantin V, empereur des Romains, 1902.

LOT (F.), La fin du monde antique et le début du moyen âge, E.H., nouvelle éd., 1968.

PAPAdOPOUlos (J. B.), Théodore II Lascaris, 1908.

PERNICE, L'imperatore Eraclio, Florence, 1905.

PigAniol (A.), L'Empire chrétien, 325-395, H.G.H.A., 1947.

Rambaud (A.), L'Empire grec au $X^{e}$ siècle. Constantin Porphyrogénète, 1870.

Runciman (St.), The Emperor Romanus Lecapenus, Cambridge, 1929.

- A History of the first Bulgarian Empire, Londres, 1930.

Schlumberger (G.), Nicéphore Phocas, $1^{\text {re }}$ éd., 1890.

—L'Épopée byzantine..., 3 v., 1896, 1900, 1905.

- Le siège, la prise et le sac de Constantinople par les Turcs en 1453.

STEIN (E.), Untersuchungen zur spätbyzantinischen Verfassungs und Wirthschaftsgeschichte (Mitt. sur osm. Gesch.), Hanovre, 1935.

VASILIEV (A.), Vizantija i Araby... za vremja Amorijskoi dinastii, Pétersbourg, 1900 (trad. franç., Byzance et les Arabes. I. Dynastie d'Amorium, C.B.H.B., 1935.)

— Id., ...za vrenija Makedonskoj dinastii, Pétersbourg, 1902 (trad. fr. C.B.H.B., en préparation).

VoGt (A.), Basile I et la civilisation byzantine à la fin du IX siècle, 1908.

\section{$3^{\circ}$ MELANGES ET RECUEILS D’ARTICLES}

(Pour les Mélanges Jubilaires voir la table des abréviations.)

DiEHL (Ch.), En Méditerranée, 1901.

- Etudes byzantines, 1905.

- Figures byzantines, 2 v., 1906, 1908.

- Dans l'Orient byzantin, 1917.

- Choses et gens de Byzance, 1926.

Ebersolt (J.), Mélanges d'histoire et d'archéologie byzantines, 1917 ext., R.H.R.

JERPHANION (G. de), La Voix des Monuments, 2 séries, 1930 et 1938.

MARRAST (Aug.), Esquisses byzantines, 1881.

RAMBAUD (AEtudes sur l'histoire byzantine, 1912.

Schlumberger (G.), Récits de Byzance et des croisades, 2 séries, 1916, 1922.

- Byzance et les croisades, 1927. 


\section{$4^{\circ}$ GEOGRAPHIE DE L'EMPIRE BYZANTIN}

PHILIPPSON, Das byzantinische Reich als geographische Erscheinung, Leyde, 1939.

Vidal de la Blache et Gallois, Géographie Universelle. VII. Péninsules méditerranéennes, par SORRE (M.), SiON (J.), CHQTEIGNEAU (Y.).

- VIII. Asie occidentale. Haute-Asie, par Blanchard (R.) et Grenard (F.), 1929.

\section{LIVRE I. - VIE PRIVÉE}

\section{$1^{\circ}$ LA FAMILLE}

Cumont (F.), La triple commémoration des morts [dans l'Église byzantine], A.I.C.R., 1918, 278 ss.

Guilland (R.), Les eunuques dans l'Empire byzantin..., R.E.B., I, 1943.

- Fonctions et dignités des eunuques, R.E.B., II, 1944.

Koukoules (Ph.), (texte grec), Le sens et l'orthographe de quelques noms de familles byzantines, E.B., V, 1928, 3-35.

- Usages relatifs aux fiançailles et au mariage..., E.B., II, 1925, 1-41.

- Usages byzantins relatifs à la naissance et au baptême, E.B., XIV, 1938, 87146.

- De la nourriture et des soins donnés aux petits enfants, E.B., XIV, 1938, 310330.

- L'assistance aux indigents dans l'Empire byzantin. Mém. L.P., pp. 254-265 (texte français).

LAmBros (Sp.), La femme chez les Byzantins, N.H., XVII, 1923.

MonNier (H.), Les novelles de Léon le Sage, Bordeaux, 1923.

Pascalis (D.), Le couvent de femmes Apikia dans l'île d'Andros, E.B., XI, 1935, 29 ss.

REINACH (Th.), Un contrat de mariage du temps de Basile le Bulgaroctone, M.Schl., 118-132.

VERLINDEN (Ch.), Esclaves du Sud-Est et de l'Est européen en Espagne à la fin du moyen age, R.S.E., 1942, 371-406.

WALTZ (P.), Inspiration païenne et sentiment chrétien dans les épigrammes funéraires du VI siècle. Ext. de l'Acropole, 1931.

\section{$2^{\circ}$ LA VIE MATERIELLE}

BEYLIE (de), L'habitation byzantine, 1902.

BJELIAIEV, Fibules byzantines, S.K., 1930, 49 ss.

Cumont (F.), L'uniforme de la cavalerie orientale et le costume byzantin, B.N., 1925,181 ss. 
ENLART (C.), Le Costume (Manuels d'archéologie fr., III), 1916.

GARNIER et AMMAN, L'habitation humaine (ch. 14, Civilis. byz. et son influence), 1892.

GAYET, Le costume en Egypte du III au XIII siècle [fouilles d'Antinoé] (Expos. Univ. 1900).

- Les portraits d'Antinoé, 1916.

KONDAKOV (N.), Les costumes orientaux à la cour byzantine, B.N., 1924, 1-49.

Koukoules (Ph.), La maison byzantine (en grec), E.B., 1936, 76-138.

- Sur quelques vêtements byzantins, E.B., IV, 1927, 89-95 et XV, 1939, 142.

- La coiffure des Byzantins, E.B., 1930, 1 ss.

- Les bains aux temps byzantins, E.B., 1935, 192-238.

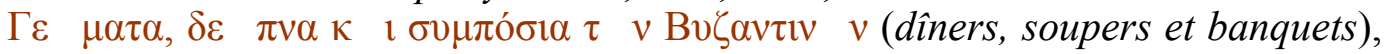
E.B., 1932, 97-60.

- Noms et espèces de pains..., E.B., 1928, 36 ss.

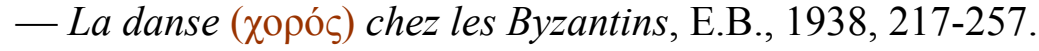

- Luttes, jeux athlétiques, tournois, E.B., 1937, 65 ss.

MOLINIER (M.), La coiffure des femmes dans quelques monuments byzantins (Mél. G. Monod, 1896), 61-70.

Schlumberger (G.), La journée d'une élégante à Byzance, dans Récits de Byzance et des Croisades, $2^{\mathrm{e}}$ série, 201-228.

VoGÜE (M. DE), Syrie Centrale : architecture civile et religieuse du $I^{e r}$ au VII s., 1865.

WeISs (H.), Kostümkunde. Geschichte der Tracht und des Geräthes im Mittelalter, Stuttgart, 1864, II, 1-303 (Romains, Byzantins, Perses).

\section{$3^{\circ}$ VIE PRIVEE DES EMPEREURS}

BREHIER (L.), Les empereurs byzantins dans leur vie privée, R.H., 1940, 1-25.

Koukoules (Ph.), Chasses de l'époque des Comnènes et des Paléologues (en grec), E.B., 1932, 3-33.

LAMBROS (Sp.), Les bouffons des empereurs byzantins (en grec), N.H., 1910, 372 SS.

MEYER (Ph.), Des Joseph Bryennios Schriften und Bildung [nomenclature des salles du palais des Blachernes], B.Z., 1896, 75-111.

Pagliaro (A.), Un gioco persiano alla corte di Bizanzio, A.C.E.B., Rome, 1936, S.B.N.I., 521-524.

Schlumberger (G.), Les îles des Princes, le palais et l'église des Blachernes, 1925.

\section{LIVRE II.-LA VIE URBAINE}

\section{$1^{\circ}$ CONSTANTINOPle}

BAXTER, The Great Palace of the Byzantine Emperors (Rapport sur les fouilles de 1934-1938), Oxford University Press, 1947. 
Demangel (M. R.), Contribution à la topographie de l'Hebdomon, 1945.

DEMANGEL et MAMBOURY, Le quartier des Manganes et la première région de Constantinople, 1939.

DIEHL (Ch.), Constantinople, V.A.C., 1924.

- Un voyageur espagnol à Constantinople [Peró Tafur], Mél. Glotz I, 319 ss., 1932.

EBERSOLT (J.), Le grand palais de Constantinople, 1910.

- Constantinople byzantine et les voyageurs du Levant, 1918.

Gerola, La veduta di Costantinopoli di Cristoforo Buondelmonti, S.B.N., III, 1931, 247-280.

JANIN (R.), Note sur les régions de Constantinople, R.E.B., III, 1945, $29-42$.

- Topographie de Constantinople byzantine, Mém. L.P., 218-232.

MACRI (M. Chr.), Des Byzantins et des étrangers dans Constantinople au moyen âge, Paris, 1928.

Mamboury (E.), Contribution à la topographie générale de Constantinople par l'étude du modèle de la ville, A.C.E.B., VI, Paris, 1948.

- et WIEGAND, Kaiserpaläste von Konstantinopel, Berlin-Leipzig, 1934.

Millet (G.), Les noms des auriges dans les acclamations de l'Hippodrome, M.K., 279.

OBerhummer, Constantinopolis. Abriss der Topographie und Geschichte. P.-W. Real Encyclopaedia, IV, 1899.

VASILIEV (A.), Quelques remarques sur les voyageurs du moyen âge à Constantinople, M.D.I., 293 ss.

- Harun-ibn-Yahia and his description of Constantinople, S.K.; V, 1932, 149-163.

- Pero Tafur... and his visit to Constantinople, Trebizond and Italy, B.N., 1932.

— The Monument of Porphyrius, D.O.P., 1948.

\section{$2^{\circ}$ VILLES DE PROVINCE}

ABEL (F.-M.), Gaza au V $V^{e}$ siècle d'après le rhéteur Choricius, R.B., 1931.

Audollent (A.), Carthage romaine, 1901.

BELOCH, Die Bevölkerung der griechisch-römischen Welt, Leipzig, 1885.

BERCHEM (VAN) et STRYGOWSKI, Amida [Diarbekir], Heidelberg, 1910.

BUCHON, Recherches sur la principauté de Morée, 1845.

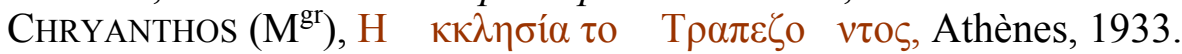

DEVREESSE ( $\mathrm{M}^{\mathrm{gr}} \mathrm{R}$.), Le patriarcat d'Antioche... jusqu'à la conquête arabe, 1945.

DIEHL (Ch.), Étude sur l'administration byzantine dans l'Exarchat de Ravenne, 1888.

- L'Afrique byzantine, 1896.

- Une république patricienne. Venise, 1904.

DUVAL (Rubens), Histoire politique, religieuse et littéraire d'Edesse... J.A., 1819, 1891-1892.

FougERES, Grèce (Guides Joanne), 1909.

- Athènes, V.A.C., 1912.

GAY (J.), L'Italie méridionale et l'Empire byzantin, 1904. 
Gelzer (H.), Studien zur byzantinischen Verwaltung Agyptens, Leipzig, 1909.

Hanotaux (G.), Histoire de la nation égyptienne, III, 1933. L'Égypte romaine (V. Chapot), p. 243-400. L'Égypte chrétienne et byzantine (Ch. DIEHL), p. 401-558.

JERPHANION (G. de), Mélanges d'archéologie anatolienne, Beyrouth, 1928.

LASSUS (J.), Antioch-on-the-Orontes, I. The excavation of 1932, Princeton, 1934

[La mosaïque de Yakto], 114-116.

- Dans les rues d'Antioche, B. des études orientales, V, 1935, 122 ss.

Lavedan (P.), Histoire de l'architecture urbaine, I, Antiquité-Moyen Age, 1926.

MASPERO (Jean), Histoire des patriarches d'Alexandrie (518-610), 1923.

- Horopollon et la fin du paganisme égyptien, B.I.F.C., XI, 1914.

MAYENCE (F.), La mission belge d'Apamée, B.A.B.L., 1935.

RouILlard (Germaine), L'administration de l'Égypte byzantine, $2^{\mathrm{e}}$ éd., 1928.

TAFrali (O.), Topographie de Thessalonique, 1913.

- Thessalonique, des origines au XIV s., 1919.

- Thessalonique au XIV siècle, 1913.

TEXIER, Description de l'Asie Mineure, 3 v., 1839-49.

VASILIEV (A.), The Goths in the Crimea, Cambridge (Massach.), 1936.

VINCENT (H.) et ABEL (F.-M.) Jérusalem nouvelle, 2 v., 1922.

ZAKITHINOS, Le despotat grec de Morée, 1932.

ZEILLER et HEBRARD, Spalato, 1912.

\section{LIVRE III. — LA VIE ÉCONOMIQUE}

\section{$1^{\circ}$ OUVRAGES GENERAUX}

Baudrillart (A.), Histoire du luxe, t. II, 335-363, Paris, 1878.

Bratianu (G.), Etudes byzantines d'histoire économique et sociale, 1938.

HEYD, Histoire du commerce du Levant, trad. fr. Furcy-Reynaud, 2 v., 1885.

Miller (W.), Essays on the Latine Orient, Cambridge, 1921.

\section{$2^{\circ}$ AGRICULTURE}

BREHIER (L.), Les populations rurales au IX siècle d'après l'hagiographie byzantine, Ext. B.N., 1926, 177 ss.

GIET (St.), Sasimes. Une méprise de saint Basile, 1941.

LEFEBVRE DES NOETTES, L'attelage. Le cheval de selle à travers les âges, 2v., 1931.

MALAFOSSE (J. DE), Les lois agraires à l'époque byzantine (Acad. de Législat.), XIX, 1949.

RochiE-HARDY (E.), The large Estates of byzantine Egypt, New York, 1931.

$3^{\circ}$ LA MONNAIE 
ANDREADES, De la monnaie et de la puissance d'achat des métaux précieux dans l'Empire byzantin, Ext. B.N., 1924, 75-115.

BLANCHET (A.), Les dernières monnaies d'or des empereurs byzantins, Ext. R.N., 1910, 78-90.

BRATIANU, (G.), L'hyperpère byzantin et la monnaie d'or des républiques italiennes, M.D., I, $37 \mathrm{ss}$.

SABATIER, Description générale des monnaies byzantines, 2 vol., 1862.

\section{$4^{\circ}$ COMMERCE D'EXTREME ORIENT}

ABEL (F. M.), L'île de Jotabé, R.B., 1938, 510 ss.

Audouin-Dubreuil (L.), Sur la route de la soie (Carnet de route, de la Méditerranée à la mer de Chine).

Chwostov, Commerce oriental de l'Egypte gréco-romaine (en russe), Kazan, 1907 (voir . s., 1910).

Dahlmann (J.), Die Thomas Legende... [plus anciens rapports du christianisme avec l'Inde], Fribourg-en-B., 1912.

Monneret de Villard(U.), Mose vescovo di Adulis, Misc. J., II, 613 ss.

PARISET, Histoire de la soie, I, 1862.

\section{$5^{\circ}$ COMMERCE DE LA MEDITERRANEE}

BREHIER (L.), Les colonies d'Orientaux en Occident au commencement du moyen âge, Ext. B.Z., XII, 1903, 1-38.

- Les origines des rapports entre la France et la Syrie (Trav. du Congrès de la Syrie, Marseille, 1918), Fasc. 2, 15-39.

ECK, Le commerce méditerranéen après l'invasion arabe, R.S.E., 1941, 33 ss

GANShOF (F.), Note sur un passage de la vie de saint Géraud d'Aurillac, M.I., 1933,295 ss.

HATZFELD (J.), Les trafiquants italiens dans l'Orient hellénique, 1919.

LAmbrechts, Les thèses de H. Pirenne sur la fin du Monde antique et les débuts du Moyen Age, B.N., XIV, 1939, 513 ss.

PirenNe (H.), Mahomet et Charlemagne, R.B.P.H., I, 1922.

- La fin du commerce des Syriens, M.B., 679 ss.

- Les villes au moyen âge, Bruxelles, 1927.

\section{$6^{\circ}$ LES DERNIERS SIECLES}

BRATIANU (G.), Recherches sur le commerce génois dans la mer Noire au XIII siècle, 1929.

- Vicina I, Bucarest, 1923.

Brehier (L.), Les Croisades, $5^{\mathrm{e}}$ éd., 1928.

DIEHL (Ch.), La colonie vénitienne à Constantinople à la fin du XIV siècle, E. Byz., 241 ss. 
LOPEZ (R.), L'origine des colonies commerciales permanentes dans le Levant byzantin et moderne, A.C.E.B., VII, Bruxelles, 1948.

MARINESCO, Contribution à l'histoire des relations économiques entre l'Empire byzantin, la Sicile et le royaume de Naples de 1419 à 1433, A.C.E.B., V, Rome, 1936, I, 209 ss.

- Manuel II Paléologue et les rois d'Aragon, B.H.A.R., 1924.

Michel (Anton), Amalfi und Jerusalem im griechischen Kirchenstreit, Rome, 1939.

RIANT, Expéditions et pèlerinages des Scandinaves en Terre Sainte, 1865.

VAsiliev (A.), The Russian Attack of Constantinople in 860, Cambridge (Mass.), 1946.

WEIGAND, Die helladische byzcintinische Seidenweberei, Mél. Lambros, 1935, 503 ss.

\section{LIVRE IV. - LA VIE SPIRITUELLE}

$1^{\circ}$ LA VIE RELIGIEUSE

Ouvrages d'ensemble

Fliche (A.) et MARTin (V.), Histoire de l'Église, t. 1V (1937), V (1938) (BréhierAigrain), VI, 1937 (Amann).

FORTSESCUE, The Orthodox Eastern Church, Londres, 1907.

JANIN (R.), Les églises orientales et les rites orientaux, 1922.

JUGIE, Le Schisme byzantin, 1941.

KATTENBUSCH, Die orthodoxe anatolische Kirche. Lehrbuch der vergleichenden Konfessionskunde, I, Fribourg-en-Br., 1892.

PARGOIRE (J.), L'Église byzantine de 527 à 847 (1905).

\section{Questions diverses}

BREHIER (L.), Le schisme oriental du XI siècle, 1899.

DUCHESNE (L.), L'Eglise au VI siècle, 1928.

GuILland (R.), La correspondance inédite d'Athanase, patriarche de Constantinople, 1280-1310, M.D., I, 121 ss.

(ECONOMOs (L.), L'état intellectuel et moral des Byzantins vers le milieu du XIV siècle..., M.D., I., 1925.

SAlAVILlE (S.), La vie monastique grecque au début du XIV siècle..., R.E.B., 1944, 119 ss.

\section{$2^{\circ}$ LES EDIFICES RELIGIEUX}

DyGGVE, Les traditions cultuelles de Delphes et l'Église chrétienne, CA., III, 1948, 9-28. 
- Ravennate palatium sacrum. La basilica ipetrale.... Copenhague, 1941.

- Le Saint-Sépulcre constantinien, A.C.E.B., VI, Paris, 1941'

GrABAR (A.), Martyrium, 2 v. et album, 1946.

LASSUS (J.), Sanctuaires chrétiens de Syrie, 1947.

LEMERLE (P.), Philippes et la Macédoine orientale à l'époque chrétienne et byzantine, 1945.

- A propos de l'édifice cultuel chrétien, B.A.B.L., 1948, 306 ss.

MALE (E.), La fin du paganisme en Gaule, R.D.M., $1^{\text {er }}$ juin 1948, 385 ss.

ORLANDOS, Architecture monastique (en grec), Athènes, 1927.

SESTON, L'église et le baptistère de Doura-Europos, Gand, 1937.

\section{$3^{\circ}$ LITURGIE ET MOBILIER}

Aigrain (R.), Liturgie. Encyclopédie..., 1930.

ANDRIEU (P.), Immixtio et Consecratio, 1924.

BATIFFOL (P.), Leçons sur la Messe, 1919.

BREHIER (L.), Les peintures du rouleau liturgique de Larva, A.I.K., Prague, 1939.

- Les trésors d'argenterie syrienne et l'école artistique d'Antioche, G.B.A., 1920.

DIEHL (Ch.), L'école artistique d'Antioche et les trésors d'argenterie syrienne, S., 1921.

SALAVILLE (S.), Liturgies orientales, trad. et comm., 2 v., 1941-1942.

\section{$4^{\circ}$ CULTE DES RELIQUES}

Du CANGe, Traité historique du chef de saint Jean-Baptiste, Paris, 1665.

EBERSOLT, Sanctuaires de Byzance, 1921.

Kaufmann, Der Menastempel und die Heiligtümer von Karm Abu Mina, Francfort, 1909.

LEIB (B.), Rome, Kiev et Byzance à la fin du XI siècle, 1924.

SChlumberger (G.), Reliquaire en forme d'église, F.E.P.M., XII, 1905, 236 ss.

\section{$5^{\circ}$ CULTE DES ICONES}

BREHIER (L.), La querelle des images, 1904.

- Les icônes dans l'histoire de l'art et la Russie, M.O., II, 150 ss.

- Icônes non faites de main d'homme, R.A., 1932, 68-77.

- Anciennes clotures de chour antérieures aux iconostases, A.C.E.B., Rome, V, 1936, II.

DoBSCHÜTZ, Christusbilder, 2 v., Leipzig, 1899.

GrabAR (A.), La Sainte-Face de Laon, S.K., 1931.

Grondiss (L.H.), Sur la doctrine des icônes chez Théodore le Studite, A.C.E.B., Paris, VI, 1948.

PERDRIZET, De la Véronique et de sainte Véronique, S.K., 1932, 1 ss.

SCHWARTZLOSE, Der Bilderstreit, Gotha, 1890. 
WulfF et AlPatov, Denkmäler der Ikonenmalerei, Dresde, 1925.

\section{$6^{\circ}$ SUPERSTITIONS}

BouCHE-LECLERCQ, Histoire de la Divination dans l'antiquité, 3 v., 1879-1881.

- Histoire de l'Astrologie grecque, 1899.

BREHIER (L.), Un patriarche sorcier à Constantinople (Jean Hylilas, 837-842), R.O.C., 1904.

Cumont (F.), L'Égypte des astrologues, Bruxelles, 1937.

JERPHANION (G. DE), La formule magique Sator-Arepo... (La voix des Monuments, II, 38-76 et 77-94).

(ECONOMOS, La vie religieuse dans l'Empire byzantin au temps des Comnènes et des Anges, 1918.

Ruelle (Ch.), La Chrysopée de Psellos, R.E.G., 1889.

SChlumberger (G.), Amulettes byzantines anciennes contre les maléfices et les maladies, R.E.G., 1892.

SwoBoDA, La démonologie de Michel Psellos, Brno, 1927.

\section{$7^{\circ}$ DISSIDENTS}

\section{a) Hérésies orientales}

CuMONT (F.), Les religions orientales dans le paganisme romain, 1907.

- Recherches sur le symbolisme funéraire des Romains, 1912.

Gregoire (H.), Pour l'histoire des églises pauliciennes, Misc. J., II, 509 Ss.

Millet (G.), La religion orthodoxe et les hérésies chez les Yougoslaves, R.H.R., 1917.

OBolensky, The Bogomiles, Cambridge, 1948.

\section{b) Juifs}

ANDREADES, Les Juifs dans l'Empire byzantin, E.B., 1929, 23-43.

Cumont (F.), Une formule grecque de renonciation an judaïsme (Wiener Studien, 1902, 462 ss.).

Giannopoulo, Communautés juives de la Grèce orientale (en grec), E.B., 1933, $187 \mathrm{sI}$.

JUSTER, Les Juifs dans l'Empire romain, leur condition juridique, économique et sociale, 2 v., 1914.

KARPPE, Les origines et la nature du Zohar, 1901.

KAUfMANN, Ein Brief... über messianische Bewegung... aus dem Jahre 1096, B.Z., 1898, 83 ss.

KouKOUles (Ph.), Glossaire hébreu-hellénique, B.Z., 1910, 422-429.

STARR (J.), The Jews in the Byzantine Empire, 641-1204, B.Ng., I, Athènes, 1939.

- The Jewries of the Levant after the fourth Crusade, Paris, 1949. 
c) Islam

GüTerbock (C.), Der Islam lui Lichte der byzantinischen Polemik, Berlin, 1912.

$$
\text { LIVRE V. - LA VIE INTELLECTUELLE }
$$

\section{$1^{\circ}$ LA LITTERATURE}

a) Ouvrages généraux

DIETERICH (K.), Geschichte der byzantinischen und neugriechischen Literatur, Leipzig, 1902.

KRUMBACHER (Voir « Ouvrages d'ensemble », p. 569).

MonTElATICI, Storia della Letteratura bizantina (324-1453), Milan, 1916.

MORAVCSIK (Voir « Ouvrages d'ensemble », p. 569).

SANDYs (E.), A History of the Classical Scholarship... Book V. The Byzantine Age (530-1350), Cambridge, 1903.

\section{b) Les livres, matière et présentation}

BIRT, Die Buchrolle..., Leipzig, 1907.

GARDTHAUSEN, Griechische Paläographie, Leipzig, 1879.

- et MARIA VOGEL, Die griechische Schreiber des Mittelalters und der Renaissance, 1909 [supplément à la Zentralblattf. Bibl. Wesen, XXXIII].

MAZON (Paul), Eschyle, B.L., 1931, Introduction, I-XXXII [les mss. grecs, considérations générales].

PIRENNE (H.), Le commerce du papyrus dans la Gaule mérovingienne. A.I.C.R., 1928,178 ss.

StRZYGOWSKI (J.), Eine alexandrinische Weltchronik, Vienne, 1906 (fragments de papyrus illustrés).

\section{c) La langue}

DeISSMAN, Die Sprache der griechischen Bibel (Theolog. Rundschau, 1912, 339 SS.).

DIETERICH (K.), Untersuchungen zur Geschichte der griechischen Sprache, B.A., 1898.

MeILlet (A.), Histoire de la langue grecque, 1913.

Renault (E.), Etude de la langue et du style de Michel Psellos, 1920.

$$
\text { d) Auteurs (Monographies sur des) }
$$

BuCKLER (Georgina), Anna Comnena, Oxford, 1929.

DRUON, Synésius, 1859.

DuchatauX, Jean Tzetzès et ses études sur Homère, T.A.R., CIX, 1902, 242-277.

- Eustathe, archevêque de Thessalonique..., T.A.R., CVIII, 143-173. 
FESTA (N.), Longibardos, B.N., 1931, 101 ss.

FISCHER (W.), Iohannes Xiphilinos, Patriarch von Konstantinopel, Plauen, 1883.

Mitchison (Naomi), Anna Comnena, Londres, 1929.

PAPADIMITROU, Theodor Prodromos, Pétersbourg, 1907.

PETIT, Essai sur la vie et la correspondance de Libanius, 1866.

VAST (H.), Le cardinal Bessarion, 1878.

\section{e) Hagiographie}

BREHIER (L.), Le romantisme et le réalisme à Byzance [d'après les Vies des saints], C, Janvier 1922.

DeleHAYE (H.),. Les légendes grecques des saints militaires, 1909.

- Les Saints stylites, Bruxelles, 1923.

HeISEnBerg (A.), Johannes Batatzes der Barmherzige, B.Z., 1905.

LOPAREV, Vizantiiskiia Jitii Sviatych, VIII-IX Viekov, V.V., 1910 à 1912 (XVII à XIX).

Norman (H.), BAynes, The Pratum Spirituale, Misc. J., II, 404 ss.

SIRARPIE TER NERSESSIAN, L'illustration du roman de Barlaam et Joasaph, 1937.

\section{f) Mélodes}

Bouvy (E.), Poètes et Mélodes. Origines du rythme tonique..., 1886.

СНАвОт (J.B.), Littérature syriaque, 1934.

DUVAL (Rubens), La littérature syriaque, 1907.

EsustratiAdes, Romanos le Mélode et ses ouvres poétiques, E.B., 1939, $182-$ 253 (en grec).

KrUMBACHER (K.), Die Akrostichis in der griechischen Kirchen-poesie, B.Ak.W., 1904.

PITRA (cardinal), Hymnographie de l'Église grecque, Rome, 1867.

g) La musique byzantine

Esustratiades (S.), Jean Coucouzelis, E.B., 1938.

GEROLD (Th.), La musique au moyen âge (musique liturgique byzantine, 46 ss.), 1932.

HeEg (Carsten), La notation ekphonétique, Copenhague, 1935.

— Du nouveau sur la musique byzantine, L'Octoechos, A.C.E.B., 1948, VII, Bruxelles.

THIBAUT (J.), Origine byzantine de la notation neumatique de l'Église latine, 1907.

- La musique instrumentale chez les Byzantins, E.O., 1901-1902, 347 ss.

TIBY (O.), La musica bizantina, Milan, 1938.

Tillyard (H.), Handbook of the middle musical notation, Copenhague, 1935.

- A musical Study of the hymns of Casia, B.Z., 1911, 402485.

WeLleSz (E.), Der Stand der Forschung auf dem Gebiete der byzantinischen Kirchenmusik, B.N., 1936, 729 ss. 


\section{h) L'épopée}

Baud-Bovy (S.) et Gregorre (H.), Notes sur l'épopée byzantine, B.N., 1938, 249 ss.

BREHIER (L.), Un héros de roman dans la littérature byzantine, ClermontFerrand, 1904.

Gregolre (H.), Digenis Akritas. The byzantine Epic in History and Poetry, New York, 1942 (Voir B A.B.L., 1947, VI-IX, 283 ss.).

- Le tombeau et la date de Digénis Akritas, B.N., 1931, 481 ss.

- Autour de Digénis Akritas, B.N., 1932, 287 ss.

\section{i) Le théâtre}

Baud-Bovy (S.), Sur un "Sacrifice d'Abraham » de Romanos et sur l'existence d'un théâtre religieux à Byzance, B.N., 1938, 321 ss.

BREHIER (L.), Les miniatures des Homélies du moine Jacques et le théâtre religieux à Byzance, F.E.P.M., XXIV, 1921.

CotTas (Venetia), Le théâtre à Byzance, 1931.

- L'influence du drame "Christos Paschôn "sur l'art chrétien d'Orient, 1931.

LA PIANA, Le rappresentazioni sacre nella letteratura bizantina..., Grottaferrata, 1912.

REICH, Der Mimus, Berlin, 1903.

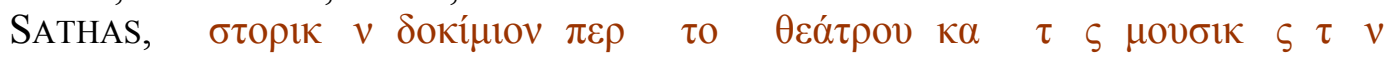

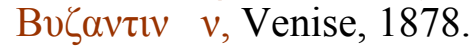

VoGt (A.), Etudes sur le théâtre byzantin, B.N., 1931, 37 ss., 623 ss.

$$
\text { j) Poésie savante }
$$

BANESCU (N.), Deux poètes byzantins inédits, Bucarest, 1913.

COUAT, La poésie alexandrine, 1882.

MAAS (P.), Das byzantinische Zwölfsilber, B.Z., 1903, 279-323.

- Metrische Akklamationen der Byzantiner, B.Z., 1912, 28-51.

\section{k) Littérature populaire}

BezoBrazov, Vizantiiskija Skazania (Contes byzantins), V.O., I, 117 ss.

GIDEL, Etudes sur la littérature grecque moderne, 1866.

KRUMBACHER (K.), Mittelgriechische Sprichiwörter, B.Ak.W., 1900.

\section{$2^{\circ}$ PHILOSOPHIE ET SCIENCES}

Anastos (Milton V.), Pletho's Calendar and Liturgy, D.O.P., 1948, IV, 185 ss. Berthelot (M.), La Chimie au Moyen Age, 3 v., 1893.

BÖRJE KNÖs, Gémiste Pléthon et son souvenir, B.L. (Lettres d'humanité 1950, 97

ss.). 
BrehIER (Émile), Histoire de la philosophie, I, L'Antiquité et le Moyen Age, $2^{\mathrm{e}}$ éd., 1948.

—Ibid., Fasc. supplém. La philosophie byzantine, par TATAKIS, 1949 (préface d'Émile Bréhier).

- La philosophie du Moyen Age, E.H., 1937.

BLOCH (I.), Byzantinische Medizin..., Berlin, 1902.

BRUNET (F.), Euvres médicales d'Alexandre de Tralles, I, 1933.

GuILland (R.), Essai sur Nicéphore Grégoras, 1926.

JugIE (M.), Georges Scholarios, professeur de philosophie, A.C.E.B., Rome VI, 1936, I, 482-494.

- La polémique de Georges Scholarios contre Pléthon, B.N., 1935, 517 se.

OUSPENSKY (Th.), Le procès d'hérésie de Jean Italos, I.R.I., 1897, 11.

STRZYGOWSKI (J.), Der Bilderkreis des griechischen Physiologus, B.A., II, 1890.

VALDENBERG, La philosophie byzantine aux $I V^{e}$ et $V^{e}$ siècles, B.N., 1927, 237 ss.

\section{$3^{\circ}$ ENSEIGNEMENT}

BREHIER (L.), L'Enseignement supérieur à Constantinople dans la dernière moitié du XI siècle, R.I.E., 1899, 97 ss.

- Notes sur l'Enseignement supérieur à Constantinople, B.N., 1926, 73-94 et 1927-1928, 13-28.

— L'enseignement classique et l'enseignement religieux à Byzance, R.P.P.S., 1941, 34-69.

COLlinet (P.), Histoire de l'École de droit de Beyrouth, 1925.

CONYBEARE, Ananias of Shirak, B.Z., 1897.

FuCHS (F.), Die höheren Schulen von Konstantinopel im Mittelalter, B.A., VIII, 1926.

GÜTERBROCK, Byzanz und Persien, Berlin, 1906.

HARRENT, Les écoles d'Antioche, 1898.

HeISENBERG (A.), Apostelkirche, Leipzig, 1908.

HUSSEY, Church and learning in the Byzantine Empire (867-1185), Oxford, 1937.

KUGENER (M.), Les brimades aux $I V^{e}$ et $V^{e}$ siècles, Liège, 1905 (ext. Rev. Un., Bruxelles).

MARIN, Les moines de Constantinople... jusqu'à Photius, 1897.

Petit DE JulleVILle, L'École d'Athènes, 1868.

SCHISSEL (O.), Marinos von Neapolis und die neuplatonischen Tugenden, B.N., I, 1928.

\section{$4^{\circ}$ L'ART BYZANTIN \\ a) Ouvrages généraux}

BREHIER (L.), L'art byzantin, 1924.

- De l'art antique à l'art médiéval, dans H.G.A., 1, 354-465, II, Art roman.

- La rénovation artistique sous les Paléologues et le mouvement des idées, M.D., II, 1 ss. 
Dalton, Byzantine Art and Archaeology, $1^{\text {re }}$ éd., Oxford, 1911.

Dienl (Ch.), Manuel d'Art byzantin, 2 v., $2^{\mathrm{e}}$ éd., 1925.

DuTHUIT-VolBACH, Art byzantin, 1933.

Exposition d'art byzantin de 1931 (Catalogue de l'), préf. de Ch. Diehl.

LEMERLE (P.), Le Style byzantin, 1943.

Millet (G.), L'art byzantin dans A. Michel, Hist. de l'Art..., I, 127-301, 1905.

- L'art chrétien d'Orient, du milieu du XII au milieu du XV siècle (même ouvrage, III, 928-962), 1908.

\section{b) Monographies (Villes et régions)}

BERTAUX, L'art dans l'Italie méridionale, 1904.

DIEHL (Ch.), L'art byzantin dans l'Italie méridionale, 1894.

- Ravenne (V.A.C.), 1903.

- Venise (V.A.C.), 1915.

- Palerme et Syracuse (V.A.C.), 1907.

Millet (G.), Les monastères et les églises de Trébizonde, B.C.H., 1895, 419 ss.

- Le Monastère de Daphni, 1899.

- Recherches au Mont-Athos, B.C.H., 1905, 123 ss.

- Monuments byzantins de Mistra, 1910.

SCHMITT (Th.), Kahrié-Djami, I.R.I., XI, 1906.

STRUCK, Mistra, Vienne et Leipzig, 1910.

STRZYGOWSKI (J.), L'ancien art chrétien de Syrie (préf. de G. Millet), 1936.

$$
\text { c) Origines }
$$

Снарот (V.), Les destinées de l'hellénisme au delà de l'Euphrate, M.S.A.F., 1904.

Cumont (F.), Fouilles de Doura-Europos, F.E.P.M., XXVI, 1923.

DUMESNIL DU BUISSON, Les peintures de la Synagogue de Doura-Europos (préface de G. Millet), Rome, 1939.

GrabAR (A.), Plotin et les origines de l'esthétique médiévale, C.A., I, 1945.

$$
\text { d) Architecture }
$$

EBERSOLT (J.), Monuments d'architecture byzantine, 1934.

- Sainte-Sophie de Constantinople, étude de topographie d'après les «Cérémonies », 1910.

— et THIERS, Les églises de Constantinople, 1913.

GRABAR et DUPONT-SOMMER [La cathédrale d'Édesse d'après une hymne syriaque], C.A., II, 1947.

MiLlet (G.), L'École grecque dans l'architecture byzantine, 1916.

RAMSAY (W.) et miss BELL, The thousand and one Churches, Londres, 1909.

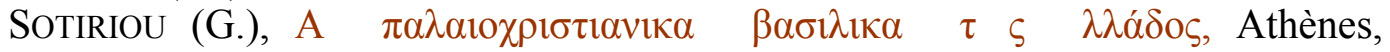
1931.

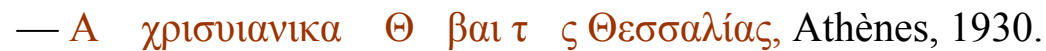

STRUCK (A.), Die mittelbyzantinische Kirchen, A.M., 1906, 79 Ss. 
e) Sculpture

BREHIER (L.), Études sur l'histoire de la sculpture byzantine, M. Scien., 3, 1911.

- Nouvelles recherches sur l'histoire de la sculpture byzantine, M. Scien., 9, 1913.

- La Sculpture et les Arts mineurs byzantins, 1936 (H.A.B., Ch. Diehl).

PICARD (Ch.), La Sculpture antique..., II, ch. 3, Origines de la sculpture byzantine, 1925.

SOTIRIOU, Icônes byzantines en relief (en grec), M.K., 125 se.

Xyngopoulos, Reliefs franco-byzantins d'Athènes (Ephemeris arch., 1932, 69 Ss.).

\section{f) Mosaïque et peintures murales}

BREHIER (L.), Les mosaïques à fond d'azur, R.E.B., III, 20 ss.

Cledat (J.), Le monastère et la nécropole de Baouit, 3 v., Le Caire, 1904-1916.

DIEHL (Ch.), La peinture byzantine (H. de l'Art byz., Ch. Diehl), 1933.

- Monuments chrétiens de Salonique, 1918.

- L'église et les mosaïques du couvent de Saint-Luc en Phocide, 1889.

GRUNEISEN (de), Sainte-Marie-Antique, Rome, 1911.

JERPHANION (de), Les églises rupestres de Cappadoce, 2 v., 3 atlas, 1925-1942.

Millet (G.), Les monuments de l'Athos, I, Les peintures, 1927.

— et TAlBOT Rice (D.), Byzantine Painting at Trebizond, Londres, 1936.

MurATOFF (P.), La peinture byzantine, 1928.

SCHMITT (Th.), Panagia Angeloktistos [Chypre], L.R.I., XV, 1911.

Whittemore (Th.), The Mosaics of Haghia Sofia at Istanbul, I, Narthex, Oxford, 1933.

— Id., II, Southern Vestibule, Oxford, 1936.

- Id., III, The Imperial Portraits of the South Gallery, Oxford, 1945.

- L'état actuel des recherches dans le monastère de Chora à Constantinople,

A.C.E.B., Bruxelles, VII, 1948.

WulfF, Die Koimesis Kirche in Nicaea und ihre Mosaiken, Strasbourg, 1903.

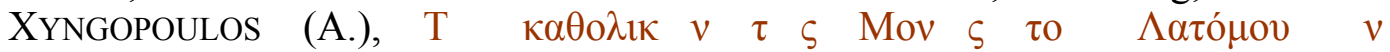

$\Theta \varepsilon \sigma \sigma \alpha \lambda$ ovík $_{\kappa} \alpha \quad \tau \quad v \alpha v \tau \quad \psi \eta \varphi 1 \delta \omega \tau$ tóv, Athènes, Deltion, 1929,

g) Iconographie

Brehier (L.), L'Art Chrétien. Son développement iconographique, 2 éd., 1928.

- La sculpture iconographique dans les églises byzantines, B.H.A.R., XI, 1925.

- Les visions apocalyptiques dans l'art byzantin. (Ext. de Arta si arheologia), Bucarest, 1930.

Grondiss (L.H.), L’iconographie byzantine du Crucifié mort sur la croix, Leyde, 1941.

MiLlet (G.), Recherches sur l'iconographie de l'Évangile aux XIV $V^{e}, X V^{e}$ et XVI s..., 1916.

- L'Ascension d'Alexandre, S., 1923, 85 ss. 
Stefanescu (J.D.), L'Illustration des liturgies dans l'art de Byzance..., Bruxelles, 1936.

TISCHENDORF, Apocalypses apocryphae, Leipzig, 1865.

\section{h) Le portrait}

BREHIER (L.), Le portrait dans l'art byzantin, Formes, XXXI, 1938, 344 as.

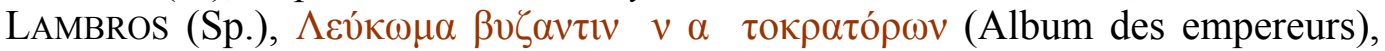
Athènes, 1930.

Millet (G.), Portraits byzantins, R.A C., 1911.

WhitTEMore (Th.), A portrait of the Empress Zoe and of Constantine IX, B.N., 1948,223 ss.

\section{i) Miniature}

Bordier (H.), Peintures des manuscrits grecs de la Bibliothèque Nationale, 1883. Buchtal (H,), The miniatures of the Paris Psalter [Paris, gr. 139], Londres, 1948.

EBersolt (J.), La Miniature byzantine, 1926.

GRABAR (A.), Miniatures byzantines de la Bibliothèque Nationale, 1939 [agrandissements].

LASSUS (J.), Les miniatures byzantines $d u$ «Livre des Rois », M.A.H., 1928.

OMONT (H.), Fac-similés des miniatures des plus anciens manuscrits grecs de la Bibliothèque Nationale (VI-XI ${ }^{\mathrm{e}}$ s.), 1902.

- Evangiles avec peintures byzantines du XI siècle, 1909.

OUSPENSKY (Th.), L'Octateuque de la Bibliothèque du Sérail à Constantinople, I.R.I., 1912.

Willoughby (H. R.), Codex 2400 and its miniatures (Rockefeller. Mc. Cormick Mss., Chicago), A. Bull., XV, 1, 1933.

j) Arts mineurs

ALFÖFDI, L'aiguière d'or de Saint-Maurice en Valais, A.C.E.B., VI, Paris, 1948. BREHIER (L.), Le coffret byzantin de Reims et les coffrets d'ivoire à rosettes, G.A.B., 1931.

Chartraire, Le trésor de la cathédrale de Sens (Memoranda, Paris, s. d.) et R.A.C., 1911.

EBERSOLT (J.), Les arts somptuaires de Byzance, 1923.

LAUER (Ph.), Le trésor du «Sancta Sanctorum » à Rome, F.E.P.M., XV, 1906.

Millet (G.), Broderies religieuses de style byzantin, 1947.

Molinier (E.), Histoire générale des arts appliqués à l'industrie. I, Les ivoires, 1896. II, L'orfèvrerie..., 1904.

SCHLumberger (G.), Mélanges d'archéologie byzantine, 1895. 


\section{$5^{\circ}$ L'EXPANSION DE L’ART BYZANTIN}

a) Orient

EUSTACHE DE LORAY, Les mosaïques du VIII siècle dans la mosquée des Omeyades à Damas. Cahiers d'art, IV, 1929.

JERPHANION (G. de), Les Miniatures du manuscrit syriaque $n^{\circ} 559$ de la Bibliothèque Vaticane. Cité du Vatican, 1930 (J. S., 1940, 145 ss.).

STRZYGOWSKI, Amra und seine Malerein (Zeit. f. bildende Kunst), Vienne, 1908.

\section{b) Occident}

BERger (S.), De la tradition de l'art grec dans les manuscrits latins des Evangiles, M.S.A.F., LII, 1891.

BOINET (A.), La miniature carolingienne, 1913.

BorChGRAVE (C. de), De l'influence des arts orientaux dans nos régions au Moyen Age (Bull. Soc. Archéol.), Bruxelles, 1948.

Bouillet, L'Eglise et le trésor de Conques, Rodez, 1905.

BREHIER (L.), L'art en France, des invasions barbares à l'époque romane, 1930.

- Le Style roman, 1941.

— Les églises d'Aquitaine à coupoles et l'origine de leur architecture, J.S., 1927.

- Ivoires chrétiens de la région de Brioude, A. Br., XX, 1939, 19 ss.

EBERSOlt (J.), Orient et Occident. Influences byzantines et orientales en France, 2 v., 1928.1929.

Focillon (H.), Art d'Occident, 1938.

- Peintures romanes des églises de France, 1938.

Grousset (R.), Hist. de l'Orient latin. L'art roman et l'art gothique, dans H.G.M.A., IX, 1945.

HILl (G.), History of Cyprus, III, The fine arts, 1117 s., Cambridge, 1948.

LeINDINGER (G.), Das sogenannte Evangeliarium Kaiser Otto III, Munich, 1911

LEITSCHUCH, Geschichte der Karolingischen Malerei, Berlin, 1894,

MALE (E.), Rome et ses vieilles églises, 1943.

- L'art religieux du XII siècle en France, 1922.

- L'art religieux de la fin du Moyen Age en France, 1908.

MERCIER, Les Primitifs français. La peinture clunysienne en Bourgogne..., 1932.

MerimeE (P.), Etude sur les arts au Moyen Age, 1841.

MuÑoz (A.), L'art byzantin à l'Exposition de Grottaferrata, Rome, 1906.

REY (R.), Le sanctuaire paléochrétien de La Daurade à Toulouse.

STRZYGOWSKi (J.), Der Dom zu Aachen, Leipzig, 1904.

Westwood, Fac-simile of Miniatures and Ornaments in Anglo-Saxon and Irish Manuscripts, Londres, 1868.

WoODRUF (Helen), The Iconography and Date of the Mosaics of La Daurade, A.

Bull., XIII, 1931, 81-104. 
c) Slaves

L'art byzantin chez les Slaves, deux recueils dédiés à la mémoire de Th. Ouspensky. I, Les Balkans, 2 v., II, L'ancienne Russie et les Slaves catholiques, 2 v., 1932.

AlPAtOFF, La Trinité dans l'art byzantin et l'icône de Roublev, Paris, 1927.

EBERSOLT (J.), Fresques byzantines de Néréditsi, F.E.P.M., XIII, 1906.

GRABAR (A.), Les influences orientales dans l'art des Balkans, 1928.

- La peinture religieuse en Bulgarie, 1928.

- L'église de Boïana, Sofia, 1924.

KondAKOV (N.P.), Ikonografiia Gospoda Boja i Spasa nachego Iisusa Christa, Pétersbourg, 1905.

- Ikonografiia Bogomateri, 2 v., 1914-1915.

Lathoud (D.), Le thème iconographique du "Pokrov" de la Vierge, M.O., II, 302 ss.

MACULEVIČ, Argenterie byzantine en Russie, M.O., II, 292 ss.

Millet (G.), L'ancien art serbe. Les Églises, 1919.

NeKRASOV, Les frontispices architecturaux dans les manuscrits russes..., M.O., II, 253 ss.

OKunev (N.), Monumenta artis Serbicae, 4 albums, Prague, 1928-1932.

PETROVIČ, La peinture serbe du moyen âge, Belgrade, 1930.

REAU (Louis), L'art russe, des origines à Pierre le Grand, 1921.

STRZYGOWSKI (J.), Die Miniaturen des serbischen Psalters, Vienne, 1906.

d) Pays roumains

Curtea Domneasca din Argés, Bucarest, 1947, B.C.M.I. (œuvre collective).

GHIKA-BuDESTI, Evolutsia Architecturii în Muntenia, I, Bucarest, 1947.

HENRY (P.), Les églises de la Moldavie du nord, des origines à la fin du XV siècle, Paris, 1930.

IORGA (N.) et BALS, L 'art roumain, Paris, 1922.

- Les arts mineurs en Roumanie, Bucarest, 1934.

STEFANESCU (J.D.), L'évolution de la peinture religieuse en Bucovine et en Moldavie, Paris, 1927.

- La peinture religieuse en Valachie et en Transylvanie, Paris, 1932.

TAFrali (O.), Monuments byzantins de Curtea-de-Argés, Sofia, 1927.

— Le trésor byzantin et roumain du monastère de Poutna, Paris, 1925. 


\section{Index}

Retour à la Table des Matières

\section{A}

abeilles (élevage des), 157; — miel (commerce $\mathrm{du}), 179$.

ABGAE (dynastie des), 114-116.

ABoulfeda, 75, 270.

ABRAHAM (mystère d'), 354.

Académie (impériale), 68 et s.; (platonicienne de Florence), 373; (romaine), 477.

Acémétes, 411.

acrostiches, 324, 327.

affranchissements, 22,30, 143, 145, 149.

Agathias de Myrina, 28, 320.

Agathias le Scholastique, 300.

Agenllus, 133.

Aix-la-Chapelle (tissu d'), 87; note $\mathrm{n}^{\circ} 458$.

Akhmin-Panopolis, 104, 233.

alchimie, 378.

AlCUIN, 460.

ALEXANDRE LE GRAND (légende d'), 74, 86 et s., 92, 341.

AleXANDRE DE TRALles, médecin, 55, 380 et s.

Alexandrie, 101404, 141, 165, 174, 182, 184, 196, 269; (littérature d'), 285 et s., 320, 374, 381, 453; (université d'), 357, 385.

Algésiras, 131.

allégoriques (figures), 461, 462; (méthodes) 361, 397; (poèmes) 319 et $\mathrm{s}$.

Amalfi, 184 et s., 459.

AMAURY, roi de Jérusalem, 65, 95.

ambons, 210.

ambre, 171.

amulettes, 246-248.

Ananias de Shirak, 374, 411.

anaphore, 218, 221.

Anastasis, 239, 311.

Anatolie, voir Asie Mineure.

Ancône, 199.

Ancyre (Angora), 118 et s.
ANDRE (Saint), 124.

Anglo-Saxons, 79, 174 et s.

ANNe CoMnene, 20, 65, 250, 277, 284, 302 et s., 382, 399, 412.

ANNE DALASSENE, 20.

Annési (Anatolie), 137.

ANTHEMIUS DE TRALLES, 378, 381, 424, 432.

anthologies, 28, 286, 320 et s.

Antinoé, 48, 104, 233.

Antioche, 34,53,105-110,111,165, 178, 181, 185, 225, 261, 299, 357.

ANTIOCHUS LE STRATEGE, 305.

antique (littérature), conservation, 286 et s., 477 et s; (enseignement), 408 et s.; (en Occident), 477 et s.

antiquité (histoire de 1'), 286, 297, 304 et s.

Apamée-sur-1 'Oronte, 111.

APION (domaines des), 140-143, 148.

apocrisiaire, envoyé du pape ou d'un patriarche, 329.

apocryphes (évangiles), 310 et s.

apprentissage (contrats d'), 192, 193.

aqueducs, 121.

Aquilée, 123, 427.

Arabes, Arabie, 16, 79, 143, 158, 176-179, 269-272, 305, 338, 390. (art des), 465 et s.; (commerce avec les), 165, 168, 176 et s., 178, 181-183, 184, 382.

architecture religieuse (plans), 207 et s., 423 et s., 429, 432 et s.; (en croix grecque), 433 et s.; construction, 431 et s.; décoration, 206, 207, 209 et s., 424 et s., 436; école grecque, 427 et s.; Syrie, 208.

archontes, 228.

AREthas, évêque de Césarée (Cappadoce), 279 et s., 337, 391.

argenterie (objets d'), 169, 171 et s., 190, 210, $455,458$.

ARgYropoulos (Jean), professeur, 284, 406, 407, 408, 479. 
ARISTOTE, 319, 357, 359, 361, 362, 364, 365, 366, 371-373, 374, 399, 402.

Arméniens, 25, 79, 216 et s., 362, 392.

Armouris (Chanson d'), 337 et s.

aromates (Côte des), 168.

art byzantin, origines, 421-423; apparition, 423-425; histoire, 426; rénovation, 442451; expansion, 131,183 et s., 457-474; influence, 465-474.

artisans, 41 et s., 192 et s.

artistes, 430 et $\mathrm{s}$.

arts somptuaires, 451-455, 473 et s.

ascendant, 269.

ascétisme, 55, 224 et $\mathrm{s}$.

Asie Mineure, 116-120, 138, 153, 161, 230 et s., 432 .

astrologie, 23, 26, 67 et s., 82, 248-251, 254, 374 et s., 376 et s.; (poèmes), 343, 345.

astronomie, 251, 373, 374 et s., 376.

ateliers, 30, 192; (du Palais), 163, 166.

ATHANASE (Saint), fondateur de Lavra, 393.

ATHENAIS-EUDOKIA, impératrice, 19, 97, 125, 234, 277.

Athènes, 125, 126, 207, 265; (églises) 427 et s., 436 .

Athingans, 258.

Athos (monastères de 1'), 156, 366, 367, 368; (architecture), 434 et s.; (peinture), 441; des Amalfitains, 185; de Chilandar, 138; d'Iviron, 185, 313; Karakallou, 185; de Koutloumous, 271; de Lavra, 139, 211, 221; du Pantocrator, 453; de Vatopédi, $238,280,441$.

atrium, 205, 207.

Attalie (Adalia), 119, 195.

audiences impériales, 59, 68.

auriges, voir cochers.

autel (table d'), 39, 208, 210 et s., 213; (portatif), 211, 462 .

autopragie, 139,142 et $\mathrm{s}$.

Autun, 174.

Avars, 77, 123, 171.

Axoum (Éthiopie), 166, 168, 170.

\section{$B$}

Bagdad, 60, 114, 178.

bains, 21, 36, 55 et s., 344 .

Baléares (îles), 131.

Balsamon, 98.

banques (domaniales), 141; (commerciales), 196, 201.

baptême, 24, 223, 224.

baptistères, 223 et $\mathrm{s}$.
BARDAS, 320, 391, 392.

Bari, 230.

BARLAAM, philosophe, 366, 368, 369, 405.

Barlaam et Joasaph, 312, 313, 314.

BASILE (Saint), 29, 137, 373, 385, 415; (liturgie de), 215, 219, 221.

basiliques (origine des), 205, 206.

Belgique (collections d'œuvres d'art byzantin), 191, 463.

Belgrade, 123, 181.

BELISAIRE, 82; (légende de), 340 et s.; voir Procope.

Benjamin de Tudele, 45, 23, 95, 188, 263, 267 et $\mathrm{s}$.

bergers, 156, 157.

BERRY (Jean, duc de), 187.

BERTANDON DE LA BROQUIERE, 353.

Béryte (Beyrouth), 112, 166, 236, 238, 324, 385 et s., 412.

BESSARION (cardinal), 69, 130, 284, 291, 370, 373, 407, 408, 479.

Bethléem, 112.

Bible (manuscrits de la), 277 et s., 279, 280.

bibliothèques, 38, 278 et s., 286 et s., 391, 401, 406, 411, 477; (monastiques), 406, 411, 418 et $\mathrm{s}$.

bijoux, parures, 18,191 et $\mathrm{s}$.

Bithynie, 138.

Blachernes (miracle de la Vierge des), 474.

blé (commerce du), 157, 171, 177, 193.

Bogomiles, 258-260.

Bordeaux, 174.

Bosnie, 258.

Bosporos (Kertch), 122, 171, 172.

Bostra (Arabie), 113.

bouffons de cour, 62, 67.

boulangers, 77, 143, 159 .

bourreaux, 268 .

boussole, 380 .

brigandage, 153 .

briquet, 41.

broderie, 190.

bronze damasquiné, 183.

buccellaires, 142 .

Bulgares, Bulgaria, 79, 125, 126, 127, 156, 181, 237, 259, 467.

BUONDELMONTI, 96.

\section{C}

CABASILAS (Nicolas), 216, 295, 316, 369 et s., $374,404,407$. 
calendrier (figuré), 278, 319, 321; (réforme du), 69, 377; (liturgique), 132, 222 et s.; (de Pléthon), 372; (de régime), 53, 54.

calices, 211 et s.

candélabres, 40.

Cappadoce, 29, 119; (églises rupestres), 51, 209, 238, 247, 428-430, 445, 454, 461.

caravanes, 165, 166.

carême, 54, 222.

carolingien (art), 460-462.

carré magique, 247 et $\mathrm{s}$.

cartes géographiques, 379, 380; voir pavements.

Carthage, 131, 173.

catéchumènes, voir tribunes.

catholique (sens du mot), 356.

Cedrenos (Georges), 159.

Cephalas (Constantin), 320.

Cérémonies (Livres des), 41, 58, 84, 92.

Cesaree de Cappadoce, 279, 337.

Ceylan, 164, 166, 168-170, 171.

chaire (épiscopale), 209; (professorale), 406.

chaise percée, 41.

Chalcédoine, 67.

CALKOKONDYLES, 305, 480.

chameaux, 147.

chancel, 208.

charistikia, 31.

Charlemagne, 74, 177, 460; (légende de), 82,190; (dalmatique dite de), 215.

Charos (Charon), 346.

charrue, 154 et $\mathrm{s}$.

chars, 32, 83, 86, 121, 144, 157.

chasse, 25, 62, 65, 66, 69, 106, 159-162, 379.

châsse, voir reliquaire.

chauffoirs, 36, 308.

chaussures, 51.

cheroubikon, chérubins, 212, 218.

chevaux, 83, 86 et s., 157, 158, 161.

cheveux, barbe, 44,46 et s.

Chine, 44, 62, 74, 158, 165 et s., 167, 169, $172,198,279$.

Chios (île de), 91, 195, 442.

chirurgie, 66.

ChORICIUS DE GAZA, 108, 289.

Christophoros DE MYtilene, 321.

Chronique (universelle), 298 et s. (de Morée), 341,342

Chypre, 17, 54, 198; (architecture française à), 427; (madone de Chiti), 441; (théâtre), 354; (trésor de Kérynia), 49, 51, 212. cimetières, 27, 28, 75.

Clavijo, 75, 96, 240.

Cluny (abbaye de), 464, 465.
Code (justinien), 98, 188; (théodosien), 98, 188.

CoDinus (Pseudo), 46, 58

coffres, coffrets, 32, 38, 192; (d'ivoire), 158, 159, 192, 286.

coiffures (chapeaux), 45, 46; (féminines), 48, 49.

colobium, 44, 459; note $\mathrm{n}^{\mathrm{o}} 2505$.

colons, 148.

Comans, 156.

commerce (avec l'Extrême-Orient), 103, 110, 164, 165.171, 194; (avec l'Occident), 103, 172-176; (avec les peuples du Nord), 171, 172.

communion (rite de la), 219; (des Apôtres), 210, 212, 215, 221.

concile quinisexte, 98

confessions, cryptes, 211, 212.

confirmation (sacrement de la), 224.

Conques en Rouergue (abbaye de), 462.

consul, 94 et s., 97; (des philosophes), 396, 398 et s., 404, 411.

Constantinople (fouilles), 52, 75 et s., 90, 91. I. (Plan), 75, 76; (témoignages anciens), 73, 74, 75. II. Quartiers, 193; (des Blachernes), 77, 83, 97; (Corne d'Or), 76, 77, 84, 196, 199, 269; (Hebdomon), 76; (du Lycos), 77; (des Manganes), 76, 231; (du Phanar), 37; (de la Propontide), 77; (de Psamathia), 80. 111. Places et rues, (Atmeldan), 75, 87; (Augustaeon), 80, 82; (Capitole), 384; (Forums), 76, 77, 80, 84; (Mésè), 77, 80; (Porte d'Or), 76,80; note $\mathrm{n}^{\circ}$ 413. IV. Monuments, 38, 55 et s., 64, 87. V. Églises (St-André-de-Krisis), 433; (Saints-Apôtres), 76, 226, 229, 413, 433; (Blachernes), 226, 324; (Boudroum-djami, Myrelaion), 434; (Fétiyé djami), 76, 444; (Chalkopratiana), 226; (Ste-Irène), 97, 433, 434; (Kahrié djami), 444, 470, 472; (du Pantocrator), 434; (des saints Serge-etBacchus), 226, 230, 425, 433; (SainteSophie), 75, 85, 208, 210, 226, 424, 431, 432, 439, 440 et s. VI. Habitants, population (notitia Urbis), 77; (chiffres de la), 76-80; (immigrés), 77, 79; (gasmuls), 79, 80, 333, 342; (musulmans), 79, 269, 270; (types de la rue), 78, 79, 80-82; (fléaux), 77 et s. VII. Circulation, (métiers), 80, 81, 82, 177; (foules), 84 et s.; (police), 59 et s.; (marchés), 80, 165 et s., 180-184; (restaurant populaire), 81; (cortèges, processions), 68, 84, 85, 97, 238. VIII. Faubourgs, (Sykes), 77, 97; (Péra), 263; (Ga- 
lata), 196, 199; (Saint-Mamas), 62, 79, 87, 180; [voir Hippodrome, palais].

contrats, 18.

conventions picturales, 422, 423 .

Corinthe, 126, 128, 195, 265.

Cosme et DAMIEN (saints anargyres), 114, 232.

cosmologie, 170 et s.

costume (hommes), 41-45, 83, 175; (femmes), 21,42 et s., 47, 48; populaire, 44; liturgique, 30, 213, 214.

coton, 175, 186.

crédit agricole, 146.

Crète, Crétois, 127, 240, 309, 450, 451.

Crimée, 122 et s., 171, 179, 181, 216.

croisades, 81, 194 et s., 263.

croix d'autel, 211, 219.

Crucifixion, 172, 219, 430, 442.

cuillers, 51, 212, 220.

cuisine (batterie de), 40, 41.

culte (des morts), 26 et s; (des martyrs), voir Martyrium.

Curtea de Argès (Valachie), église princière, 469.

Cyrille et Methode (Saints), 124, 161, 217, 390.

\section{$D$}

Damas, 178, 466.

danseuses, 48 .

Daphni (Attique), 38, 39, 230, 239, 428, 436, $439,441,445$; note $n^{\circ} 2409$.

défrichement, 154.

Deisis (supplication), 209,227,441.

DEMETRIUS (Saint), 124, 410; voir Thessalonique.

Denys L'AREOPAGITE, 357, 358, 363.

déposition de croix, 461.

descente aux enfers, 314, 315.

deuil, 26.

dévotion (pratiques de), 36, 51, 58, 61, 68, 108-110.

Didier, abbé du Mont -Cassin, 183.

DiGENIS AKRITAS (épopée de), 332-339.

diptyques (consulaires), 94 et s., 192; (liturgiques), 219.

dirigisme, 163 et s., 178, 193, 194.

dispute philosophique, 366 .

domaines ruraux, 30-32, 137-147.

domestique des scholes, chef d'une division de l'armée, 338.

douanes (impériales), 168,196,198; (franques), 176.
DOUKAS, chroniqueur, 304 et s.

Doura-Europos, 43, 205, 265 et s., 422, 423.

droit (enseignement du), 384-387, 391 et s., 395 et $\mathrm{s}$.

Dyrrachium (Durazzo), 123, 184.

\section{$E$}

échecs (jeu des), 62, 65.

éclairage, 40.

éclipses (calcul des), 377, 378.

école patriarcale, 381, 389, 399 411-415.

écoles théologiques anciennes, 108 et s., 115.

Édesse, 114, 115, 261.

EDRISI, 95, 270.

Égypte, 87, 140-143, 155, 156164,175 et s., 213.

ekboesis (clameur), 150, 151.

ekphrasis (description), 293 et s.

éléphants, 168, 177, 192.

élevage (des bestiaux), 30, 32, 118143 et s, $147,148,155$ et $\mathrm{s}$.

ÉLIE (culte du prophète), 229, 352.

ÉLIE (Saint), martyr à Damas, 308.

émaillerie, 191, 462, 463.

emboloi (portiques), 80 .

émigrants, 153.

Empereurs - ALEXANDRE, 246, 252; ALEXIS I COMNENE, 51, 60, 64-66, 126, 138, 156, 185, 193, 250, 252, 258 et s., 302, 319, 346, 363, 382, 398. AleXIS III, 67, 68, 96, 188, 246, 251. ANASTASE I, 94, 101, 164. ANASTASE II, 389. ANDRONIC I, 45, 46, 246. ANDRONIC II, 37, 68, 198, 200, 222, 251, 252, 269, 352, 403-405. ANDRONIC III, 37, 69, 201. ANDRONIC IV, 139. BASILE I, 84, 145, 177, 228, 254, 261, 262, 271, 440. BASILE II, 127, 183, 187, 394, 454. Constantin LE GRAND, 52, 164, 227, 384, 423. CON-STANTIN IV, 47. Constantin V, 47, 331. Constantin VI, 143, 249 et s., 308, 331, 390. CONSTANTIN VII Porphyrogenete, 61, 238, 283, 331, 392, 393. Constantin Monomaque, 19, 48, 98, 180, 270, 276, 301, 315, 395 et s., 440. Constantin XI Dragases, 130, 200, 228, 292. HERACLIUS, 77, 186, 235, 261, 318 et s., 388. IRENE, 87,126. ISAAC COMNENE, 62, 122. ISSAC L'ANGE, 67, 156, 270. JEAN TZIMISKES, 84, 180, 183, 238, 256, 301, 392. JEAN II COMNENE, 66, 95, 303, 440. JEAN VATATZES, 147, 197, 310, 400. JEAN V Paleologue, 198, 201. JEAN VI CANTACUZENE，69，147，272, 
277, 280, 281, 304, 405. JEAN VIII, 46, 47, 69, 161, 198, 200, 201, 264. JULIEN, 260, 331, 380, 385. JUSTIN I, 107. JUsTIN II, 123，167，227，252. JUSTINIEN LE GRAND, 56, 58, 59, 77, 81, 97, 98, 101, $103,110,113,114,115,116,118,121$, $122,125,131,132,140,143,156,164$, $167,171,172,193,214,265,266,386$, 387 et s., 423. LEON I, 49. LEON III L'ISAURIEN, 261, 270, 388 et s. LEON V L'ARMENIEN, 61, 178, 252, 253, 254. LEON VI, 18, 59, 60, 61, 145, 158, 177, $178,180,188,223,252,293,294,301$, 391, 439. MANUEL COMNENE, 45, 65, 66, 67, 196, 199, 246, 250 et s., 264, 268, 271, 303, 399. Manuel II Paleologue, 69, 139, 187, 198, 199, 264, 272, 277, 291, 294, 315, 405. Michel II LE BEGUE, 157, 252, 253, 254, 258, 390. MiCHEL III, 60, 61, 87, 98, 119, 229, 271. MiCHEL IV, 59, 61. MiCHEL V, 395. MiCHEL VI, 46, 78. Michel VII, 146, 193, 363. MicheL VIII PAleologue, 68, 197, 402 et s.; (autobiographie), 306. NiCEPHORE I, 60, 245, 253, 308. NiCEPHORE PHOCAS, 60, 61, 85, 95, 125, 127, 314. NicEPHORE BotANiATES, 46, 60, 138. PHILIPPICUS (VARDAN), 253. ROMAIN LECAPENE, 180, 181, 237 et s., 434. ROMAIN II, 62, 394. THEODORE I, 400. THEODORE II LASCARIS, 276, 290, 316, 364, 401. TheOdose II, 29, 61, 62, $91,106,131,261,279,384$ et $\mathrm{s}$. TheophiLE, 20, 47, 61, 98, 178, 236, 252, $315,390$.

encensoirs, 212.

enfants (première éducation), 23, 24.

enkolpia, 17, 214, 229.

eukyklios paideia, 391, 392, 399, 412, 418.

Éphèse, 62, 116, 117, 229, 402.

EPHREM LE SYRIEN (Saint), 324.

épikanikleiou, préposé à l'encrier et à la signature impériale, 249, 365.

épices (commerce des), 165, 175, 194.

épiclèse, 219.

épigonation, 214.

épigrammes, 28, 319-321, 322; (voir anthologies).

épistolographie. 294-296.

épitrachelion, 214.

ermites, 175.

esclaves, 22 et s., 42, 58, 60, 78, 83, 145, 151, $158,171,179$.

ÉSOPE (fables d'), 24, 346.

Espagnols, 79, 176, 184, 200. étables, 36.

étain (commerce de 1'), 175.

étiquette, 57, 58, 63, 65, 67, 69 .

étrier, 158.

EUCHITES, 243, 259.

EUDE DE DEUIL, chroniqueur, 45, 64.

EUGENE (Saint), 121.

EUGENIKOS (Jean), 49.

eunuques, 19, 21, 22, 47, 58, 65.

EUSEBE DE CESAREE, 298 et $\mathrm{s}$.

Eustathe DE ThessaloniQue, 23, 83, 84, $277,305,345,353,399$.

EUSTRATIOS DE NiCEE, 363 et s.

EUTHYME, patriarche (Vie d'), 301.

Euthymios ZigaBenos (Panoplia), 259, 271.

EUTYCHIOS, patriarche, 218.

EvAGRIOs, 298.

évangéliaires, évangiles illustrés, 279, 280, 453, 454, 461, 462.

\section{$F$}

factions (du Cirque), 9, 91-94, 95, 98, 104.

famille, 15-32, 293; (noms de), 15, 16.

fards, 17, 49, 97.

Fatimites (califes), 185.

faucons de chasse, 160.

femmes (condition des), 18-22, 24 et s., 51, 65, 94, 209 et s.

fer à cheval, 158 .

feu grégeois, 378.

fiançailles, 16 et $\mathrm{s}$.

fibules, 50 .

fidèles (obligations religieuses des), 209, 223, 224.

FILELFE (François), 21, 405, 408.

Flandre (draps de), 194, 199.

Florence, 197, 198, 199, 201.

foires, 124, 194, 195.

forges, 158 et $\mathrm{s}$.

fortunes familiales, 30-32.

fourchette, 51 et $\mathrm{s}$.

fourrures, 41, 44, 171, 179.

Francs, 63, 64, 79, 182.

France (rois de), 45, 64, 81.

FREDERIC II, 197.

funérailles, 25, 26.

\section{G}

GAKIEN, 380, 382.

Galla PlaCidia, 132.

Gasmouls, 80, 342.

Gaule mérovingienne, 55, 173-176, 458, 460. 
Gaza, 54, 55, 112, 175, 289, 356.

Gellone (sacramentaire de), 458.

Gênes, Génois, 120, 194, 196, 199, 200.

géographie, 379, 380.

Georges AKropolites, 225, 290, 402, 403; (historien), 303; (philosophe), 364, 402, 403.

GEORGeS CHRYSOKOKKES, médecin, 376, 405, 408.

GeORGeS DE Chypre, 104, 141, 402, 403.

GEORGES DE NICOMEDIE, 348.

GEORGES PISIDES, 277, 318.

GeORGES SCHOLARIOS, 291，292，371，406, $410,415$.

GEORGES LE SyNCELLE, chroniqueur, 299.

Géorgiens, 79.

Gérasa (Djerasch), 113.

GERAUD (Saint), abbé d'Aurillac, 182.

Germain, patriarche, 388. Pseudo-Germain, 216.

GiotTo, 465.

gothique (art), 465.

Goths, voir Crimée.

Gratchanitsa (Serbie), 468.

GRECO (LE), 240.

GREGoIRE LE GRAND (Saint), pape, 132, 329, $388,460$.

GREGOIRE DE NAZIANZE (Saint), 22, 28, 30, 86, 229, 294, 327, 347; (manuscrits illustrés de), 452.

Gregoire PALAMAs, 368, 369.

GREGOIRE LE SINAÏTE, 367.

GREGOIRE DE TOURS, 173, 174, 340, 341.

Grottaferrata (abbaye de), 327.

GUARINO DE VERONE, 407, 409.

guérisseurs (saints), 231, 232.

Guide de la peinture, 461.

\section{$H$}

hagiographie, 306-310.

HAGIOPOLITES, musicographe, 321.

HAROUN-BEN-JAHJa, 270.

Hautvillers (Marne) (tissu de) 186.

Hellade, 125, 126.

hellénisme (paganisme), 416, 417.

hésychia, hésychastes, 362, 367 369, 415 et s., 447, 451.

HILARION LE GEORGIEN (Saint) 217, 228, 307.

HIPPOCRATE, 53, 54, 380.

Hippodromes (de Constantinople) 9, 19, 63, 65, 67, 75, 85-96, 246 ; (cochers de l'), 86, 87, 96, 244-245; (de province), 102, 104 108, 111, 131, 143, 309; (réservés), 143.
HIPPOLYTE, 298.

histoire (genre historique), 296306.

Holobolos, 315, 327, 381, 414

homélies dramatiques, 348-350

Homere, 285, 318 et s., 338, 397 note $n^{\circ} 82$.

HORAPOLLO, 102.

horloges, 41.

horoscopes, 249.

hospice-orphelinat, 398, 399, 402

huile, 142, 175.

humanisme, 448, 449, 452, 460, 479, 480.

Huns, 122, 171, 216.

hymne Akathiste, 290, 326.

Hypatie, 102.

\section{I}

IBN-BATOUTAH, 81, 270.

IBN-KHORDADBEH, 269 et s.

icônes, 58, 232-241; (d'Édesse, voir mandy-

lion); (achéiropoiètes), 234, 236 et s.;

(doctrine des), 235, 236, 460; (russes), 470-472; (de la Vierge), 234, 237-241 ; (reproduites sur les fresques), 450, 451, 459.

Iconium (Konieb), 67, 95, 188.

iconoclastes, 235, 453.

iconographie religieuse (cycles narratifs), 428, 445, 458; (cycles liturgiques), 438 et s.; (Ancien Testament), 211, 442, 452, 453; (vie de Jésus), 23, 42, 112, 156, 190, 191, 208, 209, 212, 215, 226, 281, 436, 439, 443, 461; (divine liturgie), 446 et s.; (vie de la sainte Vierge), 38, 311, L 430, 439, 441, 442; (visions apocalyptiques), 174, 190, 191.

iconostase, 36, 208, 209, 216, 237, 473.

Illyricum, 123, 124.

imprimerie (des textes grecs), 477.

incrustations, 174,190 et s.

Inde, 49, 95, 103, 110, 165, 168, 169, 172, $185,191,194,287,309,312-314,321$, 345 et s., 379,380 .

industries (de luxe), 103, 183 et s., 185-193, 268; (rurales), 142 et s.

instruments aratoires, 154.

irlandais (manuscrits), 458, 461.

ISIDORE DE MILET, 424, 432.

Italie (voir Rome); (méridionale), 183-185; (art de l'), 464 et $\mathrm{s}$.

ivoires, 84, 155, 168, 192. 


\section{$J$}

JACQUES DE KOKKINOBAPHOS, 349.

JEAN L'AuMONIER (Vie de Saint), 28, 29, 283.

Jean Chrysostome (Saint), 17, 22,24 et s., 83, 97, 108, 155, 224, 229, 279; (liturgie de), 215, 217.

JEAN COUCOUZELIS, musicographe, 329, 403.

JEAN DAMASCENE (Saint), 235, 271, 326 et s., 329, 359, 415.

JEAN GRAMmatikos (Hylilas), patriarche, $245,389,390$.

JeAN L'ITALIEN, 315, 362, 363, 364, 399, 417.

JEAN KAMATEROS, patriarche, 249, 413.

JEAN MAUROPOUS, archevêque d'Euchaita, 321, 362, 394 et s.

JEAN LE PSICHAÏTE (Saint), 416.

JEAN XipHILIN, patriarche, 362, 395, 396.

Jérusalem, 112, 185, 305, 328, 466.

JEROME (saint), 298.

jeux Olympiques, 86 et s., 107, 108, 286.

jeux scéniques, 352, 353.

JOANNICE LE GRAND (Saint), 157.

Job (Livre de), 156.

JOSEPH BRYENNE, 64, 414.

jouets des enfants, 24.

Juifs, 102, 107, 127, 173, 177, 187, 188, 247, 248, 255, 260-269; (baptême des), 262, 263.

JUstiniana ${ }^{a}, 101$.

\section{K}

Kabbale, 246, 267.

kamelaukion, 46.

KARAGÖZ, 99.

KASIA, 20.

KeKaumenos, 20, 145, 146.

Khazars, 179, 262.

Kherson, 122, 123, 171, 180, 181.

Kiev, 79, 94, 181, 246; (Sainte-Sophie de), 94, $441,445,471$.

KinNAMOS (Jean), 303.

KOECK (Pieter), graveur hollandais, 96.

kontakion, 323-325.

KOSMAS INDIKOPLEUSTES, 169-171, 379.

Kosmas le Melode, 319, 326, 329.

\section{$L$}

labourage, 154 .

lampes, 40, 61.

Lampsaque (trésor de), 51. langue (grecque), 21, 103, 105, 114, 122, 126,265,282-284, 405, 478; (à Rome), 458, 459; (enseignée en Occident), 406408, 409, 476-478; (grecque vulgaire), 283 et s., 343, 344; (latine), 123, 282, 384, 388, 402; (copte), 103; (hébraïque), 265; (syriaque), 107.

Laodicée (Syrie), 112. Laon (icône de), 238,

latrines, 36.

Latros (mont), 428.

légendes, 191, 287, 309, 310, 340, 341, 345, 346.

LEON, évêque de Catane, 309.

LEON LE DIACRE, 301.

LeON Le MATHEMATICIEN, 321, 360, 390, 391, 416, 417.

LEONCE DE BYZANCE, 359.

léopards apprivoisés, 66.

Lesnovo (Serbie), 469.

lettres, voir épistolographie.

lettrés (condition des). 275, 276.

LiBANIUS, 105, 108, 288, 384.

lin (industrie du), 48, 185, 186.

lits, 38, 39, 51 .

littérature byzantine, 276-316; (caractéres), 285, 286, 287, 288.

liturgies, 215-223.

liturgiques (chants), 328; (livres), 220 et s.; (mobilier), 190, 191, 211-215.

livres (édition des), 280, 281.

loi agricole, 149, 150.

Lombards, 131, 132, 182, 184, 194.

LUCIEN (imitation de), 286, 314, 345.

LUITPRAND, évêque de Crémone, 53, 55, 60, $182,351$.

lutte athlétique, 62 .

Lyon (musée des tissus), 187.

\section{M}

MAÇOUDI, 262, 270.

Mâdaba (mosaïque de), 112, 113.

magie, 23, 82, 243-246, 309, 382.

МАНОМЕТ II, 78, 158, 272, 380.

Maïnotes, 128.

maisons, 30, 31, 33-37, 77, 106 et s.; (paysannes), 35, 36; (de rapport), 31, 32-34.

MALALAS, 256, 283, 299.

mandylion, 51, 116, 235, 238, 338,

Manichéens, 243, 256.

MANUEL CHRYSOLORAS, 74, 75, 406, 407.

manuscrits historiés, 84, 157, 451455, 458, 462 et s., 466, 467.

MARC-AURELE, 290, 385. 
marchands, 60, 107, 165-168, 178.

mariage, 17,18 .

Marseille, 173, 175, 176, 177.

martyrium, 29, 108, 114, 116, 117, 131, 225.

mathématiques, 374-378.

MAXIME LE CONFESSEUR, 358, 367.

MAXIMIEN, archevêque de Ravenne, 103, 214.

médecins, 53, 54, 55, 65, 380-382, 405 et s.

Melnik (Macédoine), 36.

mélodes, 221.

ménagerie impériale, 65 .

MENANDRE LE PROTECTEUR, 300.

MENAS (culte de saint), 231.

ménologe, 221 et s., 454.

mer (Baltique), 171, 179; (Noire), 120; (Rouge), 168-170.

Mersine (trésor de), 49.

Mesarites (Nicolas), 306, 413.

Mésopotamie, 114-116.

messe byzantine, 215-220.

Météores (monastères des), 428.

MiCHEL (culte de saint), 232.

MiCHEL D'ANCHIALE, patriarche 399.

Michel APOSTOLIS, 407, 409.

Michel D'AtTALie, 31, 302, 394.

Michel ITALIKOS, maître œcuménique, 413 , 414.

Michel Keroularios, patriarche. 184, 243, 254 et s., 283.

Michel KHONIATES, archevêque d'Athènes, $322,399$.

Milan, 426 et s.

mimes, 97-99, 108, 112.

miniatures, 341, 350 et s., 392, 393, 406, 440; (sur papyrus), 278, 279; (russes), 473 et s.

Mistra, 128-130, 291，370，472; (château), 128,129,130; (palais), 37, 130; (églises), 46, 128, 129, 130, 435, 445, 446, 447, 450. mobilier, 31 et s., 37-41.

mode, $45,46$.

modes musicaux, 328 et s.

moines, 224 et s., 279; (instruction des), 415; (écoles monastiques) $383,384,401$ et s., 415-419.

Monemvasia, 128, 199, 428.

monnaies, $30,49,138,142,145,164$ et s., 177-179, 193, 197; (italiennes), 32, 197 et s.

mosaïques (murales), 156, 183, 226, 427, 437442, 447; (pavements), 34, 35, 53, 86, 112, $113,206$.

Moscou, 450, 453, 474.

Mosynopolis, 146.

moulins, 142 et s., 159 . musique byzantine, 92, 93, 95, 327-332, 399; (instruments de), 85, 328, 330-332.

mysticisme, 356, 367-370.

mythologie (emploi de la), 28, 286, 290, 315, $319,452$.

\section{$N$}

Nagoritchino (Serbie), 468, 469.

Naples, 173.

Narbonne, 173.

navigation fluviale, 141 .

Négrepont (Eubée), 195.

néoplatoniciens, 357, 363, 370-373, 385.

Nicée, 68, 117, 118, 290, 364, 400, 401, 402.

NICEPHORE BASILAKES, 290.

NiCEPHORE BLEMMYdES, 290, 306, 364, 375, 379, 381, 401.

NiCEPHORE BRYENNE, 302.

Nicephore CALlistos Xanthopoulos, 298, 327.

Nicephore Chumnos, 295, 365, 375, 403; note ${ }^{\circ} 1775$.

NiCEPHORE GREGORAS, 16, 45, 69, 198, 222, 246, 251, 291, 295, 304, 316, 365, 368, $369,377,404,410,417$.

NiCEPHORE, patriarche, 236, 299, 389, 416.

NICETAS BYZANTIOS, professeur, 271, 293, 395, 396, 397.

NiCETAS KhONIATES, 45, 195, 243, 271, 303, 322, 399.

NiCETAS Stethatos, 367.

NiCOLAS DE MYRE (translation des reliques de saint), 230 et s.

NiCOLAS LE MYSTIQUE, patriarche, 270, 295 et $\mathrm{s}$.

Nicolas le StUdite, 308.

Nicomédie, 117.

NIKON LE METANOÏTE (Saint), 126, 127, 128.

nomophylax, 395, 398.

Normands, 79,179,185; (d'Italie), 126, 133, $185,194,305,442$.

notation musicale, 329 et s.

Novgonod, 122, 181; (art de), 450, 471, 472, 473 et $\mathrm{s}$.

\section{$O$}

océan (Atlantique), 173; (Indien), 168 et s.

Ochrida, 153, 427.

octateuque du Sérail, 138, 154, 186, 452.

odes (cantiques), 221.

œcuménique (maître), 385, 386, 388, 412.

office canonique, 220, 221, 222 .. 
OLEG, 180.

Olympe de Bithynie, 63, 117, 138, 157.

OLYMPIODORE, ambassadeur, 378.

Ommiades, 114.

omophorion, 214.

OPPIEN DE SyRIE(manuscrit illustré d'), 157, $192,452$.

oracles, 252, 253; (chaldéens), 247, 255, 386.

oraisons funèbres, 292 et $\mathrm{s}$.

orateur de la cour, 412, 414.

orgues, 330 et $\mathrm{s}$.

Orléans, 174.

Oronte, 105, 106, 109, 110.

Orphée, 265, 421.

orthographe, 397.

Oxyrhynchos (Égypte), 104, 140, 141, 143.

\section{$P$}

PACHYMere, 246; (histoire), 303, 328; (philosophie), 365, 401.

paganisme (néo-), 371-373. Voir Pléthon.

païens, $28,29,102,103,255,256,384,386$ et $\mathrm{s}$.

pain, 55.

PAKOURIANOS (Grégoire), 146, 159.

palais (Grand), 39, 58, 59, 65, 75, 85, 169, 187, 227, 229; (des Blachernes), 58, 64, 65, 68, 95; (du Kathisma), 91, 94; (de la Magnaure), 391; (de la régon de Constantinople), 63, 66, 67, 207; (privés), 37.

Palerme, 126, 188.

Palestine, 112-114, 226.

pamphlets, 287, 300, 314-316.

panégyriques (impériaux), 291, 292; (des saints), 306 et s.

PANTAleOn (famille des), 183, 185.

Pantocrator, 211, 430, 441, 444.

PANVINIO, graveur (1529-1568), 90, 96.

papier, 279.

pappias, 58.

papyrus, 16, 79, 104, 148, 175, 176, 221, 277 et s., 280.

paranymphe, 18 .

parchemin, 278, 279, 281.

parénétiques (traités), 293.

Parenzo (cathédrale), 427.

parèques, $148,151,152,159$.

parfums, 49, 168, 175.

pastiches, 285 et s., 315,347 .

Patras, 124.

Patria Konstantinoupoleos, 75, 341, 389.

Pauliciens, 245, 256-258.

paume (jeu de), 62, 127.
Pavie, 182.

paysages, 105, 106, 137, 138, 157, 293 et s. paysans, 84, 85, 137 et s., 143-145 148-153, $154,155,177$.

pèche, 128, 162.

PERGOLOTTI, marchand florentin, 198.

peinture murale, 429, 430, 443, 445-447,450; (en Occident), 448, 449.

pèlerins, 112, 116, 185, 194, 230, 231.

Peloponnèse, 126-130, 146, 147, 315.

pénitence (sacrement de), 224, 225. Périgueux, 463. Perm, 171, 172. Pero TAFur, 23, 47, $69,75,79,96,228,240$.

Perse, 43, 44, 166-168, 305, 313, 386, 422, 458.

phare, 119; (d'Alexandrie), 102.

phiale, fontaine monumentale, 207.

Philarete (Saint), 49, 138, 143-145, 307.

Philès, 321, 327.

Philippes (Madédoine), 124, 125, 207, 208, 210, 224, 265, 432 .

Philippopoli, 146, 256, 258.

Philopatris, 314.

PHILOPONOS, 357.

philosophe (grade de), 355, 393, 396, 399, 404.

philosophie byzantine, 355-373; (enseignement de la), 397, 398, 401, 402, 412.

Photius, patriarche, 271, 281, 289, 320, 360.

PHRANTZES, 304.

physiologus, 379.

PIERre, évêque d'Argos, 309.

PIERRE DE SICILE, 257. pierres précieuses, 211.

PIETER KOECK VAN ALAST, graveur hollandais, 96. pirates, 125, 153, 309.

PISANELlO, 46. Pise, 177, 194, 196, 201.

PITRA (cardinal), 323, 324. planète (vêtement), 42.

Planoudes (Maxime), 320, 322, 375, 404.

PlATON, 290, 357, 361, 362, 363, 365, 372, 373.

Plethon (Gémiste), 69, 130, 147, 284, 291, 364, 370-373, 410.

Plotin, 363.

PlutARQue, 276, 362.

poèmes chevaleresques, 340-342.

poésie (rythmique), 322-327; (savante), 317322.

poinçons de contrôle, 171.

Poitiers, 227.

Pola (Istrie), 427.

polycandilon, 40, 213.

polo (jeu de), voir tzykanisterion.

PORPHYRE, philosophe, 298, 359. 360, 364. 
PORPHYRIOS, aurige, 86. porteurs, 81,106 et $\mathrm{s}$. portiques (rues à), 33, 34, 106, 107, 113. portraits, 44, 45, 279, 280, 281, 440, 447-451. Port-Vendres, 177.

poupoularia, voir théâtre.

pourpre, 126, 127, 175, 188, 189.

Poutna (monastère de), 215, 470.

préfet de la Ville, 84, 94, 98, 188; (livre du), 188.

présages (croyance aux), 253, 254.

présanctiflés (messe des), 215, 220.

prêtres mariés, 32.

princesses impériales, 20, 63, 64, 85.

PRISCUS, historien, 299.

prisons privées, 142 .

Proclus, philosophe, 358, 362, 386.

Proconnèse (marbre de), 175, 425, 431.

Procope de Cesaree, 42, 77, 110, 122, 140, 164, 297, 299, 300, 424.

Procope de GAZA, 289, 356.

prophètes (procession des), 349.

prophéties, 251, 252, 254, 255.

propriété (borne de), 154, 155; (droit de), 30, 137, 138, 139.

propylées, entrée monumentale d'un édifice, 207.

prosodie, 317, 318, 323.

Protévangile de Jacques, 311.

prothesis, proskomidi, 208, 211, 216, 217, 220.

protopappas du palais, 68.

Provence (ports de), 200, 201.

proverbes, 122.

psautier, 221; (illustré), 453.

PSEllos, 23, 24, 79, 97, 243, 255, 276, 283 et s., 290, 293, 301, 310, 315, 316, 319, 321, 328 , 361-363, 378, 394, 395, 396, 397, 398.

Ptolemee (système de), 376, 377 et s., 380.

\section{$Q$}

Qoçair’Amrah, 465 et s.

\section{$R$}

RADEGONDE (Sainte), 227.

Raguse, 123, 200; note $\mathrm{n}^{\mathrm{o}} 1132$.

Ravenne, 42, 43, 50, 132, 156, 173, 206, 208, $211,212$.

recettes agricoles, 157.

Reims (draps de), 199.

reliquaires, 32, 50, 84, 172, 228, 462.

reliques, 116, 186, 211, 225-232. reliures, 281, 406.

repas, 18, 50-55, 344, 345 ; (impérial solennel), 52, 53, 68, 331; (impérial familier), $51,5961,69$.

rhéteurs, rhétorique, 288-296, 410, 411.

rhipidia, 212.

Rhodes, 199.

Rodosto (Propontide), 31, 157.

roman (art), 464.

Romanos LE MELOde, 324-327 347.

romans en prose, 311 et $\mathrm{s}$.

Rome, 87, 131, 132, 173, 181, 182, 193, 387, 423,458 et $\mathrm{s}$.

RouBleV (André), 240, 450, 472, 474.

rouleaux (volumina), 221, 280.

Russes, 74, 79, 123, 171, 179-181, 209, 237 et s., 240, 289, 337, 338. (voyageurs), 213, 238, 240; (art russe), 470-474.

\section{$S$}

sagas, 95.

Saint-Gall (abbaye de), 461.

Saint-Jean d'Acre, 196.

Saint-Luc (Phocide), 208, 428, 436, 441.

sakkos, 214.

Salerne, 184.

Salone, 123.

sarcophages, 26, 27, 424.

Sardaigne, 131.

satires, 22, 98, 315, 341 344, 345, 453, 454.

savetiers, 276. scaramange, 43, 44, 181, 188.

schédographie, 400.

sciences (classification des), 373, 374.

scolastique (byzantine), 357, 358, 364 et s.; (occidentale), 366-368.

sculpture, 423, 424, 435-437.

Sens (trésor de), 189.

Sept Dormants d'Ephèse (martyrium des), 117.

Septem (Ceuta), 131.

SEPTIME SEVERE, 87, 97.

séraphins, 212.

Serbes, 237, 258; (art des), 449, 467-469.

serfs, 30, 31, 143, 144, 148, 149, 151, 265.

serviteurs, 22, 23.

SEVERE, patriarche monophysite, 245.

Sibérie, 171, 172.

Sicile, 177, 185, 442, 459.

Si-ngan-fou, 165.

Sinaï, 278.

Sirmium (Mitrovitza), 123.

Skripu (Boétie), 145.

SKYLITZES (Jean), 283, 299. 
Slaves (des Balkans), 123-125, 209; (de Hellade), 126, 128.

smalt, petit cube de verre émaillé, 240, 444.

Smyrne, 119, 401.

SOCRATE, historien, 298.

soie (industrie de la), 48, 126, 127, 167, 175,

268; (routes de la) 165, 166, 167-169, 187-

190. so/ca, 209.

songes (explication des), 253.

sorciers, voir magie.

SOZOMENE, 298.

Spalato (Split), voir Salone,

SPANEAS (poème de), 343.

Sparte, 126-130.

sports, 24, 25, 36, 62, 66, 69, 112.

statuaire, 423.

staurothèques, 191, 227.

sticharion, 214.

Stoudios (monastère de), 229, 367, 414; (psautier de), 453.

Strabon, 106.

stylites, 106, 109, 175, 309.

suaires, 175, 189.

superstitions, 23, 26, 243-255.

surnoms, 15.

SYMEON METAPHRASTE, 310, 327.

SYMEON LE NOUVEAU, 367.

SYMEON DE THESSALONIQUE, 209, 353.

synagogues, 265, 266.

synaxaires, 222.

SYNESIUS, évêque de Cyrène, 102, 103.

synthronon, 209.

Syracuse, 309.

Syrie, 25, 33, 34, 38, 111 et s., 168, 178, 184.

Syriens (commerce et colonies des), 54, 55, 102, 107, 132, 172, 177, 190, 458.

SYROPOULOS (Sylvestre), 306.

\section{$T$}

tabellae defixionum, 244.

tailleurs, 186.

Talmud, 263, 266 et s.

tanneurs, 83.

tapis, 168, 186, 187.

TARASIOS, patriarche, 389 .

Taygète, 126, 128, 130.

Tchernigov (Russie), 471.

teinturiers, 127,188 et s.

terres (mesurage des), 137, 138.

Testament (Ancien), 221.

testaments, 22, 30, 31 .

TETALDI, marchand florentin, 78.

Thabor, 112. théâtre, 96-99, 106, 108; (religieux), 346-354; (savant), 347, 348.

Thèbes (Béotie), 23, 125, 196, 268.

THEMISTIUS, rhéteur, 77, 384.

TheOctiste, mère de Théodore Studite, 21, 22, 24.

THEODORA (épouse de justinien), 19, 51, 63, 82; (épouse de Théophile), 178, 238; (Sainte T. de Thessalonique), 22, 308.

THEODORE D'ÉDESSE (Vie de), 309.

THEODORE DE GAZA, 319, 479.

THEODORE HYRTAKENOS, professeur, 285, 403 et $\mathrm{S}$.

THEODORE MELITENIOTES, astronome, 377.

TheOdORE Metochites, 37, 45, 46, 147, 246, 277, 284, 319, 365, 376, 404.

Theodore Prodrome, 19, 22, 53, 81, 95, 98, 249, 276, 315, 344 et s., 399.

TheOdore Studite (Saint), 21, 22, 138, 236, $327,415$.

THEODORE DE TARSE, 460.

THEODORET, évêque de Cyrus, 298.

THEOKTISTE, grand logothète, 391. théologique (enseignement), 412-415; (discussion), 66, 67, 82 et s.

THEOPHANE LE GREC, peintre, 472, 473.

THEOPHANES LE CONFESSEUR, 143, 149, 283; (Chronique de), 299, 301, 389.

THEOPHANES continué, 299, 301.

THEOPHANO (Sainte), 23, 231; (épouse d'Otton II), 462.

THEOPHYLACTE, archevêque d'Ochrida, 153, $277,321$.

THEOPHYLACTE, patriarche, 86, 352.

Théophylacte de Simocatta, 295, 300, 387.

Thessalonique, 123, 124, 153, 181, 187, 199, $211,228,230,268,305,314,366,390$, 423, 427, 434, 437, 444 .

tissus historiés, 42, 43, 44, 87.

toilette (objets de), 40, 41 .

tombes, 27, 28, 108, 109.

Torcello (Vénétie), 208.

Toulouse, 458.

tournois, 65, 69.

tragoudia, 332, 337, 338, 339, 342.

Trébizonde, 37, 62, 120-122, 292, 380, 382.

tremblements de terre, $77,110$.

Trèves, 174.

tribulum (dépiquage du blé), 155.

tribunes (des églises), 206, 209, 210.

triclinium, 35 .

trictrac (jeu de), 62, 107.

Trieste, 427.

trithéistes, 357. 
tropaires, 220, 221, 323, 328 .

Turcs (peuples), 118, 153, 167, 271, 296 et s., 300; (ottomans), 199, 271, 272, 305.

TzETZES (Jean), 25, 276, 295, 322, 341, 400. tzykanisterion, 25, 62, 65, 66, 121.

\section{U}

ULFILAS (bible d'), 216, 279.

Université impériale, 29, 320, 356, 360, 383411; (nom officiel), auditorium, 384, 385; didaskaleion akoumenikon, 388; gymnasion, 296; mouseion katholicon (publicus discendi ludus), 405; (locaux), 384, 387, 389, 392, 395 et s., 404, 45; (dépendance du Sénat), 396, 399, 405, 411; (d'un juge catholique), 406; (professeurs), 279, 280, 384, 385, 389, 391, 392, 393, 396, 404406; (étudiants), 245, 387, 393-395, 397, 404, 407, 408, 412, 413; (boursiers), 401; (exercices scolaires), 393, 404, 410; (faculté de philosophie), 396, 397, 398, 399401; (professeurs privés), 394, 395, 396, 401, 404; (universités provinciales), 385, 386, 387, 400 et s.; voir droit (enseignement du).

URBAIN II, 231.

urbanisme, 104, 106, 115, 117 et s., 179.

\section{V}

vaisselle, 52, 53.

Valaques (bergers), 156.

Varègues, 179, 180.
VARRON, 373.

veilleurs de nuit, 121.

Venise, 51, 133, 196-199; (commerce et colonies), 31, 37, 79, 126, 182, 183, 184, 185, 194, 196, 199, 201, 268 et s.; (SaintMarc), 52, 53, 192, 436, 442, 459.

verrerie, 52, 53.

Vienne (Isère), 174.

vignes, 138, 151, 155.

VILLEHARDOUIN (Geoffroi de), 73; (Guillaume de), 128.

vin, 32, 142, 171, 177; (crus), 54, 147, 175.

Vladimir (Russia), 239.

\section{W}

wisigoth (art), voir Toulouse.

\section{Y}

Yakto (mosaïque de), 34, 41, 42, 43, 106.

\section{Z}

Zara, 123.

zeon (rite du) 219.

zéro (adoption du), 375.

zodiaque, 246, 249.

ZoE, impératrice (fille de Basile II), 49,440.

Zohar, 267.

ZONARAS, 98, 299.

ZOZIME DE PANOPOLIS (alchimiste), 378. 


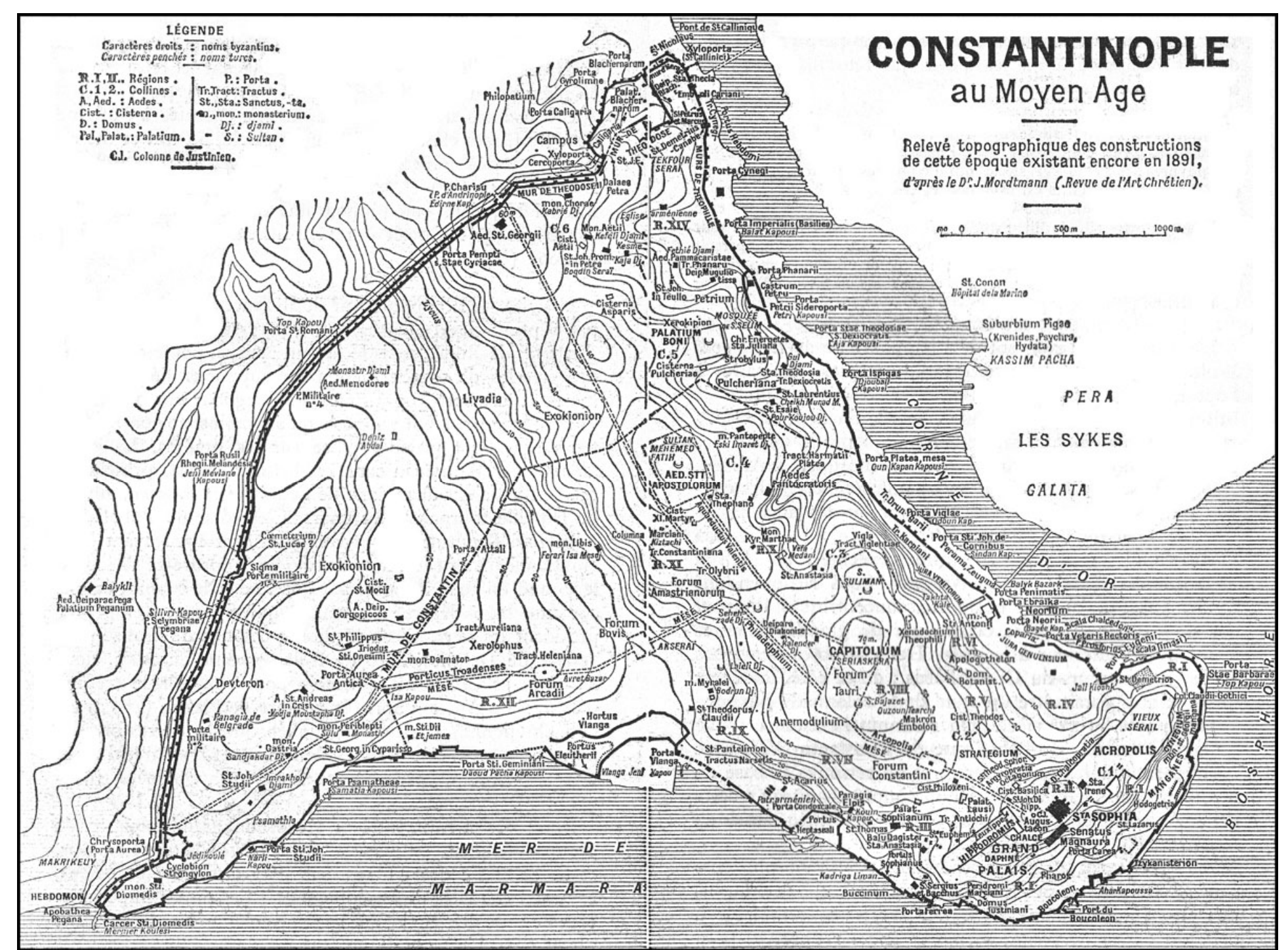

Carte - Contantinople au Moyen Age retour au texte 
